
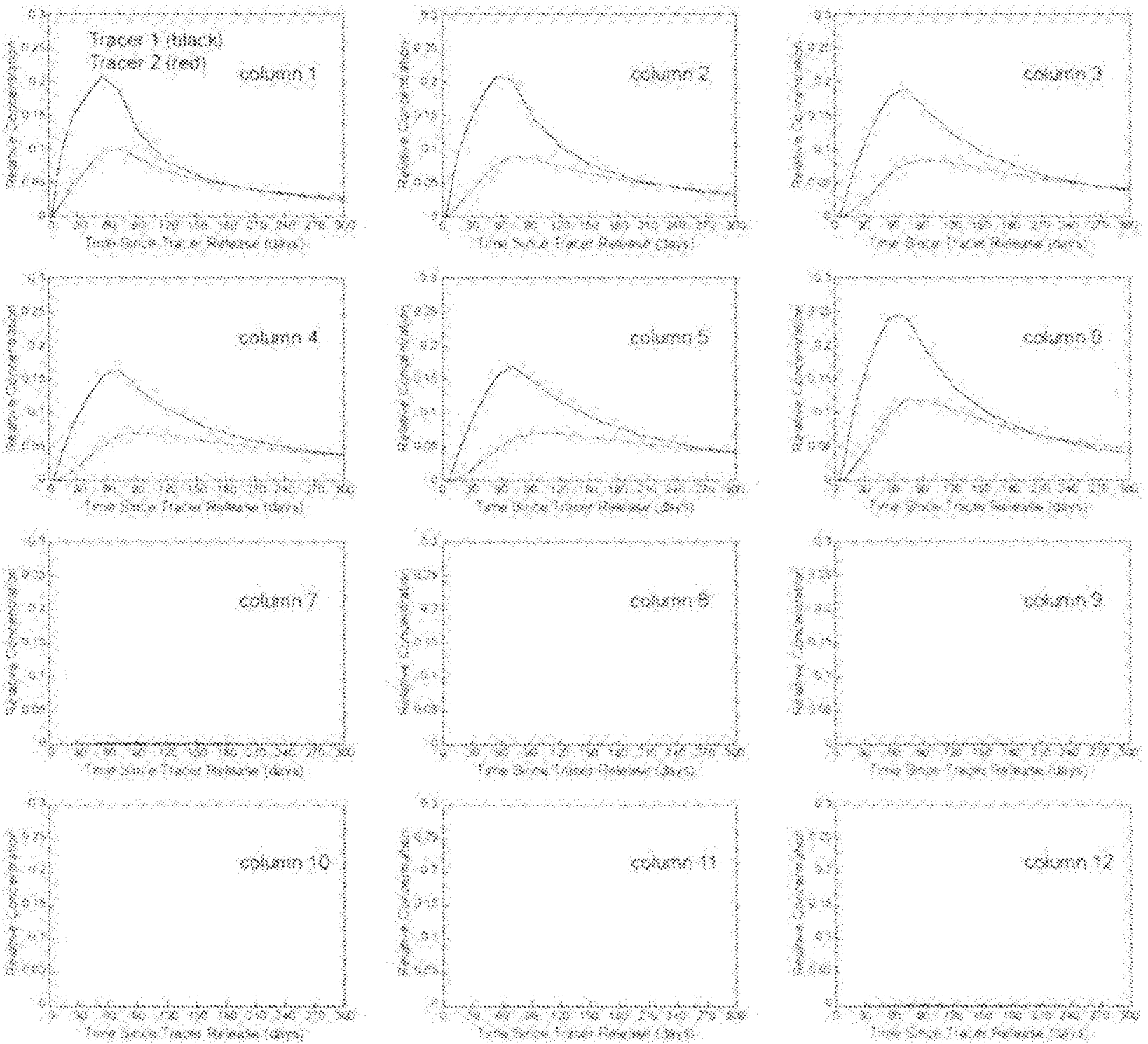

१३मे

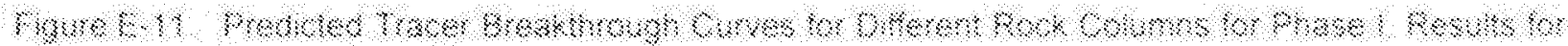
Toress sro? 

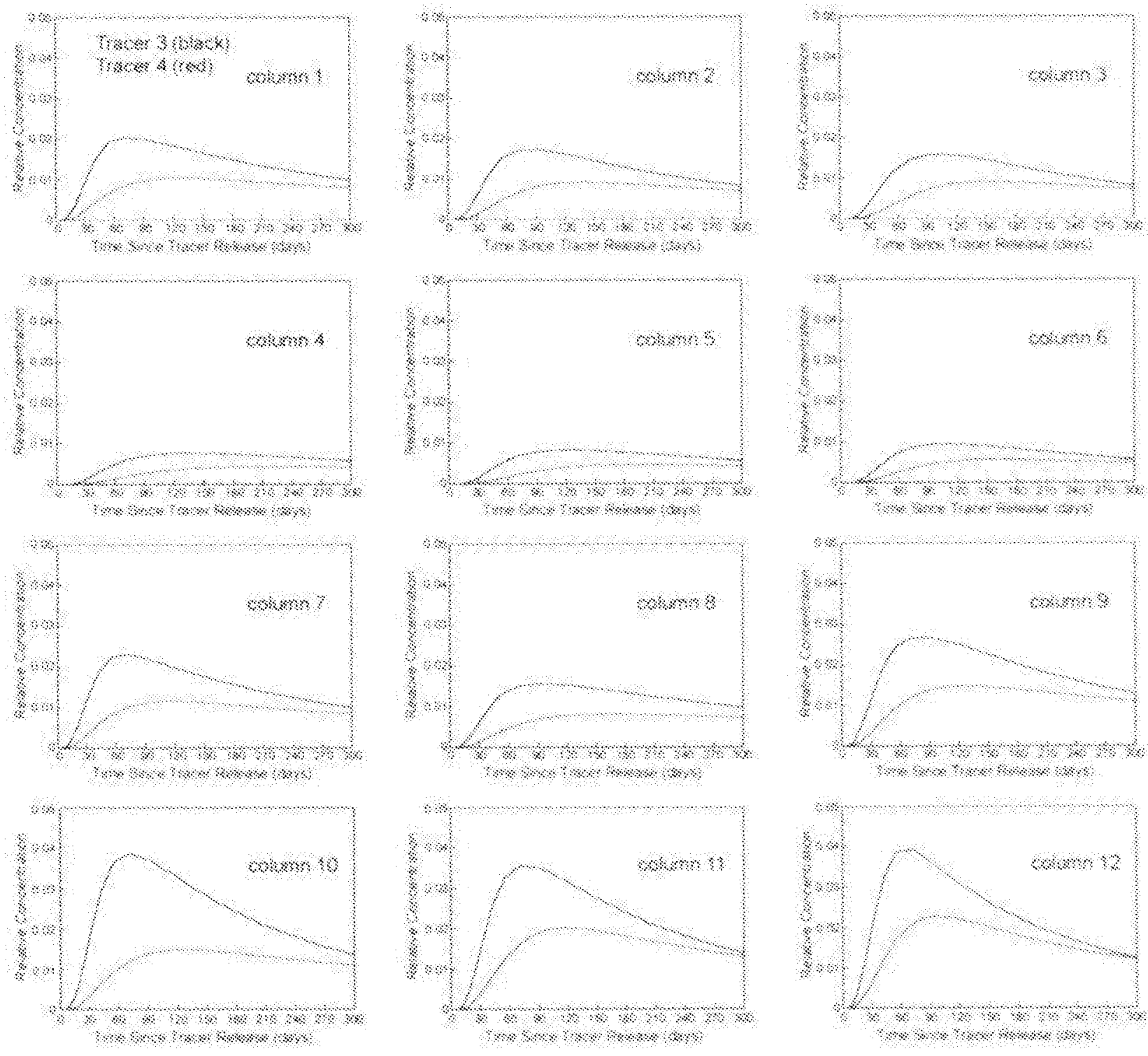

४४њ»)

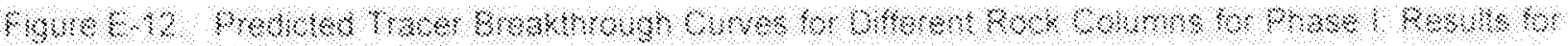

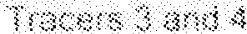



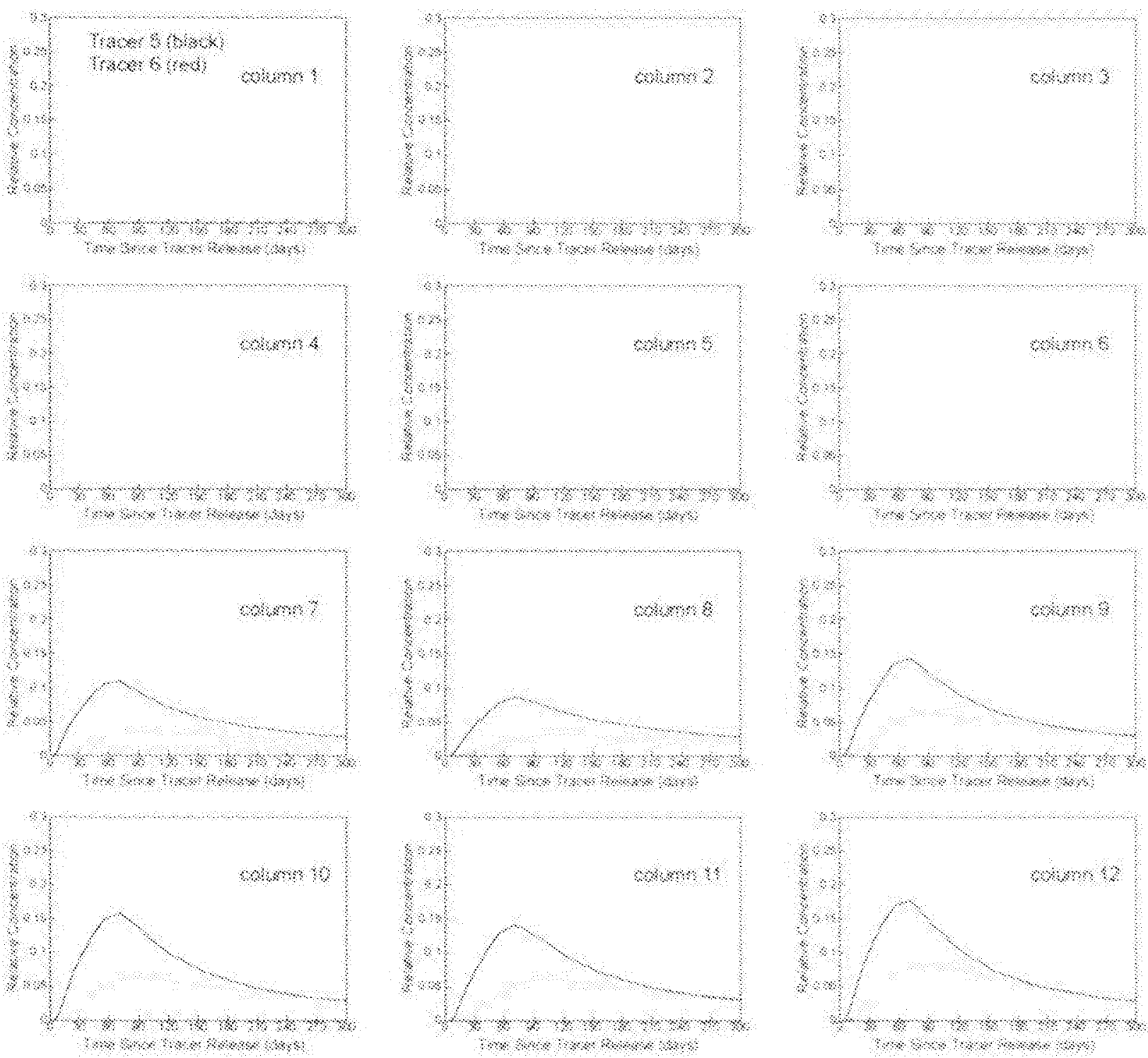

४ै। ४ै।

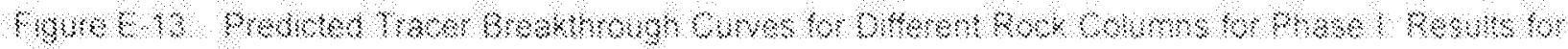

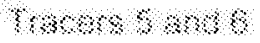




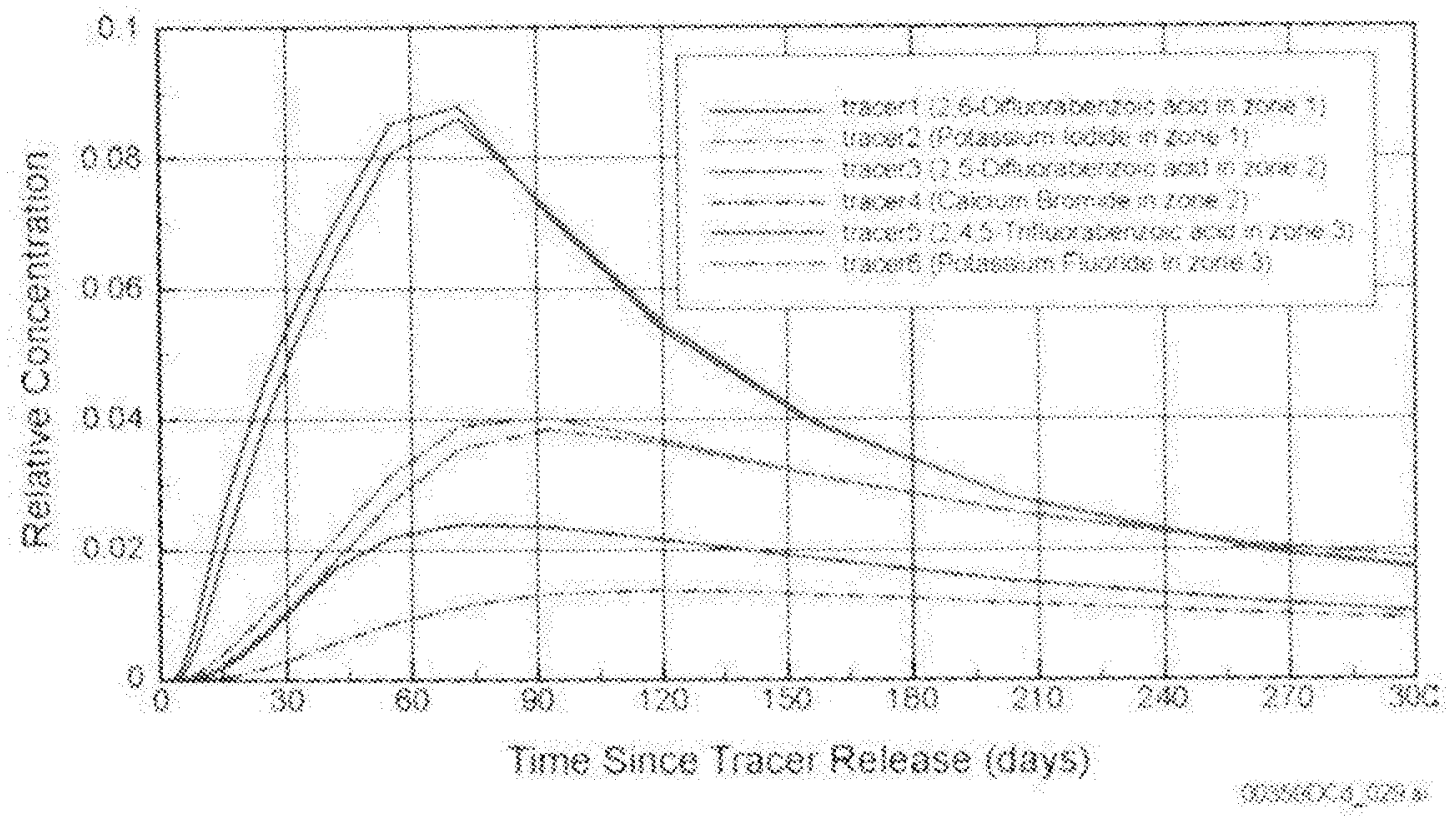

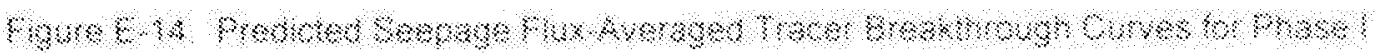

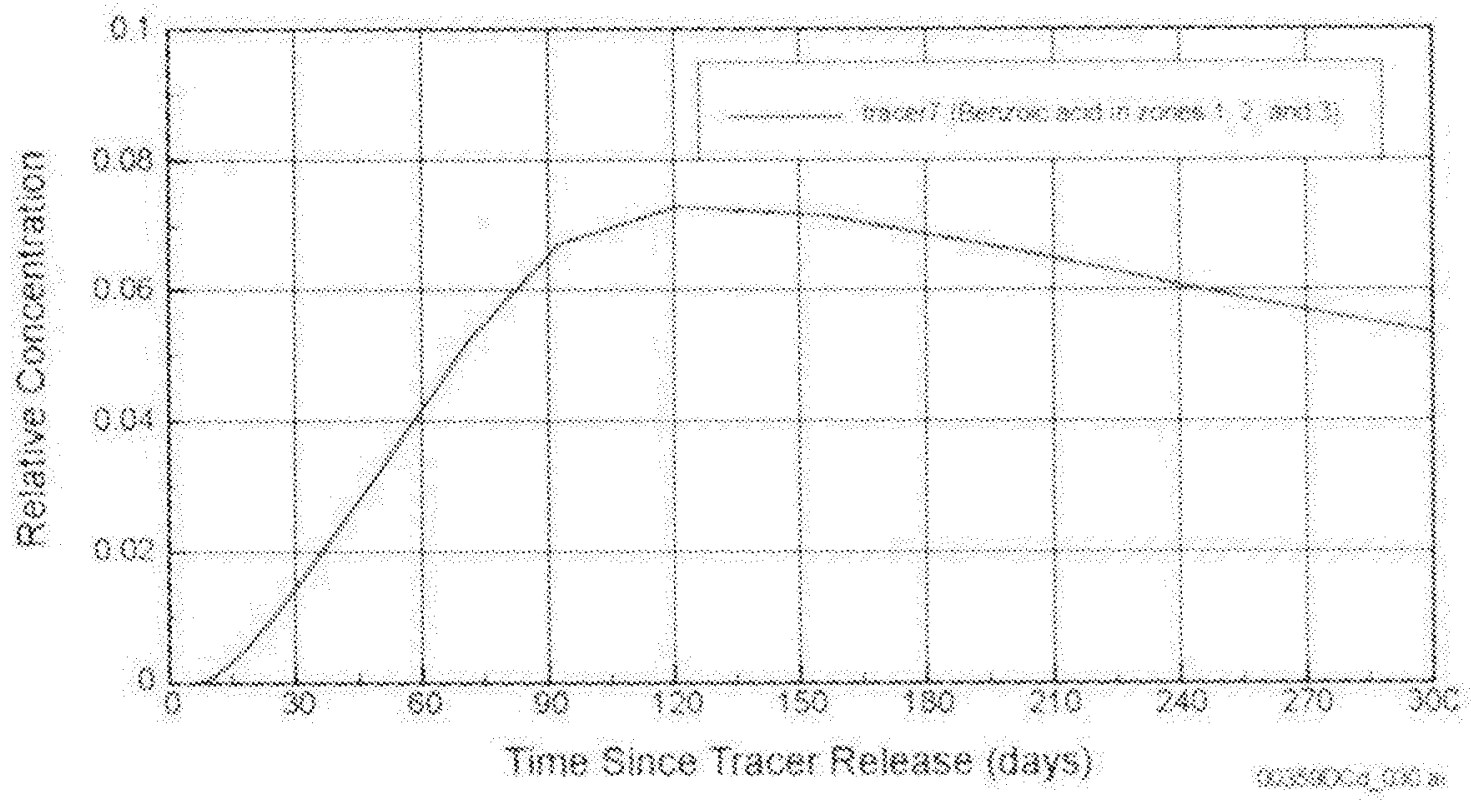

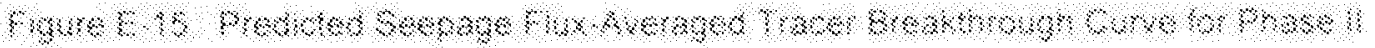



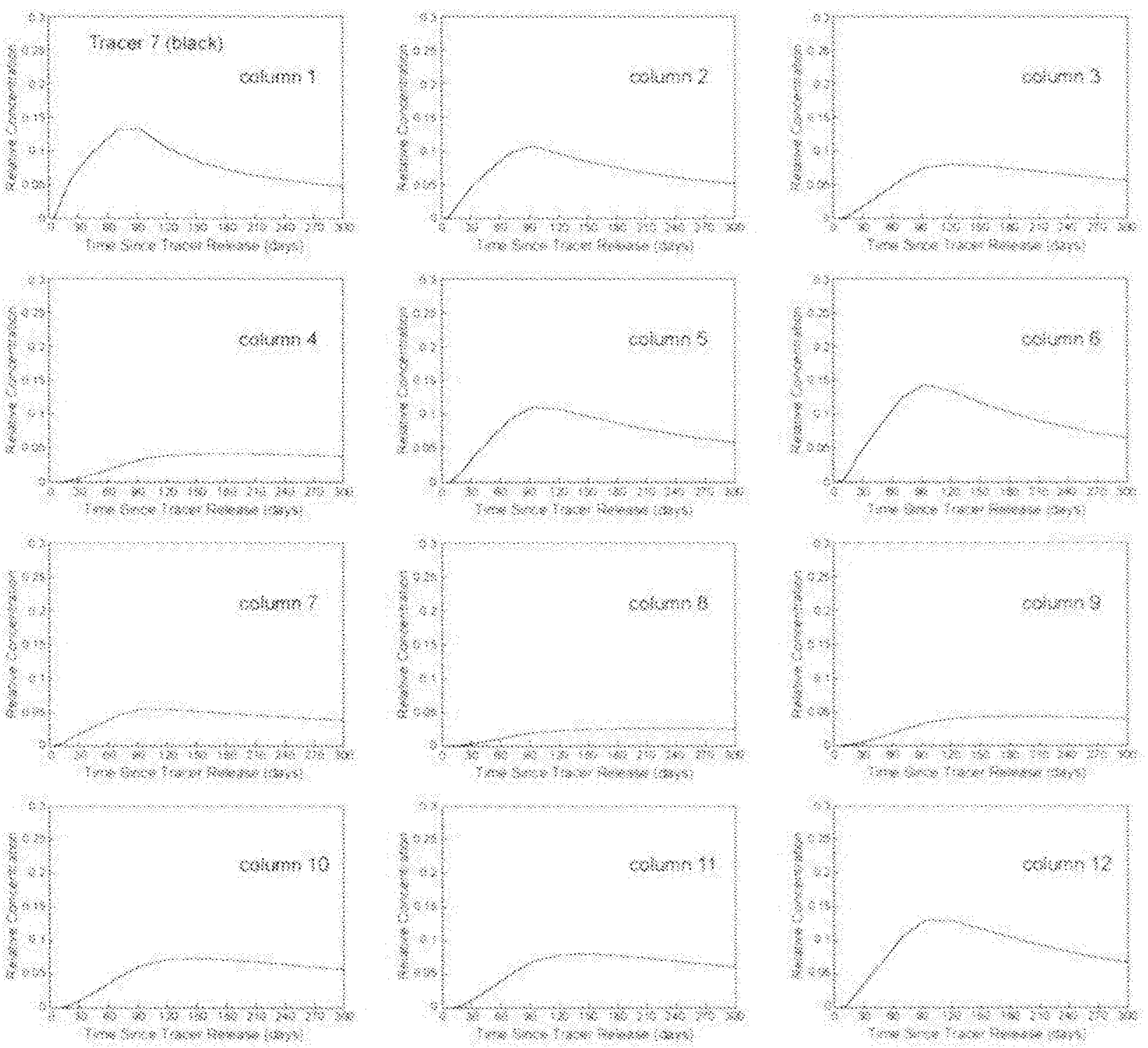

४मे

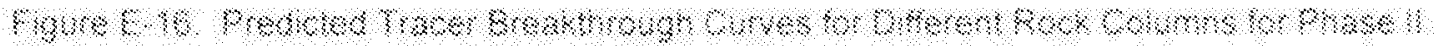

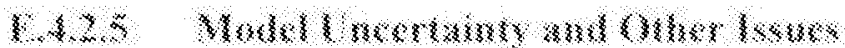

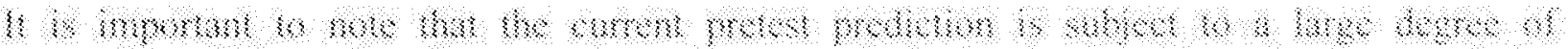

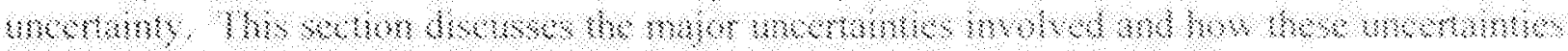

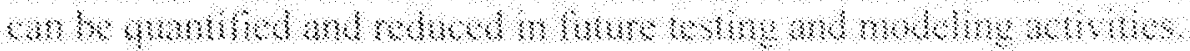

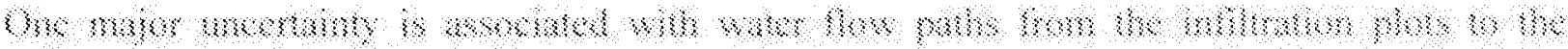

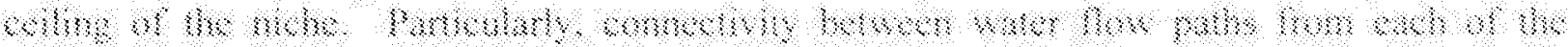

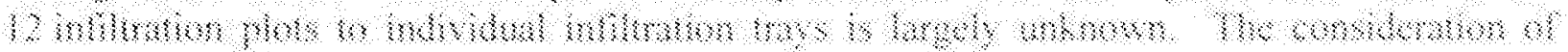

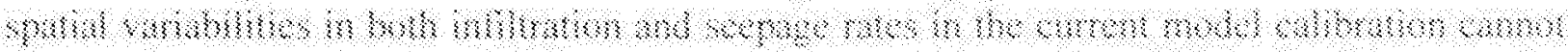

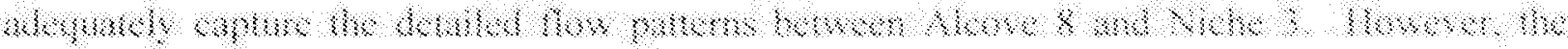

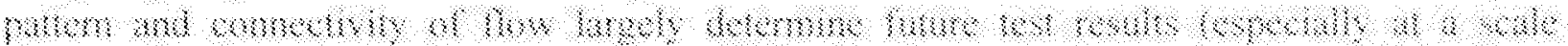

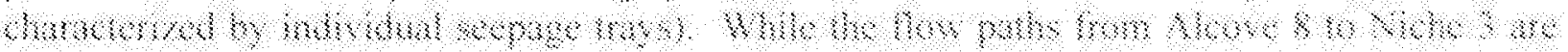


determined by the geometry of the fracture network, characterizing this fracture network and its hydraulic connectivity based on available fracture mapping data is difficult and leads to ambiguous interpretations, as is evident from the poor correlation between properties of mapped fractures on the ceiling of Niche 3 and the observed seepage rate distribution. This uncertainty regarding the flow paths can be investigated, using the future results of tracer tests that involve different tracers applied at different infiltration plots. Future calibration of the numerical model against the tracer test data will improve the characterization of the flowing fracture connectivity from the Alcove 8 infiltration plots to the ceiling and collection trays in Niche 3.

The second major uncertainty is related to the potential enhancement of matrix diffusion. Analyses of the fault test results indicated that matrix diffusion is indeed an important process for retarding the tracer transport and that the fault-matrix interface area (or the effective matrix diffusion coefficient) needed to be increased to match the test results with the corresponding numerical model (BSC 2003b, Section 7.6). This potential enhancement of matrix diffusion is supported by some studies reported in the literature (BSC 2003b, Section 7.6). However, the physical mechanisms behind this potential enhancement are not totally clear at this stage. Also, whether the similar enhancement holds for fractured rock away from the fault zone is still an open question. If the enhancement of matrix diffusion is the case for nonfault fractured zones, the current prediction results likely underestimate tracer breakthrough times and overestimate peak concentration values.

Finally, uncertainties also exist in our conceptual understanding of the temporal variability of infiltration rates. As previously indicated, significant temporal variabilities of infiltration rates (for a given water pressure head at infiltration plots) have been observed from both fault tests and large-plot tests. These variabilities cannot be explained by the interplay between capillary pressure gradients and gravity effects. The current understanding is that they may result from fracture infilled materials (particles). These materials (particles) move around and can either open or plug pore spaces in fractures near infiltration plots, resulting in fluctuation and final reduction of infiltration rates. This mechanism is only approximately considered in the model by using observed infiltration rates as a boundary condition. However, a future disturbance at the infiltration plots (e.g., changes in applied infiltration rates and (or) water-pressure head) may activate particle movement again, further modifying the effective fracture permeability and its spatial distribution below the infiltration plots. This temporal modification of rock properties is difficult to capture in the model. It should be noted that, because of this issue, one of the planned test objectives regarding estimation of relations between relative permeability and water potential might be extremely difficult to achieve.

\section{E.4.3 Summary}

Alcove 8-Niche 3 tests provide a unique opportunity to examine important flow and transport processes in the unsaturated zone of Yucca Mountain, including infiltration-seepage processes, matrix diffusion, and the character of flow and transport within a fault and fracture network. This appendix provides model-prediction results for Alcove 8-Niche 3 large-plot tests (Section E.4.2), including a discussion of the major model uncertainties and how these uncertainties can be quantified and reduced in future testing and modeling activities (Section E.4.2.5). 


\section{E.5 REFERENCES}

\section{E.5.1 Documents Cited}

Brocoum, S. 2001. "Response to Radionuclide Transport Key Technical Issue Technical Exchange Subissue 3, Agreement 6; and Structural Deformation and Seismicity Key Technical Issue Technical Exchange Subissue 3, Agreement 2 with Concurrence Copy-Enclosure not Included, March 12, 2001." Letter from S. Brocoum (DOE) to C. W. Reamer (NRC), March 12, 2001. ACC: MOL.20030922.0008.

BSC (Bechtel SAIC Company) 2003a. In Situ Field Testing of Processes. ANL-NBS-HS000005 REV02B. Las Vegas, Nevada: Bechtel SAIC Company. ACC: MOL.20030915.0238.

BSC 2003b. UZ Flow Models and Submodels. MDL-NBS-HS-000006 REV 01. Las Vegas, Nevada: Bechtel SAIC Company. ACC: DOC.20030818.0002.

Flint, L.E. 1998. Characterization of Hydrogeologic Units Using Matrix Properties, Yucca Mountain, Nevada. Water-Resources Investigations Report 97-4243. Denver, Colorado: U.S. Geological Survey. ACC: MOL.19980429.0512.

LBNL (Lawrence Berkeley National Laboratory) 1999a. 09/16/1999. Software Code: iTOUGH2. V4.0. SUN, DEC. 10003-4.0-00.

LBNL 1999b. Software Code: T2R3D. V1.4. FORTRAN 77, SUN, DEC / ALPHA. 10006-1.4-00.

Liu, H.H.; Bodvarsson, G.S.; and Finsterle, S. 2002. "A Note on Unsaturated Flow in Two-Dimensional Fracture Networks." Water Resources Research, 38, (9), 15-1 to 15-9. [Washington, D.C.]: American Geophysical Union. TIC: 253307.

Moridis, G.J.; Hu, Q.; Wu, Y-S.; and Bodvarsson, G.S. 2003. "Preliminary 3-D Site-Scale Studies of Radioactive Colloid Transport in the Unsaturated Zone at Yucca Mountain, Nevada." Journal of Contaminant Hydrology, 60, ([3-4]), 251-286. New York, New York: Elsevier. TIC: 253921.

Pruess, K. and Narasimhan, T.N. 1985. "A Practical Method for Modeling Fluid and Heat Flow in Fractured Porous Media." Society of Petroleum Engineers Journal, 25, (1), 14-26.

Dallas, Texas: Society of Petroleum Engineers. TIC: 221917.

Reamer, C.W. 2002. "Radionuclide Transport Key Technical Issue Agreements." Letter from C.W. Reamer (NRC) to S. Brocoum (DOE), February 6, 2002, with attachments.

ACC: MOL.20020920.0318.

Reamer, C.W. and Williams, D.R. 2000. Summary Highlights of NRC/DOE Technical Exchange and Management Meeting on Radionuclide Transport. Meeting held December 5-7, 2000, Berkeley, California. Washington, D.C.: U.S. Nuclear Regulatory Commission. ACC: MOL.20010117.0063. 
Schlueter, J. 2000. “U.S. Nuclear Regulatory Commission/U.S. Department of Energy Technical Exchange and Management Meeting on Structural Deformation and Seismicity (October 11-12, 2000)." Letter from J. Schlueter (NRC) to S. Brocoum (DOE), October 27, 2000, with enclosure. ACC: MOL.20010730.0232

Schlueter, J. R. 2003. "Staff Review of Information Addressing Radionuclide Transport (RT) Agreement 3.06 and Structural Deformation and Seismicity (SDS) Agreement 3.02, Status Partly Received." Letter from J.R. Schlueter (NRC) to J.D. Ziegler (DOE), February 14, 2003, with attachment. CCU \#0220036149. ACC: MOL.20030909.0374.

Ziegler, J.D. 2002. “Transmittal of Information Addressing Key Technical Issue (KTI) Agreement Items Radionuclide Transport (RT) 3.06 and Structural Deformation and Seismicity (SDS) 3.02." Letter from J.D. Ziegler (DOE) to J.R. Schlueter (NRC), June 27, 2002, with attachments. ACC: MOL.20020819.0283.

\section{E.5.2 Data, Listed by Data Tracking Number}

Data to be submitted. Model calibration using seepage rate data from Alcove 8-Niche 3 large-plot tests (Phase I). Submittal date: TBD.

Data to be submitted. Model prediction for Alcove 8-Niche 3 large-plot tests (Phase I and Phase II). Submittal date: TBD.

GS030108314224.001. Geotechnical Data for Alcove 8 (ECRB) and Niche 3 (ESF): Full Periphery Geologic Map (Drawing OA-46-356). Submittal date: 02/05/2003.

LB0306A8N3LIQR.001. Fault Infiltration Test from Alcove 8 to Niche $3(9 / 18 / 2002-$ 10/16/2002). Submittal date: 06/19/2003.

LB0308A8N3SEEP.001. Seepage Rate Data for Alcove 8-Niche 3 Large Plot Tests (Phase I). Submittal date: 09/23/2003.

LB0308A8N3TRTM.001. Water Front Travel-Time Data for Alcove 8-Niche 3 Large Plot Tests (Phase I). Submittal date: 09/23/2003. 
Revision 1

INTENTIONALLY LEFT BLANK 
Moreover, unsaturated hydrological parameters on the scale of individual fractures are required, along with conceptual models and simplifying assumptions regarding unsaturated flow within fractures and across fracture intersections. The databases required to develop a defensible discrete fracture network model are not available and are generally impracticable for site-specific simulations.

As a result, discrete fracture network models need to be calibrated against flow or seepage data in a step very similar to that performed for a continuum model. This step is required to assure that key aspects of the system at the site of interest are captured and that potential biases from model assumptions and errors in parameter values are reduced or eliminated.

Three-dimensional, calibrated discrete fracture network models are most likely capable of producing defensible seepage predictions consistent with those obtained with a calibrated and validated fracture continuum model.

\section{D.4.2.5 Discretization Issues}

In a discrete fracture network model, an individual fracture is discretely represented in the numerical model by appropriately small computational grid blocks. This is often considered the defining feature of such a model. Note, however, the flow equations solved in and between grid blocks are essentially identical to those solved by a continuum model, i.e., the only fundamental difference between the two approaches lies in the discretization.

In a numerical model, the grid blocks are computational elements needed to solve the governing equations. Continuum equations can be used if considered appropriate for a study on a given scale. Once the decision to use continuum equations is made, the domain is discretized for the numerical solution of these equations. Consequently, the size of the grid blocks does not necessarily need to be related to the size of a representative elementary volume. Specifically, fracture spacing in a classical double-porosity or dual-continuum model does not need to be smaller than the grid block size used to solve the continuum equations for the approach to be valid. As an analog, consider that the analytical solution to a flow problem provides results at an infinitely high resolution despite the finite size of the representative elementary volume underlying the governing equations.

In a discrete fracture network model, flow within the fracture plane is governed by continuum equations. Consequently, it is standard practice to discretize each fracture plane into elements that are usually much smaller than the average fracture spacing. As outlined in Section D.4.1.4, if in-plane flow is considered an important process (as is the case for flow diversion and seepage into drifts), a continuum model is an appropriate conceptualization. Discretizing in-plane flow described by continuum equations using relatively small elements is thus reasonable and does not produce a conceptual or computational problem even if fracture spacing were relatively large.

The decision whether continuum equations and associated effective parameter values are appropriate to solve a given flow problem is independent from its discretization. However, it is noted that conclusions regarding discrete flow behavior on the scale of the average fracture 
spacing or of a computational grid block should not be made based on models such as the continuum seepage models developed to support TSPA.

\section{D.4.3 Conclusion}

A calibrated, three-dimensional, heterogeneous fracture continuum model has been shown to be appropriate for simulating average seepage rates into waste emplacement drift sections that are the approximate length of a waste package.

A calibrated, there-dimensional discrete fracture network model has been evaluated as an alternative to the continuum approach.

It was demonstrated for a two-dimensional setting that both modeling approaches yield consistent results for the seepage problems at the waste emplacement drift at Yucca Mountain. The parsimony of the continuum model, its computational efficiency, and its support by available field data are considered advantages that warrant use for seepage studies at Yucca Mountain. Most importantly, the continuum model is validated against field data in the middle nonlithophysal zone and lower lithophysal zone and is well integrated into the comprehensive data analysis and modeling approach for studying the performance of the unsaturated zone at Yucca Mountain.

\section{D.5 REFERENCES}

Birkholzer, J.; Li, G.; Tsang, C-F.; and Tsang, Y. 1999. "Modeling Studies and Analysis of Seepage into Drifts at Yucca Mountain." Journal of Contaminant Hydrology, 38, (1-3), 349-384. New York, New York: Elsevier. TIC: 244160.

BSC (Bechtel SAIC Company) 2001. In Situ Field Testing of Processes. ANL-NBS-HS000005 REV 01. Las Vegas, Nevada: Bechtel SAIC Company. ACC: MOL.20020108.0351.

BSC 2003a. Seepage Calibration Model and Seepage Testing Data. MDL-NBS-HS-000004 REV 02. Las Vegas, Nevada: Bechtel SAIC Company. ACC: DOC.20030408.0004.

BSC 2003b. Abstraction of Drift Seepage. MDL-NBS-HS-000019 REV 00. Las Vegas, Nevada: Bechtel SAIC Company. ACC: DOC.20030826.0001.

Cacas, M.C.; Ledoux, E.; De Marsily, G.; Tillie, B.; Barbreau, A.; Durand, E.; Feuga, B.; and Peaudecerf, P. 1990. "Modeling Fracture Flow with a Stochastic Discrete Fracture Network: Calibration and Validation. 1. The Flow Model." Water Resources Research, 26, (3), 479-489. [Washington, D.C.]: American Geophysical Union. TIC: 222351.

Dverstorp, B. and Andersson, J. 1989. "Application of the Discrete Fracture Network Concept with Field Data: Possibilities of Model Calibration and Validation." Water Resources Research, 25, (3), 540-550. [Washington, D.C.]: American Geophysical Union. TIC: 254736.

Finsterle, S. 2000. "Using the Continuum Approach to Model Unsaturated Flow in Fractured Rock." Water Resources Research, 36, (8), 2055-2066. Washington, D.C.: American Geophysical Union. TIC: 248769. 
Jackson, C.P.; Hoch, A.R.; and Todman, S. 2000. "Self-Consistency of a Heterogeneous Continuum Porous Medium Representation of a Fractured Medium." Water Resources Research, 36, (1), 189-202. Washington, D.C.: American Geophysical Union. TIC: 247466.

Liu, H.H.; Bodvarsson, G.S.; and Finsterle, S. 2002. "A Note on Unsaturated Flow in Two-Dimensional Fracture Networks." Water Resources Research, 38, (9), 15-1 to 15-9. Washington, D.C.: American Geophysical Union. TIC: 253307.

Mongano, G.S.; Singleton, W.L.; Moyer, T.C.; Beason, S.C.; Eatman, G.L.W.; Albin, A.L.; and Lung, R.C. 1999. Geology of the ECRB Cross Drift - Exploratory Studies Facility, Yucca Mountain Project, Yucca Mountain, Nevada. [Deliverable SPG42GM3]. Denver, Colorado: U.S. Geological Survey. ACC: MOL.20000324.0614.

Nitao, J.J. 1996. "The NUFT Code for Modeling Nonisothermal, Multiphase, Multicomponent Flow and Transport in Porous Media." Eos, 74, (43), 3. Washington, D.C.: American Geophysical Union. TIC: 226135.

NRC (U.S. Nuclear Regulatory Commission) 2002. Integrated Issue Resolution Status Report. NUREG-1762. Washington, D.C.: U.S. Nuclear Regulatory Commission, Office of Nuclear Materials Safety and Safeguards. TIC: 253064.

Oreskes, N.; Shrader-Frechette, K.; and Belitz, K. 1994. "Verification, Validation, and Confirmation of Numerical Models in the Earth Sciences." Science, 263, (5147), 641-646. Washington, D.C.: American Association for the Advancement of Science. TIC: 248958.

Reamer, C.W. 2001. "U.S. Nuclear Regulatory Commission/U.S. Department of Energy Technical Exchange and Management Meeting on Total System Performance Assessment and Integration (August 6 through 10, 2001)." Letter from C.W. Reamer (NRC) to S. Brocoum (DOE/YMSCO), August 23, 2001, with enclosure. ACC: MOL.20011029.0281.

Richards, L.A. 1931. "Capillary Conduction of Liquids Through Porous Mediums." Physics, 1, 318-333. New York, New York: American Physical Society. TIC: 225383.

Schlueter, J.R. 2003. "Staff Review of Information Addressing Radionuclide Transport (RT) Agreement 3.06 and Structural Deformation and Seismicity (SDS) Agreement 3.02, Status Partly Received." Letter from J.R. Schlueter (NRC) to J.D. Ziegler (DOE/ORD), February 14, 2003, 0220036149, with attachment. ACC: MOL.20030909.0374.

van Genuchten, M.T. 1980. "A Closed-Form Equation for Predicting the Hydraulic Conductivity of Unsaturated Soils." Soil Science Society of America Journal, 44, (5), 892-898. Madison, Wisconsin: Soil Science Society of America. TIC: 217327.

Ziegler, J.D. 2002. “Transmittal of Information Addressing Key Technical Issue (KTI) Agreement Items Radionuclide Transport (RT) 3.06 and Structural Deformation and Seismicity (SDS) 3.02." Letter from J.D. Ziegler (DOE/YMSCO) to J.R. Schlueter (NRC), June 27, 2002, OL\&RC:TCG-1316, 0628023167, with attachment. ACC: MOL.20020819.0283. 
Revision 1

INTENTIONALLY LEFT BLANK 
Revision 1

APPENDIX E

ALCOVE 8-NICHE 3 PRETEST PREDICTIONS

(RESPONSE TO RT 3.06 AIN-1 AND SDS 3.02 AIN-1) 


\section{Note Regarding the Status of Supporting Technical Information}

This document was prepared using the most current information available at the time of its development. This Technical Basis Document and its appendices providing Key Technical Issue Agreement responses that were prepared using preliminary or draft information reflect the status of the Yucca Mountain Project's scientific and design bases at the time of submittal. In some cases this involved the use of draft Analysis and Model Reports (AMRs) and other draft references whose contents may change with time. Information that evolves through subsequent revisions of the AMRs and other references will be reflected in the License Application (LA) as the approved analyses of record at the time of LA submittal. Consequently, the Project will not routinely update either this Technical Basis Document or its Key Technical Issue Agreement appendices to reflect changes in the supporting references prior to submittal of the LA. 


\section{APPENDIX E \\ ALCOVE 8-NICHE 3 PRETEST PREDICTIONS (RESPONSE TO RT 3.06 AIN-1 AND SDS 3.02 AIN-1)}

This appendix provides responses for Key Technical Issue (KTI) agreements Radionuclide Transport (RT) 3.06 additional information needed (AIN)-1 and Structural Deformation and Seismicity (SDS) $3.02 \mathrm{AIN}-1$. These KTI agreements relate to the documentation of pretest predictions for the Alcove 8-Niche 3 (also referred to as Niche 3107) tests.

\section{E.1 KEY TECHNICAL ISSUE AGREEMENTS}

\section{E.1.1 RT 3.06 AIN-1 and SDS 3.02 AIN-1}

Agreement SDS 3.02 was reached during the U.S. Nuclear Regulatory Commission (NRC)/U.S. Department of Energy (DOE) Technical Exchange and Management Meeting on Structural Deformation and Seismicity held October 11 to 12, 2000, in Las Vegas, Nevada (Schlueter 2000). The agreement was reached during the course of this meeting in the discussion of SDS Subissue 3, Fracturing and Structural Framework.

Agreement RT 3.06 was reached during the NRC/DOE Technical Exchange and Management Meeting on Radionuclide Transport held December 5 to 7, 2000, in Berkeley, California (Reamer and Williams 2000). During the course of this meeting, RT Subissue 3, Radionuclide Transport through Fractured Rock, was discussed and agreement RT 3.06 was reached.

Both AINs request the following:

\section{RT 3.06 and SDS 3.02}

The NRC needs DOE to document the pre-test predictions for the Alcove 8-Niche 3 work. DOE responded that pre-test predictions for Alcove 8-Niche 3 work will be provided to NRC via letter report (Brocoum to Greeves) by mid-January 2001.

In response to these agreements, the DOE provided on March 12, 2001, the pretest predictions for the Alcove 8-Niche 3 tests (Brocoum 2001). NRC staff subsequently provided review comments on the DOE initial response and identified three AINs resulting in RT 3.06 AIN-1 and SDS 3.02 AIN-1 (Reamer 2002).

Both AINs request the following:

\section{RT 3.06 AIN-1 and SDS 3.02 AIN-1}

1) Provide the pretest predictions for the Phase II tests (flow and transport) for the Line-Release (Fault) Test and the Large Plot Test

2) Provide clarification of whether the tracer transport results for the small plot tests discussed in the pretest prediction report, and the pretest predictions in 
Attachment II, are the pretest predictions for the Small Plot Test or the Line Release (Fault) Test or both

3) Provide clarification on the specific test objectives of the Line Release (Fault) Test

An initial response to these was provided to the NRC (Ziegler 2002), which satisfied items 2 and 3 of the above NRC request. The only remaining AIN is pretest predictions for the Alcove 8-Niche 3 Phase II testing (Schlueter 2003).

\section{E.1.2 Related Key Technical Issue Agreements}

KTI agreements RT 3.06 and SDS 3.02 are related to agreements RT 3.05, SDS 3.01 and Unsaturated and Saturated Flow Under Isothermal Conditions (USFIC) 6.03. The NRC requested that the DOE address eight additional comments in its response to RT 3.05, SDS 3.01, and USFIC 6.03 (Schlueter 2003). However, as pointed out earlier, the DOE and the NRC agreed that the pretest predictions for the Phase II tests at Alcove 8-Niche 3 constitute the final piece of information needed to fully address RT 3.06 and SDS 3.02.

\section{E.2 RELEVANCE TO REPOSITORY PERFORMANCE}

These KTI agreements relate to the DOE providing documentation of pretest predictions for the Alcove 8-Niche 3 work.

During the October 2000 SDS Technical Exchange (Schlueter 2000), Subissue 3, Fracturing and Structural Framework, was discussed. The NRC expressed concerns about (1) the role of mineralized fractures in the unsaturated zone, (2) the technical basis for fracture-related parameters used in process models, and (3) tests to calibrate seepage models (Schlueter 2003). Agreement SDS 3.02 was reached with the intent to "fracture-inform" the pretest predictions for the Alcove 8-Niche 3 tests (Schlueter 2003).

During the December, 2000, RT Technical Exchange (Reamer and Williams 2000), the DOE presentation for Subissue 3, Radionuclide Transport Through Fractured Rock, included a discussion of acceptance Criterion 2a. During that discussion, it was noted that the breakthrough curves had been developed for reactive (sorbing), nonreactive (nonsorbing), and colloidal tracers from field tests. The NRC was concerned that the modeling approach of transport through fractured rock was less established than in porous media. While recognizing the Alcove 1 test provided data for developing breakthrough curves for nonsorbing tracer transport through fractured tuff, the NRC requested pretest predictions of the Alcove 8-Niche 3 tests, a meso-scale field test, as a means to enhance confidence in the understanding of the flow and transport processes, particularly for nonsorbing and moderately sorbing tracers (Reamer and Williams 2000; Schlueter 2003).

Agreement RT 3.06 and SDS 3.02 are relevant to the repository performance because results and data from the hydrological tests at Alcove 8-Niche 3 are relied upon for building confidence in the understanding of flow and transport processes through fractured rock and for validation of unsaturated zone process models supporting total system performance assessment. Specifically, matrix diffusion and seepage, as investigated in the Alcove 8-Niche 3 test, are two important 
processes by which to determine the performance of the unsaturated zone of Yucca Mountain as a natural barrier. Note, however, that the tests do not provide results that directly support the development or abstraction of unsaturated zone process models for total system performance assessment.

\section{E.3 RESPONSE}

The Alcove 8-Niche 3 tests are aimed at evaluating unsaturated zone flow, seepage response, and matrix diffusion processes. Alcove 8 (located in the Enhanced Characterization of the Repository Block Cross-Drift) has been excavated for liquid releases through a fault (fault tests) and through a network of fractures (large-plot tests). Niche 3 (located in the main drift of the Exploratory Studies Facility (ESF), approximately $20 \mathrm{~m}$ below Alcove 8) serves as the site for monitoring wetting-front migration, seepage of water originating at Alcove 8 , and tracer concentration in seeping water. Both fault testing and large-plot testing were originally planned to include two phases, each phase involving water release with and without tracers. Phase I corresponds to experimental conditions characterized by positive water pressure head $(2 \mathrm{~cm})$ at the infiltration sites (at the fault or the large plot). For Phase I testing, which is still in progress, the fault or fracture network is saturated near the infiltration plots. For Phase II testing, much smaller infiltration rates (i.e., more negative water pressure heads) will be used.

The original Phase I predictions for flow, seepage, and transport were provided in a previous transmittal (Brocoum 2001; Ziegler 2002). The original test plan called for performing the Phase I flow testing, then tracer transport testing in the fault, followed by the same types of testing using the large plot. Phase I flow and tracer testing was completed in the fault, and Phase I flow testing was performed using the large plot. Phase I tracer transport testing using the large plot was delayed pending revisions in the test plan and pretest predictions.

This appendix develops new pretest predictions for the final part of the flow testing component of the Phase I large-plot tests (which defines the initial hydrologic conditions for subsequent transport testing) and for the Phase I tracer testing part. As described in Section E.4, the predictive model has been refined from the original pretest predictions (Brocoum 2001) by calibrating to available Phase I large-plot flow test data, and incorporating modified test conditions (a detailed discussion of changes in test design is given in Section E.4.2.1). In addition, this appendix develops pretest predictions for the Phase II flow and tracer transport large-plot tests based on this updated model.

The DOE no longer has plans for Phase II fault testing because the large plot tests are expected to better characterize water flow and tracer transport in a fracture network. Accordingly, the pretest prediction for Phase II of the fault tests is not provided in this appendix.

The information in this report is responsive to NRC's AIN requests RT $3.06 \mathrm{AIN}-1$ and SDS 3.02 AIN-1. The report contains the information that the DOE considers necessary for NRC review for closure of these agreements. 


\section{E.4 BASIS FOR THE RESPONSE}

\section{E.4.1 Test Objectives and Test Settings}

The information for this section is based on In Situ Field Testing of Processes (BSC 2003a, Section 6.12). The major objectives of Alcove 8-Niche 3 tests include:

- Quantification of meso-scale (approximately $20 \mathrm{~m}$ ) infiltration and seepage processes in the unsaturated zone of Yucca Mountain

- Estimation of relations between relative permeability and water potential for unsaturated flow in fractured rock

- Evaluation of the importance of matrix diffusion in the unsaturated zone transport processes.

Figure E-1a shows the location of the test site within the ESF main drift and the Enhanced Characterization of the Repository Block Cross-Drift. Figure E-1b shows a three-dimensional representation of the test area, including several slanted (near-vertical) boreholes. Alcove 8 is located within the upper lithophysal zone of the TSw (Tptpul). Alcove 8 begins at Cross-Drift station 7+98.236 (BSC 2003a, Section 6.12). An elevation of about 1,094.0 m above mean sea level (amsl) is calculated for station 7+98.236. The elevation at station $0+00$ of Alcove 8 is approximately $0.5 \mathrm{~m}$ above station $7+98.236$ or about $1,094.5 \mathrm{~m}( \pm 0.15 \mathrm{~m})$ amsl based on Alcove 8 design drawings (BSC 2003a, Section 6.12). Niche 3 is located in the middle nonlithophysal zone of the TSw (Tptpmn). The crown of Niche 3 is approximately 2 to $3 \mathrm{~m}$ lower than the $1,076.7 \mathrm{~m}$ amsl crown elevation of the ESF at station $31+07$. The location of the Tptpul-Tptpmn contact is approximately $1,080 \mathrm{~m}$ amsl, based on GFM3.1 data (BSC 2003a, Section 6.12).

A distinctive feature of the test bed in Alcove 8 is a near-vertical fault that cuts across the floor (Figure E-2). It is open on the ceiling of Niche 3 and appears to be closed along the floor of Alcove 8. To facilitate ponded releases of water, a trench approximately $5 \mathrm{~cm}$ wide and approximately $5 \mathrm{~cm}$ deep was etched along this fault for the fault tests.

Niche 3 is approximately $4 \mathrm{~m}$ wide and extends to approximately $14 \mathrm{~m}$ from the centerline in the ESF main drift. The distance from the ceiling to the floor of the niche gradually drops from $3.25 \mathrm{~m}$ at the opening to $2.5 \mathrm{~m}$ toward the midpoint of the niche. Three $9.0-\mathrm{m}$-long, $0.0762-\mathrm{m}$ diameter horizontal boreholes were drilled approximately $0.5 \mathrm{~m}$ above the ceiling, parallel with the long axis of the niche. Additionally, there are seven $6.0-\mathrm{m}-\mathrm{long}, 0.0762-\mathrm{m}$ diameter boreholes drilled inside radially outward from the side walls of the niche (Figure E-3). The fault is visible along the ceiling of Niche 3 . 

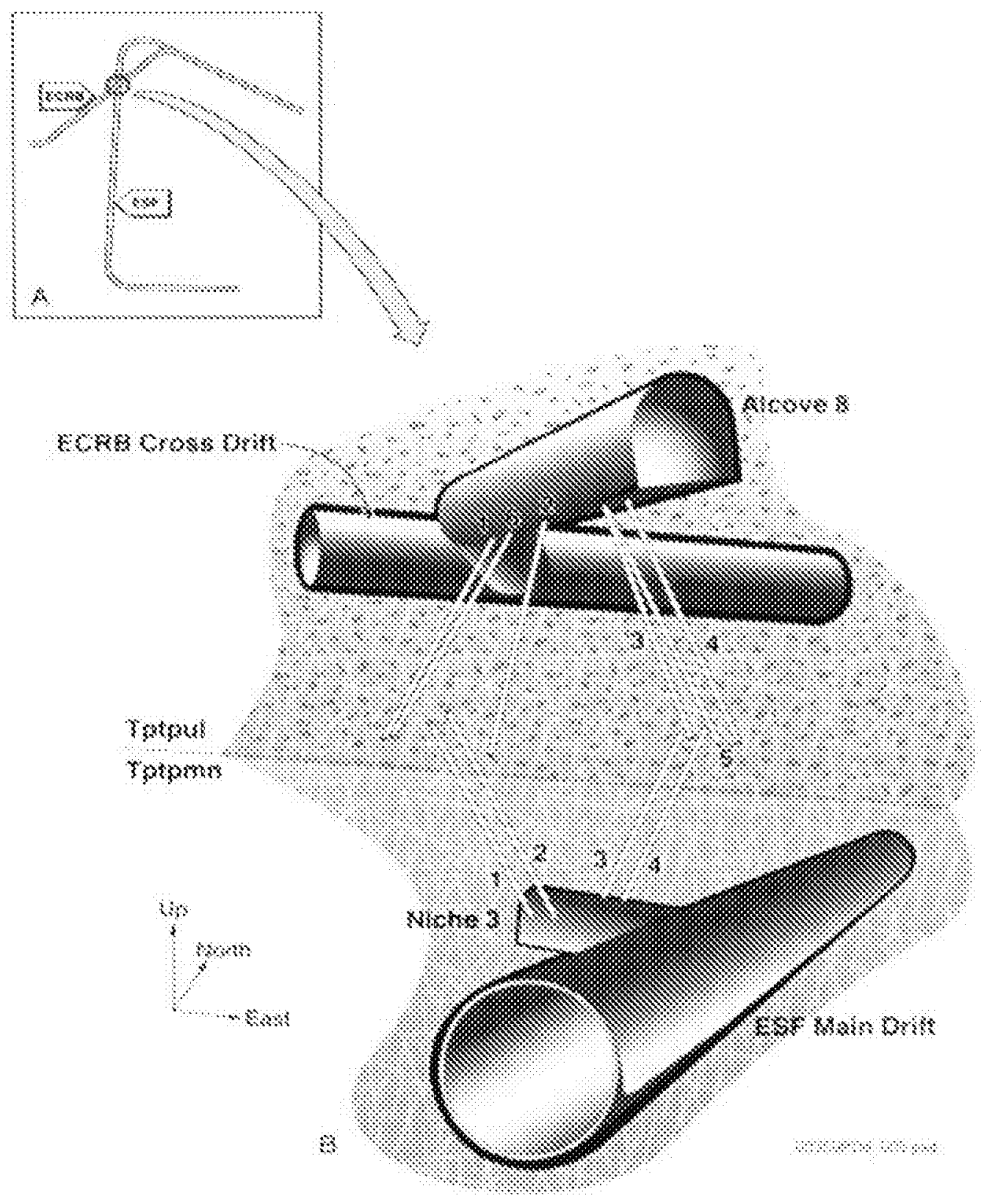

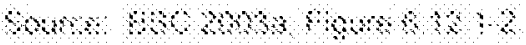

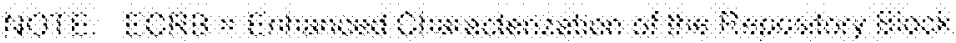

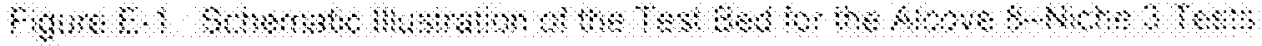




\section{3)}
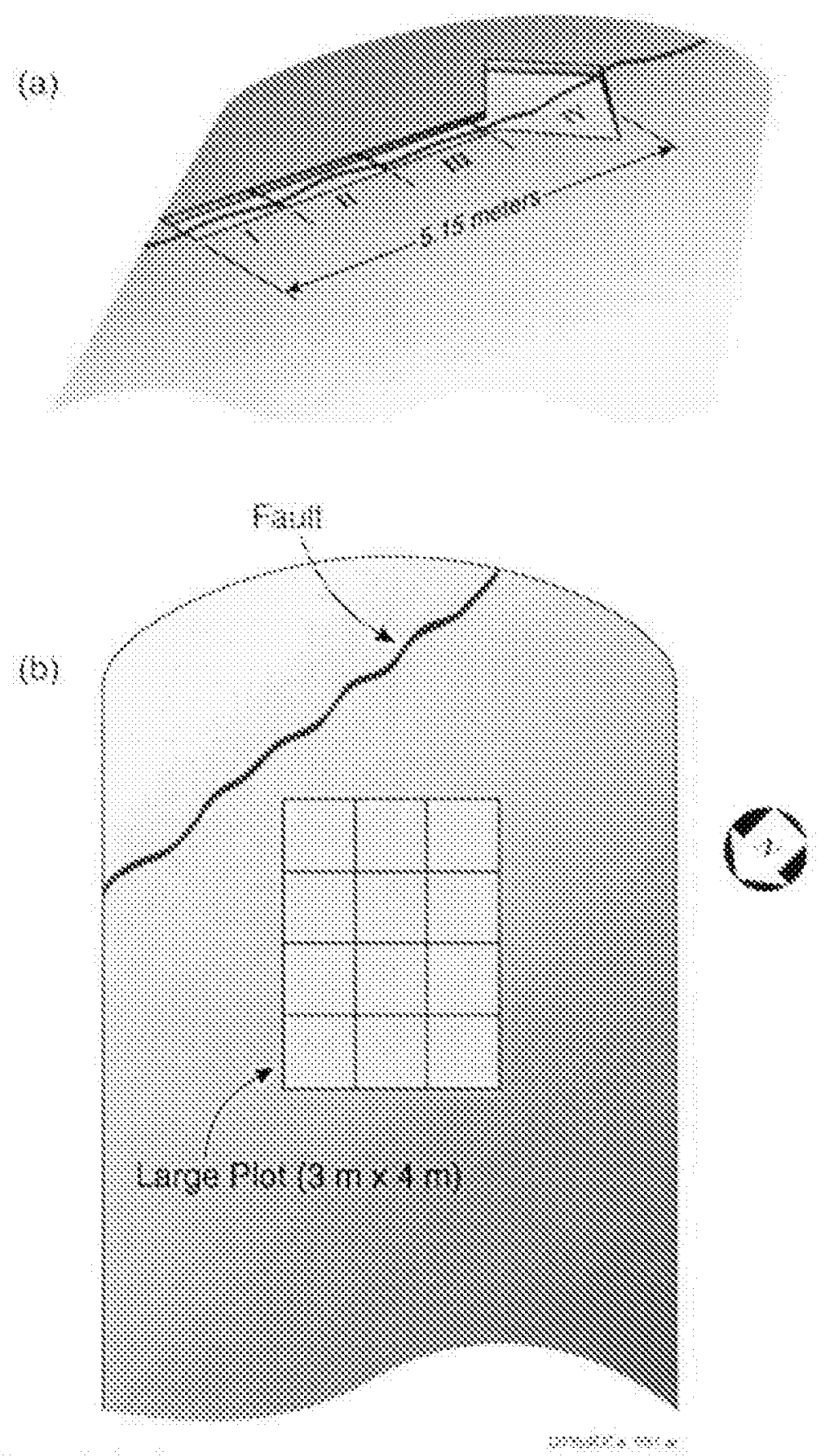

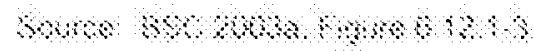

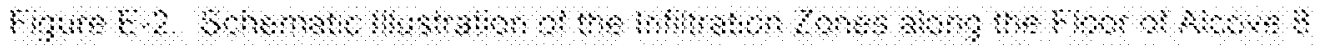




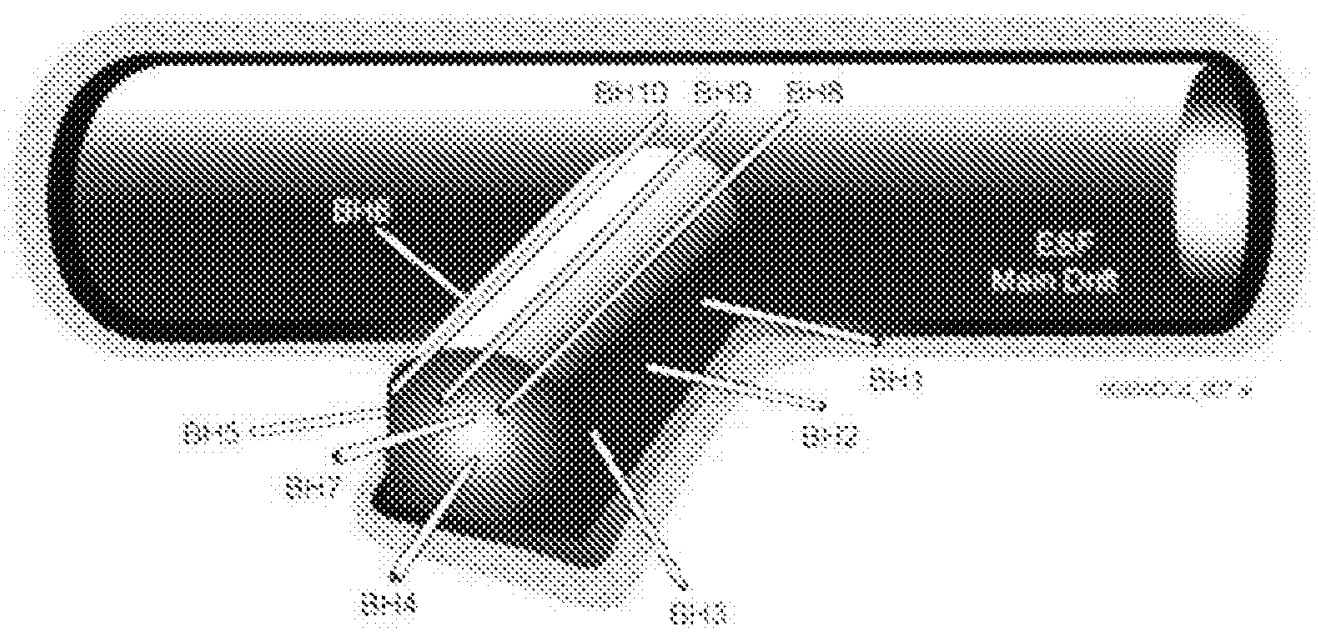

Mos 3 s.

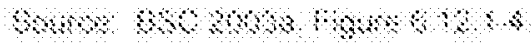

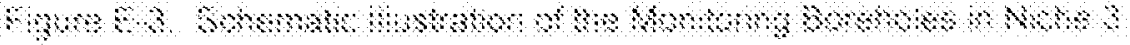

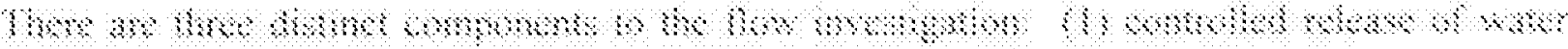

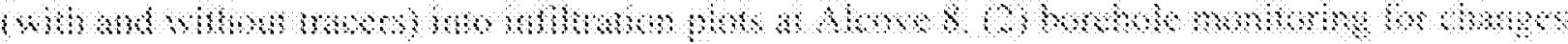

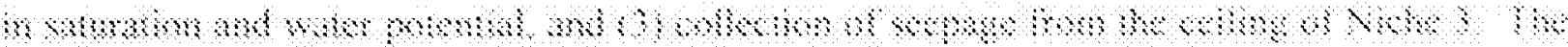

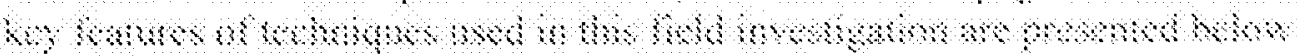

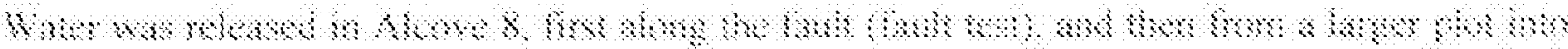

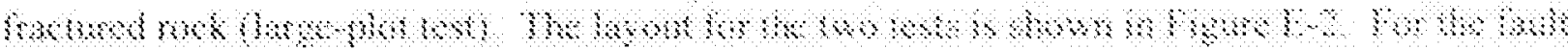

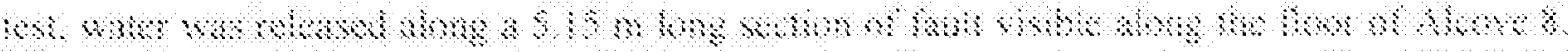

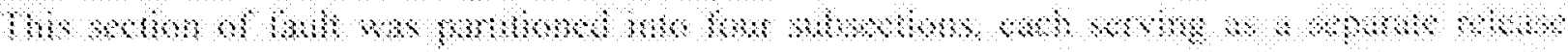

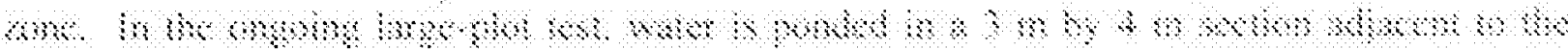

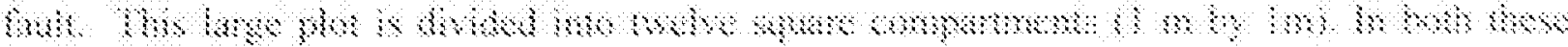

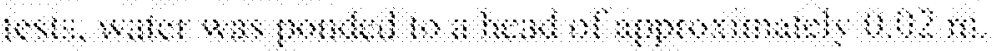

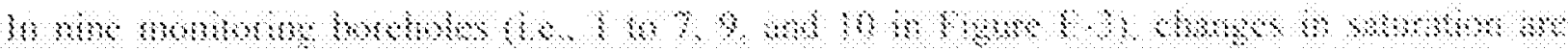

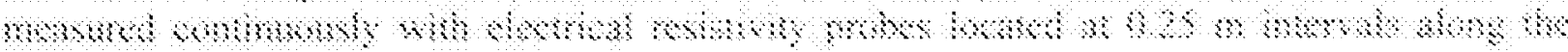

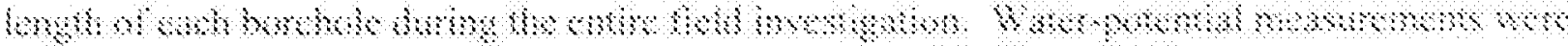

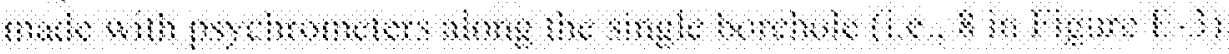

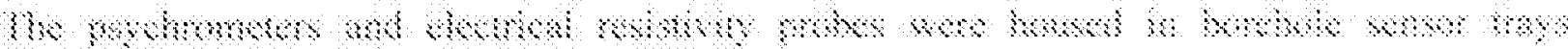

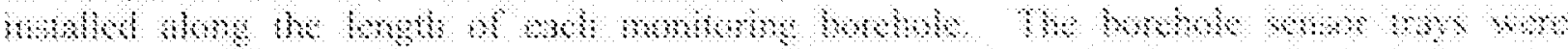

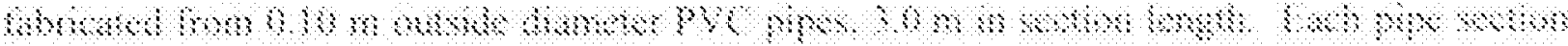

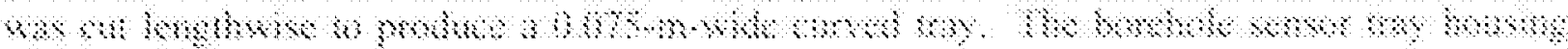

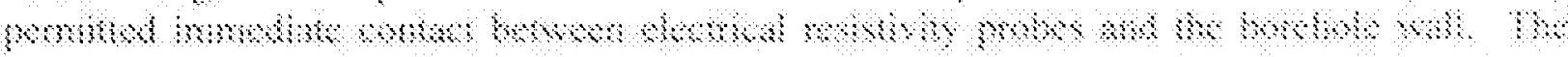

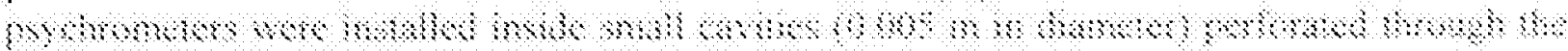

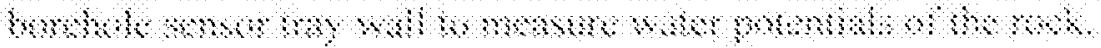


An automated water-collection system was designed to capture seepage from the niche ceiling. With this system, water dripping from the niche ceiling is collected in plastic trays and diverted to collection bottles. These bottles have been installed with pressure transducers to periodically measure the collected amount of seepage water.

Both fault tests and large-plot tests were planned to include two phases involving water release with and without tracers. Phase I corresponds to an experimental condition characterized by positive water pressure head $(2 \mathrm{~cm})$ at the infiltration plots. In this case, the fault or fracture network is saturated (at least near the infiltration plots). Phase II corresponds to an experimental condition characterized by much smaller infiltration rates (or more negative water pressure heads) than Phase I. Although useful data on the infiltration and transportation properties of the fault were acquired during Phase I, Phase II of the fault tests is no longer planned because the large plot tests are expected to better characterize flow and transport behavior in the fracture network at Alcove 8-Niche 3. More detailed discussions of fault-test results (Phase I) and model analyses of the test results are given in UZ Flow Models and Submodels (BSC 2003b, Section 7.6) and In Situ Field Testing of Processes (BSC 2003a, Section 6.12).

\section{E.4.2 Large-Plot Test and Modeling}

Information for this section is based on the following data:

- DTNs: LB0306A8N3LIQR.001, Fault Infiltration Test from Alcove 8 to Niche 3 (9/18/2002-10/16/2002), and LB0308A8N3SEEP.001, Seepage rate data for Alcove 8-Niche 3 large plot tests (Phase I)

- DTN: LB0308A8N3TRTM.001, Water front travel-time data for Alcove 8-Niche 3 large plot tests (Phase I)

- Data to be submitted, Model calibration using seepage rate data from Alcove 8-Niche 3 large-plot tests (Phase I)

- Data to be submitted, Model prediction for Alcove 8-Niche 3 large-plot tests (Phase I and Phase II).

\section{E.4.2.1 Experimental Results and Analysis}

The large-plot tests involve the release of water (without and with tracers) under both ponded (Phase I) and nonponded (Phase II) conditions in a 3- by 4-m plot referred to in this document as the large plot (Figure E-4). The early data from Phase I were used to calibrate a model for predicting the future test results. Details of the site, the experimental setup, and monitoring for the large-plot test are the same as in the previous section (Section E.4.1) with the following additions. Ponded release of water to the 3- by 4-m section along the floor of Alcove 8 began on August 20, 2002. The infiltration zone was divided into 12 sections each 1 by $1 \mathrm{~m}$ (Figure E-4). Observations from this phase of testing include the seepage rates measured at Niche 3. 


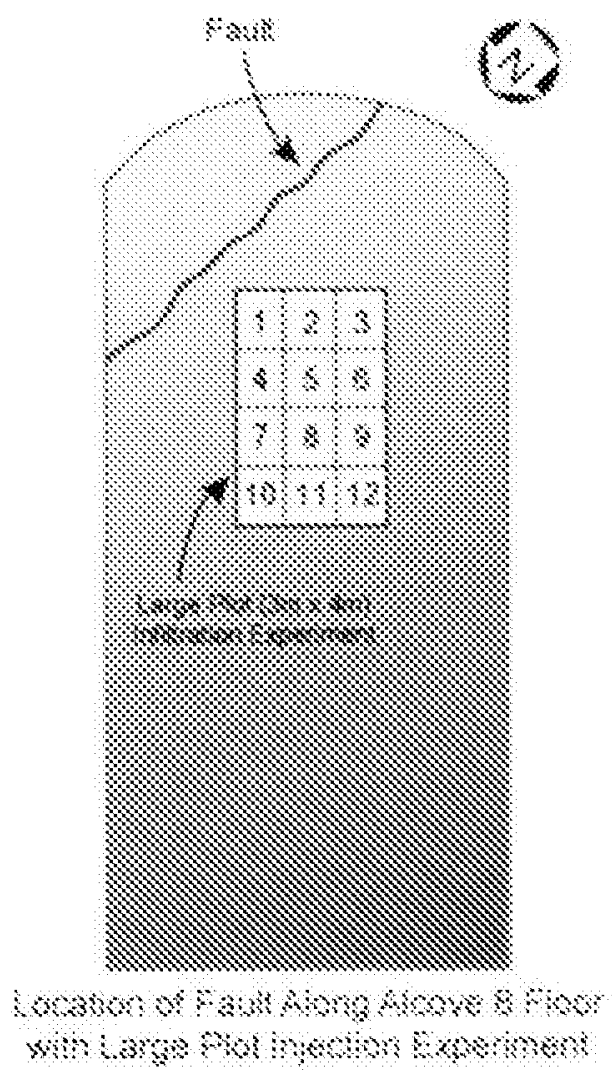

+s

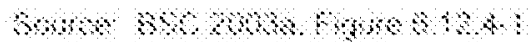

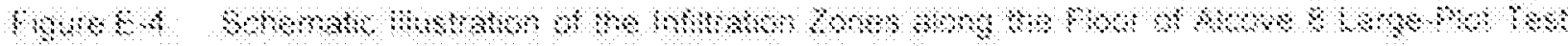

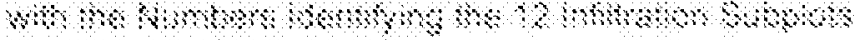

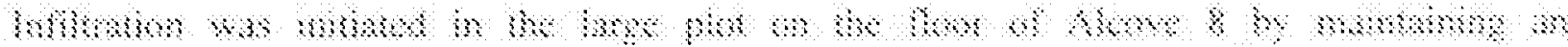

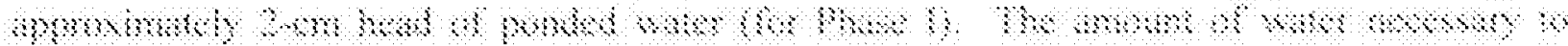

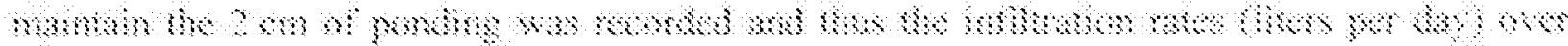

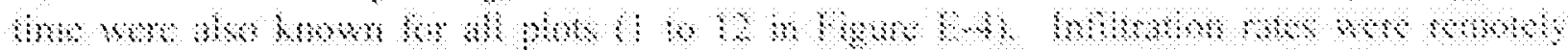

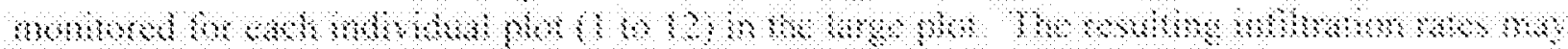

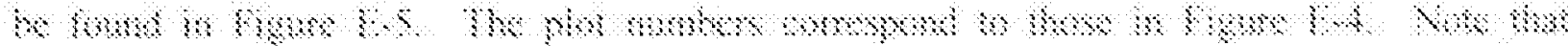

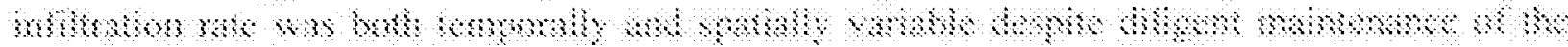

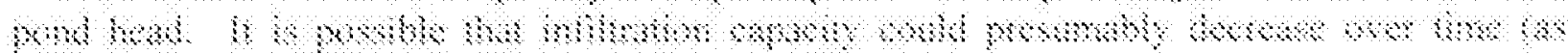

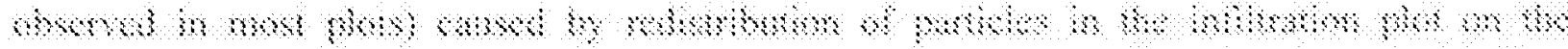

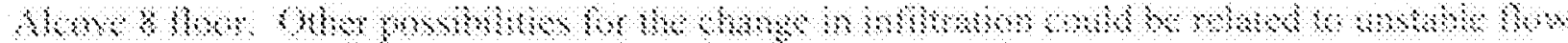

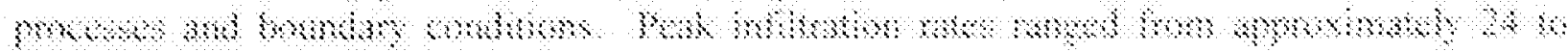
1ง)

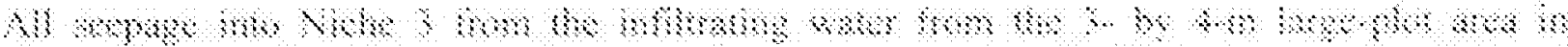

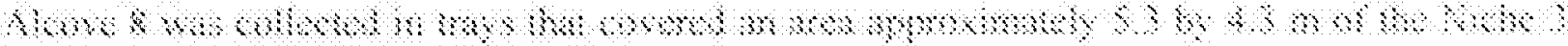

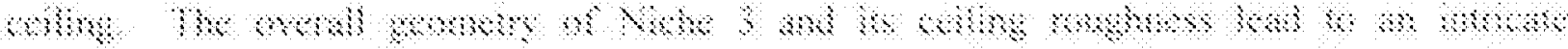

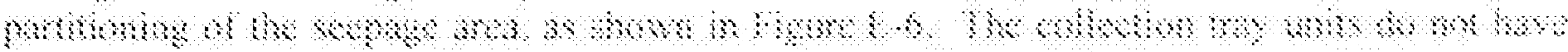

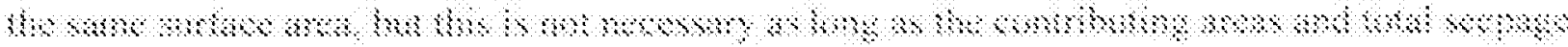
whmono whe knows. 

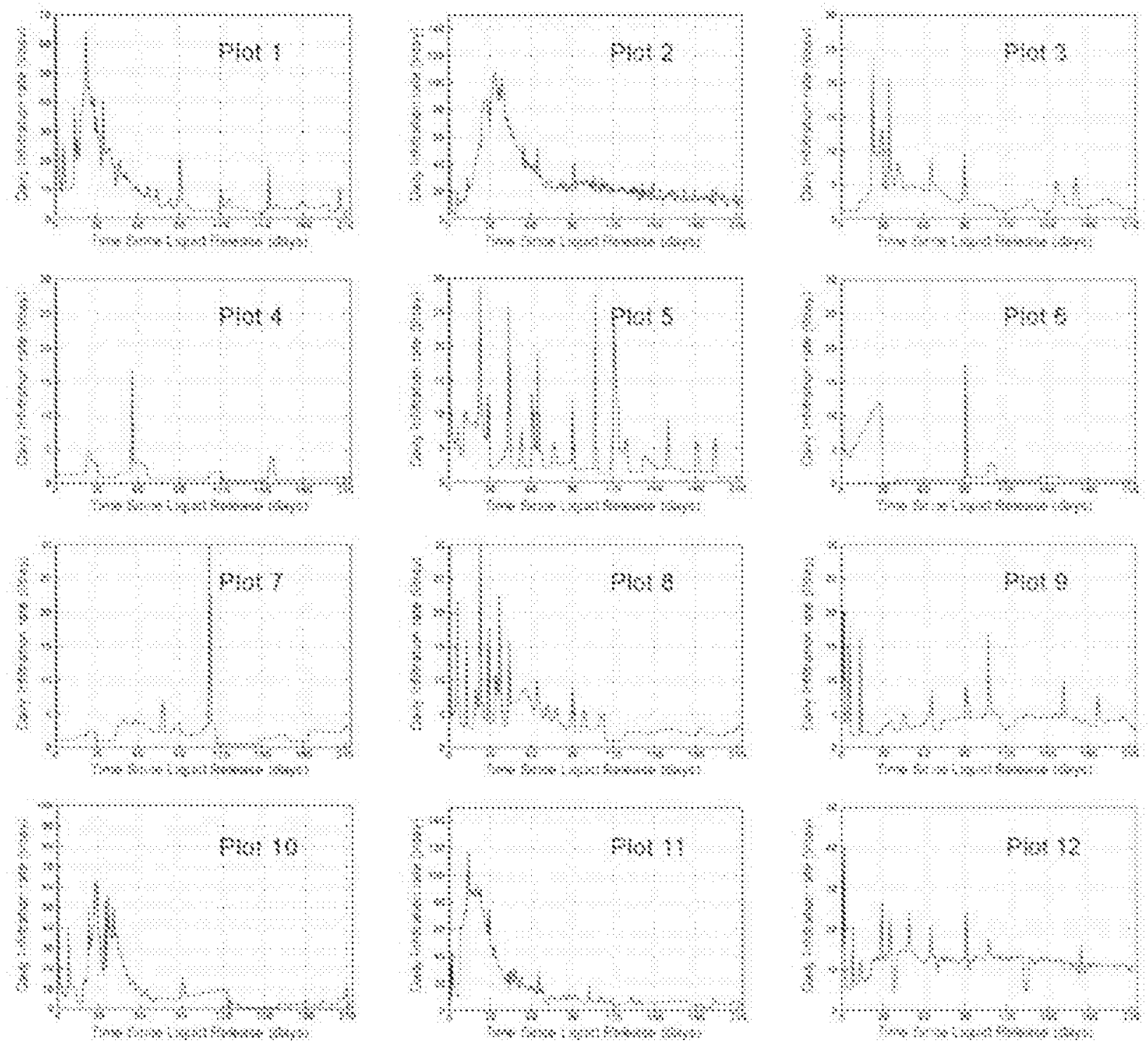

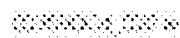

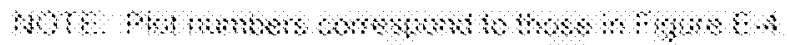

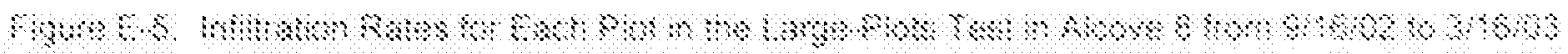




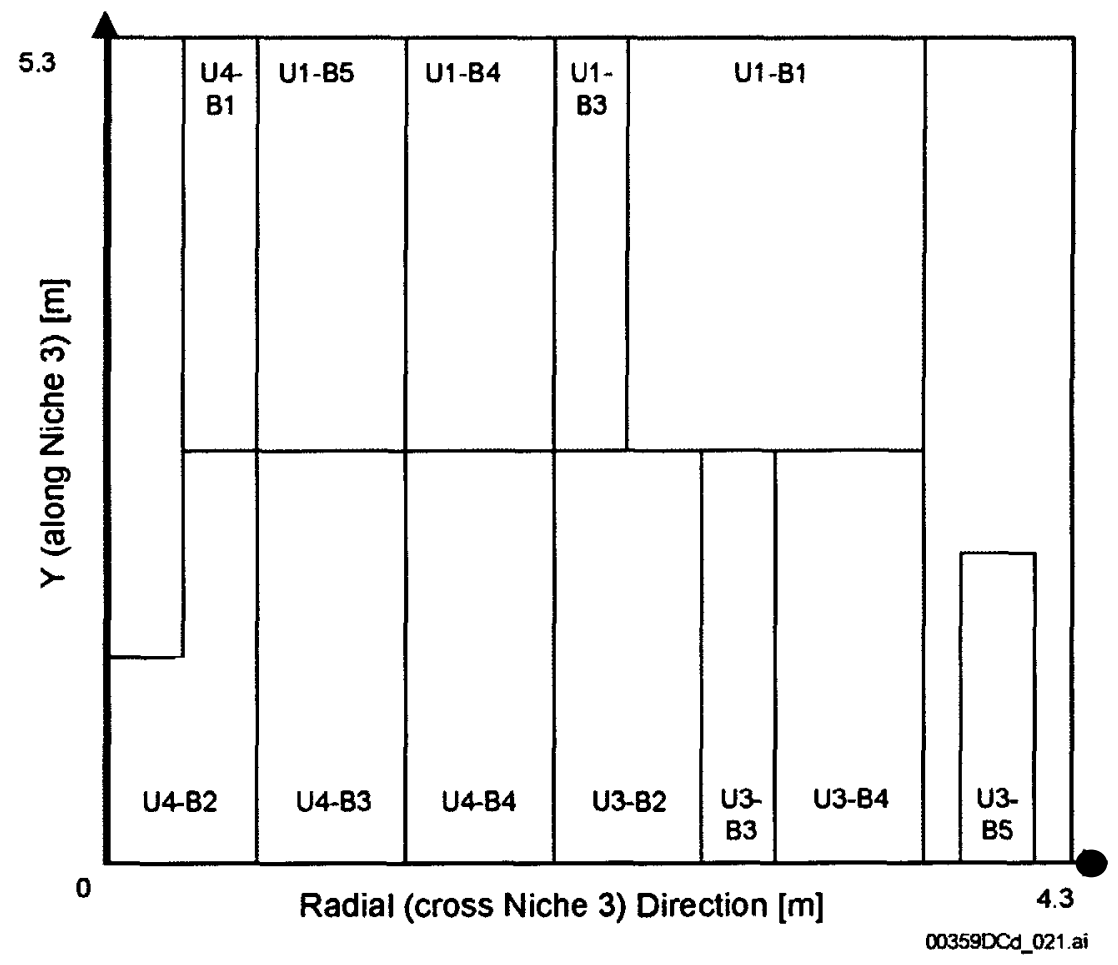

Figure E-6. Diagram of the Trays Collecting Seepage from the Ceiling of Niche 3

Seepage water from each of these trays was separately collected and stored in containers, each connected to a pressure transducer (Setra C204, 0 to 25 psi range) used to remotely monitor seepage rate and volume. Using this system, the seepage rates were measured for each container related to each collection tray.

The seepage measured over time from each tray for the period of September 16, 2002, to March 16, 2003, may be seen in Figure E-7. While the arrival time (initial breakthrough) of the seepage wetting front occurred at a relatively consistent time at all trays (approximately 30 days), the peak seepage rate and timing of the occurrence of those peaks were variable. This large variability in seepage response was consistently observed in the large-plot studies.

In addition to the data provided by the large-plot test, a full periphery geologic map of Niche 3 has been prepared by the U.S. Geological Survey (DTN: GS030108314224.001) and related to the position of the capture zones listed in Figure E-6. No direct relationship could be observed between the seepage in the trays and fracture presence or characteristics. This may be partially due to the limited nature of the fracture data. 

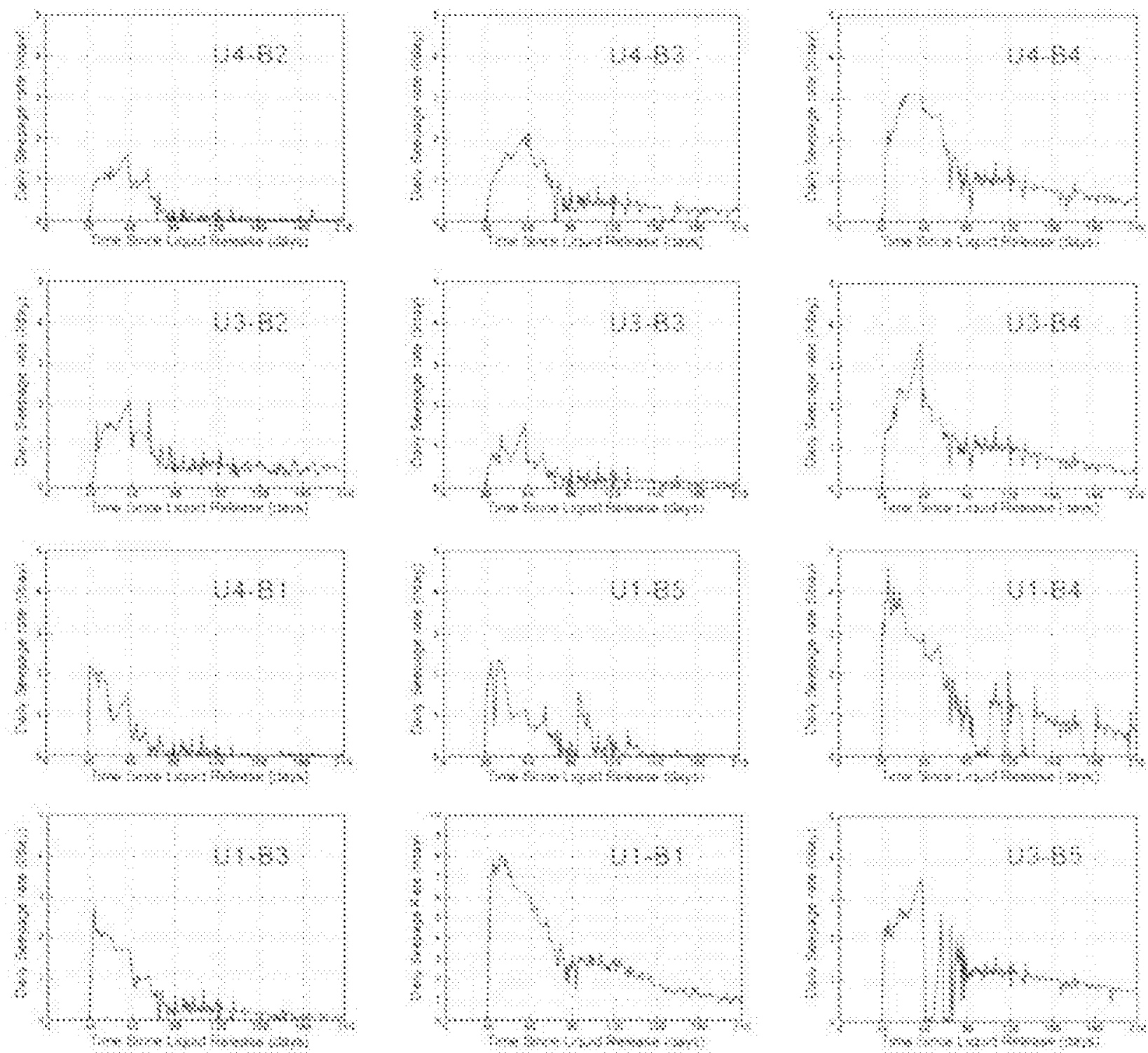

30 काष

$3+\infty$

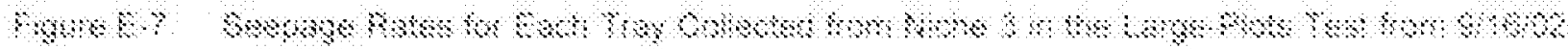

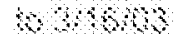

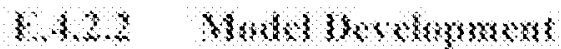

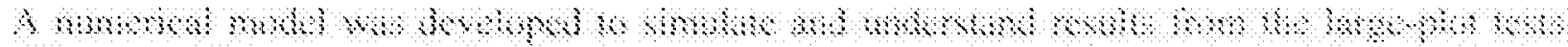

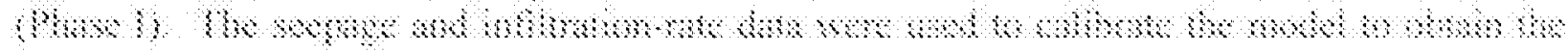

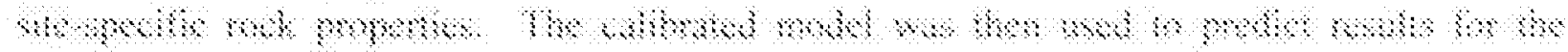

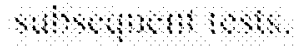

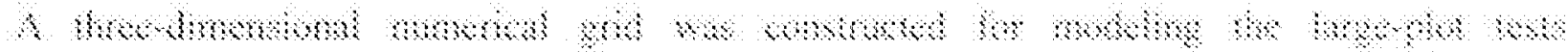

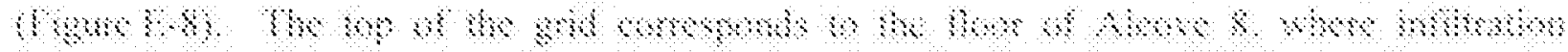

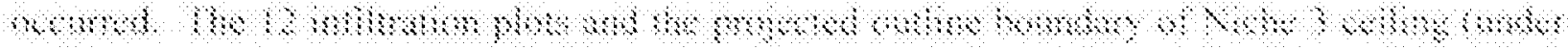

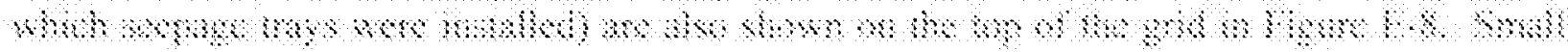




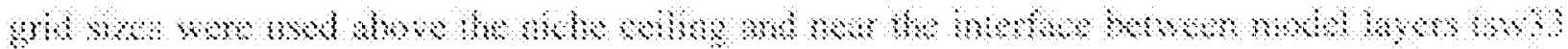

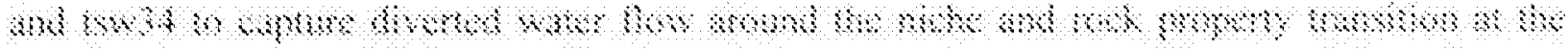

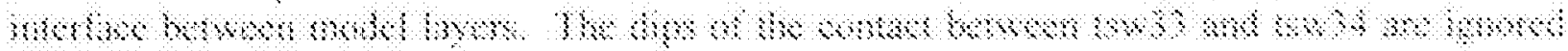

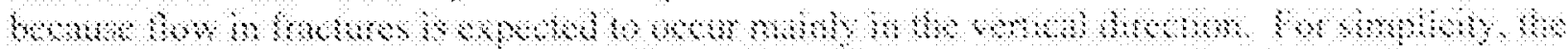

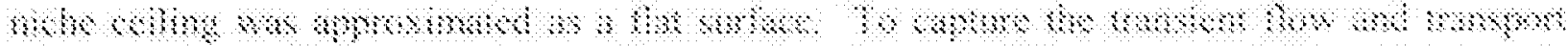

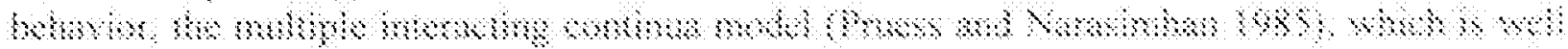

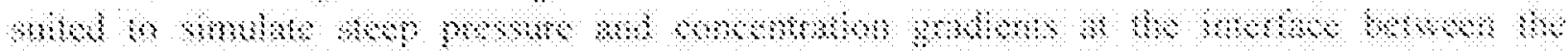

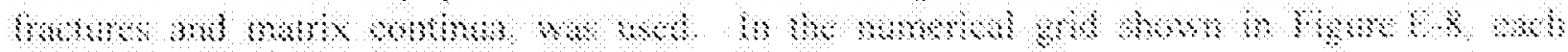
s)

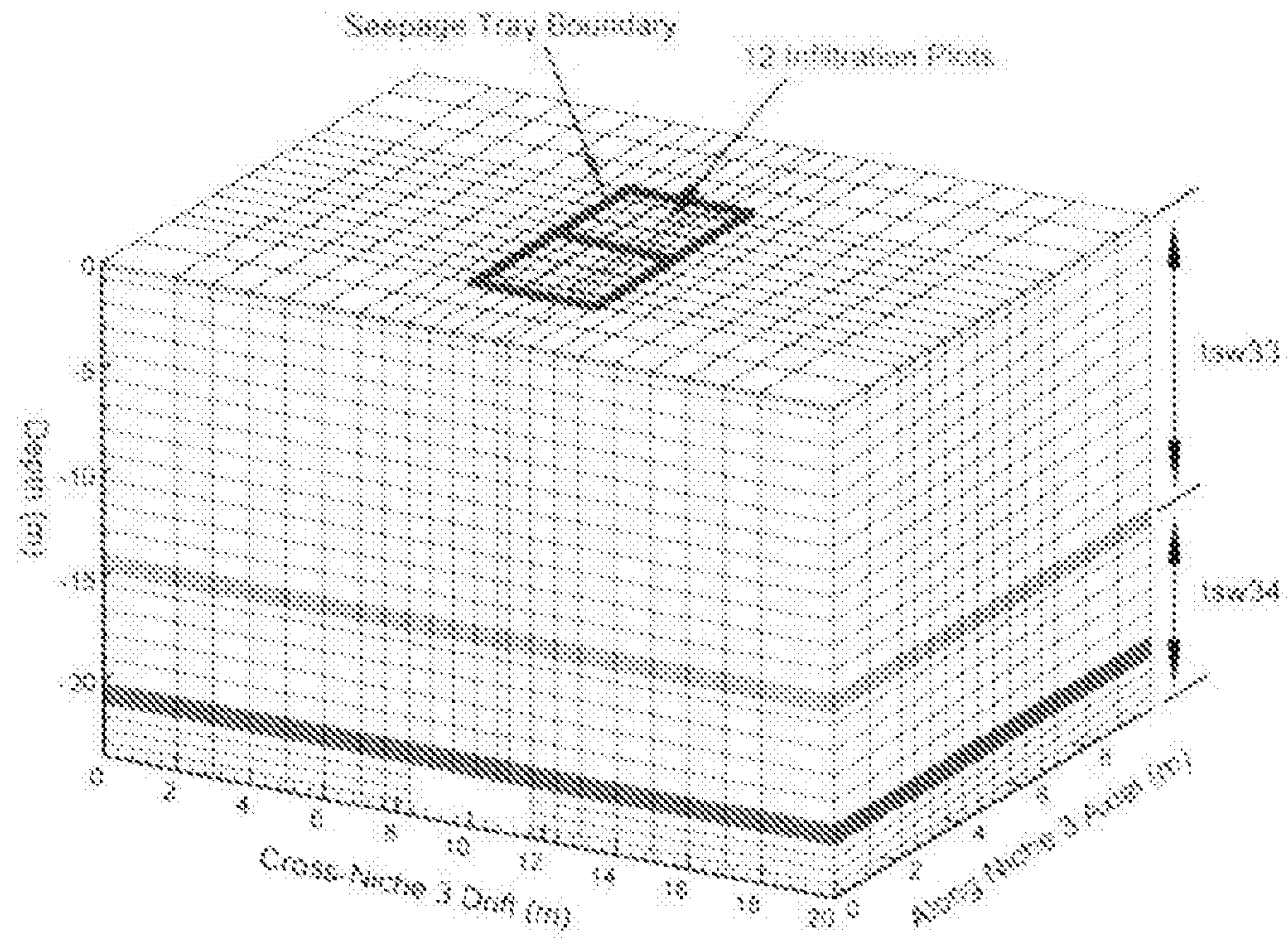

s४ מn:

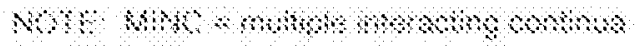

noss

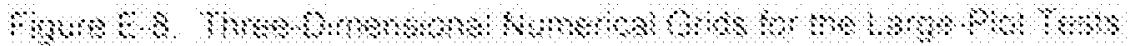

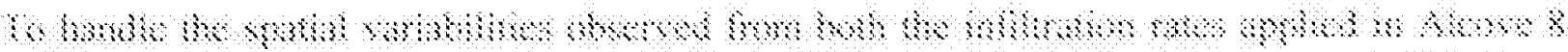

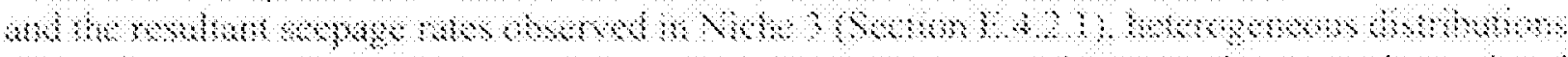

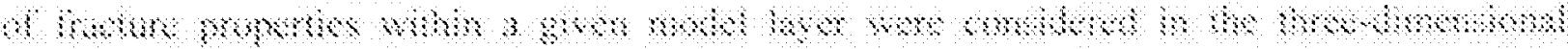

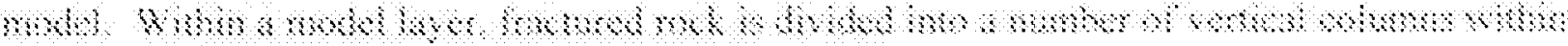

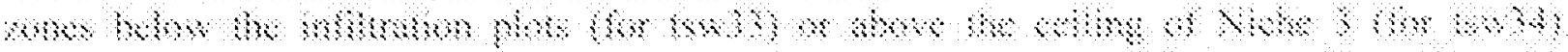

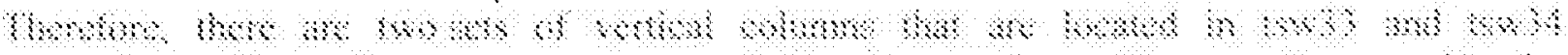

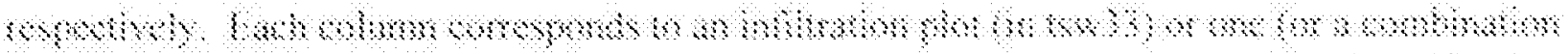

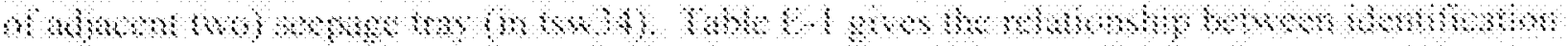

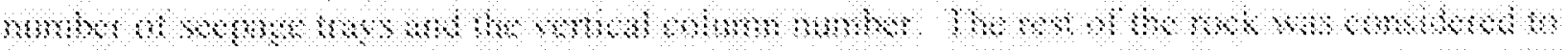

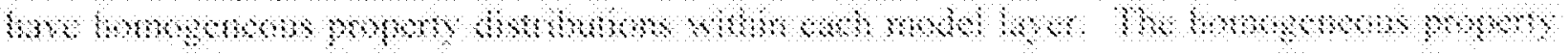

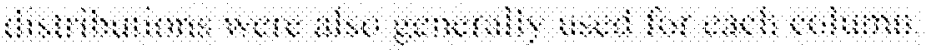


Table E-1. Relation between Seepage-Tray Identification Number and the Vertical Column Number

\begin{tabular}{|c|c|}
\hline Seepage Tray & Vertical Column \\
\hline U4-B2 & 1 \\
\hline U4-B3 & 2 \\
\hline U4-B4 & 3 \\
\hline U3-B2 & 4 \\
\hline U3-B3 & 5 \\
\hline U3-B4 & 6 \\
\hline U4-B1 & 7 \\
\hline U1-B5 & 8 \\
\hline U1-B4 & 9 \\
\hline (U1-B3) +1/4(U1-B1) & 10 \\
\hline $1 / 4(U 1-B 1)$ & 11 \\
\hline $1 / 2(U 1-B 1)$ & 12 \\
\hline
\end{tabular}

Previous fracture-network modeling demonstrated that unsaturated flow paths within a fracture network are generally vertical (as a result of gravity-dominated flow behavior) (Liu et al. 2002), supporting the use of the column-based heterogeneous distributions. Use of these vertical columns may be able to approximately capture flow behavior associated with these flow paths. Another consideration for using the simple column-based approach is data limitation. As in any field test in the area of subsurface hydrology, limited data are available for characterizing detailed flow paths between Alcove 8 and Niche 3. A simple model of heterogeneity generally involves a relatively small number of parameters that need to be calibrated. The usefulness and limitations of this approach will be investigated by comparing prediction results with future test observations.

Similar to the fault tests (Section E.4.1), considerable temporal variability in the infiltration rate occurred during the large-plot tests, although a constant water-pressure head $(2 \mathrm{~cm})$ was applied at the infiltration plot (Section E.4.2.1). This may result from in-filled materials within the fractures just below the infiltration plots (BSC 2003b, Section 7.6). In other words, the effective permeability of fractures just below the plot changed with time, although fracture properties may not change for zones away from the infiltration plots. Based on these considerations, infiltration rates (that are both spatially and temporally variable) at Alcove 8 , rather than the pressure head, were used as the boundary condition at the large infiltration plot. The side boundary corresponds to zero-flow conditions (in the direction perpendicular to the simulation domain). The niche wall boundary was modeled by a zero-capillary-pressure condition, representing capillary barrier effects. The bottom boundary corresponds to free drainage conditions. As previously noted, Flint (1998, p. 44, Table 7) reported that under ambient conditions, matrix saturation is 0.72 for tsw33 and 0.85 for tsw34. Because of the disturbance of nearby fault tests, the actual matrix saturations are expected to be higher than these values. In the model, a value of 1.0 averaged with the saturation value reported by Flint (1998, p. 44, Table 7) was used as the initial matrix saturation value for each model layer. Because of this approximation, a larger degree of uncertainty is expected to exist for initial conditions assigned in the model. Other initial conditions assumed for the rock mass within the model domain are that the rock is solute-free and has a small water saturation $(0.0105)$ in fractures. 


\section{E.4.2.3 Model Calibration}

Model calibration is needed to develop site-specific rock properties before a meaningful prediction of future test results can be made. Model calibration was performed using the inverse modeling code iTOUGH2 V4.0 (LBNL 1999a). The observed spatial distribution of the seepage rate on the ceiling of Niche 3 was explicitly considered. In addition to the observed total seepage rate as a function of time, the seepage rates from individual intersections between the niche ceiling and the vertical columns in tsw34 (Table E-1) were matched in the model calibration procedure. Note that Columns 1 to 9 in tsw34 correspond to individual seepage trays. In this case, the seepage rates used in model calibration for a column are the same as those observed from the corresponding tray. The situation is more complicated for Columns 10 to 12. Seepage rates (as a function of time) for Column 10 were taken as a summation of seepage rates from Tray U1-B3 and a quarter of the seepage rates from Tray U1-B1. Seepage rates for Columns 11 and 12 were taken as one-quarter and one-half of seepage rates from Tray U1-B1, respectively.

Model calibration adjusts rock properties such that modeling results match field observations. For model layer tsw33, calibrated rock properties are fracture permeabilities and van Genuchten alphas for vertical columns (corresponding to individual infiltration plots) and for the rest of rock mass. An initial guess of fracture permeability for a column was determined by the largest infiltration rate (for time greater than 1 day) at the infiltration plot under water pressure head of $2 \mathrm{~cm}$. The largest infiltration rate (per unit area) is considered to be the saturated hydraulic conductivity for the column. A scale factor was used to calibrate all these fracture permeability values for the columns in tsw33 such that calibrated fracture permeability for a vertical column is equal to its initial guess, multiplied by the calibrated scale factor. This way the effects of observed spatial variability of infiltration rate were approximately captured by the model calibration. (Note that a vertical column in tsw33 has a uniform property distribution.) For model layer tsw34, calibrated rock properties are again fracture permeabilities and van Genuchten alphas for vertical columns (corresponding to seepage trays) and for the rest of rock mass. While most vertical columns have uniform distributions in this model layer, Columns 1, 6, 11, and 12 were further divided into two parts, upper and lower. The upper and lower parts have different rock properties for each of the columns mentioned above in order to consider rock-damage effects on rock properties near the niche ceiling. The lower parts correspond to rock between the niche ceiling and $0.4 \mathrm{~m}$ above the ceiling. Fracture porosity calibrated from the fault tests and matrix properties used in fault-test modeling studies are used here. These properties were not varied during model calibration.

Experimental observations from boreholes about $1 \mathrm{~m}$ above the niche ceiling indicate that water-front transport times from the infiltration plots to the niche ceiling are fairly uniform (about 30 days) (DTN: LB0308A8N3TRTM.001). Simulated water transport time is related to initial matrix saturation because of matrix imbibition process. Considering the large degree of uncertainty in initial matrix saturation values used in the model, water transport time data were used as "soft" data only. To do so, zero vertical water flux along the columns at locations about $0.4 \mathrm{~m}$ above the ceiling were treated as observed data for a period of 0 to 20 days. Use of these "data" is equivalent to making sure that water transport times are generally larger than 20 days in the model. Since the major purpose of model calibration is to develop a calibrated model for predicting future test results, and considering that a large degree of uncertainty exists about the 
initial conditions of the model, relatively high weights were given to the seepage rate data at later stage of the Phase I test (time greater than 90 days). Table E-2 lists calibrated rock properties.

Note that the calibration step discussed in this section is an integral part of developing a sound model for predicting future tests to be conducted at Alcove 8-Niche 3. The model is developed using only data from the time before the prediction period. This model-developed based on prior information - is then used for pretest predictions of future experiments, as discussed in the next section.

Table E-2. Calibrated Rock Properties

\begin{tabular}{|c|c|c|c|c|c|}
\hline \multicolumn{2}{|c|}{ Model Layer } & Permeability & Van Genuchten $\alpha$ & Van Genuchten $\mathbf{m}$ & Porosity \\
\hline \multirow{13}{*}{ tsw33 } & Column 1 & $0.9926 \times 10^{-13}$ & \multirow{12}{*}{$0.2453 \times 10^{-3}$} & \multirow{13}{*}{$0.608^{*}$} & \multirow{13}{*}{$0.066^{\star}$} \\
\hline & Column 2 & $0.1685 \times 10^{-12}$ & & & \\
\hline & Column 3 & $0.2959 \times 10^{-13}$ & & & \\
\hline & Column 4 & $0.3146 \times 10^{-13}$ & & & \\
\hline & Column 5 & $0.5569 \times 10^{-13}$ & & & \\
\hline & Column 6 & $0.1845 \times 10^{-13}$ & & & \\
\hline & Column 7 & $0.1314 \times 10^{-13}$ & & & \\
\hline & Column 8 & $0.6757 \times 10^{-13}$ & & & \\
\hline & Column 9 & $0.2470 \times 10^{-13}$ & & & \\
\hline & Column 10 & $0.9786 \times 10^{-13}$ & & & \\
\hline & Column 11 & $0.1864 \times 10^{-12}$ & & & \\
\hline & Column 12 & $0.3332 \times 10^{-13}$ & & & \\
\hline & Rest rock mass & $0.1190 \times 10^{-11}$ & $0.4787 \times 10^{-3}$ & & \\
\hline \multirow{17}{*}{ tsw34 } & Column 1 (upper) & $0.225 \times 10^{-11}$ & $0.5677 \times 10^{-3}$ & \multirow{17}{*}{$0.608^{*}$} & \multirow{17}{*}{$0.010^{*}$} \\
\hline & Column 2 & $0.704 \times 10^{-12}$ & $0.1480 \times 10^{-2}$ & & \\
\hline & Column 3 & $0.448 \times 10^{-14}$ & $0.1152 \times 10^{-2}$ & & \\
\hline & Column 4 & $0.171 \times 10^{-13}$ & $0.3857 \times 10^{-2}$ & & \\
\hline & Column 5 & $0.304 \times 10^{-14}$ & $0.8647 \times 10^{-3}$ & & \\
\hline & Column 6 (upper) & $0.149 \times 10^{-13}$ & $0.2932 \times 10^{-3}$ & & \\
\hline & Column 7 & $0.434 \times 10^{-11}$ & $0.1891 \times 10^{-2}$ & & \\
\hline & Column 8 & $0.614 \times 10^{-13}$ & $0.3208 \times 10^{-2}$ & & \\
\hline & Column 9 & $0.104 \times 10^{-13}$ & $0.5316 \times 10^{-2}$ & & \\
\hline & Column 10 & $0.616 \times 10^{-14}$ & $0.9825 \times 10^{-3}$ & & \\
\hline & Column 11 (upper) & $0.189 \times 10^{-14}$ & $0.3107 \times 10^{-3}$ & & \\
\hline & Column 12 (upper) & $0.143 \times 10^{-13}$ & $0.2424 \times 10^{-3}$ & & \\
\hline & Rest rock mass & $0.495 \times 10^{-12}$ & $0.7399 \times 10^{-3}$ & & \\
\hline & Column 1 (lower) & $0.5012 \times 10^{-12 \star}$ & $0.1275 \times 10^{-2}$ & & \\
\hline & Column 6 (lower) & $0.5012 \times 10^{-12 \star}$ & $0.2052 \times 10^{-2}$ & & \\
\hline & Column 11 (lower) & $0.5012 \times 10^{-12 *}$ & $0.2360 \times 10^{-2}$ & & \\
\hline & Column 12 (lower) & $0.5012 \times 10^{-12 \star}$ & $0.1721 \times 10^{-2}$ & & \\
\hline
\end{tabular}

NOTE: *These properties are not varied during model calibration. 


\section{E.4.2.4 Model Prediction}

This section documents predictions of future Alcove 8-Niche 3 test results. Associated uncertainties in the model prediction are presented in Section E.4.2.5.

After about 210 days of ponded release of water to 12 infiltration plots, the test condition was changed on March 24, 2003, such that water is released to Plots 2 and 12 only. These two plots have the largest infiltration rates at the late stage of the ponded water release. Seepage responses to this focused-infiltration condition are expected to provide information regarding connectivity of flow paths between infiltration plots and individual seepage trays. Then the original test condition (ponded release of water to 12 infiltration plots) will be restored. After approximately steady-state infiltration and seepage processes are reestablished, different tracers are simultaneously introduced into the infiltrating water applied at different infiltration plots. Table E-3 gives the information regarding tracers to be used. Phase II tests (corresponding to 50 percent of the infiltration rate observed at the end of Phase I) will start once the multiple tracer tests are completed. Again, after approximately steady-state infiltration and seepage processes are established for the reduced infiltration rate, a tracer (pentafluorobenzoic acid, with molecular diffusion coefficient of $7.6 \times 10^{-10} \mathrm{~m}^{2} / \mathrm{s}$ ) will be introduced into infiltrating water at all 12 infiltration plots. Total mass and the concentration in infiltrating water at infiltration plots are $5 \mathrm{~g}$ and $25 \mathrm{mg} / \mathrm{l}$, respectively, for this tracer. In all the tracer tests, tracer concentrations as a function of time will be observed at Niche 3 .

Table E-3. Tracers To Be Used in Phases I and II Tests

\begin{tabular}{|c|c|c|c|c|c|c|c|c|}
\hline 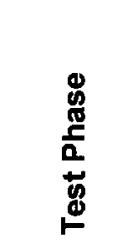 & 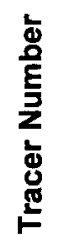 & 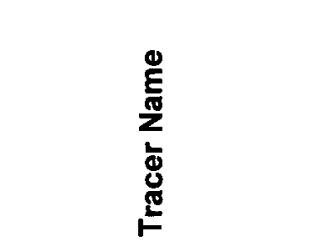 & 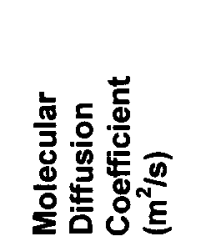 & 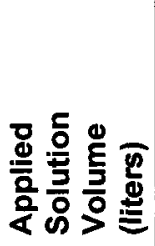 & 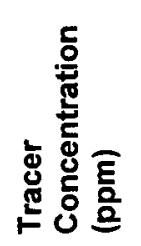 & 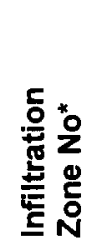 & 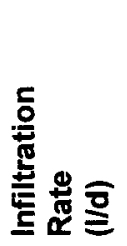 & 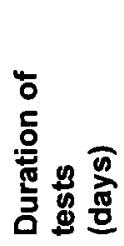 \\
\hline \multirow{6}{*}{ Phase I } & 1 & 2-6-Difluorobenzoic Acid & $8.1 \times 10^{-10}$ & 1000 & 50 & $\overline{1}$ & 18.156 & 55.08 \\
\hline & 2 & Potassium lodide & $2.045 \times 10^{-9}$ & 1000 & 10 & 1 & 18.156 & 55.08 \\
\hline & 3 & 2,5-Difluorobenzoic Acid & $8.1 \times 10^{-10}$ & 500 & 50 & 2 & 13.713 & 36.46 \\
\hline & 4 & Calcium Bromide & $2.080 \times 10^{-9}$ & 500 & 500 & 2 & 13.713 & 36.46 \\
\hline & 5 & $\begin{array}{l}\text { 2,4,5-Trifluorobenzoic } \\
\text { Acid }\end{array}$ & $7.9 \times 10^{-10}$ & 1000 & 50 & 3 & 18.020 & 55.49 \\
\hline & 6 & Potassium Fluoride & $1.475 \times 10^{-9}$ & 1000 & 50 & 3 & 18.020 & 55.49 \\
\hline Phase II & 7 & Pentafluorobenzoic Acid & $7.6 \times 10^{-10}$ & 2000 & 25 & $1,2,3$ & 24.945 & 80.18 \\
\hline
\end{tabular}

NOTE: *Zone 1 includes infiltration plots 1 and 2; zone 2 includes plots 3 to 9 ; zone 3 includes plots 10 to 12 .

Seepage rate data collected for the first 210 days (after the large-plot tests started) were used for model calibration (Section E.4.2.3). The calibrated model was used to predict test results after the first 210 days. Forward simulations using iTOUGH2 V4.0 (LBNL 1999a) were performed for predicting seepage rates. T2R3D V1.4 (LBNL 1999b) was used for simulating tracer transport. The dispersion process was ignored because it has an insignificant effect on overall solute transport behavior, as discussed in UZ Flow Models and Submodels (BSC 2003b, Section 7.6.3). Again, following Moridis et al. (2003, Table 1), the tortuosity factor for the tuff matrix are approximated by the corresponding matrix porosity. 


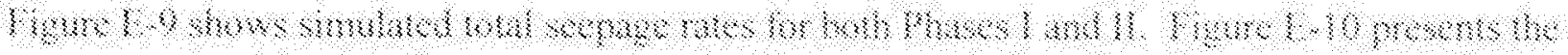

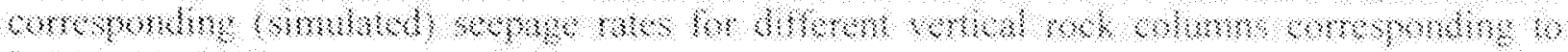

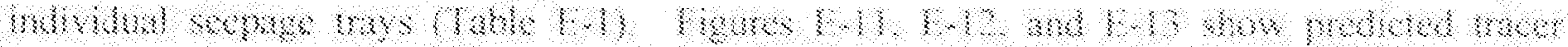

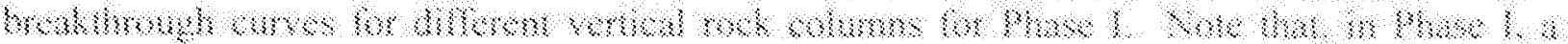

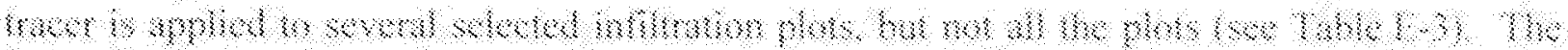

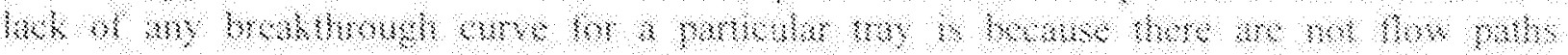

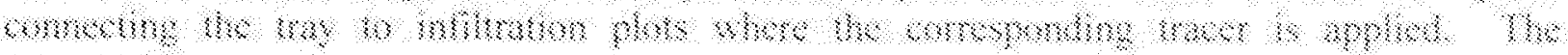

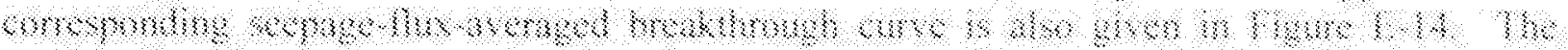

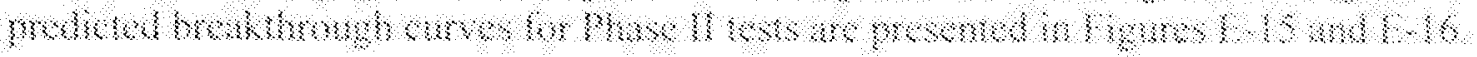

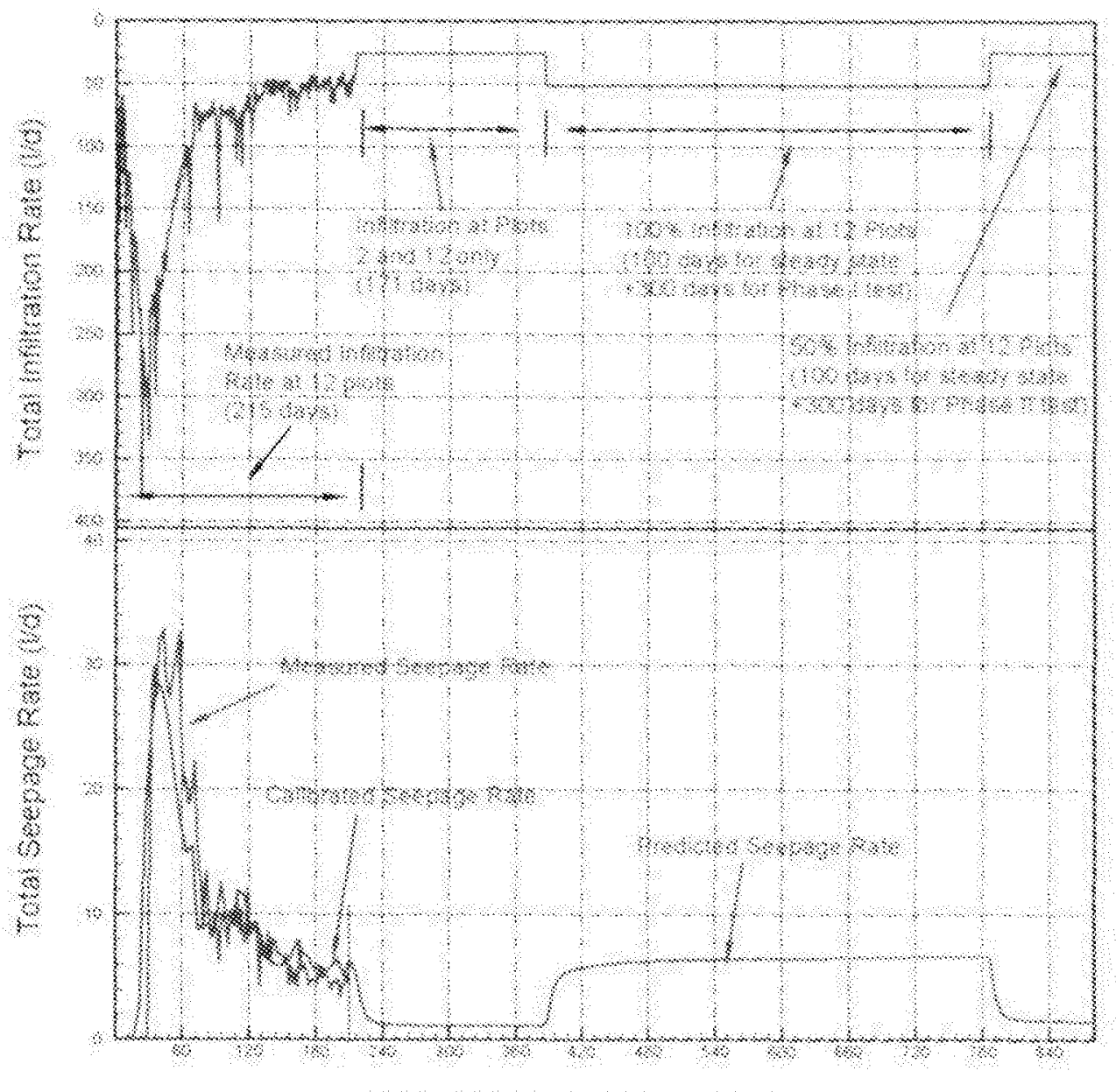

1

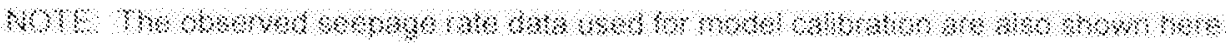

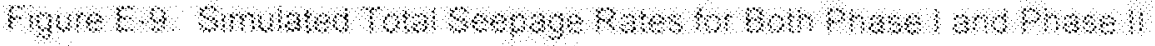



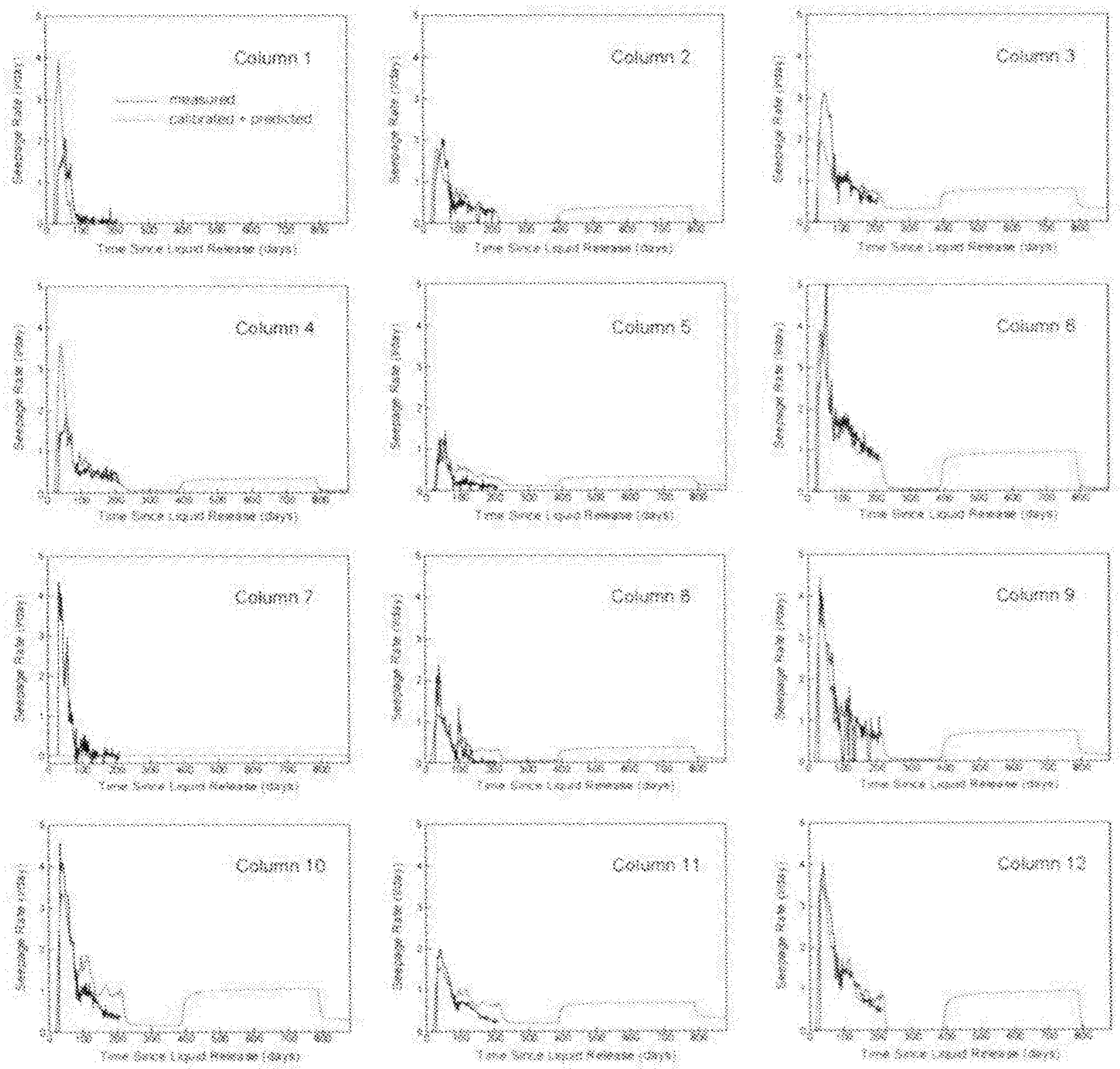

अै।

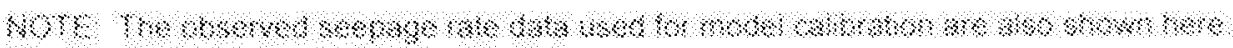

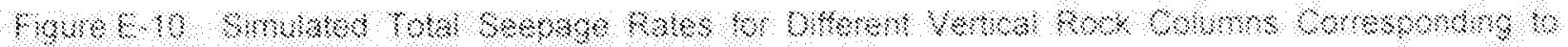

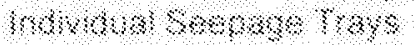




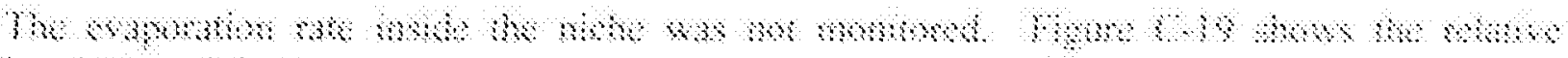

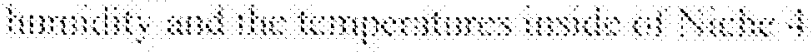

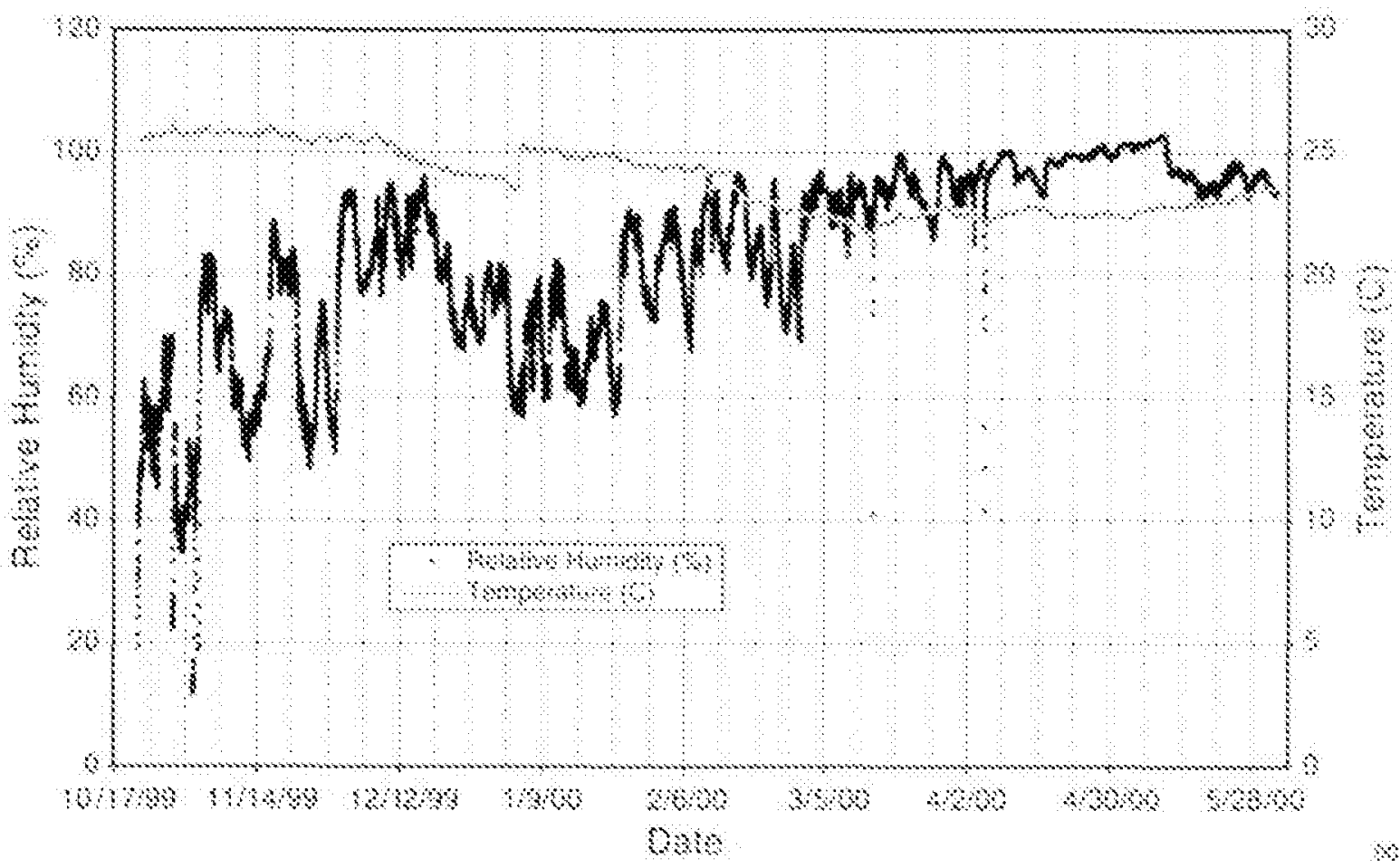

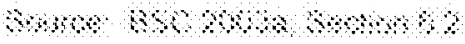

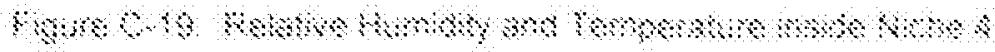

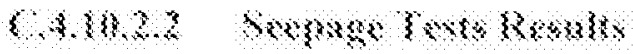

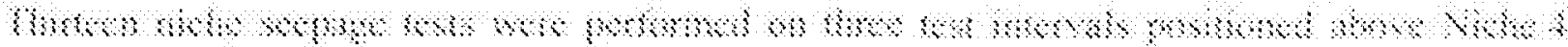

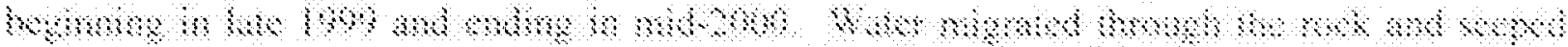

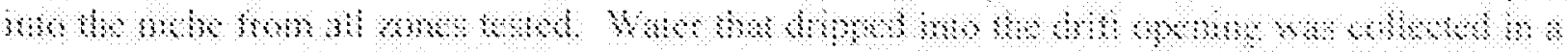

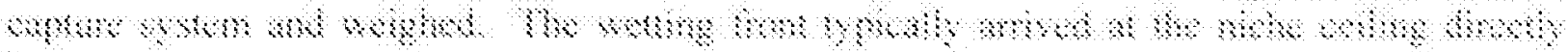

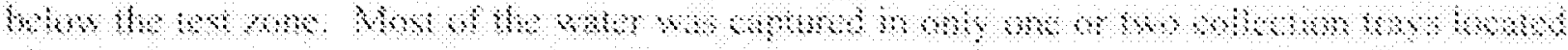

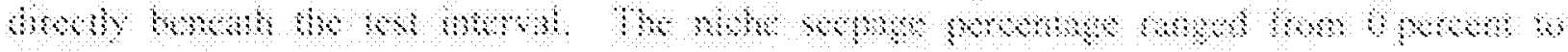
6.

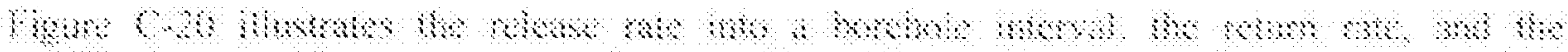

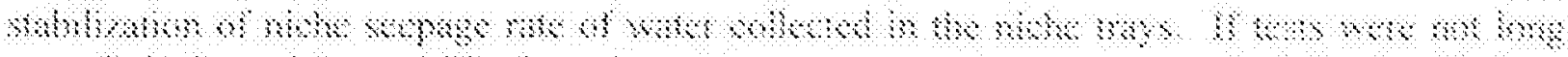

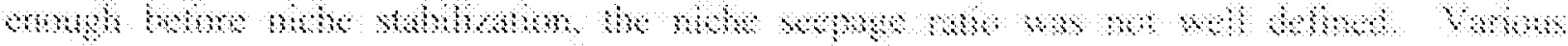

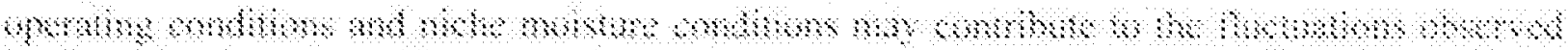

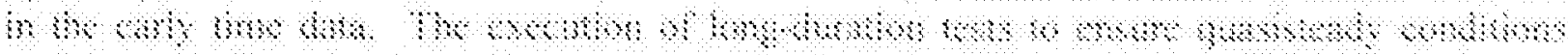

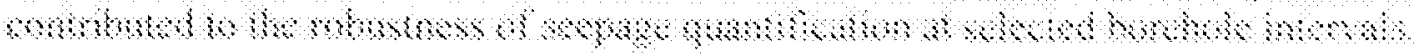




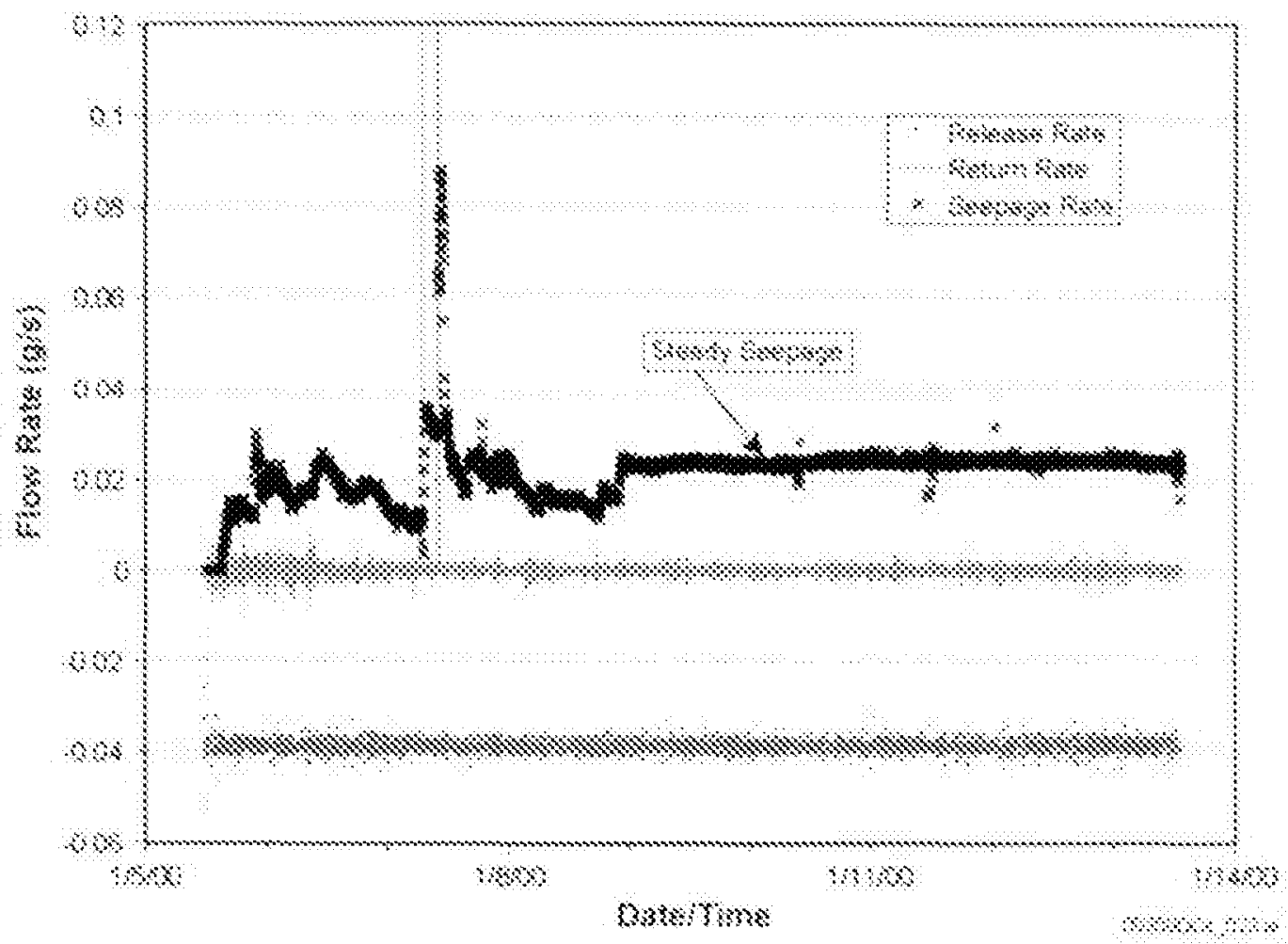

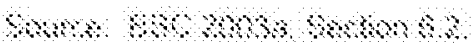

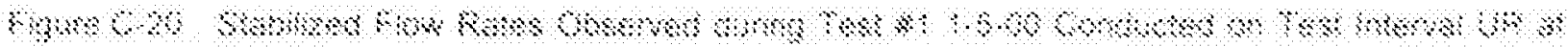
Whis 8

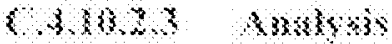

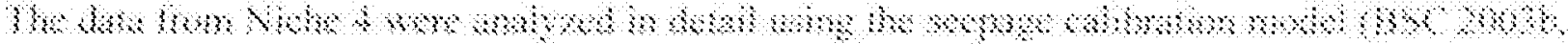

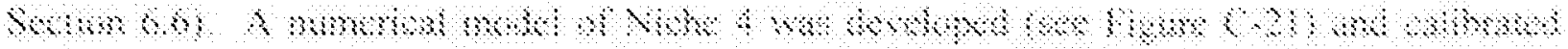

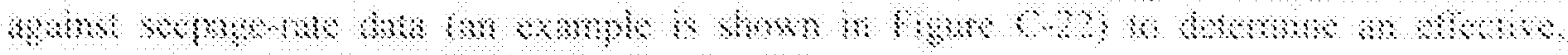

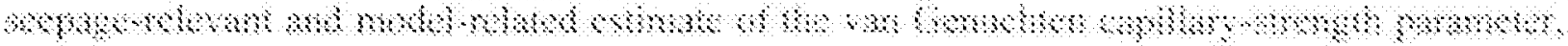

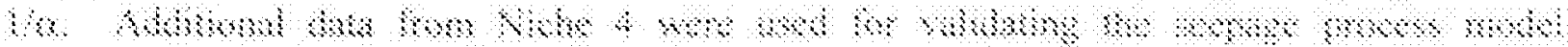

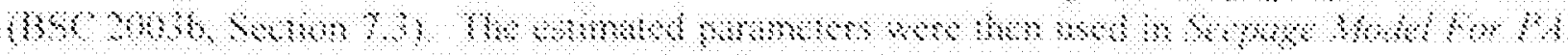

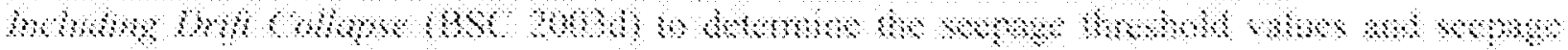

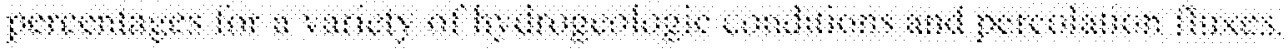




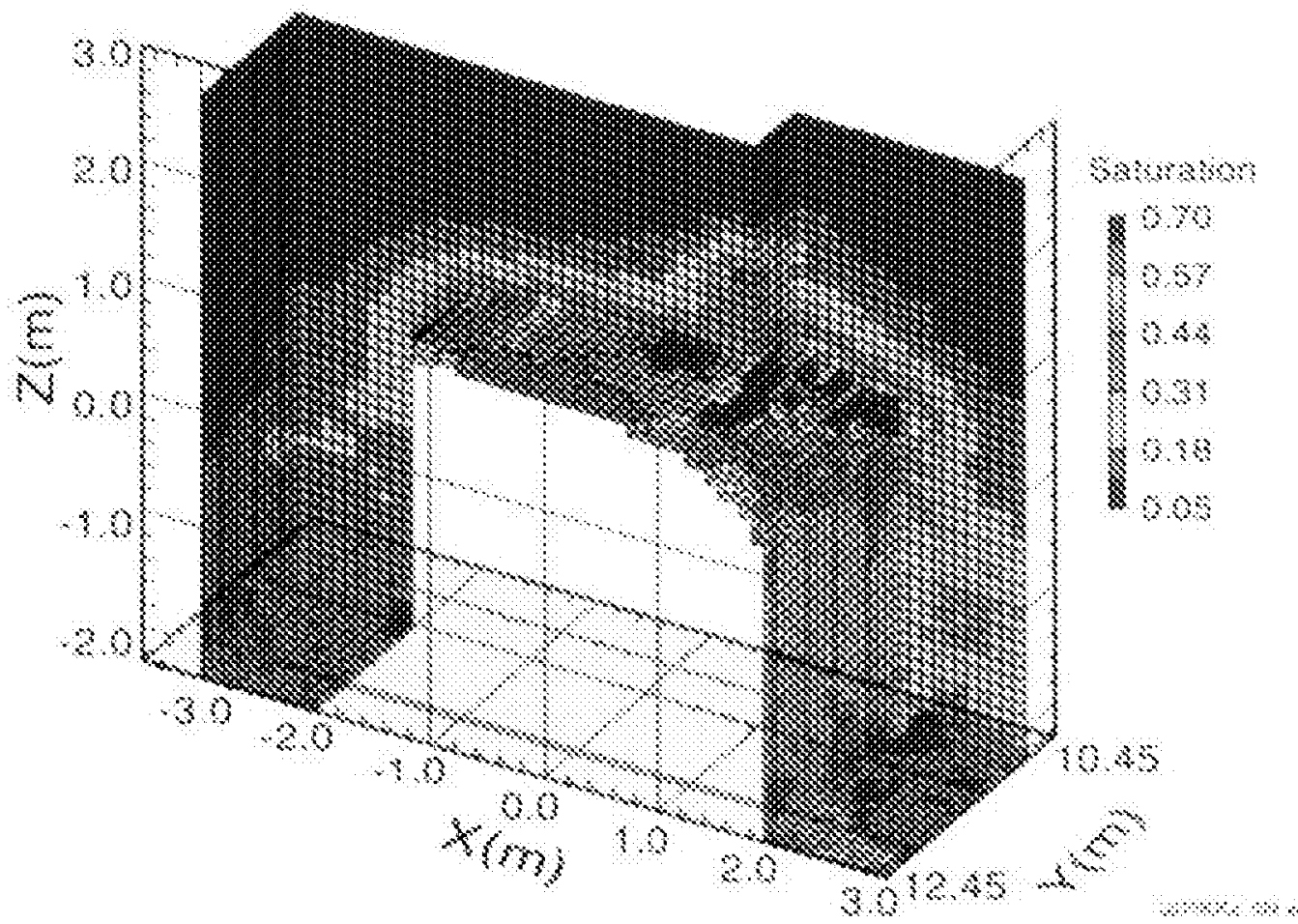

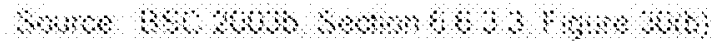

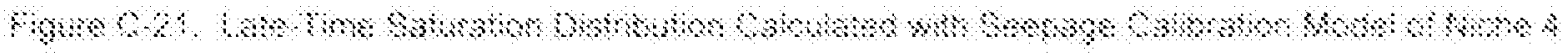

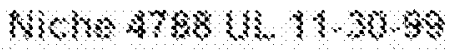

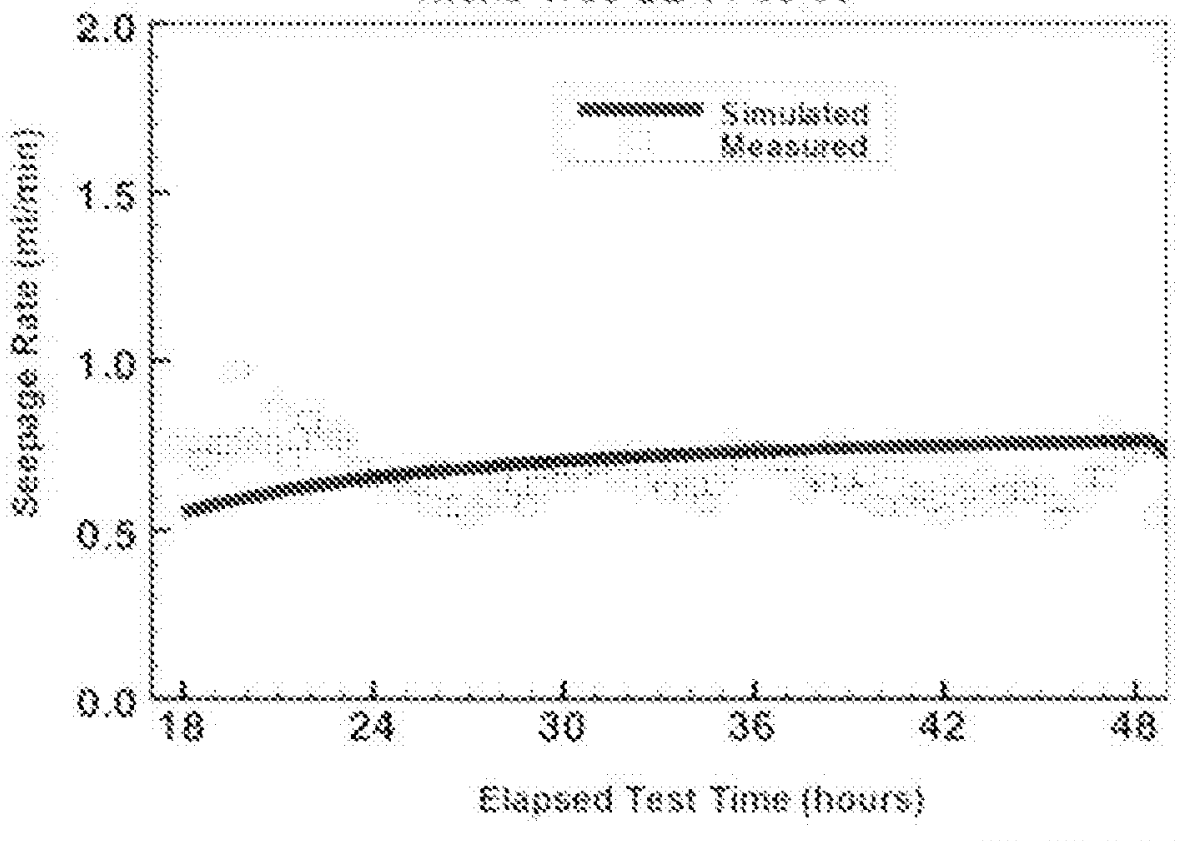

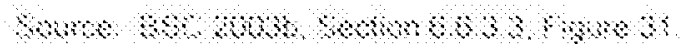

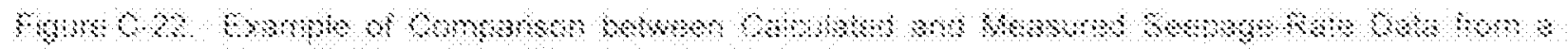

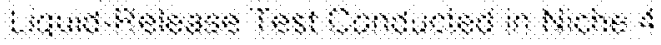




\section{C.4.11 Results for the Calcite Filling Test}

Information for the following sections is based on Analysis of Geochemical Data for the Unsaturated Zone (BSC 2002, Section 6.10) and UZ Flow Models and Submodels (BSC 2003c, Section 7.9).

\section{C.4.11.1 Background}

Observations of calcite and opal precipitations in lithophysal cavities in the Yucca Mountain unsaturated zone can be used to estimate long-term seepage rates into these small openings (BSC 2002, Section 6.10.1; Paces et al. 2001; Marshall et al. 2003) and provide estimates of infiltration rates (BSC 2003c). Calcite is assumed to precipitate from downward-percolating meteoric water because of (1) evaporation, (2) $\mathrm{CO}_{2}$ outgassing as a result of the geothermal gradient, and (3) interaction with a gas phase containing less $\mathrm{CO}_{2}$ than the gas with which the water was last equilibrated.

The calcite deposits mostly occur as patchy coatings on the footwalls of fracture cavities or as irregular to hummocky accumulations on the floors of lithophysal cavities (Paces et al. 2001; Whelan et al. 2002). Hanging-wall surfaces and cavity ceilings are almost devoid of calcite-silica deposits (Paces et al. 2001; Whelan et al. 2002). Calcite-silica deposits are present in only a small percentage of all fractures or lithophysae (Paces et al. 2001); more than 90 percent of the fractures and cavities exposed in the underground workings do not contain secondary minerals (Whelan et al. 2002).

\section{C.4.11.2 Results and Interpretation}

Detailed line survey measurements of the location and thickness of calcite and opal coatings were made along the wall of the ESF tunnel. The volume of the coatings was estimated based on the measured thicknesses and the size of the cavities. Seepage rates were calculated using a volume fraction of calcite in the coatings of 0.9 , assuming that every coating was deposited over 10 million years, and using estimates of the ratio of the volume of water to the volume of calcite obtained from the literature. The calculated seepage rates ranged from $4.2 \times 10^{-4}$ to $0.0931 /$ year. For a 5 meter long waste package inside a drift with a $5 \mathrm{~m}$ diameter, estimates of the seepage rates ranged from $0.0051 /$ year to 51 year, with corresponding seepage fluxes of $2 \times 10^{-4} \mathrm{~mm} / \mathrm{yr}$ to $0.2 \mathrm{~mm} / \mathrm{yr}$ (Marshall et al. 2003). The analysis of calcite and opal precipitation data shows that (1) not all lithophysal cavities encountered seepage and (2) seepage flux derived from mineral deposits is a very small fraction of percolation flux.

The percolation flux in the unsaturated zone depends strongly on the infiltration flux, which is a boundary condition of the unsaturated zone flow model (BSC 2003c). Observations of precipitated calcite in the unsaturated zone can also be used to constrain the infiltration flux and provide additional evidence for validation of the unsaturated zone model (BSC 2003c). One-dimensional modeling of calcite deposition in a deep surface-based borehole (WT-24) was performed using the reactive transport computer code TOUGHREACT (Xu and Pruess 1998, $2001)$ to estimate the infiltration rate. The simulated calcite abundances generally fell within the range of calcite observed in the field over a range of 2 to $20 \mathrm{~mm} / \mathrm{yr}$ infiltration rates. The $20 \mathrm{~mm} / \mathrm{yr}$ infiltration rate may be the upper bound for WT-24 location, whereas the base-case 
infiltration rate of $5.92 \mathrm{~mm} / \mathrm{yr}$ used for the flow model gave the closest match to the data. The modeled calcite abundances generally increased with increasing infiltration rate, but become less sensitive to infiltration at higher rates as a result of changes to the geothermal gradient. The calcite coating data collected from the ESF also support the validity of the active fracture concept for use in describing fracture flow in the unsaturated zone (BSC 2003e, Section 7.2.2).

\section{C.5 REFERENCES}

Ahlers, C.F.; Shan, C.; Haukwa, C.; Cohen, A.B.J.; and Bodvarsson, G.S. 1996. Calibration and Prediction of Pneumatic Response at Yucca Mountain, Nevada Using the Unsaturated Zone Flow Model. Milestone OB12M. Berkeley, California: Lawrence Berkeley National Laboratory. ACC: MOL.19970206.0285.

Bodvarsson, G.S.; Bandurraga, T.M.; and Wu, Y.S., eds. 1997. The Site-Scale Unsaturated Zone Model of Yucca Mountain, Nevada, for the Viability Assessment. LBNL-40376. Berkeley, California: Lawrence Berkeley National Laboratory. ACC: MOL.19971014.0232.

BSC (Bechtel SAIC Company) 2001a. Test Plan for: Moisture Monitoring in the ECRB Bulkheaded Cross Drift. SITP-02-UZ-001 REV 00. Las Vegas, Nevada: Bechtel SAIC Company. ACC: MOL.20011018.0011.

BSC 2001b. Test Plan for: Niche 5 Seepage Testing. SITP-02-UZ-002 REV 00. Las Vegas, Nevada: Bechtel SAIC Company. ACC: MOL.20020117.0200.

BSC 2001c. In Situ Field Testing of Processes. ANL-NBS-HS-000005 REV 01. Las Vegas, Nevada: Bechtel SAIC Company. ACC: MOL.20020108.0351.

BSC 2002. Analysis of Geochemical Data for the Unsaturated Zone. ANL-NBS-HS-000017 REV 00 ICN 02. Las Vegas, Nevada: Bechtel SAIC Company. ACC: MOL.20020314.0051.

BSC 2003a. In Situ Field Testing of Processes. ANL-NBS-HS-000005 REV02B. Las Vegas, Nevada: Bechtel SAIC Company. ACC: MOL.20030915.0238.

BSC 2003b. Seepage Calibration Model and Seepage Testing Data. MDL-NBS-HS-000004 REV 02. Las Vegas, Nevada: Bechtel SAIC Company. ACC: DOC.20030408.0004.

BSC 2003c. UZ Flow Models and Submodels. MDL-NBS-HS-000006 REV 01. Las Vegas, Nevada: Bechtel SAIC Company. ACC: DOC.20030818.0002.

BSC 2003d. Seepage Model For PA Including Drift Collapse. MDL-NBS-HS-000002 REV 02. Las Vegas, Nevada: Bechtel SAIC Company. ACC: DOC.20030709.0001.

BSC 2003e. Analysis of Hydrologic Properties Data. MDL-NBS-HS-000014 REV 00. Las Vegas, Nevada: Bechtel SAIC Company. ACC: DOC.20030404.0004.

LeCain, G.D. 1995. Pneumatic Testing in 45-Degree-Inclined Boreholes in Ash-Flow Tuff Near Superior, Arizona. Water-Resources Investigations Report 95-4073. Denver, Colorado: U.S. Geological Survey. ACC: MOL.19960715.0083. 
Marshall, B.D.; Neymark, L.A.; and Peterman, Z.E. 2003. "Estimation of Calcite Distribution in the Topopah Spring Tuff, Yucca Mountain, Nevada." Journal of Contaminant Hydrology, 62-63, 237-247. New York, New York: Elsevier. TIC: 254210.

NRC (U.S. Nuclear Regulatory Commission) 2002. Integrated Issue Resolution Status Report. NUREG-1762. Washington, D.C.: U.S. Nuclear Regulatory Commission, Office of Nuclear Material Safety and Safeguards. TIC: 253064.

Paces, J.B.; Neymark, L.A.; Marshall, B.D.; Whelan, J.F.; and Peterman, Z.E. 2001. Ages and Origins of Calcite and Opal in the Exploratory Studies Facility Tunnel, Yucca Mountain, Nevada. Water-Resources Investigations Report 01-4049. Denver, Colorado: U.S. Geological Survey. TIC: 251284.

Reamer, C.W. 2001. "Unsaturated and Saturated Flow Under Isothermal Conditions (USFIC) Key Technical Issue Agreements." Letter from C.W. Reamer (NRC) to S. Brocoum (DOE/YMSCO), June 20, 2001, with enclosure. ACC: MOL.20010913.0149.

Reamer, C.W. and Gil, A.V. 2001. "Summary Highlights of NRC/DOE Technical Exchange and Management Meeting on Total System Performance Assessment and Integration, August 6-10, 2001, Las Vegas, Nevada." Washington, D.C.: U.S. Nuclear Regulatory Commission. ACC: MOL.20010921.0121.

Reamer, C.W. and Williams, D.R. 2000. "Summary of Highlights of NRC/DOE Technical Exchanges and Management Meeting on Unsaturated and Saturated Flow under Isothermal Conditions, August 16-17, 2000, Berkeley, California." Washington, D.C.: U.S. Nuclear Regulatory Commission. ACC: MOL.20001201.0072.

Whelan, J.F.; Paces, J.B.; and Peterman, Z.E. 2002. "Physical and Stable-Isotope Evidence for Formation of Secondary Calcite and Silica in the Unsaturated Zone, Yucca Mountain, Nevada." Applied Geochemistry, 17, ([6]), 735-750. New York, New York: Elsevier. TIC: 253462.

Xu, T. and Pruess, K. 1998. Coupled Modeling of Non-Isothermal Multi-Phase Flow, Solute Transport and Reactive Chemistry in Porous and Fractured Media: 1. Model Development and Validation. LBNL-42050. Berkeley, California: Lawrence Berkeley National Laboratory. TIC: 243735. 
Revision 1

INTENTIONALLY LEFT BLANK 
Revision 1

APPENDIX D

JUSTIFICATION OF CONTINUUM APPROACH FOR SEEPAGE MODELING (RESPONSE TO USFIC 4.06) 


\section{Note Regarding the Status of Supporting Technical Information}

This document was prepared using the most current information available at the time of its development. This Technical Basis Document and its appendices providing Key Technical Issue Agreement responses that were prepared using preliminary or draft information reflect the status of the Yucca Mountain Project's scientific and design bases at the time of submittal. In some cases this involved the use of draft Analysis and Model Reports (AMRs) and other draft references whose contents may change with time. Information that evolves through subsequent revisions of the AMRs and other references will be reflected in the License Application (LA) as the approved analyses of record at the time of LA submittal. Consequently, the Project will not routinely update either this Technical Basis Document or its Key Technical Issue Agreement appendices to reflect changes in the supporting references prior to submittal of the LA. 


\section{APPENDIX D \\ JUSTIFICATION OF CONTINUUM APPROACH FOR SEEPAGE MODELING (RESPONSE TO USFIC 4.06)}

This appendix provides a response to Key Technical Issue (KTI) agreement Unsaturated and Saturated Flow Under Isothermal Conditions (USFIC) 4.06. This KTI agreement relates to a modeling study to compare continuum versus discrete fracture network models.

\section{D.1 KEY TECHNICAL ISSUE AGREEMENT}

\section{D.1.1 USFIC 4.06}

Agreement USFIC 4.06 was reached during the U.S. Nuclear Regulatory Commission (NRC)/U.S. Department of Energy (DOE) Technical Exchange and Management Meeting on Total System Performance Assessment and Integration (TSPAI) held August 6 to 10, 2001 in Las Vegas, Nevada (Reamer 2001), which was convened to discuss four TSPAI KTI subissues: (1) System description and demonstration of multiple barriers; (2) Scenario analysis within total system performance assessment (TSPA) and methodology; (3) Model abstraction within the TSPA methodology; and (4) Demonstration of the overall performance objective. During the course of this Technical Exchange, seven USFIC agreements were also modified or added, including USFIC 4.01 through 4.07. Agreement USFIC 4.06 was added at this time.

The wording of the agreement is as follows:

\section{USFIC 4.06}

Provide documentation of the results obtained from the Comparison of Continuum and Discrete Fracture Network Models modeling study. Alternatively, provide justification of the continuum approach at the scale of the seepage model grid (formerly June 20 letter, item xiii). DOE will provide documentation of the results obtained from the Comparison of Continuum and Discrete Fracture Network Models modeling study or provide justification of the continuum approach at the scale of the seepage model grid. This will be documented in Seepage Calibration Model and Seepage Testing Data AMR (MDL-NBS-HS-000004) or other suitable document expected to be available to NRC in FY 2003.

\section{D.1.2 Related Key Technical Issue Agreements}

The following KTI agreements cover material related to agreement USFIC 4.06:

Radionuclide Transport (RT) 3.05, Structural Deformation and Seismicity (SDS) 3.01, and USFIC 6.03: The NRC is concerned that the use of a continuum model is inappropriate when the spacing of flowing fractures exceeds the grid size (Schlueter 2003; NRC 2002, pp. 3.3.6-18 and 3.3.6-19). The NRC noted that in the pretest predictions of the Alcove 8-Niche 3 (also referred to as Niche 3107) tests, the grid size is one meter or less; however, studies have found fracture spacing in tsw33 to be $1.23 \mathrm{~m}$ (Ziegler 2002, Table 1). The NRC argued that using the active 
fracture concept, the spacing of fractures in which water flows would be expected to increase under less than fully saturated conditions (Schlueter 2003). Therefore, the NRC has requested that the DOE justify its use of the continuum model when the spacing of flowing fractures exceeds the grid size.

\section{D.2 RELEVANCE TO REPOSITORY PERFORMANCE}

This KTI agreement relates to the use of the continuum approach, versus a discrete fracture network approach, for modeling flow and seepage processes in a fracture network at the scale of the seepage model grid. The NRC concern was that the use of the continuum approach might not be appropriate for simulating seepage processes into waste emplacement drifts at Yucca Mountain. It is specifically mentioned that fracture networks in the host rock may not be dense enough to be treated as a three-dimensional continuum. As a result, a continuum model may not be able to capture flow diversion and seepage that may be controlled more by fracture geometry than by effective hydraulic properties of a fracture network (NRC 2002).

When water flows predominantly through fractures, a discrete fracture network model seems more appropriate than a continuum model for the reproduction and prediction of drift seepage. However, the continuum approach is adopted for the simulation of drift seepage. Justification for the continuum approach is provided from evaluation of seepage simulation results, supported by observed data from seepage experiments conducted in fractured rock on the appropriate scale. Comparison studies using both continuum and discrete fracture network models at the scale of the seepage model further strengthen the continuum approach.

The agreement is relevant to the repository performance because it concerns drift seepage modeling which provides seepage-relevant parameters and their probability distributions directly to TSPA.

\section{D.3 RESPONSE}

This KTI agreement response (USFIC 4.06) consists of two parts: (1) justification for the use of the continuum approach for seepage analyses and predictions, and (2) comparison between seepage calculations with continuum and discrete fracture network models.

Justification for the continuum approach at the scale of the seepage model grid has been documented in Seepage Calibration Model and Seepage Testing Data (BSC 2003a) and by Finsterle (2000) as well as other sources in the open literature (e.g., Nitao 1996; Jackson et al. 2000). The arguments justifying the continuum approach for the purpose of seepage modeling include:

1. The overall, integrated approach to the analysis and modeling of seepage data ensures that the model appropriately captures the site-specific behavior of the relevant processes on the scale of interest (for details, see Section D.4.1.1).

2. The successful reproduction of observed seepage-rate data-with the adjustment of a single parameter-provides confidence that the modeling approach is reasonable (for details, see Section D.4.1.2). 
3. The successful prediction of seepage-rate data provides confidence that the calibrated model is capable of capturing seepage behavior above and below the seepage threshold (for details, see Section D.4.1.3).

4. The continuum approach appropriately captures in-plane flow diversion, which is the dominant mode of flow diversion around an opening in fractured rock (for details, see Section D.4.1.4).

5. Fracture density at Yucca Mountain is high, and the fracture network is generally well connected, lending support for the use of the continuum approach on the drift scale (for details, see Section D.4.1.5)

6. Additional studies providing justification for the continuum approach are summarized in Section D.4.1.6.

The second part of the response to USFIC 4.06 (see Section D.4.2) presents comparisons between seepage predictions performed with continuum and discrete fracture network models. Use of a continuum approach can be further justified by comparing it with a discrete modeling approach. The comparison studies can be summarized as follows:

1. A continuum model and a discrete fracture network model (Finsterle 2000; BSC 2003a) yield consistent predictions of seepage threshold and seepage rates if calibrated against data from liquid-release tests (for details, see Section D.4.2.2).

2. Another two-dimensional discrete fracture network model (Liu et al. 2002; BSC 2003a) resulted in insignificant flow diversion, i.e., no capillary barrier effect exists for discrete, two-dimensional systems that neglect in-plane flow diversion (for details, see Section D.4.2.3).

3. Alternative conceptual models (such as a discrete fracture network model) require detailed, currently unavailable characterization data. More importantly, these alternative models are based on additional model assumptions that are difficult to justify, and require a calibration step similar to that needed for the continuum approach (for details, see Section D.4.2.4).

4. Comments on discretization issues are given in Section D.4.2.5.

In summary, while the seepage models do not predict the strength of individual seeps or specific drip locations, the continuum approach is considered appropriate for predicting average seepage into waste emplacement drifts in a probabilistic framework.

The information in this report is responsive to agreement USFIC 4.06 made between the DOE and NRC. The report contains the information that DOE considers necessary for NRC review for closure of this agreement. 


\section{D.4 BASIS FOR THE RESPONSE}

\section{D.4.1 Justification for the Continuum Approach}

The process models developed to provide seepage estimates for TSPA are conceptualized as heterogeneous continuum models. In general, continuum seepage models can be considered appropriate for use in the Yucca Mountain project if they are capable of predicting average seepage rates into a drift segment on the scale of a waste package. Moreover, the approach must be demonstrated to be applicable to the conditions prevailing at Yucca Mountain. It also must be transparent and defensible.

The continuum approach is considered appropriate for seepage predictions at Yucca Mountain. The following sections provide the rationale for this assessment.

\section{D.4.1.1 Overall Modeling Approach}

Seepage is a complex process that involves phenomena on a wide range of spatial and temporal scales; from mountain-scale flow redistribution to microscale processes of film flow and drop detachment; from near-steady percolation to highly transient, episodic flow events within fractures. The processes, phenomena, and factors affecting drift seepage are described in detail in Seepage Calibration Model and Seepage Testing Data (BSC 2003a, Section 6.3).

Given the complexity of the seepage process in unsaturated, fractured porous media, it is considered infeasible to develop a detailed process model with a deterministic calculation of unsaturated water flow through a fracture network that exhibits multiscale variabilities in hydraulic properties. Such a model would also include effects from small-scale roughness and small-scale heterogeneities, film flow within fractures and along the drift surface, drop formation and detachment, and other processes, including evaporation and in-drift moisture redistribution. While modeling these processes is theoretically possible, the characterization data needed are not available, and the computational demands are prohibitive. A more effective and equally valid alternative approach was therefore used in seepage modeling as described below.

A detailed deterministic model is not needed, because it is recognized that (1) detailed simulation of individual seeps is not necessary to estimate average seepage rates into waste emplacement drifts on the scale of a waste package, (2) certain factors affecting seepage can be lumped into an effective parameter, (3) calibrating a model against data from seepage experiments ensures that the model captures the relevant processes, (4) estimating effective parameters partly compensates for processes and features that are not explicitly considered in the model, and (5) the estimated parameters are optimal for the given model structure and can be directly used in a prediction model that is based on a consistent model conceptualization.

A key element of the approach chosen to obtain a defensible seepage model and to determine seepage-relevant parameters is the incorporation of site-specific, seepage-related data on the scale of interest. The data are incorporated through inverse modeling. The main advantage of this approach is that it relies directly on seepage-rate data, which inherently contain information about the relevant processes. Moreover, the calibration data (seepage rates on the scale of a drift section) are very similar to the measure of interest for the subsequent predictions. The consistency between the calibration model used to derive seepage-relevant parameters and the 
prediction model used to forecast seepage minimizes potential conceptual differences and large systematic errors.

The complexity of the model is appropriate for its purpose, i.e., for the prediction of average seepage on the scale of a drift segment. Small-scale features and processes, including discrete fracture-flow behavior, surface roughness, and film flow, are captured in effective, model-related parameters determined from site-specific data that reflect the seepage process on the appropriate scale. Calibration against seepage-rate data and the consistent conceptualization in the downstream models make this a valid and reasonable approach to characterizing and predicting seepage at Yucca Mountain.

In summary, seepage estimates in TSPA rely on site-specific data representing the seepage process itself. The numerical model serves as a transfer function providing average seepage rates for a range of hydrogeologic conditions. This transfer function is firmly based on physical principles and site-specific characterization data. It is demonstrated below that the model is capable of reproducing and predicting observable seepage data. Moreover, theoretical analyses (see Section D.4.2.1) show that the continuum approach is also capable of predicting flow and seepage behavior that cannot be directly observed in the field.

\section{D.4.1.2 Reproduction of Observed Seepage Data}

A seepage model based on the continuum approach can be considered appropriate if it is capable of reproducing observed data from seepage experiments conducted in fractured rock on the appropriate scale. The model should be able to reproduce the data without adjusting a large number of parameters (i.e., without overparameterization). Moreover, the parameter values estimated as a result of the calibration process should be reasonable. Under these conditions, it can be concluded that the continuum model appropriately captures the hydrogeological features and physical processes involved in the seepage phenomenon, providing a basis for and confidence in the subsequent model predictions.

A numerical process model was developed for reproducing seepage-rate data from liquid-release tests and to predict seepage into waste emplacement drifts (BSC 2003a). The model is conceptualized as a three-dimensional, heterogeneous fracture continuum model based on the Richards equation (Richards 1931) for saturated-unsaturated flow. The van Genuchten-Mualem constitutive relations (van Genuchten 1980) describe the capillary pressure and relative liquid permeability in the fracture continuum as functions of liquid saturation. This approach captures the main driving forces (gravity, viscous, and capillary forces) and phenomena (phase interference) relevant for modeling unsaturated flow and seepage in a geologic medium.

To appropriately include heterogeneity, the spatial structure of the air-permeability data was analyzed, and the resulting geostatistical parameters were used to generate multiple realizations of a spatially correlated permeability field, which were conditioned on the permeabilities measured in the borehole intervals. The permeability fields were eventually mapped onto the numerical grid. Multiple realizations of the underlying permeability field were generated to capture uncertainty related to the stochastic nature of the represented fracture network. 


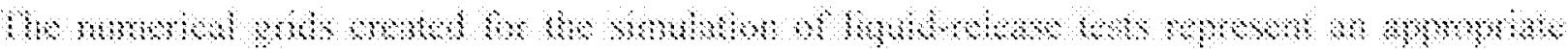

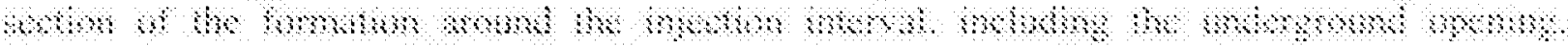

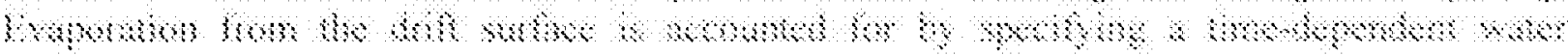

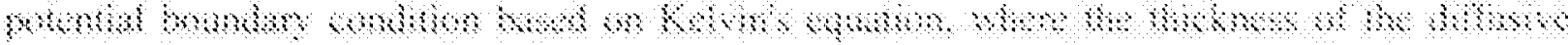

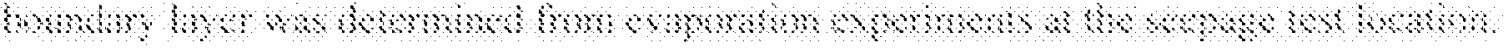

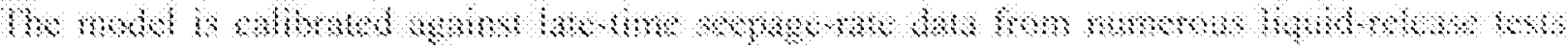

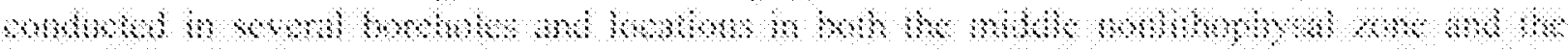

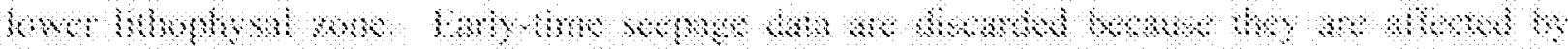

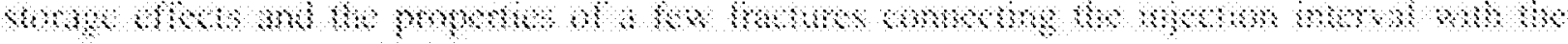

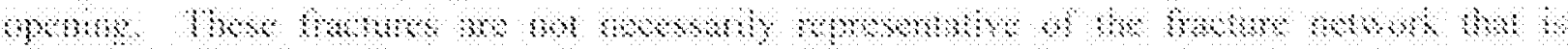

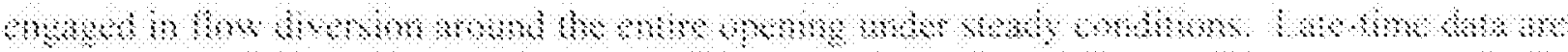

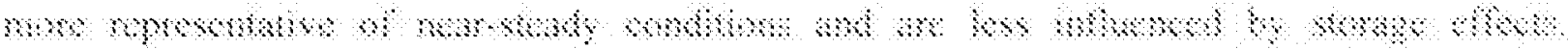

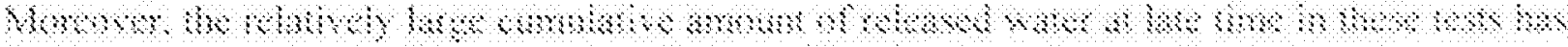

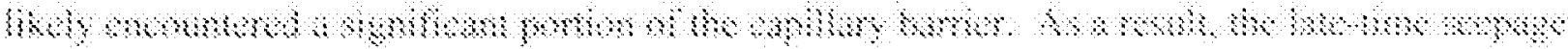

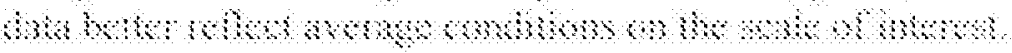

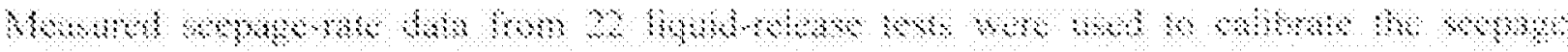

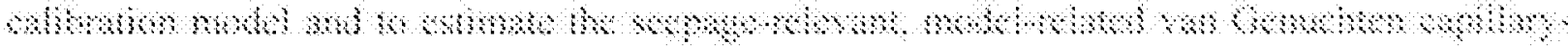

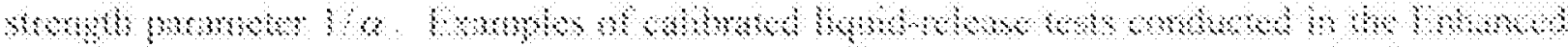

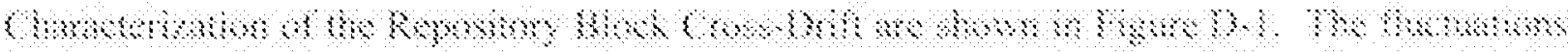

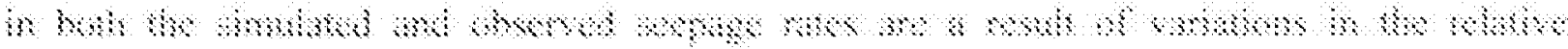

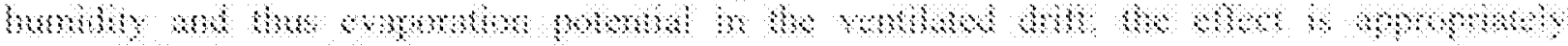
masts $\rightarrow \times s+6$
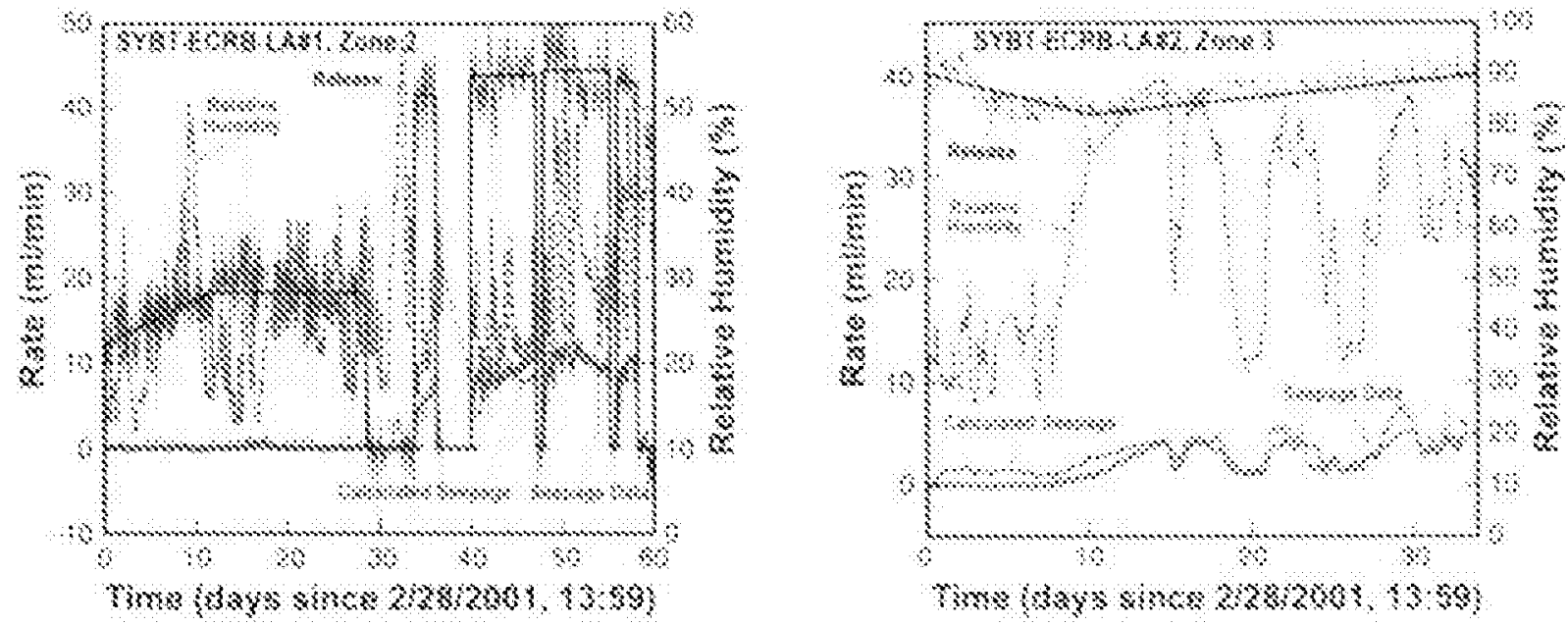

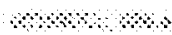

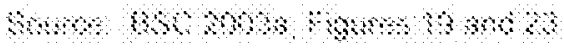

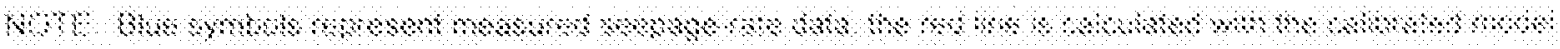

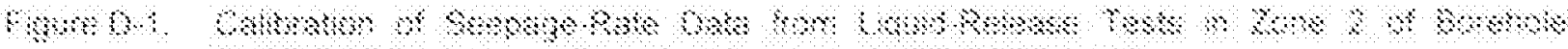

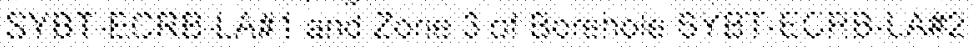


As demonstrated, the seepage continuum model is capable of appropriately capturing complex unsaturated flow and seepage processes during a highly transient liquid-release test conducted in a heterogeneous, fractured formation. Only a single parameter was adjusted to match the data, providing confidence that the salient features of the system are appropriately represented in the model. The estimated capillary-strength parameter is reasonable and consistent with its use as an effective parameter in a drift-scale seepage process model.

\section{D.4.1.3 Prediction of Seepage Rates}

Matching a model to observed data by adjusting a minimum number of parameters is a first step in demonstrating the appropriateness of the underlying model. However, the model must also be tested for its predictive capability under changed conditions. As outlined in Section D.4.1.1, the general approach was designed to minimize the extrapolation required to predict currently unobservable data (i.e., long-term seepage into waste emplacement drifts under natural, generally low percolation fluxes) from the observable data used for calibration (i.e., short-term seepage induced by relatively high-flux liquid-release tests). The field experiments were designed so that the data used for calibration reflect the process of interest on the relevant scale. Moreover, since the structure of the prediction model is very similar to that of the model used for calibration, the optimality of the model-related parameter estimates can be transferred to the prediction model.

The appropriateness of such an extrapolation of the model beyond its tested grounds were assessed. While rigorous model testing is fundamentally challenging (Oreskes et al. 1994), validation of the model for the intended purpose of supporting TSPA has been accomplished. The seepage process models were tested against observable data from seepage experiments that were not used for model calibration. The purpose of this validation exercise was to determine whether the model was appropriate and adequate for its intended use (BSC 2003a, Section 7). Remaining uncertainty has been quantified during the seepage abstraction process and propagated through TSPA (BSC 2003b, Section 6).

Model predictions are inherently uncertain as a result of uncertainty in the input parameters as well as conceptual model uncertainties. Uncertainty propagation methods (such as Monte Carlo simulations and first-order second-moment analyses) were used to estimate the prediction uncertainty, providing a quantitative acceptance criterion for model validation (BSC 2003a).

Figure D-2 shows an example of a validation run, in which seepage rates for a liquid-release test conducted in Niche 3 were predicted with the calibrated model and compared to measured data that were not used for model calibration. Linear error propagation analysis yielded the uncertainty of the model prediction as a result of uncertainty in the input parameters. The data fall within the range of predicted seepage rates. 


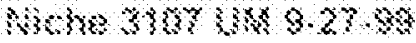

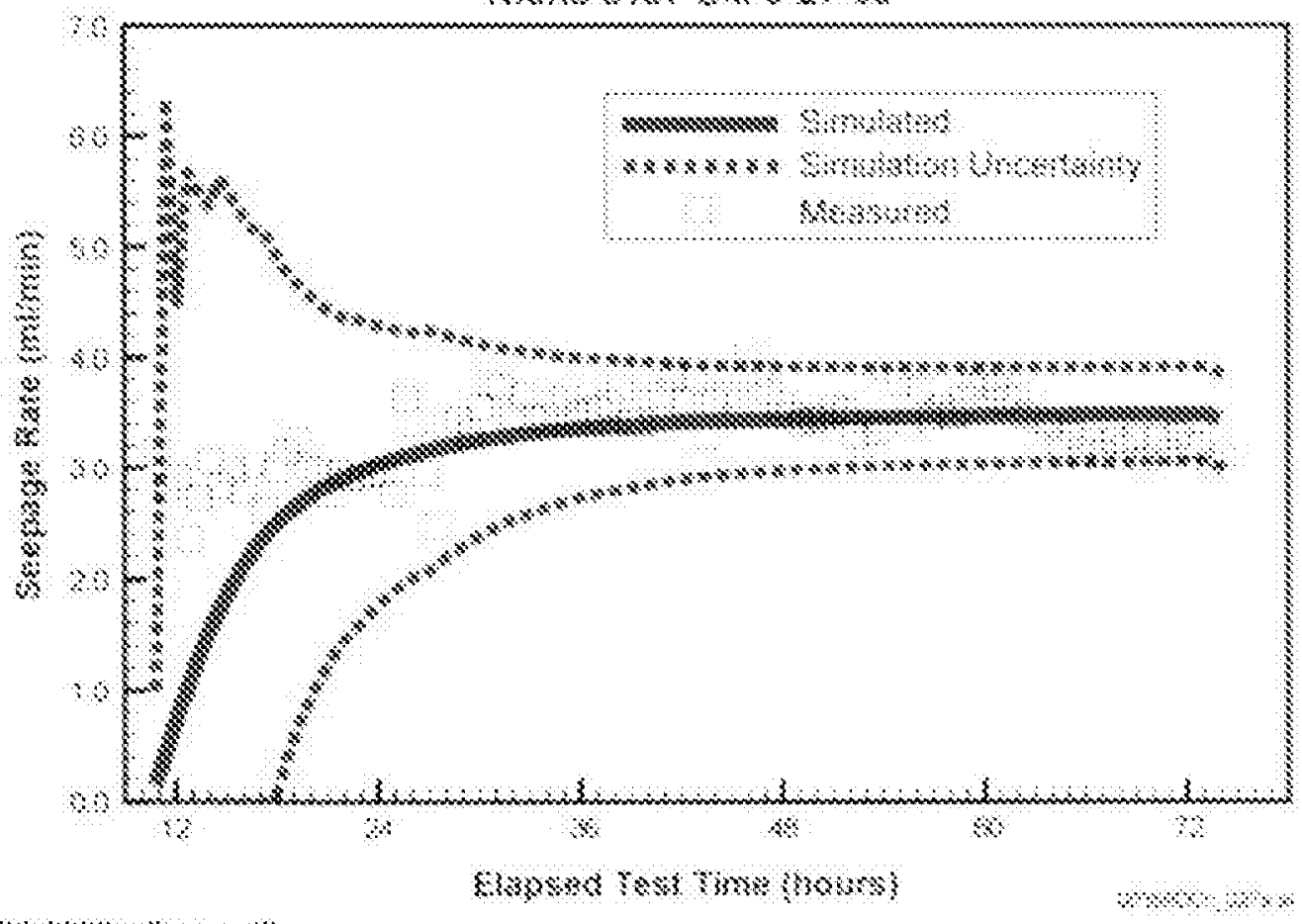

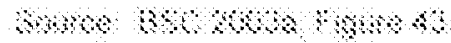

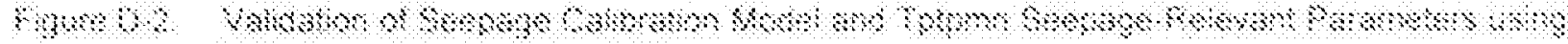

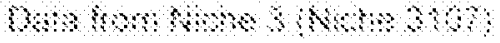

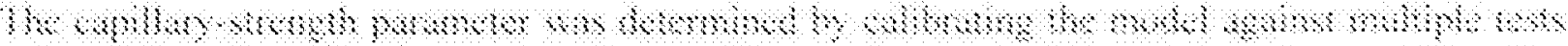

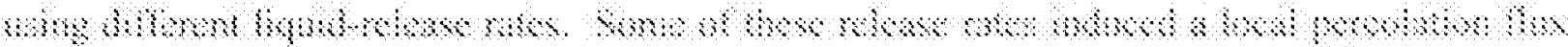

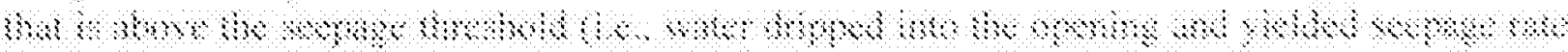

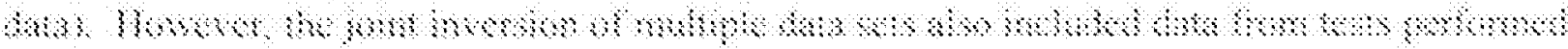

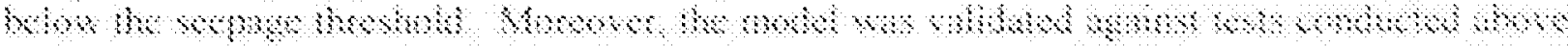

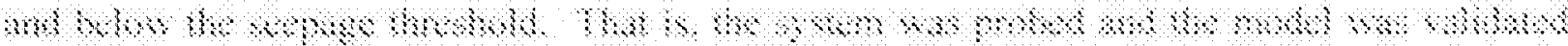

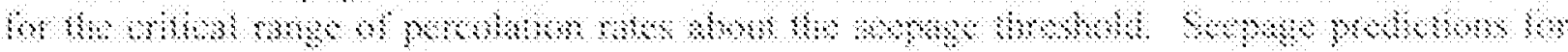

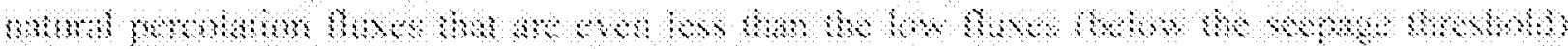

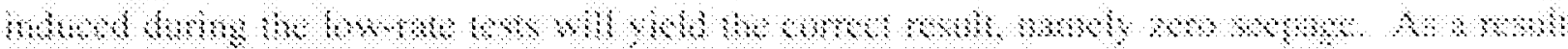

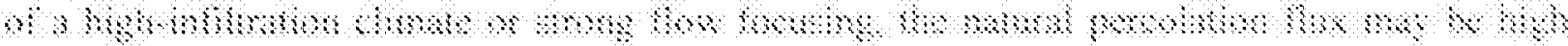

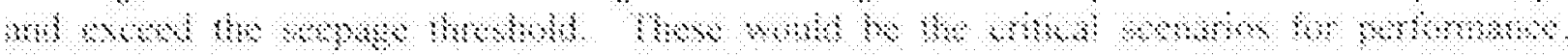

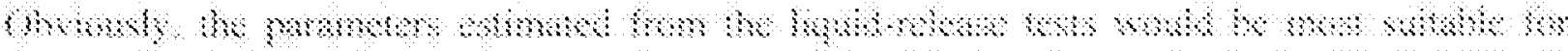

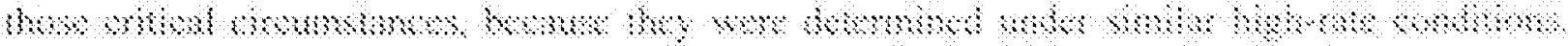

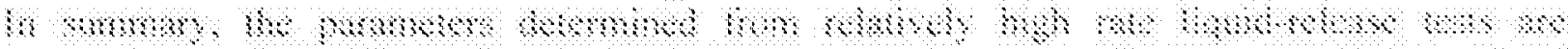

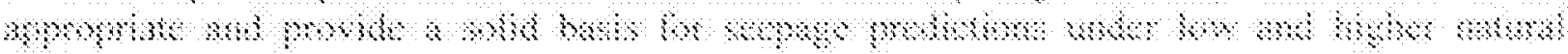

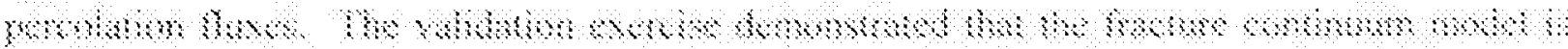

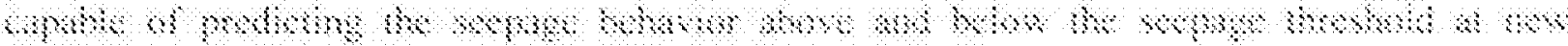
ham

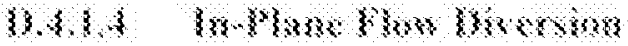

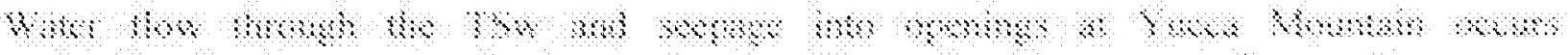

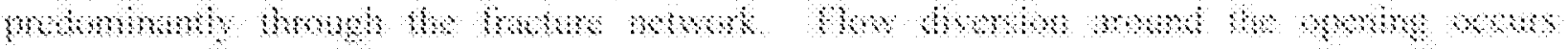


primarily within a fracture plane (hereafter referred to as in-plane diversion). Multiple fractures are involved in the flow diversion only if the fracture is too short and the flow path within the fracture plane is interrupted. In this case, water is diverted into the next connected fracture. This fracture is again unlikely to be perfectly parallel to the drift axis, allowing the in-plane flowdiversion process to continue.

The situation is schematically illustrated in Figure D-3, which shows two fractures intersected by a drift. In Figure D-3a, the two fractures are aligned with the drift axis (which is an implicit assumption made in all two-dimensional fracture network models used to predict drift seepage). As an artifact of this specific and unrealistic fracture orientation, in-plane flow diversion is prevented, and the resulting impact of discreteness on seepage is exaggerated. Two-dimensional fracture network models (including those shown by Finsterle (2000; see Figure D-4a) and Liu et al. (2002, Figures 1 to 6) represent extreme cases that may not be representative of and appropriate for site-specific seepage modeling.

In Figure D-3b, the fractures are approximately perpendicular to the drift axis. Flow diversion occurs within the fracture plane, a process that is appropriately captured by a heterogeneous fracture continuum model even for a single fracture. In-plane flow occurring in multiple fractures can be readily combined and described by an effective fracture continuum. Three-dimensional discrete fracture network models are also capable of capturing in-plane flow diversion.

Given the significance of in-plane flow diversion around the drift in combination with relatively high fracture density and variable fracture orientation (see Section D.4.1.5), a three-dimensional, heterogeneous fracture continuum model is an appropriate conceptualization. It captures the relevant processes more realistically than, for example, a two-dimensional discrete fracture network model. Note that since a two-dimensional model strongly amplifies the effects of discreteness on flow and seepage, the appropriateness of the continuum model is tested by comparison to seepage rates generated with a two-dimensional model (see Section D.4.2.2). If this rigorous test is passed, the suitability of the continuum approach in three dimensions can be inferred. 


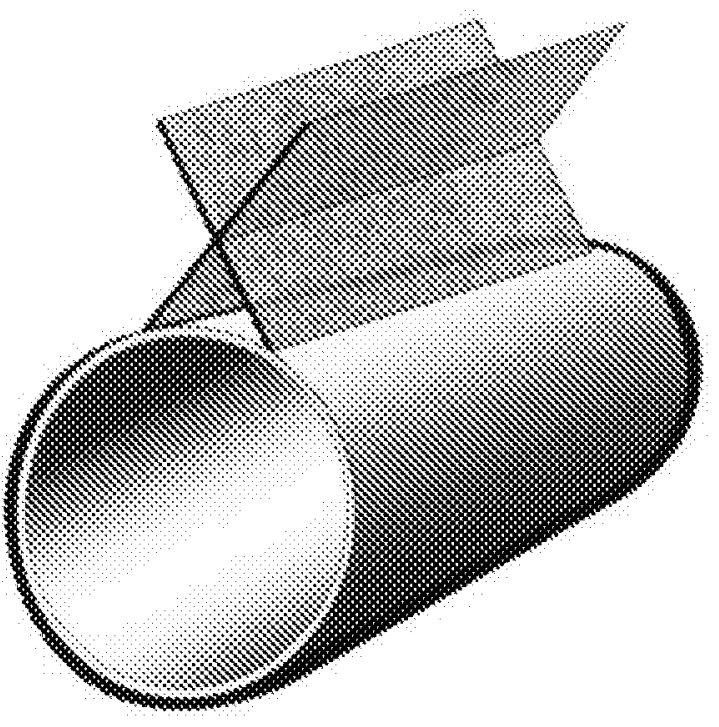

s?

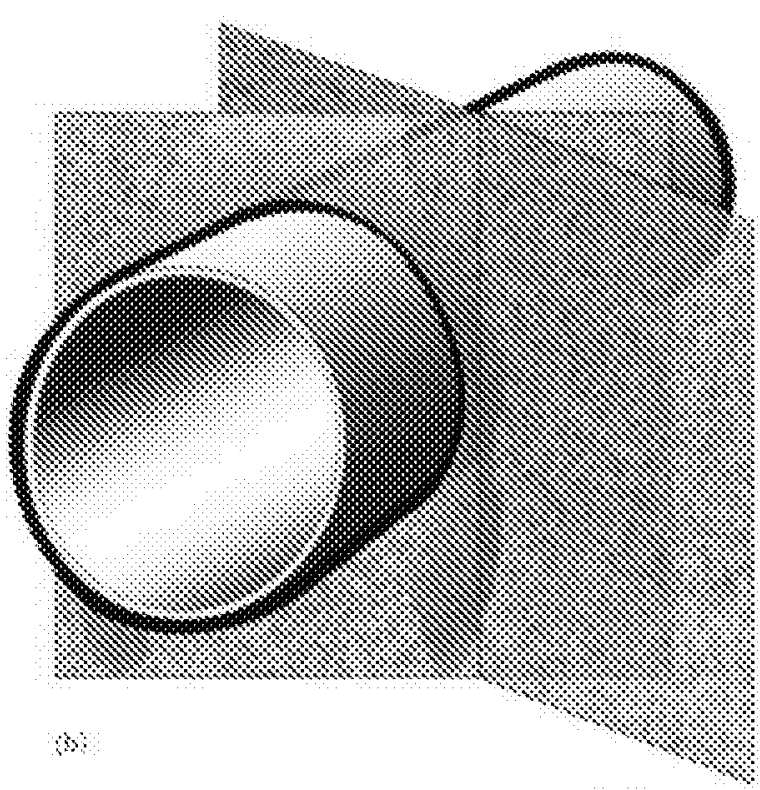

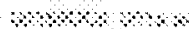

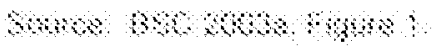

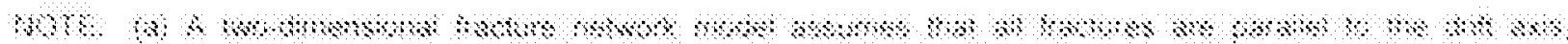

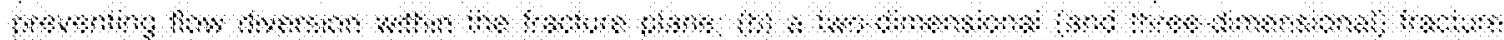

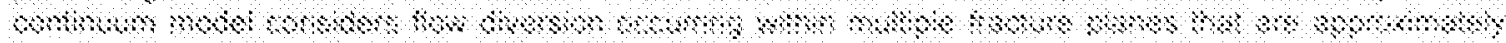
乃,

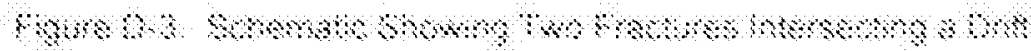

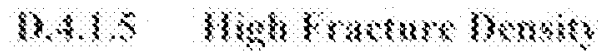

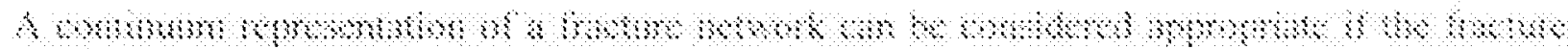

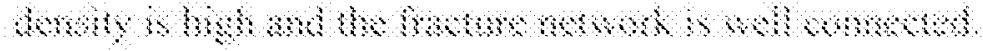

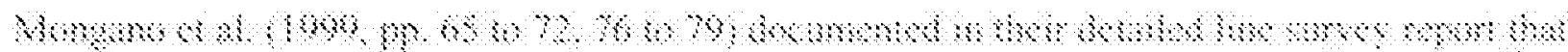

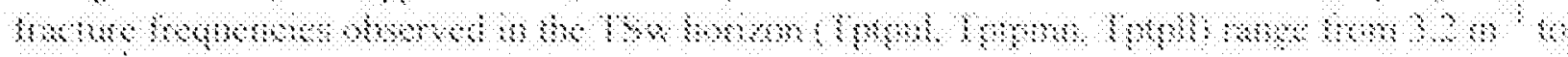

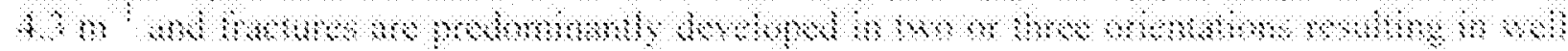

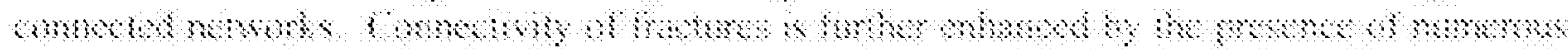

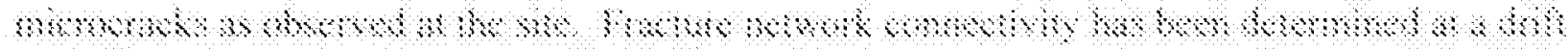

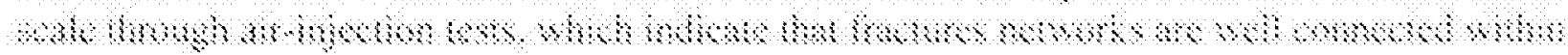

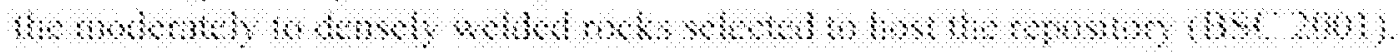

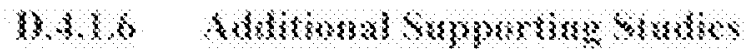

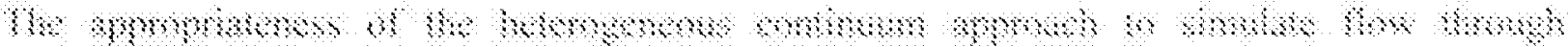

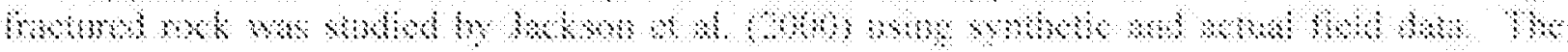
Seno

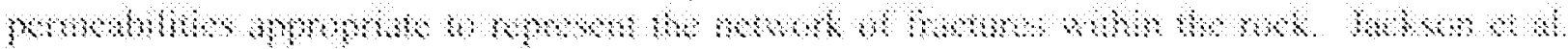

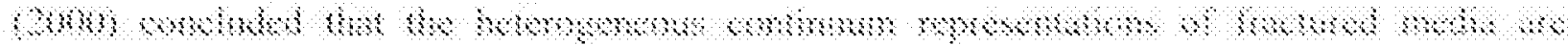


self-consistent (i.e., appropriately estimated effective continuum parameters are able to represent the underlying fracture-network characteristics).

Other studies on drift-scale seepage under ambient conditions have employed heterogeneous continuum models (Nitao 1996; Birkholzer et al. 1999).

\section{D.4.2 Comparison between Continuum and Discrete Fracture Network Models}

\section{D.4.2.1 Introduction}

Discrete fracture network models are considered to be conceptually and visually appealing alternatives to the continuum models. This approach involves the stochastic generation of fracture networks whose geometry is statistically similar to that seen on fracture trace maps or borehole logs. In addition to the geometric information, fracture hydraulic properties must be determined by calibration or derived from aperture-distribution data before flow and transport simulations can be performed. This key process and some of its pitfalls have been described in detail by Cacas et al. (1990) and Dverstorp and Andersson (1989). Moreover, when considering unsaturated flow through fracture networks, various assumptions must be made regarding phase occupancy of fracture segments, accessibility of certain portions of the fracture network, entrapment of wetting and nonwetting phases, and flow along and across fracture intersections. Flow channeling within a fracture plane-already significant in fully saturated media-becomes increasingly complex under unsaturated flow conditions. All these aspects must be conceptualized and implemented in a defensible discrete fracture network model if such an approach is chosen.

The discreteness of unsaturated fracture flow and seepage phenomena suggests the use of a discrete fracture network model for seepage studies at Yucca Mountain. As outlined in Section D.4.1, the continuum approach was chosen because it was considered appropriate for the purpose of seepage prediction into waste emplacement drifts. The following sections summarize studies comparing the two approaches, demonstrating that the results obtained with either model are consistent, provided that each model is calibrated against seepage data (see Section D.4.2.2).

\section{D.4.2.2 Seepage Predictions with Discrete Fracture Network and Continuum Model}

Finsterle (2000) compared seepage predictions calculated with a fracture continuum model to those obtained with a discrete fracture network model. The models were calibrated against one another (the discrete model providing the synthetic data) to account for the calibration step involved in the development of the continuum model. The study involved the following steps:

1. A model with a complex network of discrete features was developed (see Figure D-4a). The purpose of the model was to produce discrete flow behavior and localized seepage events (see Figure D-4b). Unsaturated flow simulations performed with this discrete fracture network model are considered to represent the response of a fractured system.

2. Air-injection tests, liquid-release experiments, and seepage under natural flow conditions were simulated using the discrete fracture network model to generate synthetic characterization, calibration, and confirmation data, respectively. 
3. A simplified heterogeneous fracture continuum model was developed based on the available synthetic air-permeability data (see Figure D-5).

4. Effective parameters were determined by calibrating the fracture continuum model against the synthetic liquid-release test data.

5. Responses from additional liquid-release tests were predicted with the continuum model and compared to results obtained with the discrete fracture network model.

6. The critical performance test for the continuum model is the examination of its ability to predict unobservable quantities (such as the seepage threshold and seepage rates under low percolation conditions). The fracture continuum model predictions were thus compared to the calculated response from the discrete system.

The main purpose of the modeling study was to gain confidence in the appropriateness of the continuum model to simulate and predict seepage into underground openings excavated from fractured rock. However, the study inherently contains a comparison between the two modeling approaches. The synthetically generated data could be replaced with actual seepage-rate data from liquid-release tests to which both models are calibrated. Subsequently, both models are used to estimate the seepage threshold under natural percolation conditions. It can be concluded that both models yield consistent results (see Figure D-6).

Note that the comparison between the two models uses the extreme assumption that all fractures are perfectly parallel to the drift axis. Even under these extreme conditions, where in-plane flow diversion is prevented, the calibrated continuum model yields reasonable seepage predictions for conditions that are different from those obtained during calibration. 

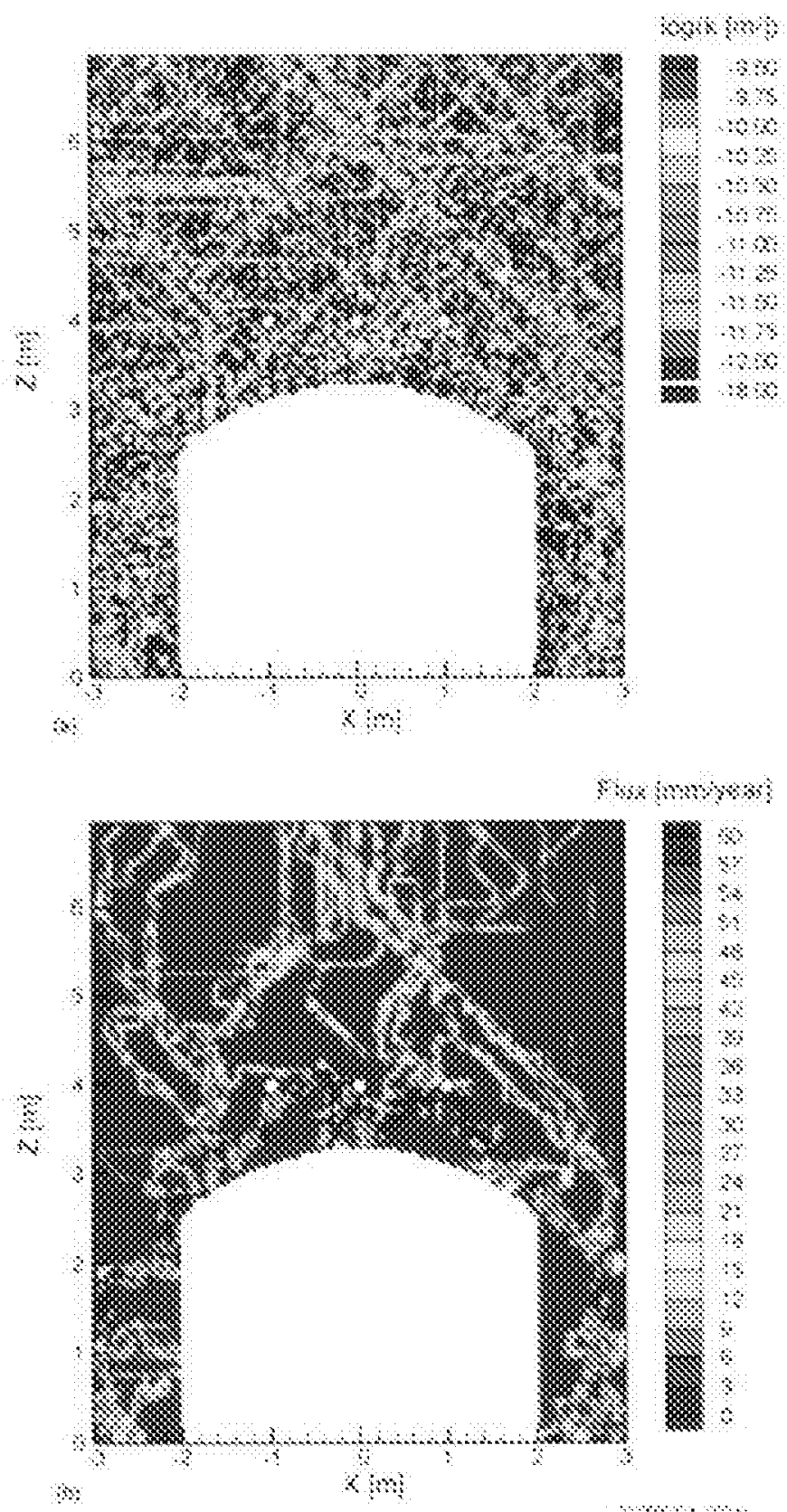

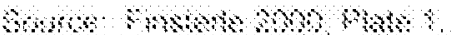

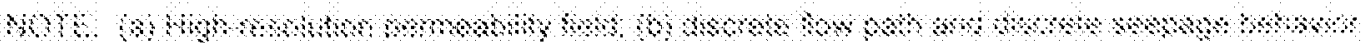

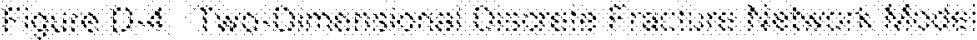



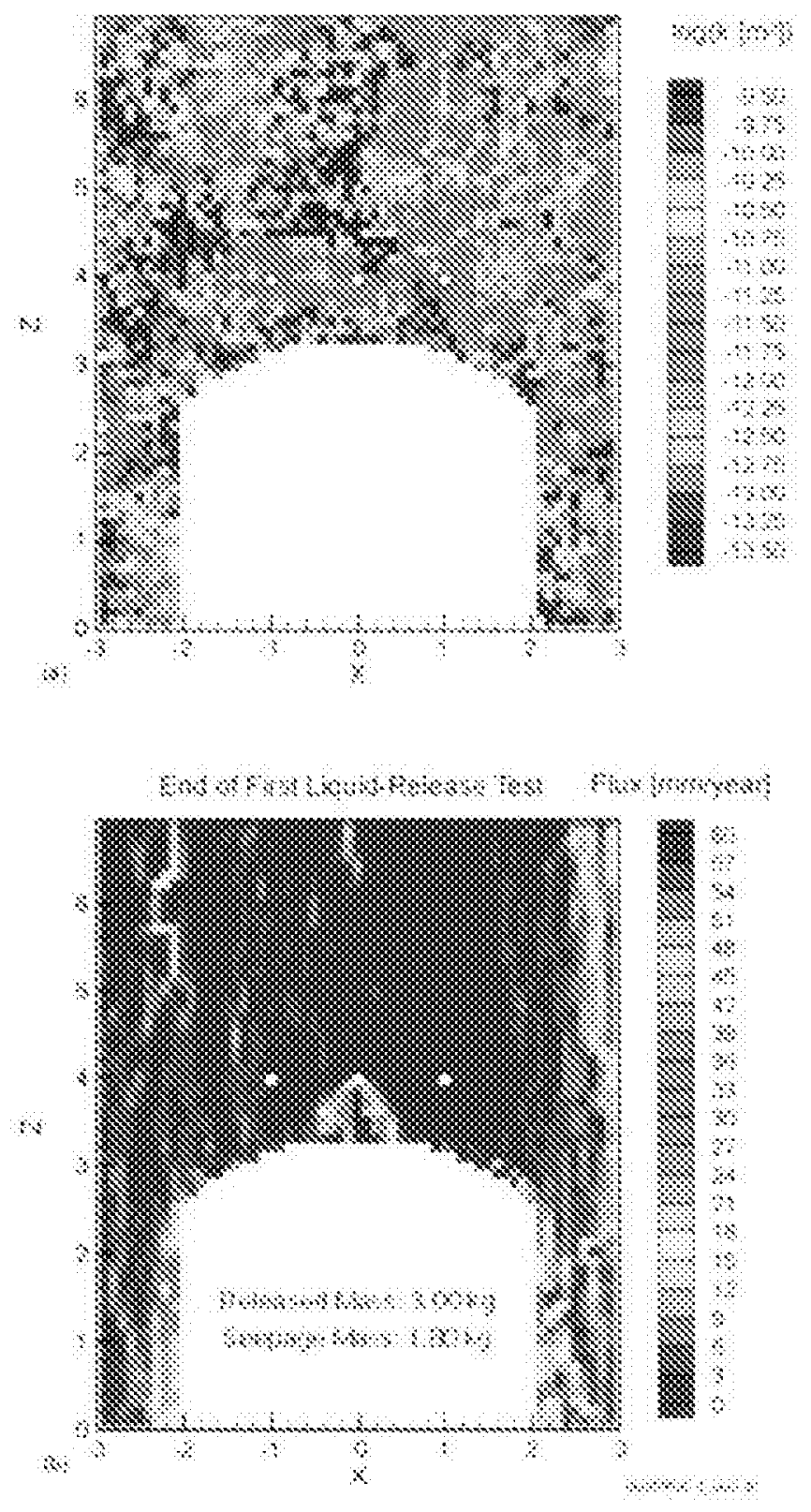

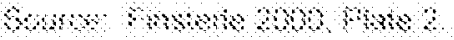

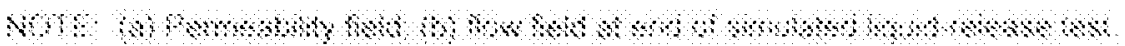

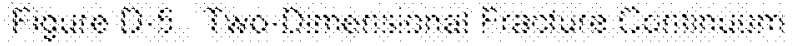




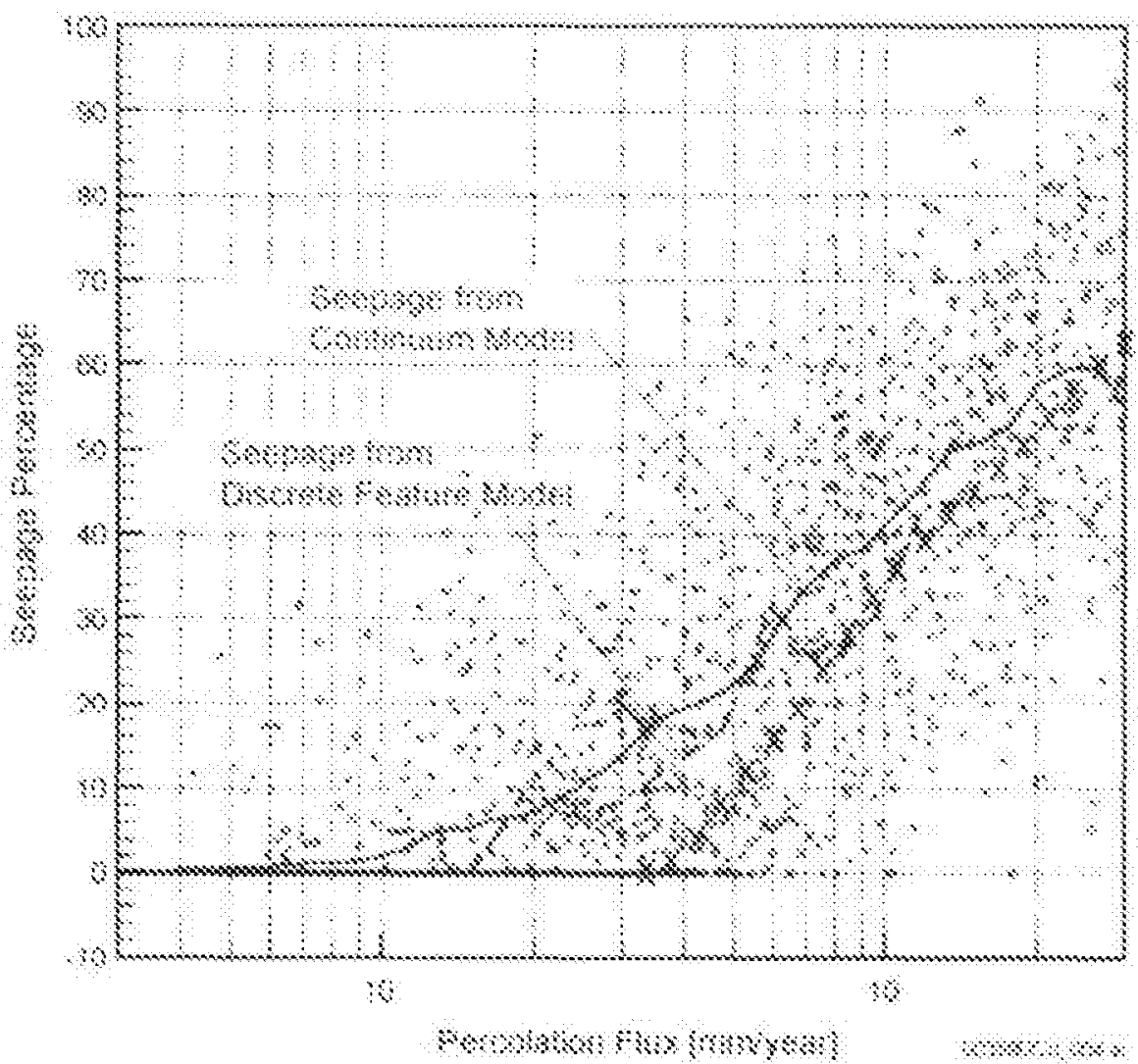

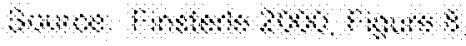

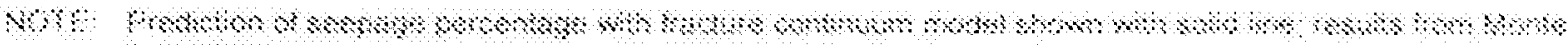

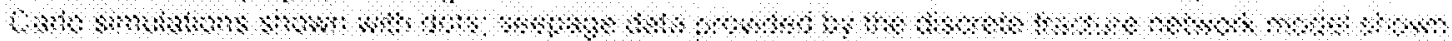

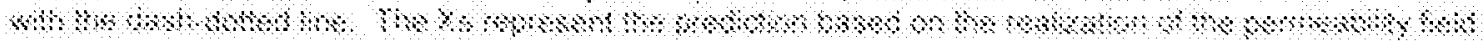

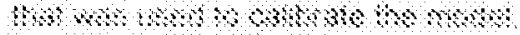

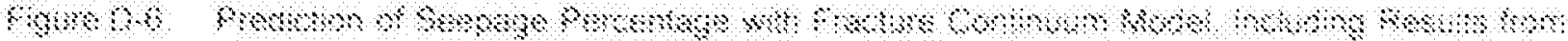

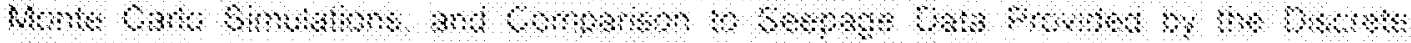
Momo hobmk kods:

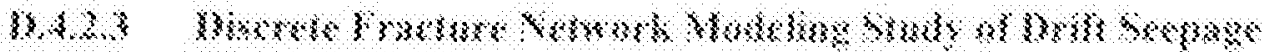

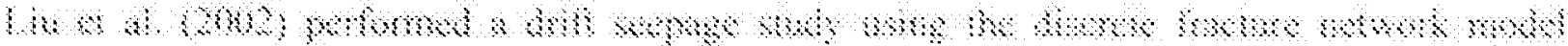

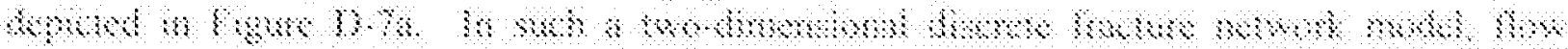

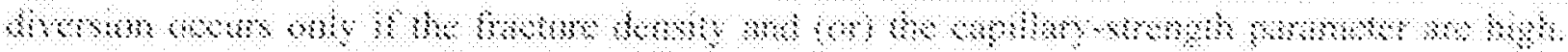

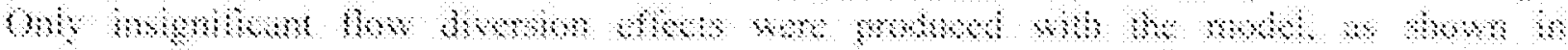

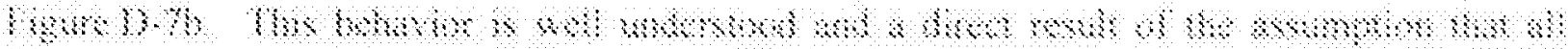

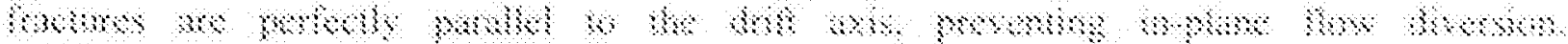

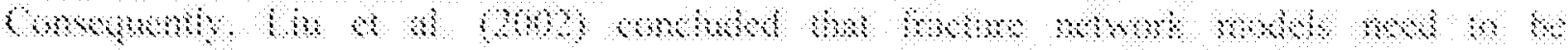

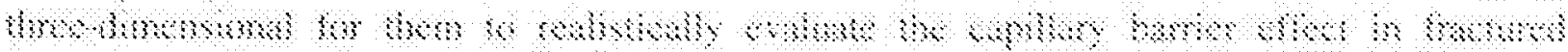

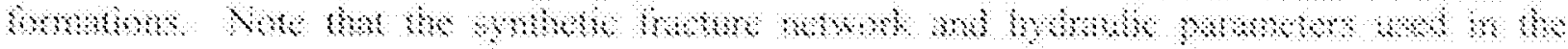

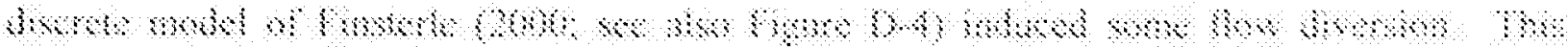

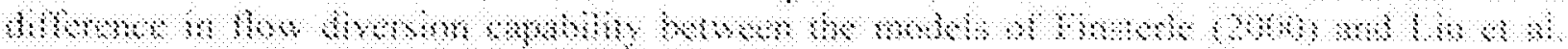

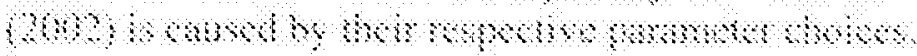




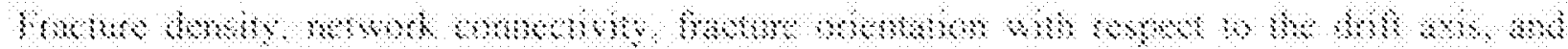

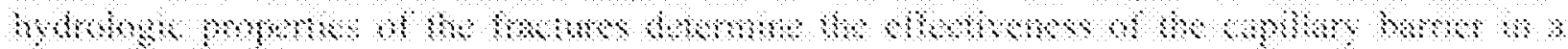

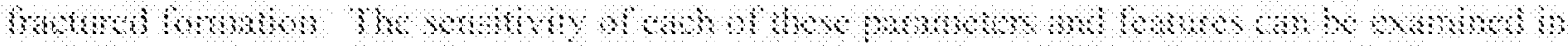

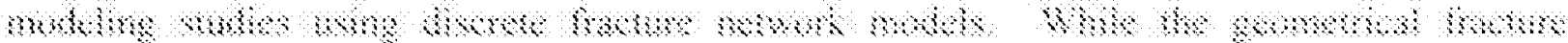

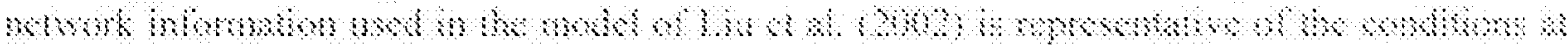

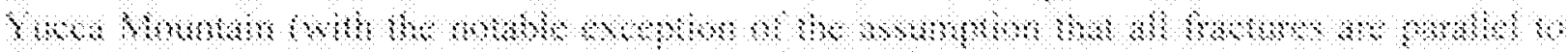

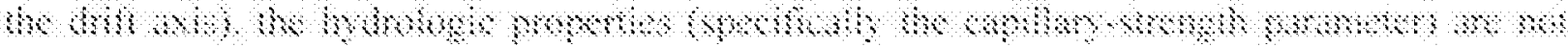

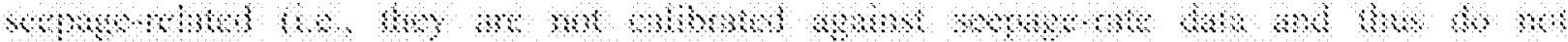

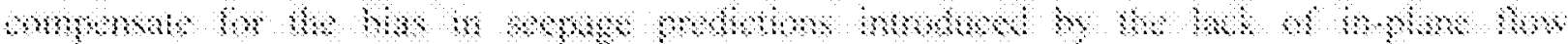

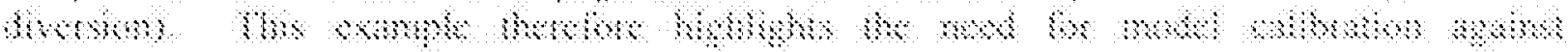

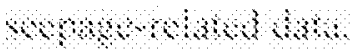
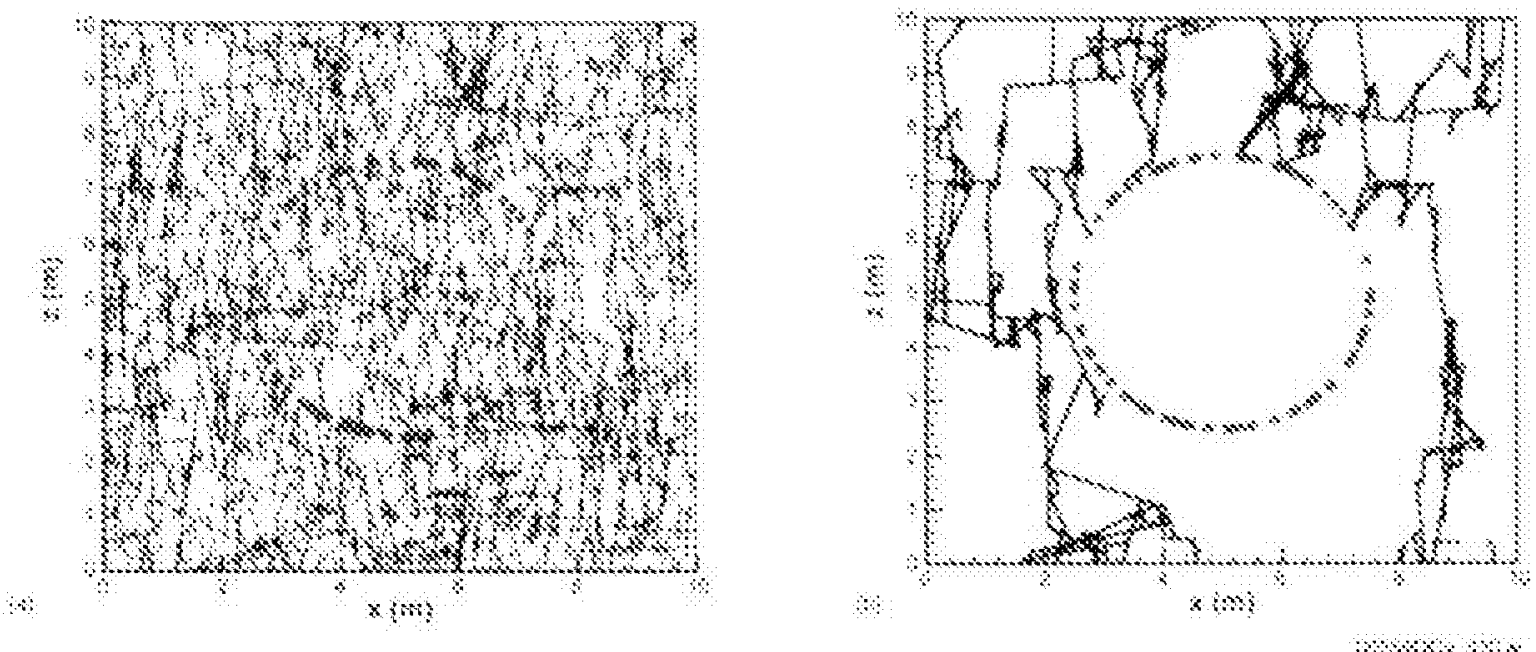

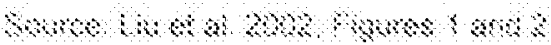

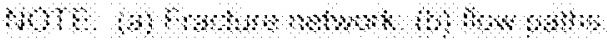

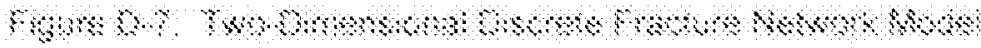

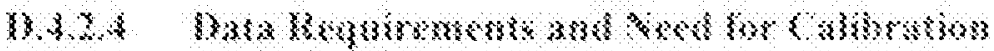

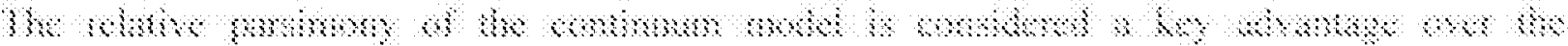
mmp

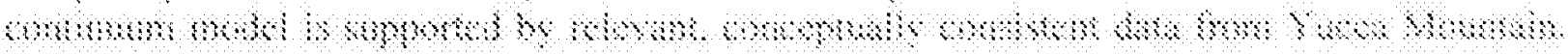

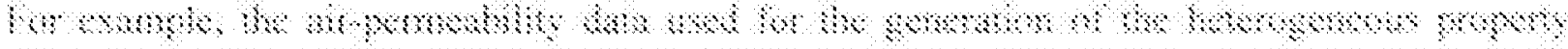

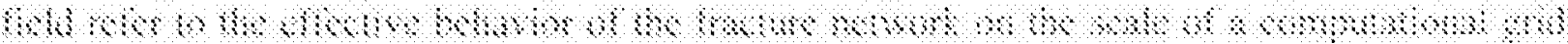

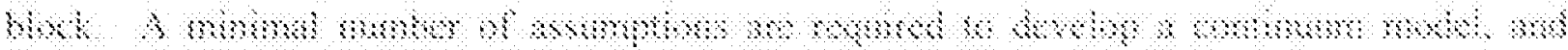

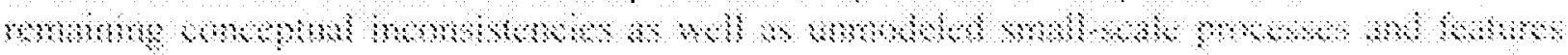

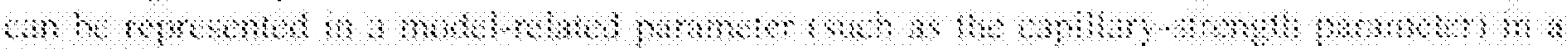

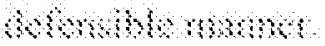

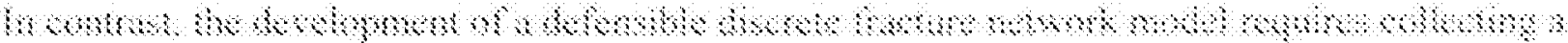

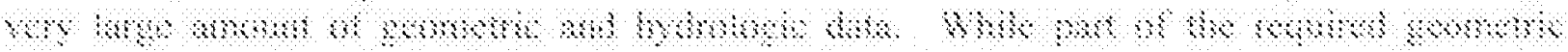

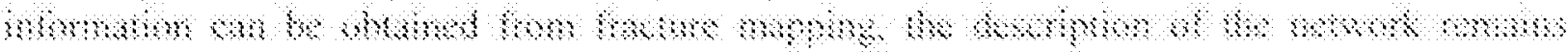

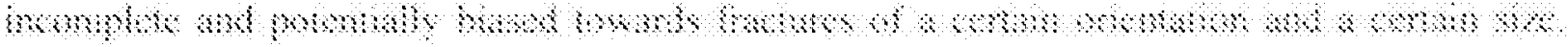


6) Results of the calcite filling observations will be documented in Analysis of Geochemical Data for the Unsaturated Zone (ANL-NBS-HS-000017) and the UZ Flow Models and Submodels (MDL-NBS-HS-000006) expected to be available to NRC FY 2003 (xi).

\section{C.1.2 Related Key Technical Issue Agreements}

Agreement Total System Performance Assessment and Integration (TSPAI) 3.25 covers material related to agreement USFIC 4.01. TSPAI 3.25 deals with testing to provide additional confidence in, or a basis for revising the total system performance assessment (TSPA) seepage abstraction and associated parameter values. The response to TSPAI 3.25 (see Appendix B) is based on the same field test data as used in response to USFIC 4.01.

\section{C.2 RELEVANCE TO REPOSITORY PERFORMANCE}

This KTI agreement relates to the DOE providing more information about ambient-condition hydrologic testing in the unsaturated zone at Yucca Mountain. During the August 2000 USFIC Technical Exchange (Reamer and Williams 2000), the DOE presentations for Subissue 4, Deep Percolation, included a discussion of seepage into emplacement drifts and of unsaturated zone flow. The DOE presented the ongoing and planned testing activities to evaluate seepage into drifts and stated that the unsaturated zone flow and transport models were extensively calibrated and validated against available data.

The NRC noted that the ongoing and planned testing was a reasonable approach for license application but requested the items as identified in the agreement to close this subissue (Reamer and Williams 2000). Of particular importance is the ongoing field test in the east-west cross-drift in which approximately a $1-\mathrm{km}$-long section of the tunnel has been sealed off from ventilation and is being allowed to return to ambient conditions (NRC 2002, p. 3.3.6-24). The NRC also noted that the analysis of calcite abundance would provide some constraints on hydrological parameters, percolation flux, and additional evidence for validation of the flow and transport model. The NRC acknowledged that this analysis could not give a definitive value or narrow range of values (NRC 2002, p. 3.3.6-24).

The agreement USFIC 4.01 is relevant to the repository performance because results and data from the hydrologic tests are relied upon for the development and validation of unsaturated zone process models and abstraction models supporting TSPA. 


\section{C.3 RESPONSE}

In situ testing and monitoring studies are being conducted to directly assess and evaluate the proposed waste emplacement environment and the unsaturated zone natural barrier to radionuclide transport at Yucca Mountain. For this KTI agreement, the field activities of interest are Alcove 8-Niche 3 (also referred to as Niche 3107), Niches 4 and 5 (also referred to as Niches 4788 and 1620), systematic hydrologic characterization, passive cross-drift hydrologic test, Alcove 7, and the calcite filling test. The responses to each aspect of the KTI agreement USFIC 4.01 can be summarized as follows, with supporting documentation provided in Section C.4:

1) A mass balance of water was considered for Alcove 8-Niche 3, but was not performed because the large scale of this test would have required a collection system that was considered infeasible. A collection system to obtain a mass balance was therefore developed for Niche 5, but its effectiveness was limited, so a complete mass balance was not obtained. Details are discussed in Section C.4.1.

2) Evaporation was monitored in Niche 5 and for the systematic hydrologic characterization tests, and this information was used for the quantitative determination of seepage-related parameters. Evaporation was not monitored in Niche 4, the passive cross-drift hydrologic test, Alcove 8-Niche 3, and Alcove 7, but relative humidity measurements were made. Estimates of evaporation can be obtained from the relative humidity measurements, coupled with appropriate assumptions about evaporative surfaces and impacts of ventilation. Estimates of evaporation for these tests have not been performed, however. Evaporation was not a relevant process over the time period that calcite observations were performed for the calcite-filling test. See Section C.4.2 for more details.

3) The test plan for the passive cross-drift hydrologic test is provided in Test Plan for: Moisture Monitoring in the ECRB Bulkheaded Cross Drift (BSC 2001a).

4) Preliminary seepage predictions for the passive cross-drift hydrologic test are described in Test Plan for: Moisture Monitoring in the ECRB Bulkheaded Cross Drift (BSC 2001a). A summary is provided in Section C.4.4.

5) The results and analysis of data from the passive cross-drift hydrologic test are provided in In Situ Field Testing of Processes (BSC 2003a) and are summarized in Section C.4.5.

6) The results from Alcove 7 are documented in In Situ Field Testing of Processes (BSC 2003a) and summarized in Section C.4.6.

7) The test plan for the Niche 5 test is provided in Test Plan for: Niche 5 Seepage Testing (BSC 2001b).

8) The results from the Niche 5 seepage tests are documented in In Situ Field Testing of Processes (BSC 2003a) and Seepage Calibration Model and Seepage Testing Data (BSC 2003b), and are summarized in Section C.4.8. 
9) The results from the Systematic Hydrologic Characterization test are documented in In Situ Field Testing of Processes (BSC 2003a), and Seepage Calibration Model and Seepage Testing Data (BSC 2003b), and are summarized in Section C.4.9.

10) The results from the Niche 4 seepage tests are documented in In Situ Field Testing of Processes (BSC 2003a), and Seepage Calibration Model and Seepage Testing Data (BSC 2003b), and are summarized in Section C.4.10.

11) The results obtained from the calcite-filling test are documented in Analysis of Geochemical Data for the Unsaturated Zone (BSC 2002) and UZ Flow Models and Submodels (BSC 2003c) and are summarized in Section C.4.11.

The information in this report is responsive to agreement USFIC 4.01 made between the DOE and NRC. The report contains the information that DOE considers necessary for the NRC to review for closure of this agreement.

\section{C.4 BASIS FOR THE RESPONSE}

\section{C.4.1 Mass Balance}

In an attempt to obtain a mass or rate balance during a liquid-release test, a slot was excavated on the side of Niche 5 to capture the water diverted around the niche (see Section C.4.7 for more details). The intent of this effort was to demonstrate that the amount of water released to the formation was balanced by the amount of water (1) recovered as seepage from the niche ceiling, (2) diverted around the opening and recovered in the slot, (3) stored in the formation, and (4) lost to evaporation. Since component (3) is difficult to measure, the liquid-release test was run to near-steady state, allowing for the calculation of a rate balance (rather than total mass balance) in which component (3) becomes insignificant. Water was collected at the side of the niche during two seepage tests conducted in Niche 5. However, because of difficulties in excavating the slot and installing the capture system, it was not possible to visually confirm if the water collected in the tarp underneath the slot was derived entirely from seepage into the slot. Even if we assumed all the water collected in the side originated from the slot, the measured data were not suitable for model calibration because (1) water could have bypassed the incomplete slot, (2) the seepage rates did not reach steady state, or (3) the data were biased by interference from a liquid-release test simultaneously conducted in a nearby borehole. While qualitative evidence was obtained that the capillary barrier was capable of diverting water around the niche (see also Section C.4.7 below), a quantitative mass or rate balance based on the measured data alone could not be obtained.

\section{C.4.2 Evaporation Monitoring during Testing}

Evaporation affects seepage-rate data collected during liquid-release tests and thus potentially introduces a bias in the estimates of seepage-relevant parameters. Moreover, the evaporation potential in the ventilated drifts may mask potential seepage observations. Therefore, an effort was made to (1) control relative humidity in seepage test locations, (2) monitor relative humidity and (or) evaporation potential, and (3) account for evaporation effects in the analysis of seepagerate data (if considered relevant). 
Evaporation monitoring in the Niche 5 and the systematic hydrologic characterization tests is discussed below in Sections C.4.2.1 and C.4.2.2, respectively. The collected data provide a sufficient basis for addressing potential evaporation issues during liquid-release testing. For the calcite filling observations, evaporation was not a relevant process over the time period that calcite observations were performed. Evaporation was not monitored in the Niche 4 test, the passive cross-drift hydrologic test, the Alcove 8-Niche 3 test, and the Alcove 7 test, but relative humidity measurements were made. Estimates of evaporation could be obtained from the relative humidity measurements coupled with appropriate assumptions about evaporative surfaces and impacts of ventilation. The results from the passive cross-drift test and the Alcove 7 test have not, however, been used in quantitative seepage modeling. In the analysis of the Niche 4 and Alcove 8-Niche 3 test results, evaporation was not incorporated since it was assumed to be minimal because the bulkhead doors at the entrance to the niches were closed and sealed, and the air space within the niches was artificially humidified.

Further detail on evaporation measurements during these tests can be found in In Situ Field Testing of Processes (BSC 2003a, Sections 6.2, 6.10, 6.11, and 6.12).

\section{C.4.2.1 Niche 5 Test}

The evaporation flux was measured inside Niche 5 (BSC 2003a, Section 6.2.1.3.5.3). Figure C-1 shows the evaporation flux inside and outside the niche during Test \#2 9-17-02. The plot indicates that the average evaporation flux outside of the niche is about a factor of 20 greater than the average evaporation flux inside the niche. The peak evaporation rates associated with the sawtooth pattern observed in the evaporation pan data collected outside the niche correspond to refilling the evaporation container with fresh warm water from the tunnel water supply system. In Seepage Calibration Model and Seepage Testing Data (BSC 2003b), the evaporation in Niche 5 was accounted for in the simulations by calculating an evaporative boundary-layer thickness based on the measured evaporation data.

\section{C.4.2.2 Systematic Hydrologic Characterization}

Evaporation pans were combined with wetted area observations to measure evaporation rates for the systematic hydrologic characterization (BSC 2003a, Section 6.11.3). Curtains were installed to minimize evaporation from the seepage face. Evaporation rates from 9 liquid release tests are summarized in Figure C-2. Evaporation was zero at two locations (LA3z3 and LA4z3) and ranged from $2.5 \mathrm{ml} / \mathrm{min}$ to $32 \mathrm{ml} / \mathrm{min}$ in the remaining seven locations. 


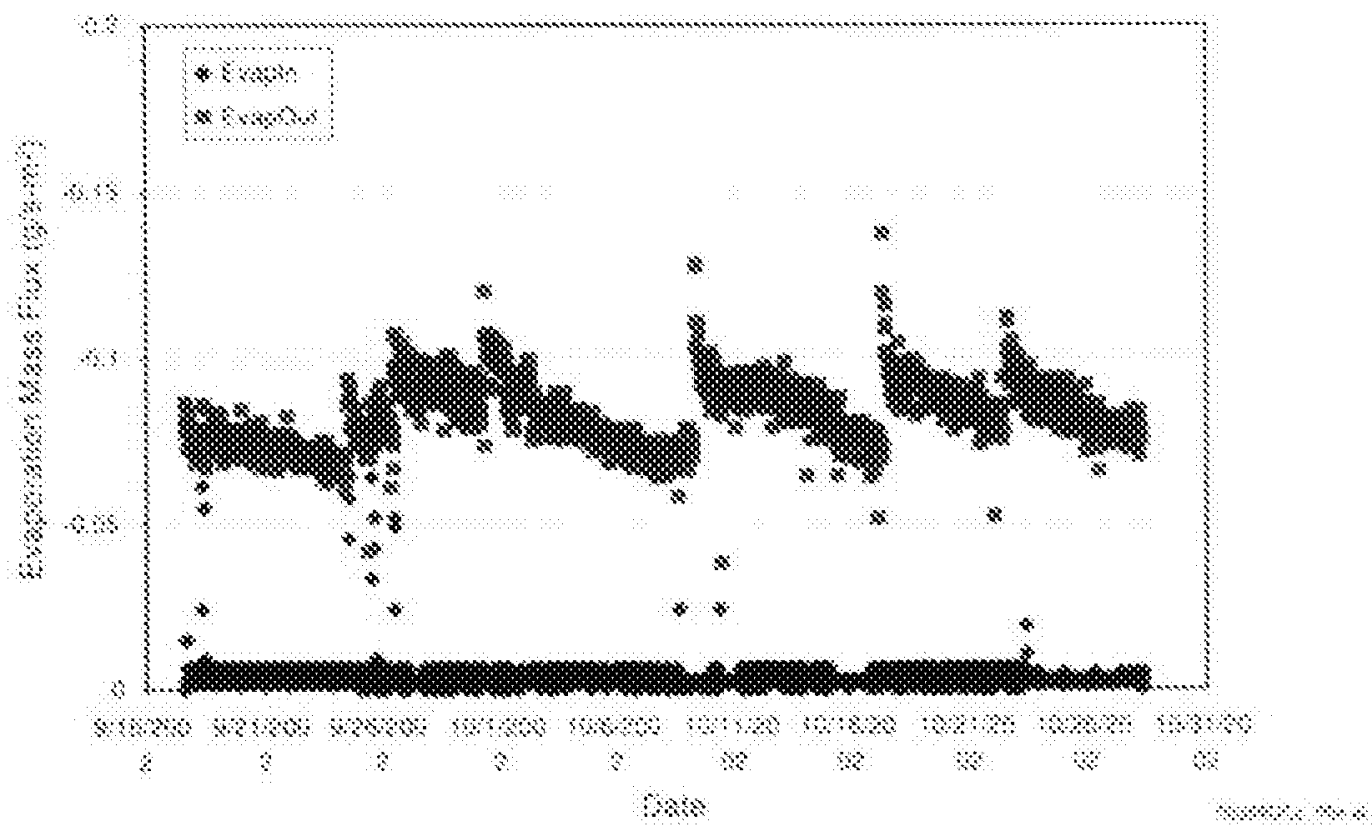

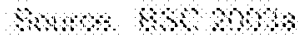

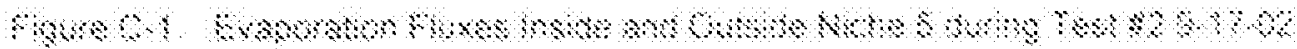

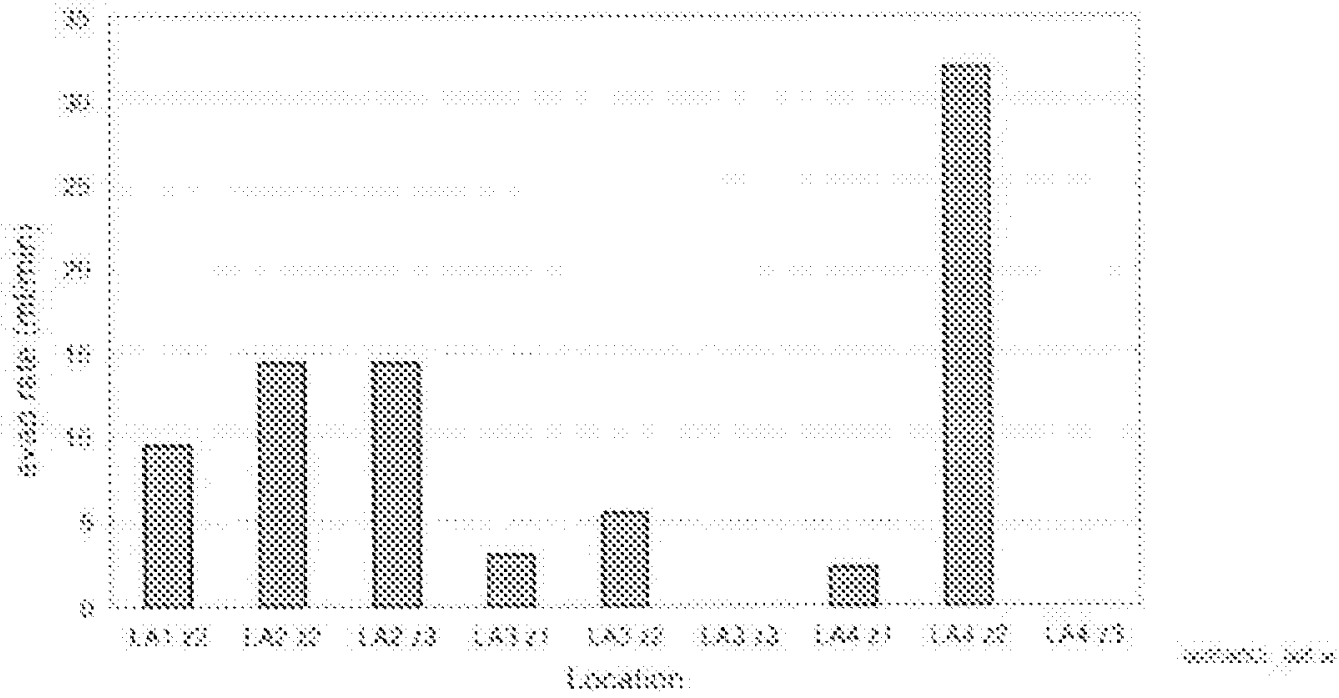

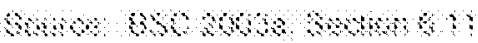

nus Me M

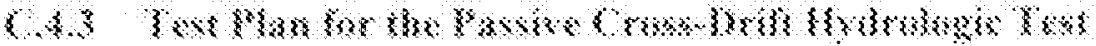

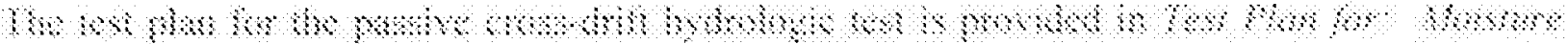

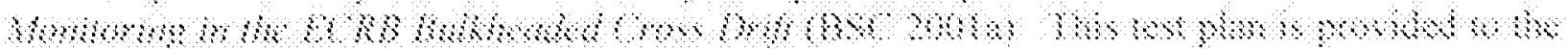

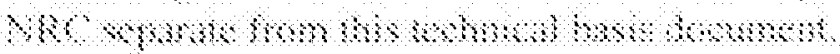




\section{C.4.4 Cross-Drift Seepage Predictions}

Modeling studies of the bulkhead experiment were carried out in 1996 and 1997 to evaluate the changes in moisture conditions in the rock surrounding the drift. The rate and extent of rock dryout during the ventilation period and rewetting after installation of the bulkhead were evaluated using the site-scale unsaturated zone flow model. In the calculations for dryout, the extent of drying was found to be less than $10 \mathrm{~m}$ within 100 years (Ahlers et al. 1996). For the rewetting period after installation of the bulkhead, the models predicted that the fractures will resaturate within 6 months for the reference case, whereas the matrix would require more than 6 years to completely resaturate (Bodvarsson et al. 1997).

The probability of seepage in the bulkheaded section of the Enhanced Characterization of the Repository Block (ECRB) was evaluated in 2000 based on a methodology similar to that used by TSPA at that time. This study assumed that the ECRB had returned to undisturbed moisture conditions in the rock for present-day climate. The prediction results were presented at the unsaturated zone process model report interactive review held at the Lawrence Berkeley National Laboratory on January 10, 2000 (BSC 2001a). Probabilistic seepage predictions of the seepage fraction and the seep flow rate into the length of the ECRB cross-drift $(1,800$ to $2,500 \mathrm{~m})$ were performed, with percolation fluxes calculated for present day climate conditions. Flow-focusing factors, permeability, and capillary-strength parameters were sampled from probability density functions, and seepage rates and seepage fraction extracted from lookup tables calculated by the seepage model for performance assessment.

Defining one seep as water entering a 5-m section of the drift, the predictions indicated there is a 50 percent chance that one or more seeps would occur in the bulkheaded section of the ECRB, a 10 percent chance that four or more seeps would occur between $2,000 \mathrm{~m}$ and 2,200 m of the cross-drift, and a 10 percent chance that two or more seeps would occur between 2,400 and $2,500 \mathrm{~m}$. A large flow rate was predicted for each of these seeps. This analysis did not consider evaporation and associated condensation, which may also be occurring in the ECRB unventilated section.

Note that the abstraction values used for these predictions are not identical to those to be used in TSPA-LA. However, the predictions are based on an approach consistent with that used for TSPA-SR. The probabilistic seepage predictions cannot be directly compared to data collected in the ECRB behind the bulkheads, because it is uncertain if the collected water originated from seepage or condensate (see Section 4.5.3.6). Nevertheless, the existence of seepage in the ECRB is not inconsistent with the probabilistic seepage predictions.

\section{C.4.5 Results and Analysis for the Passive Cross-Drift Hydrologic Test}

Information for the following sections is based on In Situ Field Testing of Processes (BSC 2003a, Section 6.10).

\section{C.4.5.1 Test Summary}

Passive moisture monitoring along the ECRB cross-drift was performed to examine the moisture dynamics and distribution in the drift with and without ventilation. In the ventilated drift sections, no continuous dripping or confirmed seepage was observed in either the Exploratory 
Studies Facility (ESF) loop or in the ECRB cross-drift. This lack of seepage may be explained by the capillary barrier mechanism, where capillary forces hold water within the rock mass, or by the effect of ventilation. Ventilation can remove large amounts of moisture, dry the rock behind the drift walls, and suppress seepage.

\section{C.4.5.2 Ventilation Effects in the Enhanced Characterization of the Repository Block Cross-Drift}

Relative humidity data from three moisture stations in the ECRB cross-drift are illustrated in Figure C-3 for the month of November 1998, right after the completion of the excavation by the tunnel-boring machine and when the ventilation was on. The moisture sensor assembly at ECRB cross-drift construction station CD 25+55 (2,555 $\mathrm{m}$ from the ECRB cross-drift entrance) is located near the Solitario Canyon fault on the western boundary of the repository block. The other two stations, at CD 14+43 and CD 21+40, measured the moisture conditions in the middle part of the ECRB cross-drift within the repository block.

The figures illustrate the temporal fluctuations and the spatial distributions of moisture conditions along the ECRB cross-drift. The data were collected every 15 minutes. CD $25+55$ was much more humid than the other two stations under the control of the same ventilation system. The day shifts had more activities than the other two shifts.

The spatial variations illustrated in Figure C-4 are based on weekly averaging over the day shifts. The differences in relative humidity are more clearly shown with the spatial distribution plot. While the magnitude varies from week to week, the spatial gradients were relatively constant. The average gradients for the two sections were 3.4 percent per kilometer between CD $14+35$ and CD $21+40$, and 25.2 percent per kilometer between CD $21+40$ and CD $25+55$. The section near the end of the tunnel apparently had more moisture removed than the section near the entrance. The average relative humidity decreased over the first 3 weeks of November at each station, but increased during the fourth week of November. This increase in average relative humidity is probably correlated with the ventilation system being shut down over the long Thanksgiving weekend.

\section{C.4.5.3 Observations along Nonventilated Sections of the Enhanced Characterization of the Repository Block Cross-Drift}

A series of bulkheads was constructed in the terminal section of the ECRB cross-drift to minimize ventilation effects. Barometric pressure, humidity, and temperature are being measured at various stations within the drift to provide information on moisture dynamics along the ECRB cross-drift. Psychrometers were installed along seven boreholes to measure the water potential and thus the extent and rewetting of the dryout zone. The evaporation rate was not monitored in the cross-drift. Periodically, the bulkhead doors sealing the nonventilated sections were opened for observations. Water samples were also collected during these times and were subsequently analyzed to determine if water originated from seepage or condensation. The 918-m-long drift section is located in the Topopah Spring lower lithophysal (Tptpll) and the lower nonlithophysal (Tptpln) tuff units. 


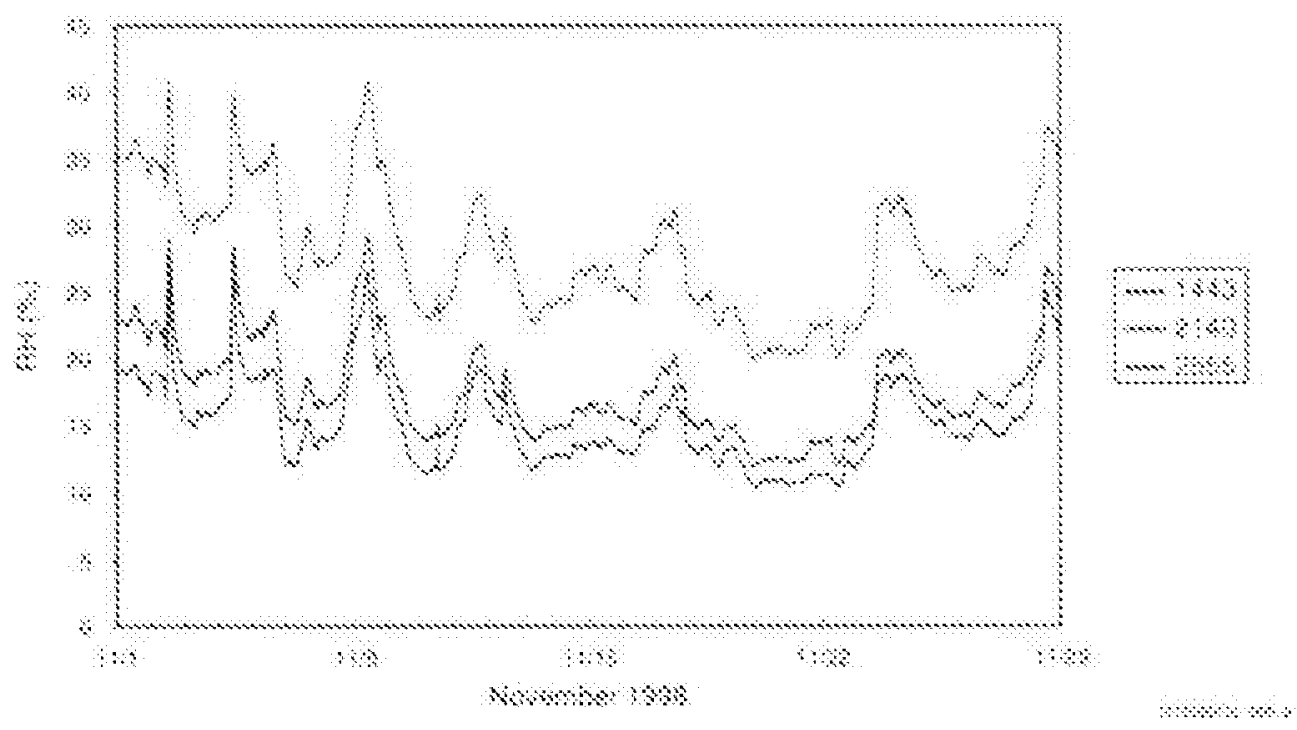

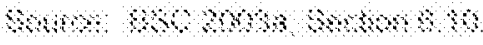

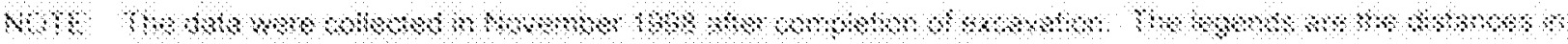

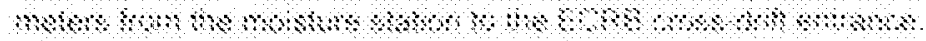

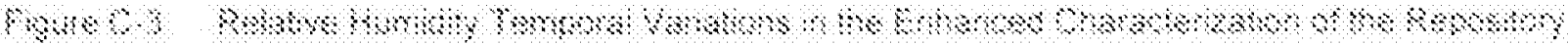
$360,0,36$

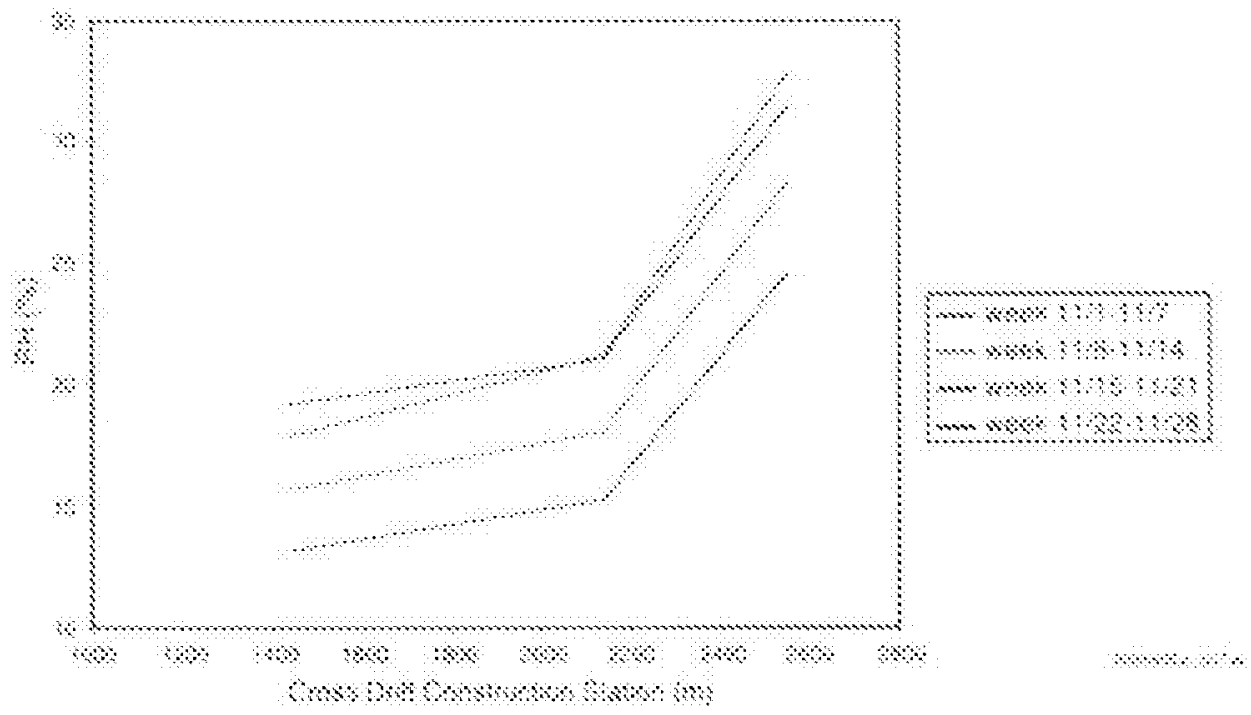

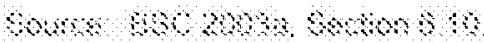

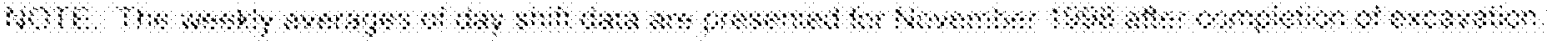

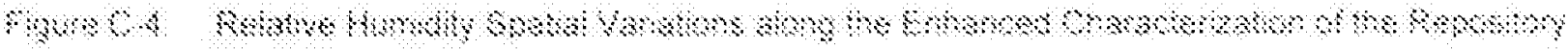
sins essan 


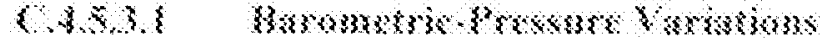

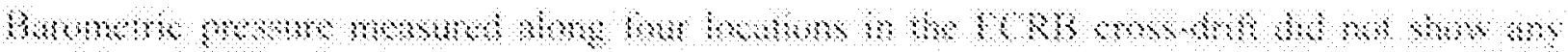

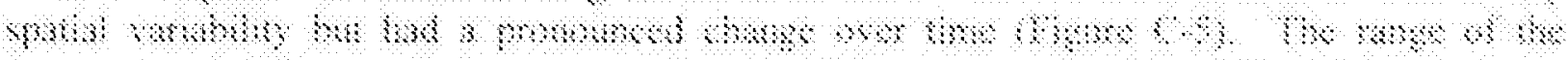

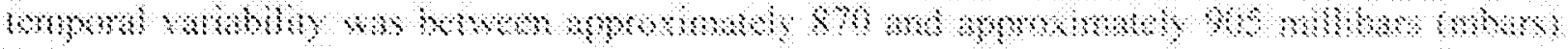

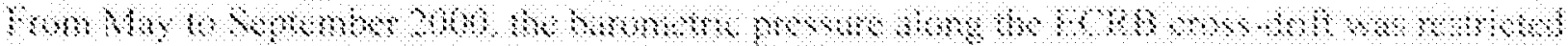

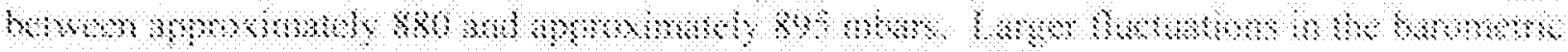

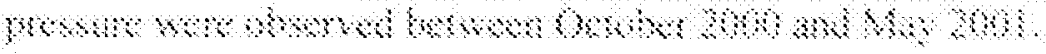

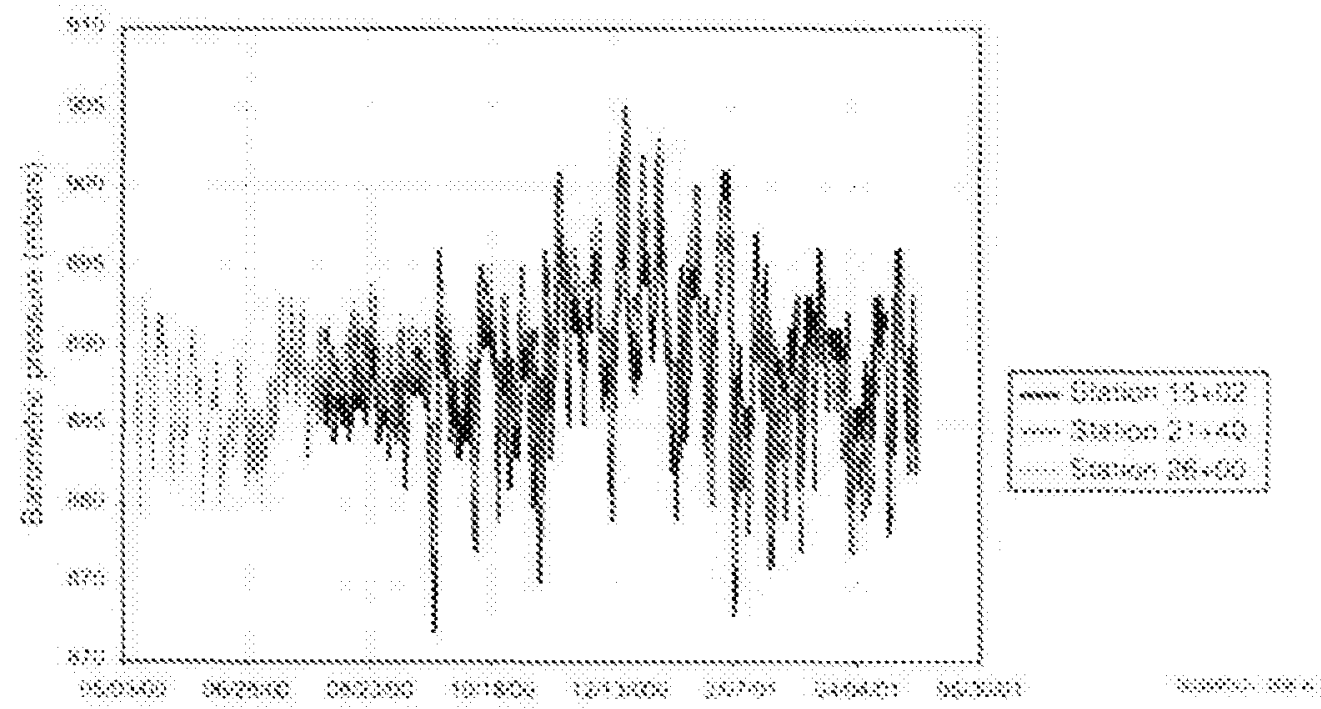

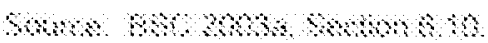

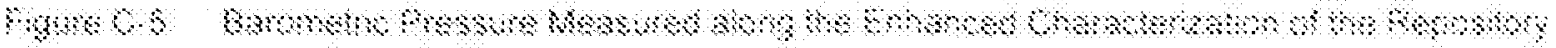

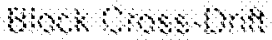

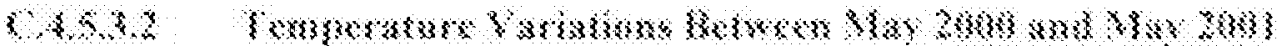

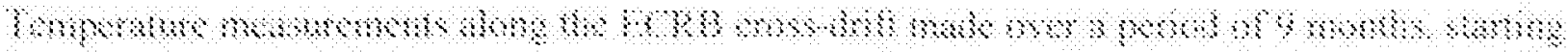

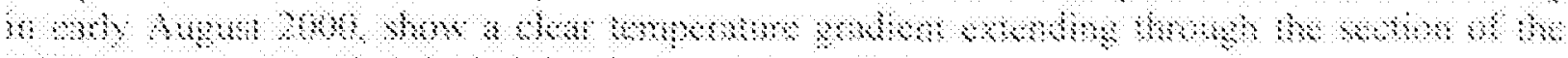

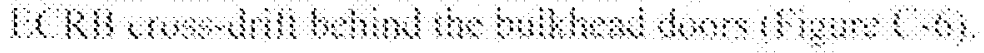




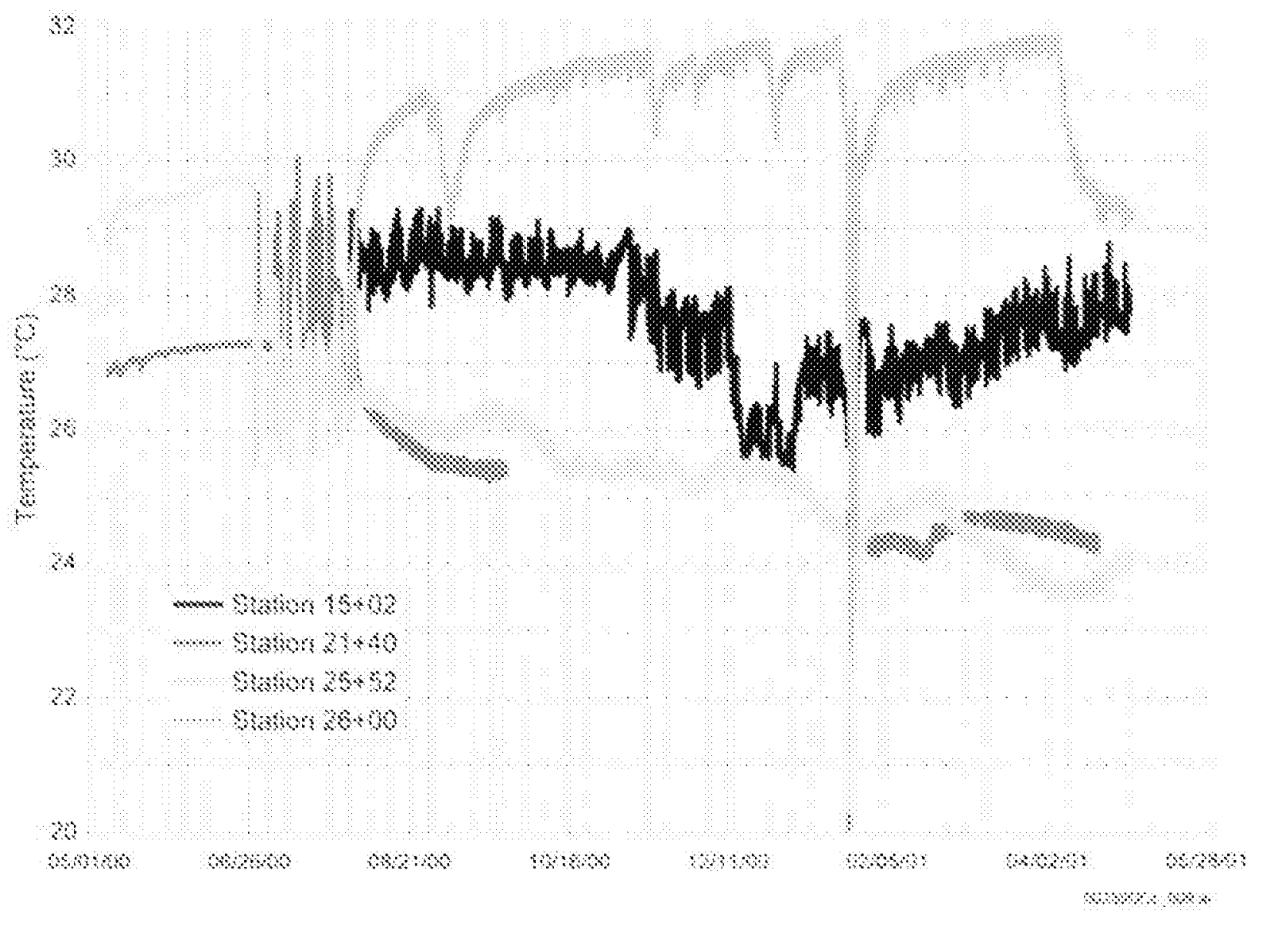

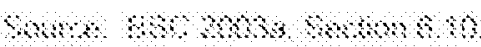

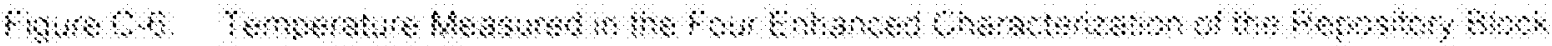
mom

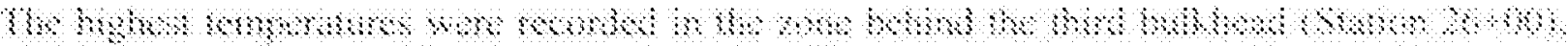

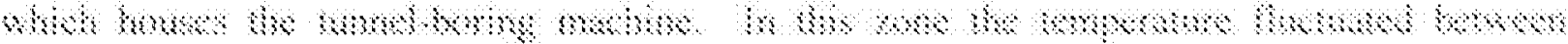
s)

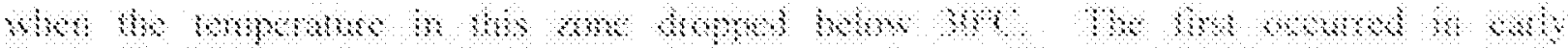

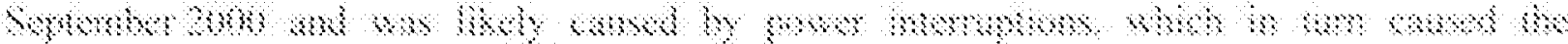

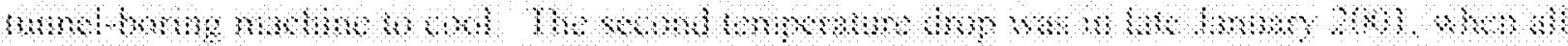

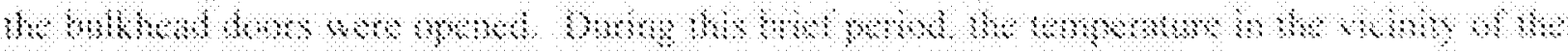

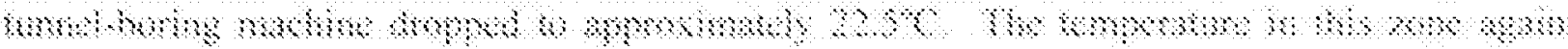

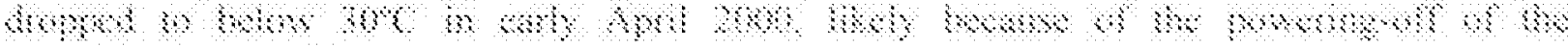

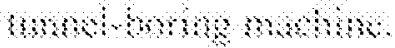

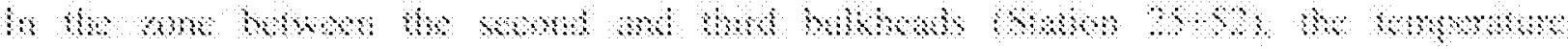

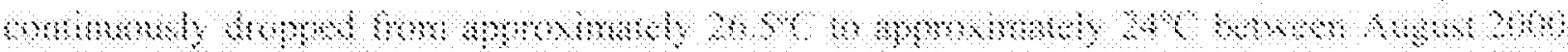

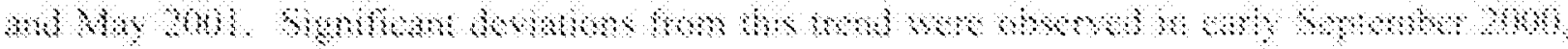

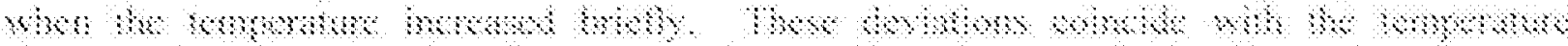

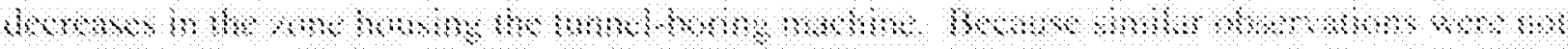

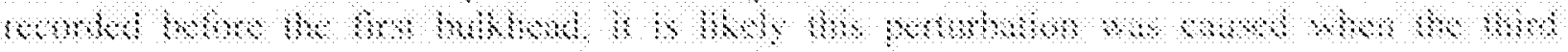

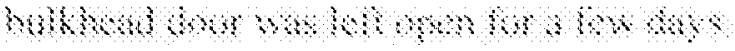


The temperature data collected between the first and second bulkhead (Station $21+40$ ) shows the region steadily cooling immediately following the closure of the bulkhead doors in July 2000 . (Because of the lack of temperature data from this location between late September 2000 and February 2001, temperature dynamics in this zone cannot be compared with the other two zones during this time.) Following the closure of the bulkhead doors in late January 2000, the temperature in this zone immediately dropped to approximately $24^{\circ} \mathrm{C}$ and remained close to that value over the next 2 months.

Temperature in the ECRB cross-drift measured immediately outside the first bulkhead shows diurnal and seasonal fluctuations (Station 15+02). While the diurnal fluctuations appear to be restricted to within $3^{\circ} \mathrm{C}$, the seasonal temperature changed from approximately $29^{\circ} \mathrm{C}$ in late August 2000 to approximately $25^{\circ} \mathrm{C}$ in late December 2000 .

In summary, the three zones defined by the bulkheads in the ECRB cross-drift appear to be partially thermally isolated from each other and also from the area outside the bulkhead when the doors are closed. The zone housing the tunnel-boring machine was warmer than the area outside the first bulkhead while the other two zones were consistently cooler when the doors were closed. During the period when the bulkhead doors were opened the temperature in each of the zones rapidly approached that of the zone outside the bulkheads.

\section{C.4.5.3.3 Relative Humidity Variations between May 2000 and May 2001}

The relative humidity in the three zones defined by the bulkheads shows spatial variability similar to the temperature data (Figure C-7). The lowest humidity was observed in the area before the first bulkhead, where it fluctuated between approximately 10 and 40 percent, with a few instances where the humidity was greater than 60 percent. In the two zones between the first and third bulkheads, the relative humidity remained close to approximately 95 percent, with some changes observed in March 2001, when the humidity in the second zone gradually fell closer to approximately 90 percent. 


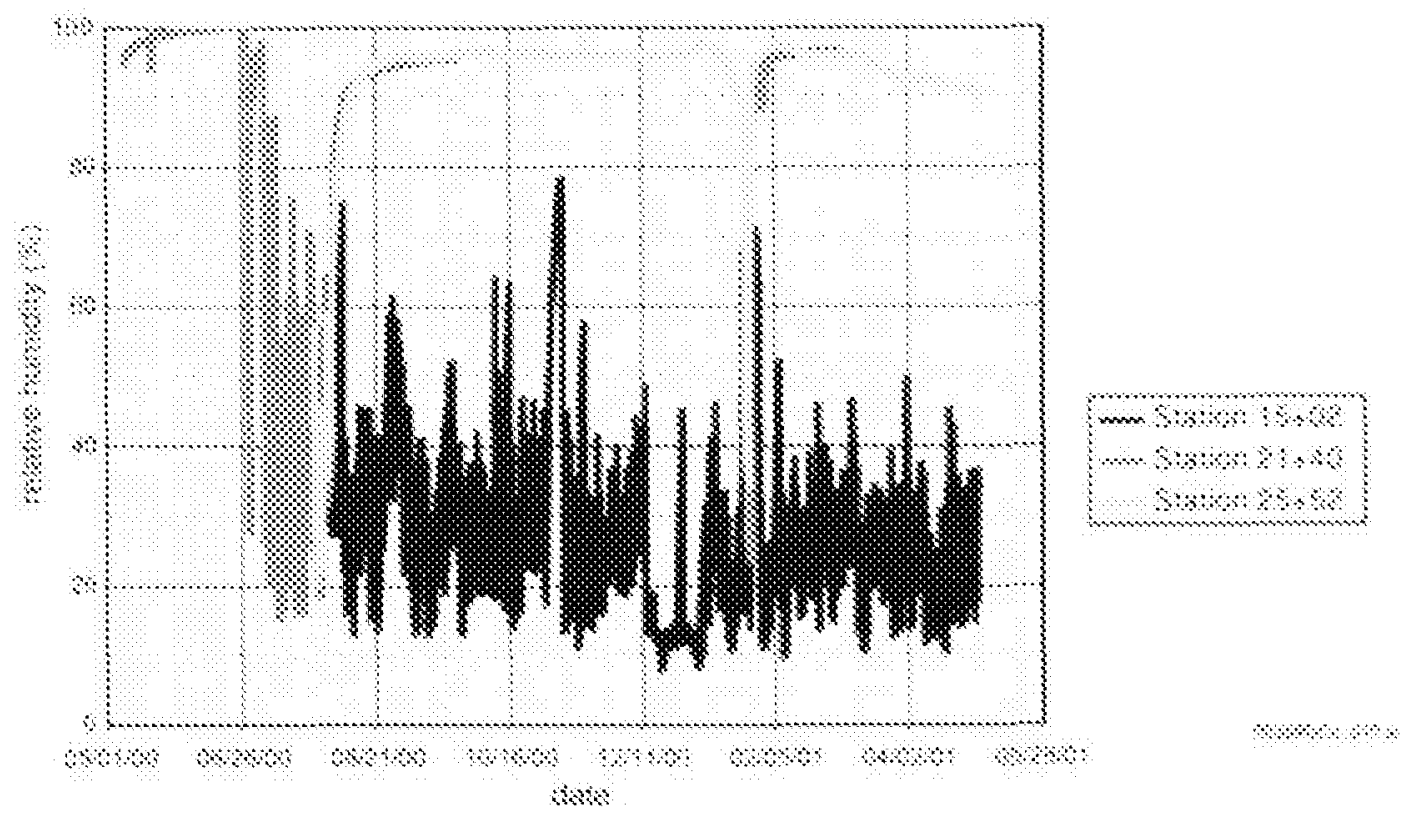

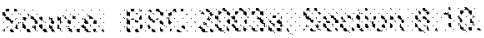

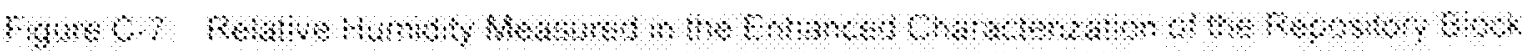
cos $\rightarrow$ sess

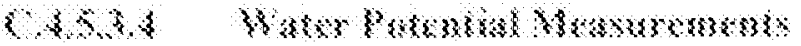

Barmpment nem

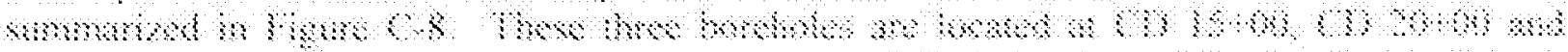

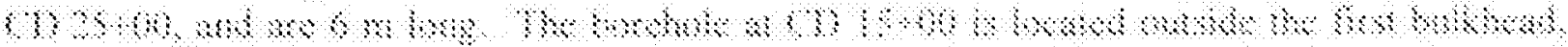

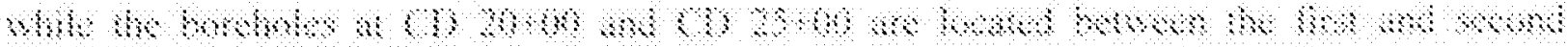

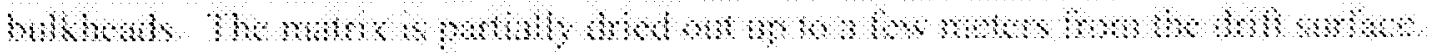



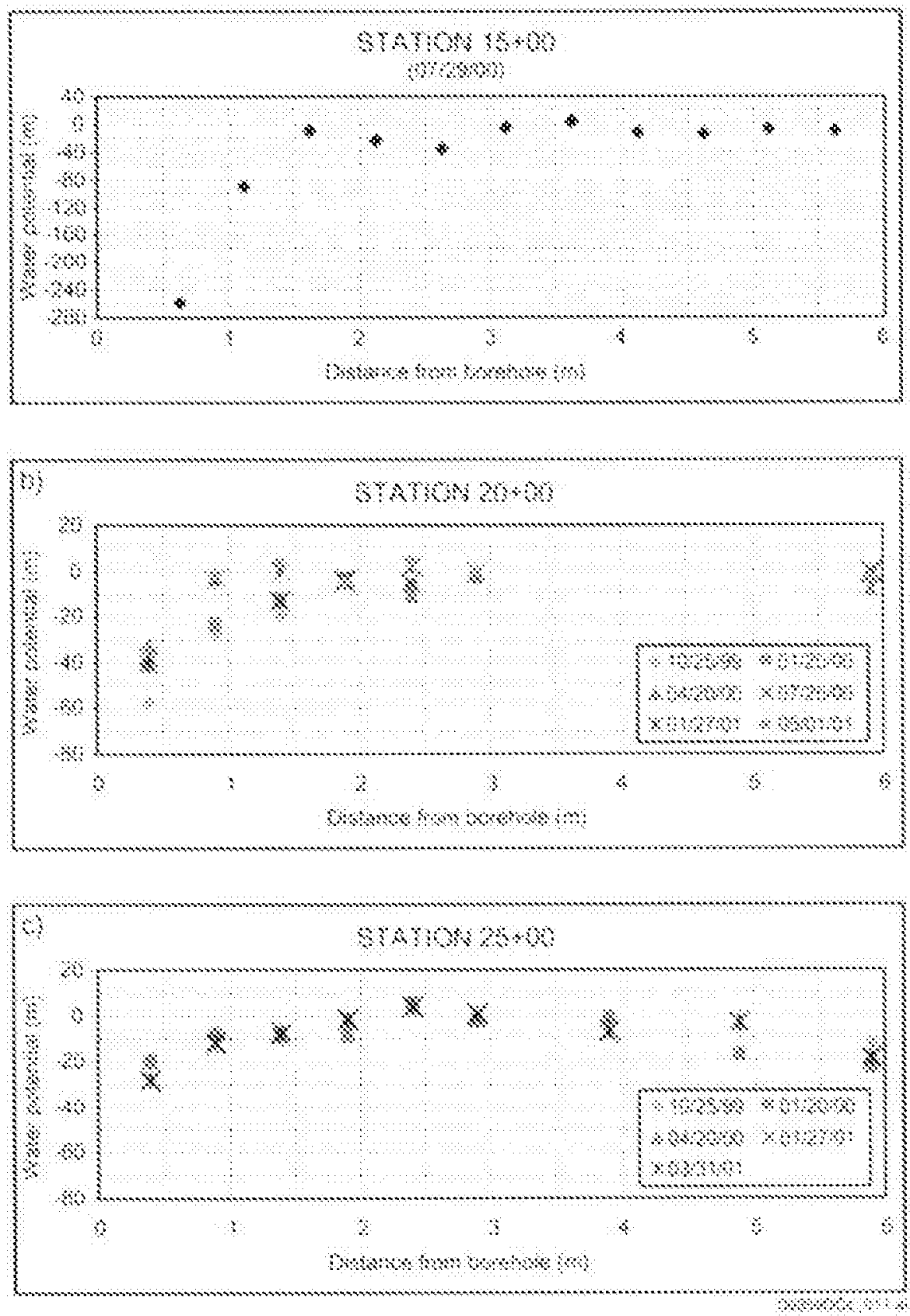

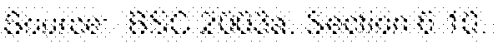

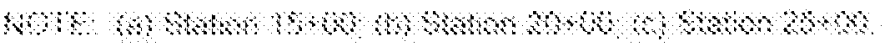

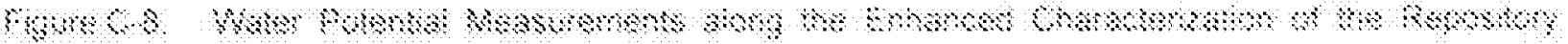
Mon 6 mon

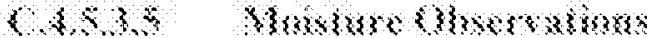

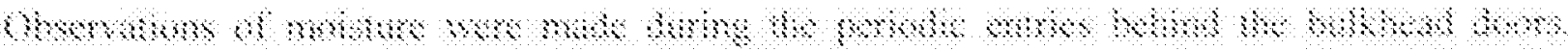

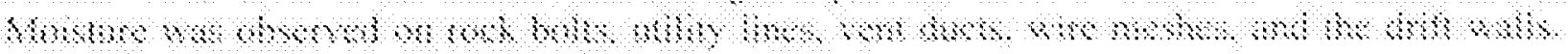

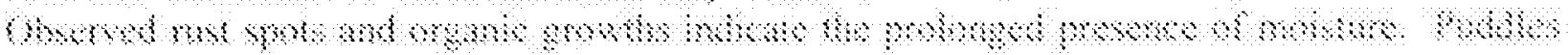




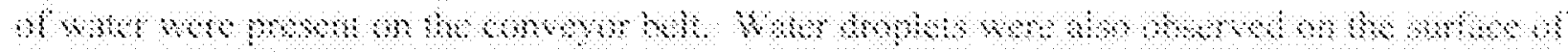

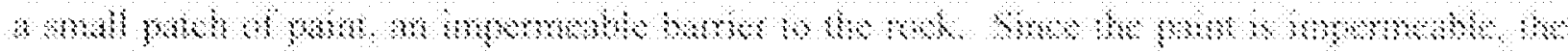

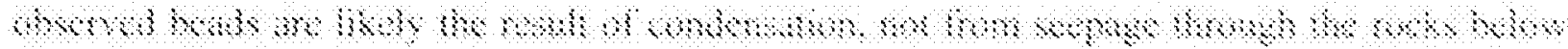

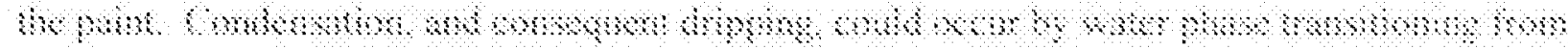

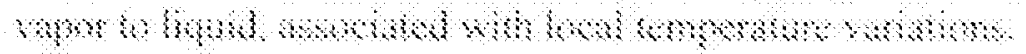

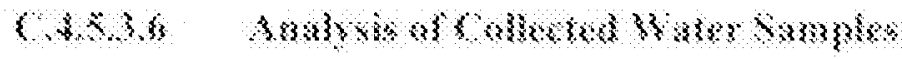

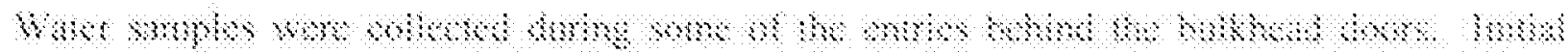

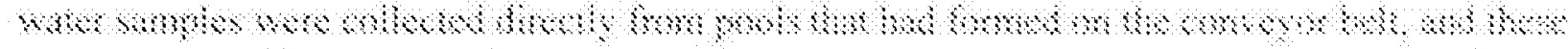

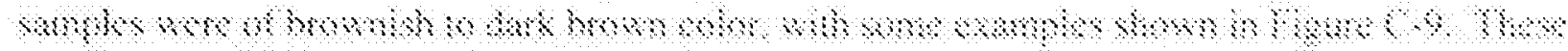

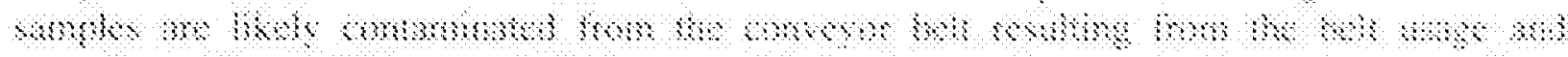

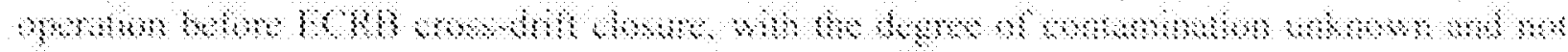

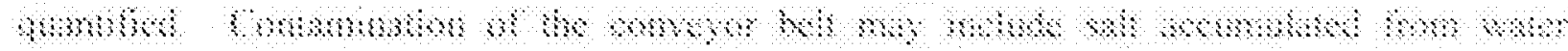

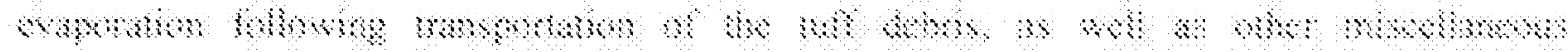

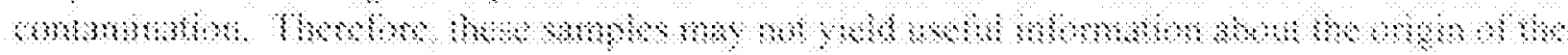

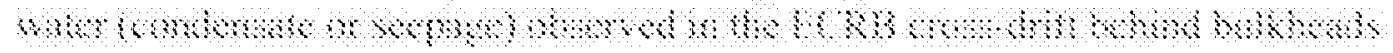

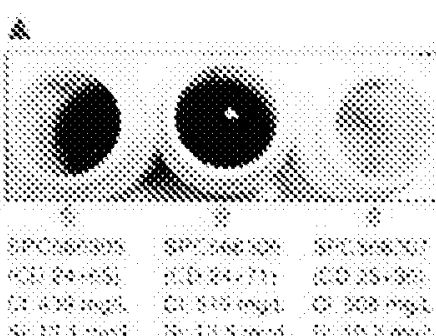

S
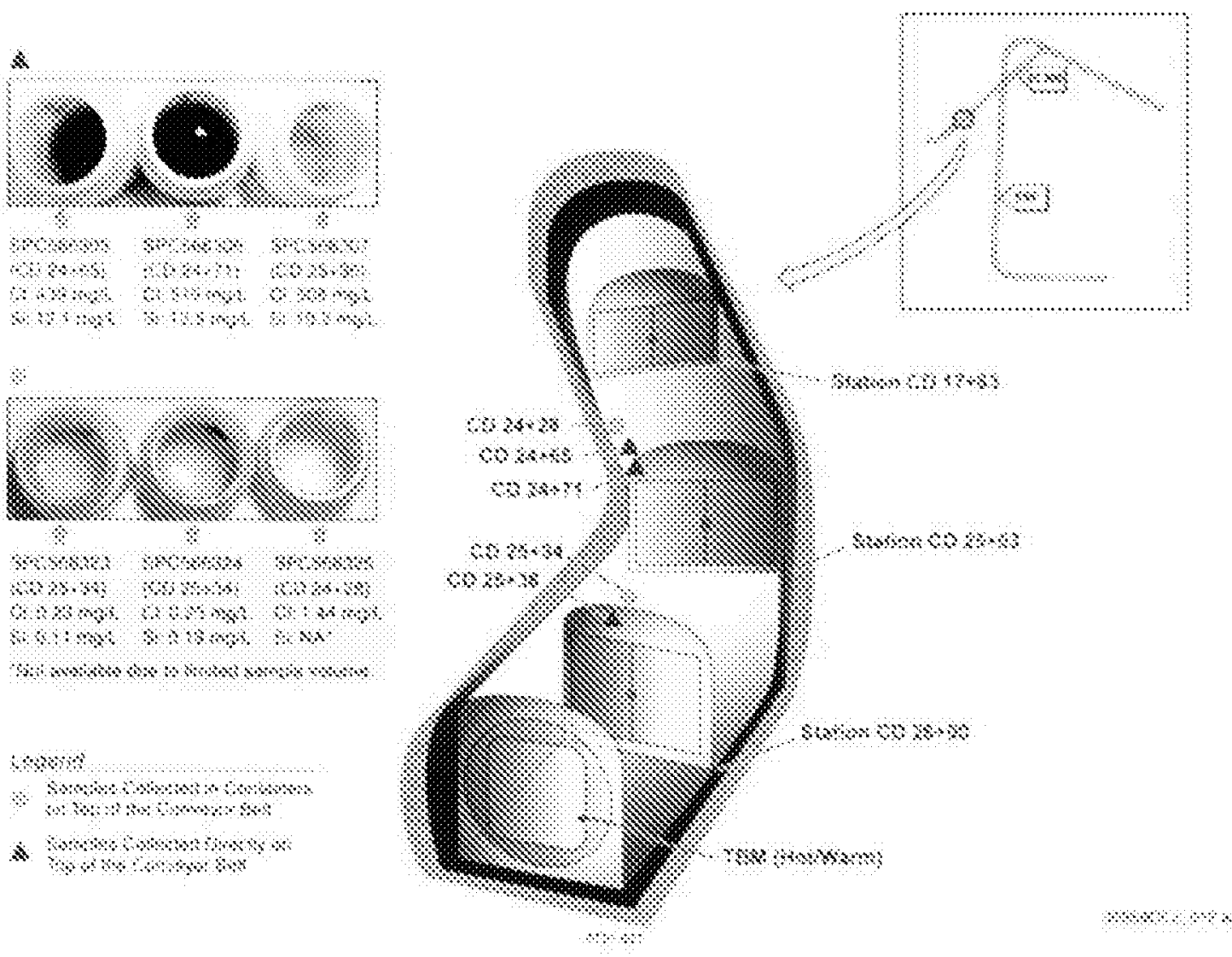

mas $18 \% 20 \%$ semp $\$$

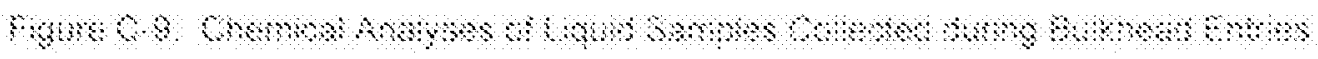

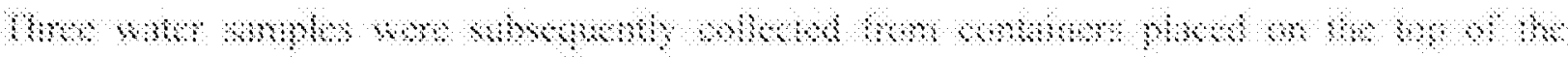

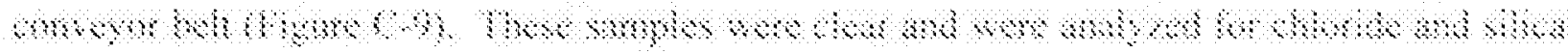




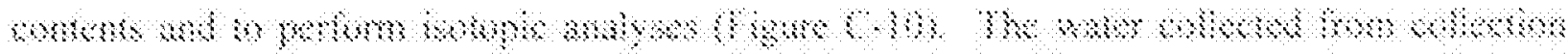

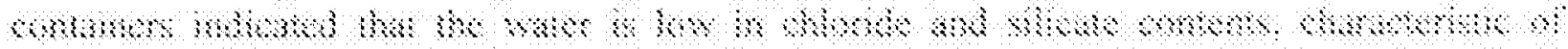

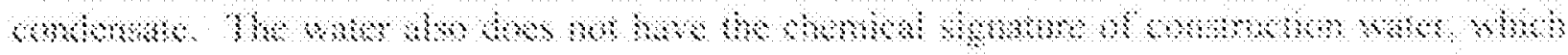

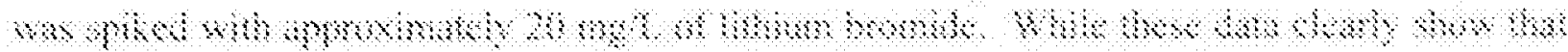

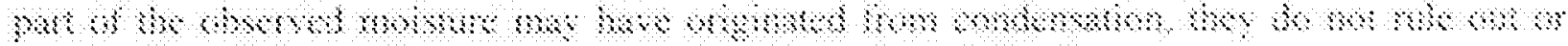

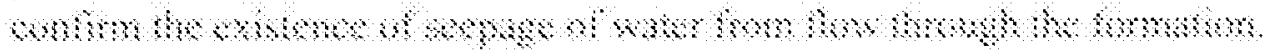

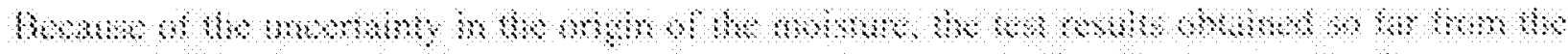

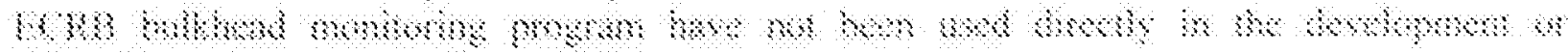
whmom का
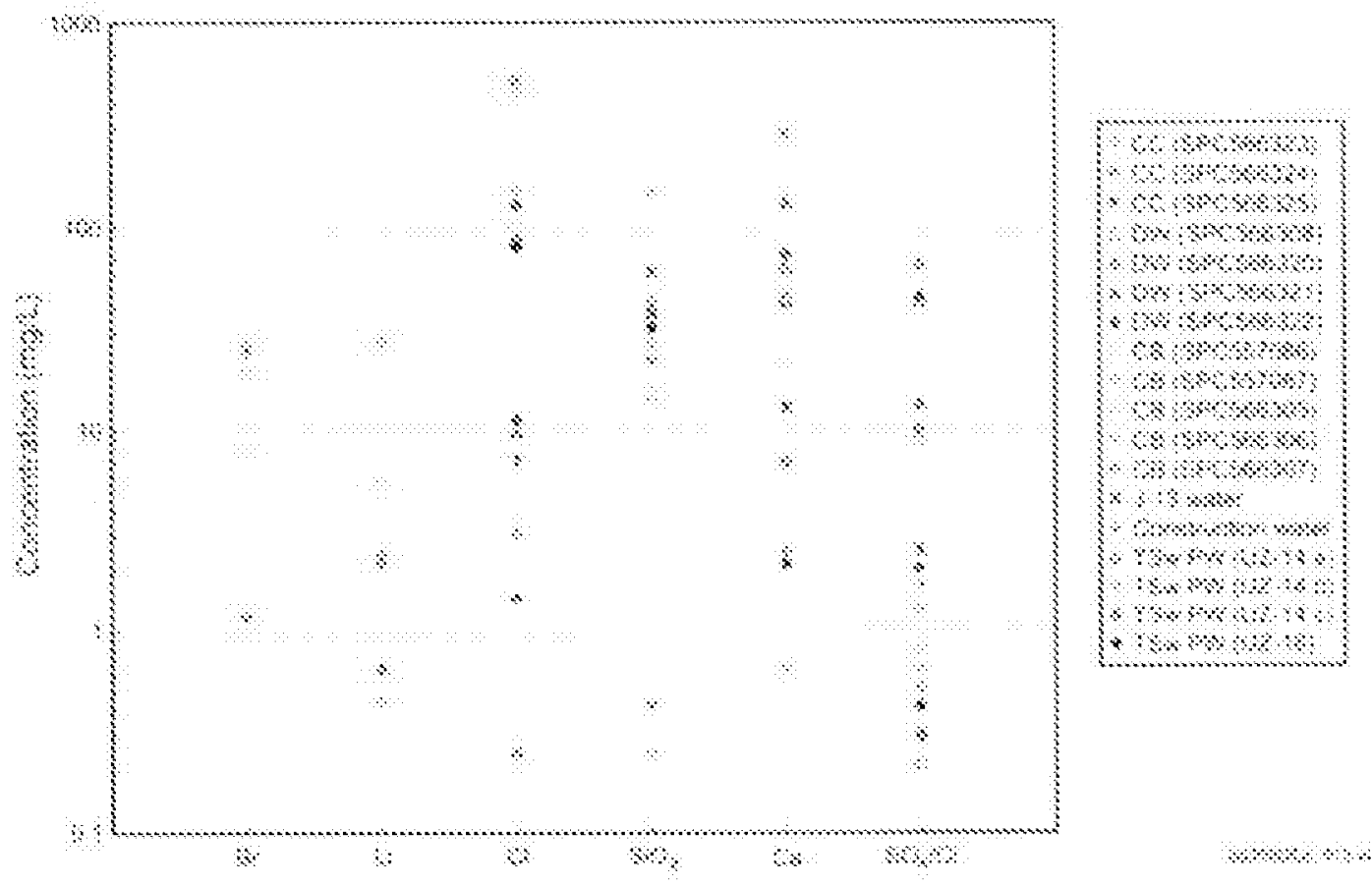

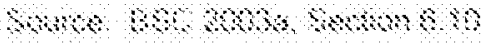

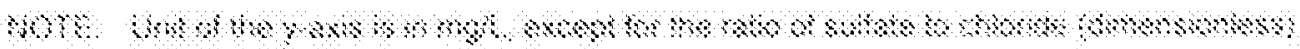

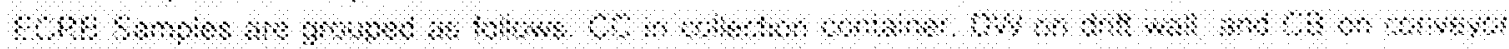
b.:

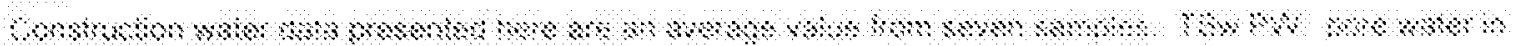

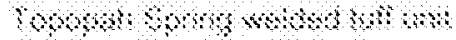

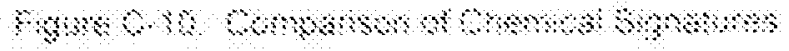

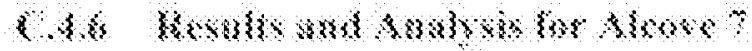

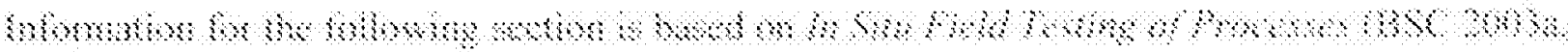

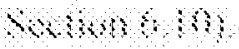

\section{CAkl Tex Summar:}

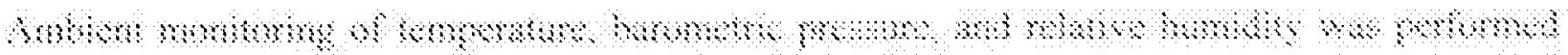

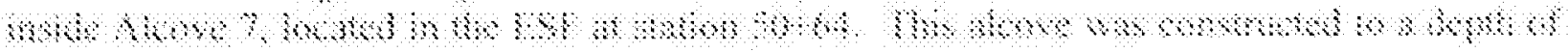


$199 \mathrm{~m}$ and penetrated the Ghost Dance fault at $167 \mathrm{~m}$. Bulkhead doors were installed $64 \mathrm{~m}$ and $132 \mathrm{~m}$ from the entrance of the alcove.

\section{C.4.6.2 Results}

Between September 25, 2001, and June 10,2002, the relative humidity behind the bulkhead doors was less than 95 percent (dry end of the thermocouple psychrometer range) and was therefore not measured. Pressure monitoring indicated that the transmission of atmospheric pressure fluctuations across the bulkhead doors showed minimal dampening (less than 5 percent) and short time lags (on the order of hours). Large temperature fluctuations (between $19.5^{\circ}$ and $27.5^{\circ} \mathrm{C}$ ) at the monitoring station located $4 \mathrm{~m}$ from the entrance of the alcove were due to seasonal temperature fluctuations down the ESF by the ventilation system. This monitoring station is located outside the bulkhead doors. Diurnal temperature fluctuations due to ventilation were as large as $1.2^{\circ} \mathrm{C}$. Temperatures behind the bulkheads indicated no discernable annual fluctuation, and the diurnal temperature fluctuations were less than $0.05^{\circ} \mathrm{C}$. Abrupt temperature decreases (up to $1.0^{\circ} \mathrm{C}$ ) were occasionally measured behind the bulkheads. These temperature decreases were correlated with the pressure recovery period following a low-pressure event. The temperature decrease may be due to a pressure gradient driving warm-dry ESF air through the fractures around the bulkheads, evaporating water, and cooling the air.

On September 18, 2001, the bulkheads were opened after being closed since October 30, 2000. Evidence of moisture was observed during this entry. Signs of moisture included drip spots on the drip collection sheets, moisture drops on the utility lines, moisture drops on the shotcrete around the bulkheads, moisture spots in the dust on an instrument enclosure, and the rock in the crown had a dark, moist appearance. The bulkhead doors were next opened on May 20, 2003. There were drip spots on the drip collection sheets, moisture drops on the utility lines, and moisture spots in the dust on an instrument enclosure. The rock in the crown had a dark, moist appearance and the fractures in the rib appeared wet.

Although moisture was present, it was not possible to collect enough water for analysis.

As in the ECRB bulkhead-monitoring program, the uncertainty regarding the source of observed moisture has so far precluded the use of test data from the Alcove 7 tests in quantitative seepage modeling.

\section{C.4.7 Test Plan for the Niche 5 Test}

The test plan for the Niche 5 test is provided in Test Plan for: Niche 5 Seepage Testing (BSC $2001 \mathrm{~b}$ ). This test plan is provided to the NRC separate from this technical basis document.

\section{C.4.8 Results and Analysis for Niche 5 Test}

Information for the following sections is based on In Situ Field Testing of Processes (BSC 2003a, Section 6.2) and Seepage Calibration Model and Seepage Testing Data (BSC 2003b, Section 6.6). 


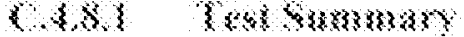

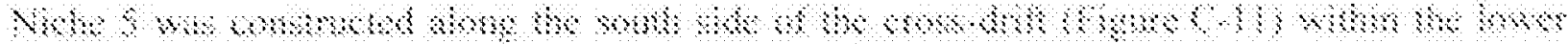

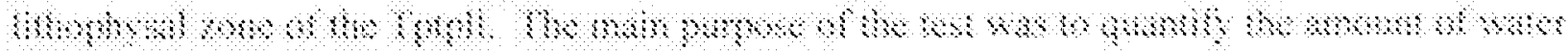

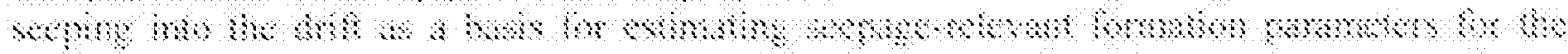

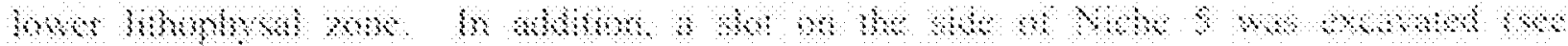

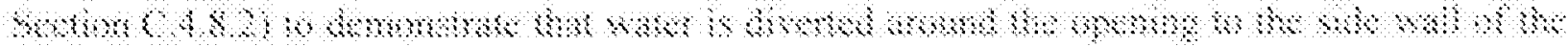

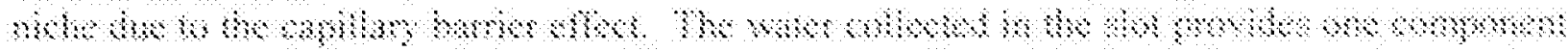

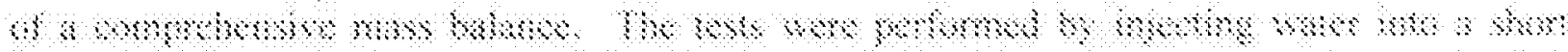

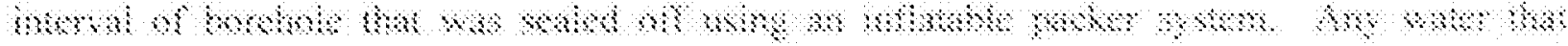

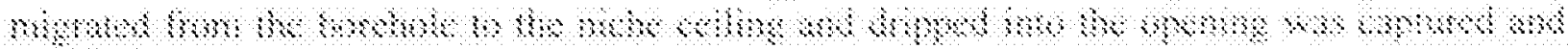
\$., $\mathrm{s}$.

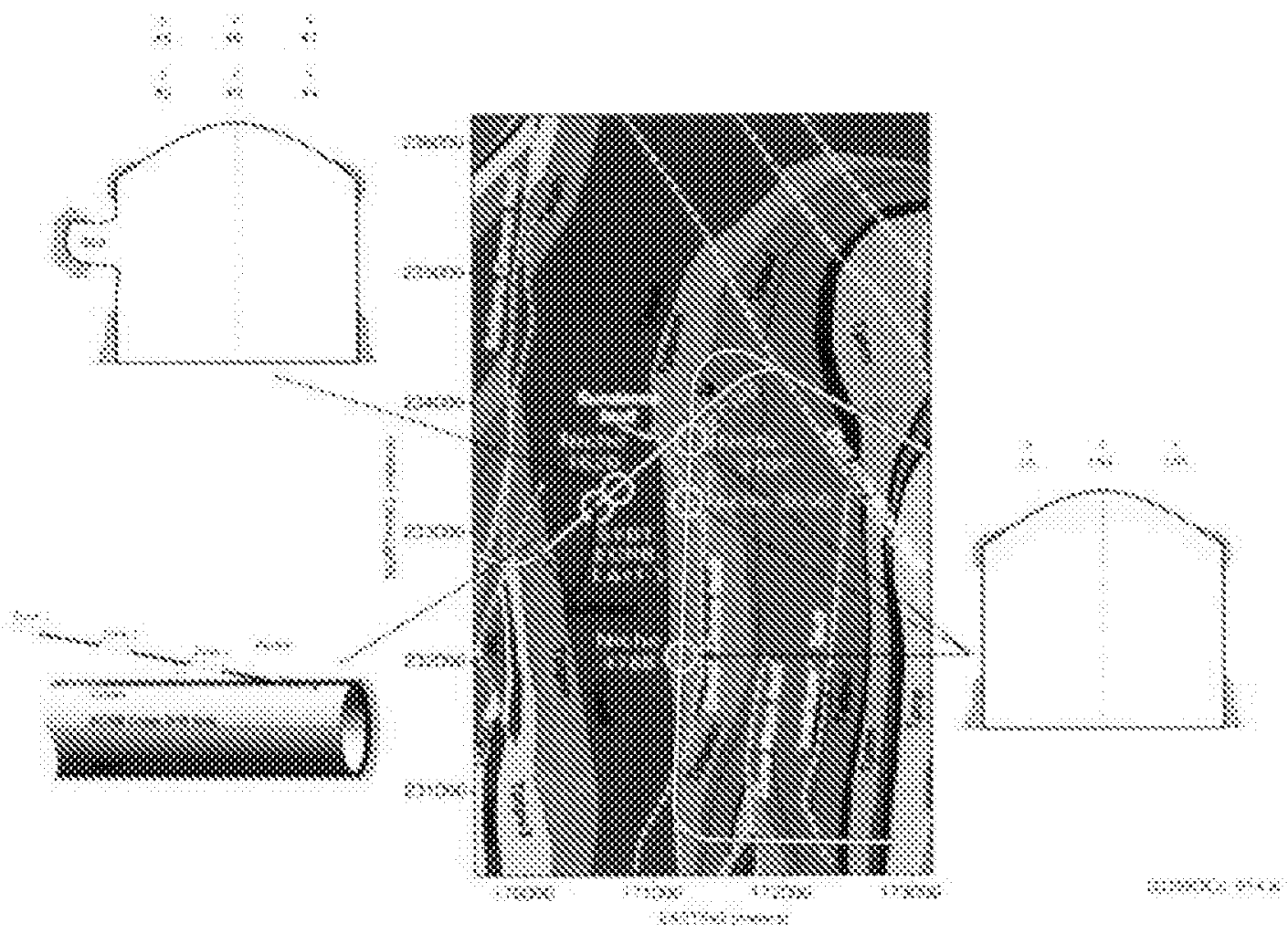

Sown a)

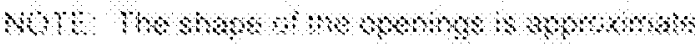

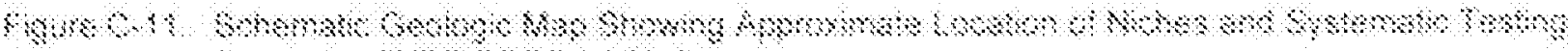

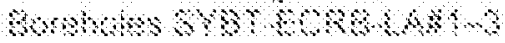

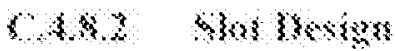

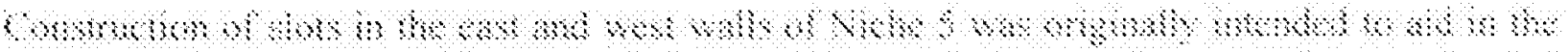

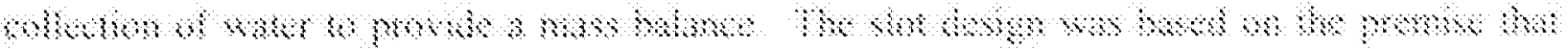

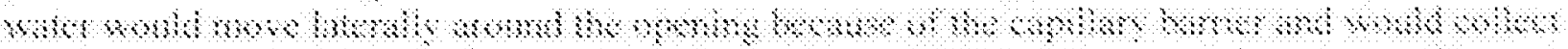

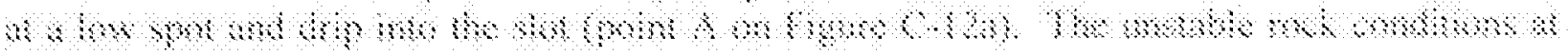




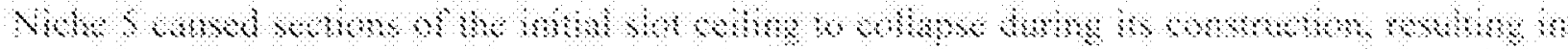

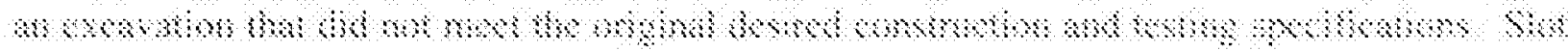

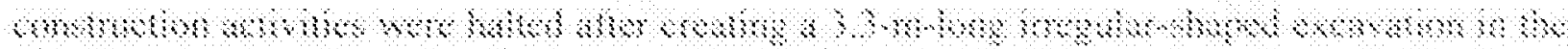

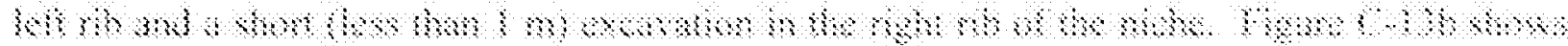

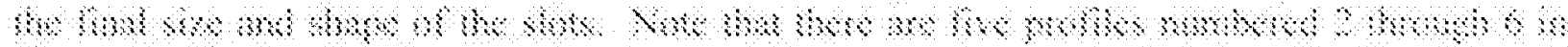

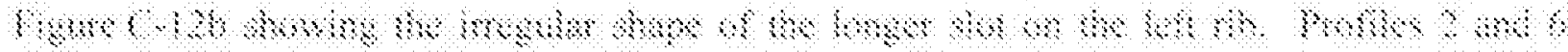

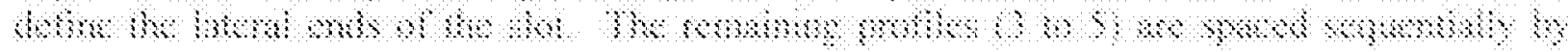

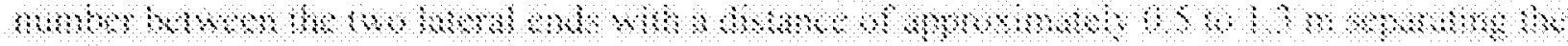
molas

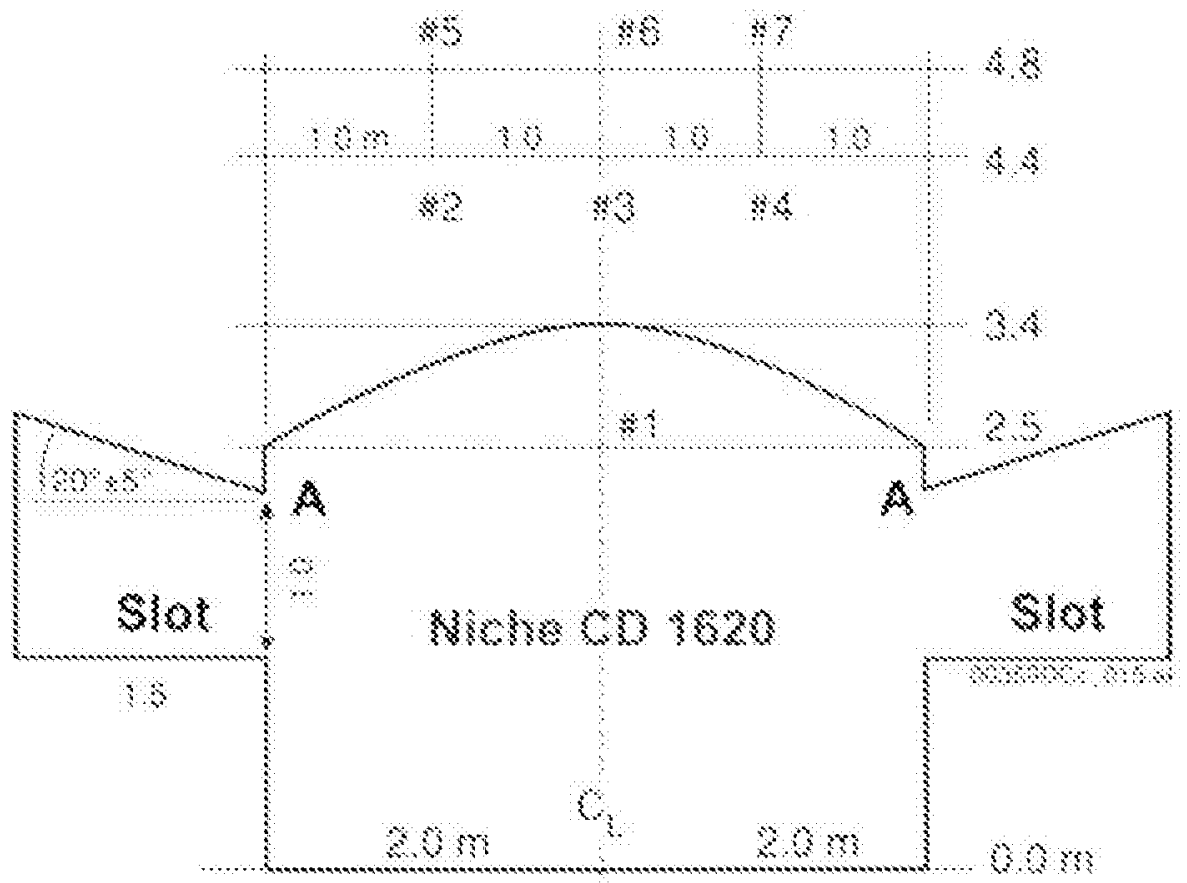

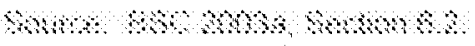

अ Wothes: 10 ? 


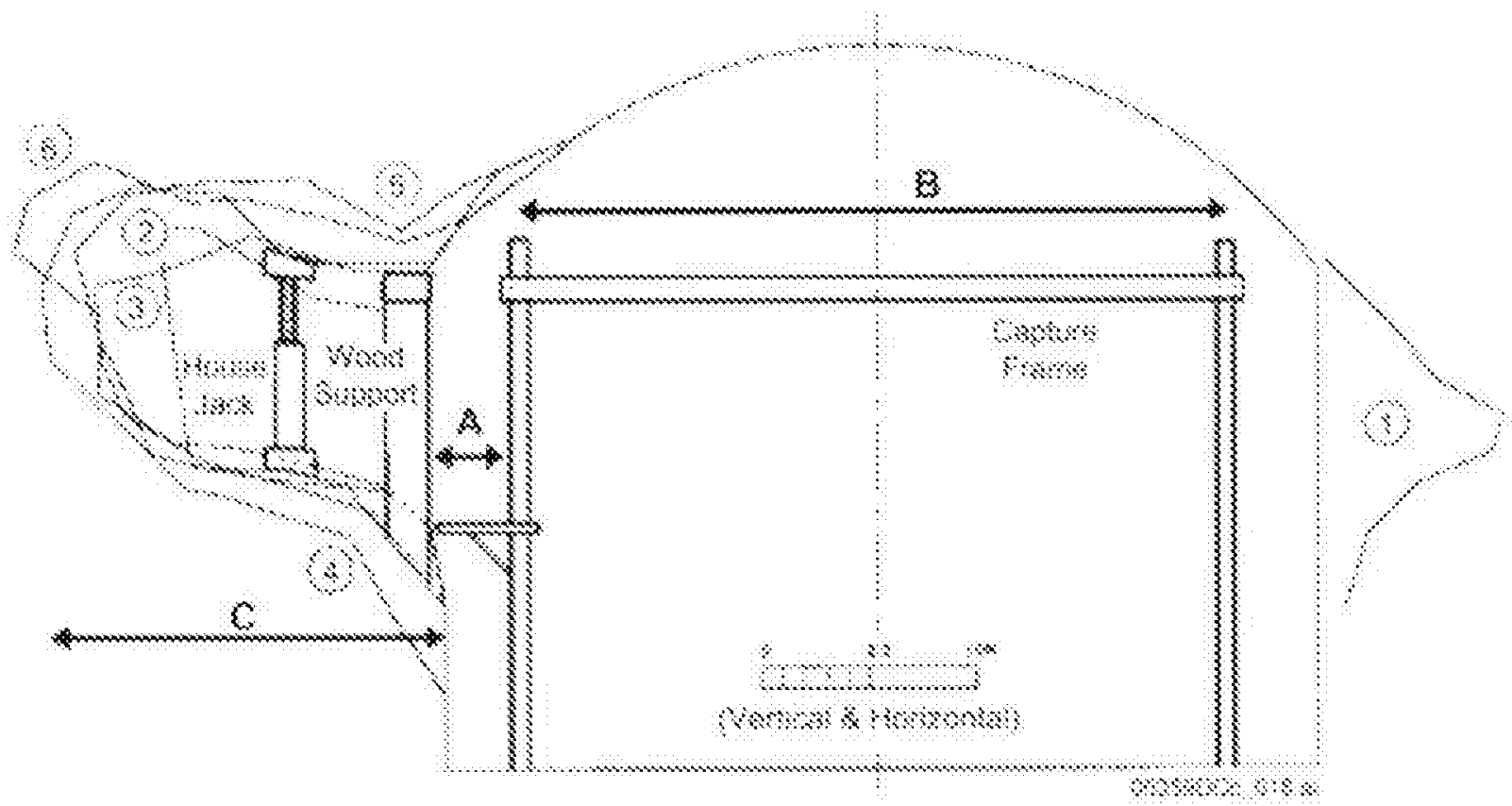

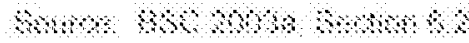

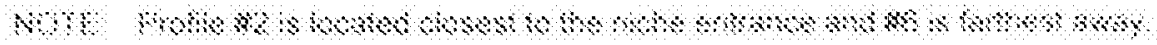

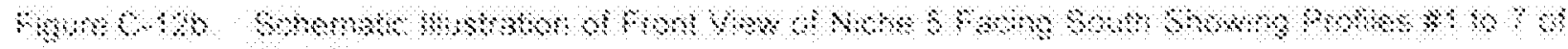
sis

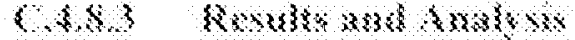

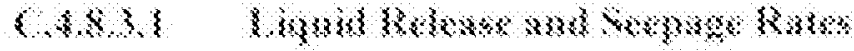

Sonm som mom

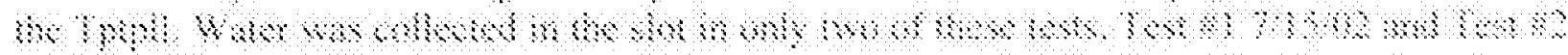

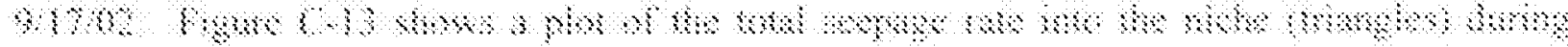

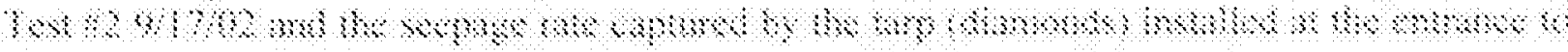

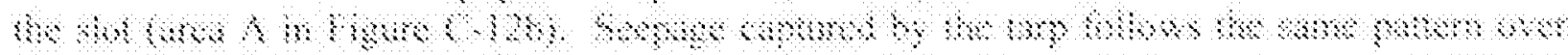

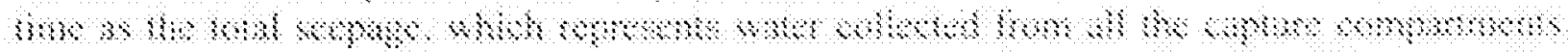

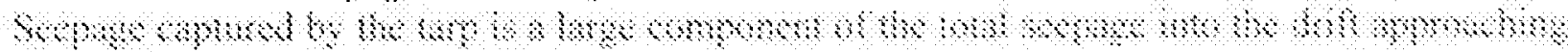

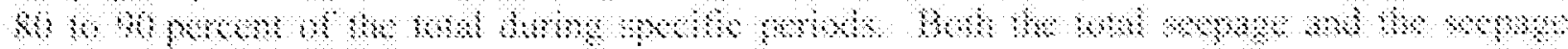

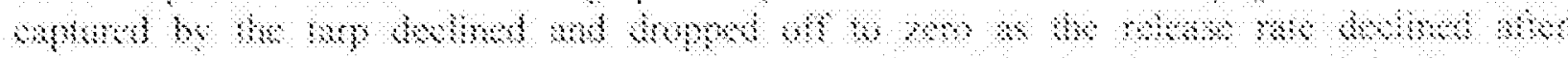

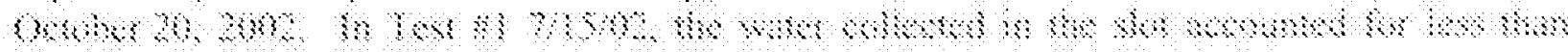

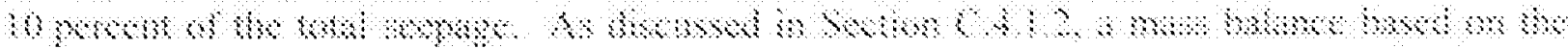

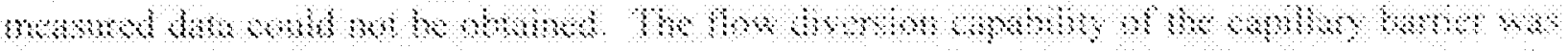
Hnm sise 14 


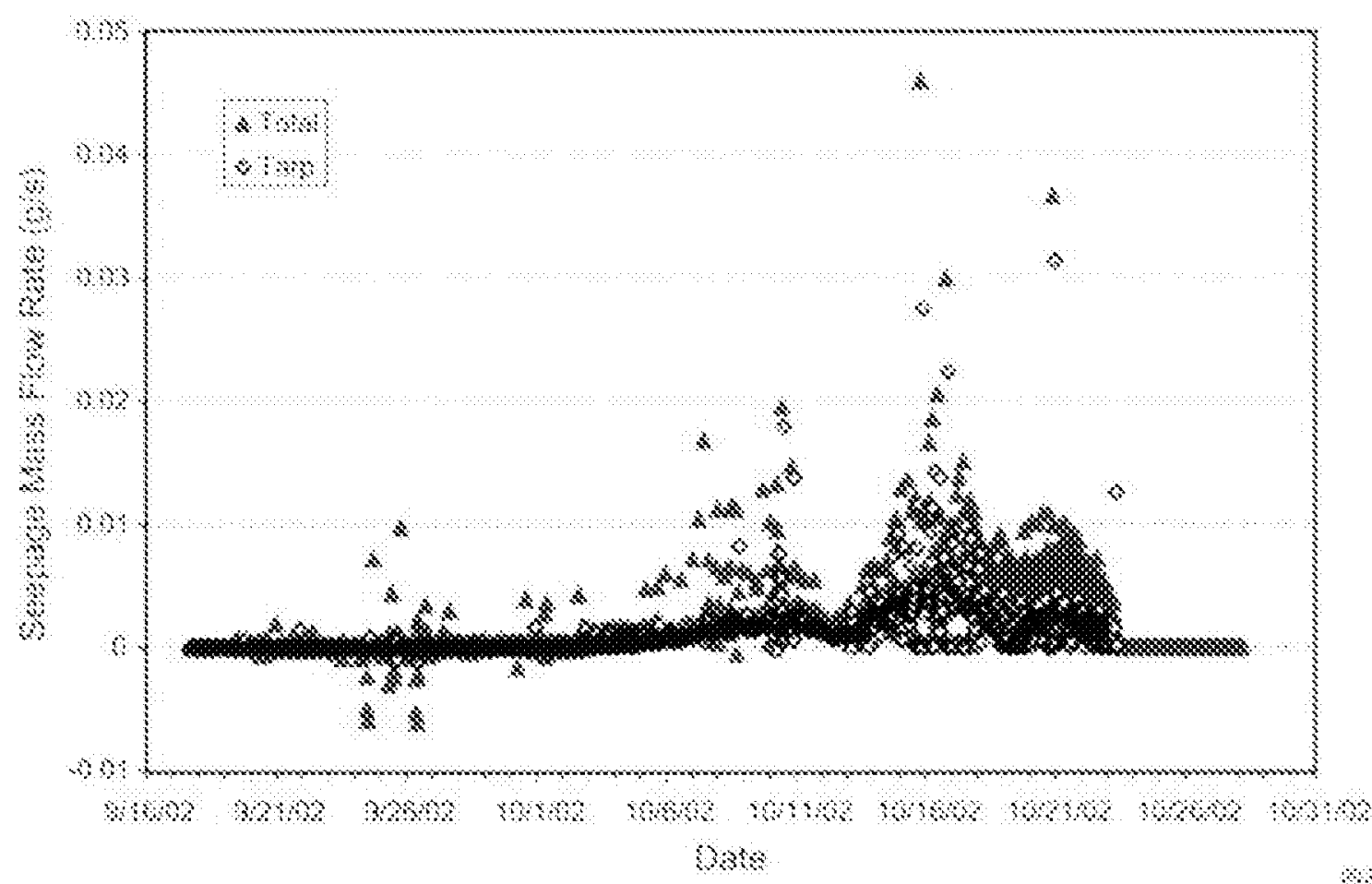

Shes $3 \times 3+\operatorname{sens} 8$

$$
38
$$

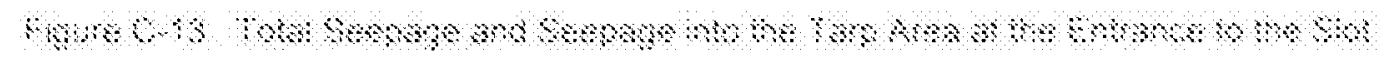

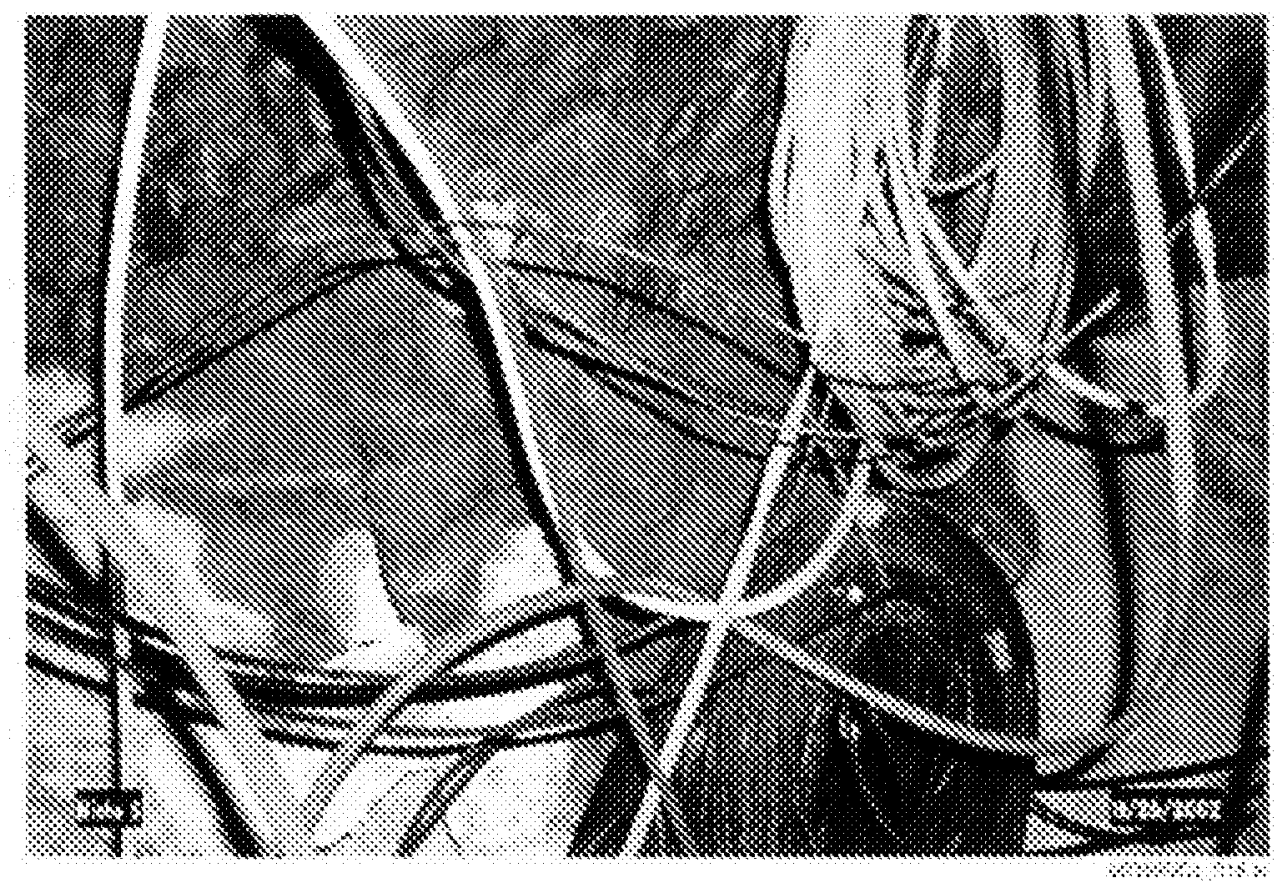

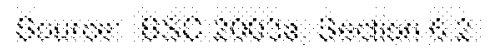

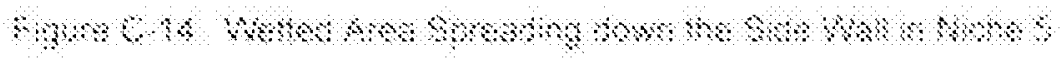




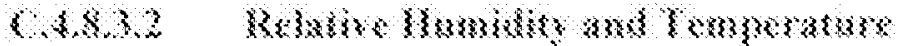

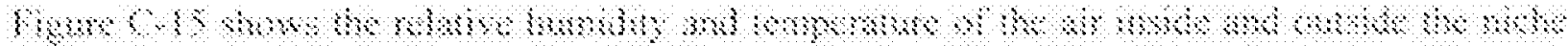

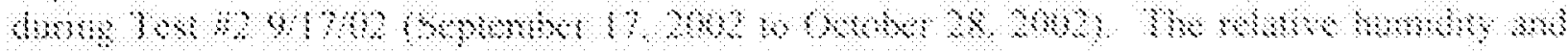

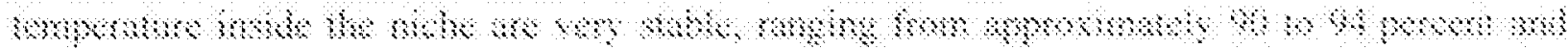

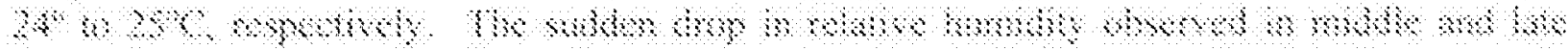

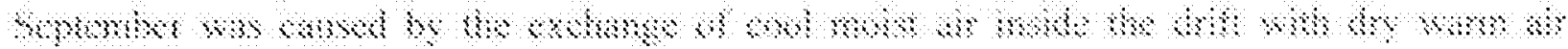

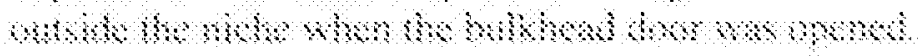

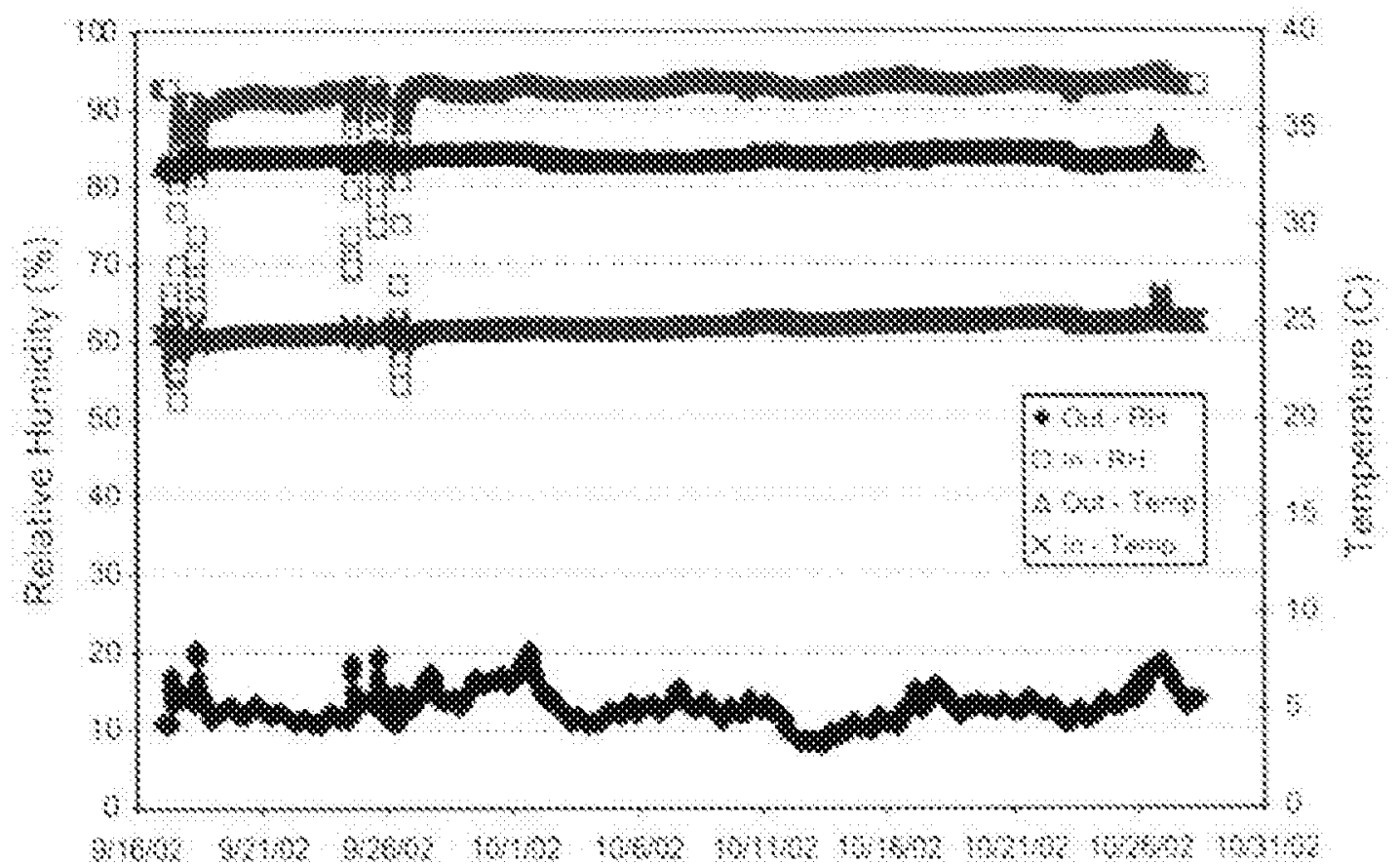

Yse

ß०००८:

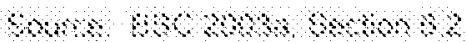

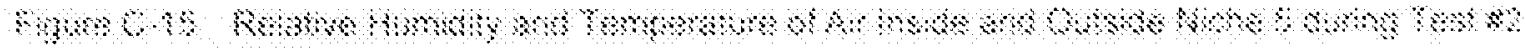
sto

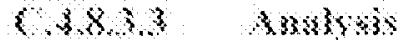

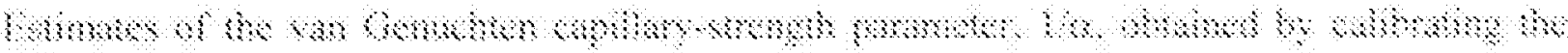

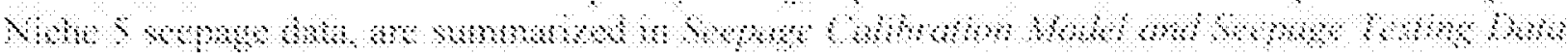

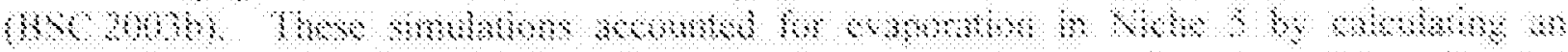

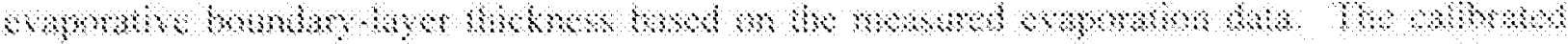

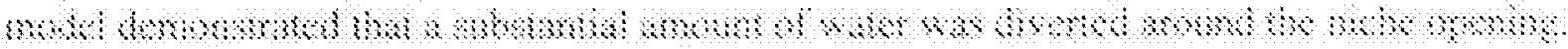

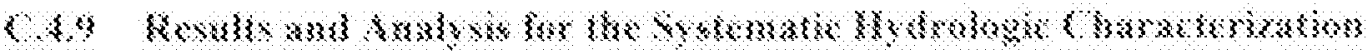

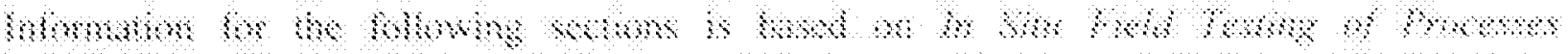

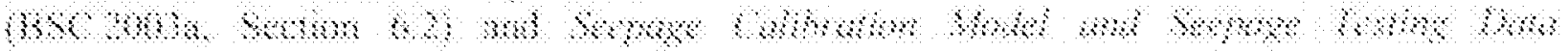

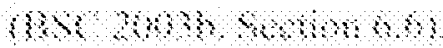




\section{C.4.9.1 Test Summary}

A systematic approach of testing at regular intervals along the drift was adopted to acquire knowledge of the heterogeneous hydrological characteristics of the lower lithophysal zone of the TSw in the ECRB cross-drift, in which over 80 percent of the repository will reside. The size and spacing of the fractures and lithophysal cavities along this unit are highly variable along the drift walls (the drift is $5 \mathrm{~m}$ in diameter) over an $800 \mathrm{~m}$ stretch. This indicates that hydrological characteristics at one particular location may not be representative of the entire unit. Air injection tests were performed to give a measure of fracture permeability. Liquid-release tests were conducted to determine the ability of the open drift to act as a capillary barrier as well as the potential of the water to seep into the drift.

\section{C.4.9.2 Results and Analysis}

\section{C.4.9.2.1 Air Injection Tests}

The air-injection tests were performed by isolating short sections of the boreholes using an inflatable packer system and then injecting compressed air at a constant rate into the isolated injection intervals. The pressure buildup in the injection interval and in nearby observation intervals was monitored with time until steady-state conditions were reached, which typically occurred within a few minutes. Air injection was terminated after reaching steady-state pressures, and the decline in air pressure was then monitored as it recovered to its initial pretest condition. Air-permeability values were derived from the steady-state pressure data based on a commonly used analytical solution (BSC 2001c, Section 6.1.2.1; LeCain 1995, p. 10, Eq. 15).

Air-permeability estimates for the three zones tested in ECRB-SYBT-LA\#2 from the steady-state pressure response to constant-flow-rate air-injection tests are tabulated in Table C-1.

Table C-1. Air-Permeability Estimates for the Three Zones in Borehole LA2

\begin{tabular}{|l|l|l|l|}
\hline \multicolumn{1}{|c|}{ Zone ID } & \multicolumn{1}{|c|}{ Zone Length $(\mathbf{m})$} & $\begin{array}{c}\text { Air Permeability } K\left(\mathbf{m}^{2}\right), \\
\text { for Packer Inflation at } \\
\mathbf{2 7 . 5} \mathbf{~ p s i}\end{array}$ & $\begin{array}{c}\text { Air Permeability } K\left(\mathbf{m}^{2}\right), \\
\text { for Packer Inflation at } \\
\mathbf{3 2 . 5} \mathbf{~ p s i}\end{array}$ \\
\hline LA2 zone 1 & 1.83 & $2.5 \times 10^{-11}$ & $2.3 \times 10^{-11}$ \\
\hline LA2 zone 2 & 1.83 & $2.7 \times 10^{-11}$ & $2.5 \times 10^{-11}$ \\
\hline LA2 zone 3 & 5.18 & $1.1 \times 10^{-11}$ & $0.95 \times 10^{-11}$ \\
\hline
\end{tabular}

Source: BSC 2003a, Section 6.11.

\section{C.4.9.2.2 Liquid Release Tests}

Multiple liquid-release tests were performed in the ECRB cross-drift by sealing a short section of the borehole above the opening using an inflatable packer system and then releasing water at a specified rate into the isolated test interval. Any water that migrated from the borehole and dripped into the opening was captured and weighed. The cumulative seepage was recorded as a function of time. The evaporation rate was monitored using an evaporation pan and wetted area observations. 


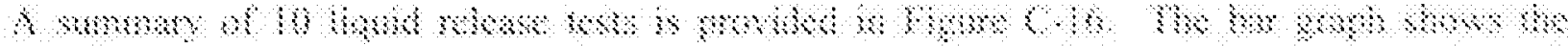

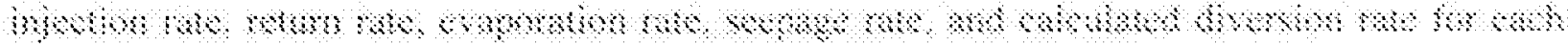

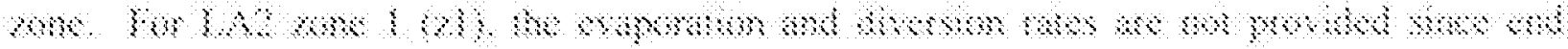

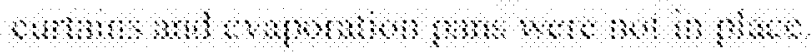

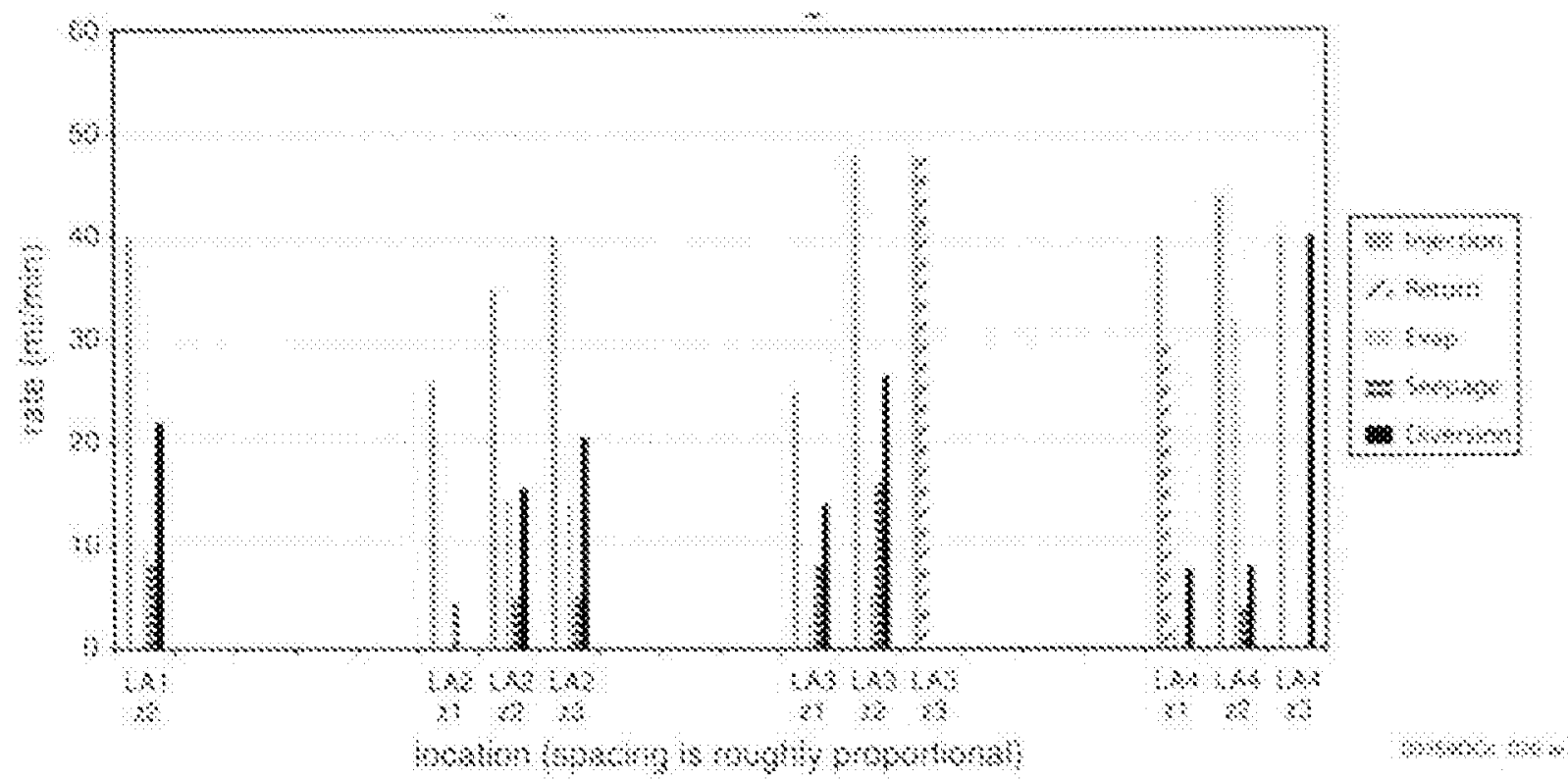

$\operatorname{sen} \operatorname{sen} \sin \operatorname{sen} 3: 1$

Moн

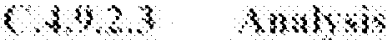

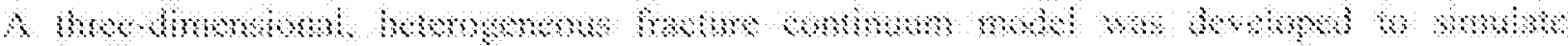

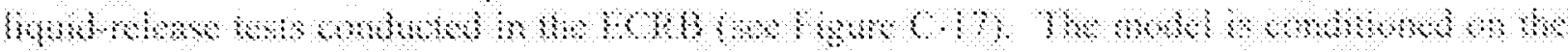

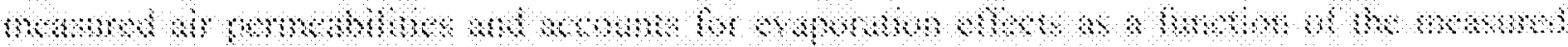

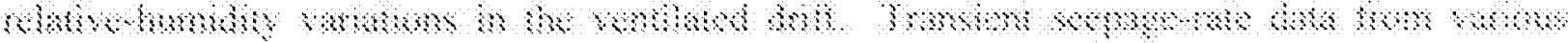

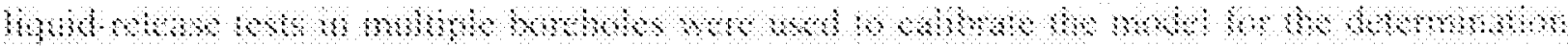

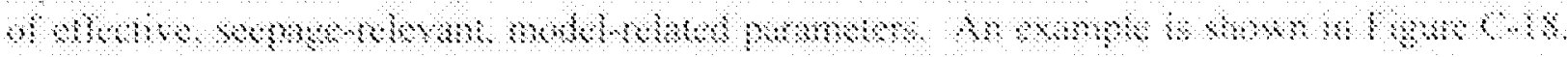

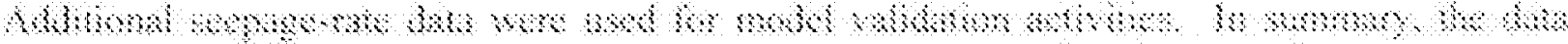

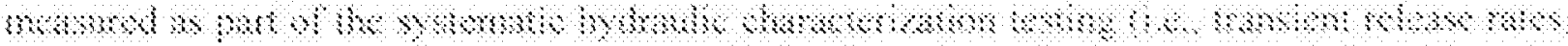
के

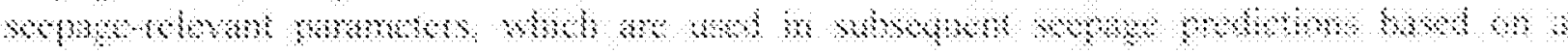
wom 


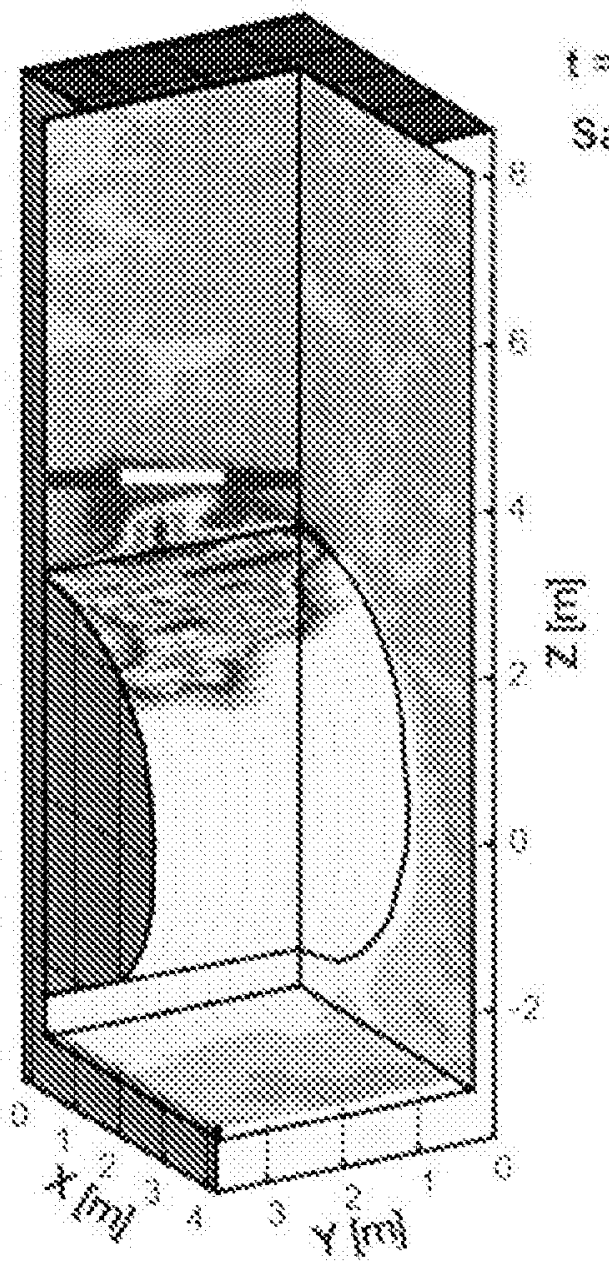

8 * 8 bays

Saruration

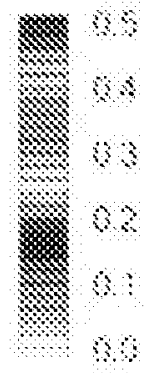

$\sum_{i}$

(1)

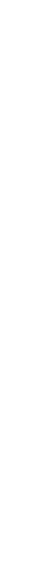

\$४ळ

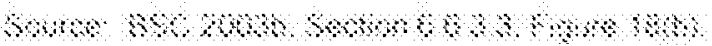

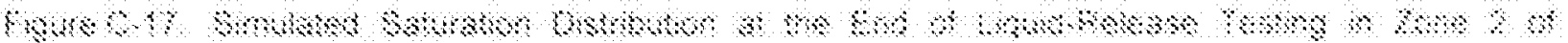

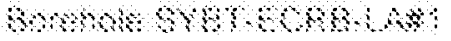




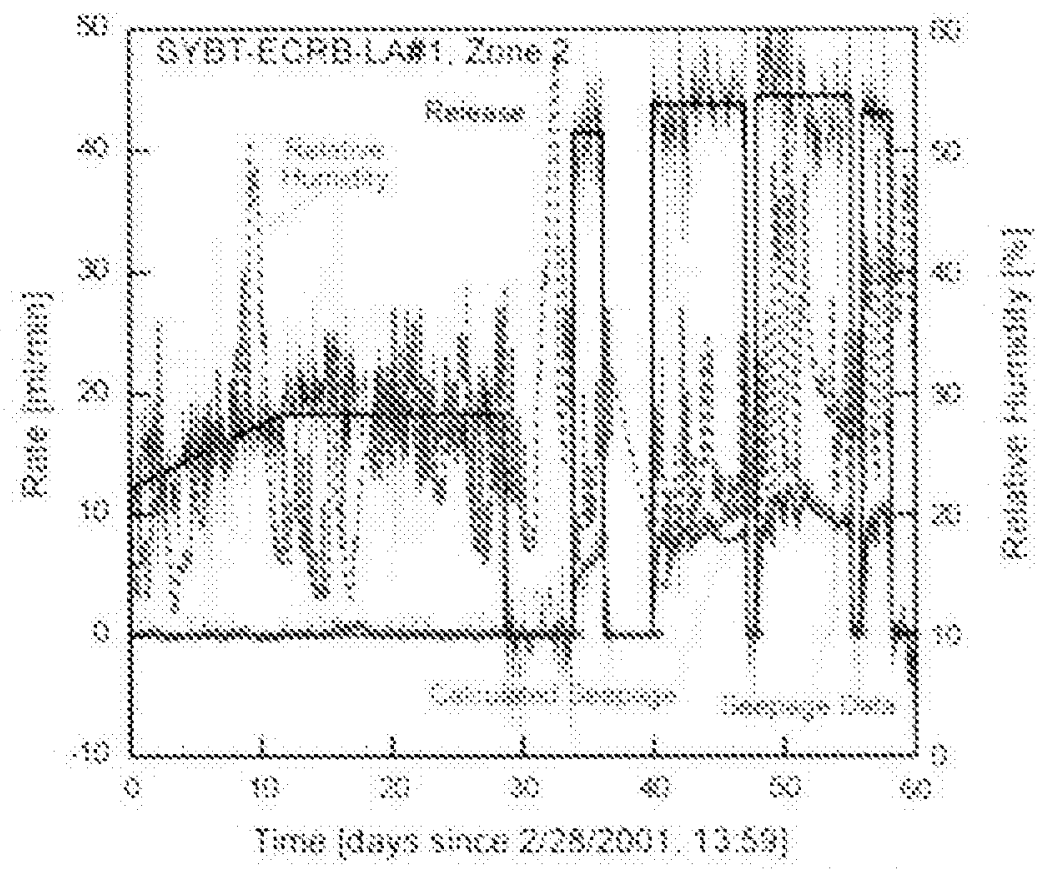

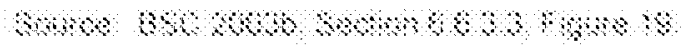

+ि)

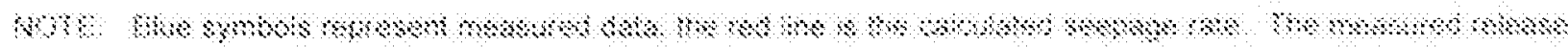

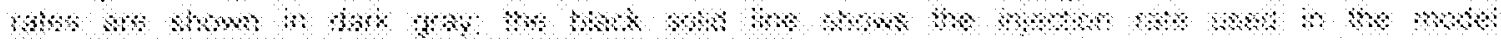

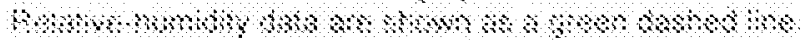

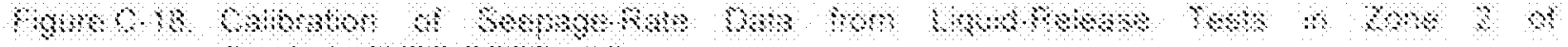

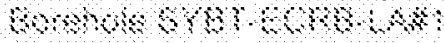

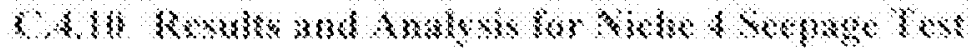

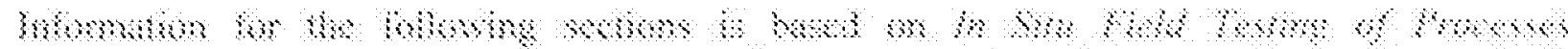

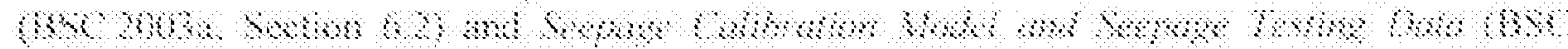
$\$ 13,8 \times 1006, \%$

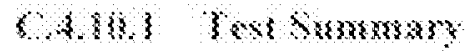

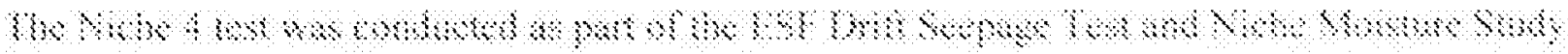

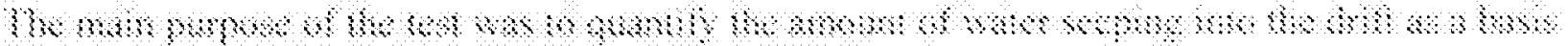
th smmm

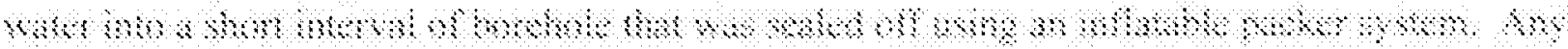

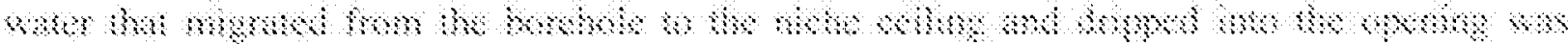

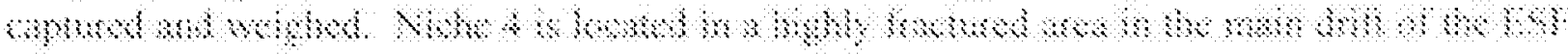
13

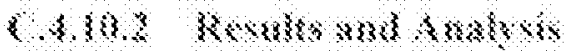

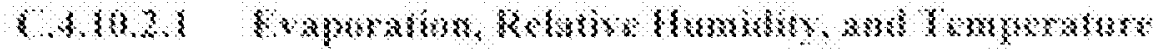

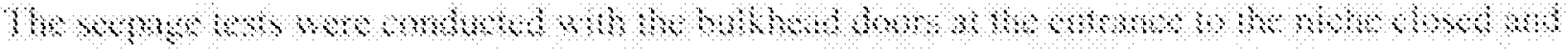

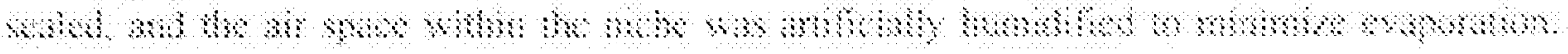


100 percent relative humidity was insignificant and did not lead to a bias in the estimated parameters. This additional study increased the confidence in the previously obtained estimates of seepage parameters for the middle nonlithophysal zone. The data from these tests are described in In Situ Field Testing of Processes (BSC 2003a, Section 6.2); the analysis of the data is discussed in Seepage Calibration Model and Seepage Testing Data (BSC 2003b).

\section{B.3.2 Confidence Building in the Total System Performance Assessment Seepage Abstraction}

The Passive Cross-Drift Hydrologic test, the Alcove 8-Niche 3 Test, and liquid-release tests in Niche 2 were not used for the determination of seepage-relevant parameters. However, several aspects of these tests are used to confirm the current understanding of the seepage process and corroborate the corresponding conceptual models and analyses underlying the TSPA seepage abstraction as outlined below.

\section{B.3.2.1 Passive Cross-Drift Hydrologic Tests}

These tests included monitoring of moisture in boreholes; measurement of in-drift temperature, humidity and barometric pressure; visual inspection of wetness; and chemical/isotopic analyses of water samples. These observations were conducted in ventilated and nonventilated sections of the ECRB Cross-Drift. The data available to date are not sufficient to conclusively identify the source of the observed moisture. However, the limited available data of temperature and relative humidity gradients suggest that condensation accounts for most of the observed water (BSC 2003a, Section 6.10). The issue is further discussed in the response to USFIC 4.01 (Appendix D).

\section{B.3.2.2 Alcove 8-Niche 3 Tests}

In the first phase of Alcove 8-Niche 3 testing, where water was injected along a fault exposed in Alcove 8, the observed wetting-front advance and wetting plume showed that flow occurred predominantly along the fault zone. This precluded the data from being used for calibration or validation of the drift-scale seepage model and its abstraction, which is concerned with seepage from fractured rocks in the lithophysal and nonlithophysal zones and specifically located in areas free of faults. However, these tests along with other modeling efforts (BSC 2003c) provide corroboration and build confidence in the seepage models. The seepage rate observed in Niche 3 was consistently less than 10 percent of the infiltration rate (after the seepage rate had stabilized). This low fraction of seepage is consistent with the general seepage concept used in the seepage process models.

\section{B.3.2.3 Niche 2 Tests}

The short-term tests conducted in Niche 2 were significantly influenced by storage effects and the local properties of a few fractures connecting the release point with the niche ceiling. Thus, the data were not suitable for quantitative calibration of the seepage process model. However, they provided qualitative seepage information that generally agrees with the conceptual model of seepage and were used for model validation purposes. The data from these tests are described in In Situ Field Testing of Processes (BSC 2003a, Section 6.2); the analysis of the data is discussed in Seepage Calibration Model and Seepage Testing Data (BSC 2003b). 


\section{B.3.3 Seepage-Relevant Parameters That Could Not Be Estimated from Test Data}

The concept of "flow focusing" describes potential concentration of downward flow onto a particular drift segment as governed by intermediate-scale heterogeneity on the order of a few drift diameters. It is required to relate the percolation flux calculated with the mountain-scale model of the unsaturated zone with the drift-scale, seepage prediction model. All the liquid-release test data available refer to a scale on the order of one drift diameter, and are thus insufficient to provide direct quantitative estimation of the flow-focusing factor. Therefore, flow-focusing factors for the TSPA for the license application (LA) seepage abstraction were derived from models that are able to describe the immediate-scale heterogeneity, bridging the gap between the site scale and the drift scale models (Bodvarsson et al. 2003; BSC 2003c, Section 6.6.3).

The information in this report is responsive to agreement TSPAI 3.25 made between the DOE and NRC. The report contains the information that DOE considers necessary for the NRC to review for closure of this agreement.

\section{B.4 BASIS FOR THE RESPONSE}

\section{B.4.1 Revision of the Total System Performance Assessment Seepage Abstraction and Related Parameters}

The data basis and modeling approach supporting seepage abstraction have been greatly widened and improved since the first revision of the TSPA seepage model, substantially reducing uncertainties in the seepage-relevant parameters and the subsequent prediction of seepage into waste emplacement drifts. Relative humidity has been monitored, and evaporation effects have been included in the models used to analyze the seepage-rate data. All estimates of permeability and capillary strength have been compiled in a comprehensive analysis to determine their spatial variability and uncertainty.

Relative humidity and evaporation rate data from Niche 5 tests were utilized to calibrate a diffusive evaporation model under various ventilation conditions (BSC 2003b, Section 6.6.1.4). The calibrated evaporation boundary layer thicknesses and relative humidity measurements were used to model evaporation from the drift walls for the Niche 5 and Systematic Hydrologic Characterization tests. Analysis of seepage rates at high drift relative humidity values showed that the effect of evaporation on modeled evaporation rate is insignificant for relative humidity values greater than 85 percent (BSC 2003b, Section 6.6.1.4). As a result, evaporation was not modeled for the closed off and artificially humidified Niches 3 and 4 .

Data from Niche 5 tests and other tests were used to determine permeability and capillary strength and to provide a basis for additional confidence in the revision of the TSPA seepage abstraction. The air-injection data were used to generate spatially correlated permeability maps for the drift-scale models. At the scale of individual grid blocks of the drift-scale models, a high, effective (continuum) permeability may be attributed to larger fracture apertures (which implies low capillary strength) or to higher fracture density (which would not affect capillary strength). Because the potential correlation between permeability and capillary strength is unknown, the van Genuchten 1/ $\alpha$ parameter is interpreted as an effective parameter taken to be constant for a 
given test bed in the drift-scale models. The seepage calibration model was used to estimate the van Genuchten 1/ $\alpha$ parameters for the lower lithophysal and middle nonlithophysal zones (Tptpll and Tptpmn) of the Topopah Spring tuff unit by calibrating the drift-scale seepage models against the field liquid-release test data. To quantify a key aspect of the uncertainty in the van Genuchten $1 / \alpha$ parameter provided to TSPA-LA seepage abstraction, the seepage calibration model utilized multiple realizations of permeability field for each test bed. The mean value computed from the multiple $1 / \alpha$ estimates was considered as representative for the respective test bed.

Each seepage data set is obtained from a certain test bed that can be considered one realization from a number of statistically similar geologic systems. The lack of knowledge regarding the details of this specific realization makes the inversely determined van Genuchten $1 / \alpha$ parameter estimate uncertain. This estimation uncertainty was analyzed by performing multiple inversions of the same data set using different realizations of the underlying heterogeneous permeability field. The estimated $1 / \alpha$ parameter for each test bed was represented using probabilistic distributions (instead of a single value) (BSC 2003d, Section 6.34). The mean van Genuchten $1 / \alpha$ values corresponding to the different test beds were compiled to provide spatial variability of the $1 / \alpha$ parameter. The uncertainty in the probability distribution chosen to represent the spatial variability was accounted for by varying the mean of the chosen (uniform) probability distribution within appropriate ranges. A symmetric triangular distribution was chosen to provide the random adjustment of the mean because it is an appropriate model for uncertain quantities whose most likely value and estimated range of parameters are known. The chosen uncertainty distribution also accounts for other potential sources of uncertainty such as measurement uncertainty (BSC 2003d, Section 6.6.1.3).

In the drift-scale models, the van Genuchten $1 / \alpha$ parameter is conceptualized as an effective property that represents not only the average hydraulic characteristics of individual fractures but also the connectivity, density, geometry, and orientation of the fracture network as it relates to the geometry and orientation of the underground opening. The effective parameter also incorporates seepage processes that cannot be explicitly implemented in the conceptual model (such as film flow and small-scale roughness in the drift ceiling). Therefore, the estimated van Genuchten 1/ $\alpha$ values are not expected to be representative of only the largest apertures on the drift-wall.

The conceptual model and approach developed for the seepage calibration model were used in the seepage model for performance assessment to predict seepage threshold and seepage percentage for a variety of hydrogeologic conditions and percolation fluxes. The seepage model for performance assessment simulations were also performed with 20 realizations of the permeability map for each parameter set.

The seepage calibration model and seepage model for performance assessment provided the TSPA-LA seepage abstraction with the basis for determining the distributions and uncertainties of the van Genuchten 1/ $\alpha$ parameter, seepage rates, and seepage percentages. The TSPA-LA seepage abstraction utilizes appropriate air-injection test data to derive the spatial distribution of the absolute permeability. Analysis of preexcavation measurements in the middle nonlithophysal zone (Niches 1 (also referred to as Niche 3566), 2, 3, and 4) is provided in In Situ Field Testing 
of Processes (BSC 2001, Table 6.1.2-3), giving the mean and standard deviation of the small-scale permeabilities. Statistical parameters for preexcavation air-permeability data from the lower lithophysal zone (measured in Niche 5) were calculated in Abstraction of Drift Seepage (BSC 2003d, Attachment III). Postexcavation permeability data for the middle nonlithophysal zone (measured in Niches 2, 3, and 4) and the lower lithophysal zone (measured in Niche 5 and systematic testing borehole SYBT-ECRB-LA\#2) were analyzed in Seepage Calibration Model and Seepage Testing Data (BSC 2003b, Section 6.5.2 and Table 10). The mean values and the standard deviations of all appropriate small-scale permeability data conducted at each of the test locations are summarized in Table B-1, for both undisturbed and disturbed conditions. Here, standard deviations reflect spatial variability within the test bed, on a 1-foot test interval scale. The intermediate-scale variability of permeability refers to the variation of this parameter and was determined from the means of small-scale permeability measurements within the repository rock units (BSC 2003d). In addition, all available permeability data from surface-based boreholes and underground test beds were reviewed, appropriate scaling laws were developed, and the data were compiled to determine the permeability distribution reflecting spatial variability and uncertainty.

Table B-1. Summary Statistics of Air Permeabilities Derived from Small-Scale Air-Injection Tests for Undisturbed and Excavation-Disturbed Conditions in the Middle Nonlithophysal Zone (Tptpmn) and the Lower Lithophysal Zone (Tptpll)

\begin{tabular}{|l|c|c|c|c|}
\hline \multirow{2}{*}{\multicolumn{1}{|c|}{ Location }} & \multicolumn{2}{c|}{ Undisturbed Permeability } & \multicolumn{2}{c|}{ Disturbed Permeability } \\
\cline { 2 - 5 } & Mean log(k) & Std. Dev. & Mean log(k) & Std. Dev. \\
\hline Niche 3 (Tptpmn) & -13.4 & 0.70 & -12.14 & 0.80 \\
\hline Niche 1 (Tptpmn) & -13.0 & 0.92 & - & - \\
\hline Niche 2 (Tptpmn) & -13.4 & 0.81 & -11.66 & 0.72 \\
\hline Niche 4 (Tptpmn) & -13.0 & 0.85 & -11.79 & 0.84 \\
\hline Niche 5 (TptpII) & -11.5 & 1.12 & -10.95 & 1.31 \\
\hline SYBT-ECRB-LA\#2 (TptpII) & - & - & -10.73 & 0.21 \\
\hline
\end{tabular}

Source: BSC 2003c, Table 6.6-3.

The following sections describe the use of the liquid-release and air-injection test data from Niche 5, Systematic Hydrologic Characterization, as well as Niches 3 and 4 for the calibration and validation of the seepage calibration models for the lower lithophysal zone and middle nonlithophysal zone.

\section{B.4.1.1 Niche 5 and Systematic Hydrologic Characterization Tests (Lower Lithophysal Zone)}

Summaries of the test data and analyses for Niche 5 and the Systematic Hydrologic Characterization are provided in the responses to KTI USFIC 4.01 (Sections D.4.8 and D.4.9, respectively). The data from these tests are described in In Situ Field Testing of Processes (BSC 2003a, Sections 6.2 and 6.11); the analyses of the data are discussed in Seepage Calibration Model and Seepage Testing Data (BSC 2003b). 


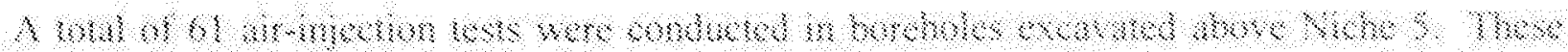

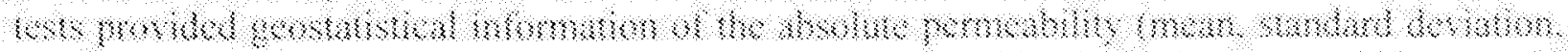

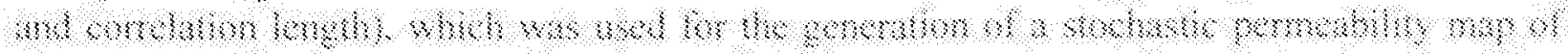

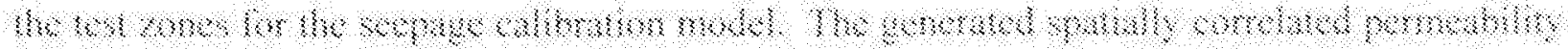

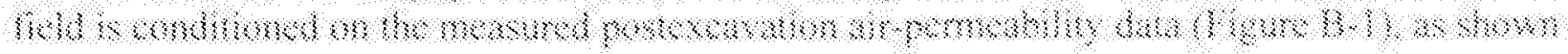

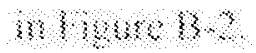

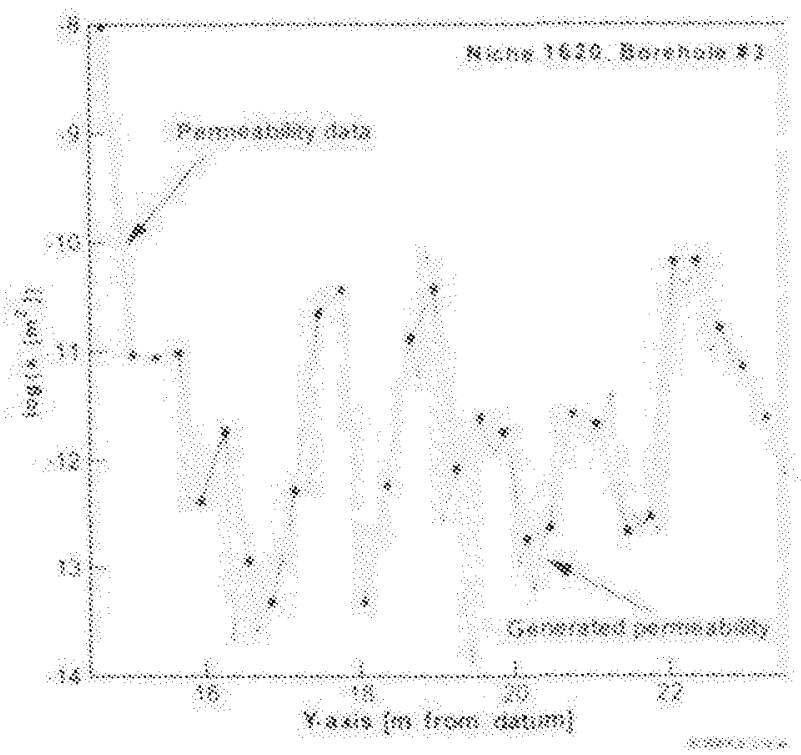

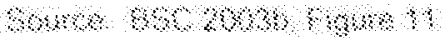

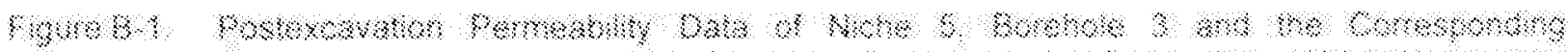

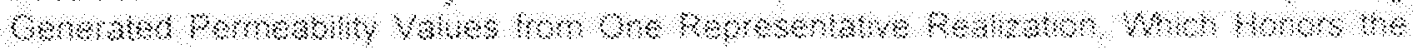

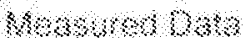

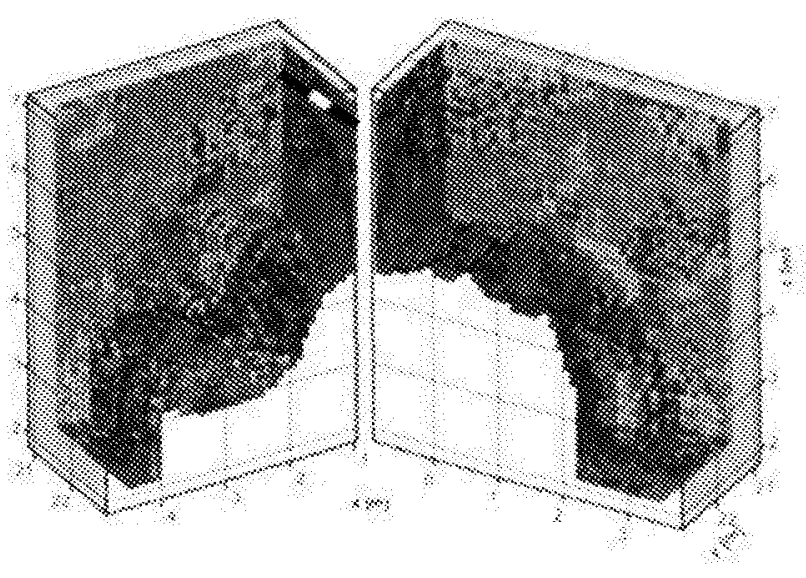

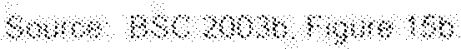

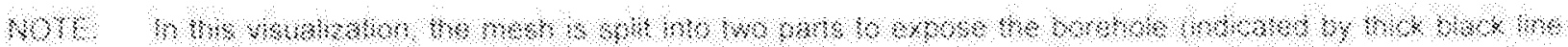

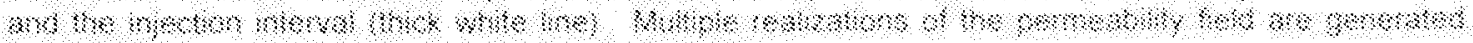

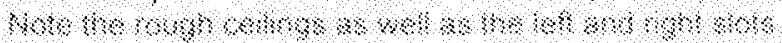

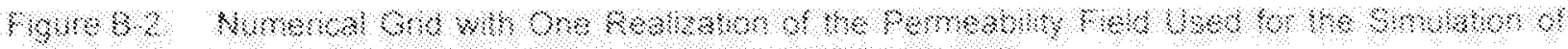

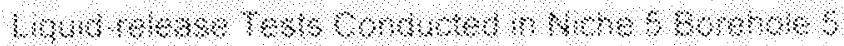




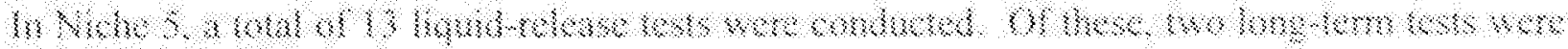

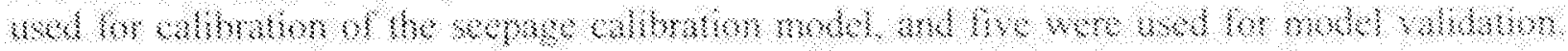

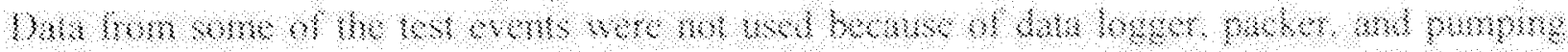

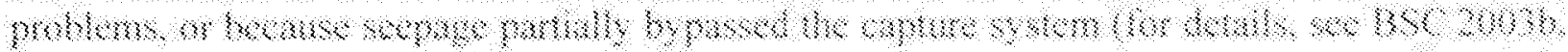

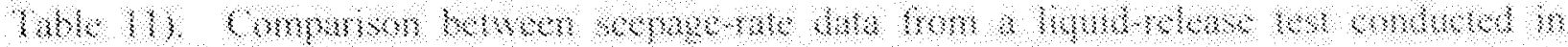

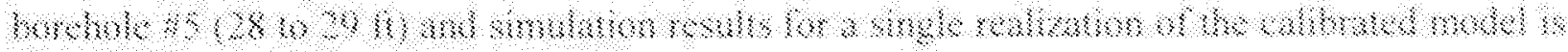

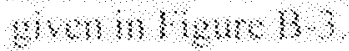

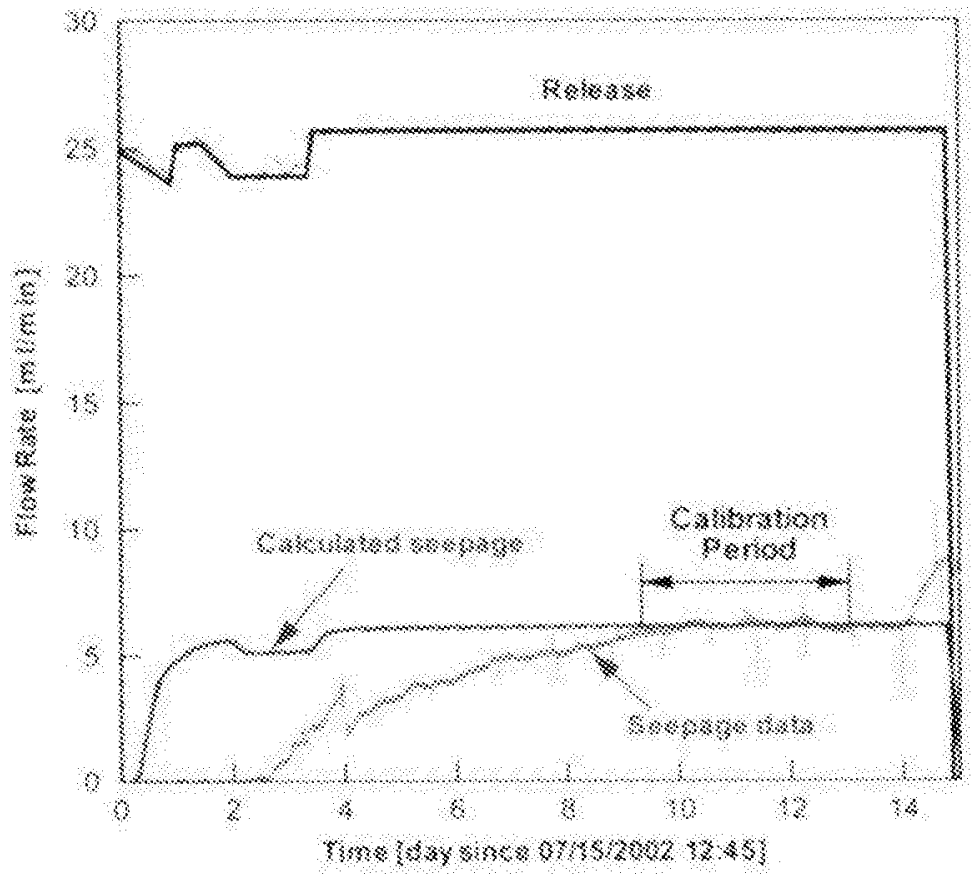

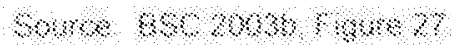

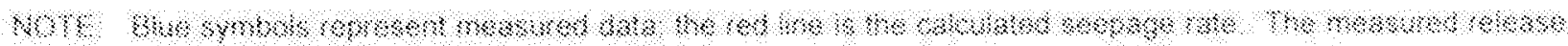
H

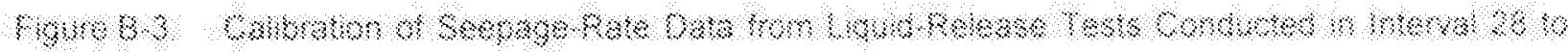

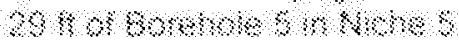

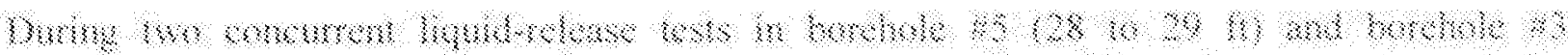

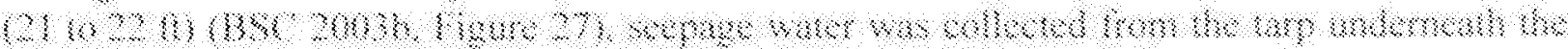

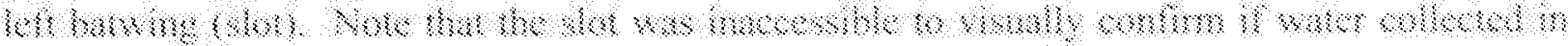

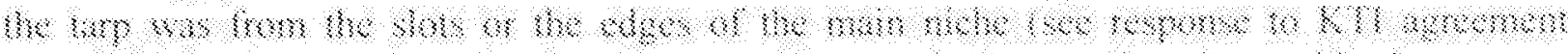

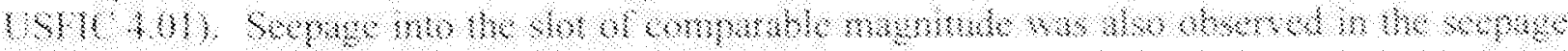

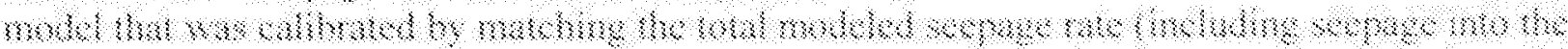

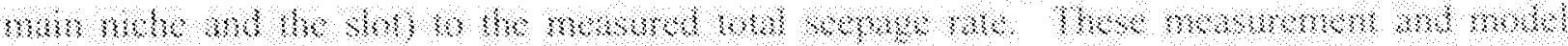

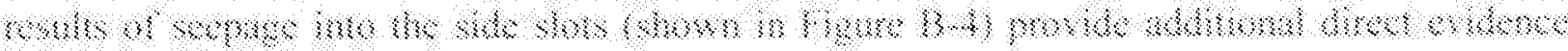

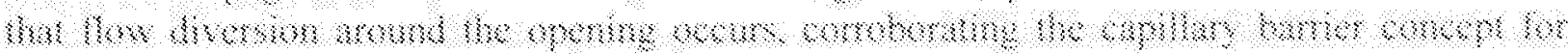

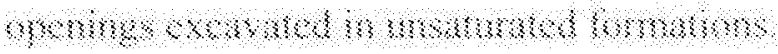




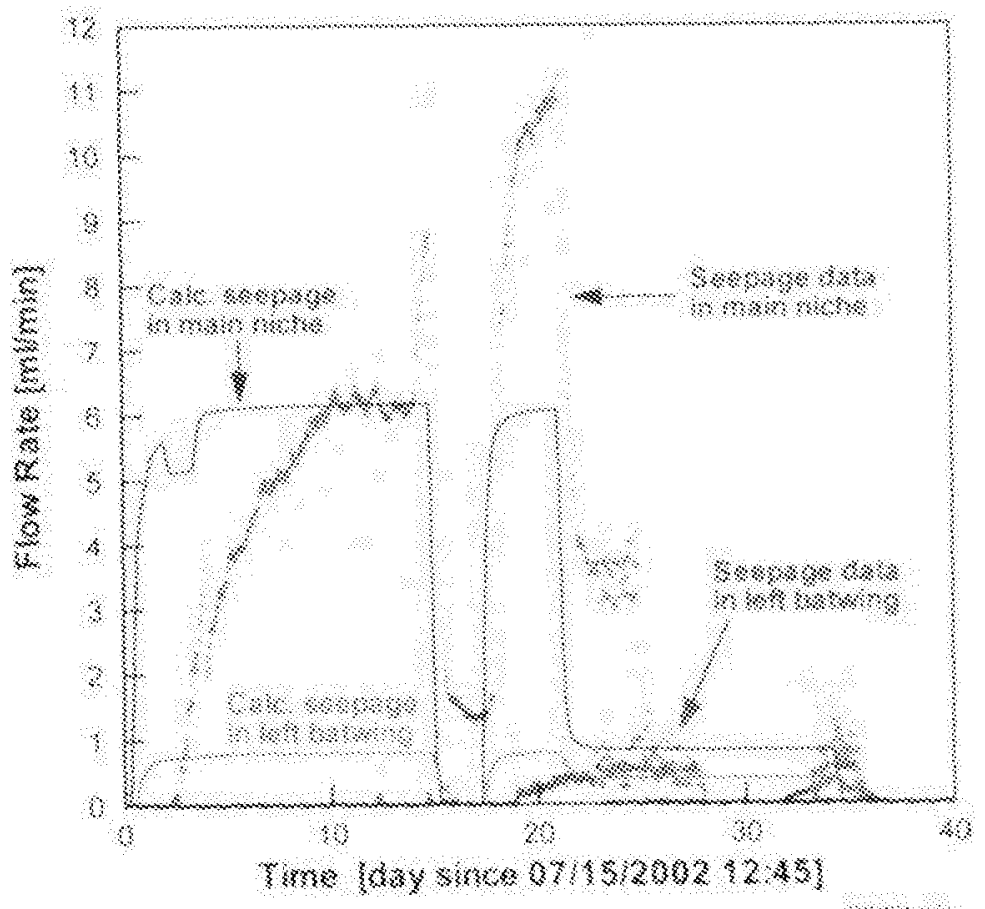

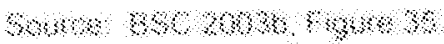

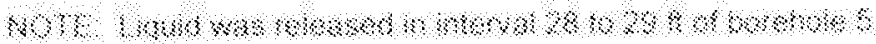

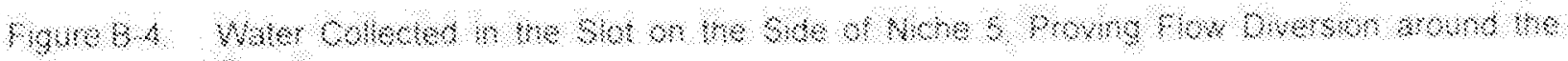
opentrys

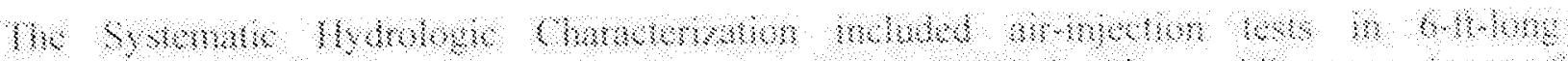

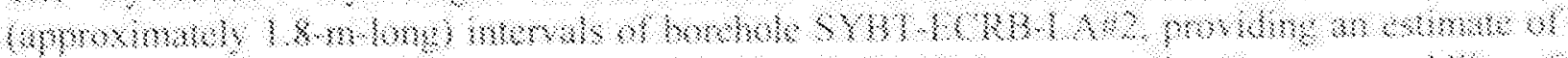
mon ho

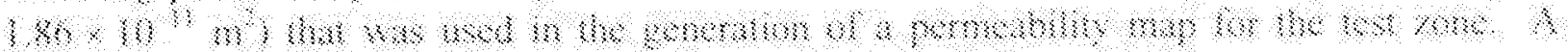

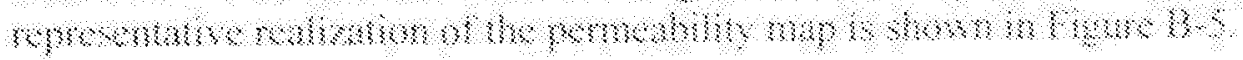




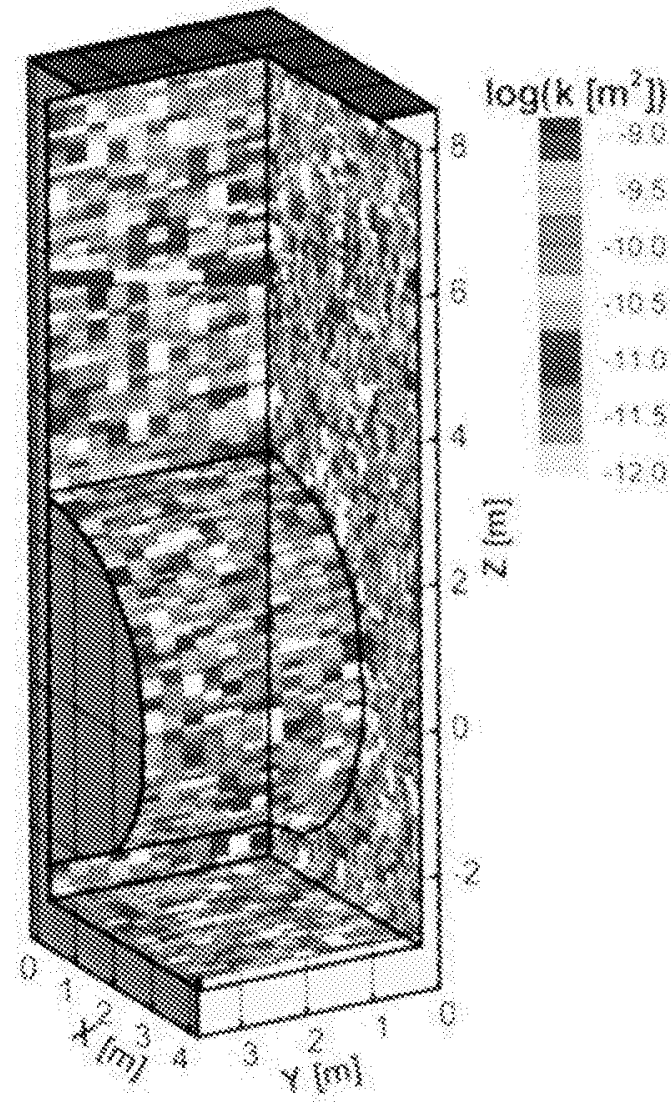

अ०े

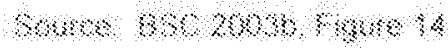

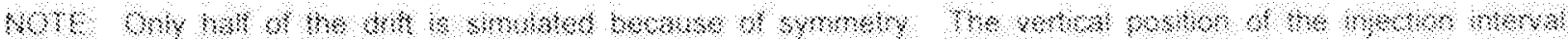

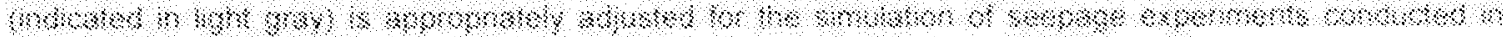

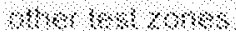

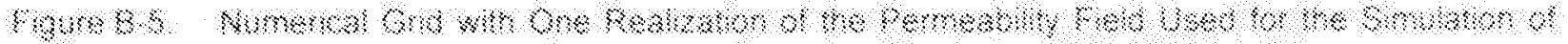

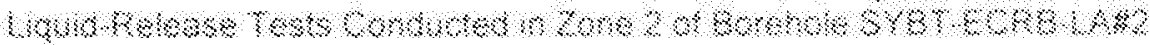

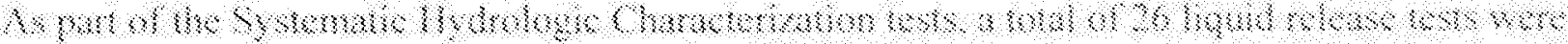

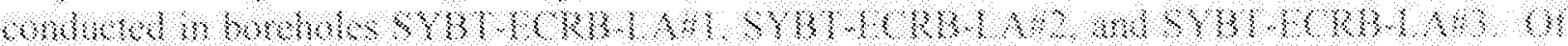

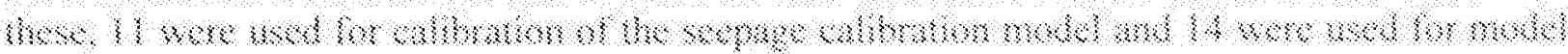

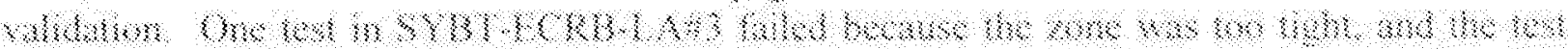

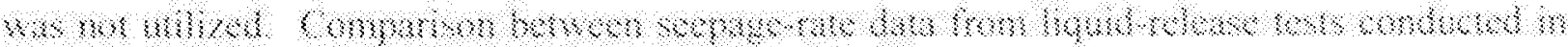

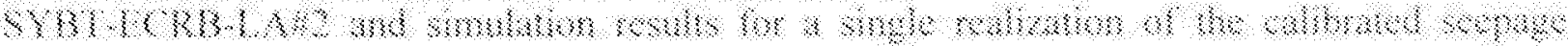

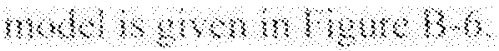




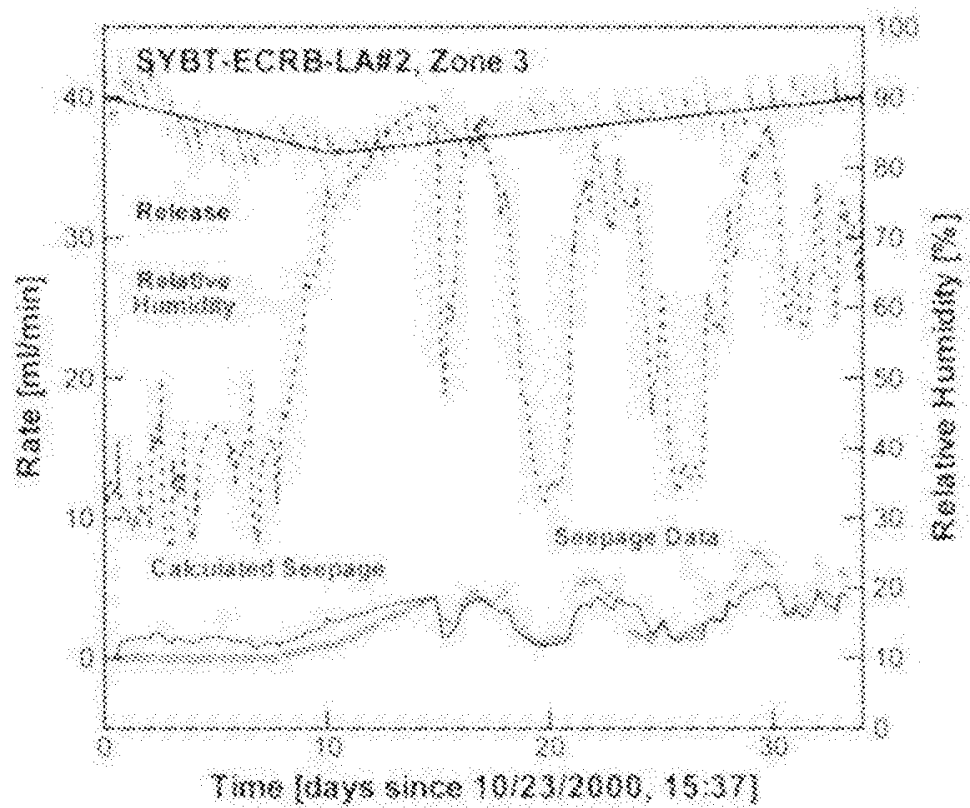

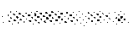

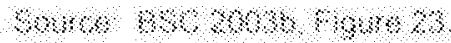

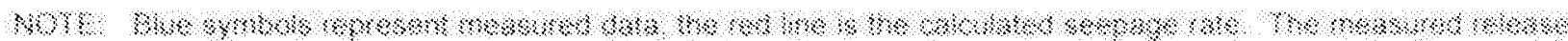

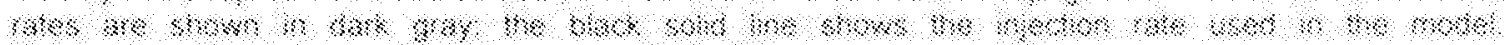

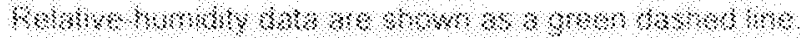

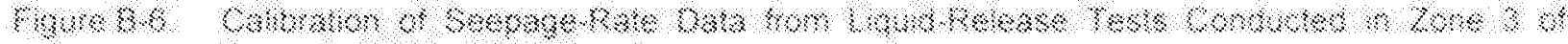

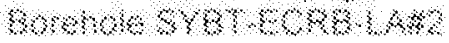

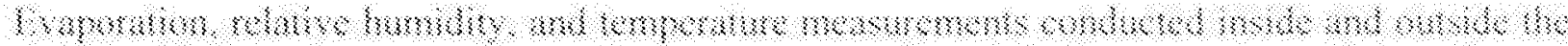

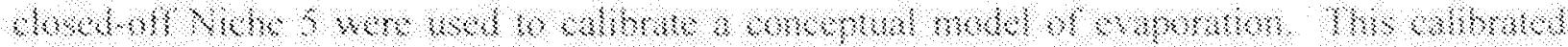

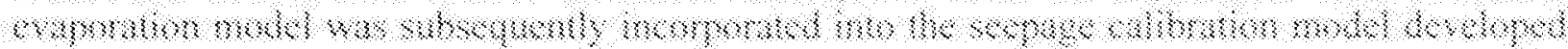

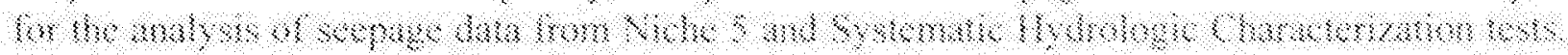

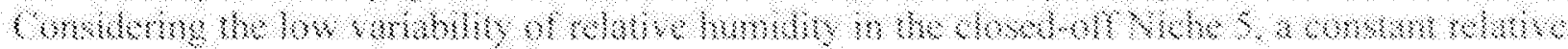

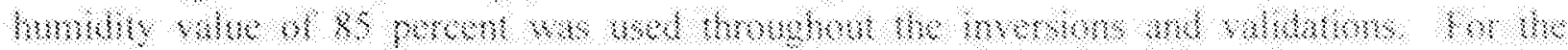

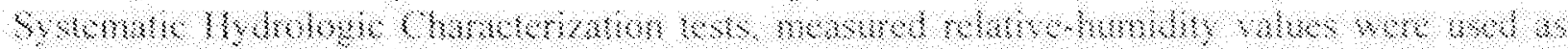

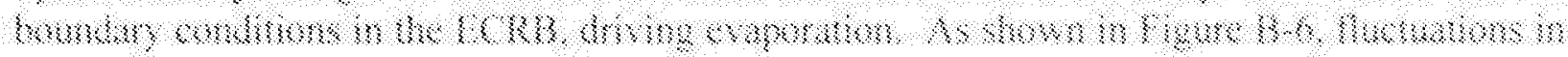

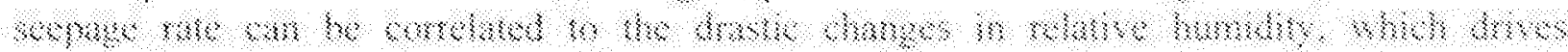

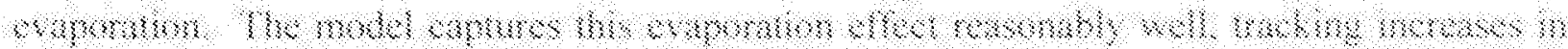

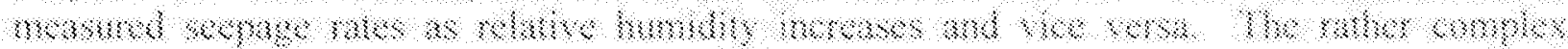

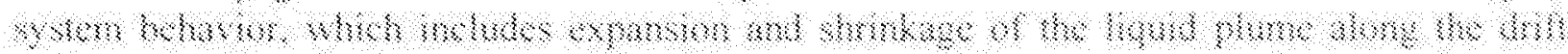

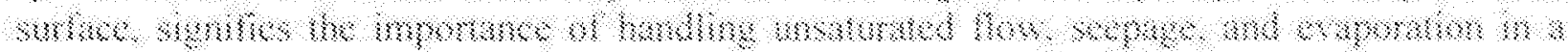

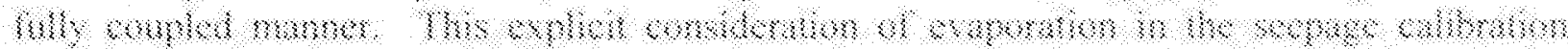

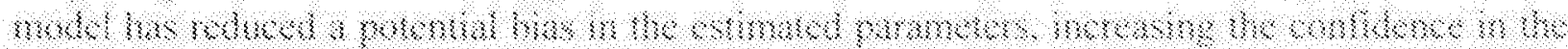

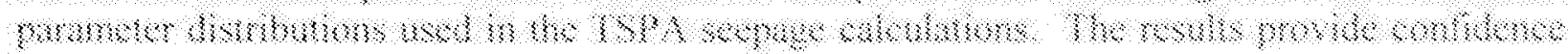

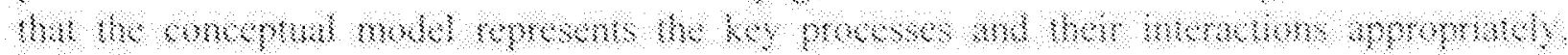
$31030,40 \%$

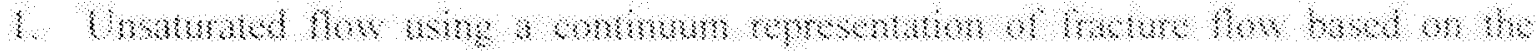

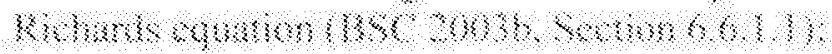


2. Seepage into the opening, accounting for the capillary-barrier effect (BSC 2003b, Section 6.6.1.2);

3. Vaporization of water from the drift surface, using a simplified evaporation model (BSC 2003b, Section 6.6.1.3).

In summary, the air-injection and liquid-release tests conducted in Niche 5 and the Systematic Hydrologic Characterization Tests were used to determine the seepage-relevant parameters (specifically permeability and capillary strength) of the lower lithophysal zone (Tptpll) and provided additional confidence in the conceptual model used to simulate seepage and related processes (e.g., evaporation).

\section{B.4.1.2 Niches 2, 3, and 4 (Middle Nonlithophysal Zone)}

A total of 225 air-injection tests were performed in 10 boreholes above Niches 2, 3, and 4 . The geostatistics of these permeabilities were used to generate stochastic permeability fields for the niches (BSC 2003b, Section 6.6.2.1). Meshes created for simulation of liquid-release tests in Niches 2, 3, and 4 are shown in Figure B-7.

In Niche 3, liquid-release tests were conducted in two intervals, borehole UM 4.88-5.18 and borehole UL 5.49-5.80. Only some of the tests in UM 4.88-5.18 resulted in seepage and were suitable for calibration. Of these, three tests that resulted in seepage were simultaneously used for calibration to provide a single van Genuchten $1 / \alpha$ value of $741 \mathrm{~Pa}$, representative for the conditions at Niche 3 (see also Section B.4.2.2). The remaining tests were used to validate the process model. Because Niche 3 was closed off by a bulkhead, and the relative humidity was expected to be high, evaporation was not explicitly considered in the calibration and validations models.

In Niche 4, twelve liquid-release tests were conducted in three intervals (UL, 7.62 to $7.93 \mathrm{~m}$; $\mathrm{UM}, 6.10$ to $6.40 \mathrm{~m}$; and UR, 5.18 to $5.48 \mathrm{~m}$ ). Of these, 6 tests (2 tests per interval) were used for calibration to provide one van Genuchten $1 / \alpha$ value for each of the boreholes UL, UM, and UR. The remaining tests were used to validate the process model. Because Niche 4 was closed off by a bulkhead and artificially humidified to get close to 100 percent relative humidity, evaporation was not explicitly considered in the calibration and validations models. Comparisons between seepage-rate data from liquid-release tests conducted in three different borehole intervals of Niche 4 and simulation results of the calibrated seepage model are given in Figure B-8. 
(8)
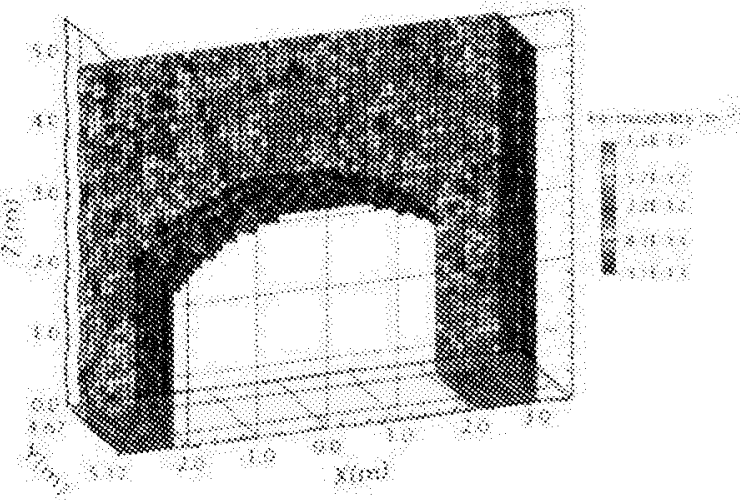

$\$$

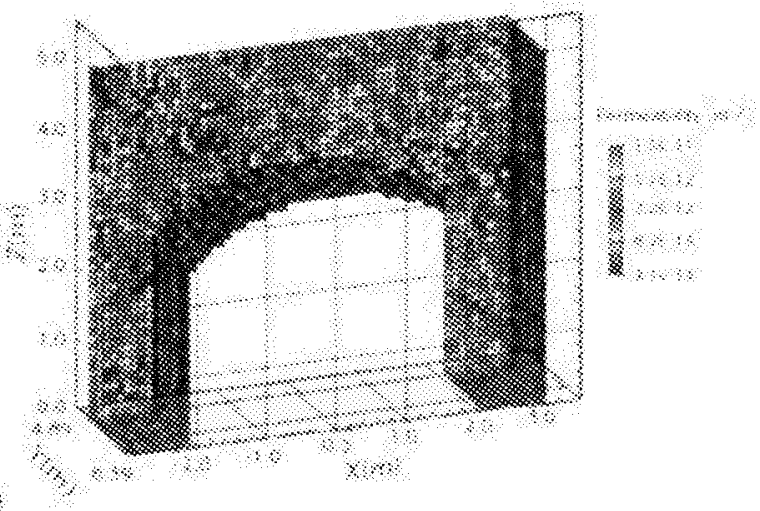

(\%)

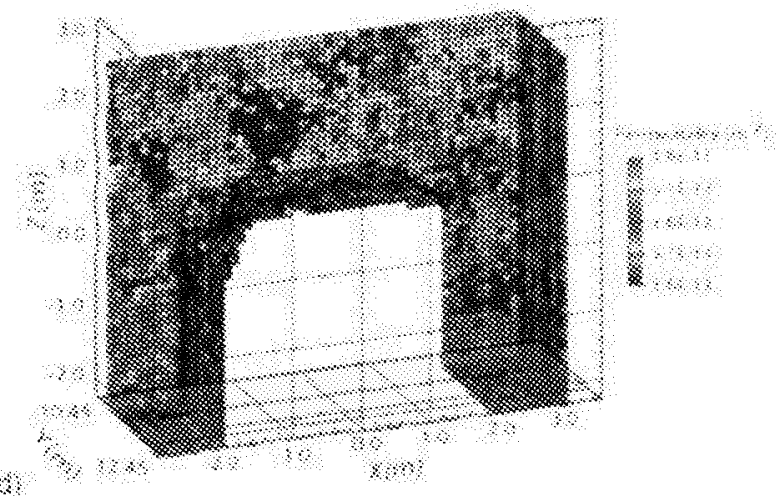

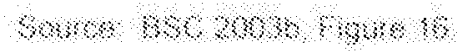

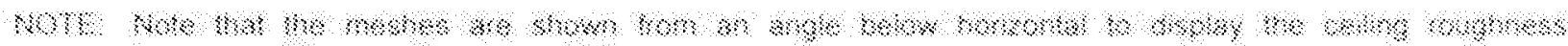

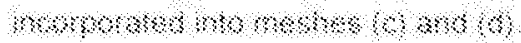

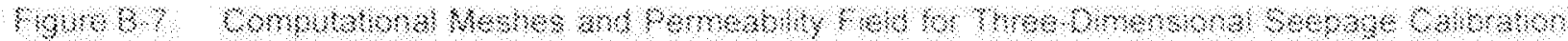

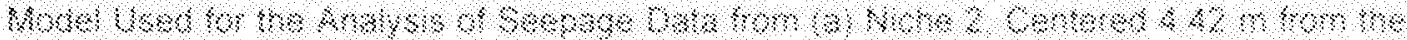

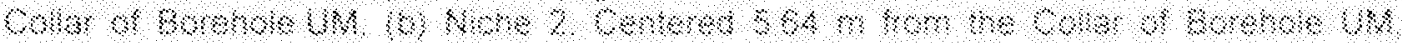

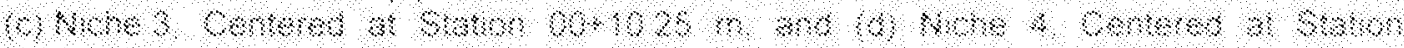
$40+1148, \mathrm{H}$

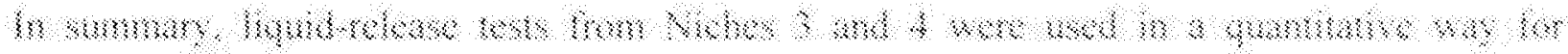

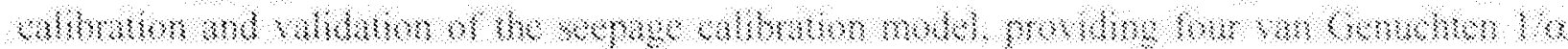

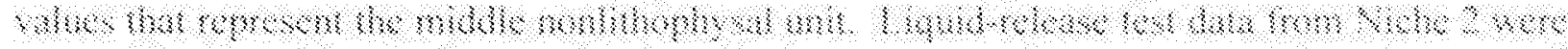

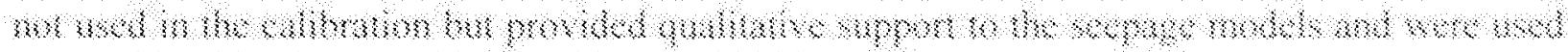

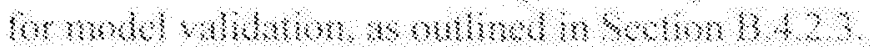



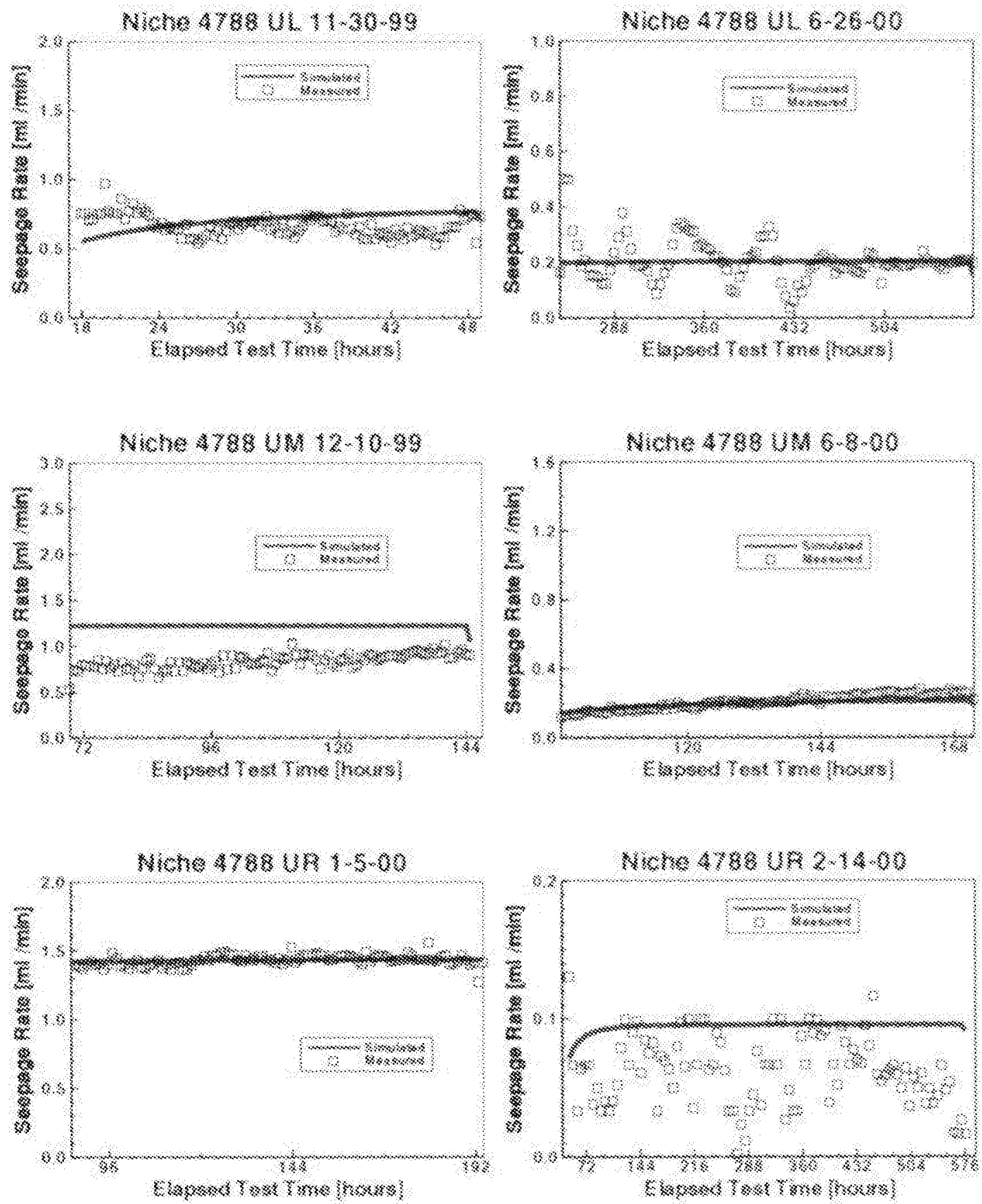

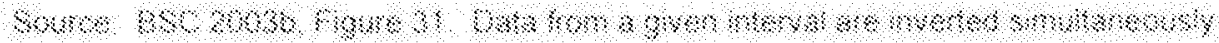

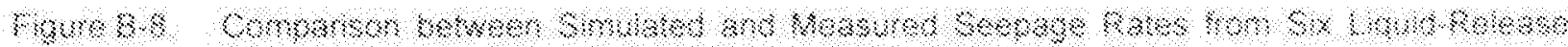

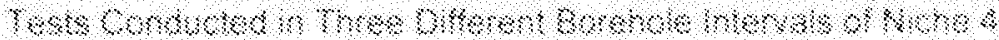




\section{B.4.2 Confidence Building in the Total System Performance Assessment Seepage Abstraction}

The data from the Passive Cross-Drift tests, Alcove 8-Niche 3 tests, and Niche 2 tests can be used to (1) qualitatively confirm DOE's understanding of the seepage process and (2) corroborate the corresponding conceptual models and analyses underlying the seepage abstraction. These aspects are discussed in subsequent sections.

\section{B.4.2.1 Passive Cross-Drift Hydrologic Tests}

The results of the Passive Cross-Drift Hydrologic tests are provided in detail in In Situ Field Testing of Processes (REV 01, BSC 2001; REV 02B, BSC 2003a, Section 6.10). Summaries of the major features of these tests are given in the responses to KTI USFIC 4.01.

A long section of the ECRB close to the portal was open to the prevailing ventilation conditions of the tunnel. Tests under this ventilated regime were aimed at checking whether seepage could occur under natural percolation flux conditions. In the ventilated drift sections of the ECRB Cross-Drift, no continuous dripping (or seepage) was observed. The absence of seepage could imply (1) sufficiently strong capillary forces keeping the percolating water inside the formation and thus preventing seepage and (or) (2) significant evaporation removing potentially seeping water. Both of these aspects of seepage exclusion (strong capillary barrier and evaporation) were integral parts of the seepage calibration model (BSC 2003b, Section 6.3.1) that provided seepage-relevant formation parameters to the seepage abstraction and TSPA calculations.

The terminal section of the ECRB Cross-Drift was closed off by a series of bulkheads to minimize ventilation effects. Within these isolated sections, barometric pressure, relative humidity, and temperature were measured at various stations. The evaporation rate was not monitored in the Cross-Drift. Periodically, the bulkhead doors sealing the nonventilated sections were opened for observations. Water samples were collected and were subsequently analyzed to determine if water originated from seepage or condensation. These tests are aimed at evaluating seepage and moisture dynamics under nonventilated conditions (i.e., when near-ambient conditions are re-established in the repository).

The relative humidity values measured in the closed-off sections were almost constant from July 2000 to May 2001, as shown in Figure B-9a. In the two zones between the first and third bulkheads, the relative humidity remained close to 95 percent, with some changes observed in March 2001, when the humidity in the second zone gradually fell closer to 90 percent. During late January 2001, the relative humidity in these sections dropped drastically when the bulkheads were opened for visual inspection. The relative humidity recovered to its original value very rapidly after the bulkheads were closed again. Similar drastic declines and rises of temperature were also observed in the innermost section, as seen in Figure B-9b. 


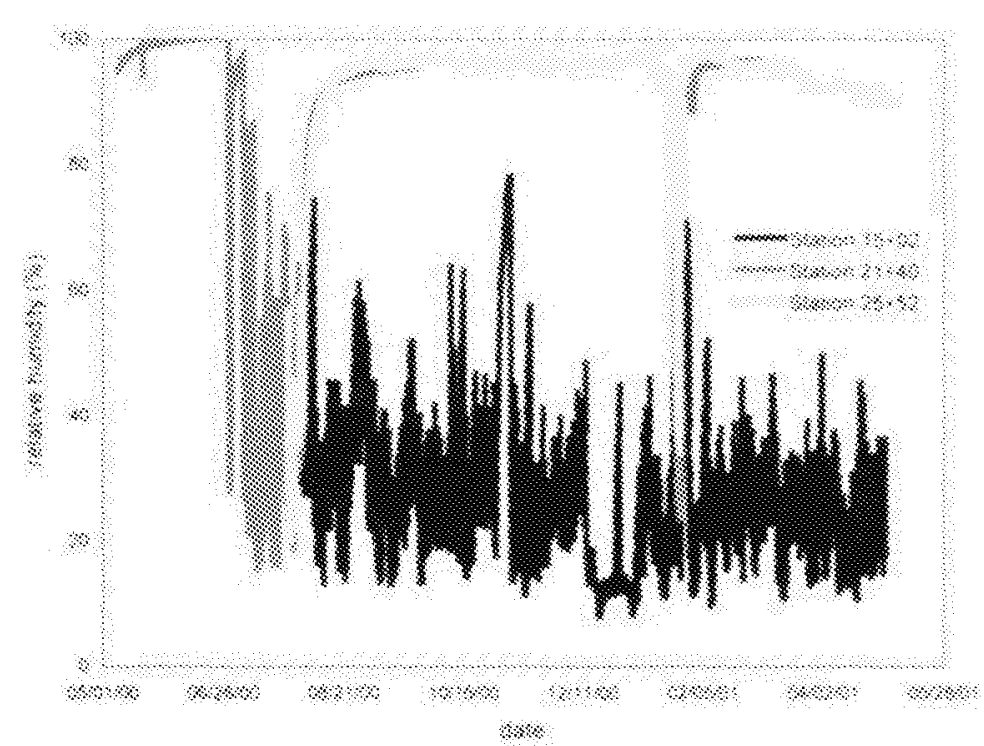

(s)

$(4)$

(४)

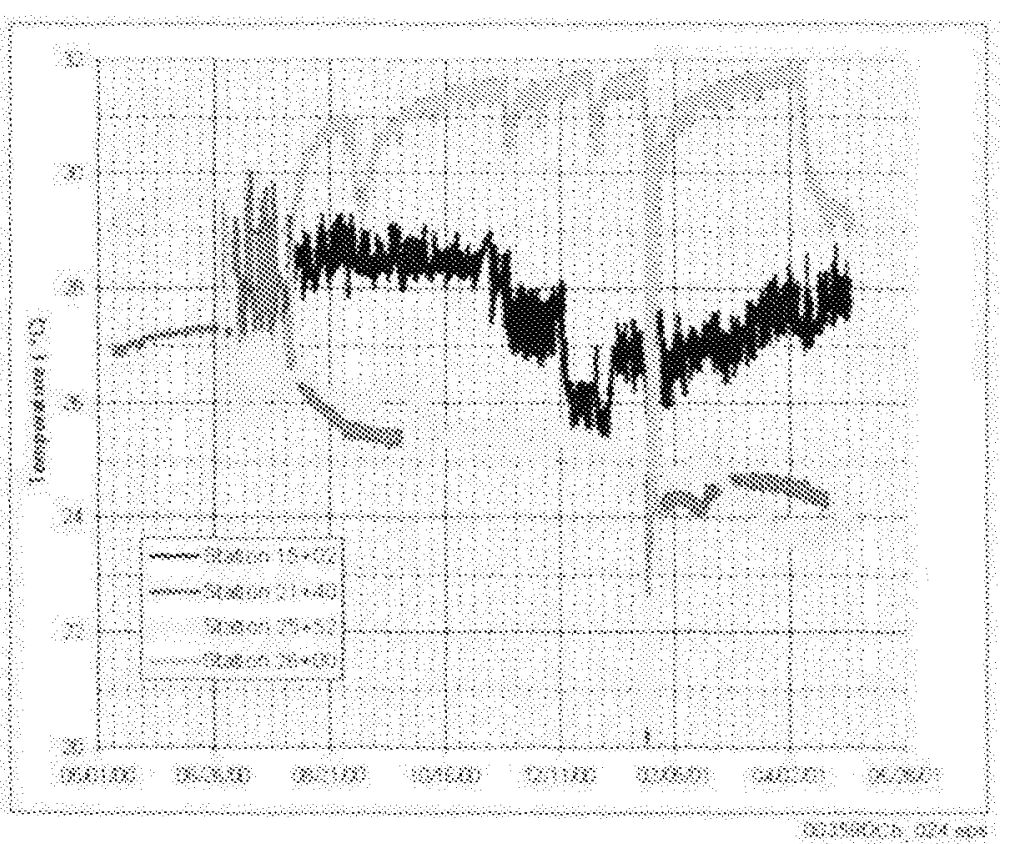

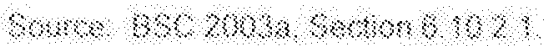

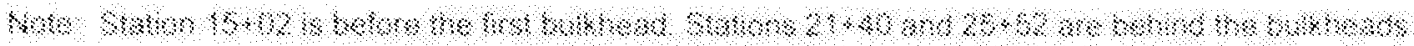

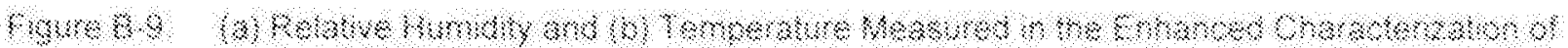

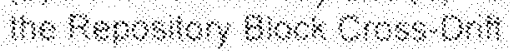

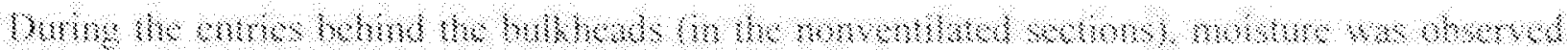

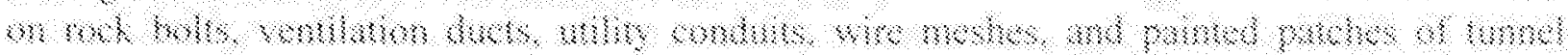

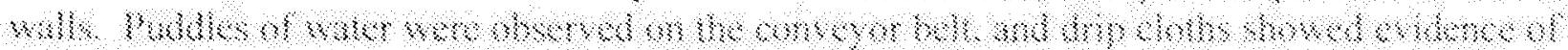

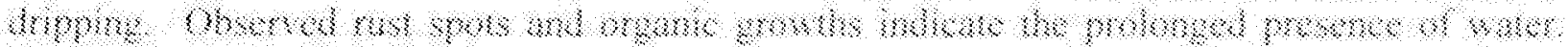

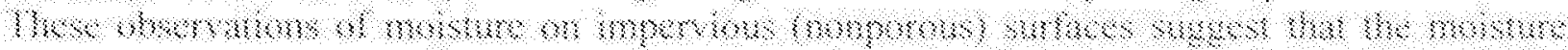

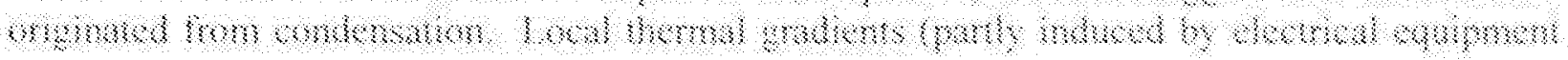


in the closed-off drift sections) in the ECRB environment near 100 percent relative humidity are the likely causes for the observed condensation.

The initial water samples collected from the puddles on the conveyor belt were dark in color. Because the surfaces of the conveyor belt were likely contaminated, the chemical analyses of these samples were not expected to provide meaningful signatures of the source of the puddles. Subsequent samples were collected from clean containers placed on the conveyor belt. These samples were found to be low in chloride and silica content, a characteristic feature of condensate. The samples were also found to lack the chemical signature of the construction water that is spiked with $20 \mathrm{mg} / \mathrm{L}$ of lithium bromide. While these data clearly show that part of the observed moisture originated from condensation, they do not rule out or confirm the existence of seepage of water from flow through the formation.

Note that results of in situ moisture monitoring since the construction of the Exploratory Studies Facility and ECRB as well as the Drift Scale Test (see Section 3.3.1) indicate no occurrence of potential seepage except at the nonventilated sections of the ECRB and Alcove 7. Although the origin of moisture and the amount of condensate could not be conclusively determined primarily due to test limitations, the effects of seepage including seepage chemistry have been incorporated into TSPA (see Sections 4.9 and 4.10 and the technical basis document on the in-drift chemical environment).

In summary, while the origin of moisture could not be conclusively determined, the available evidence suggests that condensation effects contributed significantly to the observed water.

\section{B.4.2.2 Alcove 8-Niche 3 Tests}

This test is aimed at evaluating unsaturated zone flow, seepage response, and matrix diffusion processes. Alcove 8 was excavated off the ECRB Cross-Drift in the upper lithophysal zone. Approximately $20 \mathrm{~m}$ below the floor of Alcove 8, Niche 3 was excavated off the Exploratory Studies Facility in the middle nonlithophysal zone. A nearly vertical fault runs from Alcove 8 to Niche 3. The interface between the upper lithophysal zone and middle nonlithophysal zone is approximately $15 \mathrm{~m}$ below the floor of Alcove 8 . The results of Phase I tests concerned with infiltration of water along the 5-m-long fault line exposed in Alcove 8 are given in In Situ Field Testing of Processes (BSC 2003a, Section 6.12) and UZ Flow Models and Submodels (BSC 2003c, Section 7.6).

In the first phase of the Alcove 8-Niche 3 test, water was applied along the fault in Alcove 8 at three different times. In the first set, water was released from a $30-\mathrm{cm}$ diameter circular infiltrometer. In the second set, water was released from a $70-\mathrm{cm}$ by $70-\mathrm{cm}$ square infiltrometer. In the third stage, the approximately 5-m-long fault segment was divided into four sections, and ponded infiltration experiments were conducted with a head of approximately $2 \mathrm{~cm}$. Two conservative tracers (pentafluorobenzoic acid, or PFBA, and LiBr) were released along the fault during a 9-day period. Wetting-front advance and development of a wetting plume were monitored using electrical resistance probes installed in boreholes above the ceiling of Niche 3 . Seepage into Niche 3 was collected by a series of capture trays equipped with an automated gauging system. 


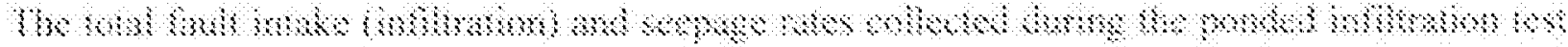

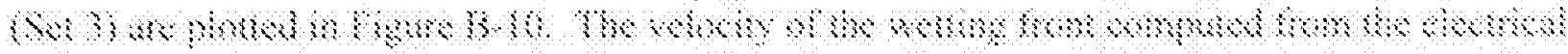

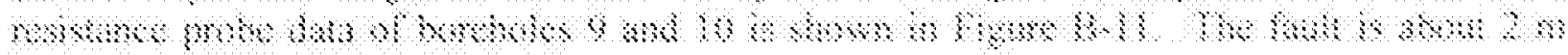

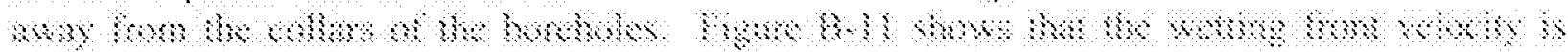
क४⿻
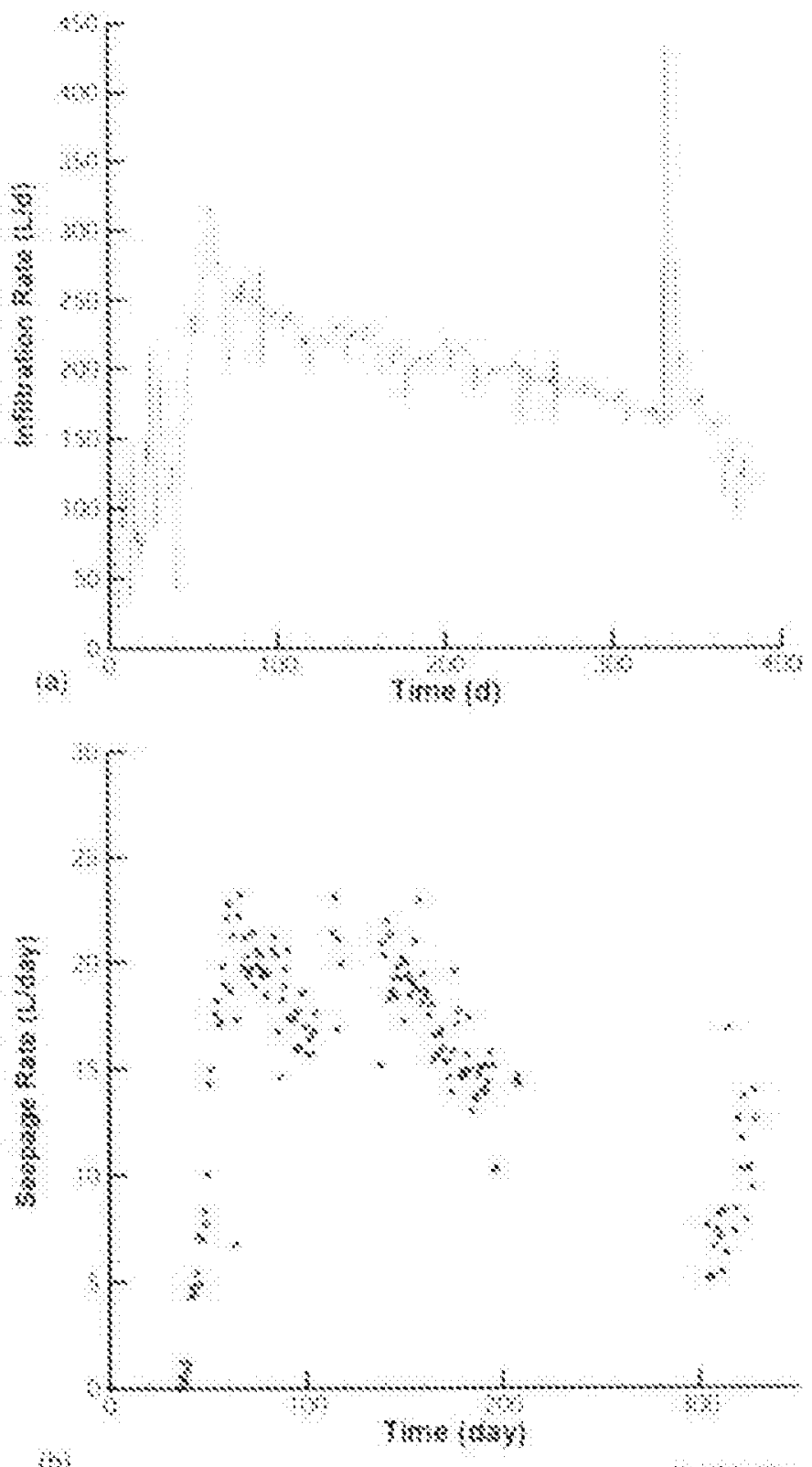

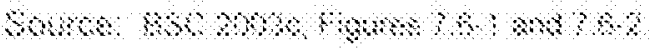

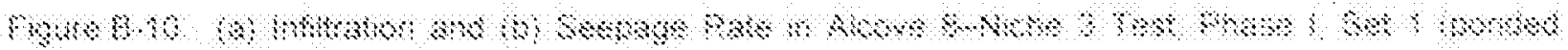
inkminoses: 


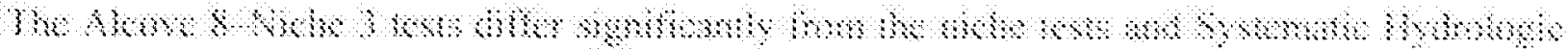

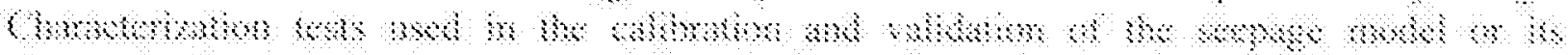

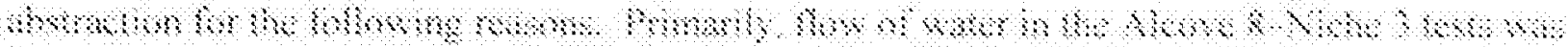

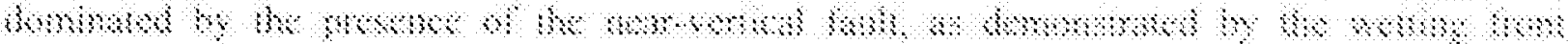

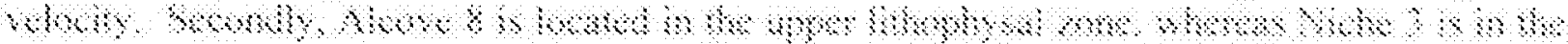

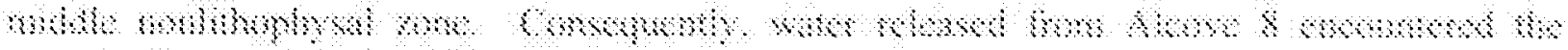

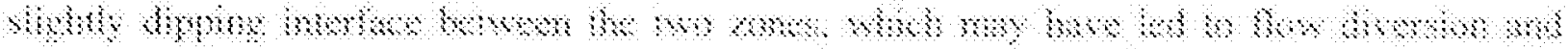

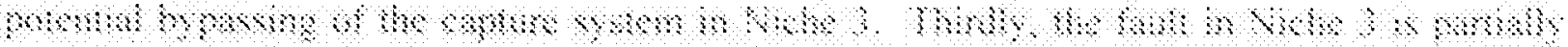

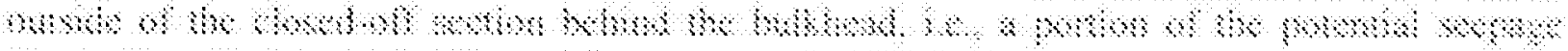

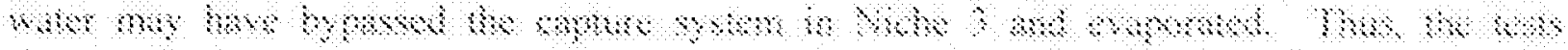

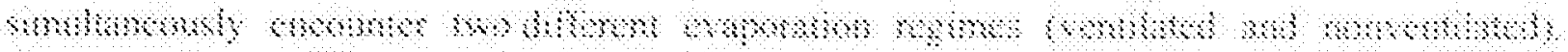

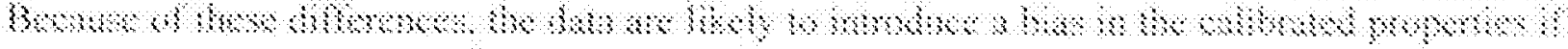

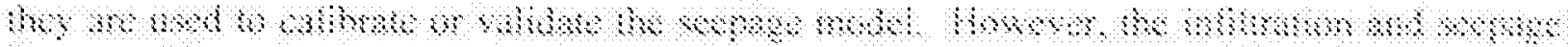

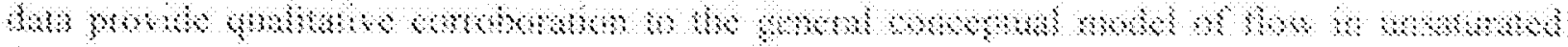

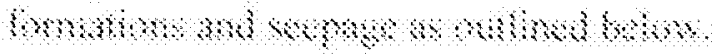

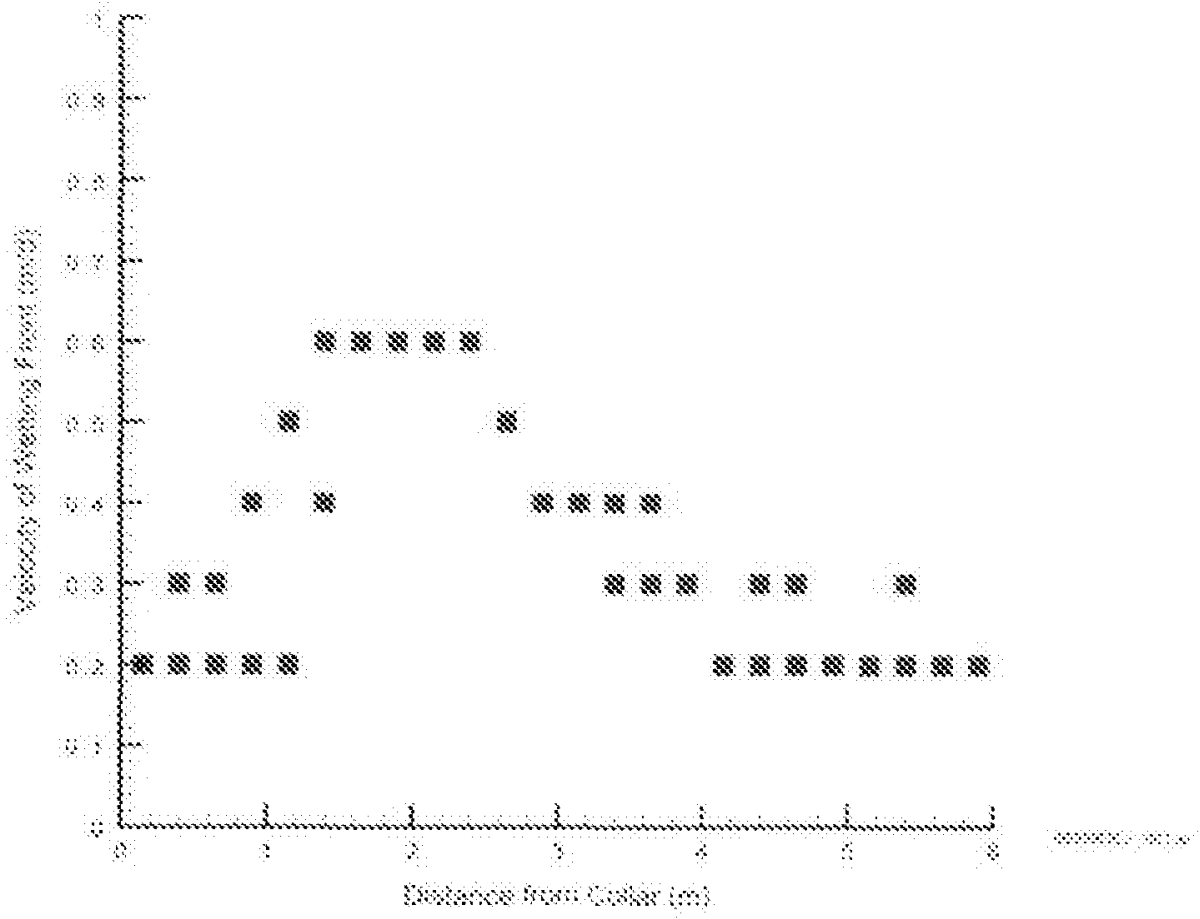

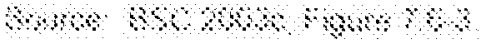

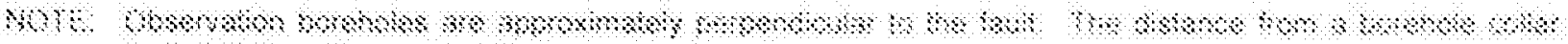

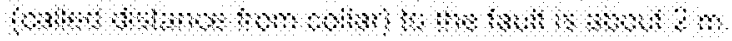

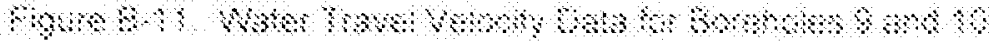

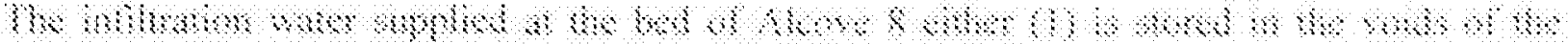

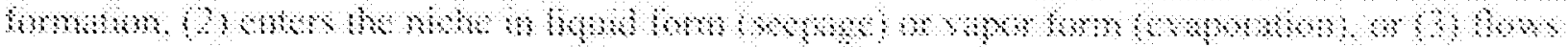

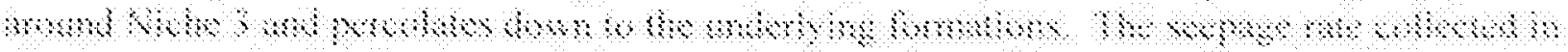

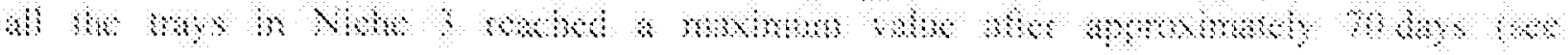


Figure B-10b) and declined gradually afterwards. The infiltration rate also started declining at about the same time (see Figure B-10a). The stabilization of the seepage rate is indirect evidence that the storage component has reached the maximum level. The fact that flow occurred through a narrow range around the fault (see Figure B-11) also implies that storage occurred only in a restricted region surrounding the fault. The seepage percentage during this period was consistently less than 10 percent. The foregoing observations suggest that 90 percent of the infiltration water was either being diverted around Niche 3 or was evaporating. Both of these aspects (capillary barrier effect and evaporation) contribute to seepage exclusion; they were integral parts of the analysis with the seepage calibration model (BSC 2003b, Section 6.3.1) that provided seepage-relevant formation parameters.

The infiltration rate, seepage rate, wetting front velocity, and tracer breakthrough data were used to validate the three-dimensional unsaturated zone flow models (BSC 2003c, Section 7.6). Inverse modeling using the seepage rate and wetting-front advance data resulted in a calibrated van Genuchten $1 / \alpha$ value of $914 \mathrm{~Pa}$ for the fault zone. This value is on the same order as that of the fracture continuum of Niche $3(741 \mathrm{~Pa})$ derived from the seepage calibration model (see Section B.4.1.2 above). Deviations between the predicted breakthrough curves of two conservative tracers and measured data were within the validation acceptance criteria.

In summary, the Alcove 8-Niche 3 test provided additional confidence in the conceptual model of seepage for the following reasons: (1) the low seepage percentage measured in the Alcove 8-Niche 3 tests was consistent with the conceptual model of seepage, and (2) the calibrated capillary strength parameter for the Alcove 8-Niche 3 test is within the same order of magnitude as that determined from the analysis of liquid-release tests conducted in Niche 3 .

\section{B.4.2.3 Niche 2 Tests}

In Niche 2, liquid-release tests were conducted for short durations. These short-term tests are very sensitive to storage effects and the properties of a few fractures connecting the injection interval to the niche opening. Thus, the data were used only for validation of the seepage model (BSC 2003b, Section 7.3). The data qualitatively agree with the general conceptual model of seepage in that seepage rate is significantly less than the release rate. Fifty Monte Carlo simulations performed for the prediction of seepage rates in Niche 2 showed that the majority of the seepage data ( 24 out of 27 tests) fall within the range defined by the Monte Carlo simulations as shown in Figure B-12. 


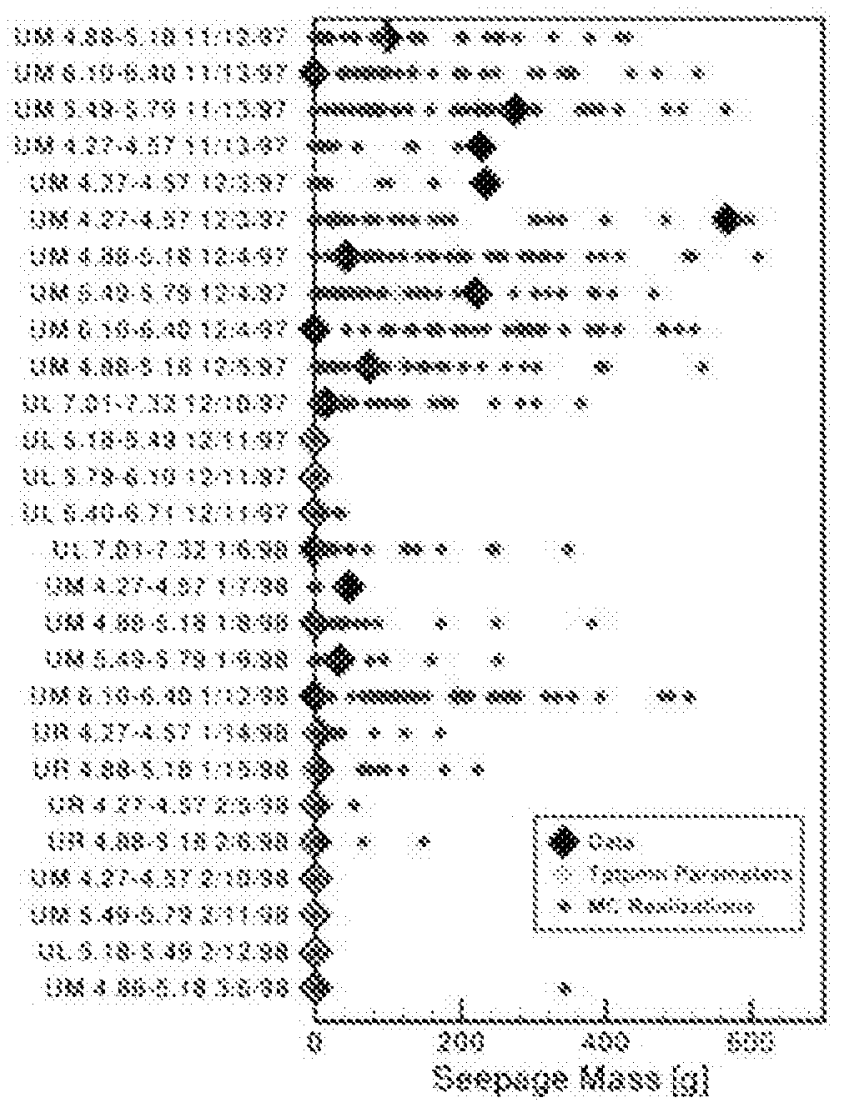

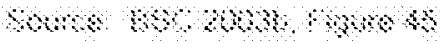

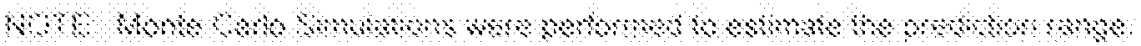

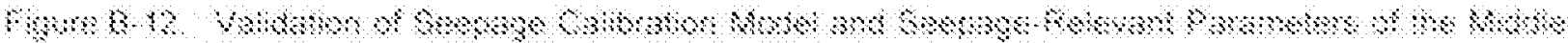

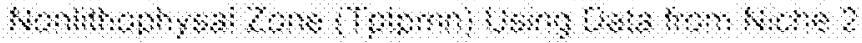

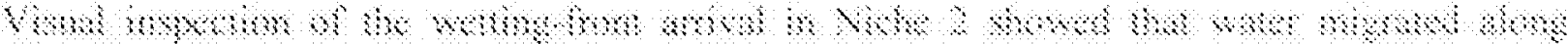

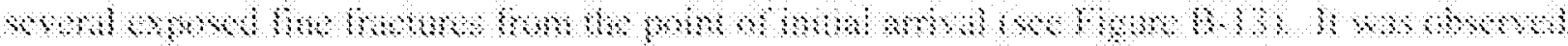
Bno was mum

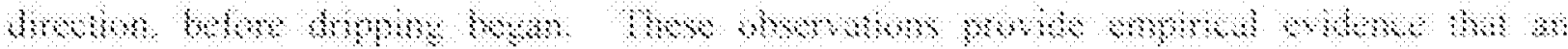

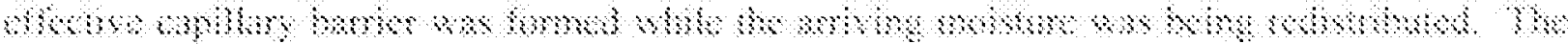

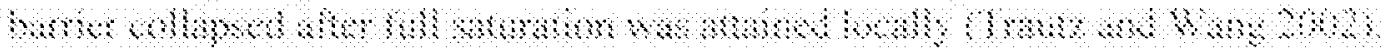




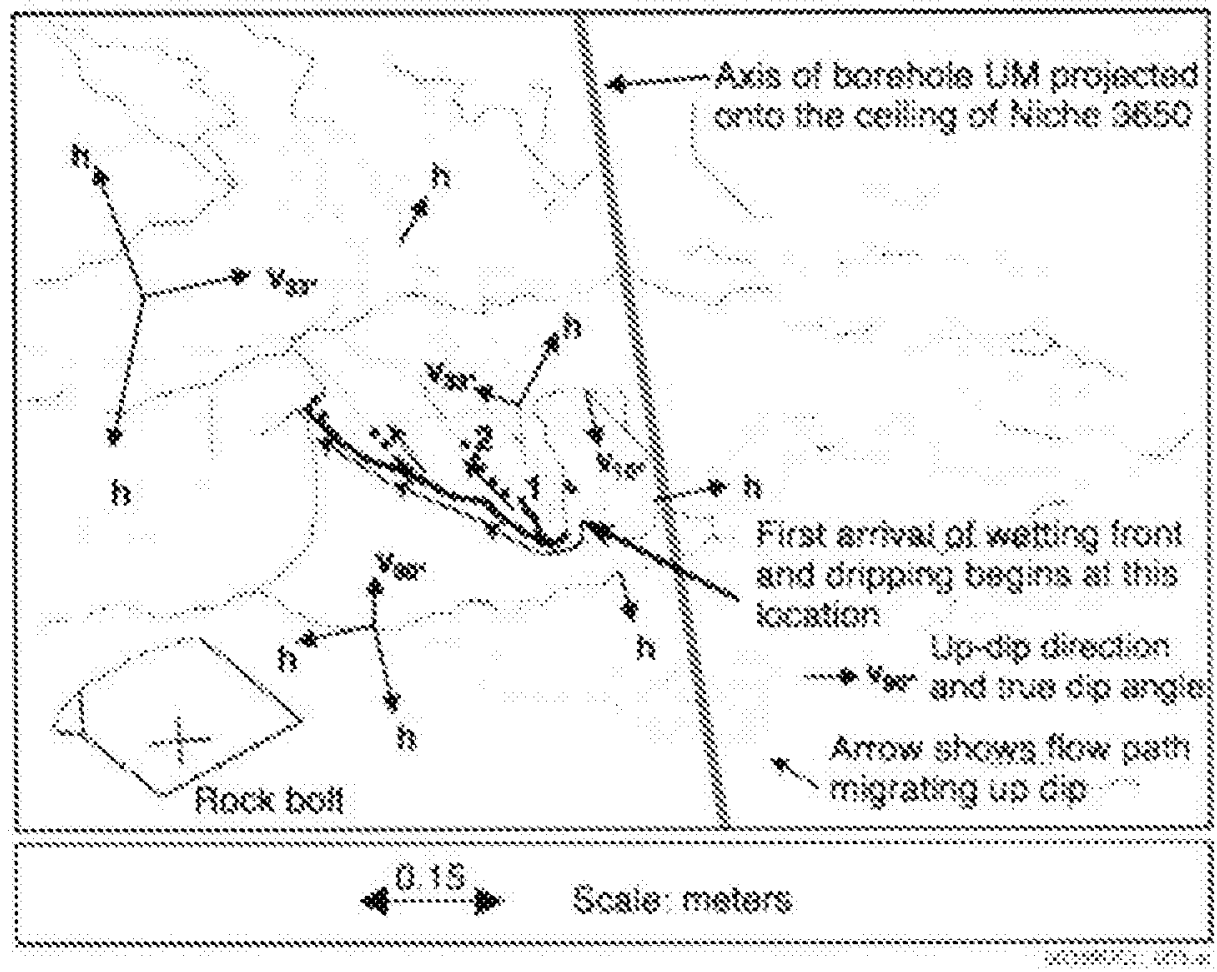

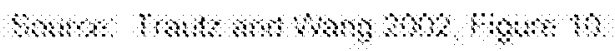

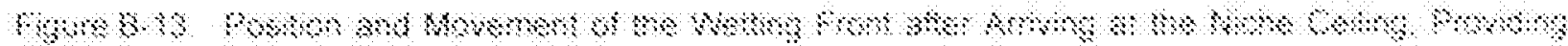

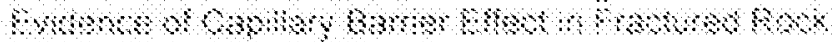

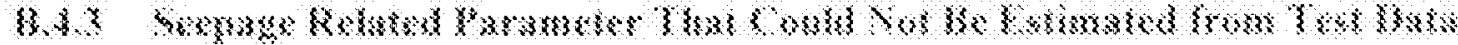

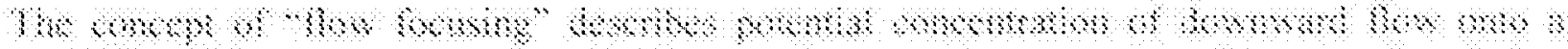

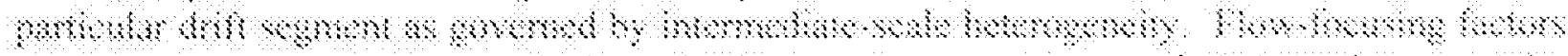

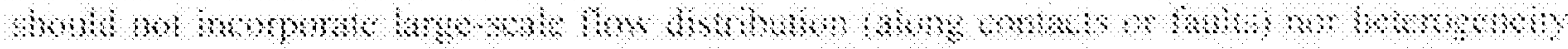

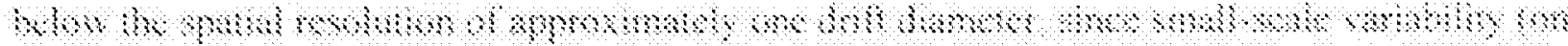

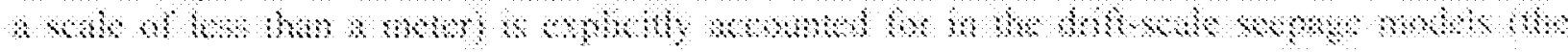

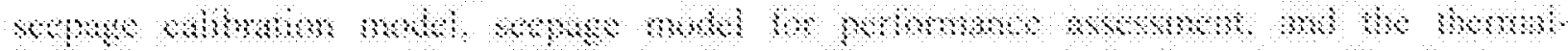

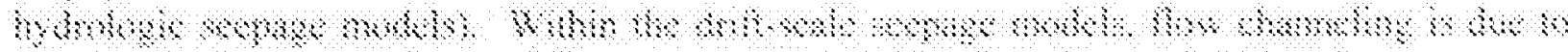

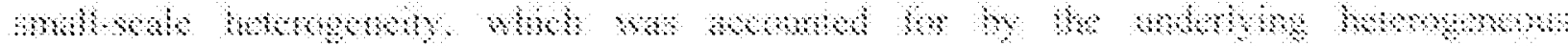

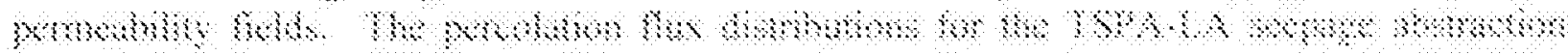

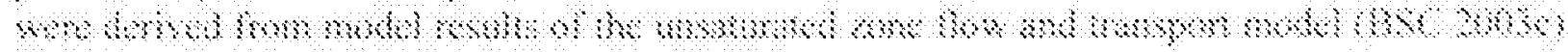

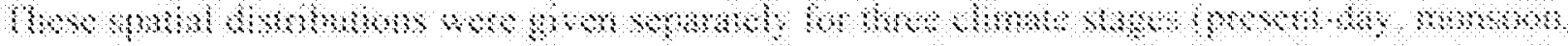

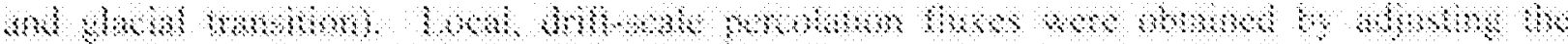

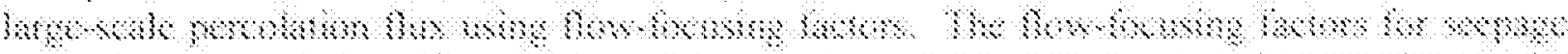

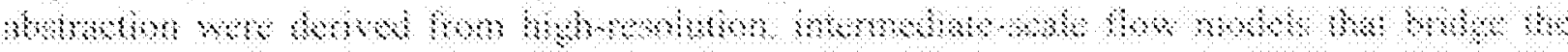

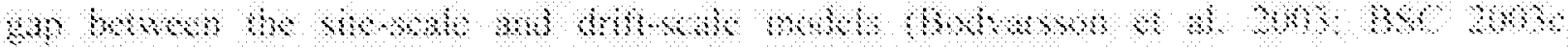
sebonos? 


\section{B.5 REFERENCES}

Bodvarsson, G.S.; Wu, Y-S.; and Zhang, K. 2003. "Development of Discrete Flow Paths in Unsaturated Fractures at Yucca Mountain." Journal of Contaminant Hydrology, 62-63, 23-42. New York, New York: Elsevier. TIC: 254205.

BSC (Bechtel SAIC Company) 2001. In Situ Field Testing of Processes. ANL-NBS-HS000005 REV 01. Las Vegas, Nevada: Bechtel SAIC Company. ACC: MOL.20020108.0351.

BSC 2003a. In Situ Field Testing of Processes. ANL-NBS-HS-000005 REV02B. Las Vegas, Nevada: Bechtel SAIC Company. ACC: MOL.20030915.0238.

BSC 2003b. Seepage Calibration Model and Seepage Testing Data. MDL-NBS-HS-000004 REV 02. Las Vegas, Nevada: Bechtel SAIC Company. ACC: DOC.20030408.0004.

MOL.20030728.0198.

BSC 2003c. UZ Flow Models and Submodels. MDL-NBS-HS-000006 REV 01. Las Vegas, Nevada: Bechtel SAIC Company. ACC: DOC.20030818.0002.

BSC 2003d. Abstraction of Drift Seepage. MDL-NBS-HS-000019 REV 00. Las Vegas, Nevada: Bechtel SAIC Company. ACC: DOC.20030826.0001.

NRC (U.S. Nuclear Regulatory Commission) 2002. Integrated Issue Resolution Status Report. NUREG-1762. Washington, D.C.: U.S. Nuclear Regulatory Commission, Office of Nuclear Materials Safety and Safeguards. TIC: 253064.

Reamer, C.W. 2001. "U.S. Nuclear Regulatory Commission/U.S. Department of Energy Technical Exchange and Management Meeting on Total System Performance Assessment and Integration (August 6 through 10, 2001)." Letter from C.W. Reamer (NRC) to S. Brocoum (DOE/YMSCO), August 23, 2001, with enclosure. ACC: MOL.20011029.0281.

Trautz, R.C. and Wang, J.S.Y. 2002. "Seepage into an Underground Opening Constructed in Unsaturated Fractured Rock Under Evaporative Conditions." Water Resources Research, 38, (10), 6-1 through 6-14. Washington, D.C.: American Geophysical Union. TIC: 253348. 


\section{APPENDIX C}

\section{IN SITU FIELD TESTING RESULTS AND ANALYSES} (RESPONSE TO USFIC 4.01) 
Revision 1

\section{Note Regarding the Status of Supporting Technical Information}

This document was prepared using the most current information available at the time of its development. This Technical Basis Document and its appendices providing Key Technical Issue Agreement responses that were prepared using preliminary or draft information reflect the status of the Yucca Mountain Project's scientific and design bases at the time of submittal. In some cases this involved the use of draft Analysis and Model Reports (AMRs) and other draft references whose contents may change with time. Information that evolves through subsequent revisions of the AMRs and other references will be reflected in the License Application (LA) as the approved analyses of record at the time of LA submittal. Consequently, the Project will not routinely update either this Technical Basis Document or its Key Technical Issue Agreement appendices to reflect changes in the supporting references prior to submittal of the LA. 


\section{APPENDIX C \\ IN SITU FIELD TESTING RESULTS AND ANALYSES (RESPONSE TO USFIC 4.01)}

This appendix provides a response for Key Technical Issue (KTI) agreement Unsaturated and Saturated Flow under Isothermal Conditions (USFIC) 4.01. This KTI agreement relates to the performance and documentation of specific hydrologic tests conducted at Yucca Mountain.

\section{C.1 KEY TECHNICAL ISSUE AGREEMENT}

\section{C.1.1 USFIC 4.01}

Agreement USFIC 4.01 was first reached during the U.S. Nuclear Regulatory Commission (NRC)/U.S. Department of Energy (DOE) Technical Exchange and Management Meeting on Unsaturated and Saturated Flow Under Isothermal Conditions held August 16 to 17, 2000, in Berkeley, California (Reamer and Williams 2000). During the course of this meeting, USFIC Subissue 4, Deep Percolation, was discussed, and KTI agreement USFIC 4.01 was reached.

Subsequent to this technical exchange, NRC staff reviewed agreement USFIC 4.01 and proposed modifications to the agreement. This proposal was transmitted in a letter from the NRC to the DOE dated June 20, 2001 (Reamer 2001). The proposed revisions were later discussed at the NRC/DOE Technical Exchange and Management Meeting on Total System Performance Assessment and Integration held August 6 to 10, 2001, in Las Vegas, Nevada. At this meeting, an agreement was reached on the final wording of agreement USFIC 4.01 (Reamer and Gil 2001). The NRC originally requested some test plans as well as results from several tests and modeling studies (Reamer 2001). In reaching the final agreement, the DOE and NRC agreed to limit the agreement to test plans and test results, with related modeling issues covered in separate agreements.

The wording of the final agreement is as follows.

\section{USFIC 4.01}

The ongoing and planned testing are a reasonable approach for a licensing application with the following comments:

i. Consider a mass balance of water for Alcove 8-Niche 3 cross over test;

ii. Monitor evaporation during all testing;

iii. Provide the documentation of the test plan for the passive cross-drift hydrologic test;

iv. Provide the NRC with any cross-drift seepage predictions that may have been made for the passive cross-drift hydrologic test; 
v. Provide documentation of the results obtained and the analysis for the passive cross-drift hydrologic test. This documentation should include the analysis of water samples collected during entries into the cross-drift (determination whether the water comes from seepage or condensation);

vi. Provide documentation of the results obtained and the analysis for the Alcove 7 test. This documentation should include the analysis of water samples collected during entries into Alcove 7 (determination whether the water comes from seepage or condensation);

vii. Provide the documentation of the test plan for the Niche 5 test;

viii. Provide documentation of the results obtained and the analysis for the Niche 5 test;

ix. Provide documentation of the results obtained and the analysis for the Systematic Hydrologic Characterization test;

x. Provide documentation of the results obtained and the analysis for the Niche 4 test;

xi. Provide documentation of the results obtained from the calcite-filling test. Include interpretation of the observed calcite deposits found mostly at the bottom of the lithophysal cavities;

DOE stated that:

1) A mass balance of water for the Alcove 8-Niche 3 test has been considered, but is not feasible due to the size of the collection system that would be required. A collection system to obtain a mass balance is being developed for the Niche 5 test (i);

2) Evaporation will be monitored for all tests where evaporation is a relevant process (ii);

3) Test plans for Niche 5 and the cross-drift hydrologic tests are expected to be available to NRC FY 2002 (iii, viii);

4) The cross-drift seepage predictions will be documented in the Seepage Calibration Model and Seepage Testing Data AMR (MDL-NBS-HS000004) expected to be available to NRC by FY 2003 (iv);

5) DOE will document the results for the tests identified above (except calcite filling observations) in the In-Situ Field Testing of Processes AMR (ANL-NBS-HS-000005) expected to be available to NRC in FY 2003 (v), (vi), (vii), (ix), (x); 


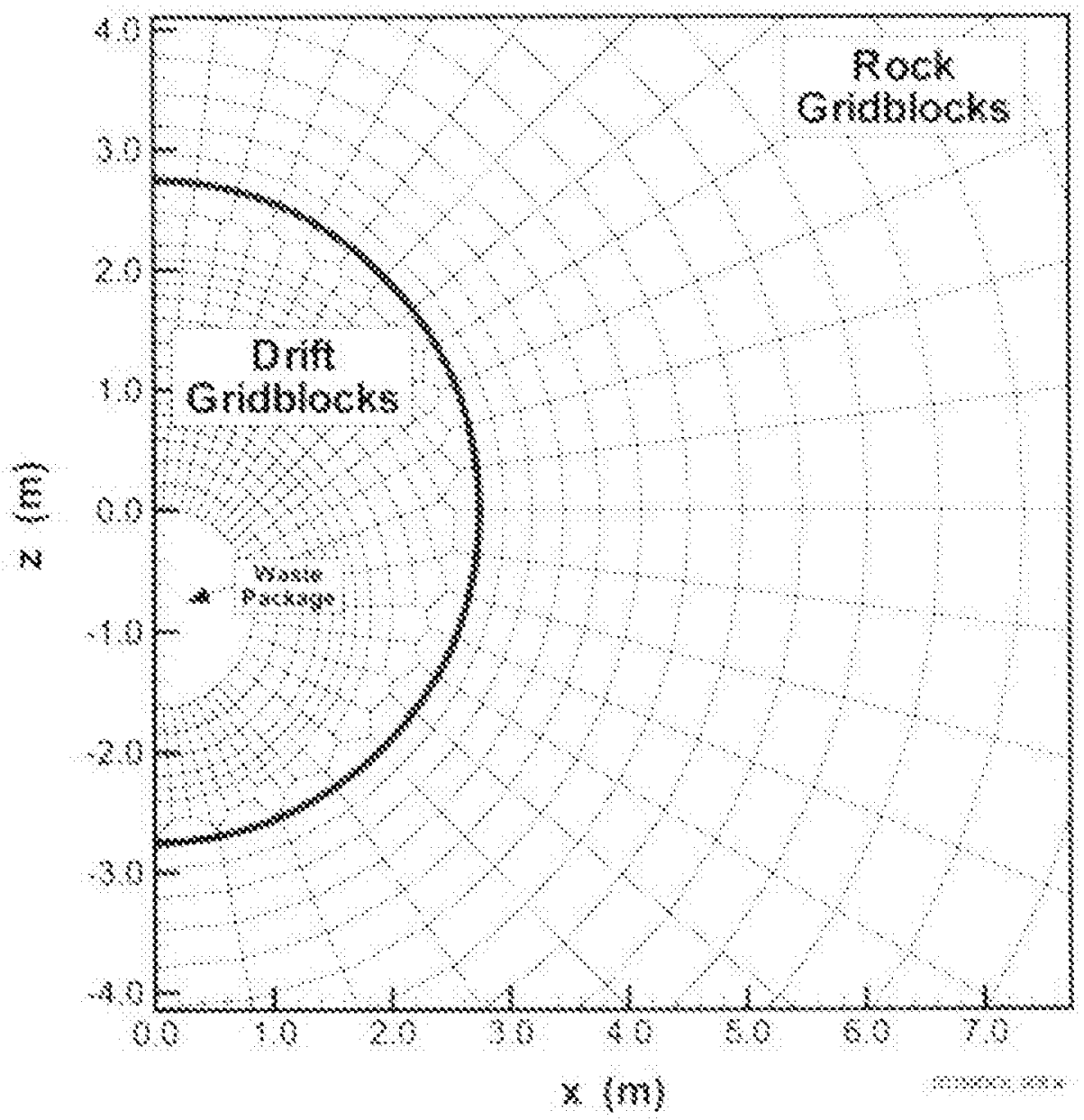

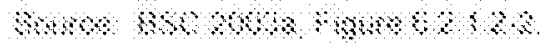

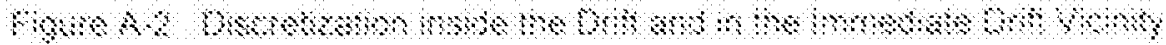

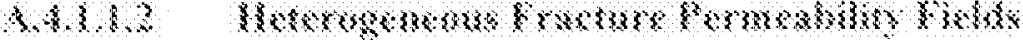

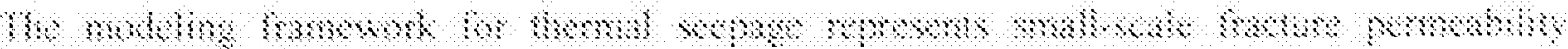

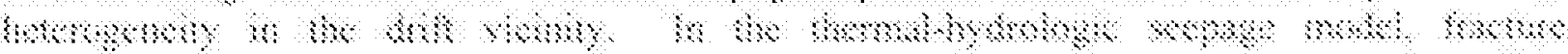

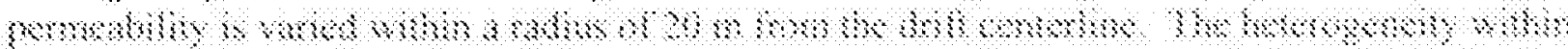

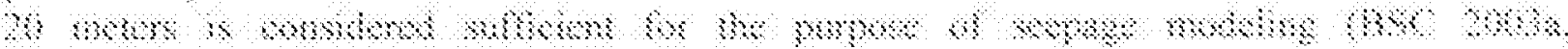

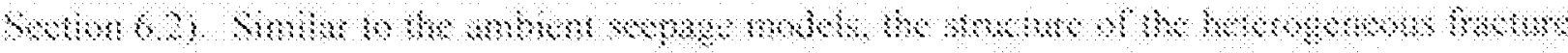

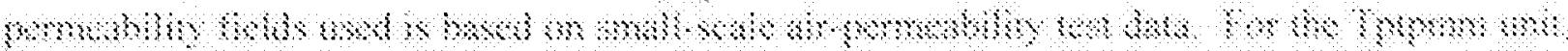

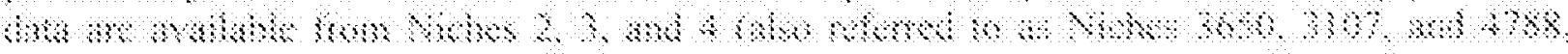

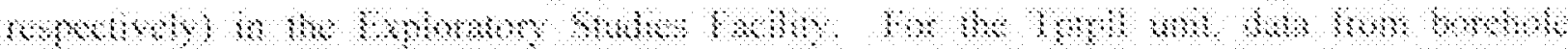

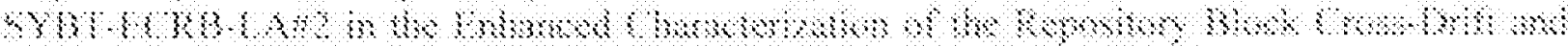

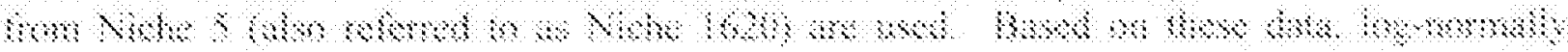

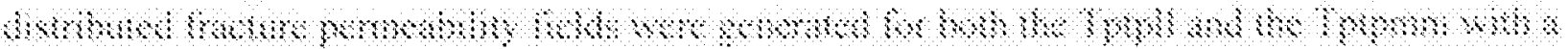

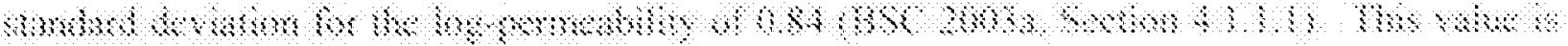

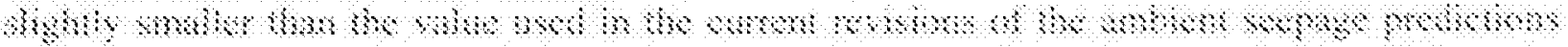

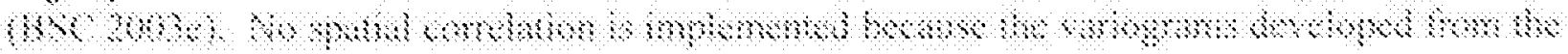




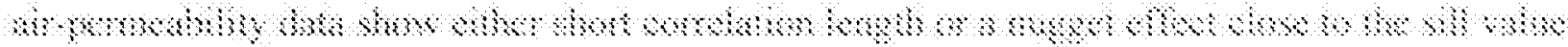

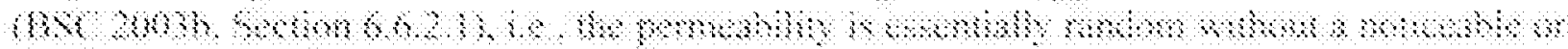
monome omotsms.

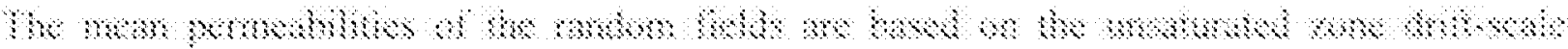

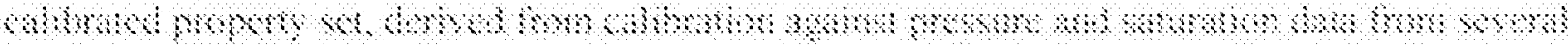

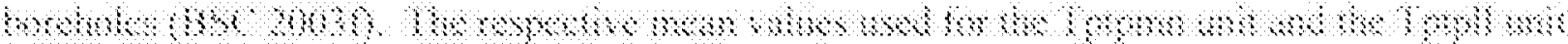

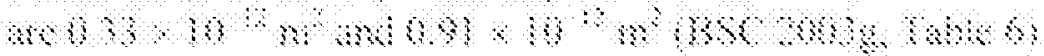

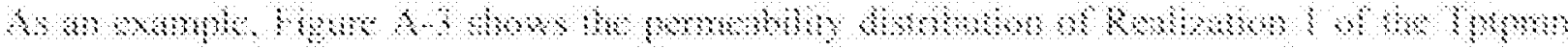

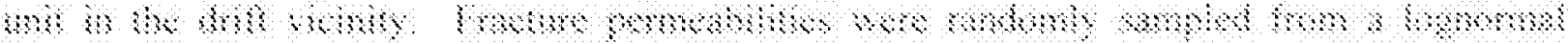

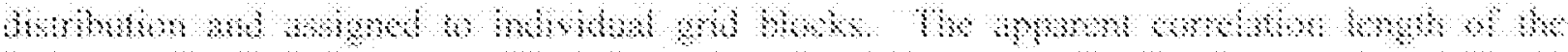

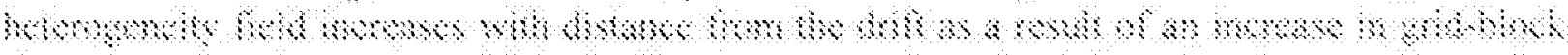

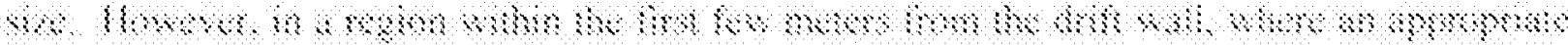

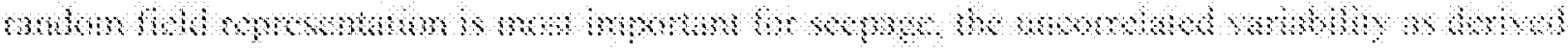

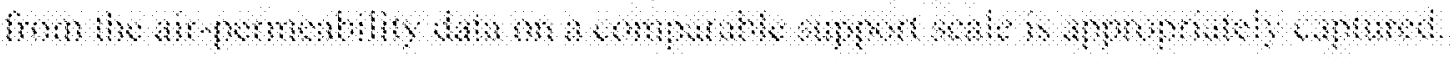

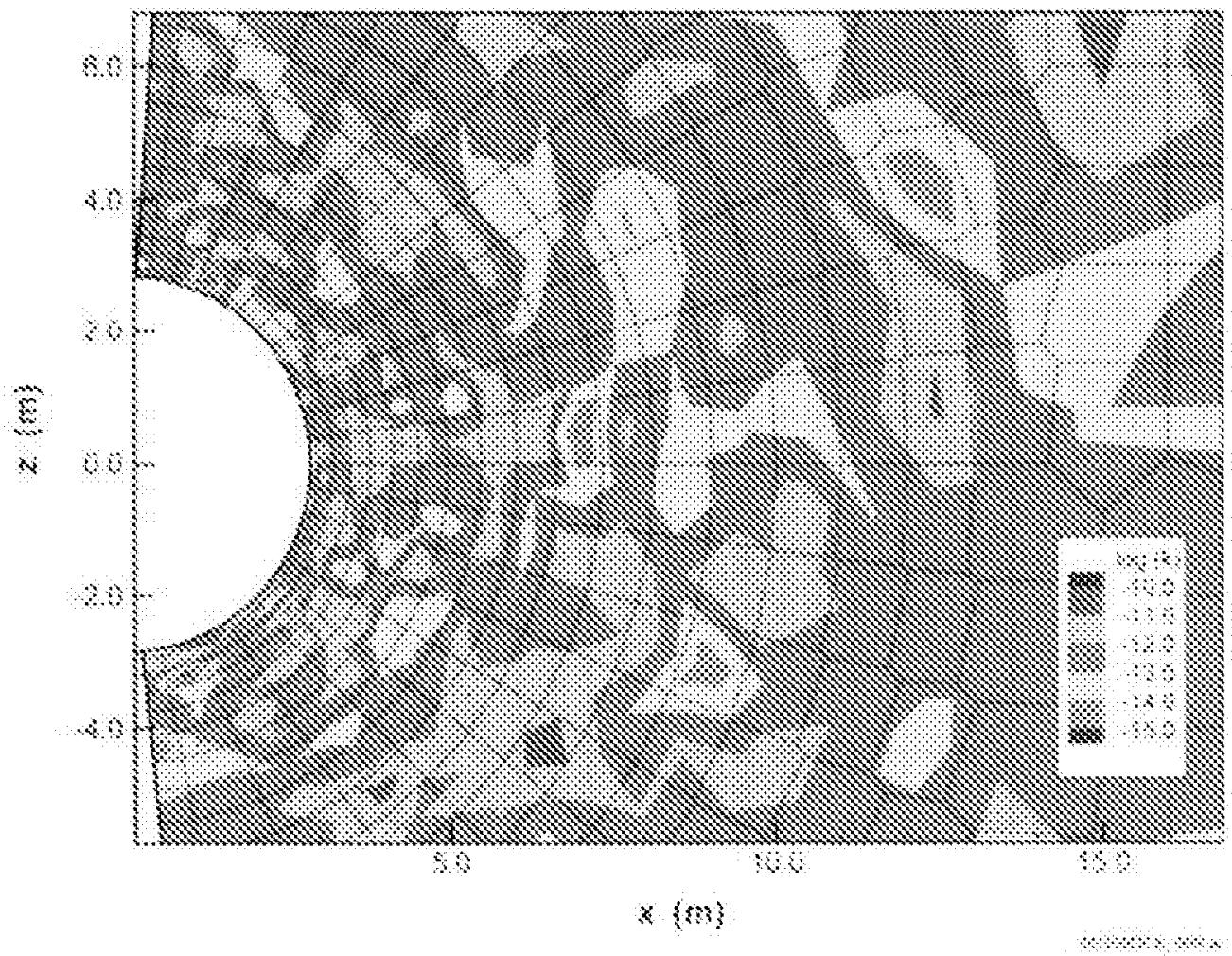

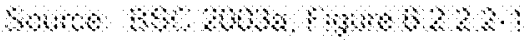

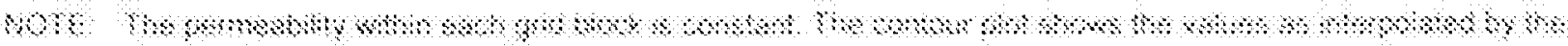

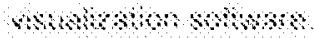

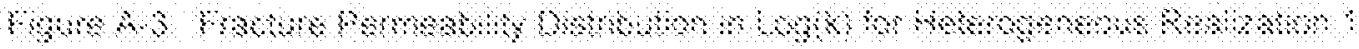




\section{A.4.1.1.3 Modeling Results}

The drift-scale thermal model was applied to a wide range of sensitivity cases to study the potential for thermally driven seepage (BSC 2003a, Sections 6.2.2.2 and 6.2.3.2).

The thermal modes and the percolation fluxes considered cover a wide range of the variability and uncertainty in thermal-hydrologic conditions expected in the repository. For a given set of thermal-hydrologic rock properties, the predicted thermal conditions (maximum rock temperature, extent of the superheated rock zone, and duration of the boiling period) are mainly driven by the assumed heat load and the magnitude of percolation. One thermal mode, the low-temperature mode, results in rock temperatures that never reach boiling conditions. It was shown that thermal effects on flow and seepage are negligible in this case so that the potential for thermal seepage can be estimated from ambient seepage results. The other thermal modes give rise to boiling of water in the fractured rock close to waste emplacement drifts. Simulation results demonstrate that the thermal perturbation of the flow field (causing increased downward flux from the condensation zone toward the drifts) is strongest during the first few hundred years after closure, corresponding to the time period when rock temperature is highest and the vaporization barrier is most effective. Even for high percolation fluxes into the model domain and strong flow channeling as a result of fracture heterogeneity, water cannot penetrate far into the superheated rock during the time that rock temperature is above boiling, and model results show no seepage. The majority of the vaporized (and subsequently condensed) matrix water is diverted around the dryout zone and drains away from the drift, as shown in Figure A-4. The magnitude of percolation affects the temperature conditions in the fractured rock. For a given thermal load, high percolation fluxes tend to cool the rock temperatures, result in a shorter boiling period, and cause more distinct heat-pipe effects compared to small percolation fluxes.

At the time when temperature has returned to below-boiling conditions and fractures start rewetting at the drift (for mean infiltration without flow focusing around 1,000 years after emplacement), the capillary barrier at the drift wall continues to operate, reducing (or preventing) water seepage into the drift. Since the thermal and hydrological conditions in the fractured rock will be perturbed from heating for a long time, simulation of thermal seepage was performed for 4,000 years after waste emplacement. The performance of the capillary barrier during this time period was evaluated in comparison to results from long-term ambient seepage (steady-state) simulations that were conducted to provide reference values for seepage at different percolation rates. The results indicate that thermal seepage never occurs in simulation cases where the respective long-term ambient seepage is zero. In cases where long-term ambient seepage is obtained (typically, cases with high percolation fluxes, heterogeneous fracture permeability fields, small fracture-capillary strength parameter in the drift vicinity, and inclusion of the effect of discrete fractures in the immediate drift vicinity using a specific drift wall boundary condition) thermal seepage is possible. These are cases that have been identified as promoting seepage in ambient seepage studies (Birkholzer et al. 1999; BSC 2003e). In such cases, seepage is predicted to begin several hundred to a few thousand years after rock temperature has returned below boiling, the delay caused by the slow saturation buildup in fractures; there is no seepage during the time period of above-boiling temperatures in the rock. Thermal-seepage percentages are always smaller than the respective ambient reference values (Figure A-5), indicating that there is no enhanced seepage as a result of reflux of water (because most of the condensate has long drained down away from the drift), and that the long-term 


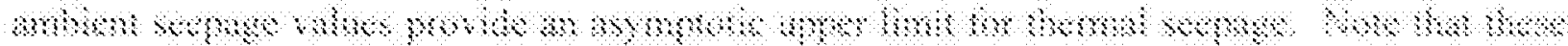

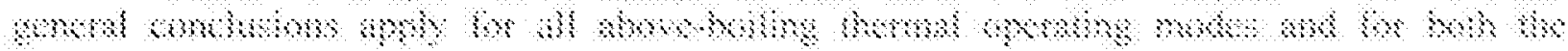

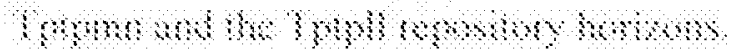

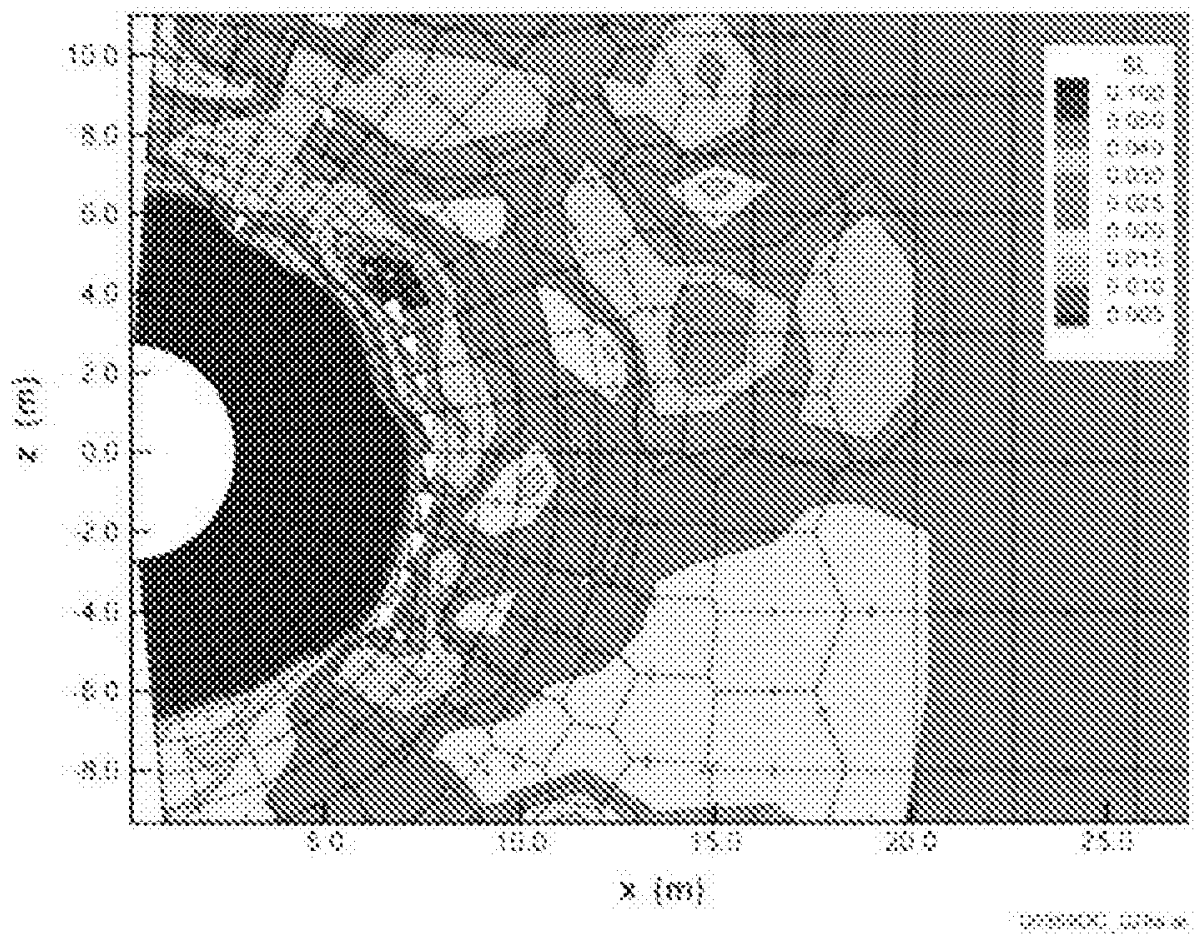

sems 6 -

Nh s om

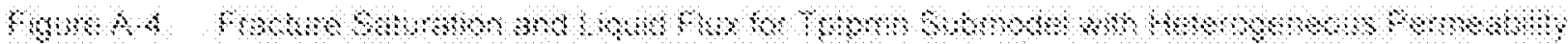

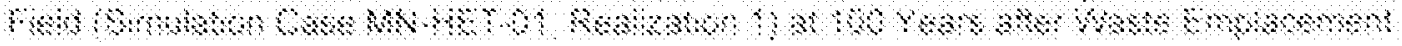




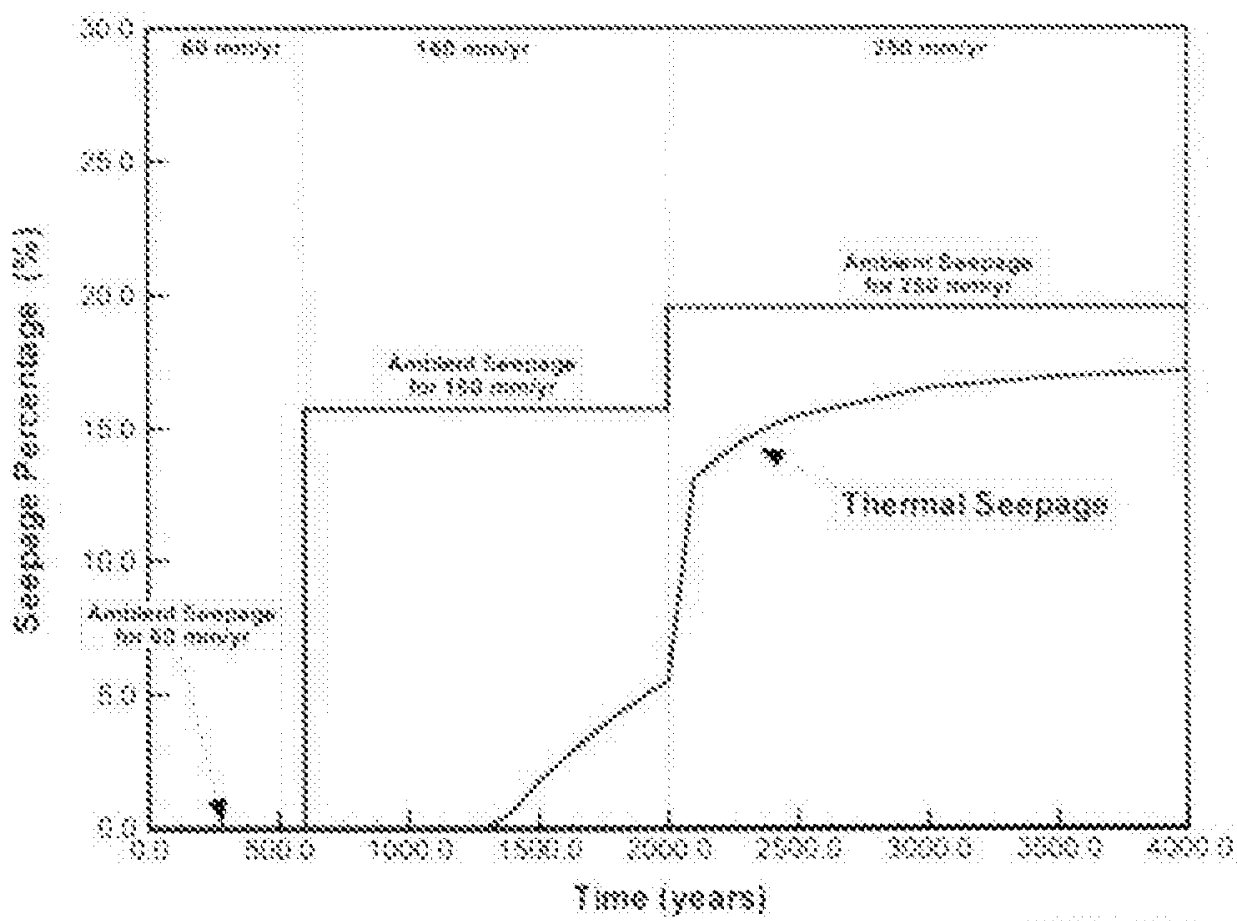

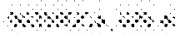

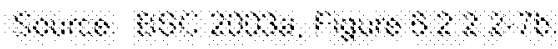

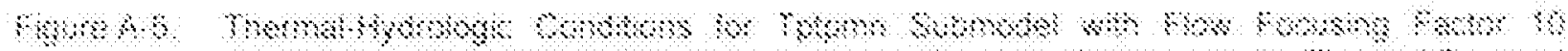

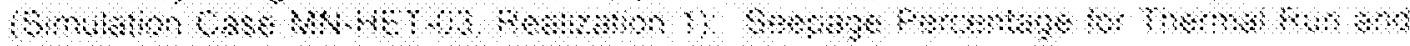
sompom smmentsis

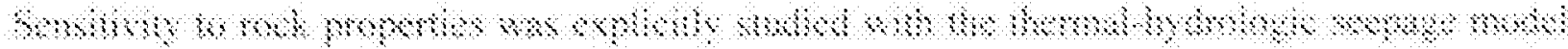

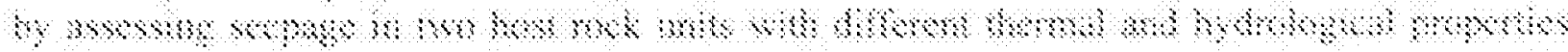

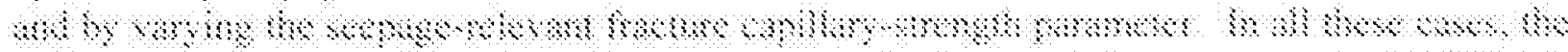

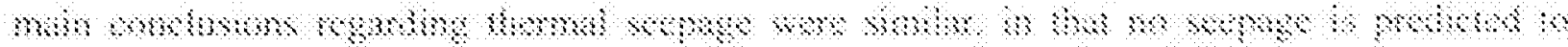

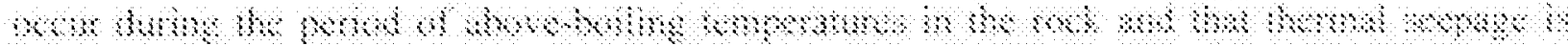

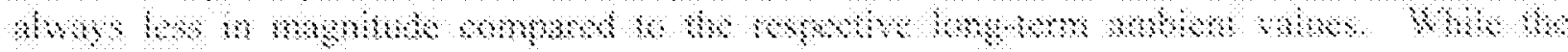

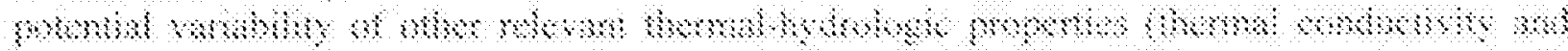

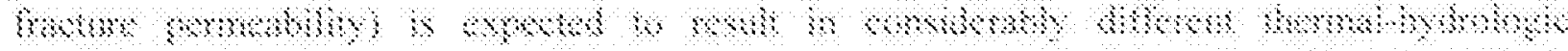

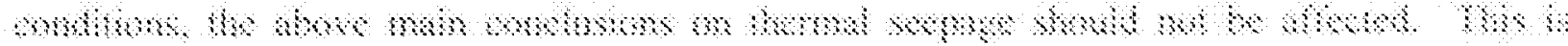

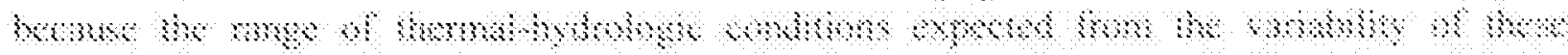

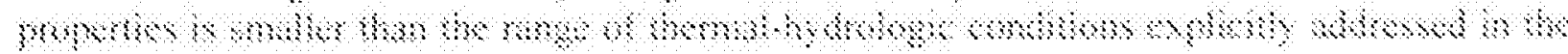
mo

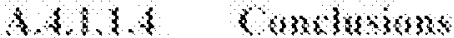

The \$nmo on

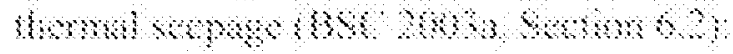

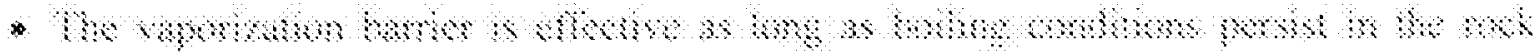

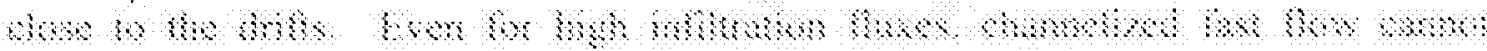

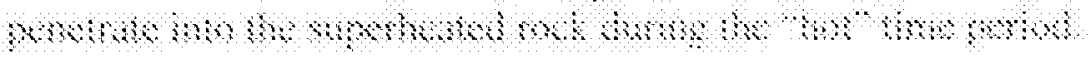


- The period of above-boiling temperature coincides with the period of present-day mean infiltration, which is significantly smaller than infiltration during monsoon or glacial transition climate. This means that two effective barriers (the vaporization barrier and the capillary barrier) are operating simultaneously during the first several hundred years after waste emplacement.

- Thermal seepage is always smaller than the long-term ambient seepage percentage calculated from steady-state simulation runs using the respective infiltration rate of the three climate periods.

- In general, thermal seepage may start to occur when the rock temperature is below boiling. Whether thermal seepage occurs (after the vaporization barrier has vanished) depends on the effectiveness of the capillary barrier, as evaluated by the long-term ambient seepage simulations for the steady state. The time when thermal seepage starts to occur depends on the time-dependent rewetting of the fractures at the drift wall.

- The Tptpll unit shows a higher peak temperature at the drift wall, a larger superheated zone, and a longer period of above-boiling temperature compared to the Tptpmn unit.

\section{A.4.1.2 Three-Dimensional Effects}

These effects are discussed in Section A.3.1.2.

\section{A.4.1.3 Effect of High-Permeability Features Crossing the Drift}

These effects are discussed in Section A.3.1.3.

\section{A.4.2 Comparison of Model Results to the Phillips Analytical Solution}

Information for this section is based on Drift-Scale Coupled Processes (DST and TH Seepage) Models (BSC 2003a, Section 6.3).

As discussed in Section A.3.2, an alternative conceptual model was developed to support the findings of the thermal-hydrologic seepage model. The alternative model is an improved version of the model developed by Phillips (1996). Phillips' model was modified because it yielded an unrealistic solution at early times. The alternative conceptual model is described in more detail in the following sections. The alternative conceptualization is highly simplified and therefore conservative, particularly because (1) it is not clear if such finger-flow behavior is characteristic for Yucca Mountain, and (2) the solution assumes fracture geometries that are not realistic (vertical continuous fracture connecting high-saturation condensation zone with drifts).

\section{A.4.2.1 Alternative Conceptual Model}

An alternative conceptual model is used to corroborate the results and conclusions of the thermal-hydrologic seepage model. The alternative conceptual model considers the possibility that unsaturated fracture flow may occur in fast-flowing preferential pathways (thin fingers) that drain downward intermittently. Water buildup in the condensation zone above waste emplacement drifts can provide a potential source of such downward finger flow, carrying water 
at flow rates much larger than the average percolation under ambient conditions. Such high-flux conditions may promote the potential of seepage during the thermal period at Yucca Mountain, because finger flow may penetrate far into the superheated rock zone (i.e., rock temperature above the boiling point of water) around waste emplacement drifts.

The alternative conceptual model, referred to as the thermal-hydrologic model for episodic finger flow, is applied to investigate the potential impact of episodic finger flow on thermal seepage. The thermal-hydrologic model for episodic finger flow analyzes the fate of episodic preferential flow events that originate somewhere in the condensation zone above the repository and percolate downward towards the emplacement drifts. Figure A-6 shows an illustration of episodic fingers flowing through fractures and penetrating into the superheated rock in the vicinity of waste emplacement drifts. As flow arrives at the superheated rock region around drifts, water begins to boil off. Depending on magnitude and duration of each flow event as well as on the temperature and pressure conditions in the fractured rock, the water may completely vaporize above the drift crown, or it may penetrate far into the superheated region and reach the drift.

\section{A.4.2.2 Modeling Procedure}

The first step in applying the thermal-hydrologic model for episodic finger flow is to derive estimates for the possible characteristics of episodic finger flow at Yucca Mountain. Experimental data from a comprehensive laboratory study by Su et al. (1999) are used for that purpose, and a simplified finger-flow model for downward drainage is developed (Section A.4.2.3). The second step is to simulate the fate of such episodic finger-flow events when the flow penetrates into the superheated rock region above waste emplacement drifts, using the semianalytical solution of Birkholzer (2002; BSC 2003a). The conceptual model and the semianalytical solution are presented in Section A.4.2.4. The solution is implemented at several discrete times after waste emplacement to cover the range of rock temperature conditions and extent of superheated zone around drifts. The third and final step is to evaluate the results; namely, the relative percentage of water arriving at the drift crown at different times after emplacement, in relation to the perturbed flow situation above the drifts at these times (i.e., the elevated downward flux from the condensation zone towards the drift). 


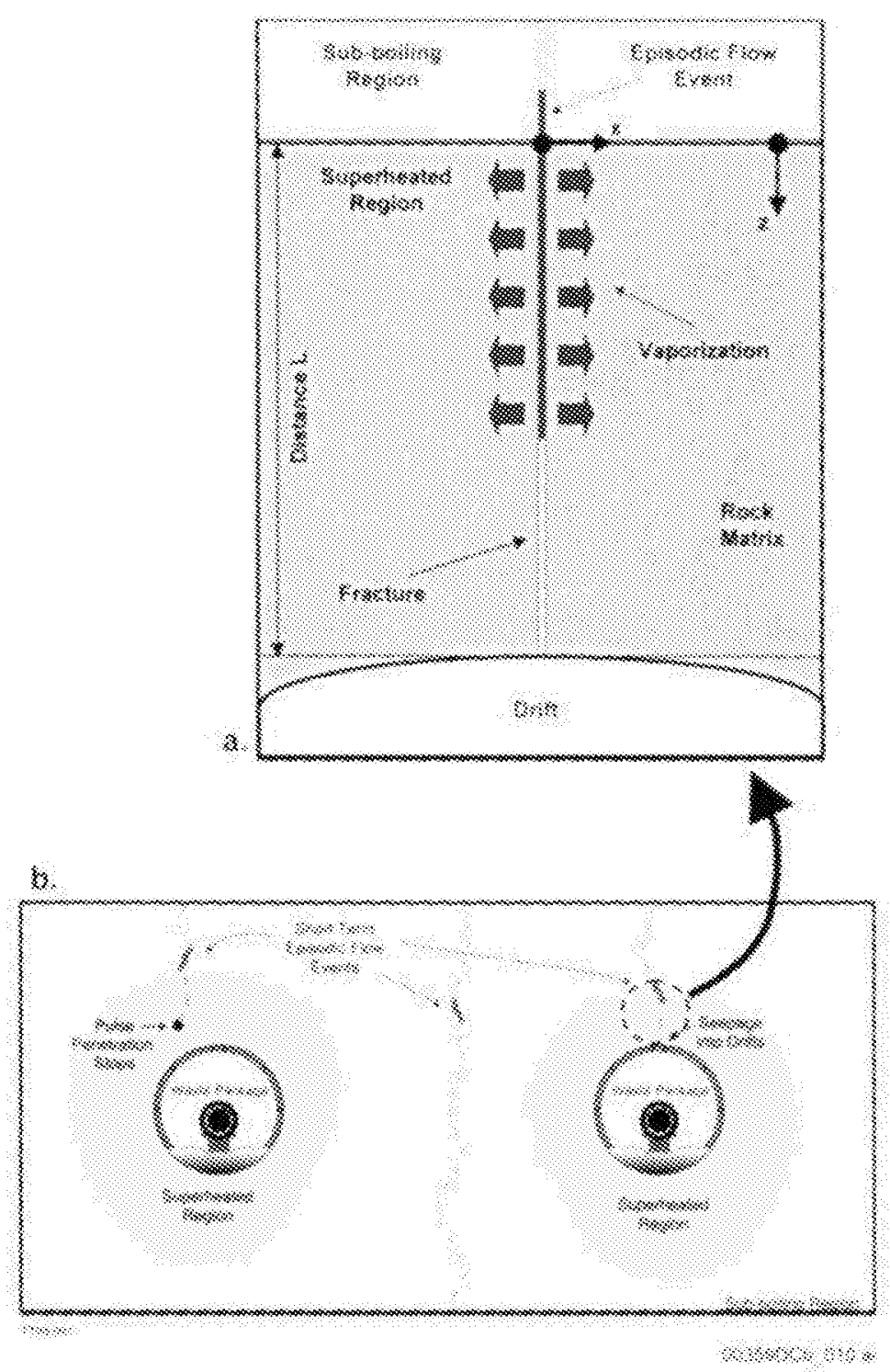

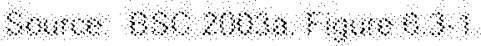

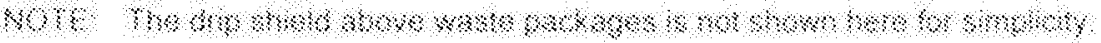

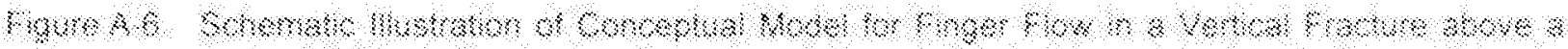

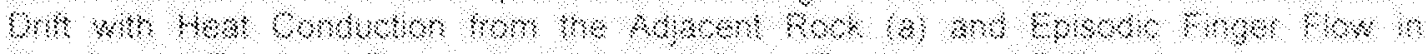

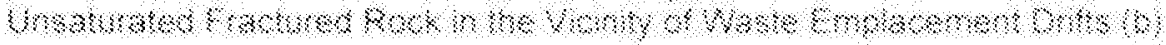

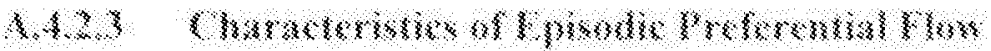

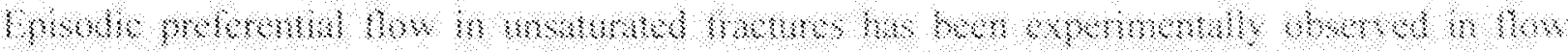

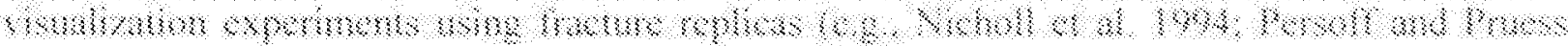

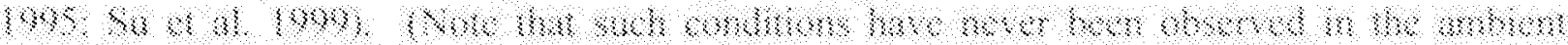

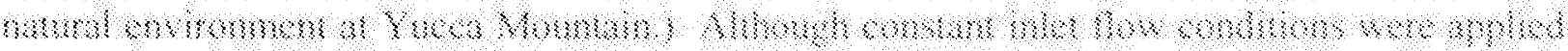

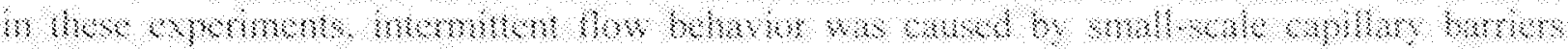

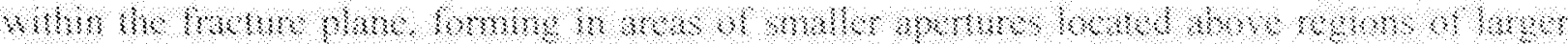

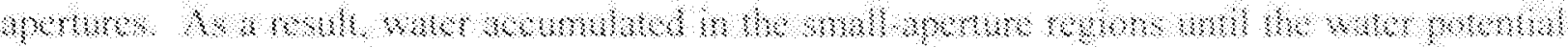


exceeded the capillary-force difference. Once this occurred, a large portion of the accumulated water moved rapidly downward in a thin finger. When the capillary pool emptied, the finger snapped and reformed at some later time. Typically, the observed water volumes per event were small, of the order of milliliters.

Interestingly, Su et al. (1999, p. 1032, Table 4) report a small range of water volumes accumulating in and draining from capillary pools for the entire suite of experiments, fairly unaffected by the order-of-magnitude variation in flow rate imposed at the inlet boundary. Also, the width of the rivulets was observed to be independent of the applied flow rate, while the temporal frequency of flow events correlated well with the flow rate imposed at the inlet boundary. These observations are consistent with the concept of capillary-induced episodic flow patterns, in which the accumulation and flow distribution of water depends on local aperture variation, while the time required between subsequent flow events (required for water accumulation) depends on the rate of overall downward percolation in the fractured rock. Adopting this concept for the thermal conditions at Yucca Mountain, it is assumed that the thermally perturbed percolation fluxes in the condensation zone (as predicted by the thermal-hydrologic seepage model) drain downward in episodic finger-flow patterns. The characteristics of individual fingers (i.e., finger geometry, water volume per flow event and flow rate) are assumed to be independent of the actual percolation flux magnitude. Their frequency, however, is directly correlated to the percolation flux (i.e., strongly elevated downward fluxes at early stages of heating should result in finger flow that occurs more often in time and space).

In this study, it is assumed that such intermittent flow behavior can also occur in the unsaturated fractures at Yucca Mountain, particularly during the thermal period when condensate above the superheated zone is expected to provide a significant source of water above waste emplacement drifts. Since there are neither experimental studies with fracture test samples from Yucca Mountain nor replicas mimicking Yucca Mountain fractures, the flow characteristics observed in the above experiments were used as estimates for potential episodic preferential flow in unsaturated fractures at Yucca Mountain. The fracture replica analysis of Su et al. (1999) is probably the best suited for this purpose because the realistic geometry of natural fractures is accounted for and detailed quantitative measurements are provided in their analysis. The fracture replica in this experimental work was taken from the granitic rock of the Stripa Mine in Sweden. Differences between fractures from the Yucca Mountain tuff and the Stripa Mine granite (with respect to aperture distributions, surface roughness, and contact angle) will bring out differences in flow behavior and distribution. This approach is valid for a qualitative analysis intended to demonstrate the impact of an alternative flow concept on water arrival at the drift during the thermal period at Yucca Mountain.

Basic characteristics defining episodic finger flow (namely, water volume of individual flow events, $V$, fracture aperture $b$, and finger width $w$ ), are directly extracted from the experimental results described by $\mathrm{Su}$ et al. (1999). Using representative values for these parameters, additional parameters are derived from a simplified conceptual flow model, assuming gravity-driven, laminar, and fully developed flow in vertical one-dimensional channels of uniform width, in fractures of uniform aperture and infinite extent. This simplified flow model is conservative because it provides a direct fast-flow connection between the condensation zone and the heated drift. These derived parameters (flow velocity $v_{P}$, mass flow rate $m_{P}$, and duration 
of flow $t_{P}$ ) are input to the semianalytical solution. (The flow duration denotes the time period needed for the finger to flow past a given location.)

The experimental data of Su et al. (1999, Sections 2 and 3) suggest the following representative values for fracture aperture $b$, water volume $V$, and finger width $w$. Assuming log normal distribution, the geometric mean aperture of the fracture replica investigated by Su et al. (1999, p. 1024) is $0.141 \mathrm{~mm}$, while the standard deviation is 0.559 in natural log space. Comparison of these statistical parameters with conditions at Yucca Mountain is difficult, since comparable small-scale measurements are not available for the fractures in the Tptpmn and the Tptpll. However, first-order estimates of hydraulic aperture can be derived from fracture frequency and fracture permeability data. Following Particle Tracking Model and Abstraction of Transport Processes (CRWMS M\&O 2000, Section 6.2.1, Equation 25, Table 4), the geometric mean of fracture hydraulic aperture in the Tptpmn unit is approximately $0.1 \mathrm{~mm}$ with a standard deviation of 0.479 in natural log space. These mean and standard deviation values are slightly smaller than the mean aperture and standard deviation reported by Su et al. (1999, p. 1024). Data on water volumes are derived using the 17 (out of 21) flow visualization experiments by Su et al. (1999, Table 4) that exhibit episodic behavior, giving a geometric mean of $0.161 \mathrm{~mL}$ and a standard deviation of 0.438 (in natural $\log$ ). The geometric mean values of fracture aperture and water volume are applied as base cases. In addition, uncertainty is covered in a sensitivity analysis in which these base-case values are varied by adding or subtracting the respective standard deviation (in log space). For finger geometry, Su et al. (1999, p. 1032) report a fairly consistent finger width of about $1 \mathrm{~mm}$, often forming behind advancing water drops that are slightly larger, on the order of $4.5 \mathrm{~mm}$. Since these two values are not sufficient to derive statistical properties, two equally probable cases with $w=1 \mathrm{~mm}$ and $w=4.5 \mathrm{~mm}$ are considered. Therefore, the range of apertures used in the thermal-hydrologic model for episodic finger flow reflects the range of typical fracture apertures at Yucca Mountain.

Table A-1 lists the input properties and the calculated flow characteristics of all simulation cases studied in the analysis below. Case 1, for example, uses the geometric mean values of fracture aperture and water volume with a finger width of $1 \mathrm{~mm}$, which gives a downward flow velocity of $0.054 \mathrm{~m} / \mathrm{s}$, a mass flow rate of $7.3 \times 10^{-6} \mathrm{~kg} / \mathrm{s}$, and a flow event duration of 21.2 seconds. Using the same aperture and water volume, but a wider $(4.5 \mathrm{~mm})$ finger, the downward flow velocity is still $0.054 \mathrm{~m} / \mathrm{s}$, but mass flow rate is larger at $3.3 \times 10^{-5} \mathrm{~kg} / \mathrm{s}$, while the flow duration is smaller at $5.2 \mathrm{~s}$ (Case 2). In the sensitivity cases, either fracture aperture is varied (Cases 1a and $2 a$ for larger aperture, Cases $1 b$ and $2 b$ for smaller aperture) or the water volume is adjusted (Cases $1 \mathrm{c}$ and $2 \mathrm{c}$ for larger water volume, Cases $1 \mathrm{~d}$ and $2 \mathrm{~d}$ for smaller water volume). Changes in aperture invoke changes in flow velocity, mass flow rate, and duration of flow event, while changes in water volume affect only the flow duration. Typically, a larger aperture is associated with a fast, intense, and short flow event. Larger water volumes are related to longer flow duration. 
Table A-1. Suite of Episodic Flow Events Analyzed with the Thermal-Hydrologic Model for Episodic Finger Flow

\begin{tabular}{|l||c|c|c|c|c|c|}
\hline \multicolumn{1}{|c||}{} & \multicolumn{2}{|c|}{ Input extracted from Su et al. (1999) } & \multicolumn{3}{c|}{ Output derived using $b, V$, and $w$ as } \\
input
\end{tabular}

Source: BSC 2003a, Table 6.3.1.2-1.

\section{A.4.2.4 Water Penetration into Superheated Rock}

The semianalytical solution of Birkholzer (2002, BSC 2003a) is used to determine the maximum penetration distance of episodic fingers subject to vigorous vaporization from the hot rock. In case the flow from these events penetrates through the entire superheated zone above drifts, the solution also gives the total amount of water arriving at the drift crown. A brief review of the mathematical formulation and solution procedure is given below. This solution provides an exact simulation method for early and late time periods of flow events that can be episodic or continuous.

The basic conceptual model for the semianalytical solution of finger penetration into superheated rock is schematically depicted in Figure A-4, showing a superheated region of length $L$ above the crown of a waste emplacement drift. Here, the ambient rock water has long been boiled off, and fractures and rock are essentially dry. The rock temperature in the superheated zone is above the boiling temperature at prevailing pressure. Initially, before finger flow occurs, the temperature field is uniform in the lateral $x$-direction and a function of location in the vertical $z$-direction. Episodic flow events of given mass flow rate $m_{P}$, duration $t_{P}$, and finger width $w$ enter the superheated region at $z=0$ and $t=0$. The infiltrating water is already heated up to almost boiling temperature $T_{P}$ upon arrival at the superheated region and begins boiling as it passes the boiling-point isotherm. As was presented in the previous section, the downward flow of the finger is gravity-driven and strictly one-dimensional. Upon contact with the water, the rock 
surface cools to boiling temperature, and a steep temperature gradient is established in the surrounding matrix when the liquid front in the fractures reaches the considered position. With time, the thermal perturbation penetrates farther into the rock, the thermal gradient decreases, and heat flow from the matrix to the fracture is reduced. As conduction in the matrix is slow compared to the vertical movement of the liquid pulse, the conductive heat flow within the matrix and from the matrix to the fracture is considered as strictly lateral, perpendicular to the fracture plane. Note that the accumulation time between two consecutive episodic flow events is usually longer than the flow duration $t_{P}$, so that for all practical purposes the rock temperature has equilibrated to its initial state before the next flow event arrives.

The downward flow rate at a location $z$ in the superheated region can be derived from an energy balance between the energy required for vaporization of water and the energy supplied by heat conduction from the rock. Using an analytical solution of Carslaw and Jaeger (1959, pp. 58 to 62 ) to solve for the lateral temperature distribution in the rock matrix, this energy balance is as follows (Birkholzer 2002, p. 5, Eq. 9)

$$
\frac{\partial m(z, t)}{\partial z}=-\frac{2 w \lambda_{d r y}}{h} \frac{T_{R I}-T_{P}}{\sqrt{\pi \kappa\left(t-t_{0}(z)\right)}}
$$

Here, $m(z, t)$ is mass flow rate at location $z$, time $t, \lambda_{d r y}$ is dry thermal conductivity of the rock matrix, $h$ is specific enthalpy of vaporization, $T_{R I}$ is the initial rock temperature, and $\kappa$ is rock thermal diffusivity. The period $t_{0}(z)$ denotes the time interval after initial entry of the water finger into the superheated zone until the arrival of the tip of the liquid finger at location $z$. Equation A-1 is valid as long as the thermal gradient in the rock is nearly uniform across the width of the liquid finger. Since thermal perturbation distance of the thermal calculation into the rock grows with $(\kappa t)^{1 / 2}$, the maximum time period $t_{m}$ associated with a uniform thermal gradient is of order

$$
t_{m}=\frac{w^{2}}{\kappa}
$$

For $t>t_{m}$, the nearly one-dimensional heat flow perpendicular to the fracture-rock interface transforms to a more circular spreading of heat and Equation A-1 can no longer be applied. However, in most cases of practical concern, $t_{m}$ is much larger than the timescale of interest.

A simple Lagrangian solution scheme is used to solve Equation A-1 for episodic flow events of given flow rate and duration (Birkholzer 2002, pp. 10 to 12; BSC 2003a). A time-marching procedure tracks the movement of finite water masses traveling downwards while part of the water boils off. The semianalytical solution scheme is shown to be accurate, robust, and extremely fast. For details on the numerical methods, for verification and validation of the solution (in comparison with TOUGH2 modeling results and an analytical solution), refer to Birkholzer (2002, pp. 10 to 12 and 42 to 44 ).

\section{A.4.2.5 Thermal-Hydrologic Model for Episodic Finger-Flow Results}

The long-term evolution of thermal-hydrological conditions in the rock is accounted for by applying the thermal-hydrologic model for episodic finger flow at 11 selected times after waste 
emplacement, covering the time period during which repository temperatures remain above boiling (about 1,000 years). The thermal parameters required as input for the thermal-hydrologic model for episodic finger flow, namely the vertical temperature profile and the extent of the superheated region, are obtained from the thermal-hydrologic seepage model. Figure A-5 provides results of the thermal-hydrologic model for episodic finger flow considering 11 discrete times and using the flow event referred to as Case 1 in Table A-1 (i.e., finger width is $1 \mathrm{~mm}$ ). The red symbols give the maximum penetration distance into the superheated rock, while the blue symbols show the relative amount of water arrival at the drift. The maximum penetration distance should be compared to the dotted curve showing the extent of the superheated region above the drift crown. According to this figure, no water would reach the drift for the first 450 years after emplacement because of intense heat in a sufficiently large hot region. At later times, the possible maximum penetration (in the absence of the drift opening) becomes larger than the boiling zone (i.e., water would arrive at the drift crown). The relative amount of water reaching the drift increases significantly between 450 years and 750 years after emplacement, as a result of the decreasing rock temperature and the smaller superheated rock zone. Eventually, after 950 years, the effect of vaporization becomes marginal so that the water mass arriving at the drift is almost equal to the initial mass of the episodic flow event.

In Figure A-6, the relative rates of water arrival at the drift crown at given times are related to the flux perturbation in the condensation zone at these times. The red line shows the so-called flux elevation factor, which is defined as the maximum downward flux in the condensation zone divided by the undisturbed ambient percolation of $6 \mathrm{~mm} / \mathrm{yr}$. The maximum downward flux is calculated at the 11 selected times from the thermal-hydrologic seepage model. As the circular symbols indicate, the most significant flux elevation occurs at 75 years of heating, where the maximum downward flux is $73.2 \mathrm{~mm} / \mathrm{yr}$, more than 12 times that of the ambient flux of $6 \mathrm{~mm} / \mathrm{yr}$. With time progressing, this effect declines rapidly and is essentially negligible at 1,500 years after waste emplacement. (Increasing infiltration, resulting from climate changes at 600 years, causes the spike at 650 years (BSC 2003a, Section 6.3).) The blue line gives the water flux arriving at the drift crown when the combined effect of flux perturbation and vaporization barrier is considered. Note that this flux is given relative to the undisturbed ambient percolation at the respective time and is obtained by multiplying the flux-elevation factor with the relative mass-arrival rate given in Figure A-7. If the displayed values are larger than one, the amount of water potentially arriving at the drift wall exceeds the ambient percolation flux.

It is obvious from Figure A-8 that vaporization reduces the impact of flux perturbation in the condensation zone by a large percentage. For the first 450 years of heating, vaporization is so effective that the amount of water arriving at the drift crown is zero. Between 450 and 650 years, vaporization is still strong enough to reduce the elevated fluxes to values smaller than the ambient percolation (i.e., the resulting flux ratio is smaller than one). These are important results, clearly demonstrating that the time period of strongly elevated vertical flux in the condensation zone coincides with the time period of very effective vaporization. Thus, even if the downward flux from the condensation zone towards the drift would flow entirely in episodic finger-type patterns - an extreme flow conceptualization that has never been observed at Yucca Mountain - the vaporization barrier would be fully effective for several hundred years. Only at later times, when vaporization effects diminish, is the flux arriving at the drift slightly higher than the natural ambient percolation. However, note that these results are based on various simplifications that tend to promote the potential amount of water reaching drifts, most of them 


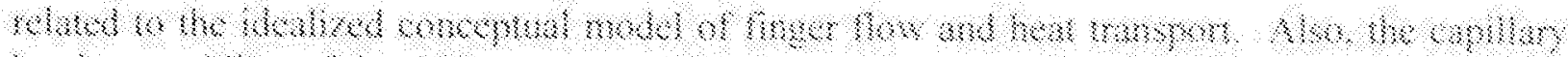

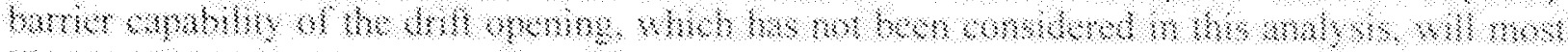

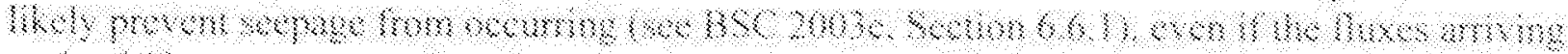

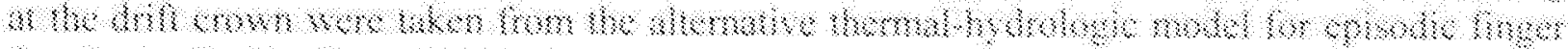

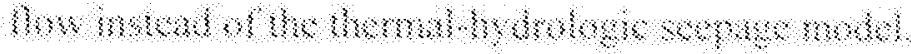

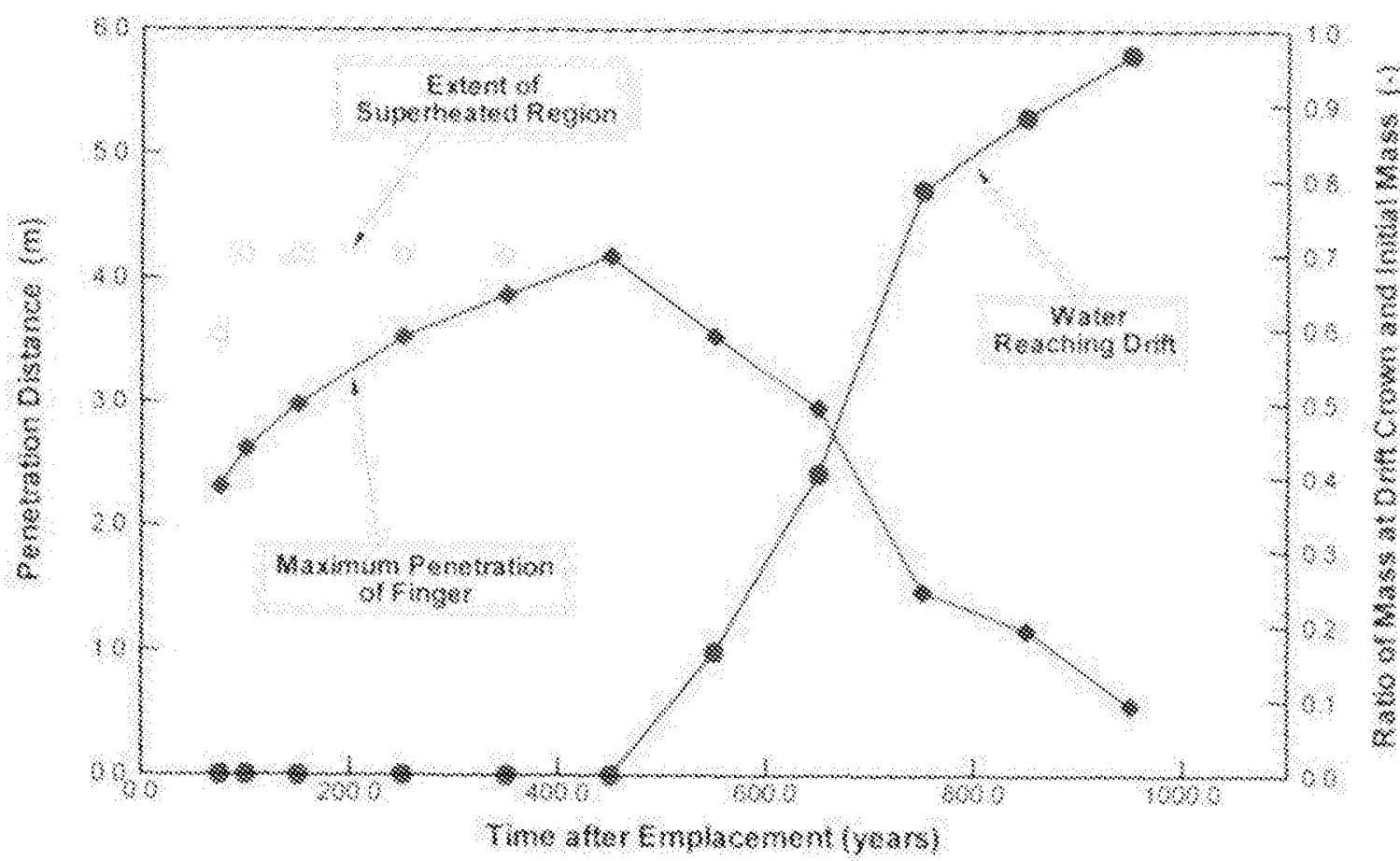

њ४»

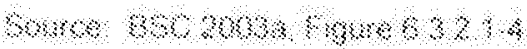

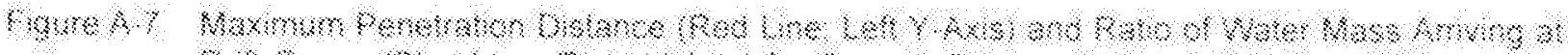

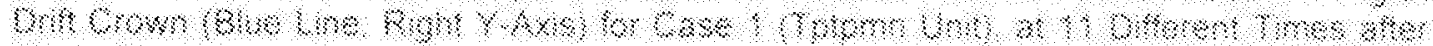

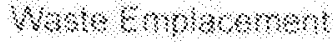




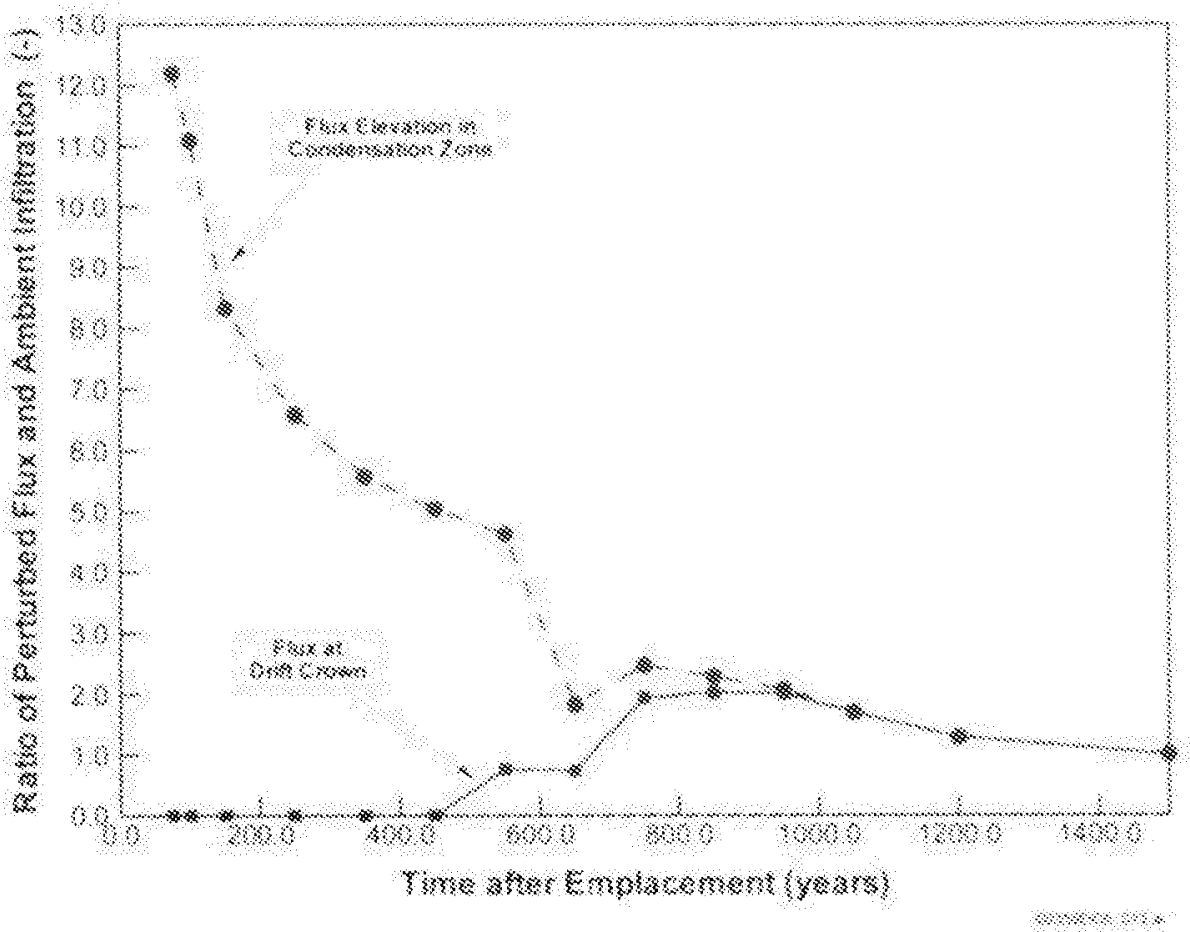

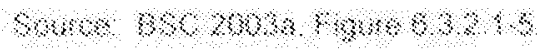

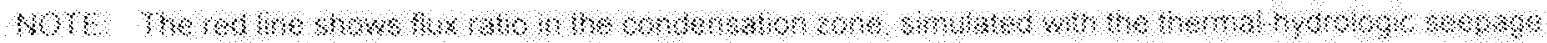

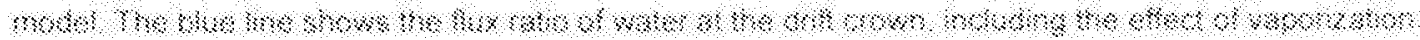

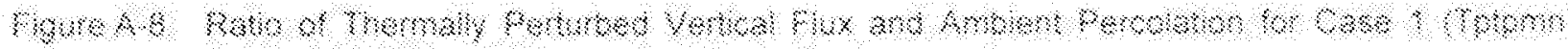

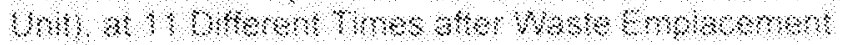

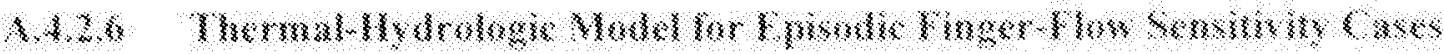

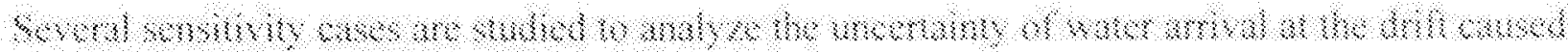

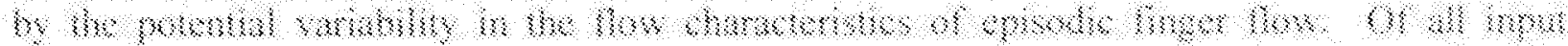

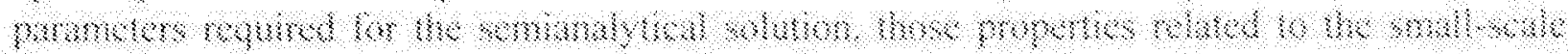

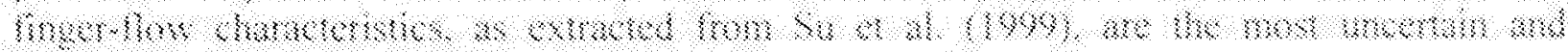

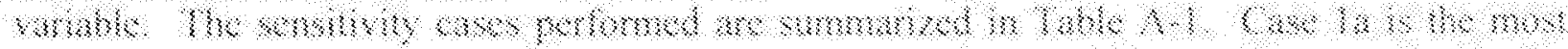

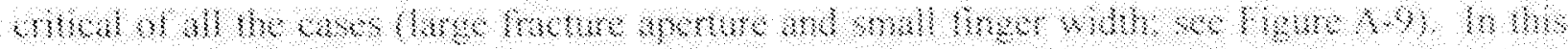

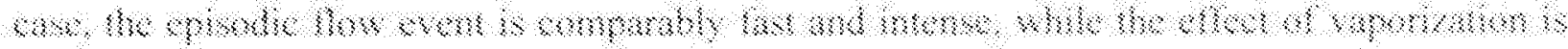

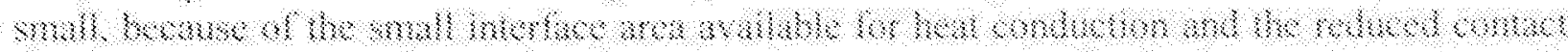

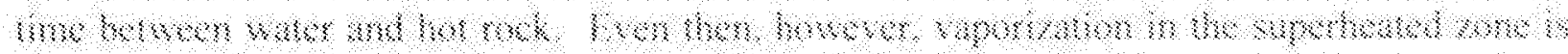

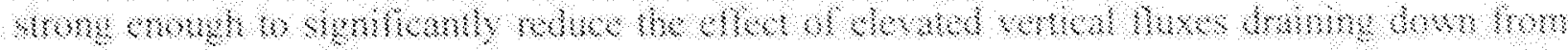

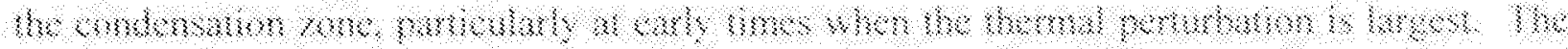

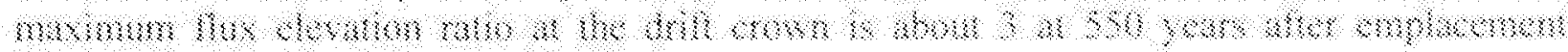

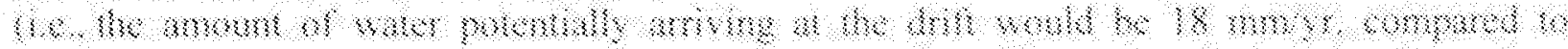

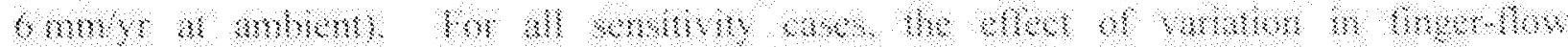

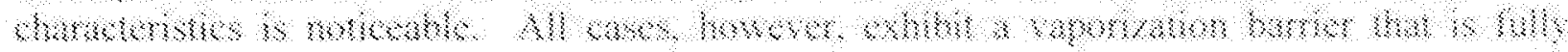

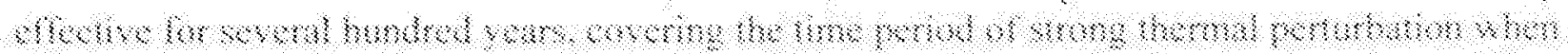

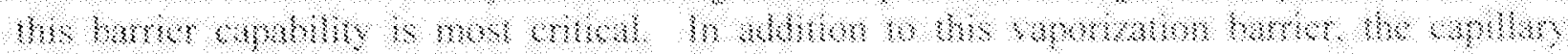




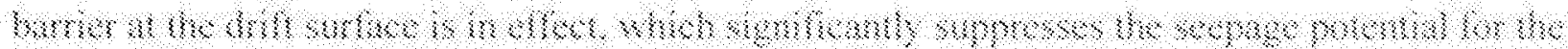

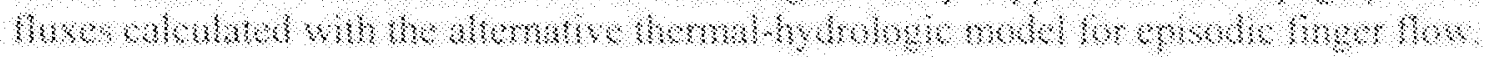

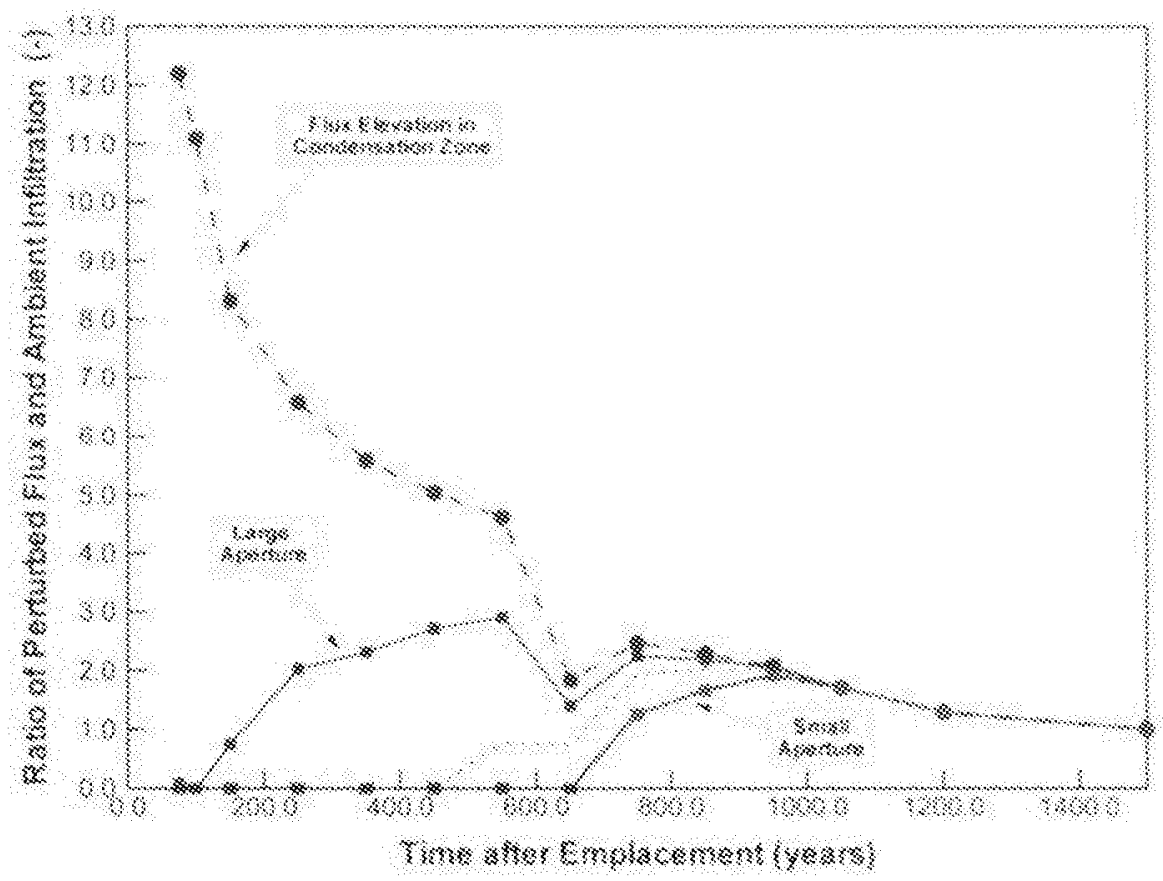

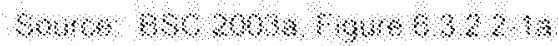

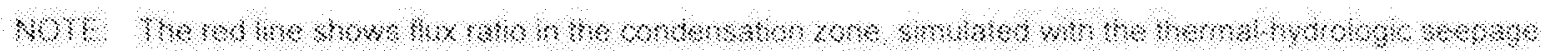

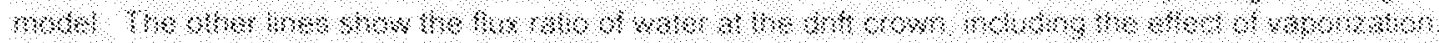

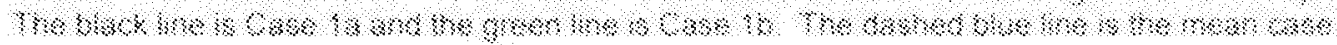

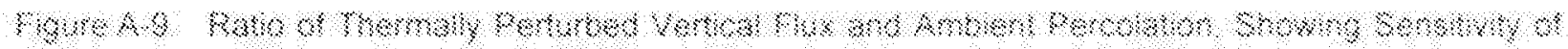

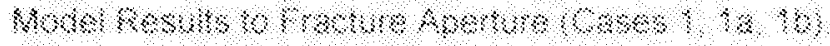

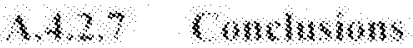

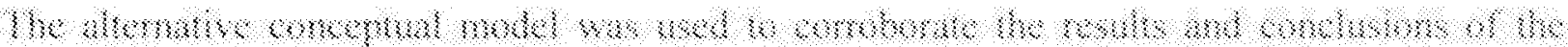

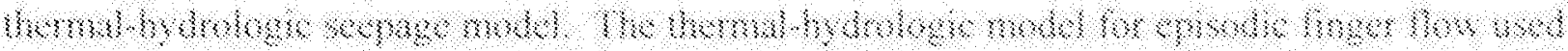

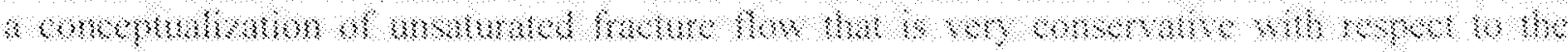

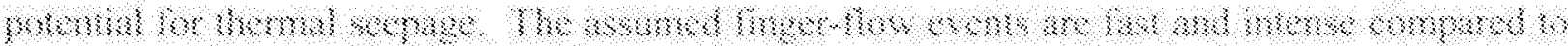

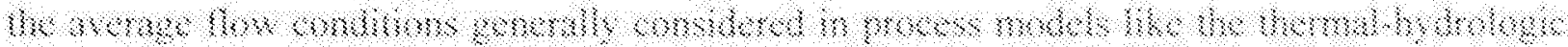

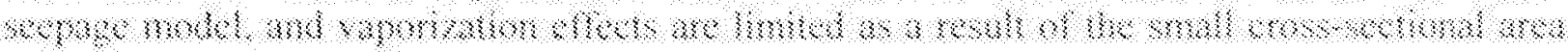

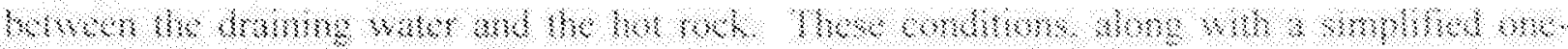

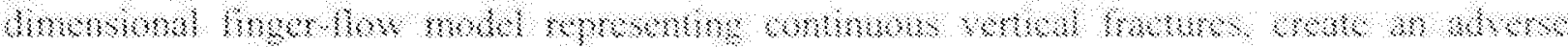

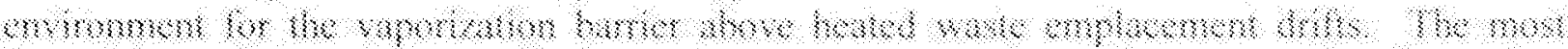

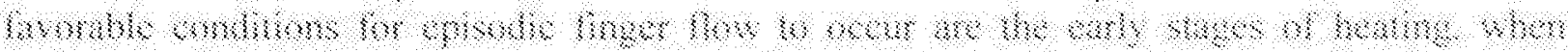

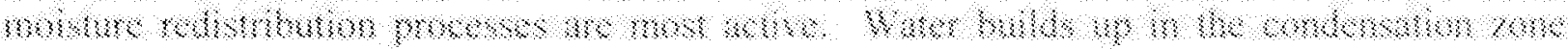

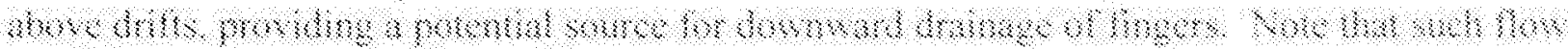

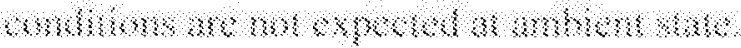


In spite of this conservatism, the thermal-hydrologic model for episodic finger-flow results were fairly consistent with the process model results obtained with the thermal-hydrologic seepage model. Most importantly, the thermal-hydrologic model for episodic finger flow demonstrated that finger flow is not able to penetrate through the superheated rock during the first several hundred years of heating, when rock temperature is high and boiling conditions exist in a sufficiently large region above the drifts. These are the conditions in which the largest thermal perturbation occurs, i.e., when the potential for episodic finger flow is highest. Only later, when the boiling zone is small and the impact of vaporization is limited, can finger flow arrive at the drift crown. The fact that water can reach the drift during the period of above-boiling temperatures makes the alternative conceptual model distinct from the thermal-hydrologic seepage model. However, the strong thermal perturbation observed at early heating stages has already diminished during this time period, and the net result of water arrival at the drift-considering the combined impact of water buildup in the condensation zone and vaporization in the superheated zone--is similar to ambient percolation. These findings are consistent over a wide range of finger-flow characteristics studied in a sensitivity analysis (Section A.4.2.6), covering the potential uncertainty in finger-flow patterns. Thus the thermalhydrologic model for episodic finger-flow model results clearly support the main findings of the thermal-hydrologic seepage model, adding confidence into the model and reducing the conceptual model uncertainty. Of the two host rock units, the Tptpll unit allows less water to arrive at the drift wall, as a result of the higher rock temperature and the larger superheated rock zone above the drift. This again is consistent with the thermal-hydrologic seepage model. The water fluxes potentially arriving at the drift surface during the cooldown period are most likely significantly below the seepage threshold (see BSC 2003e, Section 6.6.1), even though these fluxes are calculated using a conservative alternative model for episodic finger flow. It is, therefore, reasonable to assume that no seepage will occur during the boiling period.

Because no seepage experiments under elevated temperature conditions have been performed at Yucca Mountain, this alternative conceptual model makes use of experimental data from a granite fracture from the Stripa mine (Section A.4.2.3). The thermal-hydrologic model for episodic finger flow is inherently conservative and thus considered suitable for a bounding calculation that corroborates the thermal-hydrologic seepage model in a qualitative manner.

\section{A.5 REFERENCES}

\section{A.5.1 Documents Cited}

Birkholzer, J.T. 2002. TH_PULSE: Program for Calculating Infiltration of Episodic Liquid Fingers in Superheated Rock Fractures, Theory, User's Manual, and Sample Applications. LBNL/PUB-277. Berkeley, California: Lawrence Berkeley National Laboratory. TIC: 53581.

Birkholzer, J. 2003. "Penetration of Liquid Fingers into Superheated Fractured Rock." Water Resources Research, 39, (4), 9-1 through 9-21. [Washington, D.C.]: American Geophysical Union. TIC: 254362.

Birkholzer, J.; Li, G.; Tsang, C-F.; and Tsang, Y. 1999. "Modeling Studies and Analysis of Seepage into Drifts at Yucca Mountain." Journal of Contaminant Hydrology, 38, (1-3), 349-384. New York, New York: Elsevier. TIC: 244160. 
BSC (Bechtel SAIC Company) 2001. FY 01 Supplemental Science and Performance Analyses, Volume 1: Scientific Bases and Analyses. TDR-MGR-MD-000007 REV 00 ICN 01.

Las Vegas, Nevada: Bechtel SAIC Company. ACC: MOL.20010801.0404;

MOL.20010712.0062; MOL.20010815.0001.

BSC 2002. Thermal Testing Measurements Report. ANL-NBS-HS-000041 REV 00. Las Vegas, Nevada: Bechtel SAIC Company. ACC: MOL.20021004.0314.

BSC 2003a. Drift-Scale Coupled Processes (DST and TH Seepage) Models. MDL-NBS-HS000015 REV 00C. Las Vegas, Nevada: Bechtel SAIC Company. ACC: MOL.20030910.0160.

BSC 2003b. Seepage Calibration Model and Seepage Testing Data. MDL-NBS-HS-000004 REV 02. Las Vegas, Nevada: Bechtel SAIC Company. ACC: DOC.20030408.0004

BSC 2003c. Abstraction of Drift Seepage. MDL-NBS-HS-000019 REV 00. Las Vegas, Nevada: Bechtel SAIC Company. ACC: DOC.20030826.0001.

BSC 2003d. Drift-Scale Coupled Processes (DST and THC Seepage) Models. MDL-NBS-HS000001 REV 02. Las Vegas, Nevada: Bechtel SAIC Company. ACC: DOC.20030804.0004.

BSC 2003e. Seepage Model for PA Including Drift Collapse. MDL-NBS-HS-000002 REV 02. Las Vegas, Nevada: Bechtel SAIC Company. ACC: DOC.20030709.0001.

BSC 2003f. Calibrated Properties Model. MDL-NBS-HS-000003 REV 01. Las Vegas, Nevada: Bechtel SAIC Company. ACC: DOC.20030219.0001.

BSC 2003g. Analysis of Hydrologic Properties Data. MDL-NBS-HS-000014 REV 00. Las Vegas, Nevada: Bechtel SAIC Company. ACC: DOC.20030404.0004.

Carslaw, H.S. and Jaeger, J.C. 1959. Conduction of Heat in Solids. 2nd Edition. Oxford, Great Britain: Oxford University Press. TIC: 206085.

CRWMS M\&O (Civilian Radioactive Waste Management System Management and Operating Contractor) 2000. Particle Tracking Model and Abstraction of Transport Processes.

ANL-NBS-HS-000026 REV 00. Las Vegas, Nevada: CRWMS M\&O.

ACC: MOL.20000502.0237.

Nicholl, M.J.; Glass, R.J.; and Wheatcraft, S.W. 1994. "Gravity-Driven Infiltration Instability in Initially Dry Nonhorizontal Fractures." Water Resources Research, 30, (9), 2533-2546.

Washington, D.C.: American Geophysical Union. TIC: 243493.

NRC (U.S. Nuclear Regulatory Commission) 2002. Integrated Issue Resolution Status Report. NUREG-1762. Washington, D.C.: U.S. Nuclear Regulatory Commission, Office of Nuclear Material Safety and Safeguards. TIC: 253064.

Persoff, P. and Pruess, K. 1995. "Two-Phase Flow Visualization and Relative Permeability Measurement in Natural Rough-Walled Rock Fractures." Water Resources Research, 31, (5), 1175-1186. [Washington, D.C.]: American Geophysical Union. TIC: 229697. 
Phillips, O.M. 1996. "Infiltration of a Liquid Finger Down a Fracture into Superheated Rock." Water Resources Research, 32, (6), 1665-1670. [Washington, D.C.]: American Geophysical Union. TIC: 239025.

Reamer, C.W. and Gil, A.V. 2001. Summary Highlights of NRC/DOE Technical Exchange and Management Meeting of Range on Thermal Operating Temperatures, September 18-19, 2001. Washington, D.C.: U.S. Nuclear Regulatory Commission. ACC: MOL.20020107.0162.

Reamer, C.W. and Williams, D.R. 2001. Summary Highlights of NRC/DOE Technical Exchange and Management Meeting on Thermal Effects on Flow. Meeting held January 8-9, 2001, Pleasanton, California. [Washington, D.C.]: U.S. Nuclear Regulatory Commission.

ACC: MOL.20010202.0095 through MOL.20010202.0108.

Su, G.W.; Geller, J.T.; Pruess, K.; and Wen, F. 1999. "Experimental Studies of Water Seepage and Intermittent Flow in Unsaturated, Rough-Walled Fractures." Water Resources Research, 35, (4), 1019-1037. Washington, D.C.: American Geophysical Union. TIC: 245798.

Williams, N.H. 2003. "Contract No. DE-AC28-01RW1210 - Transmittal of White Paper, Effects of Neoprene on Water in the Drift Scale Test." Letter from N.H. Williams (BSC) to J.D. Ziegler (DOE/ORD), February 4, 2003, 0129035843, with enclosure.

ACC: MOL.20030206.0211.

YMP (Yucca Mountain Site Characterization Project) 2002. Effects of Introduced Materials in the Drift Scale Test. North Las Vegas, Nevada: Yucca Mountain Site Characterization Office. ACC: MOL.20020304.0044.

\section{A.5.2 Software Code}

LBNL (Lawrence Berkeley National Laboratory) 2003. Software Code: TOUGH2. V1.6. PC/MS-DOS under Windows 98, Sun UltraSparc OS 5.5.1, DEC-Alpha OSF1 V4.0. 10007-1.6-01. 
Revision 1

INTENTIONALLY LEFT BLANK 
Revision 1

\section{APPENDIX B}

USING TEST DATA TO REDUCE UNCERTAINTY IN TOTAL SYSTEM PERFORMANCE ASSESSMENT SEEPAGE ABSTRACTION (RESPONSE TO TSPAI 3.25) 
Revision 1

\section{Note Regarding the Status of Supporting Technical Information}

This document was prepared using the most current information available at the time of its development. This Technical Basis Document and its appendices providing Key Technical Issue Agreement responses that were prepared using preliminary or draft information reflect the status of the Yucca Mountain Project's scientific and design bases at the time of submittal. In some cases this involved the use of draft Analysis and Model Reports (AMRs) and other draft references whose contents may change with time. Information that evolves through subsequent revisions of the AMRs and other references will be reflected in the License Application (LA) as the approved analyses of record at the time of LA submittal. Consequently, the Project will not routinely update either this Technical Basis Document or its Key Technical Issue Agreement appendices to reflect changes in the supporting references prior to submittal of the LA. 


\section{APPENDIX B}

\section{USING TEST DATA TO REDUCE UNCERTAINTY IN \\ TOTAL SYSTEM PERFORMANCE ASSESSMENT SEEPAGE ABSTRACTION (RESPONSE TO TSPAI 3.25)}

This appendix provides a response to Key Technical Issue (KTI) agreement Total System Performance Assessment and Integration (TSPAI) 3.25. This KTI agreement relates to the seepage abstraction and associated parameters used in total system performance assessment (TSPA).

\section{B.1 KEY TECHNICAL ISSUE AGREEMENT}

\section{B.1.1 TSPAI 3.25}

Agreement TSPAI 3.25 was reached during the U.S. Nuclear Regulatory Commission (NRC)/U.S. Department of Energy (DOE) Technical Exchange and Management Meeting on Total System Performance Assessment and Integration held August 6 to 10, 2001, in Las Vegas, Nevada (Reamer 2001), which was convened to discuss four TSPAI KTI subissues: (1) system description and demonstration of multiple barriers; (2) scenario analysis within the TSPA methodology; (3) model abstraction within the TSPA methodology; and (4) demonstration of the overall performance objective. During the course of the technical exchange, TSPAI 3.25 was reached in the area of Subissue 3.

The wording of the agreement is as follows:

\section{TSPAI 3.25}

DOE should use the Passive Cross Drift Hydrologic test, the Alcove 8-Niche 3 tests, the Niche 5 test, and other test data to either provide additional confidence in or a basis for revising the TSPA seepage abstraction and associated parameter values (e.g., flow-focusing factor, van Genuchten alpha for fracture continuum, etc.), or provide technical basis for not using it (UZ2.3.4). DOE will utilize field test data (e.g., the Passive Cross Drift Hydrologic test, the Alcove 8-Niche 3 tests, the Niche 5 test, and other test data) to either provide additional confidence in or a basis for revising the TSPA seepage abstraction and associated parameter values (e.g., flow-focusing factor, van Genuchten alpha for fracture continuum, etc.), or provide technical basis for not using it. This will be documented in Seepage Calibration Model and Seepage Testing Data AMR (MDL-NBS-HS-000004) expected to be available to NRC in FY 2003.

\footnotetext{
${ }^{1}$ UZ2.3.4 refers to the TSPAI Technical Exchange and Management Meeting held August 6 through 10, 2001, in Las Vegas, Nevada, regarding flow paths in the unsaturated zone, Acceptance Criterion 3, Item 4 (Reamer 2001).
} 


\section{B.1.2 Related Key Technical Issue Agreements}

KTI agreement Unsaturated and Saturated Flow Under Isothermal Conditions (USFIC) 4.01 is related to TSPAI 3.25 in that it also requires documentation of test plan and test results, including the Passive Cross-Drift Hydrologic test, the Alcove 8-Niche 3 (also referred to as Niche 3107) tests, and the Niche 5 (also referred to as Niche 1620) test. USFIC 4.01 is addressed in Appendix C.

\section{B.2 RELEVANCE TO REPOSITORY PERFORMANCE}

This KTI agreement relates to gaining additional confidence in the seepage abstraction and in associated parameter values. Data from hydrologic tests such as the Passive Cross-Drift Hydrologic test, Alcove 8-Niche 3 tests, the Niche 5 test, and the Systematic Hydrologic Characterization tests are available for seepage model calibration and validation and to provide additional confidence in the seepage abstraction.

The agreement stems from the NRC concern that previous seepage tests in Niche 2 (also referred to as Niche 3650 ) yielded results that may be biased by ventilation dryout, the close proximity of the injection boreholes to the niche ceiling, and the injection rates that are much higher than ambient percolation flux. The NRC was also concerned that the range of permeability developed from air-injection tests in Niche 2 may not include or appropriately bound the permeability variability in the lower lithophysal unit. NRC staff requested the DOE to provide additional confidence in the calibrated fracture properties and to demonstrate the estimated alpha values are consistent with the largest apertures typical for the grid-block scale. The NRC also requested further clarification on the incorporation of the alpha parameter uncertainty into the TSPA seepage abstraction (NRC 2002).

The agreement is relevant to the repository performance since the abstraction of seepage and the associated parameter values are directly used in TSPA calculations and in the evaluation of the unsaturated zone barrier.

\section{B.3 RESPONSE}

The KTI agreement pertains to the documentation and use of subsurface seepage and tracer tests (1) as a basis for revising the TSPA seepage abstraction or (2) to provide additional confidence in the TSPA seepage abstraction and associated parameter sets. The field testing specifically aimed at resolving seepage-related issues has been expanded significantly since the initial short-term, small-volume liquid-release tests conducted in Niche 2 . The new tests provide the relevant data of sufficient quality to address the NRC concern related to the early tests. All available field test data were reviewed and considered for inclusion in the seepage models. Data from the previous Niche 2 tests are no longer used for the determination of seepage-relevant parameters but only for the validation of the seepage calibration model.

The first part of the response to this KTI agreement (Section B.3.1) addresses the direct quantitative use of data from subsurface tests (including the Niche 5 test and Systematic Hydrologic Characterization test) in revising analyses and models and subsequently the TSPA seepage abstraction. The second part (Section B.3.2) deals with the subsurface tests (including Alcove 8-Niche 3 tests and Passive Cross-Drift Hydrologic tests) that provided confidence in the 
seepage models and abstraction by corroborating the conceptual seepage model. These first two parts discuss the use of the available data in support of seepage abstraction and the determination of seepage-relevant parameters. The last part (Section B.3.3) discusses the seepage-relevant parameters that could not directly be estimated from the available test data, such as the flow-focusing factor. The technical basis for these responses is provided in Section B.4.

\section{B.3.1 Revision of the Total System Performance Assessment Seepage Abstraction and Related Parameters}

The data basis and modeling approach supporting seepage abstraction have been greatly widened and improved since the first revision of the TSPA seepage model, substantially reducing uncertainties in the seepage-relevant parameters and the subsequent predictions of seepage into waste emplacement drifts. Data from the Enhanced Characterization of the Repository Block (ECRB) Systematic Hydrologic Characterization tests and Niche 5 were used by the seepage calibration model for the determination of seepage-relevant parameters for the lower lithophysal zone (Tptpll) of the Topopah Spring Tuff. Data from Niches 3 and 4 (also referred to as Niches 3107 and 4788, respectively) were used for parameter estimation in the middle nonlithophysal zone (Tptpmn) of the Topopah Spring Tuff. Relative humidity has been monitored, and evaporation effects have been included in the model used to analyze the seepage-rate data. All estimates of air permeability and capillary strength $(1 / \alpha)$ have been compiled in a comprehensive analysis to determine their spatial variability and uncertainty.

\section{B.3.1.1 Systematic Hydrologic Characterization Tests and Niche 5 Tests (Lower Lithophysal Zone)}

Data from air-injection and liquid-release tests conducted in Niche 5 and in the ECRB for Systematic Hydrologic Characterization were used to determine seepage-relevant parameters (specifically permeability and capillary strength), thus providing a defensible basis for and additional confidence in the revision of the TSPA seepage abstraction. These data were used in a quantitative manner for the estimation of seepage-relevant parameters for the lower lithophysal zone. The data were also used to validate the process model.

These data directly reflect the seepage process (1) in the hydrogeologic unit of interest and (2) on the scale of interest. In addition, their use in a procedure that yields model-related parameters provided the basis to quantify and reduce the uncertainty of the subsequent seepage predictions. Relative humidity and evaporation-rate data were incorporated into the process model to reduce the potential bias introduced by evaporation effects within the drifts. The data from these tests are described in In Situ Field Testing of Processes (BSC 2003a, Sections 6.2 and 6.11); the analysis of the data is discussed in Seepage Calibration Model and Seepage Testing Data (BSC 2003b).

\section{B.3.1.2 Niches 3 and 4 (Middle Nonlithophysal Zone)}

Part of the test data from Niches 3 and 4 were used to determine seepage-relevant parameters for the middle nonlithophysal zone. The remaining test data were used for model validation. An analysis was performed to demonstrate that evaporation in the closed-off niches with near 
uncertainty of seepage-relevant properties and processes. Seepage is variable in space because of variability in percolation flux and heterogeneity in key hydrologic properties, specifically fracture permeability and capillary strength. In addition, seepage may be affected by heat output from the decaying radioactive waste, from changes in hydrologic properties as a result of mechanical and chemical effects, from changes in the drift shape due to drift degradation, and from the presence of rock bolts used for ground support. Several of these factors are also time-dependent, such as percolation flux and thermal effects. The methodology of incorporating each of these factors in seepage abstraction is directly based on the process-model results described in Sections 4.3 through 4.8. The general procedure has two main steps, as follows:

1. The ambient seepage results (see Section 4.4) provide the basis for the quantitative evaluation of seepage as a function of key hydrologic properties. The key hydrologic parameters defining ambient seepage (capillary-strength, permeability, and local percolation flux) are described by appropriate probability distributions. Depending on the considered geologic unit, the selected nominal or disruptive scenarios, and the assumed rock strength reduction case, seepage rates will be sampled either from the lookup table for nondegraded drifts or from the lookup table for collapsed drifts (for details, see BSC 2003a, Section 6.5.1.5).

2. The parameters and (or) ambient seepage rates are then adjusted to account for potentially important factors, such as thermal, mechanical, and chemical effects on properties and seepage, and other factors (see Figure 2-2).

In Step 1, it is recognized that the amount of seepage is sensitive to key hydrologic properties that are both spatially variable and uncertain. For ambient seepage, these key hydrologic properties are the capillary-strength parameter, the permeability, and the local percolation flux. One of the main tasks of the seepage abstraction model is to define appropriate probability distributions. The probabilities assigned to the relevant parameters distinguish explicitly between spatial variability and uncertainty, using separate distributions. For example, spatial variability of the capillary-strength parameter $1 / \alpha$ is described by a uniform distribution, whereas the uncertainty is represented by a triangular distribution, with a mean of zero and a range value defining the uncertainty of the parameter. Potential sources of uncertainty included in this triangular distribution are (1) measurement uncertainty, (2) spatial variability uncertainty, (3) conceptual model uncertainty, and (4) estimation uncertainty. A schematic illustration of the random sampling procedure is given in Figure 4-16. During a TSPA calculation, the triangular distribution is randomly sampled, providing an adjusted mean value to account for uncertainty. Next, random sampling from the spatial variability distributions are added to the adjusted mean at each location in the repository area. Details of the procedure and the development of the underlying probability distributions can be found in Abstraction of Drift Seepage (BSC 2003a, Section 6.6). 


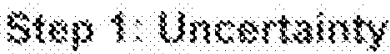

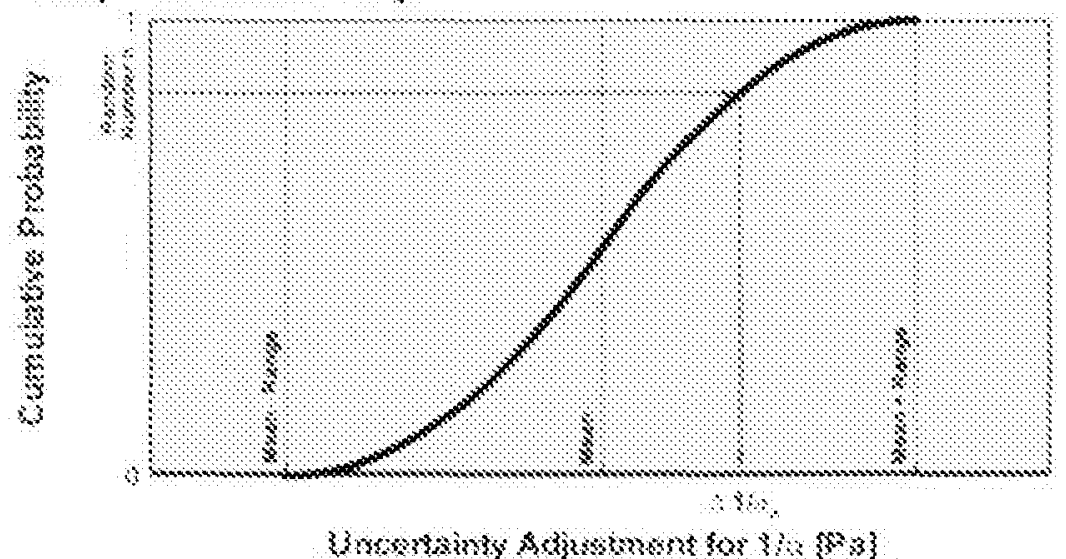

Steo 2: Sextial Variability

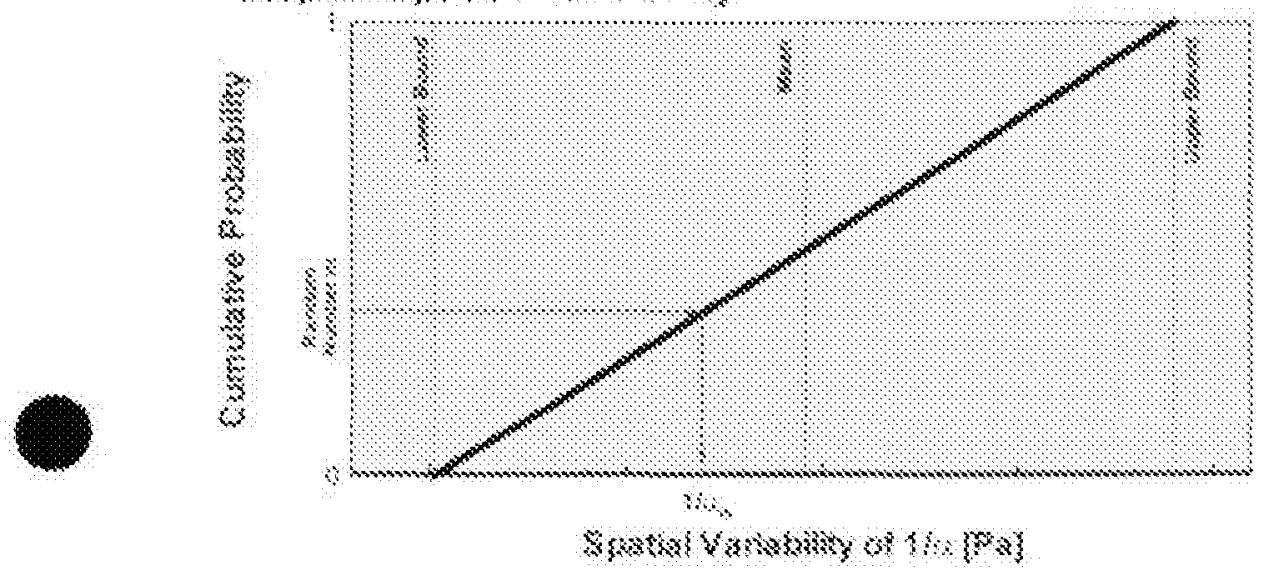

Reasting Value:

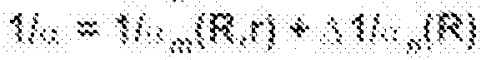

ms

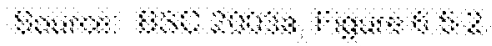

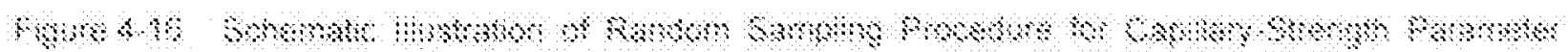

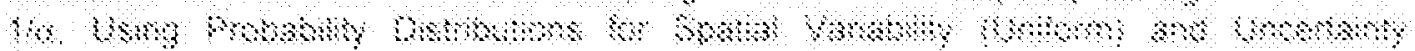
(momensis:

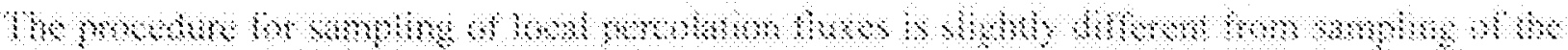

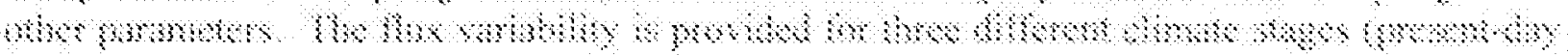

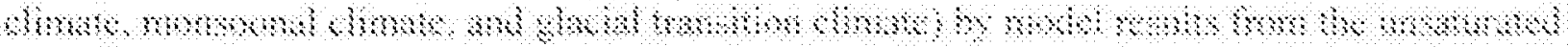

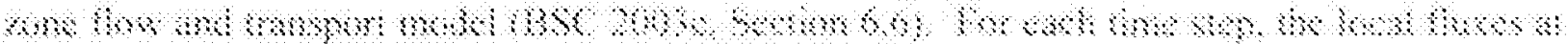

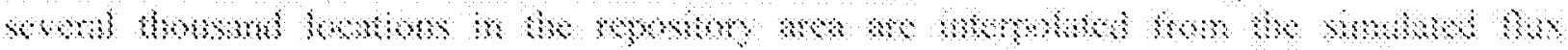

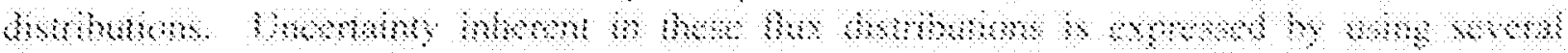

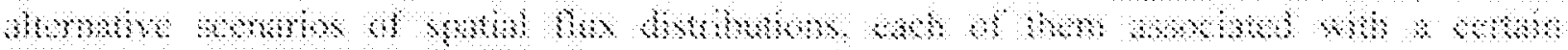

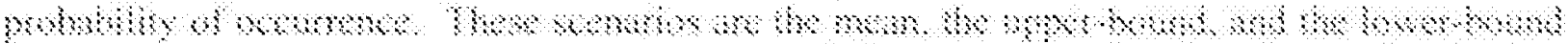

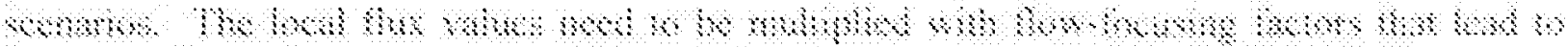

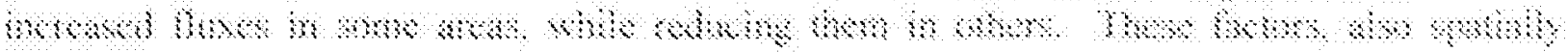

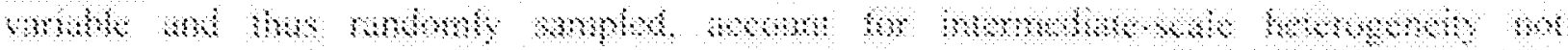

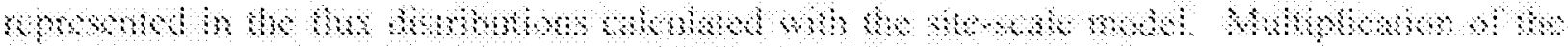

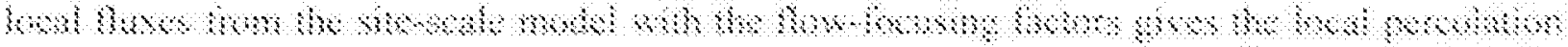

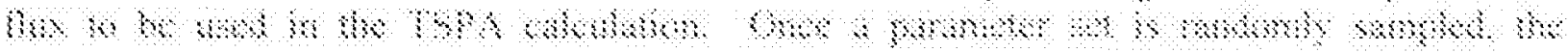


corresponding seepage rate is extracted from the lookup tables generated for intact or collapsed waste emplacement drifts.

In Step 2, the impact of additional factors affecting seepage is evaluated. These factors include the ground support with rock bolts, the expected transient changes in hydrologic properties as a result of thermal, mechanical, and chemical effects, and the thermal perturbation of the flow field as a result of boiling in the rock. The method proposed in the seepage abstraction is to account for these factors in a simplified form using the ambient seepage results as a basis and adjusting them as suggested by the relative importance of each factor. To incorporate uncertainty, the simplifications made in this process are usually conservative yet strive to be as realistic as possible.

The expected time-dependent alterations of seepage-relevant properties, stemming from thermal-hydrologic-mechanical and thermal-hydrologic-chemical effects in response to the elevated temperatures in the repository, can be neglected in the seepage simulations conducted in the TSPA. The thermal-hydrologic-mechanical simulations discussed in Section 4.6 suggest that temperature-induced stress changes give rise to changes in the vertical fracture permeability in the vicinity of waste emplacement drifts. However, these permeability changes do not result in significant changes in the flow fields. In particular, the seepage rates calculated for a permeability field including thermal-hydrologic-mechanical permeability changes were similar to, but slightly smaller than those calculated for a permeability field representative of the initial postexcavation conditions. The seepage model performance assessment simulation results provide reasonably accurate (slightly conservative) estimates of the expected seepage rates at long-term conditions with coupled thermal-hydrologic-mechanical property changes. Therefore, the impact of thermal-hydrologic-mechanical property changes is neglected in the seepage abstraction (i.e., the seepage abstraction model uses the ambient seepage rates without accounting for the transient thermal-hydrologic-mechanical changes in seepage-relevant properties).

The thermal-hydrologic-chemical simulations discussed in Section 4.8 suggest formation of a precipitation cap about 7 to $8 \mathrm{~m}$ above the drift crown. The zone of decreased fracture permeability acts as an "umbrella" that partially deflects percolating water sideways, limits the amount of flux at the drift crown, and reduces seepage. Seepage abstraction does not incorporate this effect, considering the considerable uncertainty and potential variability in these simulated results. It should be recognized, however, that the simulated trend of a precipitation cap forming at some distance above the drift crown appears to be reliable in a qualitative sense. This adds confidence in the seepage abstraction results. The amount of seepage is likely to be smaller than the abstracted seepage because of thermal-hydrologic-chemical effects.

Two alternative abstraction models are proposed for seepage during the period of strong thermal perturbation at Yucca Mountain. The first (simple) model does not take credit for the vaporization barrier that prevents seepage at above-boiling rock temperatures. In the second (more realistic) abstraction model, thermal seepage is set to zero for the period of above-boiling rock temperatures in the drift vicinity.

In summary, the abstraction is based on seepage predictions from detailed process models that have been validated in previous analyses to ensure appropriate representation of the physical 
processes and relevant parameters. These results are either propagated to the TSPA without changes (i.e., seepage lookup table) or have been simplified within the abstraction process (i.e., thermal seepage, thermal-hydrologic-chemical and thermal-hydrologic-mechanical alterations, and drift degradation).

From the seepage look-up tables and the respective simplifications for additional factors, probabilistic seepage rates and uncertainties can be calculated as a function of seepage-relevant parameters. In the abstraction, appropriate spatial variability and uncertainty distributions have been developed for these parameters, based on either process model results (i.e., capillary strength or percolation flux) or in situ measurements (permeability).

\subsection{SEEPAGE IN TOTAL SYSTEM PERFORMANCE ASSESSMENT}

The purpose of the seepage component in TSPA is to calculate the seepage rate (amount of seepage per time) and the seepage fraction (the fraction of waste packages affected by seepage) as functions of time and location in the repository. The calculation is performed using a probabilistic approach that accounts for the spatial and temporal variability and inherent uncertainty of seepage-relevant properties and processes. The resulting information takes the form of probability distributions for seepage events. These distributions are used for subsequent TSPA calculations that may handle, for example, waste form degradation or radionuclide transport.

The TSPA procedure of calculating seepage is schematically illustrated in Figure 4-17. The TSPA calculation runs over several time steps to account for the temporal variability of relevant processes. Within each time step, random sampling of uncertainty distributions is conducted for a sufficiently large number of realizations (labeled $R$ ). Within each realization, the seepage rate is evaluated at a sufficiently large number of spatial locations (labeled $r$ ) in the repository area. Over all locations, the resulting number of locations with seepage, relative to the total number of locations, defines the fraction of waste packages encountering seepage for the realization and the time considered.

For illustration of the expected seepage behavior in the repository, a probabilistic seepage calculation was conducted following the abstraction method described in Abstraction of Drift Seepage (BSC 2003a, Section 6.8). Summary results indicate the importance of the natural barrier formed by the unsaturated rock at and above the repository horizon. For drifts located in the main geological unit of the repository (Tptpll) and assuming the expected (mean) infiltration climate scenario, the mean seepage percentage is about 8 percent during the glacial transition climate, when most seepage is expected. This means that, on average, more than about 92 percent of the percolating water is diverted around the emplacement drifts. The calculation procedure was also applied to various sensitivity cases. Note that the calculation results from Abstraction of Drift Seepage (BSC 2003a, Section 6.8) are not directly utilized in the performance assessment; the seepage component in the TSPA simulations will conduct a similar seepage calculation embedded in the TSPA Monte Carlo simulation procedure. 


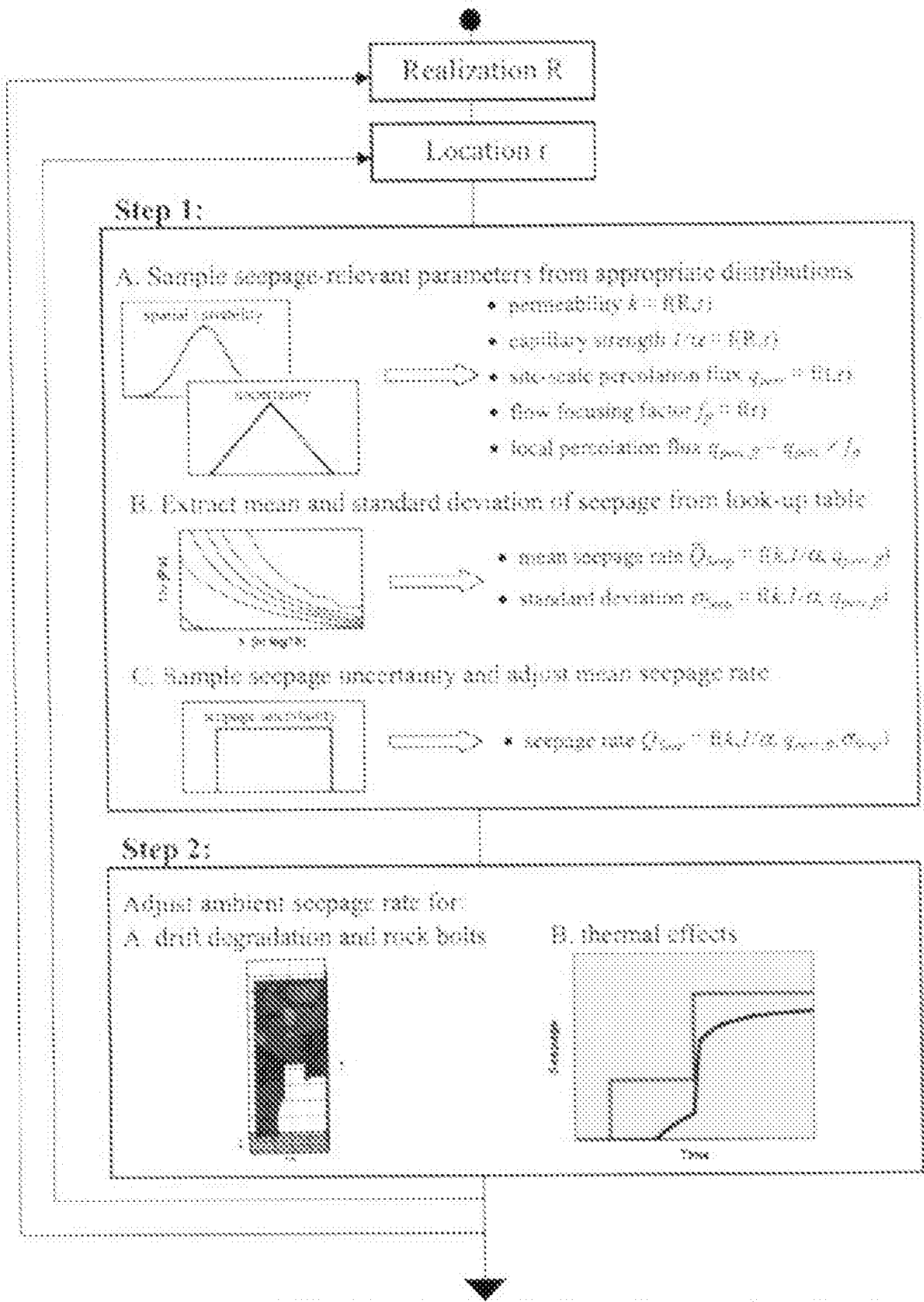

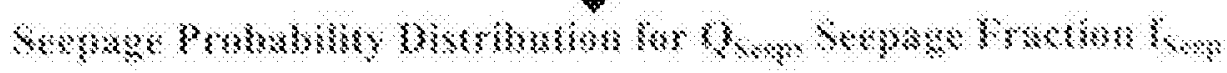
s.

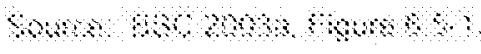

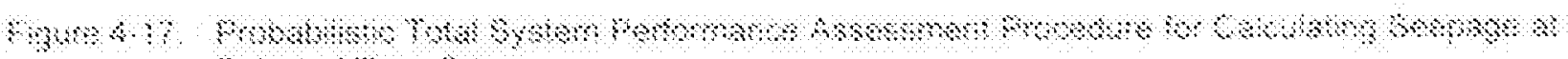

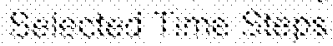


Finally, it is useful to qualitatively compare the observations made in the ECRB Cross-Drift and Alcove 7, with the representation of seepage in the abstraction model for TSPA (BSC 2003a, Section 6.8). The abstraction model for drift seepage was prepared for use in TSPA, and tested by substituting recommended parameter distribution functions for the independent variables: focused percolation flux, permeability, and capillary strength. The results show that approximately 8 percent of waste packages (averaged over the entire repository layout area) are predicted to experience seepage, for the mean infiltration case and present-day climate conditions (BSC 2003a, Table 6.8-1). In addition, the seepage abstraction results in an average of $1.7 \mathrm{~L} / \mathrm{yr}$ per waste package, or about $20 \mathrm{~L} / \mathrm{yr}$ per waste package with a seep. Percolation flux is greater in some parts of the site area (BSC 2003c, Section 6.6, Figure 6.6-6) and is above average in the host rock under Yucca Crest that is traversed by the ECRB Cross-Drift. Accordingly, the seepage abstraction model predicts at least an 8 percent likelihood that seepage will occur (at rates of about $20 \mathrm{~L} / \mathrm{yr}$ ) in any $5.1-\mathrm{m}$ long drift interval, through several hundred meters of the Cross-Drift. Similar conclusions were reached in the pretest predictions for the ECRB Cross-Drift passive monitoring test (BSC 2001d, Section 6.1).

These results are not inconsistent with the possibility that the source of liquid water in the ECRB is seepage. However, as noted in Section 3.2, it is probable that these observations are the result of condensation from the humid air in the drift. This humid air was primarily derived from moisture in the form of water vapor coming into the drift following the cessation of ventilation. This moisture flux is not explicitly quantified in the seepage model (which, as noted in Section 4.4, assumes 100 percent relative humidity at the drift wall) and is generally a small fraction of the seepage amount for relative humidities approaching 100 percent (BSC 2003e, Figure 33). 
Revision 1

INTENTIONALLY LEFT BLANK 


\section{SUMMARY}

Seepage into waste emplacement drifts affects the performance of the high-level radioactive waste repository at Yucca Mountain, Nevada. The number of waste packages contacted by water, the dissolution and mobilization of radionuclides, and the release of radionuclides depend on the rate, chemical composition, and the spatial and temporal distribution of water seeping into the emplacement drifts. Seepage will also affect the conditions below the drift, specifically the saturation reduction in the matrix and the fractures (referred to as the drift shadow zone) which, in turn, can affect diffusive releases from the drift to the natural environment and the potential for (or absence of) fast advective transport of radionuclides through the fracture network.

Theoretical analyses, numerical modeling studies, field experiments, and natural analogs suggest that seepage into underground openings excavated in unsaturated formations is smaller than the percolation flux at the given location. This is mainly a result of capillary pressures holding water in the formation, diverting it around the cavity, and preventing it from entering the underground opening.

The effectiveness of this capillary barrier will depend on the percolation flux, the hydrogeologic properties of the formation, the geometry of the drift opening, the properties of the drift wall, and the in-drift conditions determining the evaporation potential. In addition, a vaporization barrier will develop when the emplacement drifts are ventilated or heated to above-boiling. Seepage may be further reduced as a result of thermal and mechanical property changes in the vicinity of the drifts and the development of a precipitation cap by a coupled thermal-hydrologic-chemical process.

A large number of seepage experiments under ambient temperature conditions were performed in several niches and along the ECRB Cross-Drift. Qualitative and quantitative data were collected to further understand the seepage process and to estimate seepage-relevant formation parameters. A suite of conceptually consistent seepage process models was developed, effectively propagating seepage-related data and their uncertainties from the field to the probabilistic seepage prediction model as part of TSPA calculations. The modeling approach was designed to address many technical issues (including the impacts of discrete fractures, drift surface roughness, film flow, and evaporation) in a reasonable manner. The models were validated against field and laboratory data and tested against alternative conceptualizations.

The effects of increased repository temperatures on rock properties were investigated experimentally (see Section 3.3) and in associated modeling studies (see Sections 4.6 and 4.8). The resulting impact on seepage under thermal conditions was examined (see Section 4.5) and included in the seepage abstraction (see Section 4.9).

The effectiveness of the capillary barrier and the presence of a seepage threshold can be directly observed from liquid-release tests conducted at different rates, which show that seepage ceases at a nonzero injection rate. Moreover, calcite depositions in lithophysal cavities at Yucca Mountain (assuming that they originate from seepage) indicate that water enters only a small fraction of these underground openings at an average rate that is significantly smaller than the percolation flux. 
The data collected in the passive ECRB Cross-Drift hydrologic test, and Alcove 7, which have been isolated from ventilation, have been interpreted qualitatively as discussed in the previous sections. These data include small variations in temperature or relative humidity that reflect natural variation in host rock conditions, and stronger effects such as the drying and adjacent condensation observed in response to heat sources in the ECRB. Waters collected so far have chemical characteristics of condensates, without the chemical signature of tagged construction water. While these data clearly show that part of the observed moisture originated from condensation, they do not rule out or confirm the existence of formation of water seeping into the drifts. As discussed in Section 4.10, the existence of seepage in the ECRB Cross-Drift is not inconsistent with the probabilistic abstraction of drift seepage developed for use in TSPA, although the contribution from vapor-phase migration and subsequent condensation has not been quantified.

The following general conclusions are drawn:

- Hydrologic process simulation with a calibrated and validated model is the preferred means for predicting seepage, because (1) the key process relevant to seepage (i.e., flow of water under unsaturated conditions) is directly modeled based on established physical laws, (2) only a few presumptions need to be made because the model directly simulates the seepage process of interest, (3) the approach has the potential to simulate conditions that cannot be observed in the field, and (4) numerical models are flexible enough to accommodate the realistic initial and boundary conditions as they occur during seepage experiments.

- The testing and modeling approach is adequate for providing the conceptual basis and parameters for the TSPA seepage model. The approach consists of analyzing seepage by means of a numerical process model that is calibrated against seepage-rate data from liquid-release tests conducted within the repository host units. Seepage experiments provide calibration data that reflect the process of interest. The measured data automatically reflect the factors and features pertinent to seepage. The effective parameters are capable of reproducing observed seepage data and are thus likely to yield reasonable seepage predictions. Moreover, the experiments test the capillary-barrier effect on the scale of interest. The water encountering the niche or drift is partly diverted around the opening, activating the relevant portion of the fracture network on the appropriate scale.

- The estimation of seepage-relevant, model-related, effective parameters on the drift scale is an appropriate methodology provided that the structure of the prediction model is consistent with the model used for calibration.

- Seepage properties are spatially variable. The variability has been examined by performing liquid-release tests at various sites along the ESF and the ECRB Cross-Drift. Available permeability data haven been analyzed to develop appropriate distributions reflecting spatial variability as well as uncertainty.

- It is recognized that the amount of seepage is sensitive to key hydrologic properties that are both spatially variable and uncertain. For ambient seepage, these key hydrologic 
properties are the capillary-strength parameter, the permeability, and the local percolation flux. Appropriate probability distributions have been defined in the seepage abstraction (see Section 4.9), representing the spatial variability and uncertainty inherent in these parameters in a realistic manner. Relevant sources of uncertainty have been identified, described, and accounted for in this process, including measurement uncertainty, conceptual model uncertainty, estimation uncertainty, and spatial variability uncertainty.

- Property changes as a result of coupled thermal-hydrologic-mechanical and thermal-hydrologic-chemical effects will have minor and generally beneficial impacts on seepage; they were conservatively neglected in the seepage abstraction. Larger perturbations (such as a drift collapse as a result of seismic events or cohesion loss of the fractured rock) can lead to more substantial changes in seepage; they were analyzed and appropriately captured in the seepage abstraction.

In summary, the extensive testing and modeling program undertaken to understand and characterize seepage from fractured rock provides an adequate basis for predicting seepage into waste emplacement drifts under ambient and thermal conditions at Yucca Mountain.

The report summarizes responses to certain seepage-related KTI agreements between the DOE and the NRC. The KTI agreements addressed in this report are listed in Table 1-1. 
Revision 1

INTENTIONALLY LEFT BLANK 


\section{REFERENCES}

Birkholzer, J. 2003. "Penetration of Liquid Fingers into Superheated Fractured Rock." Water Resources Research, 39, (4), 9-1 through 9-21. Washington, D.C.: American Geophysical Union. TIC: 254362.

Birkholzer, J.; Li, G.; Tsang, C-F.; and Tsang, Y. 1999. "Modeling Studies and Analysis of Seepage into Drifts at Yucca Mountain." Journal of Contaminant Hydrology, 38, (1-3), 349-384. New York, New York: Elsevier. TIC: 244160.

Birkholzer, J. and Tsang, C.F. 1997. "Solute Channeling in Unsaturated Heterogeneous Porous Media." Water Resources Research, 33, (10), 2221-2238. Washington, D.C.: American Geophysical Union. TIC: 235675.

BSC (Bechtel SAIC Company) 2001a. In Situ Field Testing of Processes. ANL-NBS-HS000005 REV 01. Las Vegas, Nevada: Bechtel SAIC Company. ACC: MOL.20020108.0351.

BSC 2001b. Unsaturated Zone Flow Patterns and Analysis. MDL-NBS-HS-000012 REV 00. Las Vegas, Nevada: Bechtel SAIC Company. ACC: MOL.20011029.0315.

BSC 2001c. Drift Degradation Analysis. ANL-EBS-MD-000027 REV 01 ICN 01. Las Vegas, Nevada: Bechtel SAIC Company. ACC: MOL.20011029.0311.

BSC 2001d. Test Plan for: Moisture Monitoring in the ECRB Bulkheaded Cross Drift. SITP-02-UZ-001 REV 00. Las Vegas, Nevada: Bechtel SAIC Company. ACC: MOL.20011018.0011.

BSC 2002a. Total System Performance Assessment-License Application Methods and Approach. TDR-WIS-PA-000006 REV 00. Las Vegas, Nevada: Bechtel SAIC Company. ACC: MOL.20020923.0175.

BSC 2002b. Thermal Testing Measurements Report. ANL-NBS-HS-000041 REV 00. Las Vegas, Nevada: Bechtel SAIC Company. ACC: MOL.20021004.0314.

BSC 2002c. Analysis of Geochemical Data for the Unsaturated Zone. ANL-NBS-HS-000017 REV 00 ICN 02. Las Vegas, Nevada: Bechtel SAIC Company. ACC: MOL.20020314.0051.

BSC 2002d. Natural Analogue Synthesis Report. TDR-NBS-GS-000027 REV 00 ICN 02. Las Vegas, Nevada: Bechtel SAIC Company. ACC: MOL.20020520.0288.

BSC 2003a. Abstraction of Drift Seepage. MDL-NBS-HS-000019 REV 00. Las Vegas, Nevada: Bechtel SAIC Company. ACC: DOC.20030826.0001.

BSC 2003b. Drift-Scale Coupled Processes (DST and TH Seepage) Models. MDL-NBS-HS000015 REV 00C. Las Vegas, Nevada: Bechtel SAIC Company. ACC: MOL.20030910.0160.

BSC 2003c. UZ Flow Models and Submodels. MDL-NBS-HS-000006 REV 01. Las Vegas, Nevada: Bechtel SAIC Company. ACC: DOC.20030818.0002. 
BSC 2003d. Drift Degradation Analysis. ANL-EBS-MD-000027 REV 02. Las Vegas, Nevada: Bechtel SAIC Company. ACC: DOC.20030709.0003.

BSC 2003e. Seepage Calibration Model and Seepage Testing Data. MDL-NBS-HS-000004 REV 02. Las Vegas, Nevada: Bechtel SAIC Company. ACC: DOC.20030408.0004.

BSC 2003f. In Situ Field Testing of Processes. ANL-NBS-HS-000005 REV02B. Las Vegas, Nevada: Bechtel SAIC Company. ACC: MOL.20030915.0238.

BSC 2003g. Drift Scale THM Model. MDL-NBS-HS-000017 REV 00. Las Vegas, Nevada: Bechtel SAIC Company. ACC: DOC.20030818.0003.

BSC 2003h. Drift-Scale Coupled Processes (DST and THC Seepage) Models. MDL-NBS-HS000001 REV 02. Las Vegas, Nevada: Bechtel SAIC Company. ACC: DOC.20030804.0004.

BSC 2003i. Seepage Model For PA Including Drift Collapse. MDL-NBS-HS-000002 REV 02. Las Vegas, Nevada: Bechtel SAIC Company. ACC: DOC.20030709.0001.

CRWMS M\&O (Civilian Radioactive Waste Management System Management and Operating Contractor) 1998. Drift Scale Test As-Built Report. BAB000000-01717-5700-00003 REV 01. Las Vegas, Nevada: CRWMS M\&O. ACC: MOL.19990107.0223.

Liu, H.H.; Doughty, C.; and Bodvarsson, G.S. 1998. "An Active Fracture Model for Unsaturated Flow and Transport in Fractured Rocks." Water Resources Research, 34, (10), 2633-2646. Washington, D.C.: American Geophysical Union. TIC: 243012.

Marshall, B.D.; Neymark, L.A.; and Peterman, Z.E. 2003. "Estimation of Past Seepage Volumes from Calcite Distribution in the Topopah Spring Tuff, Yucca Mountain, Nevada." Journal of Contaminant Hydrology, 62-63, 237-247. [New York, New York]: Elsevier. TIC: 254210.

Or, D. and Ghezzehei, T.A. 2000. "Dripping into Subterranean Cavities from Unsaturated Fractures under Evaporative Conditions." Water Resources Research, 36, (2), 381-393. Washington, D.C.: American Geophysical Union. TIC: 246982.

Paces, J.B.; Neymark, L.A.; Marshall, B.D.; Whelan, J.F.; and Peterman, Z.E. 2001. Ages and Origins of Calcite and Opal in the Exploratory Studies Facility Tunnel, Yucca Mountain, Nevada. Water-Resources Investigations Report 01-4049. Denver, Colorado: U.S. Geological Survey. TIC: 251284.

Philip, J.R.; Knight, J.H.; and Waechter, R.T. 1989. "Unsaturated Seepage and Subterranean Holes: Conspectus, and Exclusion Problem for Circular Cylindrical Cavities." Water Resources Research, 25, (1), 16-28. Washington, D.C.: American Geophysical Union. TIC: 239117.

Pruess, K.; Wang, J.S.Y.; and Tsang, Y.W. 1990. "On Thermohydrologic Conditions Near High-Level Nuclear Wastes Emplaced in Partially Saturated Fractured Tuff, 2. Effective Continuum Approximation." Water Resources Research, 26, (6), 1249-1261. [Washington, D.C.]: American Geophysical Union. TIC: 224854. 
Richards, L.A. 1931. "Capillary Conduction of Liquids Through Porous Mediums." Physics, 1, 318-333. [New York, New York: American Physical Society]. TIC: 225383.

Trautz, R.C. and Wang, J.S.Y. 2002. "Seepage into an Underground Opening Constructed in Unsaturated Fractured Rock Under Evaporative Conditions." Water Resources Research, 38, (10), 6-1 through 6-14. [Washington, D.C.]: American Geophysical Union. TIC: 253348.

USGS (U.S. Geological Survey) 2001. Simulation of Net Infiltration for Modern and Potential Future Climates. ANL-NBS-HS-000032 REV 00 ICN 02. Denver, Colorado: U.S. Geological Survey. ACC: MOL.20011119.0334.

van Genuchten, M.T. 1980. "A Closed-Form Equation for Predicting the Hydraulic Conductivity of Unsaturated Soils." Soil Science Society of America Journal, 44, (5), 892-898. Madison, Wisconsin: Soil Science Society of America. TIC: 217327.

Wang, J.S.Y. and Elsworth, D. 1999. "Permeability Changes Induced by Excavation in Fractured Tuff." Rock Mechanics for Industry, Proceedings of the 37th U.S. Rock Mechanics Symposium, Vail, Colorado, USA, 6-9 June 1999. Amadei, B.; Kranz, R.L.; Scott, G.A.; and Smeallie, P.H., eds. 2, 751-757. Brookfield, Vermont: A.A. Balkema. TIC: 245246.

Wang, J.S.Y.; Trautz, R.C.; Cook, P.J.; Finsterle, S.; James, A.L.; and Birkholzer, J. 1999. "Field Tests and Model Analyses of Seepage into Drift." Journal of Contaminant Hydrology, 38, (1-3), 323-347. New York, New York: Elsevier. TIC: 244160.

Whelan, J.F.; Paces, J.B.; and Peterman, Z.E. 2002. "Physical and Stable-Isotope Evidence for Formation of Secondary Calcite and Silica in the Unsaturated Zone, Yucca Mountain, Nevada." Applied Geochemistry, 17, ([6]), 735-750. [New York, New York]: Elsevier. TIC: 253462. 
Revision 1

INTENTIONALLY LEFT BLANK 


\section{Note Regarding the Status of Supporting Technical Information}

This document was prepared using the most current information available at the time of its development. This Technical Basis Document and its appendices providing Key Technical Issue Agreement responses that were prepared using preliminary or draft information reflect the status of the Yucca Mountain Project's scientific and design bases at the time of submittal. In some cases this involved the use of draft Analysis and Model Reports (AMRs) and other draft references whose contents may change with time. Information that evolves through subsequent revisions of the AMRs and other references will be reflected in the License Application (LA) as the approved analyses of record at the time of LA submittal. Consequently, the Project will not routinely update either this Technical Basis Document or its Key Technical Issue Agreement appendices to reflect changes in the supporting references prior to submittal of the LA. 
Revision 1

APPENDIX A

EFFECTS OF HETEROGENEITY ON THERMAL SEEPAGE (RESPONSE TO TEF 2.08 AND GEN 1.01 (COMMENT 15)) 


\section{APPENDIX A \\ EFFECTS OF HETEROGENEITY ON THERMAL SEEPAGE (RESPONSE TO TEF 2.08 AND GEN 1.01 (COMMENT 15))}

This appendix provides a response for Key Technical Issue (KTI) agreement Thermal Effects on Flow (TEF) 2.08 and General Agreement (GEN) 1.01, Comment 15. These agreements relate to the effects of spatial heterogeneity on thermal seepage.

\section{A.1 KEY TECHNICAL ISSUE AGREEMENT}

\section{A.1.1 TEF 2.08 and GEN 1.01 (Comment 15)}

Agreement TEF 2.08 was reached during the U.S. Nuclear Regulatory Commission (NRC)/U.S. Department of Energy (DOE) Technical Exchange and Management Meeting on Thermal Effects on Flow held January 8 to 9, 2001, in Pleasanton, California (Reamer and Williams 2001). The agreement resulted from the technical discussion of Subissue No. 2: Thermal effects on temperature, humidity, saturation, and flux. Work in progress to determine the effects of heterogeneity on the potential for thermally driven seepage was discussed, including (1) using further refinement of the grid for the heterogeneous field, (2) using three-dimensional effects since preliminary assessment indicates that the two-dimensional models are conservative, and (3) evaluating the effect of high-permeability features (e.g., fault) crossing the drift.

Agreement GEN 1.01 was reached during the NRC/DOE Technical Exchange and Management Meeting on Range of Thermal Operating Temperatures, held September 18 to 19, 2001 (Reamer and Gil 2001). At that meeting, NRC provided additional comments, resulting in GEN 1.01 (Comment 15), which relates to the effects of spatial heterogeneity on thermal seepage (TEF 2.08). The specific page number referral cited below as part of GEN Comment 15 is from FY 01 Supplemental Science and Performance Analyses, Volume 1: Scientific Bases and Analyses (BSC 2001).

The wording of these agreements is as follows:

\section{TEF 2.08}

Provide the Mountain-Scale Coupled Processes AMR, or another appropriate AMR, documenting the results of the outlined items on page 20 of the OI 7 presentation (considering the NRC suggestion to compare model results to the O.M. Phillips analytical solution documented in Water Resources Research, 1996). The DOE will provide the updated Mountain-Scale Coupled Processes Model AMR (MDL-NBS-HS-000007) Rev 01 to the NRC in FY 02, documenting the results of the outlined items on page 20 of DOE's Open Item 7 presentation at this meeting. The DOE will consider the NRC suggestion of comparing the numerical model results to the O.M. Phillips analytical solution documented in WRR (1996). 
Note that page 20 of DOE's Open Item (OI) 7 presentation includes the following:

Refined Grid Case: Mountain Scale Model (Continued)

Spatially Heterogeneous Fracture Permeability

- Work is in progress to determine the effects of heterogeneity on the potential for thermally driven seepage:

- Using further refinement of grid for heterogeneous field

- Using three-dimensional effects since preliminary assessment indicates that the two-dimensional models are conservative

- Evaluating the effect of high-permeability features (e.g., fault) crossing the drift.

\section{GEN 1.01 (Comment 15)}

The analytical approach in this section moves in the direction of resolving part of agreement TEF 2.08 that states, The DOE will consider the NRC suggestion of comparing the numerical model results to the O.M. Phillips analytical solution. However, this approach should factor into consideration changes in water properties such as increased boiling temperatures of concentrated solutions. Also, taking $\underline{u}$ in this approach to be condensate drainage in the reflux zone instead of net infiltration would give a transient period of increased seepage for a few hundred years after closure.

Basis - Increased boiling temperatures of concentrated solutions will increase the distance a liquid rivulet can flow into the above-boiling region. This would have the effect of increasing seepage into drifts during the thermal period of the HTOM as modeled using the approach developed in the section starting on page 4-58.

Evidence from the DST indicates some condensate drainage could have high concentrations of dissolved solids.

\section{DOE Initial Response to GEN 1.01 (Comment 15):}

The analytical approach was used as an alternative conceptual model for thermal seepage. DOE will compare the analytical model with numerical model results, consistent with existing agreement TEF 2.08. Should the site be approved, the DOE will, as appropriate, re-evaluate the impact of a lower-temperature operating mode upon existing KTIs, which were established on the basis of the higher-temperature operating mode. The changes in water properties, such as increased boiling temperatures of concentrated solutions, may only be significant for the high-temperature operating mode. Preliminary data concerning boiling temperature in the DST indicates that this effect is not significant. 
Note that data from DST geochemical sampling have not shown high concentrations of dissolved solids.

A very limited number of samples from a single borehole did show high $\mathrm{Cl}$ content (but low silica content). These samples were taken early in the heating cycle of the DST and are believed to be contaminated from the drilling of the sampling boreholes. This will be documented in the AMR Unsaturated Zone Thermal Testing Analysis, expected to be issued in FY 2003.

\section{A.1.2 Related Key Technical Issue Agreements}

None.

\section{A.2 RELEVANCE TO REPOSITORY PERFORMANCE}

As discussed in the previous section, TEF 2.08 relates to DOE providing documentation on the results of work to determine the effects of heterogeneity on the potential for thermally driven seepage, which was discussed during the January 2001 NRC/DOE Technical Exchange (Reamer and Williams 2001). NRC was concerned that the heterogeneity of fracture permeability, as reflected in the test-derived tsw34 values that span several orders of magnitude within a single geological layer, may not be adequately represented in the model. NRC requested the documentation of spatially heterogeneous fracture permeability using refinement of the grid for the heterogeneous fields in three dimensions and to evaluate the effect of high-permeability features (e.g., faults) crossing the drifts (NRC 2002, p. 3.3.6-12).

In addition, NRC stated that a rigorous demonstration that the seepage model for total system performance assessment abstraction is valid for its intended purpose would require testing model results against relevant data not used in the original development of the model. However, NRC recognized that such data might not be available for the model. For thermally driven seepage, NRC suggested comparing the numerical model results with the Phillips (1996) analytical solution as a means of model validation (NRC 2002, p. 3.3.6-24).

The agreement TEF 2.08 is relevant to the repository performance because the evaluation of thermally driven seepage is affected by heterogeneity and the thermal seepage results from the thermal-hydrologic simulations will be abstracted for use in the total system performance assessment.

\section{A.3 RESPONSE}

This KTI reflects the NRC concern that thermal flux perturbation with boiling and subsequent condensation of water may give rise to enhanced reflux toward waste emplacement drifts, thereby increasing the possibility of thermally driven seepage. This could be particularly important in strongly heterogeneous flux, where flow channeling or flow fingering may occur. This concern was addressed in Drift-Scale Coupled Processes (DST and TH Seepage) Models (BSC 2003a). A drift-scale thermal-hydrologic process model was developed (thermal-hydrologic seepage model), which incorporates all relevant thermal-hydrologic processes and accounts for small-scale heterogeneity in the drift vicinity. The thermal-hydrologic seepage model was applied to explicitly simulate thermally perturbed 
channelized fluid flow down to the drift and to directly calculate transient seepage rates during the period of elevated temperatures (see Section A.3.1). The numerical results of the thermalhydrologic seepage model were compared to an improved semianalytical solution based on the Phillips solution (Phillips 1996) that was introduced as an alternative conceptual model in Drift-Scale Coupled Processes (DST and TH Seepage) Models (BSC 2003a). The alternative semianalytical model is discussed and results are presented in Section A.3.2. GEN 1.01 Comment 15 is addressed in Section A.3.3.

The information in this report is responsive to agreements TEF 2.08 and GEN 1.01 (Comment 15) made between the DOE and NRC. The report contains the information that DOE considers necessary for the NRC to review for closure of these agreements.

\section{A.3.1 Effects of Heterogeneity on Thermally Driven Seepage}

As mentioned above, the effects of heterogeneity on thermal seepage are documented in Drift-Scale Coupled Processes (DST and TH Seepage) Models (BSC 2003a, Section 6.2).

\section{A.3.1.1 Grid Refinement for Heterogeneous Field}

The thermal-hydrologic seepage model was developed to simulate thermal seepage into the waste emplacement drifts at Yucca Mountain (BSC 2003a). The drift-scale model explicitly accounts for small-scale fracture permeability heterogeneity as developed for ambient seepage simulations (BSC 2003b) and also applies other important model concepts from ambient seepage (small fracture capillarity, seepage boundary condition treatment at the rock-drift interface). The small-scale heterogeneity is based on air permeability measurements conducted on a 1-foot measurement scale in various boreholes above niches in both the lower lithophysal and the middle nonlithophysal unit. Small-scale heterogeneity may lead to channelized reflux from the condensation zone back to the heated drift and is also an important factor for ambient seepage, as explained in Drift-Scale Coupled Processes (DST and TH Seepage) Models (BSC 2003a).

Variability of rock properties and boundary conditions on a larger scale (i.e., variability between different repository sections) is accounted for by simulating various sensitivity cases primarily for factors known to impact thermal seepage. These factors are, for example, the thermal-operating mode, the local percolation flux, and selected drift-scale rock properties.

The thermal-hydrologic behavior of fractured rock is simulated in two-dimensional vertical domains perpendicular to the drift axis.

The gridblock size is kept sufficiently small in the vicinity of the drift and at geologic contacts but is coarser elsewhere to achieve computing efficiency. At the drift wall, gridblocks are about $20 \mathrm{~cm}$ in the radial direction (i.e., the grid block size is sufficiently small to describe the small-scale heterogeneity). The area within approximately $50 \mathrm{~m}$ above the drift is more finely discretized than areas beyond to better capture thermal-hydrologic effects important for seepage into drifts. The inside of the drift is also finely discretized to accurately capture the heat transfer from the waste package to the drift surface.

Further details on the thermal-hydrologic seepage model are provided in Section A.4.1.1. 


\section{A.3.1.2 Three-Dimensional Effects}

A fully three-dimensional simulation of drift-scale thermal seepage has not been performed. Several simulation cases must be studied with the thermal-hydrologic seepage model to account for the variability in rock properties and boundary conditions important for thermal seepage; therefore, a full three-dimensional simulation of the coupled processes is not feasible because of computational limitations. Similar to the ambient seepage models, the thermal-hydrologic seepage model focuses on near-drift conditions, using a refined discretization in the drift vicinity. However, at the same time, the thermal-hydrologic simulation requires a large vertical model domain because the thermally disturbed zone extends far into the overlying and underlying geological units. The main deviations between a three-dimensional and a two-dimensional model occur at the end of each emplacement drift and at the edges of the repository. Such effects are accounted for in Drift-Scale Coupled Processes (DST and TH Seepage) Models (BSC 2003a, Sections 6.2.2.1.3 and 6.2.4.2) by considering several sensitivity cases for the thermal load. Also note that, with respect to the effectiveness of the capillary barrier for seepage into drifts, a two-dimensional representation gives a conservative prediction of seepage for most cases of heterogeneous fracture permeability fields because the potential diversion of flow in the third dimension is neglected (BSC 2003c, Section 6.4.3.1).

\section{A.3.1.3 Effect of High-Permeability Features Crossing the Drift}

The impact of faults has not been examined specifically for thermal seepage. The impact of large-scale features on the temperature distribution is captured by the mountain-scale thermal-hydrologic models, which provide the boundary conditions for the thermal seepage models. Sensitivity studies performed to analyze the impact of increased mean permeability on thermal-hydrologic processes are summarized in $F Y 01$ Supplemental Science and Performance Analyses, Volume 1 (BSC 2001, Table 5.4.3-1). Virtually no changes in rock temperature occur for the cases with one-standard-deviation permeability variation above and below the mean and for the case with a two-standard-deviations smaller permeability. Significant impact was predicted, however, for the case with permeability two standard deviations above the mean, where the predicted peak temperature was about $11^{\circ} \mathrm{C}$ lower and the duration of the boiling period was a few hundred years shorter than in the other cases. However, calculation of local seepage from a fault is considered less important as it is unlikely that waste packages will be placed in known fault locations.

\section{A.3.2 Comparison of Model Results to the Phillips Analytical Solution}

Unsaturated fracture flow may occur in fast-flowing preferential pathways (thin fingers) that drain downward intermittently. Water buildup in the condensation zone above heated waste emplacement drifts can provide a potential source of such downward finger flow, carrying water at flow rates much larger than the average infiltration. Such conditions may promote the potential of seepage during the thermal period at Yucca Mountain because finger flow may penetrate far into the superheated rock zone (i.e., rock temperature above boiling point of water) around waste emplacement drifts. It is not clear whether process models using a continuum representation, such as the thermal-hydrologic seepage model, are able to capture such small-scale processes, even though small-scale heterogeneity in fracture permeability has been 
incorporated. Therefore, an alternative conceptual model was applied (see Section A.4.2) to investigate the potential impact of episodic finger flow on thermal seepage.

Phillips (1996) developed an analytical solution for the infiltration distance of a liquid finger flowing in a super-heated fractured rock as a function of time. This solution provides an asymptotic approximation of the long-term behavior, but it predicts unrealistic flow velocities at early times because of simplifying assumptions used to derive this solution. (The flow velocities are much larger than the gravity-driven flow velocity in the absence of vaporization.) An improved semianalytical solution (Birkholzer 2003; BSC 2003a) was developed, resolving the inability of Phillips solution to describe early-time behavior (BSC 2003a). This solution replaces the conservative Phillips (1996) solution.

The improved semianalytical solution (see Section A.4.2) is used as an alternative conceptual model for thermal seepage, referred to as the thermal-hydrologic model for episodic finger flow, confirming the results of the thermal-hydrologic seepage model. The thermal-hydrologic model for episodic finger flow uses a simplified conceptualization of unsaturated fracture flow that is very conservative with respect to the potential for thermal seepage (BSC 2003a, Section 6.3.4). The assumed finger-flow events in the thermal-hydrologic model for episodic finger flow are fast and intense compared to the average flow conditions generally considered in process models like the thermal-hydrologic seepage model, and vaporization effects are limited as a result of the small cross-sectional area between the draining water and the hot rock. Also, finger flow is assumed to occur in vertical continuous fractures directly connecting the condensation zone above drifts with the drift crown. The fracture apertures used in the thermal-hydrologic model for episodic finger flow reflect the range of typical fracture apertures at Yucca Mountain (see Section A.4.2.3). Extreme aperture cases (such as large cracks or faults) were not used since the thermal-hydrologic model for episodic finger flow is already very conservative. In spite of this conservatism, the thermal-hydrologic model for episodic finger-flow results are fairly consistent with the process model results obtained with the thermal-hydrologic seepage model. Most importantly, the thermal-hydrologic model for episodic finger flow demonstrates that finger flow is not able to penetrate through the superheated rock during the first several hundred years of heating, when rock temperature is high and boiling conditions exist in a sufficiently large region above the drifts. These are the conditions when the potential for episodic finger flow is highest.

Section A.4.2 provides additional details.

\section{A.3.3 Response to GEN 1.01, Comment 15}

The analytical approach described in Section A.3.2 (thermal-hydrologic model for episodic finger flow) was used as an alternative conceptual model for thermal seepage and compared with the results of the thermal-hydrologic seepage model. The thermal-hydrologic model for episodic finger flow explicitly accounts for condensate drainage in the reflux zone. This model demonstrates that vaporization reduces the impact of flux perturbation in the condensation zone by a large percentage. For the first several hundred years of heating, vaporization is so effective that water is not able to penetrate through the superheated rock, even when the flux is 12 times greater than the ambient flux of $6 \mathrm{~mm} / \mathrm{yr}$. These results clearly demonstrate that the time period of strongly elevated vertical flux in the condensation zone coincides with the time period of very effective vaporization. Additional details are provided in Section A.4.2.3. 
Increased boiling temperatures of concentrated solutions are not considered important. This is justified because the data from the Drift Scale Test geochemical sampling generally show that concentrations of dissolved solids are relatively low (BSC 2002, Section 6.3.4). The liquid saturation generally has to be much less than 1 percent to produce concentrations that are significantly higher (BSC 2003d, Section 6.4.6.1). Under such conditions, the liquid is nearly immobile because of the very small relative permeability for the liquid phase.

Although relatively low concentrations of dissolved solids were measured in many of the samples collected from the Drift Scale Test, some water samples showed relatively high concentrations of dissolved solids and low $\mathrm{pH}$ values relative to background values. The samples were limited to regions where the rock was well above the boiling temperature, and generally above $140^{\circ} \mathrm{C}$. A series of field and laboratory tests were conducted to determine whether the high concentrations of dissolved solids were due to degradation of the packer materials or because of water-rock interactions under thermal load (YMP 2002; Williams 2003). The results of the field test confirmed that the source of elevated fluoride was due to the packer materials and not the host rock. The laboratory tests supported this finding and also demonstrated that the volcanic tuff is not a source of hydrofluoric gas. Laboratory tests also demonstrated that neoprene can release significant quantities of chloride, especially when reacted with a higher temperature vapor system. Because of this potential problem, precautions will be taken to not introduce such packer materials into an operating repository, especially in regions of elevated temperatures.

\section{A.4 BASIS FOR THE RESPONSE}

\section{A.4.1 Effects of Heterogeneity on Thermally Driven Seepage}

The following sections describe the modeling analysis using a drift-scale process model for thermal seepage influenced by small-scale heterogeneity. The numerical grid and the heterogeneity structure used in the thermal-hydrologic seepage model, as well as simulation results, are presented in Section A.4.1.1. In addition, Sections A.3.1.2 and A.3.1.3 have discussed the dimensionality of the model and the explicit consideration of high-permeability features crossing the drift.

\section{A.4.1.1 Grid Refinement for Heterogeneous Field}

Information for this section is based on Drift-Scale Coupled Processes (DST and TH Seepage) Models (BSC 2003a, Section 6.2).

\section{A.4.1.1.1 Numerical Grids for Thermal-Hydrologic Simulations}

The thermal-hydrologic seepage model was developed using TOUGH2 (LBNL 2003) to simulate thermal seepage into the waste emplacement drifts at Yucca Mountain. This model is based on a continuum assumption simulating the average flow behavior in the fractured rock. The model features small-scale fracture permeability heterogeneity as developed for ambient seepage simulations and also applies other important model concepts from ambient seepage (small fracture capillarity, seepage boundary condition treatment at the rock-drift interface). 


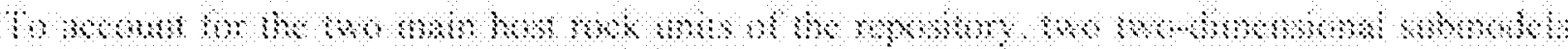

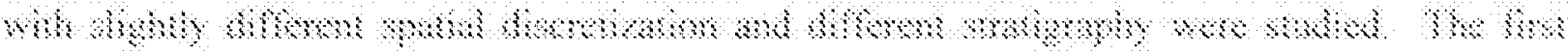

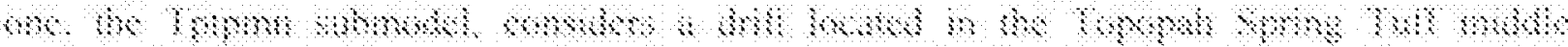

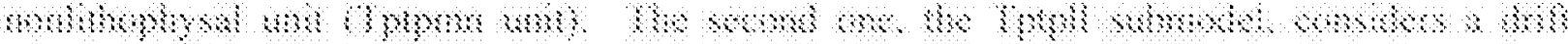

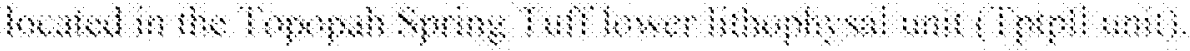

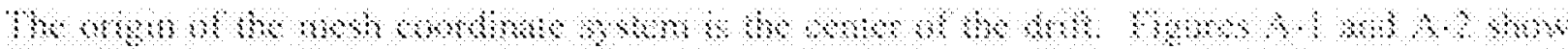

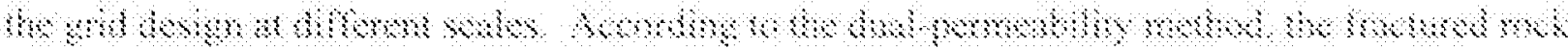

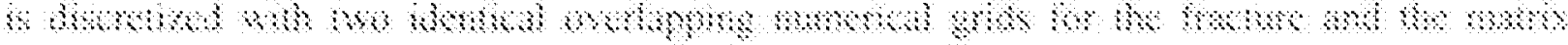

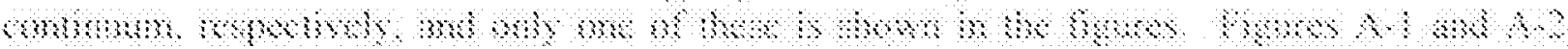

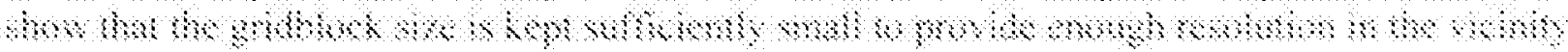

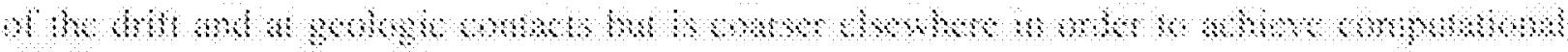
की०००:

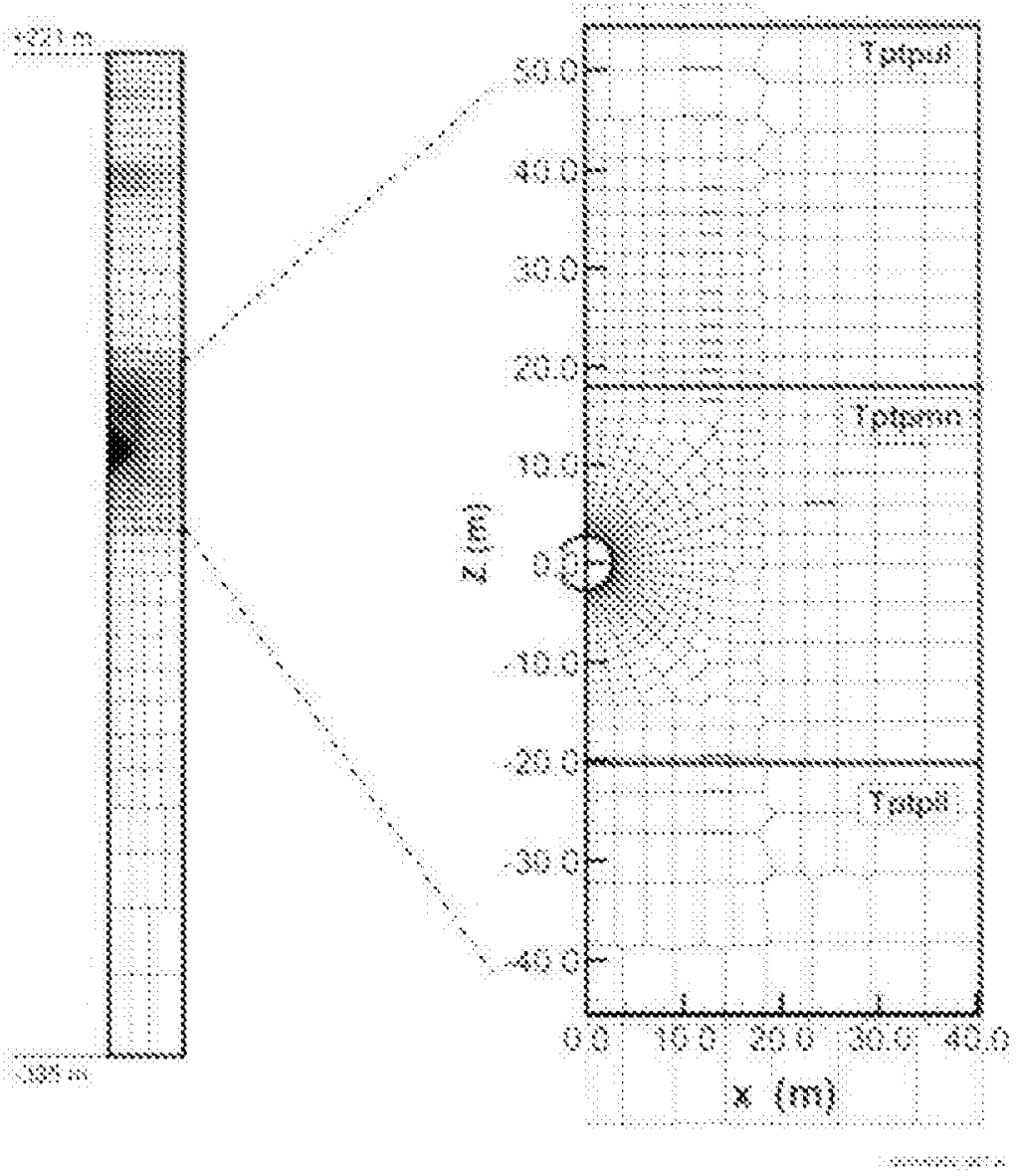

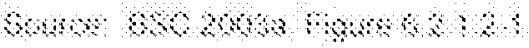

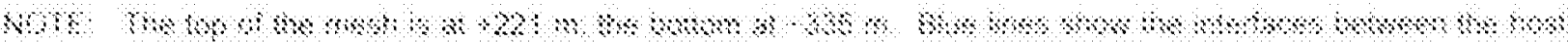

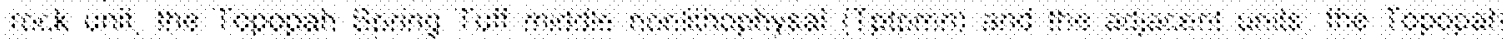

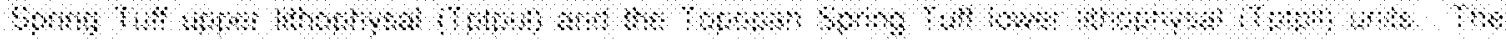

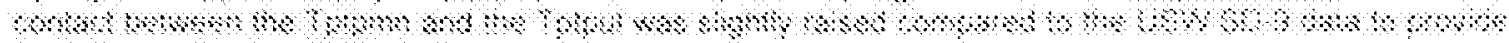

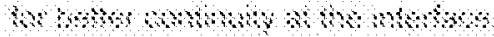

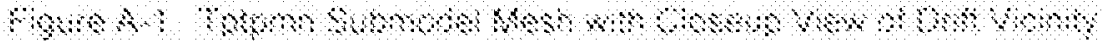


discrete fractures terminating at the drift ceiling) are not explicitly modeled but are lumped into an effective capillary-strength parameter determined by calibrating the model against seepage-rate data, which contain the relevant information about these effects. This conceptualization and approach are considered a suitable basis for a model designed to make predictions of seepage averaged over a drift section of the length of a waste package.

The numerical process model used for reproducing seepage-rate data from liquid-release tests and to predict seepage into waste emplacement drifts solves the Richards equation (Richards 1931) for saturated-unsaturated flow through porous materials. The van Genuchten-Mualem constitutive relations (van Genuchten 1980) describe the capillary pressure and relative liquid permeability in the fracture continuum as a function of liquid saturation. This approach captures the main driving forces (gravity, viscous, and capillary forces) and physical phenomena (phase interference) relevant for modeling unsaturated flow and seepage in a geologic medium.

To appropriately include small-scale heterogeneity, the spatial structure of the air-permeability data was analyzed, and the resulting geostatistical parameters were used to generate multiple realization of a spatially correlated permeability field, which were conditioned on the permeabilities measured in borehole intervals. The permeability fields were eventually mapped onto the numerical grid; an example is shown in Figure 4-1. The numerical grids created for the simulation of liquid-release tests represent an appropriate section of the formation around the injection interval, including the underground opening.

Evaporation from the drift surface is accounted for by specifying a time-dependent water-potential boundary condition based on Kelvin's equation, where the thickness of the diffusive boundary layer was determined from evaporation experiments at the seepage test location. 


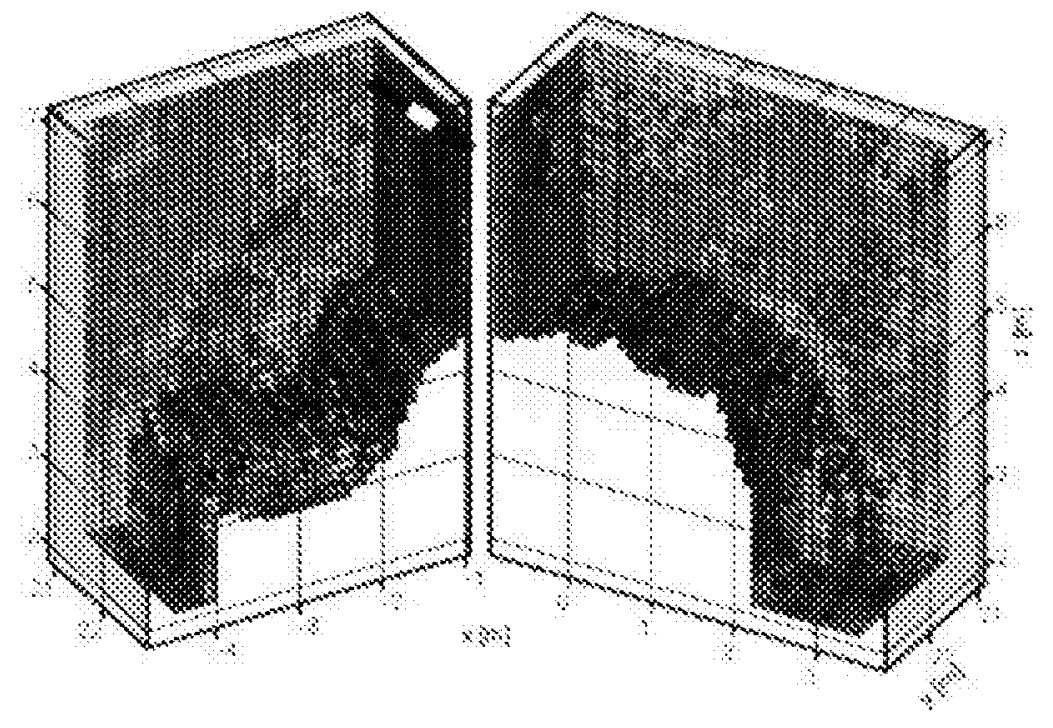

3.

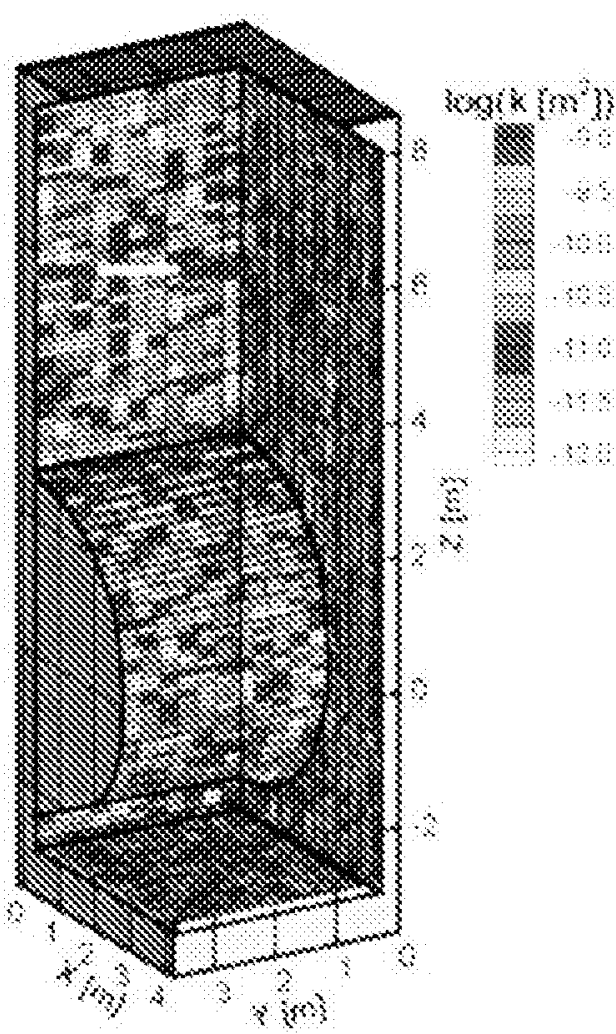

$(1)$ $\$+\infty$

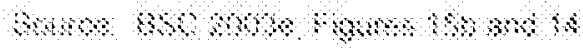

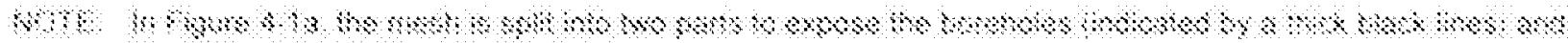
She

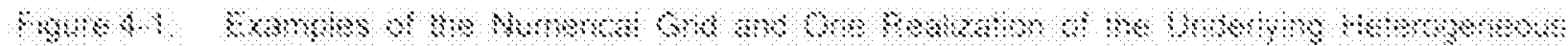

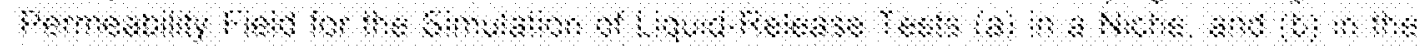

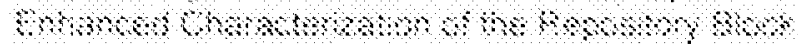

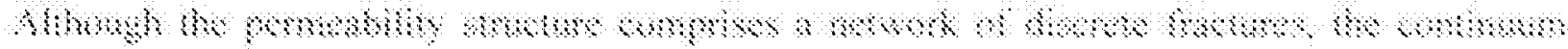

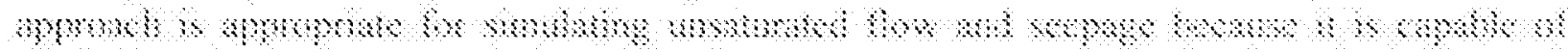

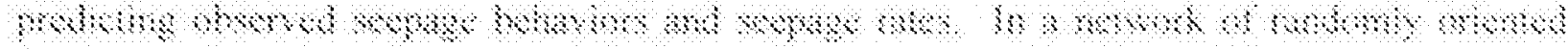

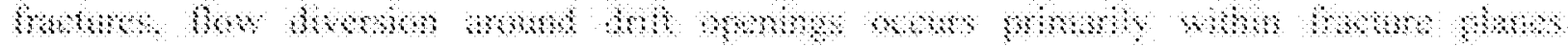

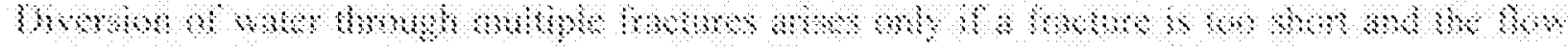

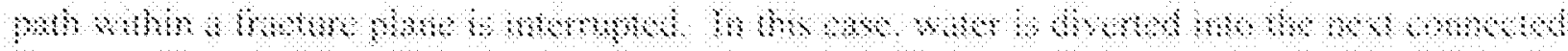

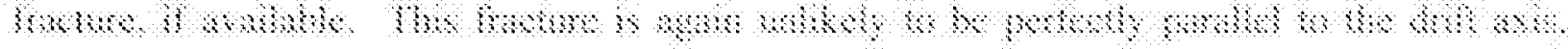

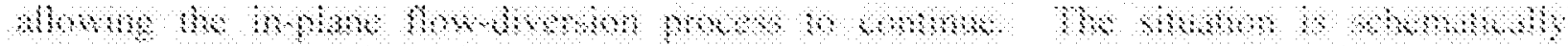

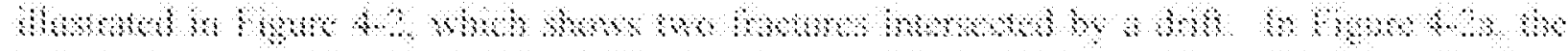

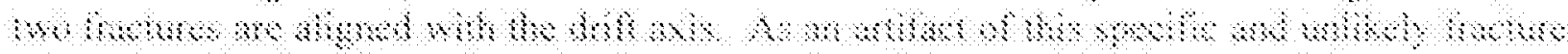

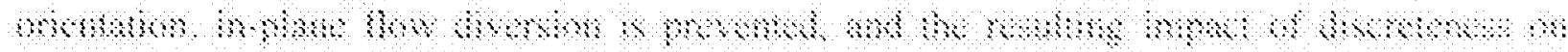

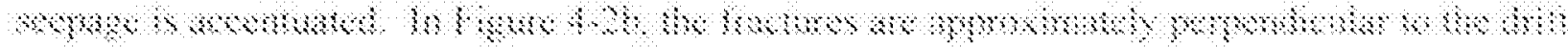

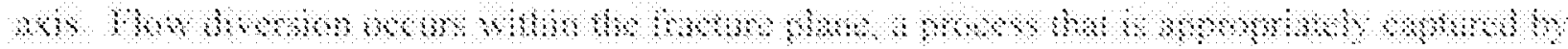




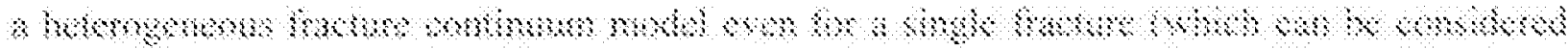

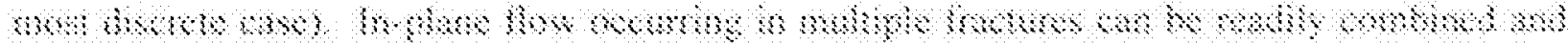

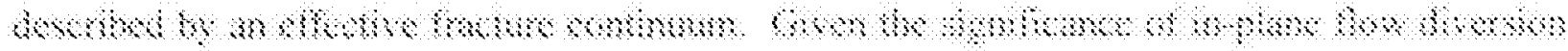

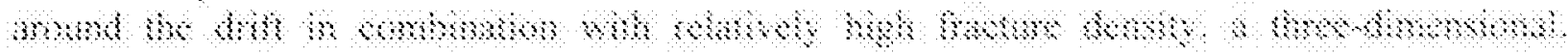

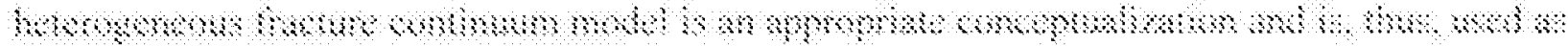

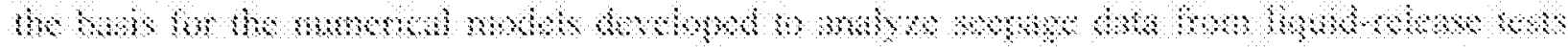

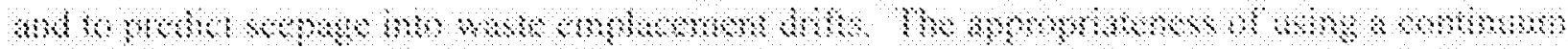

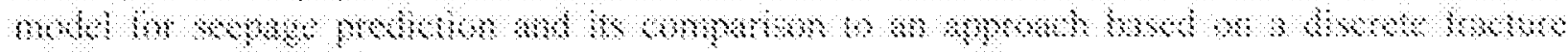

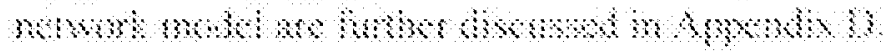

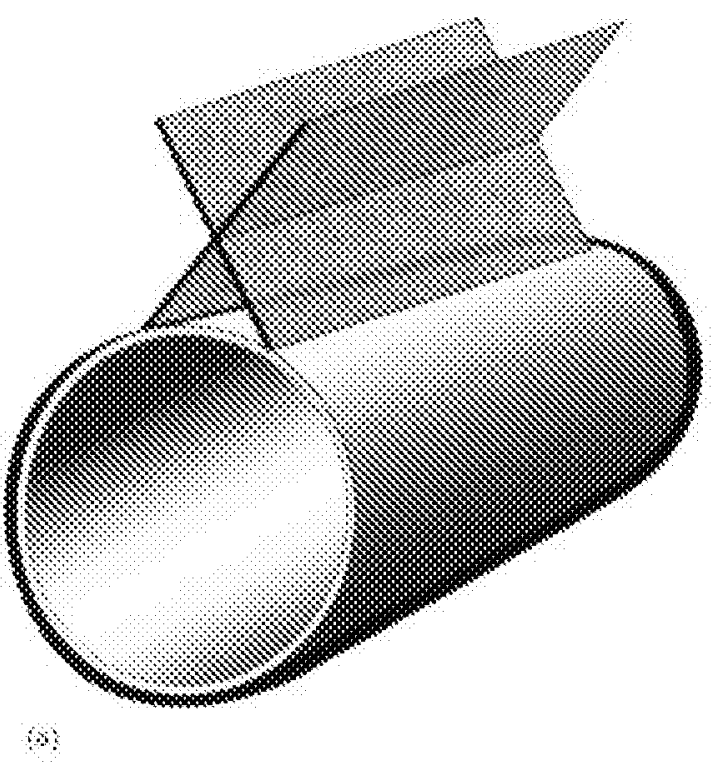

3

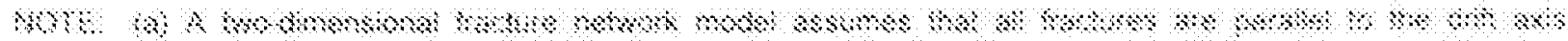

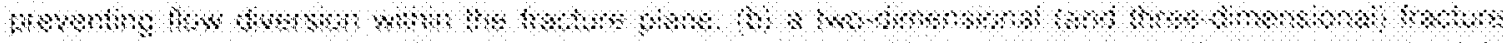

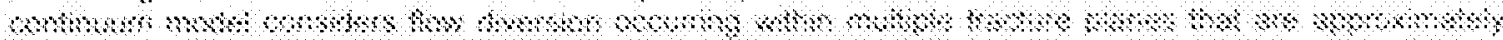

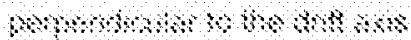

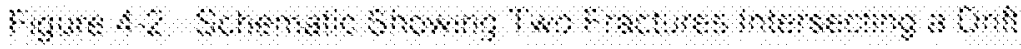

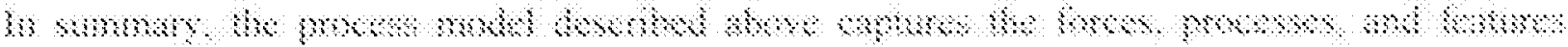

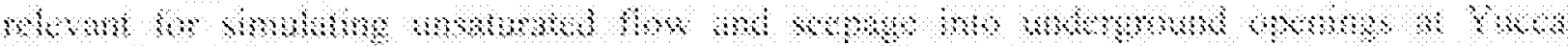

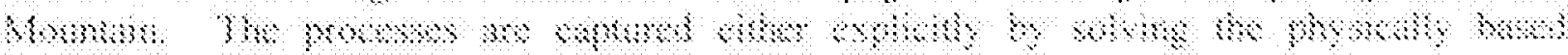

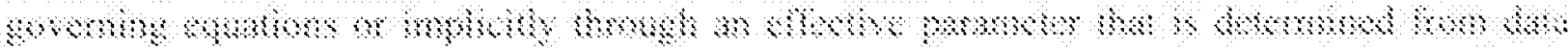

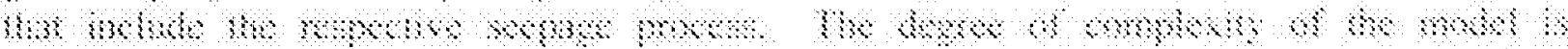

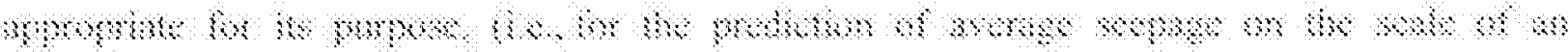

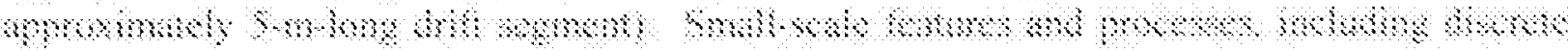

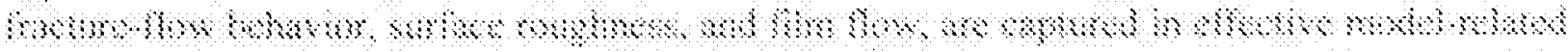

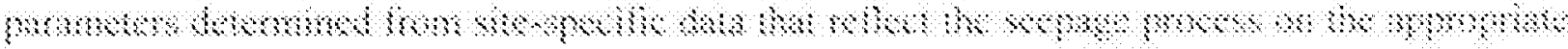

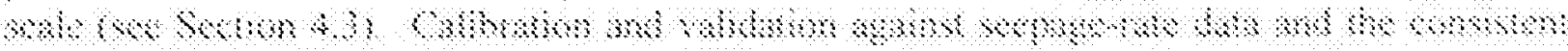

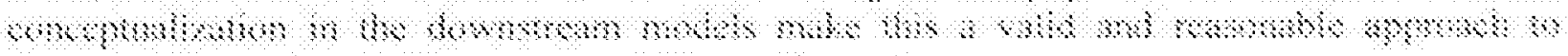
Sxpm 


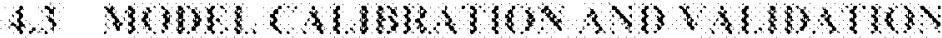

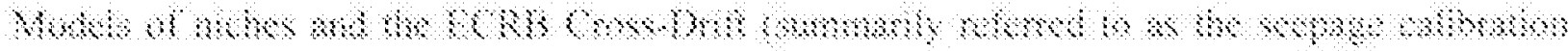

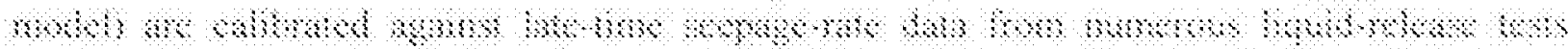

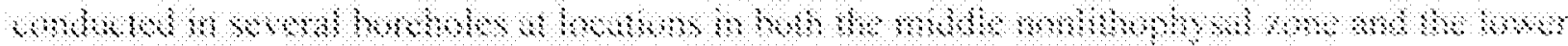

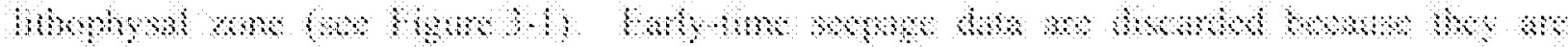

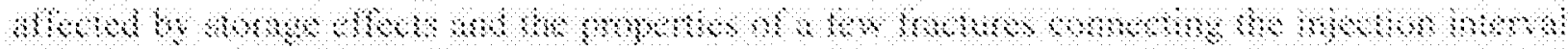

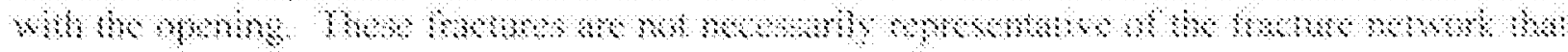

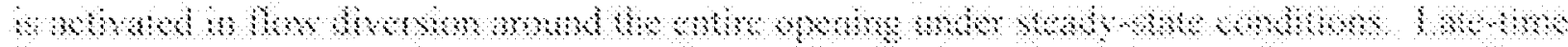

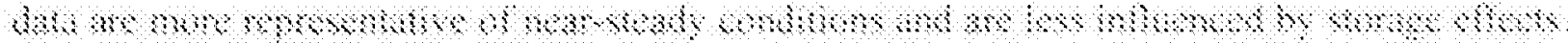

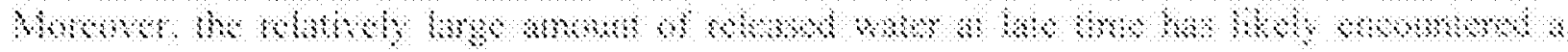

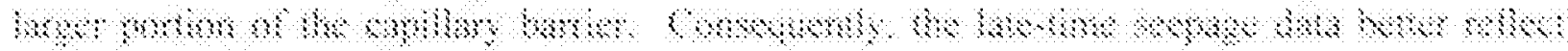

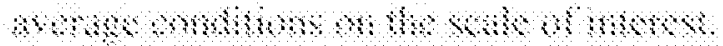

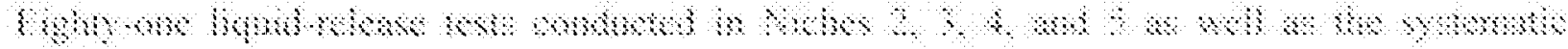

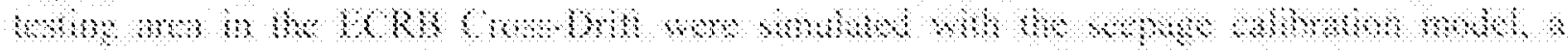

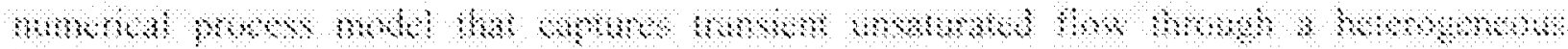

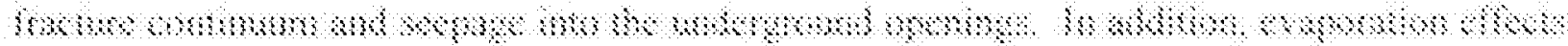

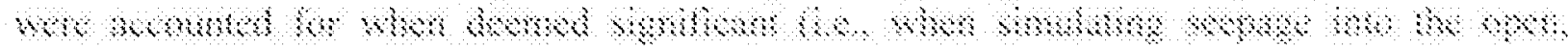

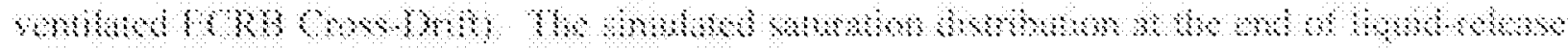

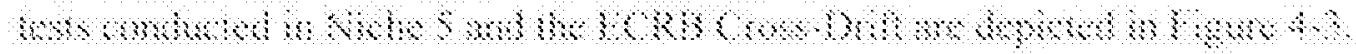

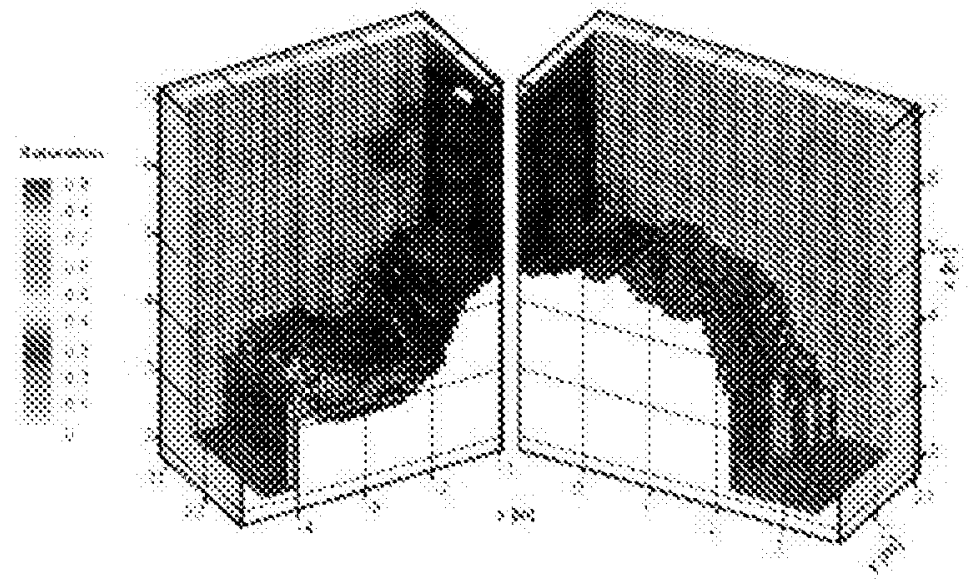

3

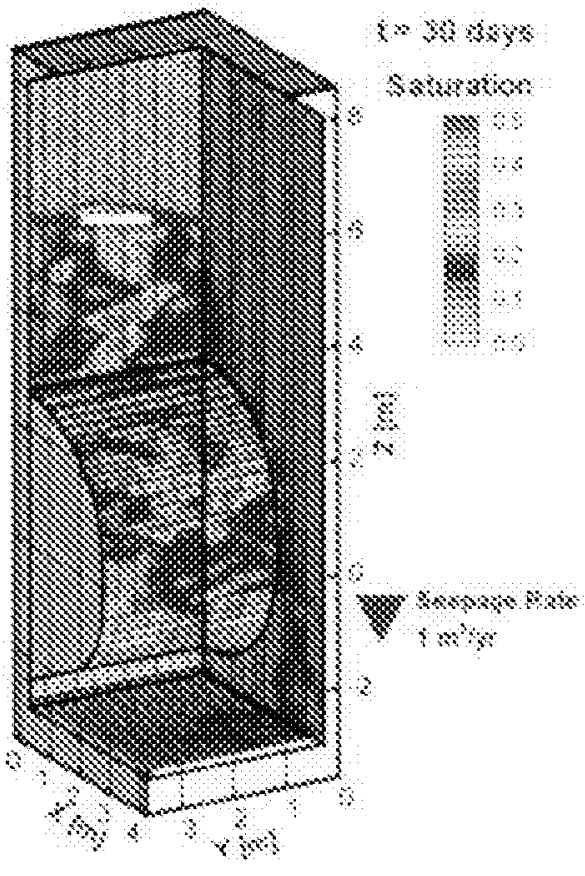

3

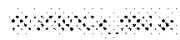

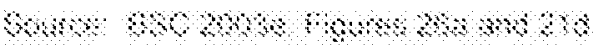

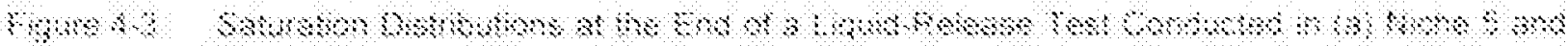

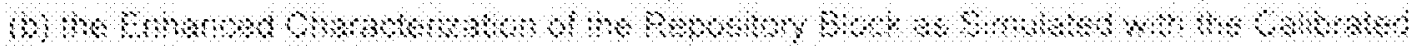

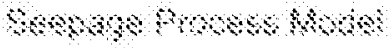


Measured seepage-rate data from 22 liquid-release tests performed in boreholes above Niches 3, 4 , and 5 and along the ECRB Cross-Drift were used to calibrate the seepage calibration model and to estimate the seepage-relevant, model-related van Genuchten capillary-strength parameter $1 / \alpha$. The remainder of the seepage-rate data was used to validate the seepage calibration model, (i.e., to determine whether it is appropriate and adequate for its intended use). The choice of the tests used for calibration and validation is discussed in Seepage Calibration Model and Seepage Testing Data (BSC 2003e, Section 6.6.3.2)

Examples of calibrated liquid-release tests conducted along the ECRB Cross-Drift and in Niche 5 are shown in Figure 4-4. For the tests conducted along the ECRB (Figure 4-4a, b, and c), a significant component of the fluctuations in both the simulated and observed seepage rates are a result of variations in the relative humidity and, thus, evaporation potential in the ventilated drift; the effect is appropriately captured by the model. No such fluctuations are observed in the Niche 5 test, where relative humidity was approximately constant at 85 percent.

Figure 4-5 shows examples of validation runs, in which seepage rates for liquid-release tests conducted in Niche 3 were predicted with the calibrated model using a single parameter set and compared to measured data that had not been used for model calibration. Linear error propagation analysis yielded the uncertainty of the model prediction as a result of uncertainty in the input parameters. The data fall within the range of predicted seepage rates. Based on the acceptance criteria outlined in Seepage Calibration Model and Seepage Testing Data (BSC 2003e, Section 7.2), seven of the eight test predictions are considered acceptable. In Test UM 4.88-5.18, the observed late-time seepage rates are slightly larger than the relatively narrow uncertainty band. The prediction would be considered acceptable if the chosen uncertainty in the input parameters were marginally increased (e.g., to account for uncertainty as a result of the stochastic nature of the underlying heterogeneous permeability field). This uncertainty will be included in TSPA calculations. 


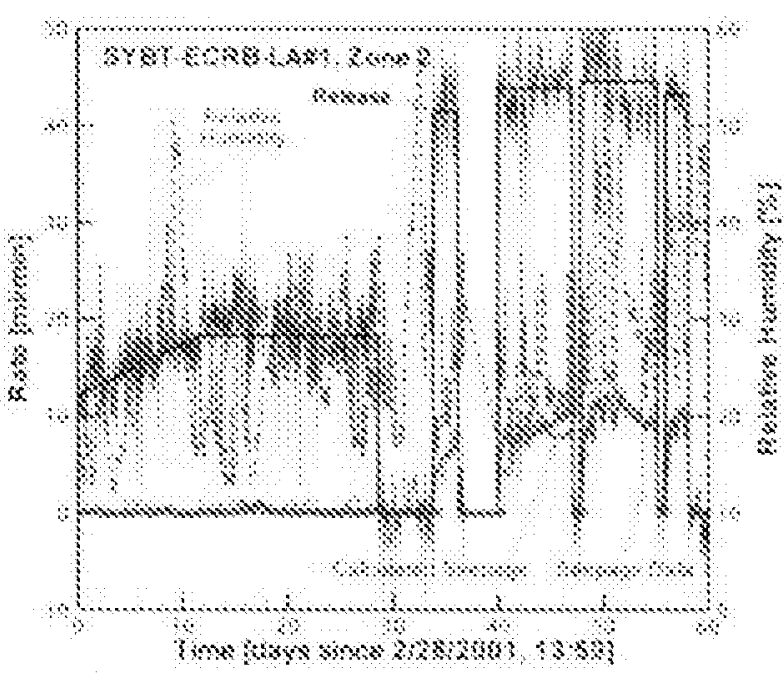

(a)

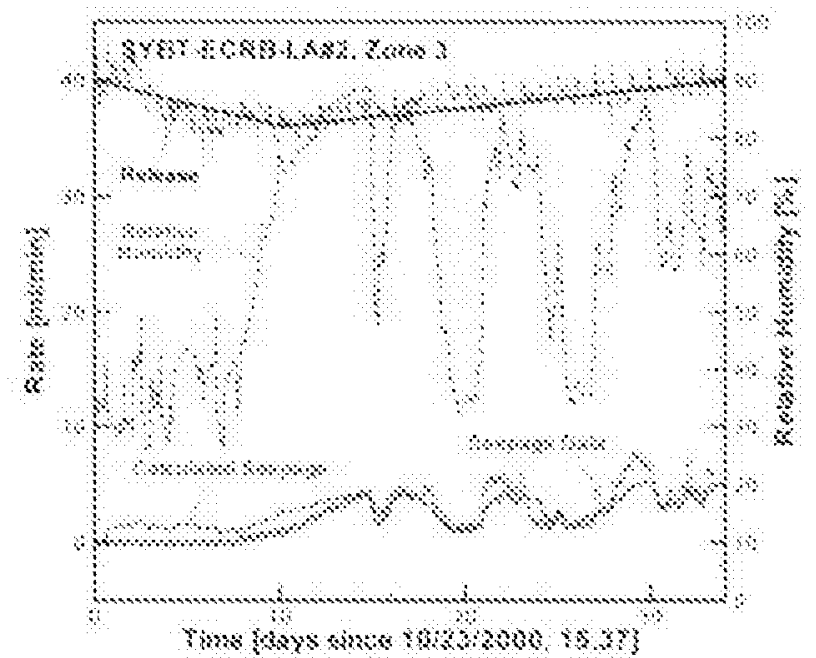

(c)

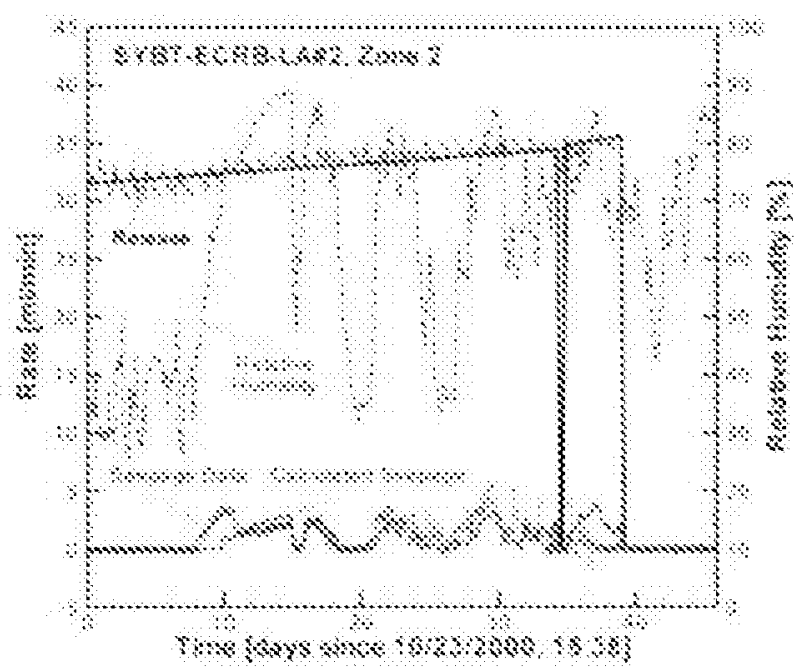

(b)

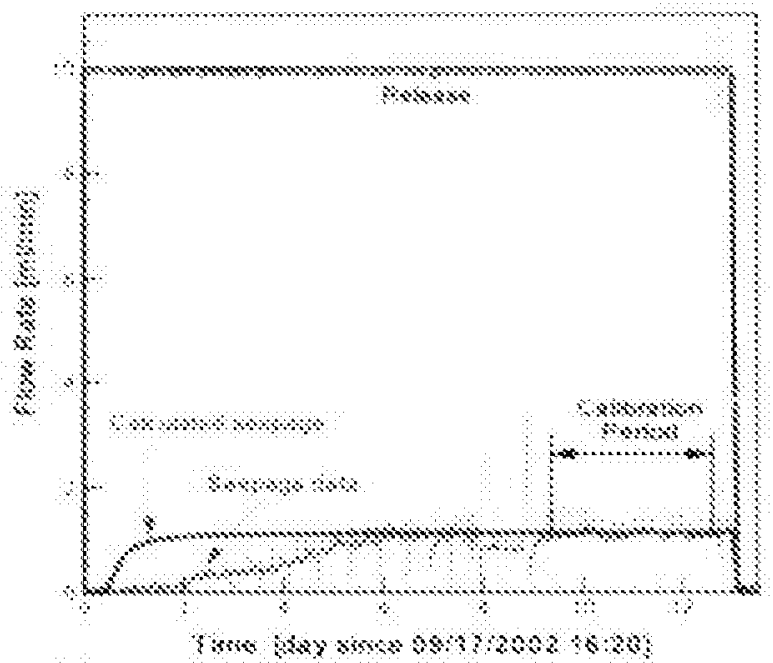

(o)

-

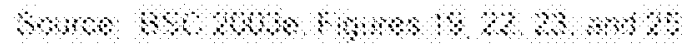

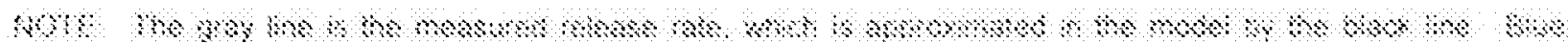

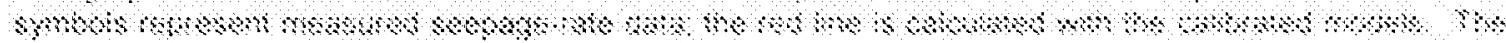

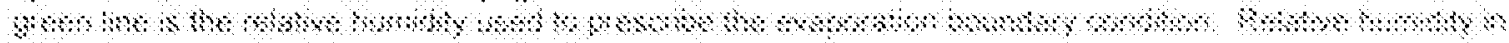

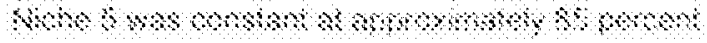

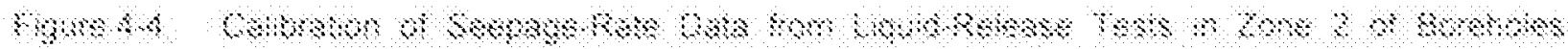

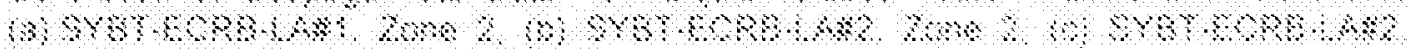

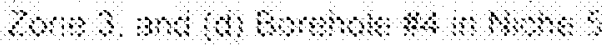



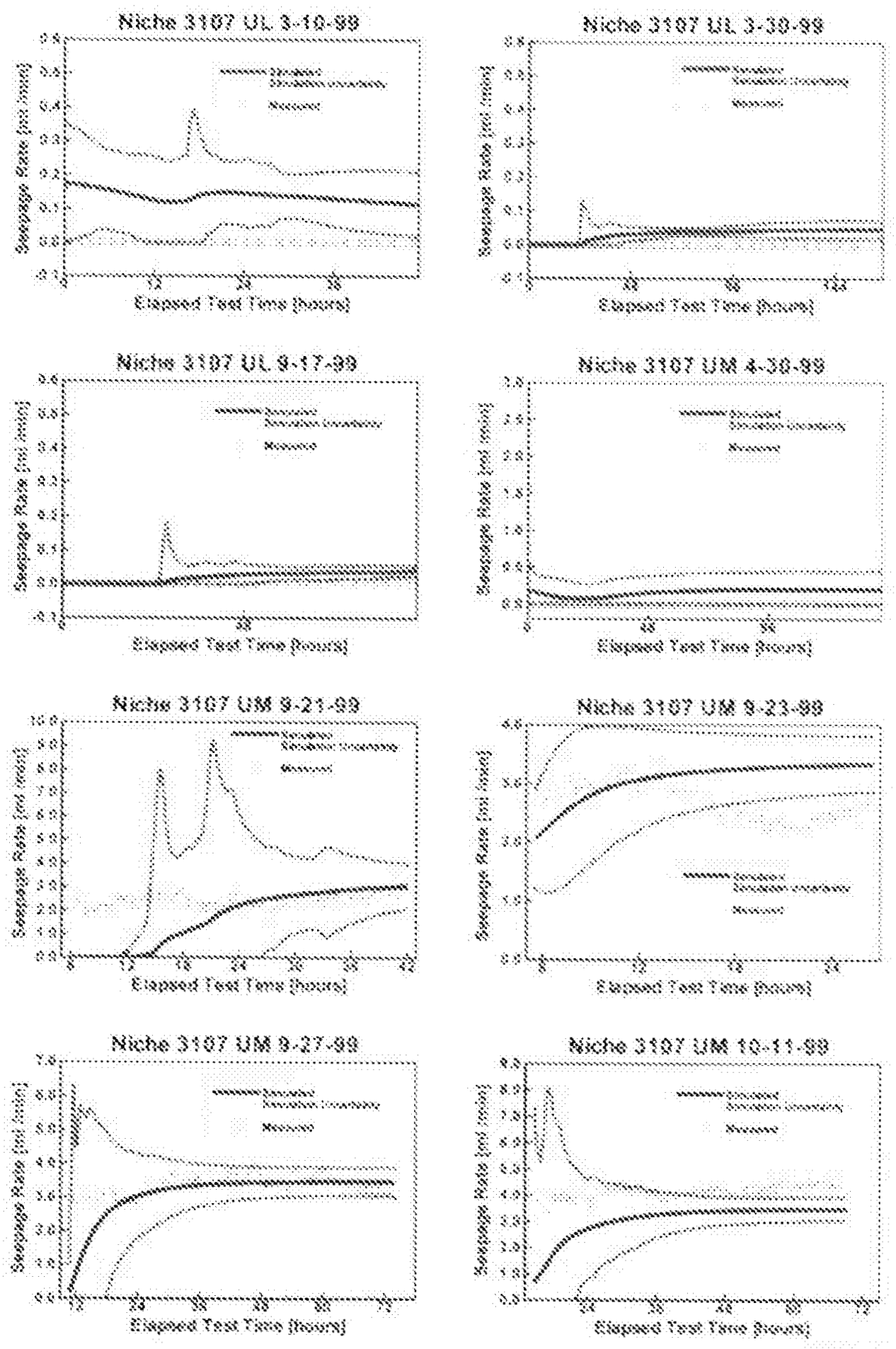

sume $80.30 \mathrm{~s} \times \mathrm{gum}$ s

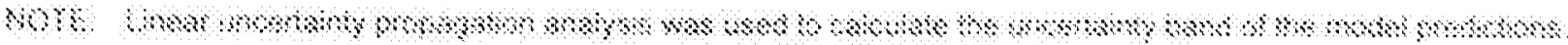

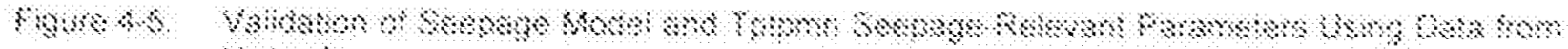
Moks 8 
The capillary-strength parameter for each tested borehole interval was determined by calibrating the model against multiple tests using different liquid-release rates. Some of these release rates induced a local percolation flux that was above the seepage threshold (i.e., water dripped into the opening and yielded seepage-rate data valuable for calibration). However, tests were also performed below the seepage threshold. Moreover, the model was validated against tests conducted above and below the seepage threshold. The system was probed and the model was validated for the critical range of percolation rates about the seepage threshold. Seepage predictions for natural percolation fluxes that are even less than the low fluxes (below the seepage threshold) induced during the low-rate tests will yield the correct result, namely, zero seepage. A high-infiltration climate or strong flow focusing can cause the natural local percolation flux to exceed the seepage threshold.

In summary, the capillary strength parameters determined from relatively high-rate liquid-release tests provide a solid basis for seepage predictions under low and high natural percolation fluxes. The validation approach demonstrates that the seepage process model is capable of predicting the behavior above and below the seepage threshold.

The analysis of seepage-rate data for the determination of seepage-relevant parameters can be summarized as follows:

1. The testing and modeling approach is considered adequate for providing the conceptual basis and parameters for predictive seepage models. The approach consists of analyzing seepage by means of a numerical process model that is calibrated against seepage-rate data from liquid-release tests conducted within the repository host units.

2. The estimation of seepage-relevant, model-related, effective parameters on the scale of interest is an appropriate methodology provided that the structure of the prediction model (see Sections 4.4 and 4.5) is consistent with the model used for calibration (the seepage calibration model).

3. Seepage properties are spatially variable. The variability has been examined by performing liquid-release tests at various sites along the ESF and the ECRB. Spatial variability in the estimated van Genuchten capillary-strength parameter $1 / \alpha$ is relatively large compared to the estimation uncertainty at a given location. The main contribution to the estimation uncertainty is small-scale heterogeneity that can only be described stochastically. Random fluctuations in seepage-rate data lead to insignificant uncertainty in the parameter estimates.

\subsection{PREDICTION OF AMBIENT SEEPAGE}

While the seepage calibration model described in Section 4.3 simulates liquid-release tests and seepage into niches and the ECRB for calibration and validation purposes, the seepage model for performance assessment was developed to predict total seepage into a section of a waste emplacement drift under ambient percolation conditions (BSC 2003i). Isothermal flow simulations were performed over wide ranges of selected key parameters. The key parameters affecting ambient seepage are the effective capillary-strength parameter, the reference permeability, and the local percolation flux imposed at the upper model boundary. Conceptually 


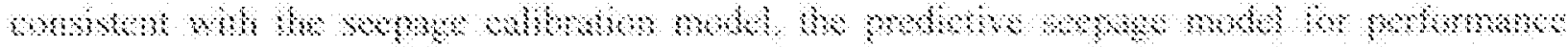

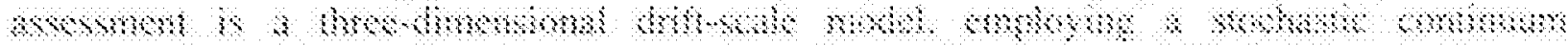

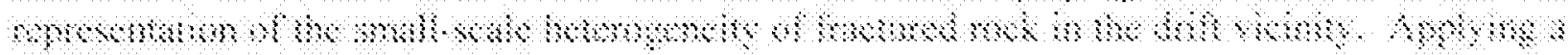

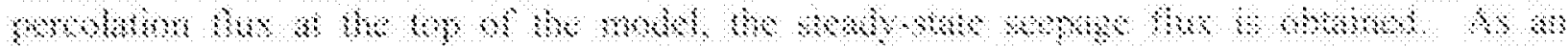

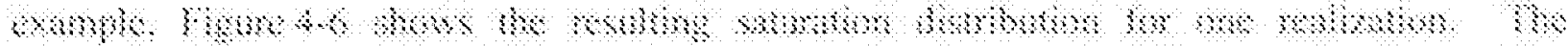

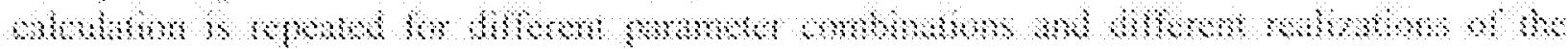

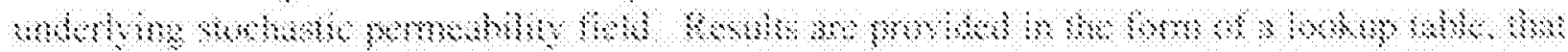

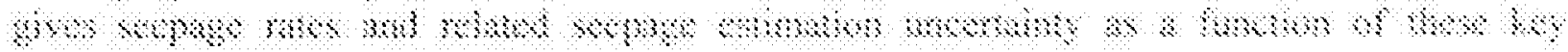

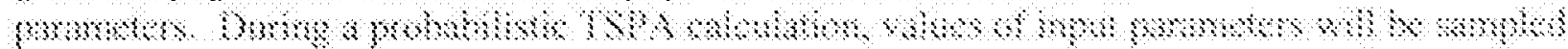

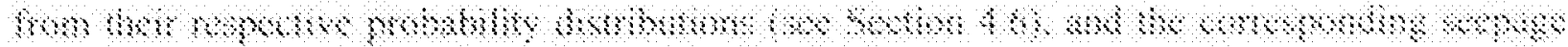

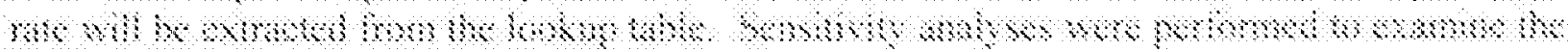

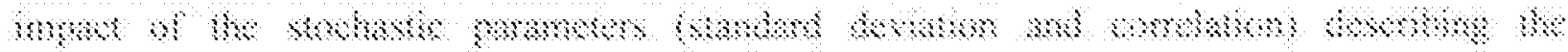

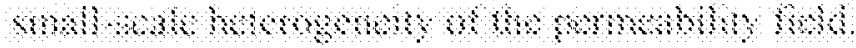

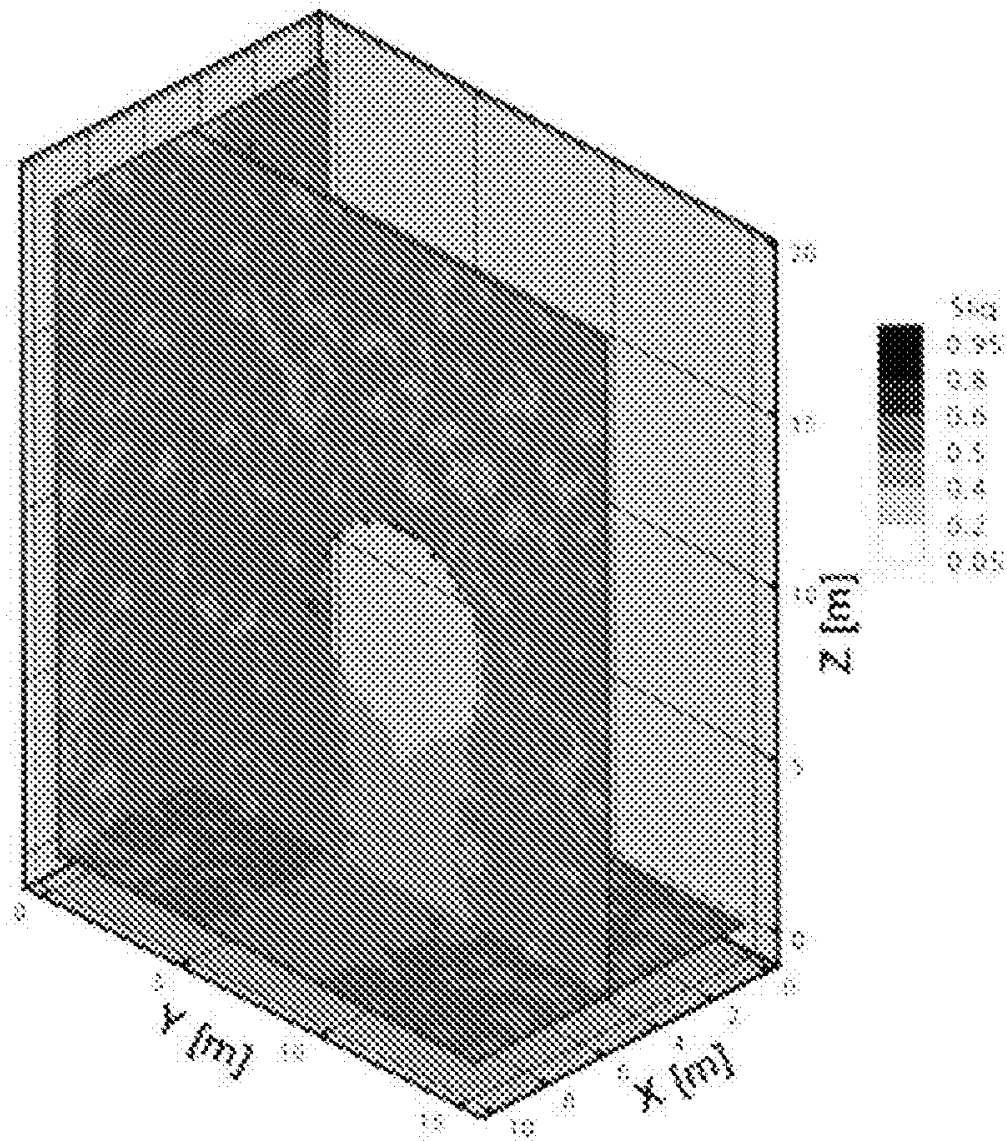

$\operatorname{sen}$

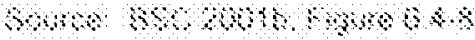

MH Mo ow

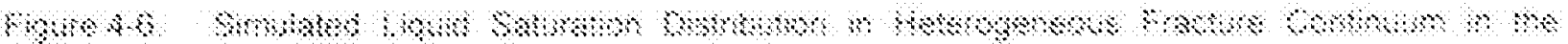

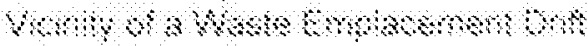


The seepage model assumes that the relative humidity within the drift is constant and 100 percent. This assumption is appropriate for times significantly following the cessation of ventilation that steady state humidities in the drift are appropriate. This assumption effectively forces all incoming moisture into the drifts to be liquid water (i.e., seepage). Observation made in the ECRB (presented in Section 3.2) described the possible effects associated with transient moisture flux from the drift wall into the drift and the subsequent redistribution of that moisture due to small temperature differences along the drift.

The systematic simulations performed by the seepage model performance assessment cover a wide range of capillary-strength values $1 / \alpha$ (from $100 \mathrm{~Pa}$ to $1,000 \mathrm{~Pa}$ ), mean permeability values $\log _{10}\left(k\left[\mathrm{~m}^{2}\right]\right.$ ) (from -14 to -10 ), and local percolation flux (from 1 to $1,000 \mathrm{~mm} / \mathrm{yr}$ ). For each parameter combination, 20 realizations of the heterogeneous permeability fields were simulated. The range of results from the 20 realizations provides information about the estimation uncertainty in the predicted seepage rates because of uncertainty in the stochastic small-scale heterogeneity.

Example results from the seepage model performance assessment are illustrated in Figure 4-7. The figure gives contours of the simulated seepage percentage into a drift with a diameter of $5.5 \mathrm{~m}$ as a function of the capillary-strength parameter $1 / \alpha$ and the mean fracture permeability for selected percolation fluxes between $1 \mathrm{~mm} / \mathrm{yr}$ and $1,000 \mathrm{~mm} / \mathrm{yr}$. (These percolation fluxes are local; they include potential flow focusing effects.) The seepage percentage (the ratio between the seepage rate and percolation flux over the drift area) indicates the flow diversion capability of the capillary barrier at the drift surface. As expected, the seepage percentage is large for small capillary strength, small permeability, and large percolation flux. In these cases, seepage may approach 100 percent (i.e., there is no flow diversion at the drift wall), and the entire percolation flux seeps into the drift. In contrast, the seepage percentage is small for all cases with strong capillarity, large permeability, and small percolation flux. In many of these cases, there is no seepage at all; the entire percolation flux is diverted around the drift by capillary forces because the percolation flux is below the seepage threshold for the given parameters. 


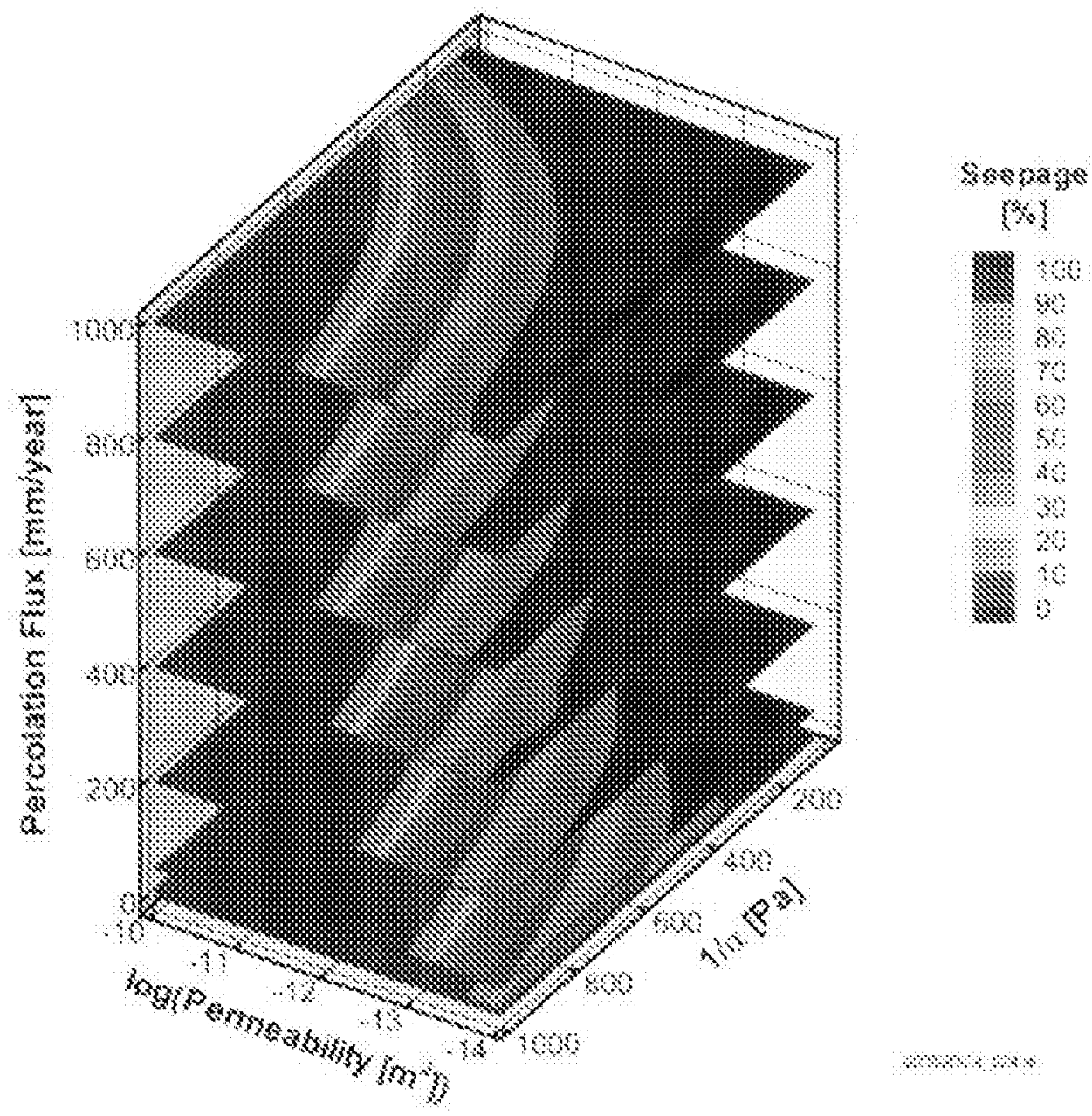

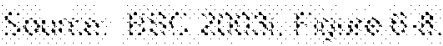

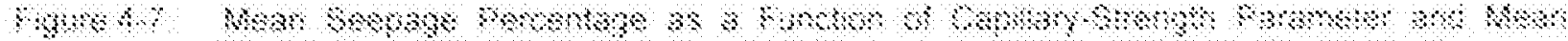

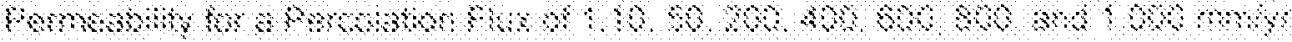

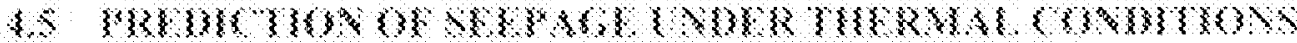

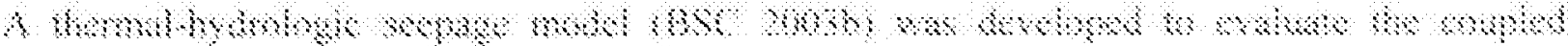

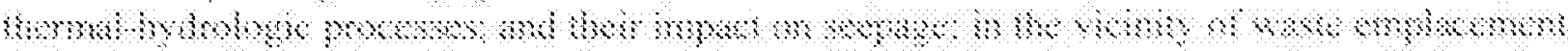

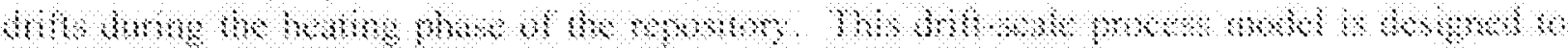

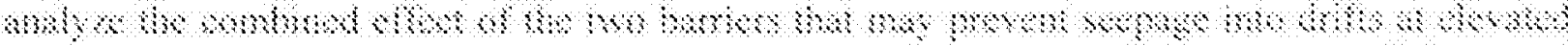

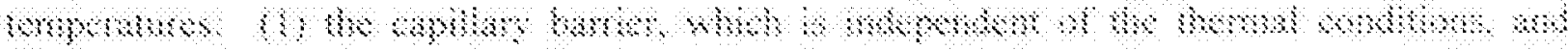

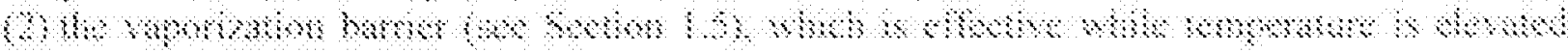

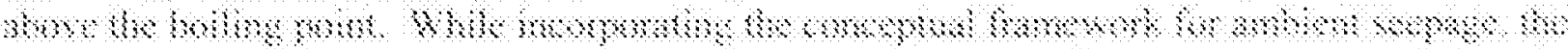
therm

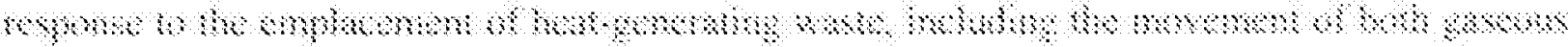

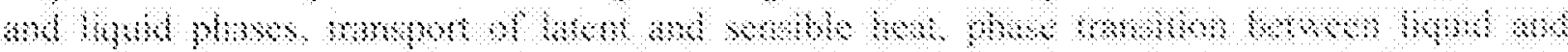

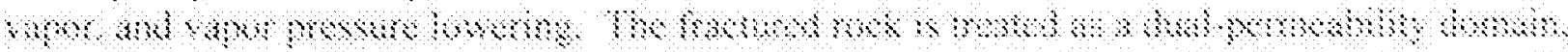

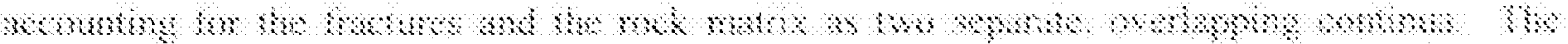

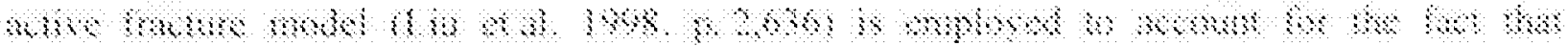


unsaturated flow may be restricted to a limited number of (active) fractures and that flow within a fracture is likely to be channelized. A stochastic continuum model is implemented for fractures near the drift that considers the small-scale variability of permeability to account for flow channeling. The capillary-strength parameter close to the drift wall was derived from the properties provided by the calibration against seepage-rate data (see Section 4.3).

Transient simulations in a two-dimensional cross section (extending from the ground surface to the water table; see Figure 4-8) were performed explicitly to calculate percolation to the drift during the heating phase of the repository, and to calculate directly transient seepage rates into the drift under elevated temperature conditions. Relevant parameters varied in the evaluation of thermal seepage are the thermal operating mode, the local percolation flux, and selected rock properties. Results of this model were used in the seepage abstraction to develop an appropriate methodology of adjusting the seepage model performance assessment results to account for thermally perturbed conditions.

The thermal-hydrologic seepage model was validated by comparison with in situ heater tests conducted at Yucca Mountain (BSC 2003b, Section 7), with particular focus on the DST. The model validation included quantitative evaluation of continuously measured temperature data with a detailed analysis of subtle temperature signals indicative of thermal-hydrologic coupling, as well as qualitative evaluation of periodic measurements that monitored moisture redistribution processes using geophysical methods, air-injection data, and withdrawal of liquid water in packed-off boreholes.

The thermal hydrologic seepage model predictions regarding the effectiveness of the vaporization barrier were also tested by comparison with an alternative conceptual model of water flow in the superheated rock environment (BSC 2003b, Section 6.3). In this alternative model, the thermally perturbed downward flux from the condensation zone toward the superheated rock zone is conceptualized to form episodic preferential-flow events (finger flow). The effectiveness of the vaporization barrier was then tested for the extreme conditions where downward flux in small fingers is fast and large in magnitude compared to average flow. A semi-analytical solution (Birkholzer 2003) was employed to simulate the complex flow processes of episodic finger flow in a superheated fracture. With this solution, the maximum penetration distance into the superheated rock was determined for specific episodic flow events and thermal conditions, and the amount of water arriving at the drift crown was calculated. It was shown that finger flow is not likely to penetrate through the superheated rock during the first several hundred years of heating, when rock temperature is high and boiling conditions exist in a sufficiently large region above the drifts. Only later, when the boiling zone is small and the impact of vaporization is limited, may channelized water arrive at the drift crown. This issue is further discussed in Appendix A.

The thermal-hydrologic seepage model was applied to simulate the thermal-hydrologic coupled processes for a period of 4,000 years after waste emplacement. A series of selected simulation cases was conducted for the Tptpmn and Tptpll submodels, comprising different thermal loads, various percolation flux scenarios, different capillary-strength parameters, and different conceptual models for fracture-matrix interaction (see overview of simulation cases in BSC $2003 \mathrm{~b}$, Section 6.2.1.6). The simulation results relevant for seepage abstraction are briefly discussed below. 


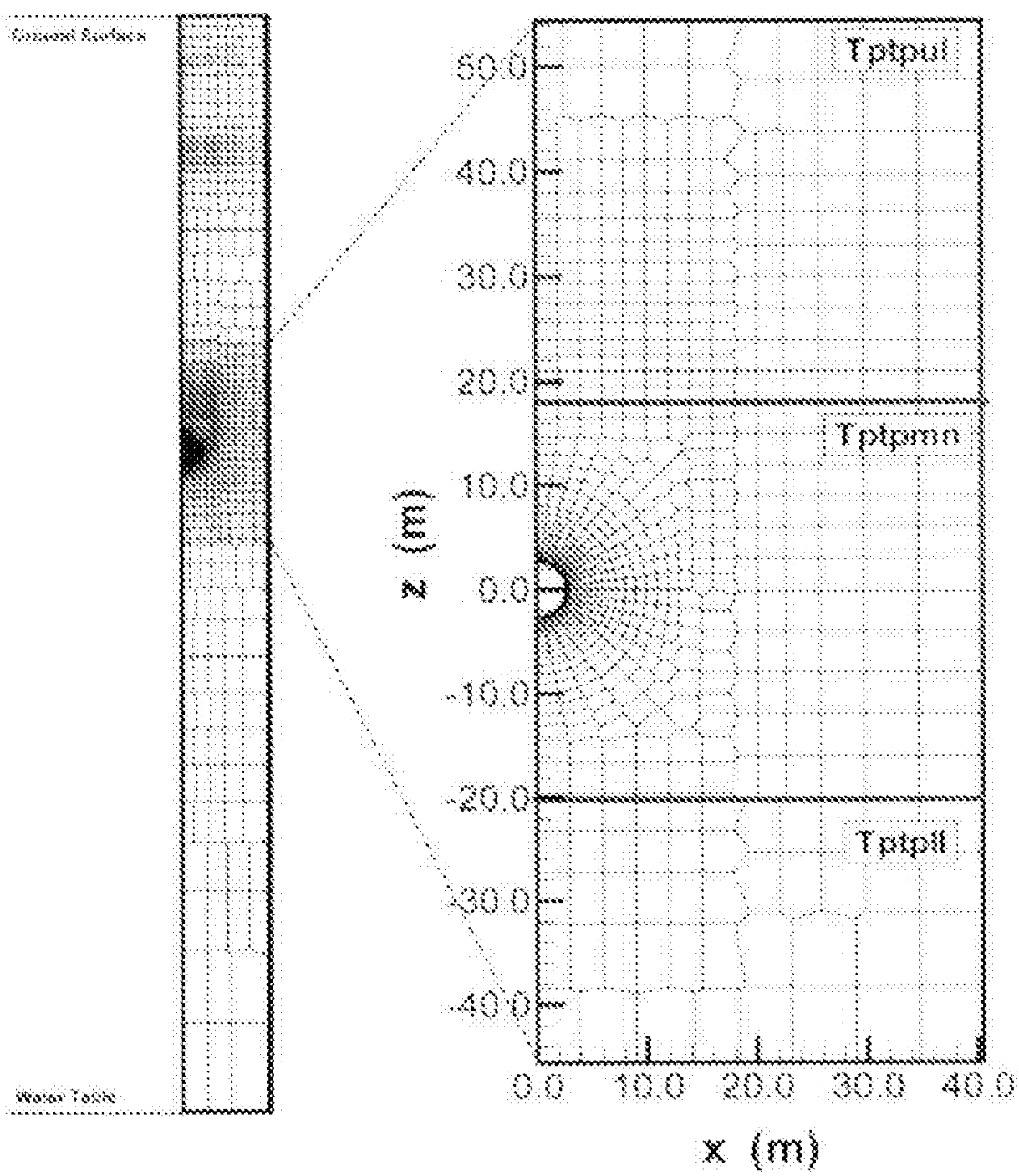

बे + +

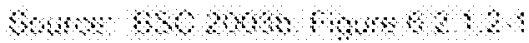

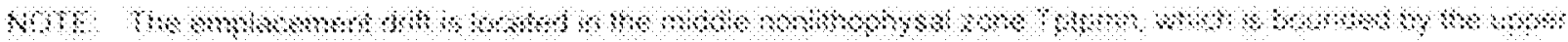
\$6p

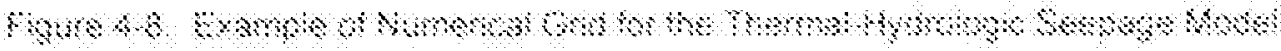

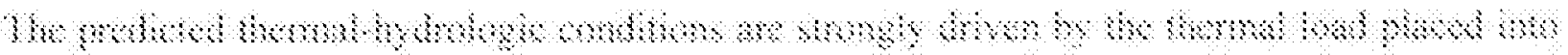

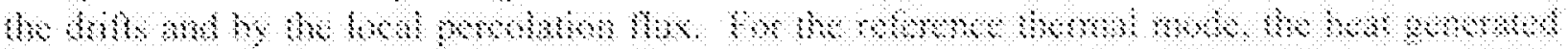

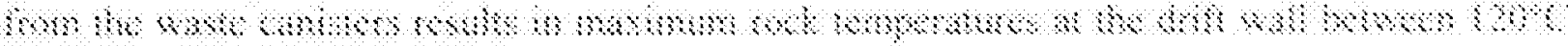

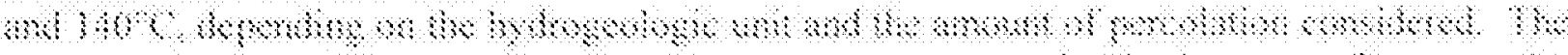

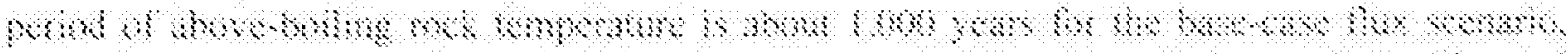

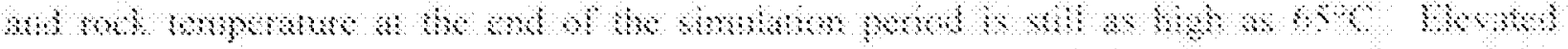

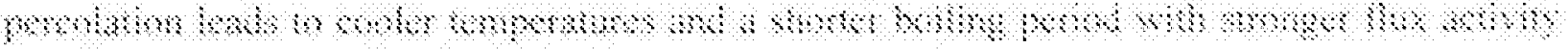

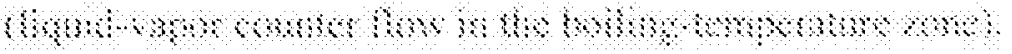


In general, seepage under thermal conditions (thermal seepage) is possible only when (a) water arrives at the drift wall (depending on the vaporization impact), and (b) the saturation at the drift wall exceeds a given threshold value, defined by the capillary barrier effect at the rock-drift interface. The modeling results consistently demonstrate that the thermal perturbation of the flow field, causing increased downward flux from the condensation zone toward the drifts, is strongest during the first few hundred years after closure, corresponding to the time period when rock temperature is highest and the vaporization barrier is most effective. Even for high percolation fluxes into the model domain and strong flow channeling as a result of fracture heterogeneity, water cannot penetrate far into the superheated rock during the time that rock temperature is above boiling. Thus, the potential for seepage is small. The majority of the mobilized water is diverted around the dryout zone and drains away from the drift, as shown in Figure 4-9a. At the time when temperature has returned to below-boiling conditions (see Figure 4-9b), fractures start to be rewetted at the drift wall. However, while the vaporization barrier has become less effective, the capillary barrier at the drift wall will continue to reduce (or prevent) water seepage into the drift.

Transient seepage rates were explicitly calculated by the thermal-hydrologic seepage model to quantify the potential for seepage during the thermally perturbed time period. These transient seepage rates were compared with results from ambient (steady-state) simulations to evaluate the vaporization barrier. Example results illustrating the evolution of thermal seepage for one realization and a flow-focusing factor of 10 are given in Figure 4-10. No water arrives at the drift during the boiling period (i.e., even without heating of the repository). The capillary barrier at the drift wall is predicted to be fully effective during the first 600 years after waste emplacement. As rock temperature decreases during cool down and the first stepwise change in infiltration occurs at 600 years, the saturation values build up strongly. The change to monsoonal climate at 600 years (from 60 to $160 \mathrm{~mm} / \mathrm{yr}$ ) brings the saturation up to the threshold value for seepage at about 1,400 years after emplacement while still in the monsoon climate period. With the stepwise increase of infiltration at 2,000 years, the seepage percentage increases strongly, and water starts to seep at a second location along the drift wall in the model. At the end of the simulation period, the thermal seepage percentage is at about 17 percent, only slightly smaller than the long-term ambient value of 19.5 percent for a $250 \mathrm{~mm} / \mathrm{yr}$ percolation flux. This provides additional confidence because as two simultaneously acting barriers prevent seepage. 

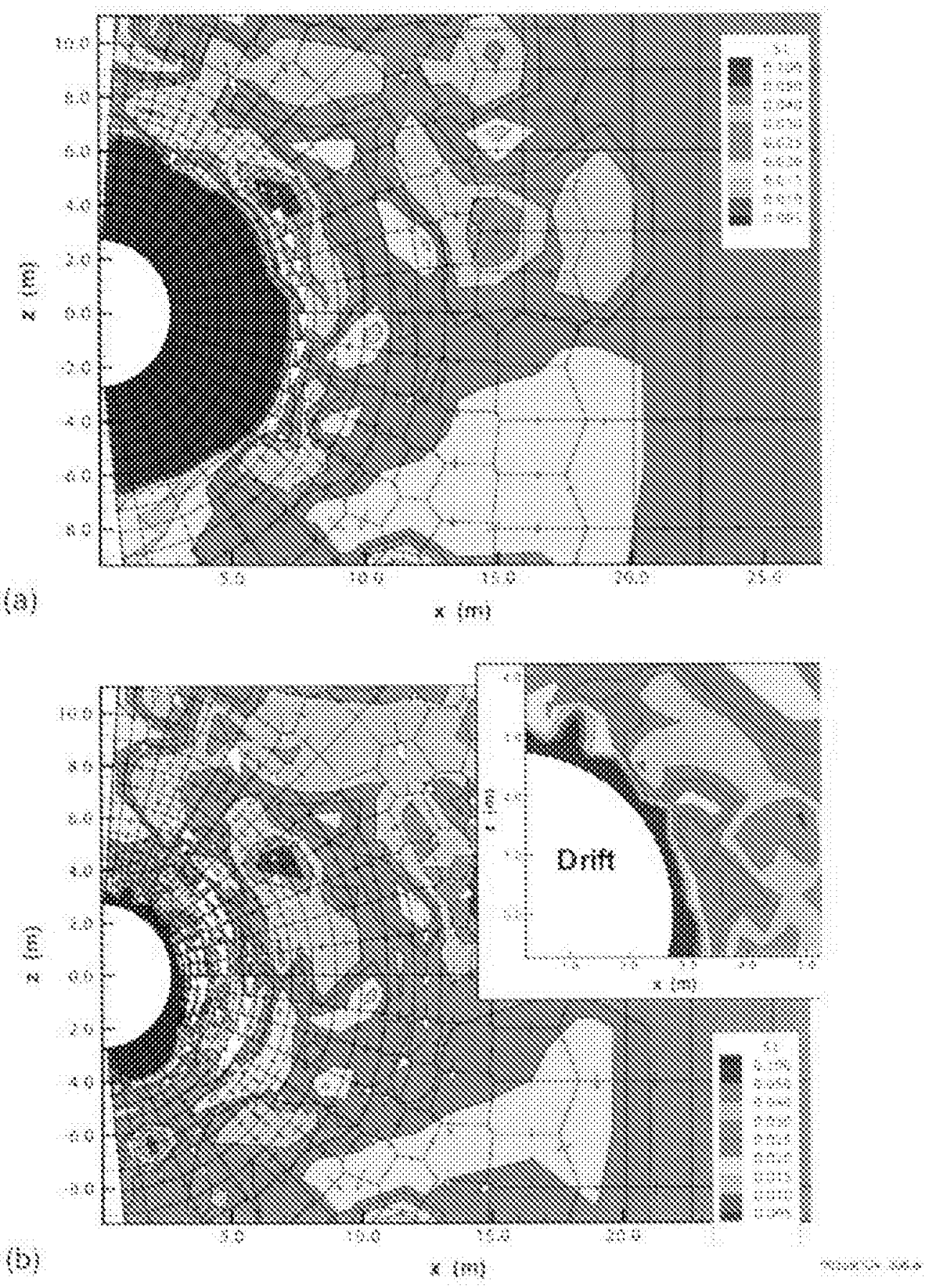

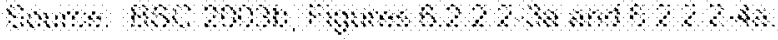

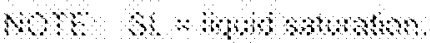

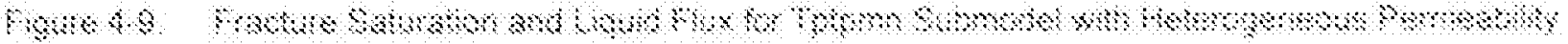

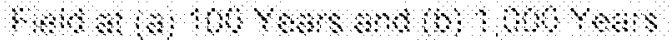




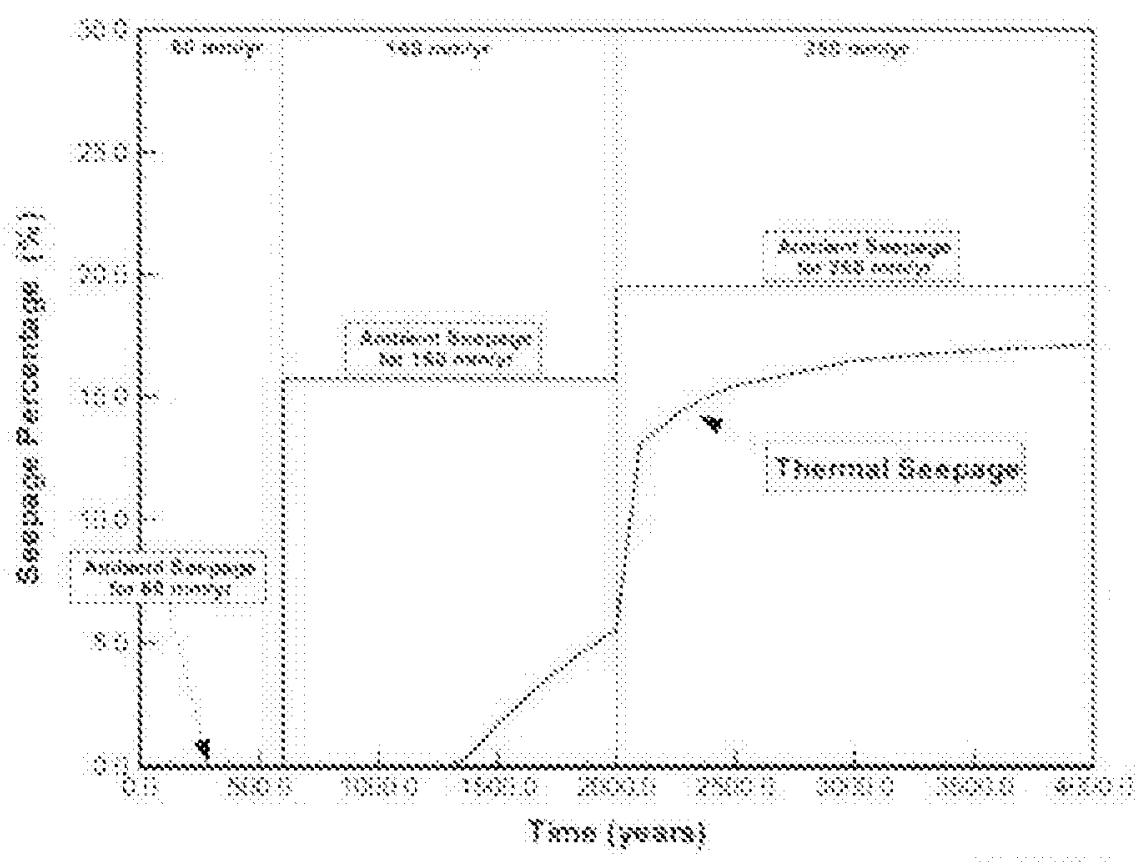

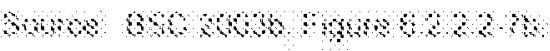

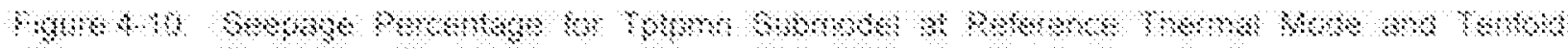
Parmatem

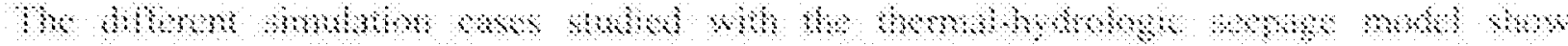

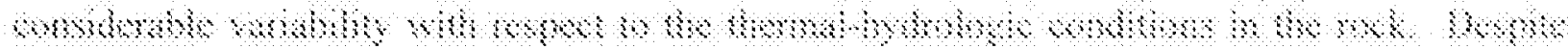

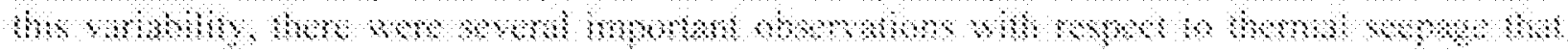

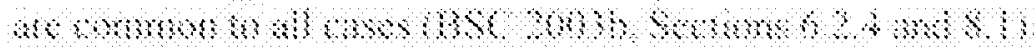

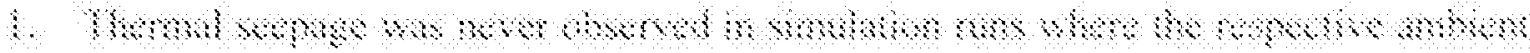
swme $\mathrm{s} \%$ \%

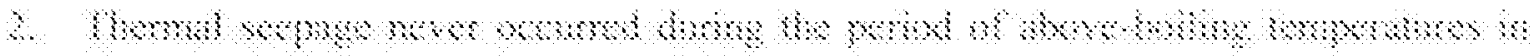

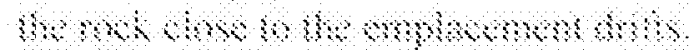

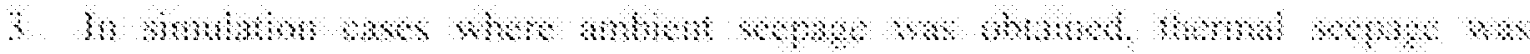

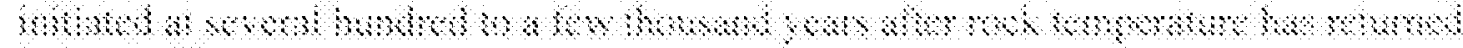
tho $\$$ mins

2. Thmm

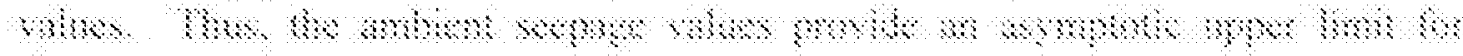
\$amat sapas: 


\subsection{EVALUATION OF COUPLED THERMAL, HYDROLOGIC, AND MECHANICAL EFFECTS ON SEEPAGE}

A drift-scale thermal-hydrologic-mechanical model (BSC 2003g) was developed to assess the magnitude and distribution of stress-induced changes in hydrologic properties and to analyze the impact of such changes on the percolation flux in the rock mass around a repository drift. Heating of the rock will cause thermal expansion of the rock, which in turn will change the stress field around emplacement drifts. Thermally induced changes in the stress field will act upon preexisting fractures, with the result of changing the hydrologic properties of the rock mass.

The modeling framework for the thermal-hydrologic-chemical processes is similar to the thermal-hydrologic seepage model described in Section 4.5. However, while the thermal-hydrologic seepage model focuses on the thermal-hydrologic conditions to evaluate seepage rates for various seepage-relevant parameter cases, the thermal-hydrologic-mechanical simulations concentrate on the heat-induced stress changes and resulting impact on the flow field and formation properties. The model was validated by comparison with rock-mass displacement data (for thermal-mechanical processes) and air-permeability data (for thermal-hydrologicmechanical processes) measured during the heating phase of the DST (BSC 2003g, Section 7). Figure 4-11a shows the predicted changes in air permeability (a seepage-relevant parameter) as a result of both thermal expansion and saturation changes (dryout and condensation effects) during the DST. The overall favorable comparison with measured air permeabilities (see Figure 4-11b) provides confidence that the model predictions can be used as a basis for assessing the impact of property changes induced by coupled thermal, hydrologic, and mechanical processes on seepage.

Predictive simulations of thermal-hydrologic-mechanical effects for the Tptpmn and Tptpll units (BSC 2003g, Sections 6.5 and 6.6) generally show a decrease in vertical permeability in the immediate drift vicinity as a result of temperature-induced stresses, while the horizontal permeabilities remain essentially unchanged from the initial postexcavation values. These anisotropic property changes suggest that flow is more easily diverted around the drift, decreasing the potential for seepage.

The impact of these permeability changes on the flow field was investigated by comparison of the fully coupled thermal-hydrologic-mechanical simulations with thermal-hydrologic simulations (in which the stress-induced property changes were neglected). This analysis indicated that the flow field differences are small to moderate. The reduction in vertical permeability appeared to give rise to less water reaching the drift crown, suggesting that the anisotropic thermal-hydrologic-mechanical property changes would increase the likelihood of flow being diverted around the drift and, thus, decrease the potential for seepage. To confirm this point, ambient seepage calculations were conducted with the thermal-hydrologic-mechanical model using the initial postexcavation permeability field without thermal-hydrologic-mechanical changes and the permeability field at 10,000 years after emplacement, including thermalhydrologic-mechanical changes. Results from these simulations indicate that thermal-hydrologic-mechanical effects lead to slight reduction in seepage (on the order of less than 10 percent), and that an ambient seepage model without consideration of anisotropic thermal-hydrologic-mechanical property changes conservatively predicts seepage rates with sufficient accuracy. 


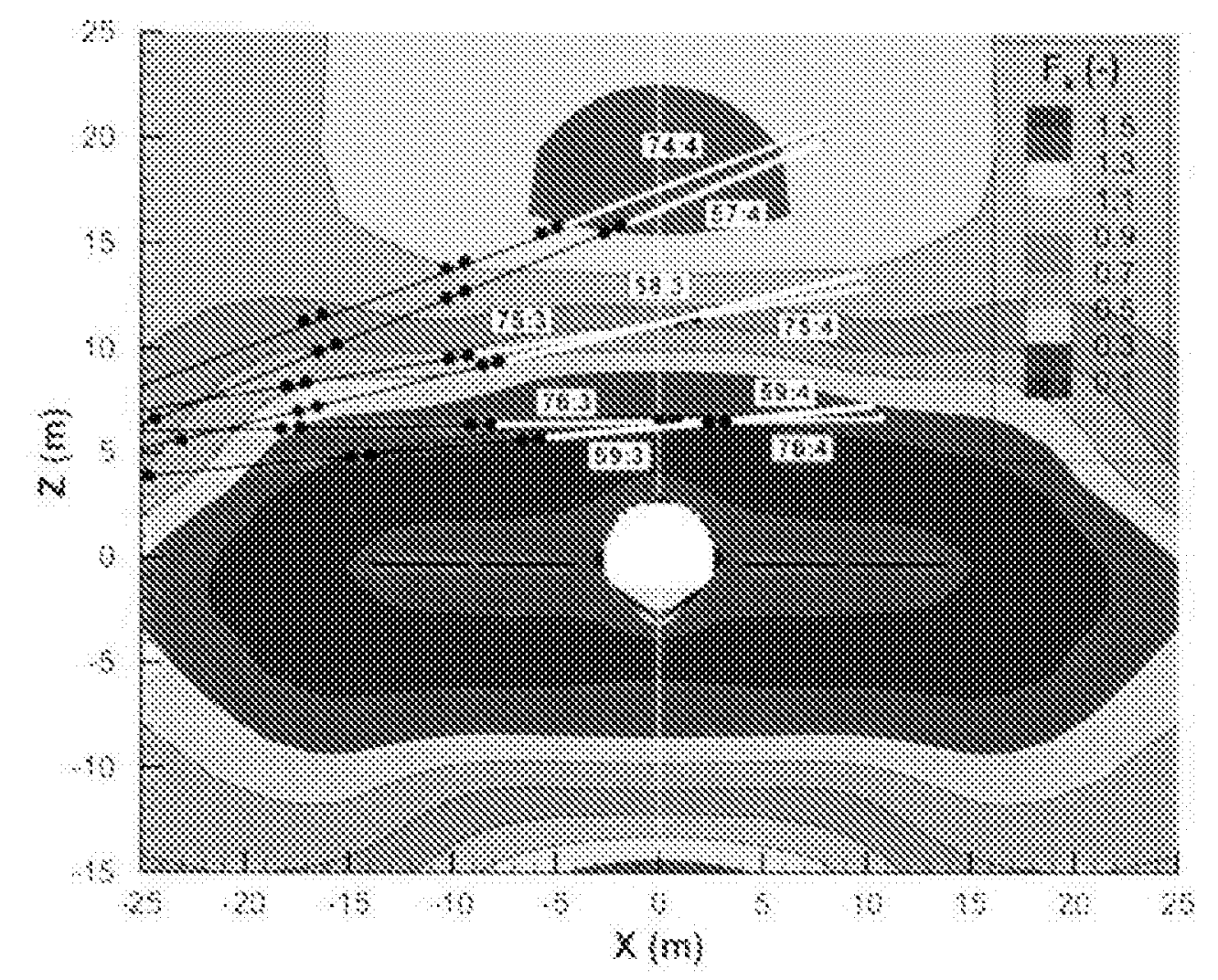

(B)

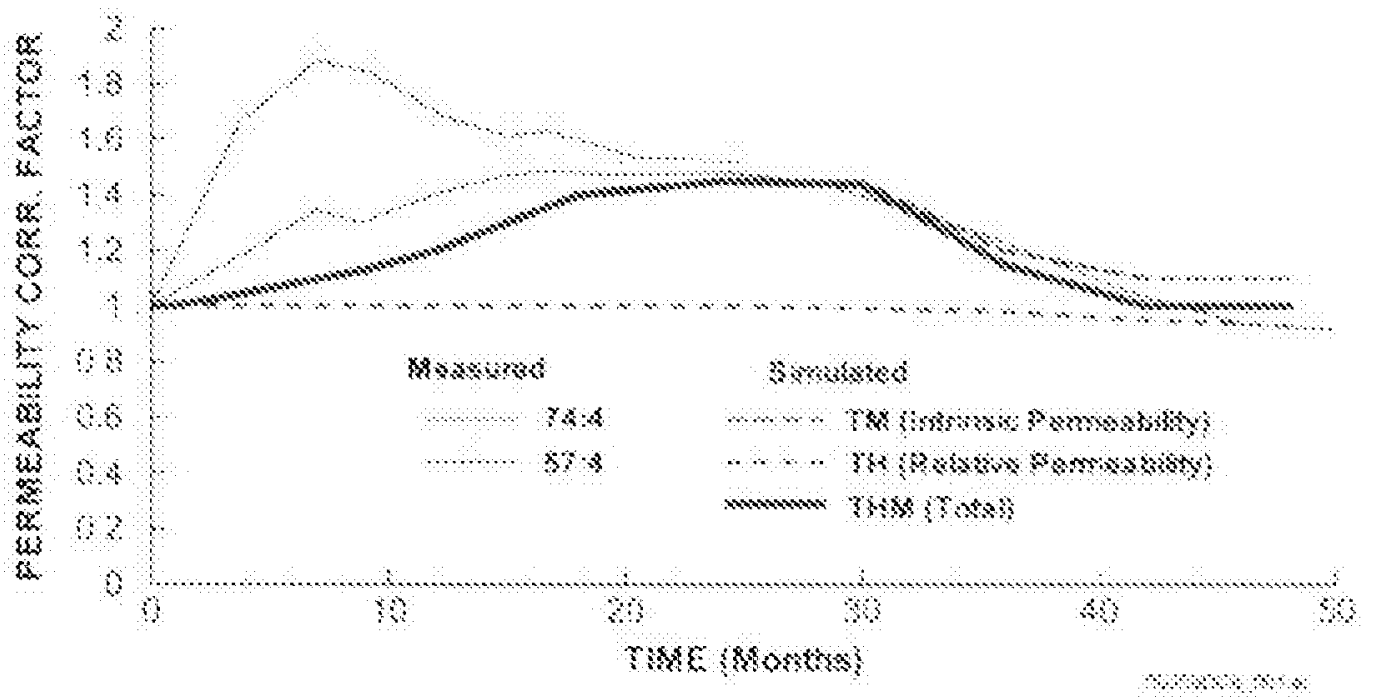

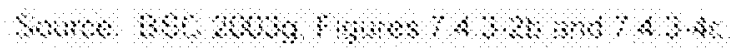

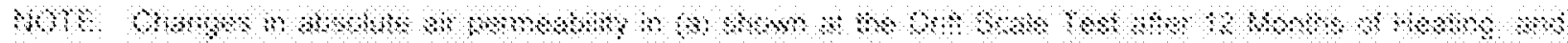

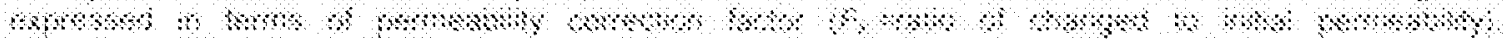

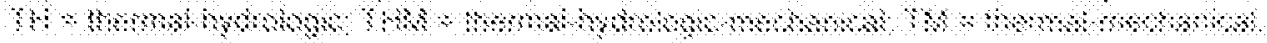

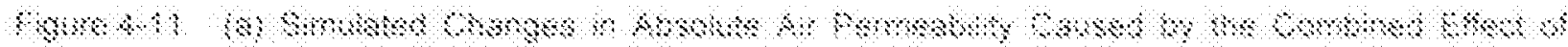

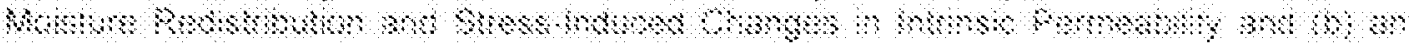

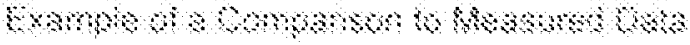




\subsection{EVALUATION OF DRIFT DEGRADATION EFFECTS ON SEEPAGE}

As discussed in Section 2.3.3, waste emplacement drifts may degrade with time as a result of thermal stress, seismic ground motion, and time-dependent degradation of rock strength. Damage to the drifts may be rather small, with local rockfall at the ceiling of otherwise intact drift openings, or, in extreme cases, may result in partial or complete drift collapse, with rubble rock material filling the enlarged drifts. These changes affect the potential for drift seepage.

Various drift degradation models were developed for both nonlithophysal and lithophysal rock types (BSC 2001c; BSC 2003d). Degradation in the nonlithophysal units is primarily controlled by geologic structure. Drift damage due to rockfall in the nonlithophysal rock will be relatively minor even for low-probability seismic ground motions and strongly reduced joint cohesion and friction angle. An example of a resulting drift profile based on a discrete key-block analysis is shown in Figure 4-12. Flow and seepage calculations were performed for selected representative drift profiles (an example is shown in Figure 4-13) to examine the impact of changes in drift shape on seepage. The simulation results indicate that the relatively small rockfall volume and the correspondingly minor drift shape changes will lead to limited effects on seepage (less than 10 percent) for all degradation cases expected to occur in the middle nonlithophysal zone.

On the other hand, given the weaker rock in the lithophysal zones, strong seismic events and reduction in joint cohesion and tensile strength may lead to a complete collapse of the opening. Collapsed drifts are predicted to approximately double in size and fill with rock fragments. Complete drift collapse may lead to significantly different seepage behavior. However, even though the collapsed drifts are filled with rubble material, capillary barrier effects will still give rise to considerable flow diversion at the interface between the standing rock and the rubble-filled drift, because of the large scattered voids between the fragmented rock particles. Also, a gap can be expected between the ceiling and the collapsed, consolidated rubble material. Therefore, capillary-driven flow diversion remains an important mechanism reducing seepage in collapsed drifts. A worst-case drift profile was selected as representative of the drift collapse scenarios depicted in Drift Degradation Analysis (BSC 2003d), and systematic seepage simulations for the collapsed drift were conducted. Comparison with results from the nondegraded drift scenario (see Figure 4-7) indicate a moderate increase in seepage percentage caused by the larger size of the collapsed drift (reducing the effectiveness of flow diversion around the drift) and by the nonzero capillary strength in the drift (reducing the effectiveness of the capillary barrier). The simulation results demonstrate that most of the percolation flux is still diverted around the collapsed drift for most of the considered parameter range; actual seepage fluxes, however, are increased more because of the larger footprint of the collapsed drift. 
Revision 1

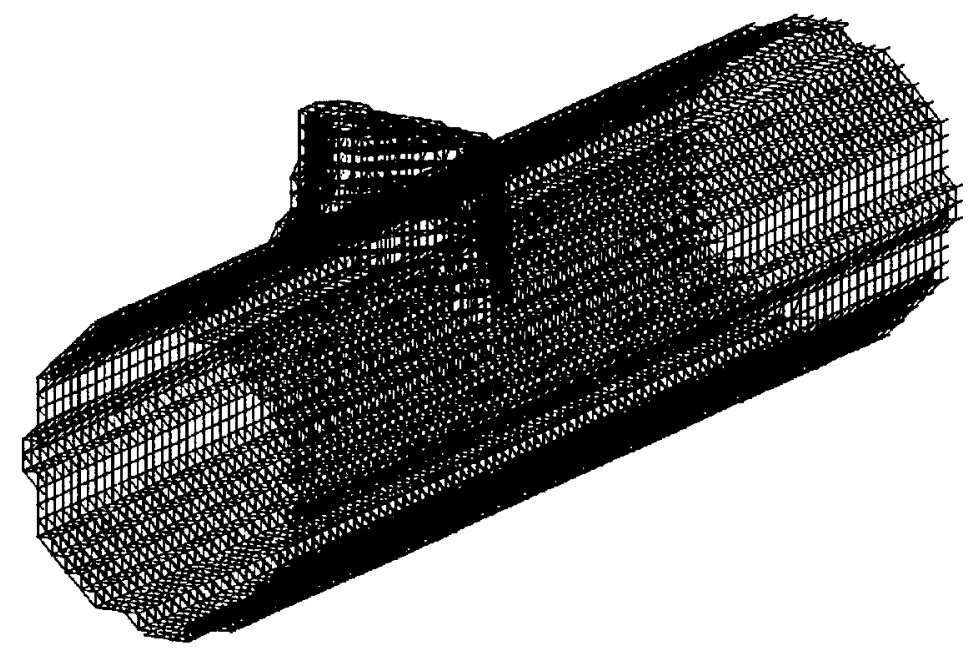

(a) Isometric View

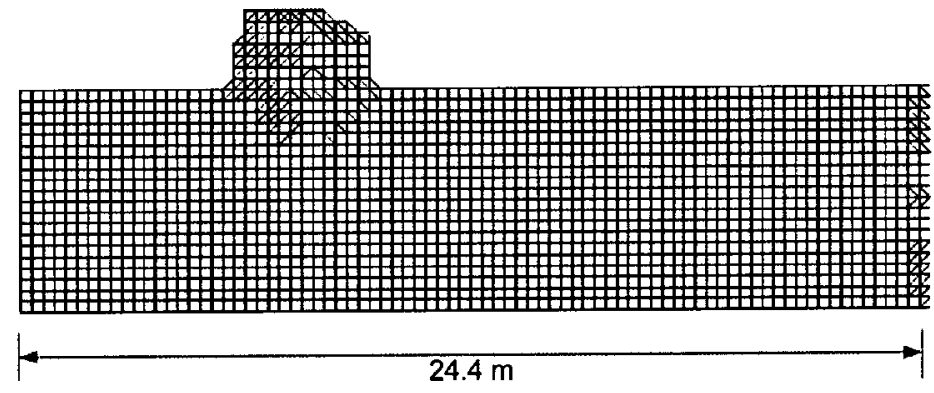

(b) Side View

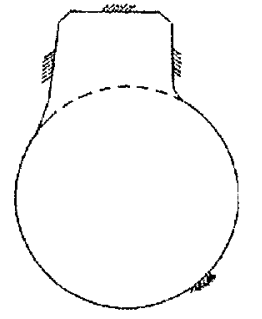

(c) Cross Section View 003590Cb_002.ai

Source: BSC 2001b, Figure 6.4.1.

Figure 4-12. Calculated Drift Shape Changes as a Result of Rockfall in the Nonlithophysal Zone 


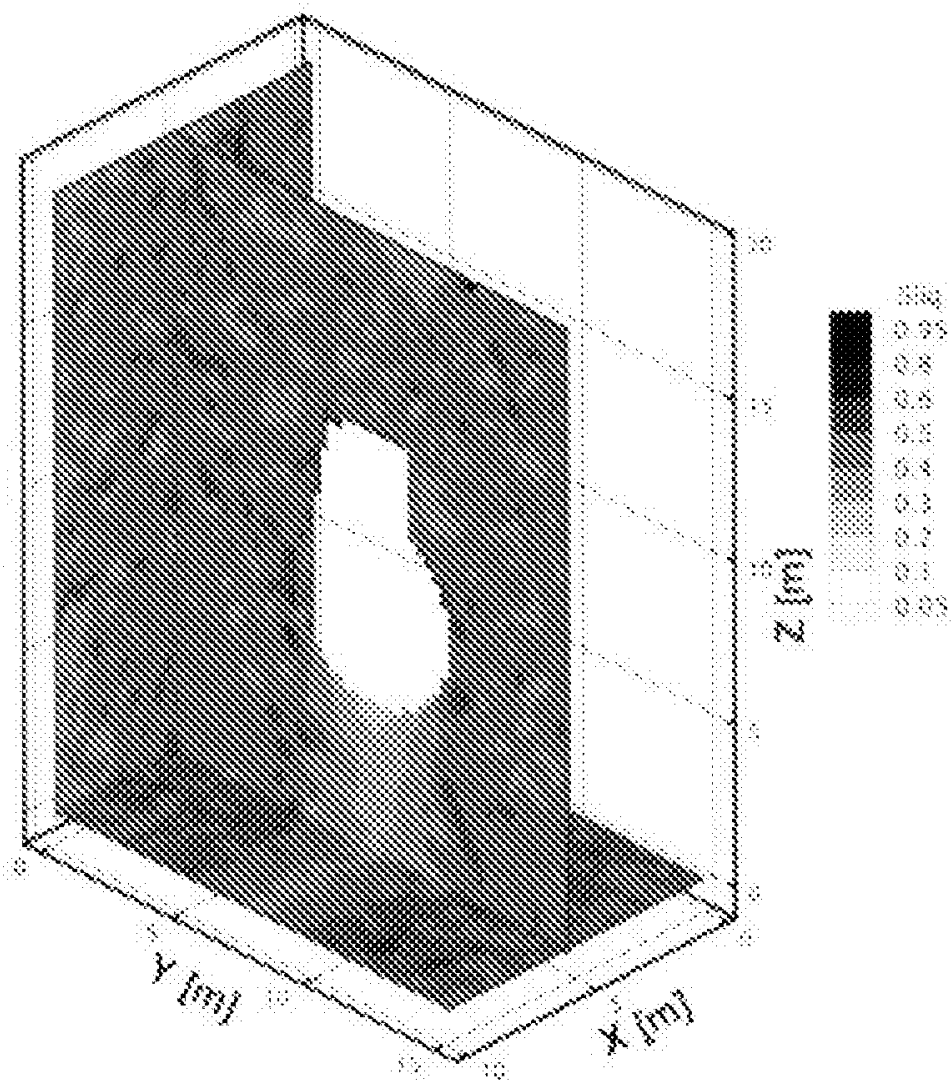

$\operatorname{sis} \alpha$

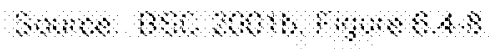

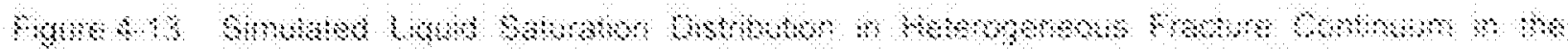

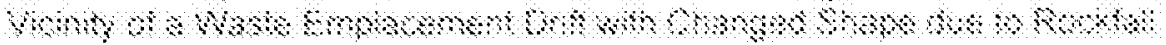

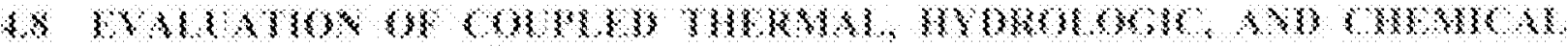

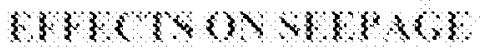

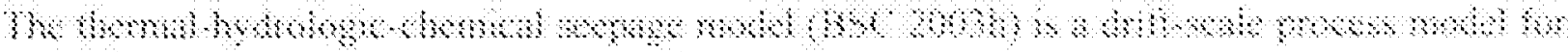

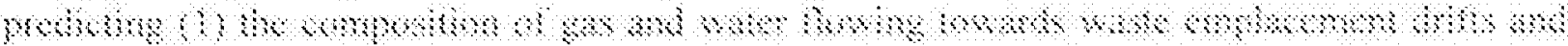

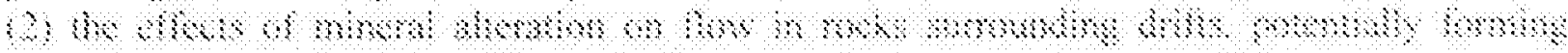

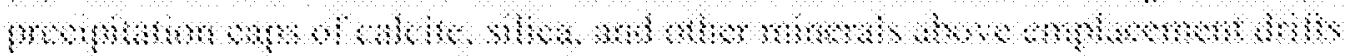

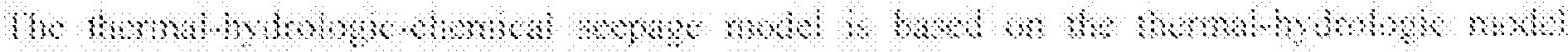

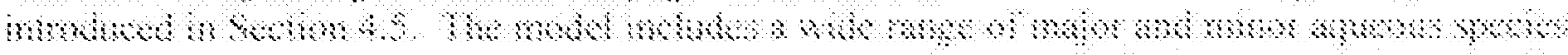

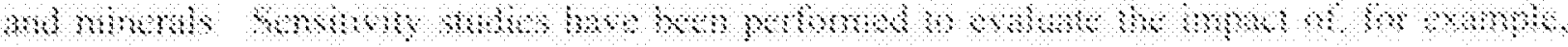

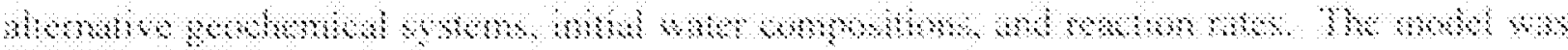

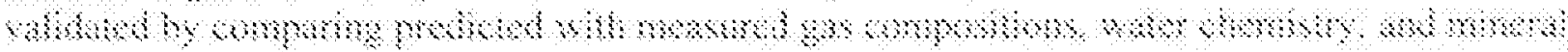

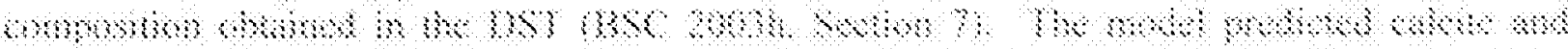

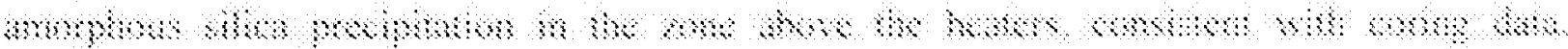

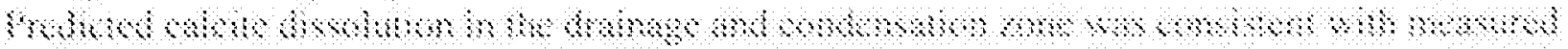

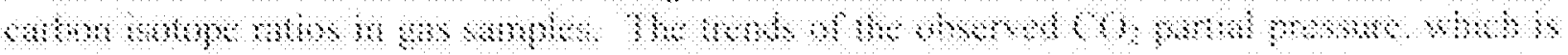

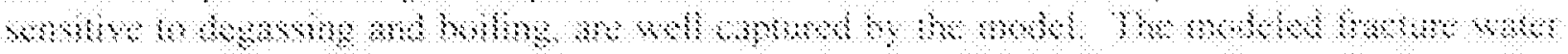

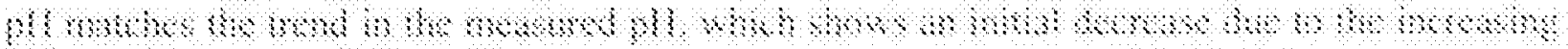

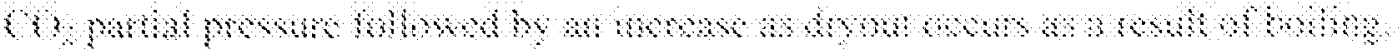


Model results were also compared with measured water compositions from a laboratory plug-flow dissolution experiment. In addition, a fracture-sealing laboratory experiment was simulated to compare precipitation data (see Section 3.3.2). In general, the model captured the trends in gas composition, water chemistry, and mineral precipitation reasonably well.

The simulation results suggest that a thin region of significantly decreased fracture permeability will form several meters above the crown of waste emplacement drifts, created by mineral deposition at the boiling front (mainly silica, and to a lesser extent calcite). There is no indication that significant precipitation occurs immediately at the drift wall. This means that the local permeability and porosity in the boundary layer above the drift wall, important for the capillary barrier behavior, are not significantly affected by rock alterations induced by coupled thermal, hydrologic, and chemical effects. Figure 4-14 illustrates the spatial distributions of permeability changes and demonstrates its impact on the flow conditions at 2,400 years after waste emplacement. While the permeability values directly at the drift wall remain unchanged, there is a permeability decrease by a factor of 10 in an area 7 to $8 \mathrm{~m}$ above the drift. As a result, percolating water will be partially deflected sideways at this low-permeability zone, so that less water arrives at the drift crown (BSC 2003h, Figure 6.8-42). Since the amount of seepage is correlated to the local percolation flux, this kind of "umbrella effect" would give rise to less seepage compared to a simulation without permeability changes. Note that the permeabilities shown at 2,400 years remain essentially unchanged for the rest of the simulation period of 100,000 years, because the silica solubility decreases with declining temperature. The thermal-hydrologic-chemical induced changes of hydrologic properties are essentially irreversible, potentially reducing the long-term percolation flux reaching the drift wall.

Drift-Scale Coupled Processes (DST and THC Seepage) Models (BSC 2003h, Section 6.8.5.4) presents several sensitivity cases for mineral alteration results using different initial water compositions, which show significantly different permeability changes. Fracture-porosity changes in these simulations depend strongly on the initial porosity estimate for the fracture continuum, which is uncertain (BSC 2003h, Section 8.2). It is also expected that variability in the thermal-hydrologic conditions (e.g., stemming from thermal-load differences and percolation-flux variability) and model dimensionality would bring out other differences in the precipitation patterns and the effectiveness of the diversion effect described above. Accordingly, the effect is not included explicitly in the abstraction of seepage for TSPA. The abstraction does include a wide range of uncertainties (in percolation flux, flow focusing, permeability, and capillary strength). 


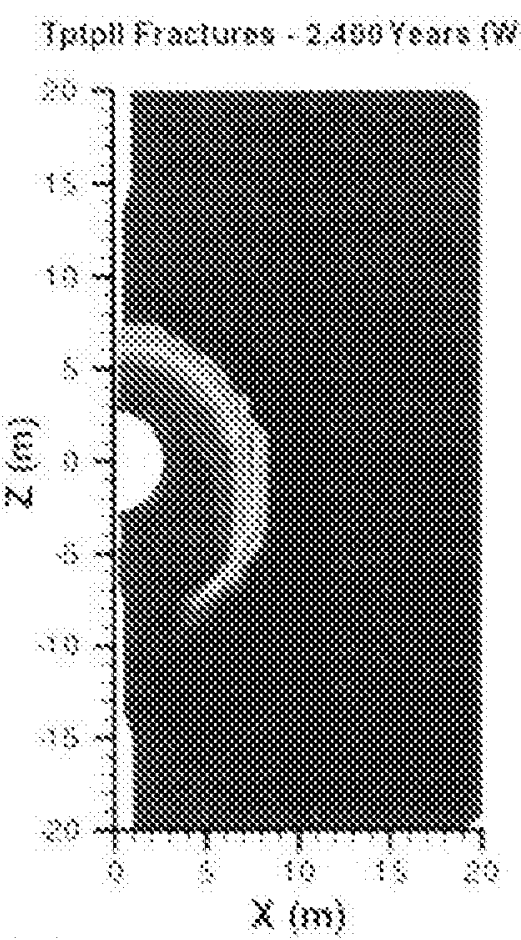

(3)

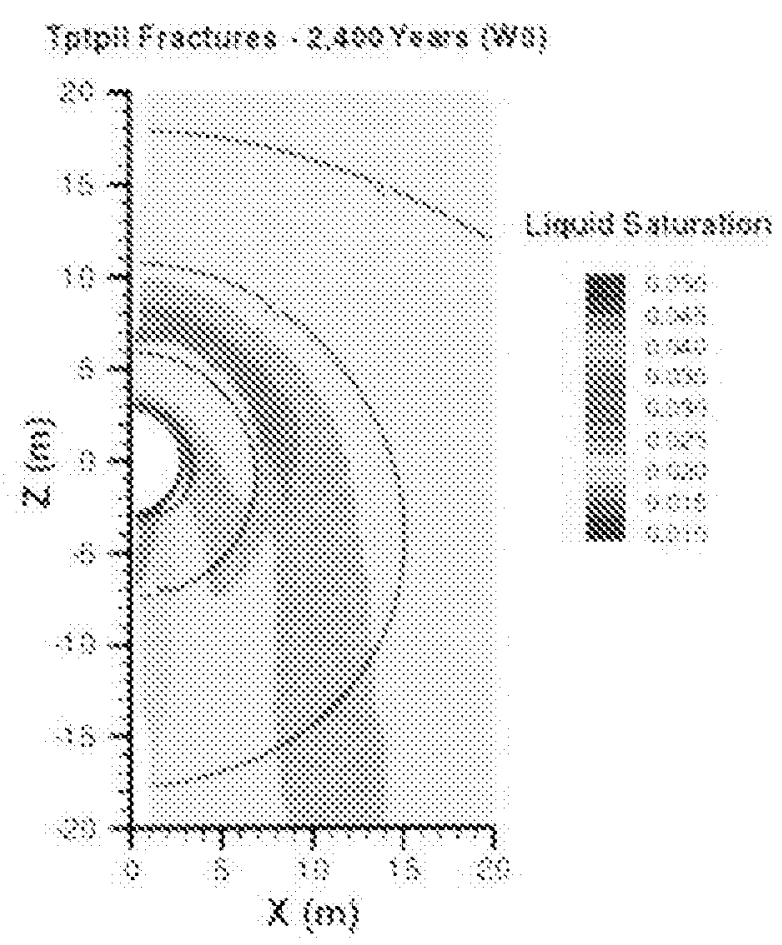

\$)

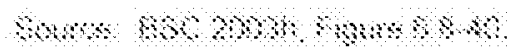

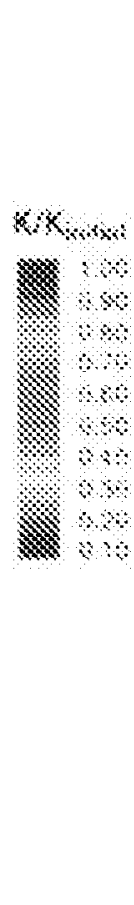

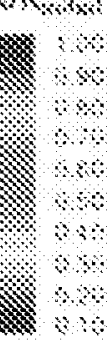

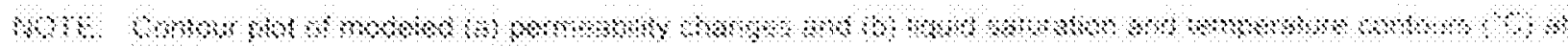
Shlowers.

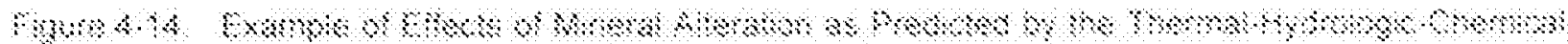

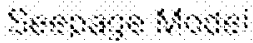

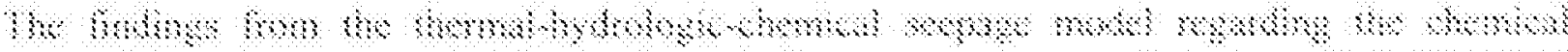

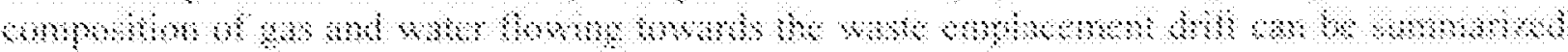
s. Khom:

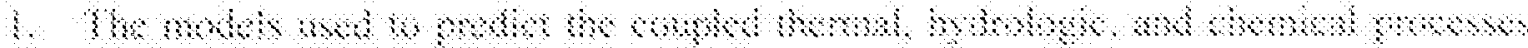

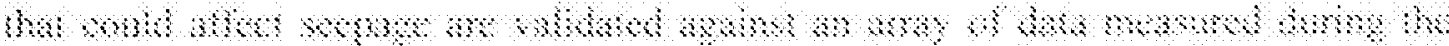

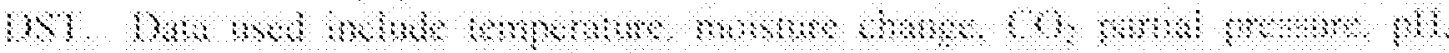

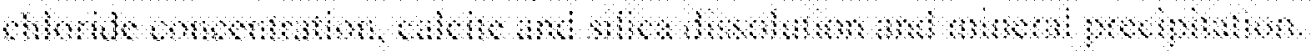

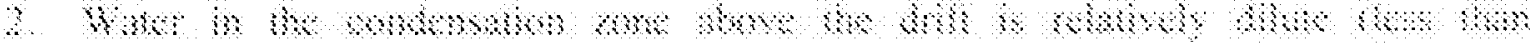

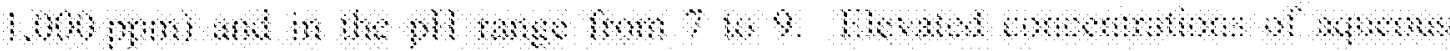

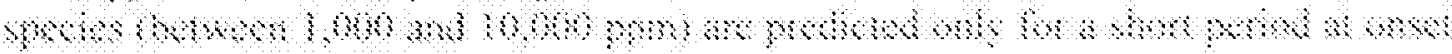

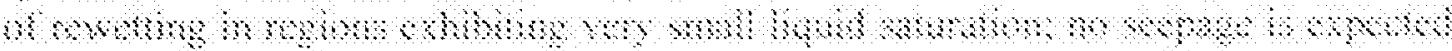

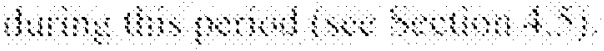

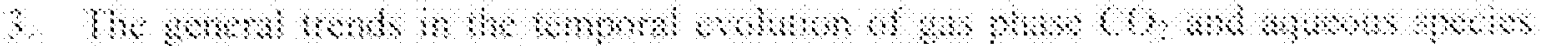

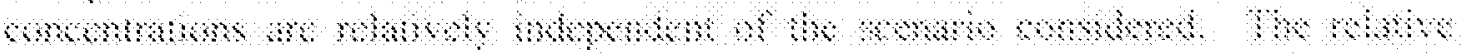

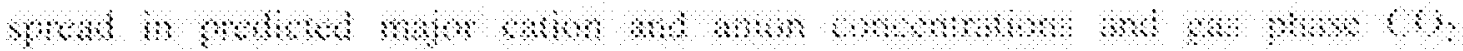

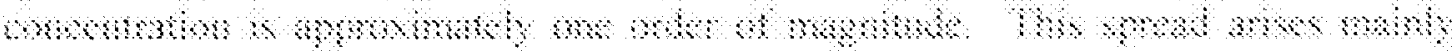


from the natural variability of the initial pore water composition. The chemistry of potential seepage water is at all times similar to that of the initial, dilute pore waters.

4. It is unlikely that $\mathrm{CaCl}_{2}$ waters will evolve. The presence of $\mathrm{CaCl}_{2}$ brines with their high boiling point would have increased the potential for seepage and corrosion.

5. Heterogeneity in fracture permeability has an insignificant effect on predicted water composition.

\subsection{SEEPAGE ABSTRACTION}

An abstraction model was developed for evaluating the future amount and distribution of seepage into the waste emplacement drifts at Yucca Mountain (BSC 2003a). The purpose of the seepage abstraction is to provide the necessary methodology, tools, parameter distributions, lookup tables, and simplifications needed for TSPA to perform a probabilistic analysis of seepage rate (amount of seepage per time) and the seepage fraction (the fraction of waste packages affected by seepage) as functions of time and location in the repository.

The information generated by the seepage process models is compiled into a form that can be used in probabilistic TSPA calculations. The following three process models, which are consistent in their conceptual treatment of flow diversion and capillary barrier behavior, provide the basis for seepage abstraction:

1. The seepage calibration model provides the conceptual basis for seepage modeling and derives seepage-relevant parameters through calibration of the model against seepage-rate data from liquid-release tests (BSC 2003e; see also Section 4.3).

2. The seepage model for performance assessment predicts drift seepage rates for long-term ambient conditions at Yucca Mountain, for a wide range of seepage-relevant parameters, and for potentially important perturbing effects. The latter include the effect of rock bolts on flow paths and the impact of drift shape changes caused by degradation (BSC 2003i; see also Section 4.4). Drift degradation is expected as a result of thermal stresses, seismic events, and time-dependent decrease in rock strength.

3. The thermal-hydrologic seepage model predicts drift seepage during the period when water-flow processes in the drift vicinity are perturbed by heating of the rock (BSC 2003b; see also Section 4.5).

Additional input from scientific analyses or from process models is required to define probability distributions that appropriately cover uncertainty and spatial variability of seepage-affecting parameters. In addition to the capillary strength in the fractures close to the drift calibrated with the seepage calibration model, the most important parameters defining the amount of seepage are the local percolation flux and the formation's permeability close to the drifts (BSC 2003e). Information on these parameters is derived mainly from the following sources:

1. Site-scale and intermediate-scale unsaturated zone flow simulations-The unsaturated zone flow and transport model provides three-dimensional site-scale flow fields to 


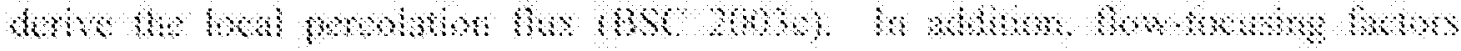

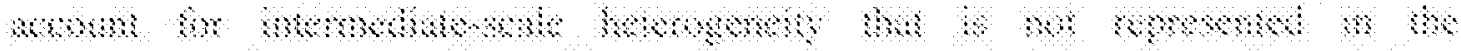
\$ m momm

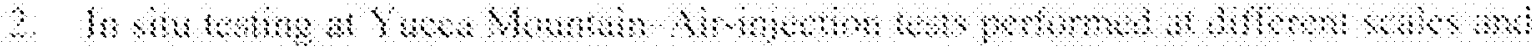

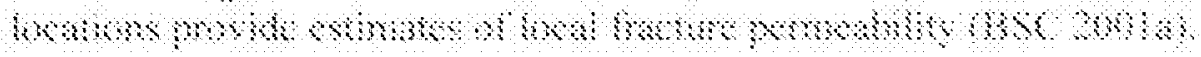

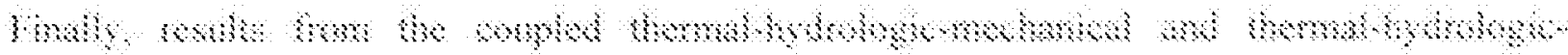

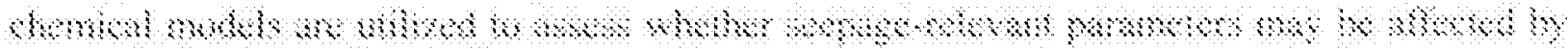

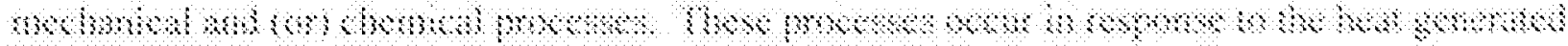

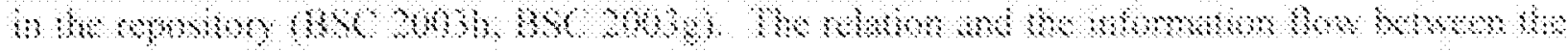

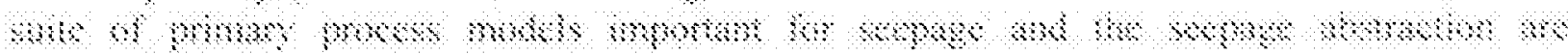

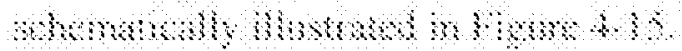

\section{$\operatorname{tsp}$}

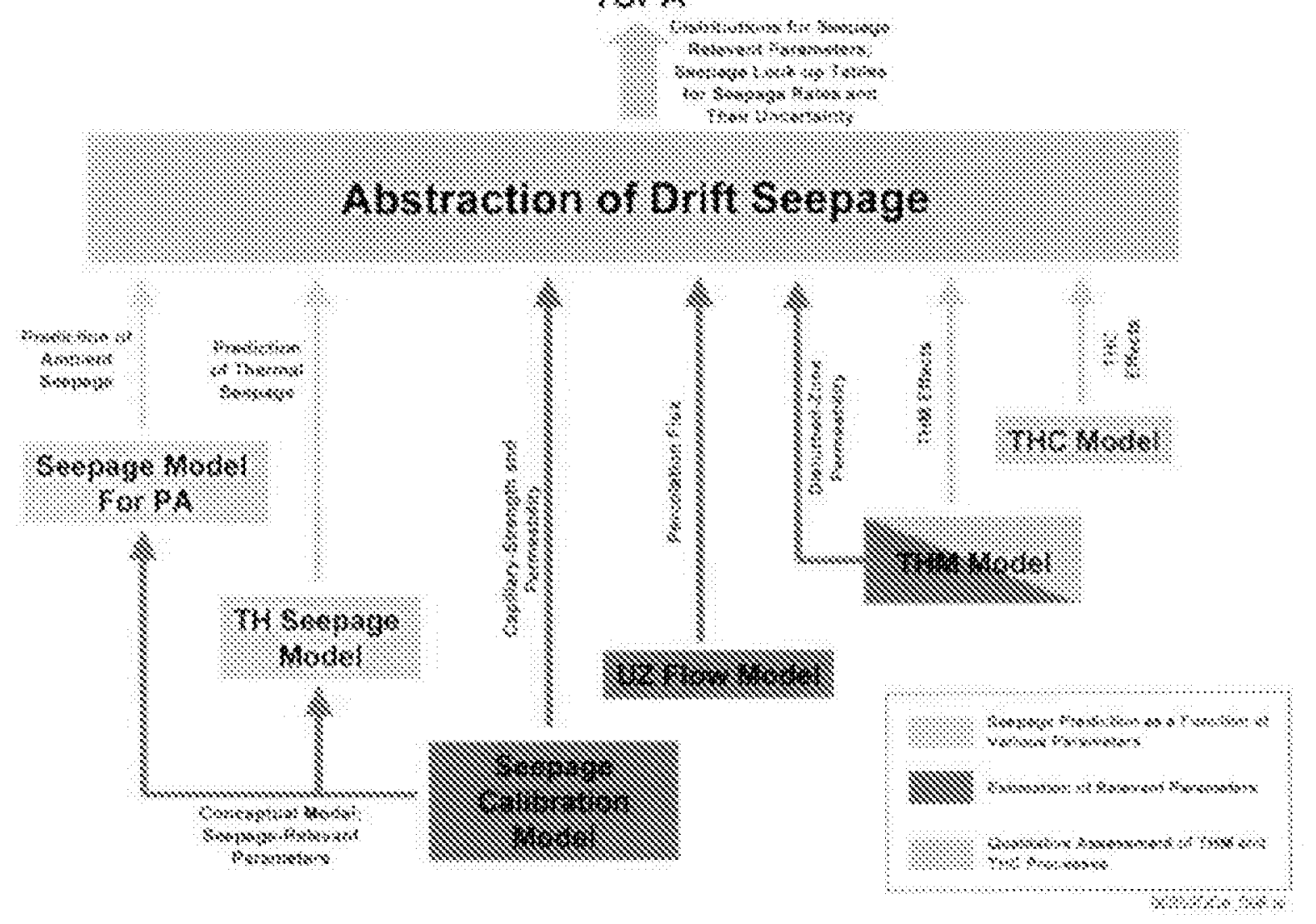

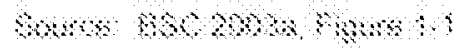

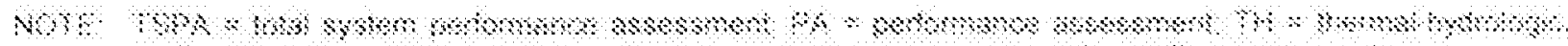

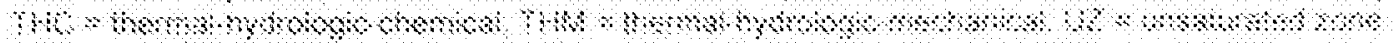

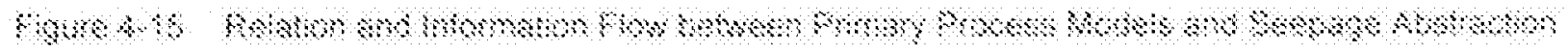

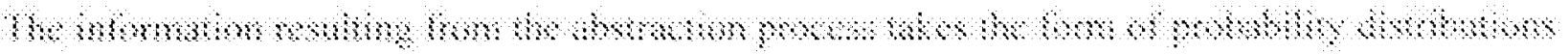

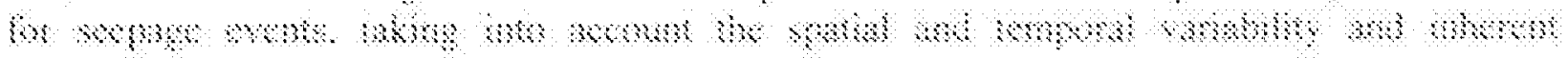


seepage. In addition, small-scale surface roughness tends to increase seepage if the amplitude of the irregularity is comparable to the boundary-layer thickness. The boundary-layer thickness is determined by the capillary rise in the fractures (i.e., it is on the order of a few centimeters).

\subsection{THERMAL, HYDROLOGIC, CHEMICAL, AND MECHANICAL IMPACTS ON SEEPAGE}

\subsubsection{Introduction}

As outlined in Section 2.2, hydrogeologic properties (specifically permeability and capillary strength) and their spatial heterogeneity determine the flow diversion capacity of the fracture network and, thus, seepage behavior. Initially, the undisturbed rocks in the repository host units are likely to be altered as a result of stress redistribution during drift excavation, which typically leads to local opening of fractures and potentially the creation of new microfractures in the drift vicinity (BSC 2001a, Section 6.1.2.2; Wang and Elsworth 1999, pp. 752 to 756). These changes affect porosity, permeability, and capillarity of the fracture system in the vicinity of emplacement drifts. Later, the heat emanating from the radioactive material will induce changes as a result of coupled thermal-hydrologic-mechanical and thermal-hydrologic-chemical effects. Thermal expansion of the rock matrix will induce thermal stresses and associated aperture changes. Also, thermal effects will lead to dissolution and precipitation of minerals, affecting the porosity, permeability, and capillarity of the fracture system.

\subsubsection{Excavation Effects}

Because of excavation, stress is redistributed and fractures are generally expected to dilate near the crown of the drift. Such fracture dilation depends on the orientation of the fracture set and generally occurs within one drift radius. An increase in fracture aperture generally causes an increase in fracture permeability and a decrease in capillary strength-both key parameters affecting seepage. The measured increase in permeability from preexcavation to postexcavation values reflects this excavation effect (Wang et al. 1999).

\subsubsection{Drift Degradation}

It is possible that the initially circular-shaped open emplacement drifts will degrade with time as a result of thermal stress, seismic ground motion, and time-dependent degradation of rock strength (BSC 2003d). Thermal stresses are caused by the heat generated from the decaying nuclear waste. Significant stresses can also be caused by seismic ground motions. Time-dependent degradation of rock strength (joint mechanical properties) may be a result of over-stressing from thermal heating and of static fatigue of the rock resulting from stress corrosion mechanisms. These effects may lead to rock mass damage and rockfall into emplacement drifts, changing the drift shape and size. Depending on the type of rock, the stress conditions, and the time-dependent rock mechanical properties, damage to the drifts may be small, with sparse local rockfall from the ceiling of otherwise intact drift openings, or (in extreme cases) damage may result in partial or complete drift collapse, with rubble rock material filling the enlarged drifts. These changes affect the potential for drift seepage. Local breakouts in the drift ceiling may lead to geometry changes that can either increase seepage by reducing or preventing flow diversion around the opening (e.g., by creating low points) or reduce seepage by 
resulting in a drift geometry that promotes flow diversion (e.g., by creating a more parabolic drift shape through breakouts near the apex of the drift). The larger size and potentially different shape of collapsed drifts can also reduce the potential for flow diversion; furthermore, the larger footprint of the collapsed drift leads to an increase in the total amount of percolation flux arriving at the drifts, which, in turn, can affect the total amount of seepage. In addition, the capillary-barrier effect at the drift wall may be affected by the rubble rock particles filling the opening because the capillary strength inside the opening will be different from the zero capillarity condition in the initially open drift.

\subsubsection{Seepage under Thermal Conditions}

The heat generated by the decay of radioactive wastes will result in rock temperatures elevated for thousands of years after emplacement. For average rock properties, percolation flux, and heat load, the drift wall will be at above-boiling temperatures for approximately 1,000 years. Elevated temperatures (below boiling, but above ambient conditions) will prevail throughout the compliance period (BSC 2003b, Section 8). For the current repository design concept, these temperatures will be high enough to cause boiling conditions in the drift vicinity, giving rise to local water redistribution and altered flow paths. Key thermal-hydrologic processes occurring around a drift are shown schematically in Figure 2-4 for an idealized, circular-shaped drift. The figure indicates that heating of the rock will cause pore water in the rock matrix to boil and vaporize. The vapor will move away from the drift through the permeable fracture network, driven primarily by a pressure increase caused by boiling. In cooler regions away from the drift, the vapor will condense in the fractures, where it can drain either toward the heat source from above or shed around the drift into the zone below the heat source. Condensed water can also imbibe from fractures into the matrix, leading to increased liquid saturation in the rock matrix. With continuous heating, a superheated (above-boiling temperature) dryout zone will develop closest to the heat source, separated from the condensation zone by a nearly isothermal zone maintained nominally at the boiling temperature. This nearly isothermal zone is characterized by a continuous process of boiling, vapor transport, condensation, and migration of water back toward the heat source (vapor-liquid counter flow resulting from capillary forces or gravity drainage), a process often referred to as a heat pipe (Pruess et al. 1990).

For the current repository design concept, the dryout zone around drifts will extend to a distance of approximately 5 to $10 \mathrm{~m}$ from the drift wall (BSC 2003b, Section 6.2). Boiling conditions in the rock are expected to exist for about 1,000 years after emplacement. While these values reflect average conditions, there may be significant spatial and temporal variability of the thermal-hydrologic conditions within the repository. One factor causing heterogeneity is the spatial and temporal variability directly related to the thermal load in different drift sections, stemming from heat output variations between individual waste packages and different emplacement times. Another factor is the heterogeneity of the formation properties and spatial distribution of the local percolation fluxes. Thermal rock properties, such as thermal conductivity, directly affect the conductive transport of heat. Hydrologic properties and local percolation fluxes, on the other hand, affect the significance of thermal-hydrologic coupling as they determine the effectiveness of convective heat transport. While heat conduction is the major component of energy transport in Yucca Mountain tuff, the impact of thermal-hydrologic coupling can be quite large. For example, a large percolation flux above a drift segment, combined with relatively high permeability, may cause heat-pipe effects that give rise to rock 


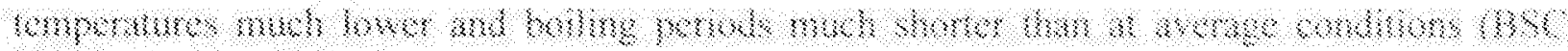

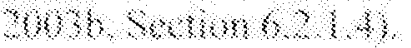

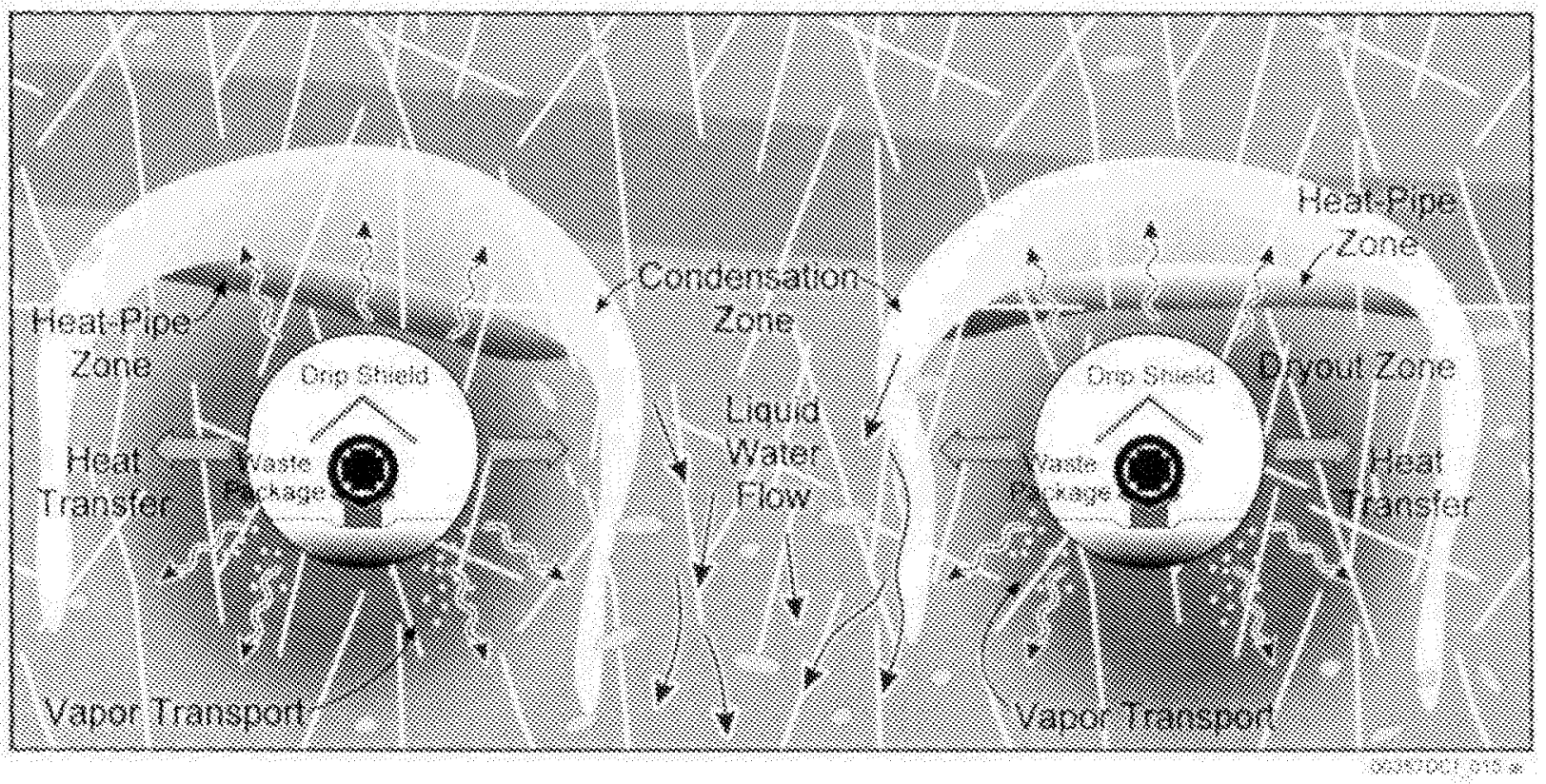

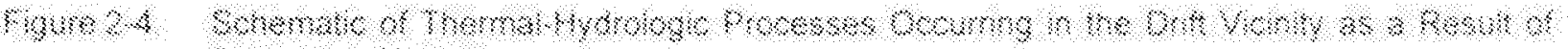

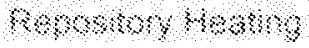

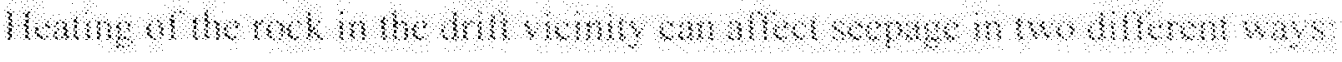

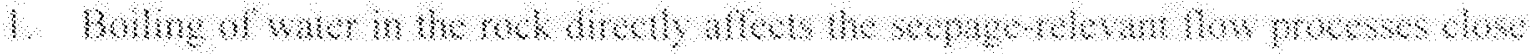

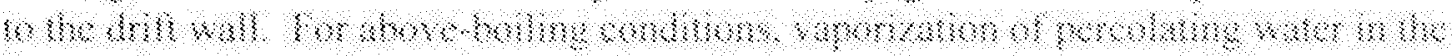

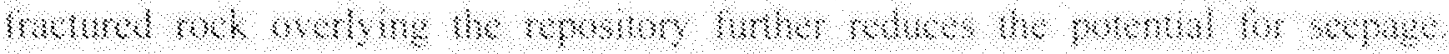

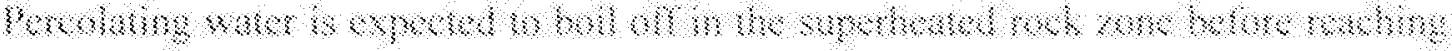

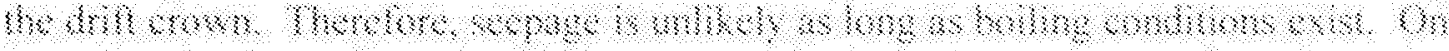

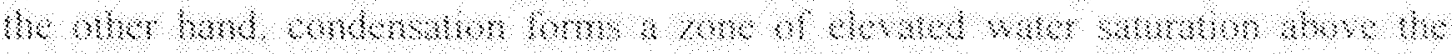

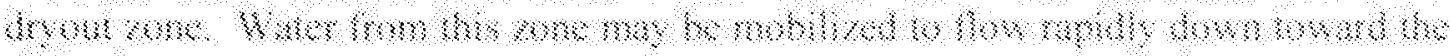

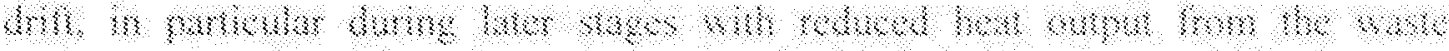

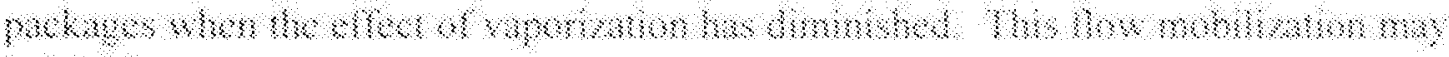

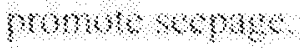

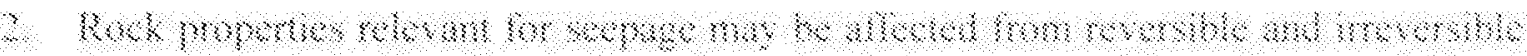

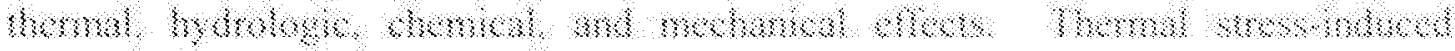

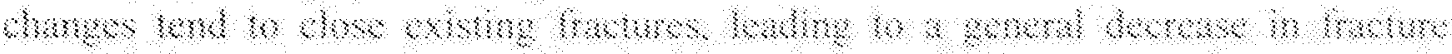

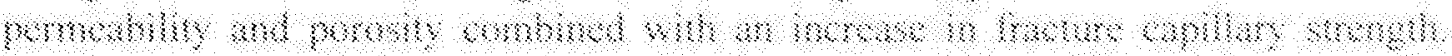

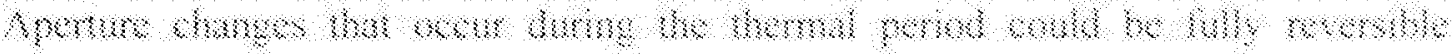

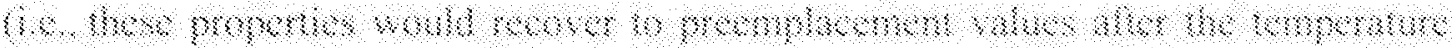

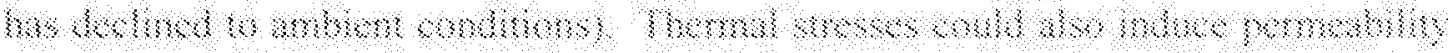

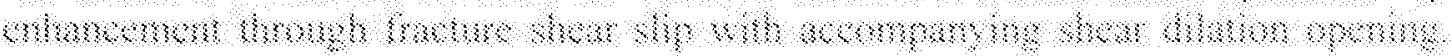

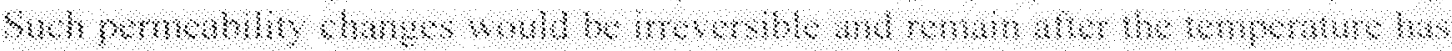

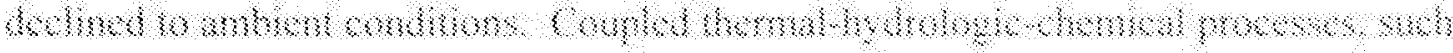


as mineral precipitation and dissolution in fractures and matrix, also have the potential to irreversibly modify permeability, porosity, and capillary strength of the system. The molar volumes of minerals created by hydrolysis reactions (i.e., anhydrous phases, such as feldspars, reacting with aqueous fluids to form hydrous minerals, such as zeolites or clays) are commonly larger than the molar volumes of the primary reactant minerals. Consequently, dissolution-precipitation reactions commonly lead to porosity and permeability reductions. The extent of mineral-water reaction is controlled by the surface areas of the mineral phases in contact with the aqueous fluid, as well as heterogeneity in the initial distribution of minerals in the fractures. Therefore, changes in porosity and permeability caused by these processes may also be heterogeneously distributed. Typically, chemical effects on hydrologic properties are irreversible.

As mentioned in Section 2.3.3, emplacement drifts may completely collapse in extreme cases as a result of thermal and seismic stresses and degradation of joint mechanical properties. The thermal conditions in a collapsed drift will be different from those in an open drift, mainly because the thermal-hydrologic processes in a drift filled with rock fragments are different from those in an open, air-filled drift. The extent to which these differences can be important for seepage under thermally elevated conditions is governed by the time at which significant drift collapse occurs. Significant differences should only be expected when drift collapse occurs during the boiling period.

The impact of repository heat on the hydrologic, chemical, and mechanical conditions was examined in a heater experiment referred to as the Drift Scale Test (DST). A short description of the DST can be found in Section 3.3.1. The related modeling documented in Drift-Scale Coupled Processes (DST) and TH Seepage Models (BSC 2003b) is mainly used to corroborate the abstraction of coupled processes on the evaluation of seepage under thermal conditions, as discussed in Sections 4.6 and 4.8.

\subsection{IN-DRIFT CONDITIONS}

Preclosure ventilation will cause partial rock drying in the drift vicinity and will also remove a significant amount of heat and moisture. While this relatively short ventilation period is expected to have minor impact on the postclosure performance of the repository, in-drift moisture conditions are important during seepage testing (see Sections 3.1 and 3.2) and the analysis of seepage-rate data (see Section 4.3).

Reduced relative humidity in the underground opening leads to evaporation of water at the drift surface and the development of a dryout zone in the vicinity $(5$ to $10 \mathrm{~m})$ of the cavity. In a liquid-release test at ambient conditions (or natural percolation during the ventilated period), part or all of the water reaching the ceiling of the opening may evaporate, depending on the evaporation potential in the drift and the wet area exposed to evaporation. The evaporation potential depends on the relative humidity in the opening and the thickness of a diffusive boundary layer at the drift surface, which in turn is governed by the air velocity in the ventilated drift. Total evaporation depends on the evaporation potential and the wetted area available for evaporative mass transfer. 
Wetting of the drift ceiling depends on the formation properties, the spreading mechanism along the drift surface, and evaporation itself. Under natural percolation conditions, evaporation in a ventilated drift prevents sufficient wetting at the drift surface and thus seepage. However, the development of a wet spot and its relation to in-drift conditions has been studied during the seepage tests conducted in several niches and along the ECRB Cross-Drift (see Section 3.1). Temporal reduction of the wet spot size during continued water release can be correlated to increased evaporation as a result of changes in the ventilation regime, highlighting the coupled nature of the processes.

The importance of evaporation effects on the interpretation of seepage data from liquid-release tests conducted under ambient temperature conditions has been recognized. The issue has been addressed by (1) increasing relative humidity in the testing area (using bulkheads, end curtains, and humidifiers), (2) monitoring relative humidity and evaporation from a free water surface (pan experiments), and (3) inclusion of evaporation into the process model used to analyze seepage-rate data.

If evaporation is significantly reduced, wetting of the drift surface is expected. Wet surfaces and film flow are an integral part of the capillary barrier concept, providing evidence that the capillary barrier is engaged. Wet surfaces were observed in the passive Cross-Drift hydrologic test (see Section 3.2).

Additional discussion of evaporation issues can be found in Appendix C. 


\section{FIELD OBSERVATIONS AND SEEPAGE TESTING DATA}

\subsection{LIQUID-RELEASE TESTING}

\subsubsection{Description of Liquid-Release Tests}

Drift-scale liquid-release tests were initiated in 1997 to investigate potential seepage into an underground opening representing a waste emplacement drift. Short drifts (ranging from $6.3 \mathrm{~m}$ to $15.0 \mathrm{~m}$ in length and referred to as niches) were constructed at various locations along the ESF and the ECRB Cross-Drift. Boreholes were installed prior to and after the niches were excavated to facilitate characterization of the rock using air-injection tests and investigation of seepage processes using liquid-release tests. The locations of the niches were chosen so that they represent different hydrogeologic units and rocks with different fracture statistics. A second study, referred to as the systematic borehole testing program, was initiated in 2000 to complement the niche seepage experiments. The purpose of the program is to provide broad, systematic coverage and characterization of the host rock by performing air-injection and liquid-release tests in approximately 20 -m-long boreholes drilled at a $15^{\circ}$ angle upward and parallel to the drift axis into the ceiling every $30 \mathrm{~m}$ along the ECRB Cross-Drift. Test locations are illustrated in Figure 3-1.

The purpose of these experiments was to release water from borehole intervals located above drift sections or niches and to collect the water that seeps into the openings. These seepage-rate data contain information about the seepage process reflecting most of the factors discussed in Section 2. They have been analyzed to infer seepage-relevant, model-related effective parameters on the drift scale. The tests were generally performed by (1) injecting air to characterize the permeability distribution, (2) introducing water from a borehole interval above the opening, (3) recording the induced seepage, (4) monitoring temperature and relative humidity, (5) observing the formation and growth of the wetted spot at the ceiling and (6) studying the general seepage behavior.

Multiple liquid-release tests were performed in the niches and along the ECRB Cross-Drift to observe, document, and quantify any water migrating to and seeping into the underground openings. The tests were performed by sealing a short section of the borehole above the opening using an inflatable packer system and then releasing water at a specified rate into the test interval. Any water that migrated from the borehole to the ceiling and dripped into the opening was captured and measured. Qualitative observations during the tests helped provide an understanding and corroboration of flow diversion and seepage concepts. Moreover, a quantitative analysis of the seepage-rate data provided calibrated values of seepage-relevant formation parameters (see Section 4.3).

The effectiveness of the capillary barrier and the presence of a seepage threshold can be directly observed from liquid-release tests conducted at different rates, which show that seepage ceases at a nonzero injection rate, referred to as a seepage threshold.

Seepage tests are further described in Appendices B and C. 


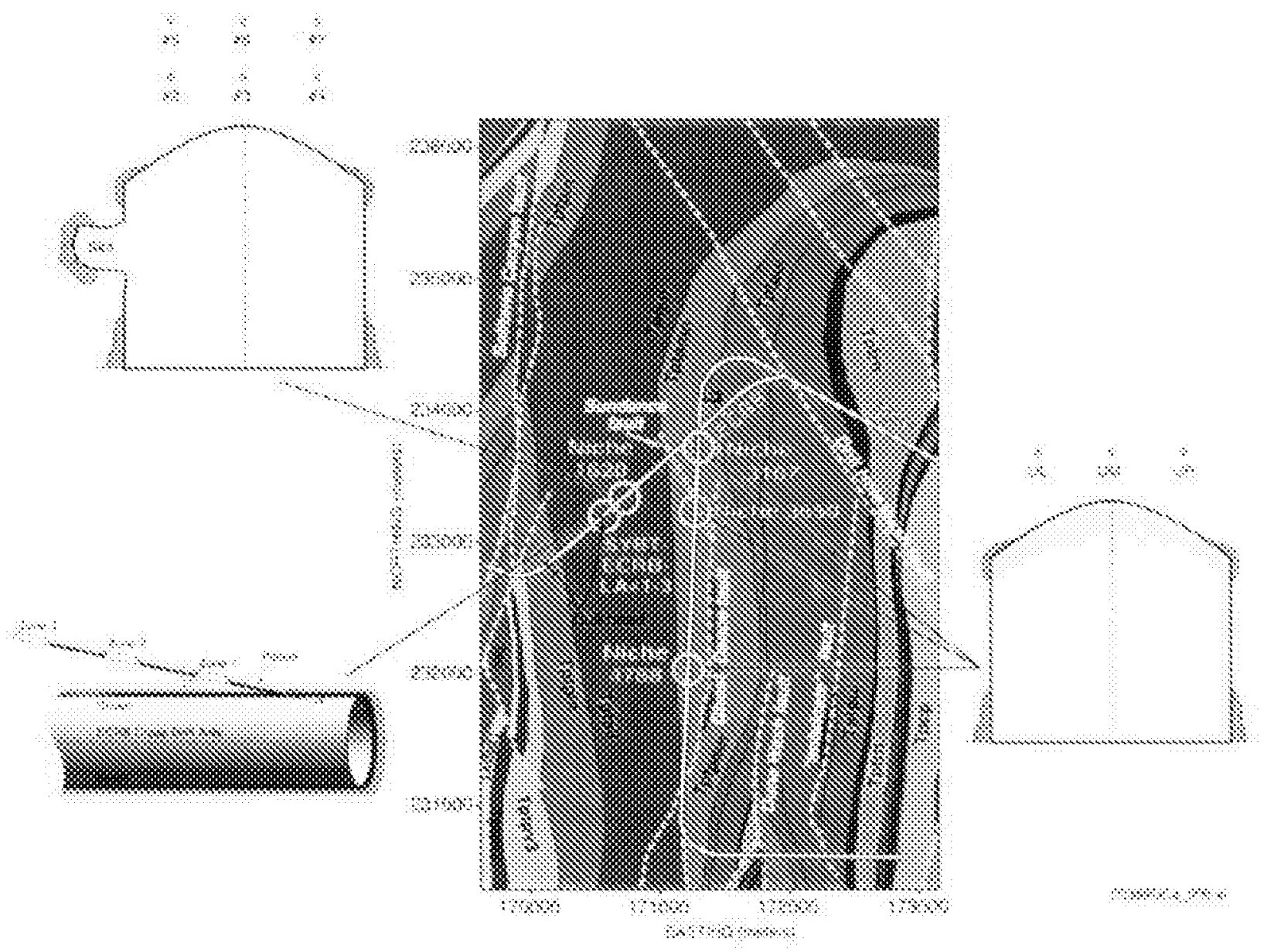

$\$ \infty \mathrm{s}, \mathrm{s}+\mathrm{s}+\mathrm{s}$

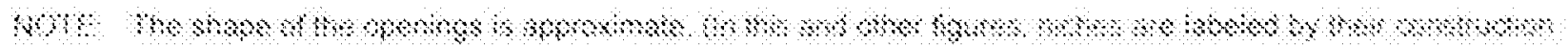

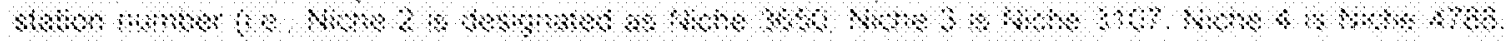

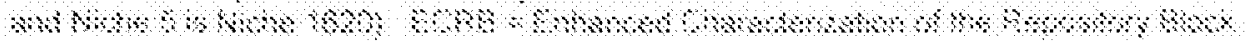

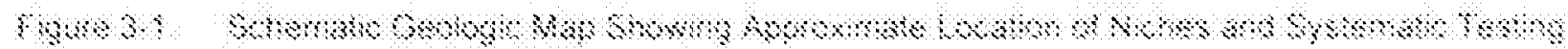

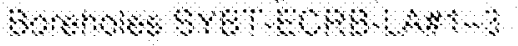

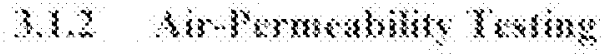

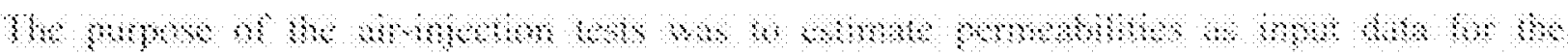

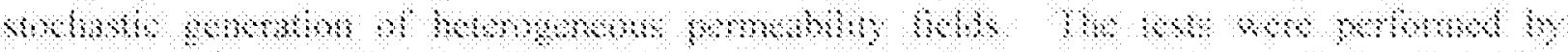

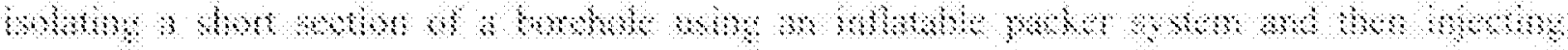

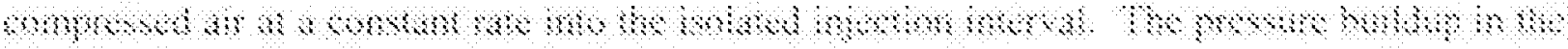

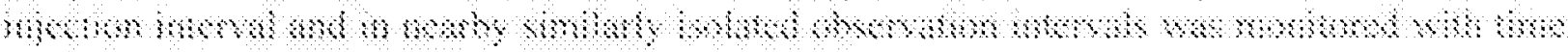

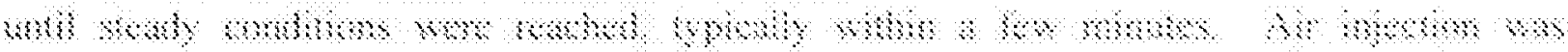

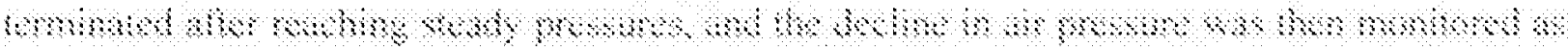

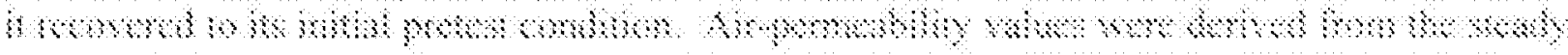

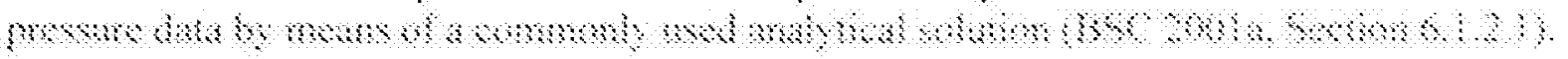


Permeabilities determined from air-injection tests are considered representative of the absolute permeability of the excavation-disturbed zone around the opening. Since air-injection tests are a standard method to obtain permeability values, the use of these values as the basis for model calibration, seepage prediction, and the development of probability distributions for TSPA ensures consistency and reduces a potential bias that would likely be introduced by relying on different measurement methods.

Air permeabilities were measured before and after mining of the niches. The results showed that permeability around the niches and the ECRB Cross-Drift was affected by excavation (BSC 2001a, Section 6.1.2.2; Wang and Elsworth 1999, pp. 752 to 756). Since seepage is determined by the formation properties and excavation effects in the immediate vicinity of the opening, it is reasonable to use postexcavation air-permeability data for seepage calculations.

\subsubsection{Relative-Humidity Monitoring}

Reduced relative humidity in the underground openings leads to partial evaporation of the water that reaches the cavity wall, potentially affecting seepage. To diminish, control, and quantify this effect, relative humidity in the closed-off niches was artificially increased to reduce the evaporation potential, and relative humidity was monitored. Figure 3-2 shows an example of temperature and relative humidity data measured in Niche 4 (also referred to as Niche 4788).

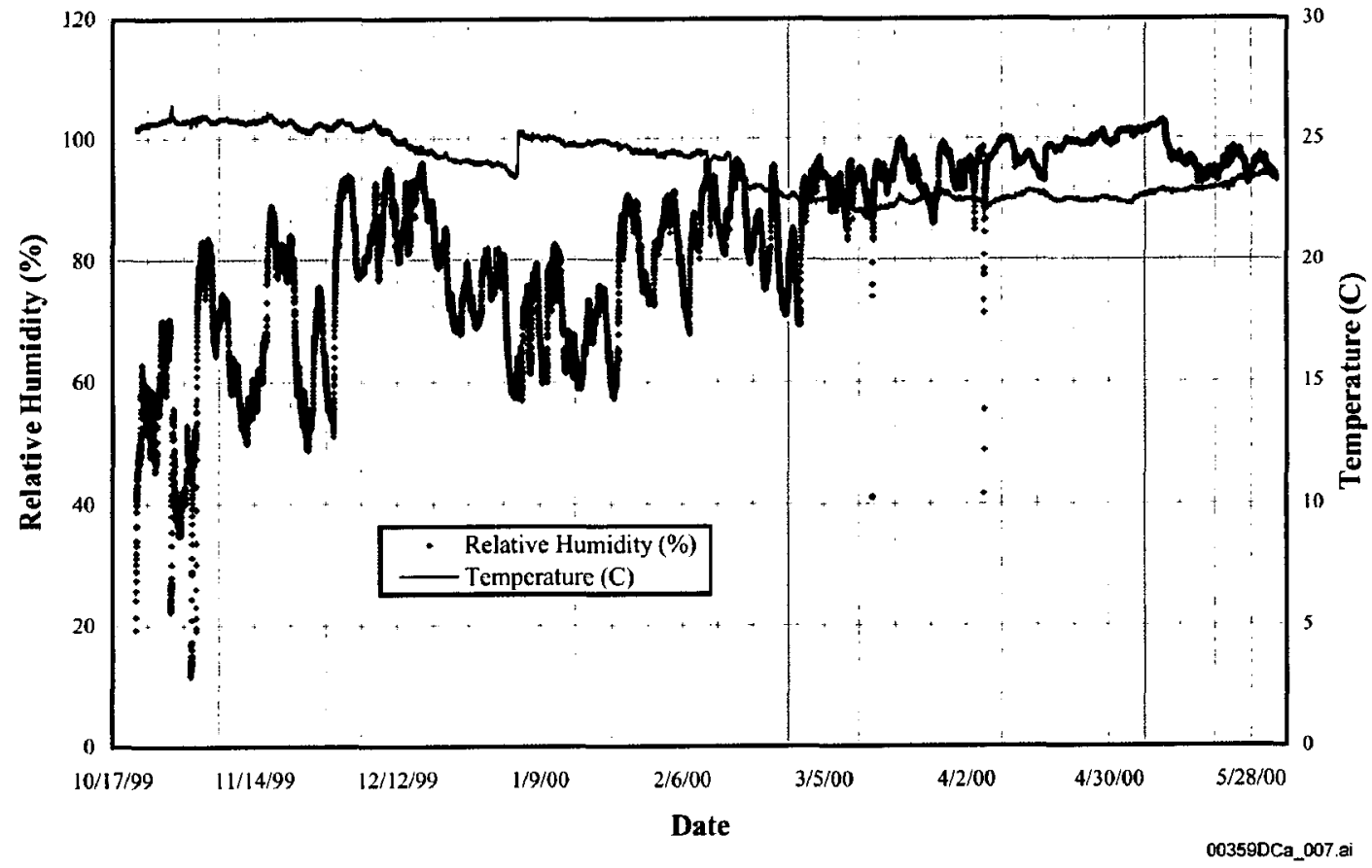

Source: BSC 2001a, Figure 6.2.1-5.

Figure 3-2. Temperature and Relative Humidity Measurements in Niche 4 
In a closed-off and humidified niche, potential evaporation at the wall or in the capture system is expected to be small compared to the amount of water being released. Seepage experiments in the middle nonlithophysal zone (Tptpmn) of the Topopah Spring welded unit were conducted in niches that were closed off by a bulkhead, which reduces air circulation and thus leads to comparatively high relative humidity. Moreover, a humidifier was used in some of the experiments to increase relative humidity to a value close to 100 percent. The measured evaporation rates and a related sensitivity analysis indicate that evaporation effects in the closed-off niches are insignificant and can be neglected in the analysis of seepage-rate data (BSC 2003e, Section 6.7). On the other hand, relative humidity in the open ECRB Cross-Drift is significantly lower and exhibits relatively strong fluctuations depending on weather and ventilation conditions. Evaporation-rate data from pan experiments were used to estimate the thickness of the diffusive boundary layer, which affects the evaporation potential. Evaporation in the ventilated ECRB Cross-Drift was found to be a greater fraction of the observed seepage rate, compared to the niche tests and was taken into account for the analysis of seepage tests conducted in the open drift.

The monitoring of relative humidity is further discussed in Appendix C.

\subsubsection{Liquid-Release Tests in Niches and along the Enhanced Characterization of the Repository Block}

Multiple liquid-release tests were performed in Niches 2, 3, 4, and 5 (also referred to as Niches $3650,3107,4788$, and 1620 , respectively), as well as in the systematic testing boreholes SYBT-ECRB-LA\#1 to 3. Water was released at various rates from a short section of the borehole above the opening. Any water that migrated from the borehole to the ceiling and dripped into the opening was captured and measured. In many intervals, multiple liquid-release tests were conducted using different release rates with different durations of inactivity between individual test events. Only a very small amount of water was released in early tests conducted in Niche 2. To reduce the impact of storage effects and to test a more representative portion of the fracture network involved in flow diversion around the opening, later tests in Niches 3, 4, and 5 and along the ECRB Cross-Drift used significantly more water in an attempt to reach near-steady seepage conditions. These later tests were used for parameter estimation purposes, as described in Section 4.3.

Figure 3-3 shows contours of the wetting front spreading across the niche ceiling during a liquid-release test. Water issued from the formation through fractures and micro-cracks and spread along the rough and dusty surface. Dripping was initiated at discrete points. As indicated in Figure 3-4, seepage rates measured during a representative liquid-release test appear to stabilize after about 4 days of continuous water injection. In this example, the high release rate resulted in a near-steady seepage rate that was approximately half the release rate.

Appendices $\mathrm{B}$ and $\mathrm{C}$ contain additional information on seepage testing. 

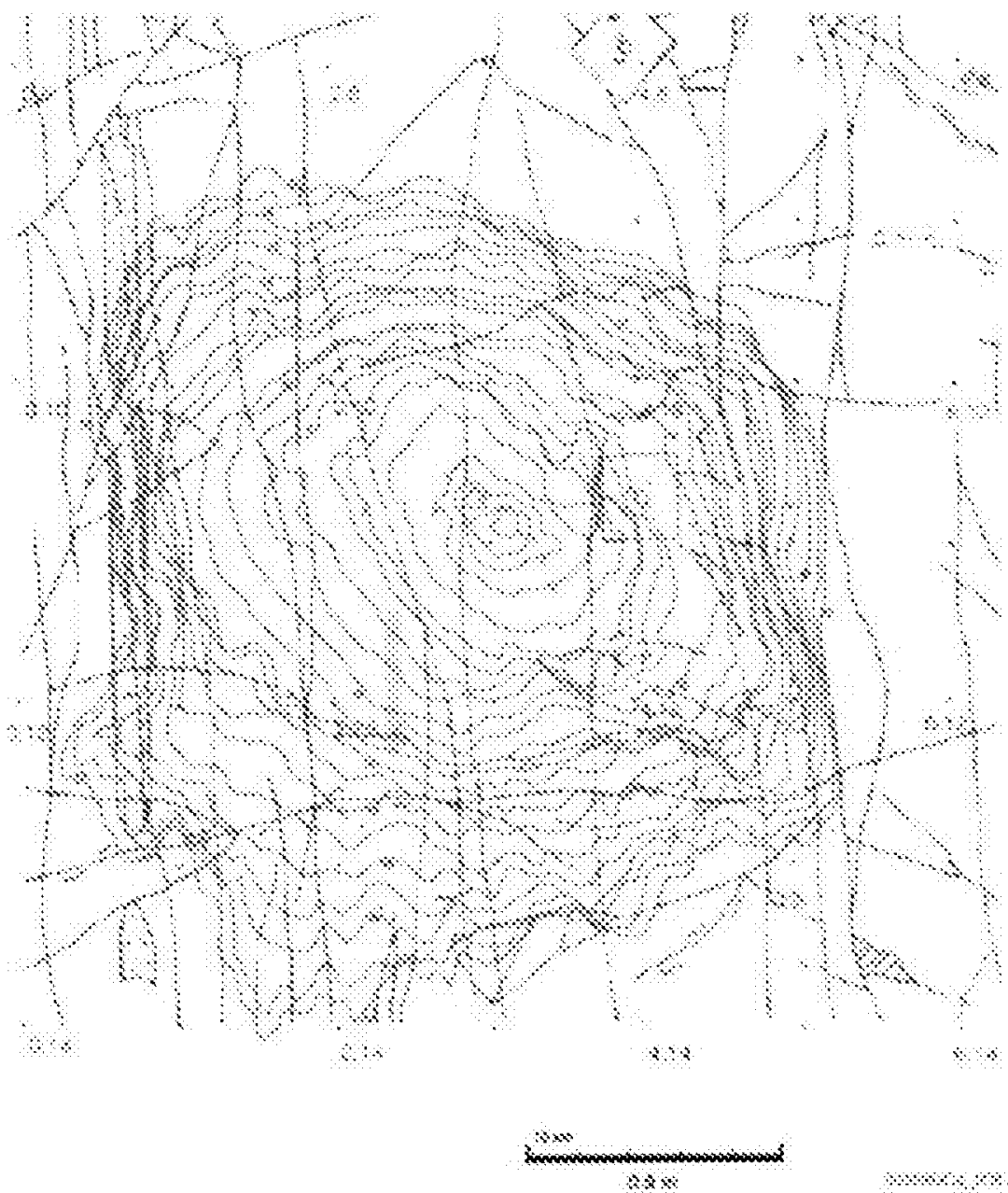

ans

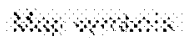

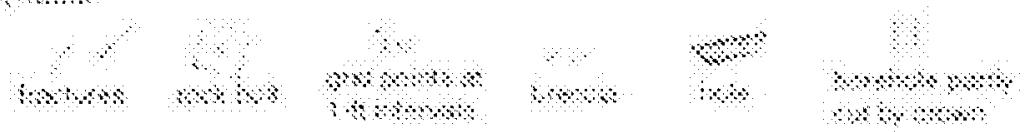

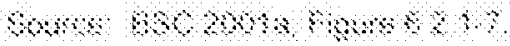

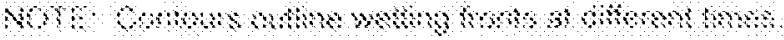

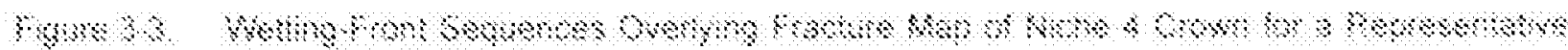

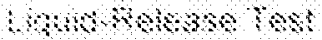




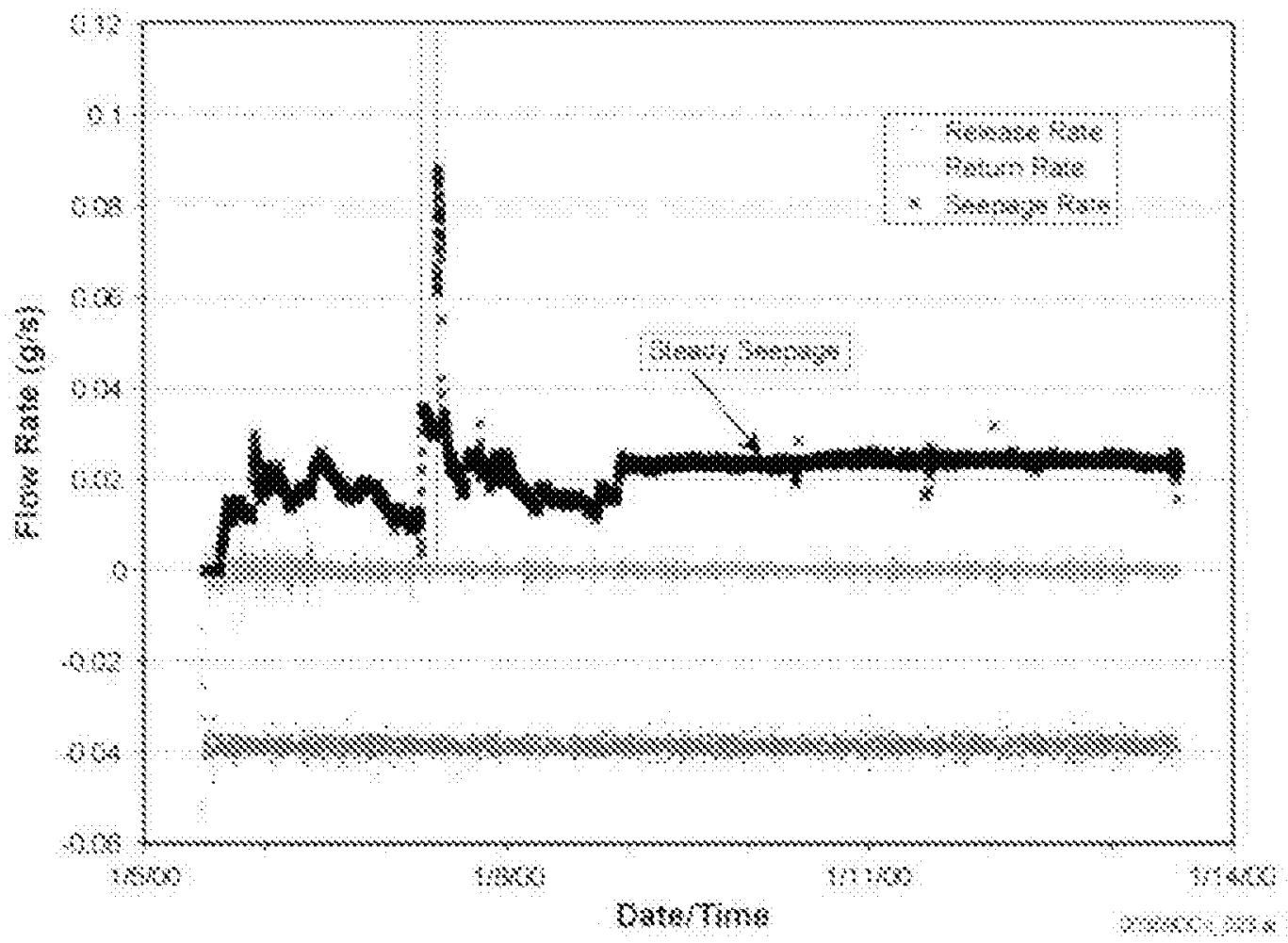

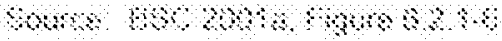

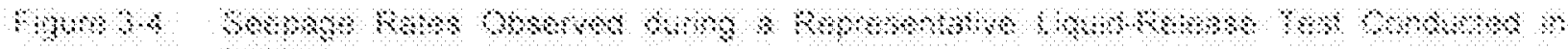
\$ns

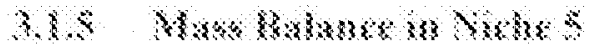

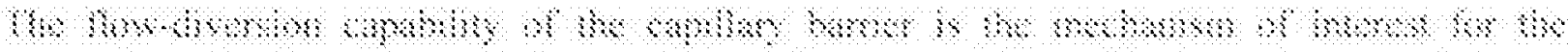

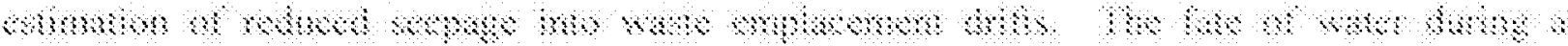

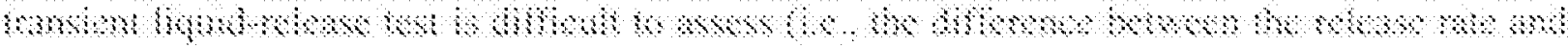

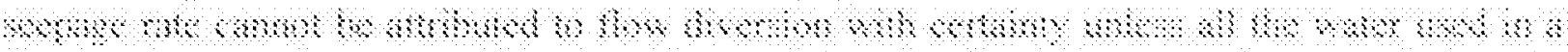

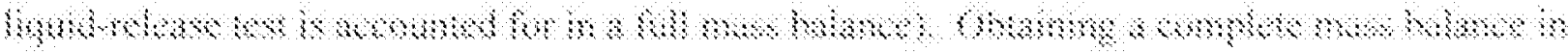

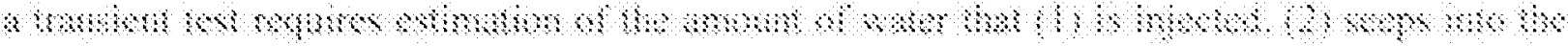

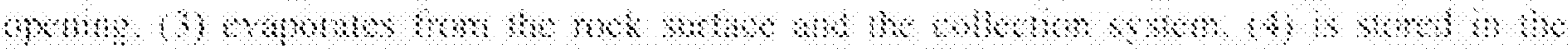

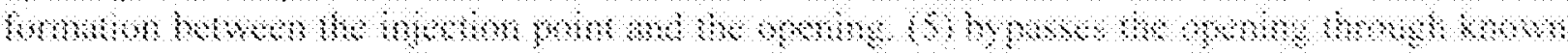

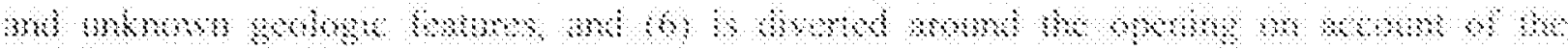
mismonmes 6 s?

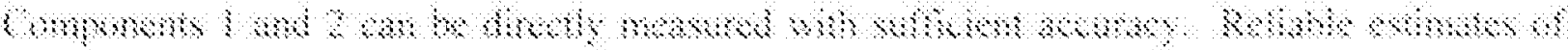

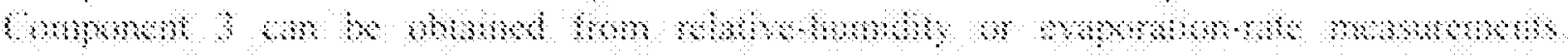

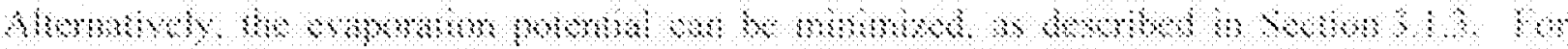

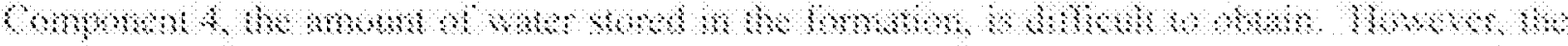

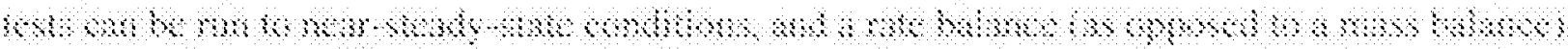

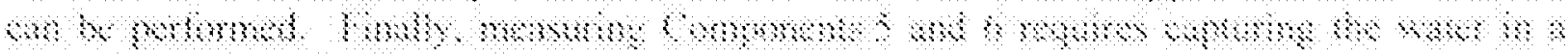

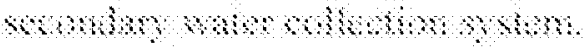


Performing such a water mass balance was considered for the Alcove 8-Niche 3 test (see Section 3.1.6) but was not performed due to the large scale of the test and the correspondingly large secondary collection system that would be required. Instead, an attempt was made to obtain a mass balance in the Niche 5 seepage tests. The main element of this attempt was the construction of a slot on the side of the niche to capture the water that is diverted around the opening (i.e., Component 6). Relative humidity in Niche 5 was increased to reduce the contribution of Component 3 , and a long-term liquid-release test was performed to minimize storage effects (Component 4). The relatively close proximity of the injection point to the drift ceiling reduces the risk that water bypasses the niche through unknown, unique geologic features (Component 5). Since near seepage conditions were achieved, a rate balance (rather than total mass balance) was performed, which is more appropriate in light of the eventual estimation of near steady seepage rates under repository conditions.

Water was collected at the side of the niche during two seepage tests conducted in Niche 5. However, because of difficulties in excavating the slot and installing the capture system, it was not possible to visually confirm that the water collected in the slot near the wall was derived entirely from seepage into the slot. While qualitative evidence was obtained that the capillary barrier was capable of diverting water around the niche, a quantitative mass or rate balance based on the measured data alone could not be obtained. The seepage predictions, therefore, continue to rely on (1) established understanding of the physics underlying flow diversion around a capillary barrier, (2) extensive site-specific and seepage-related characterization data, (3) qualitative evidence demonstrating flow diversion and water exclusion, (4) calibration and validation of a physically based process model that captures all components of the mass balance (storage, evaporation, flow diversion, and seepage), and (5) propagation of uncertainties and variabilities and probabilistic treatment of seepage in TSPA calculations.

The mass-balance issue is further described in Appendix C.

\subsubsection{Alcove 8-Niche 3 Testing}

Evaluation of seepage is among the multiple objectives of the ongoing testing at Alcove 8-Niche 3. Alcove 8 (located in the ECRB Cross-Drift, see Figure 3-5) was excavated and prepared to perform liquid-releases tests into a fault and a network of fractures. Approximately $20 \mathrm{~m}$ below Alcove 8-Niche 3 (located in the main drift of the ESF at construction station 3107 ) serves as the site for monitoring of seepage. The interior of the niche was instrumented with trays for seepage collection. In addition, a series of boreholes surrounding Niche 3 was instrumented with sensors to detect the arrival of the wetting front.

Liquid water and tracers were released at the floor of Alcove 8 (located in the upper lithophysal zone, Tptpul) along approximately $5 \mathrm{~m}$ of an exposed fault. The amount of water seeping from the fault into Niche 3 (which is located in the middle nonlithophysal zone, Tptpmn) and tracer concentrations were monitored as functions of time. An example is presented in Figure 3-6, showing the seepage rate is approximately 10 percent of the injection rate.

Seepage-related issues are further discussed in Appendix C. Pretest predictions are described in Appendix E. 


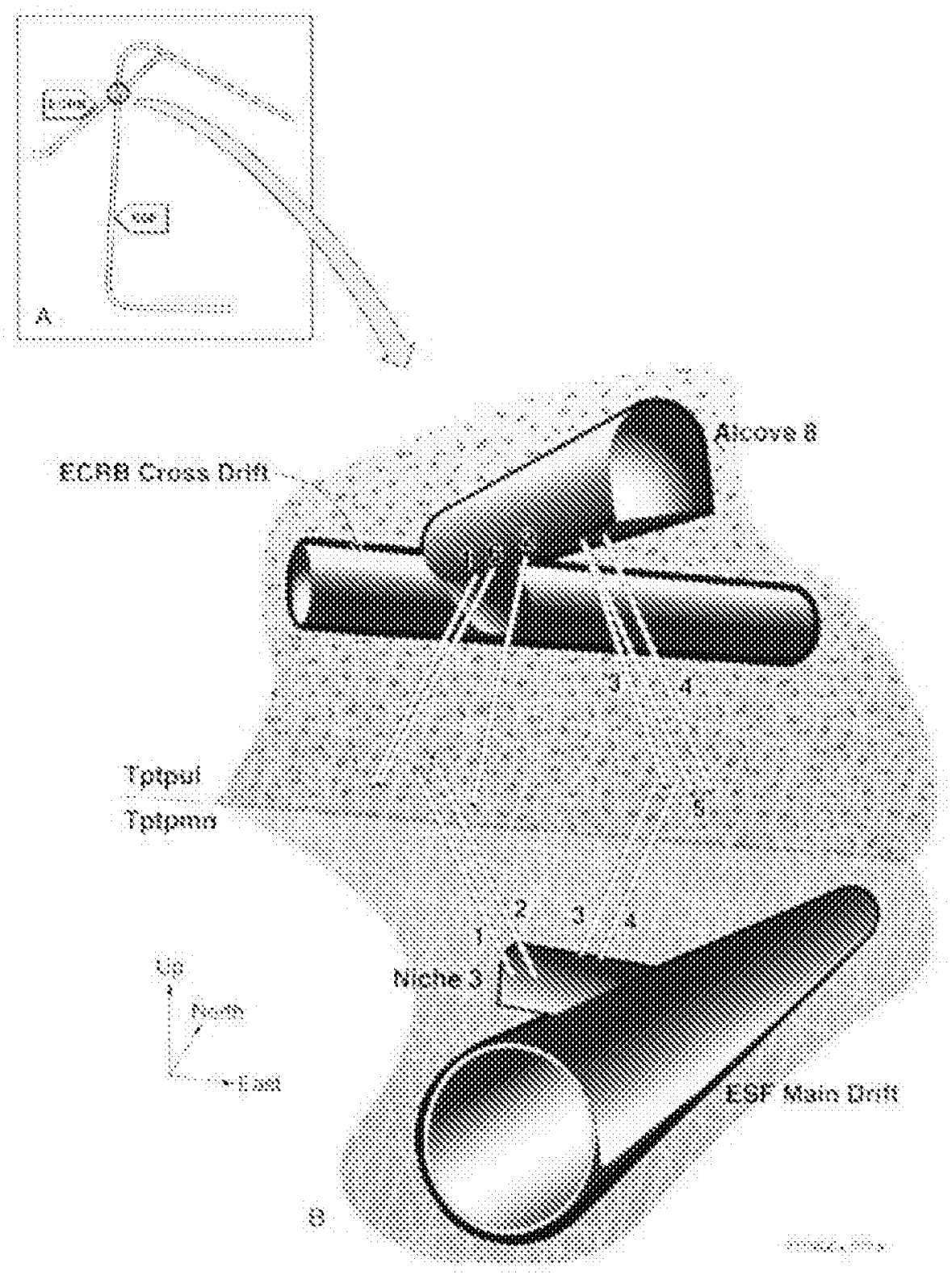

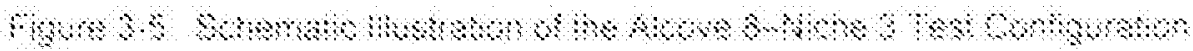




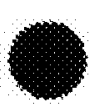

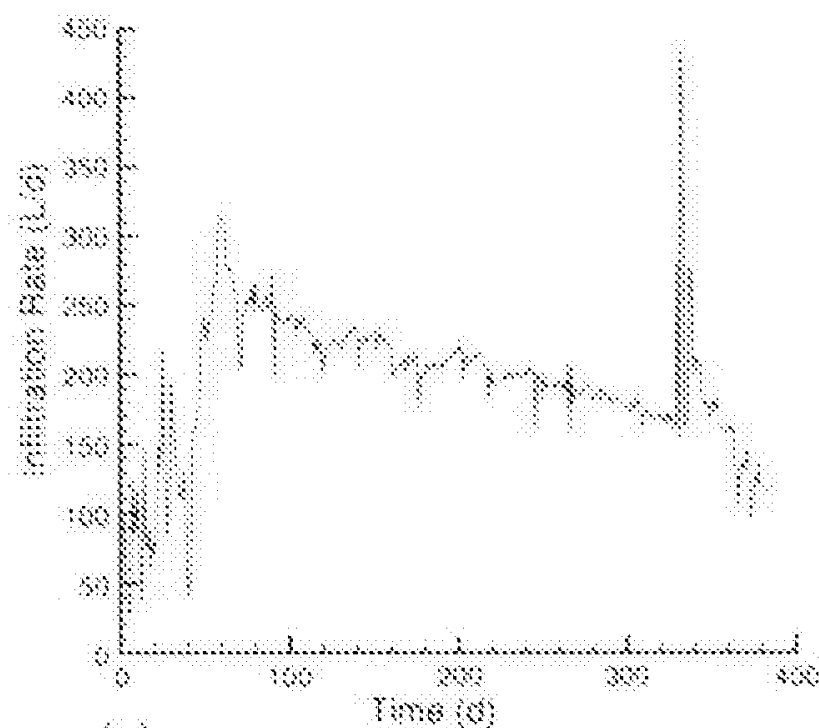

(a)

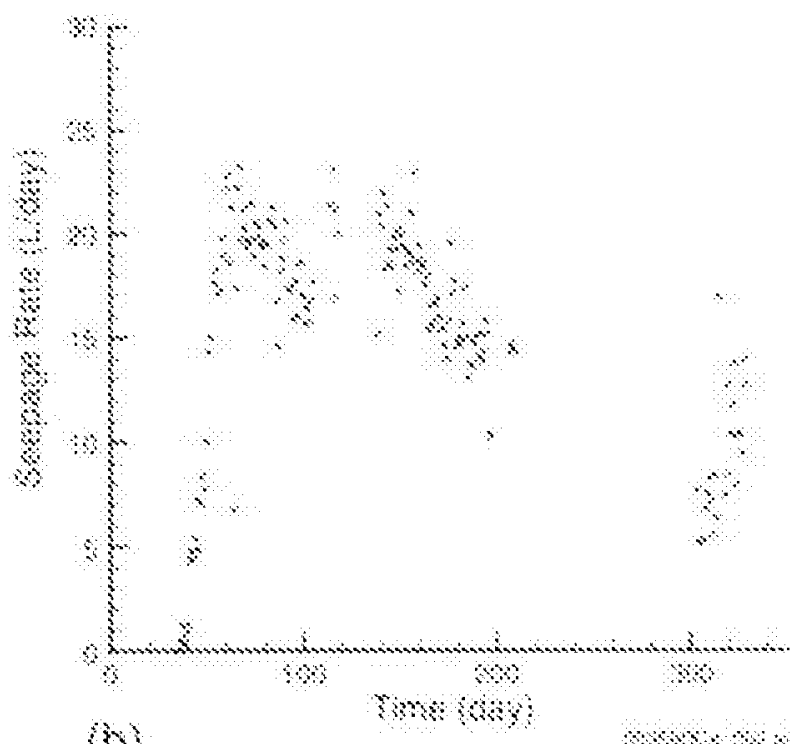

(b) $3+\infty$

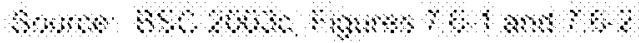

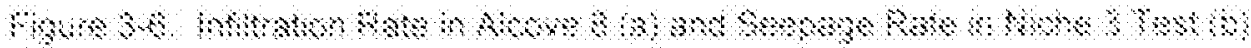

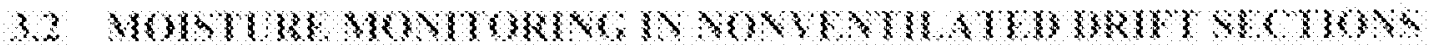

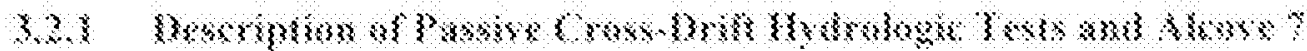

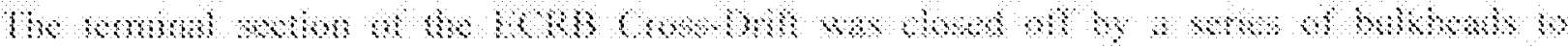

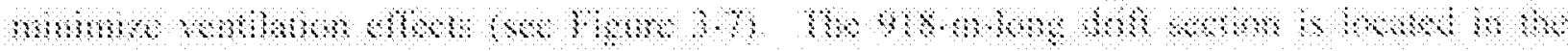

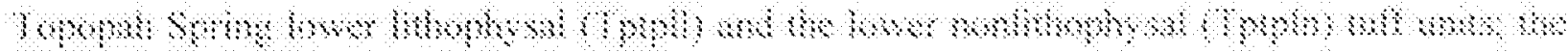

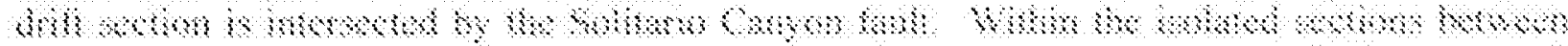

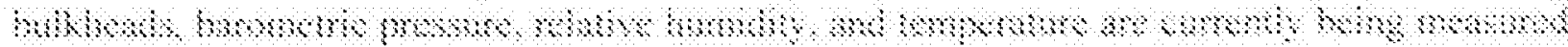

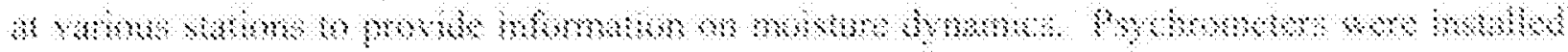

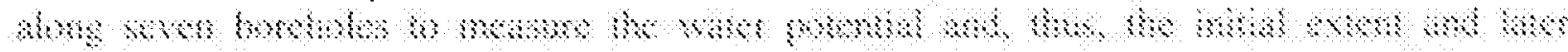

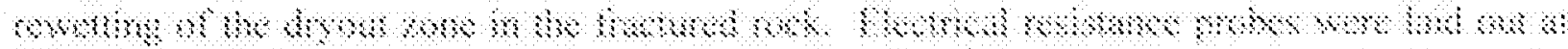

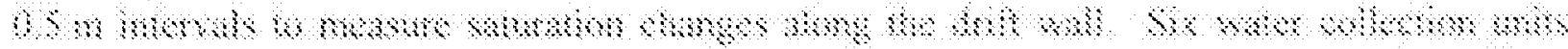

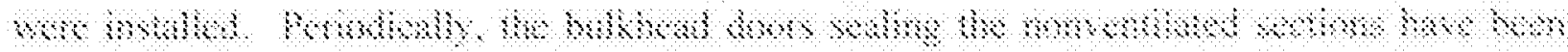

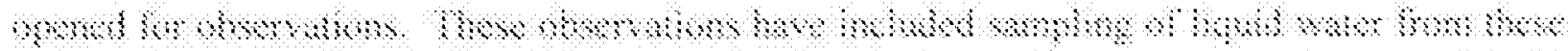

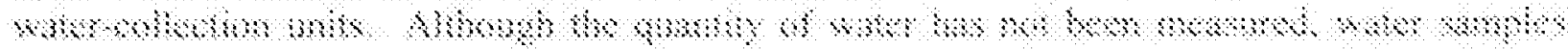

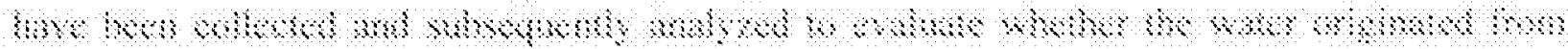

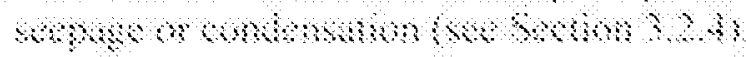

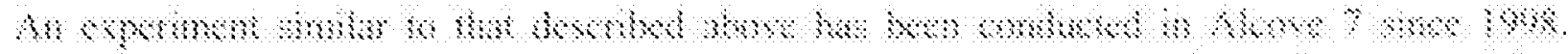

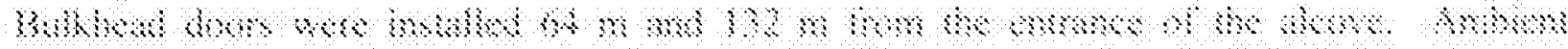

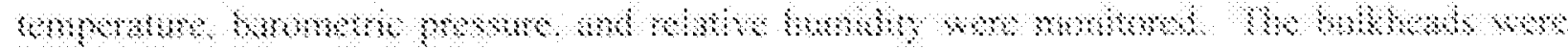

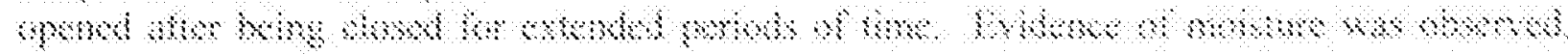

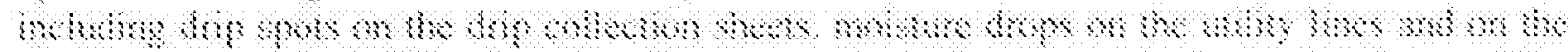

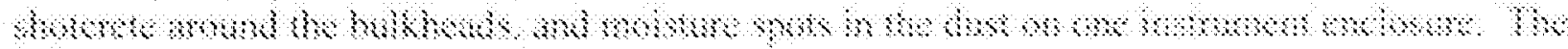

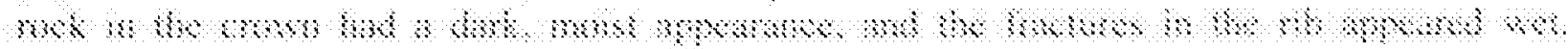




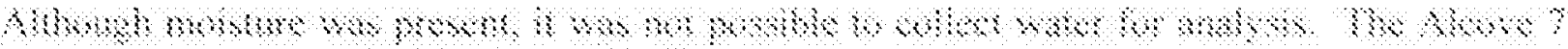

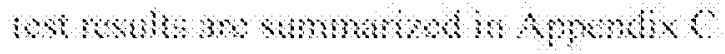

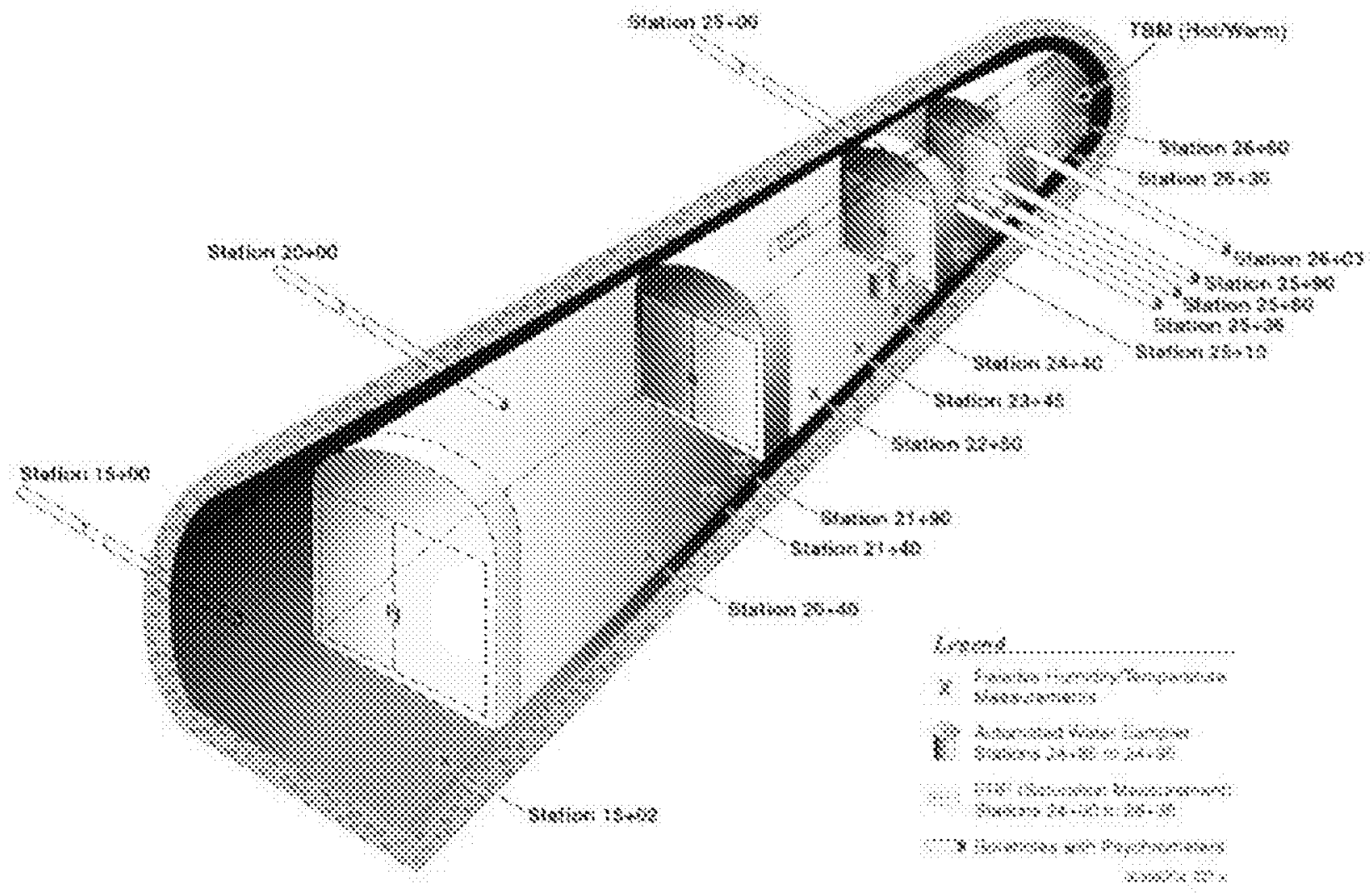

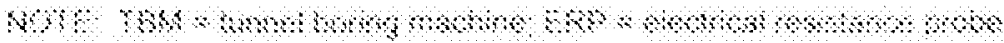

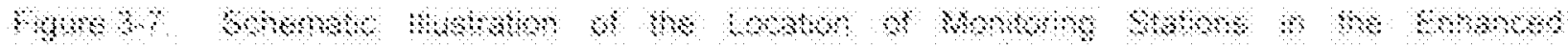

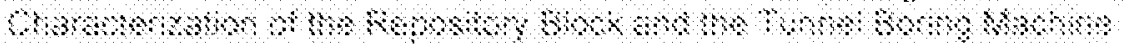

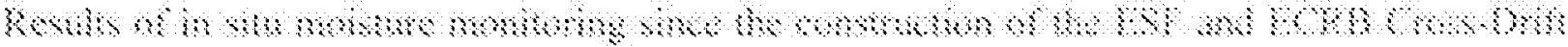

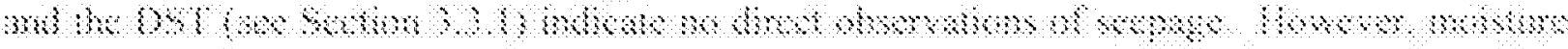

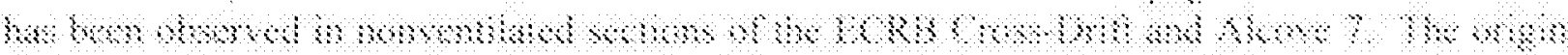

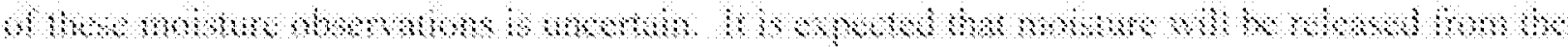

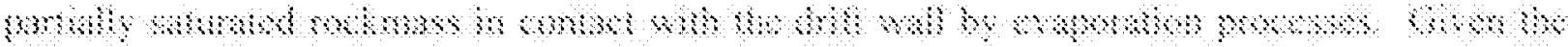

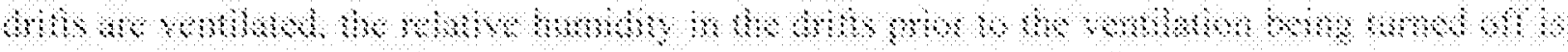

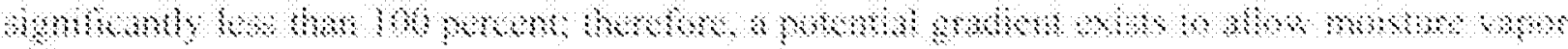

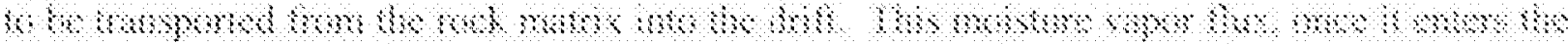

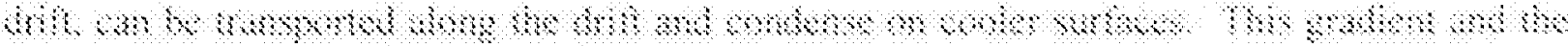

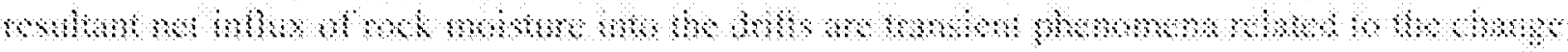

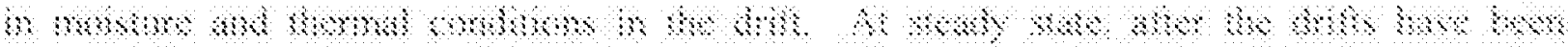

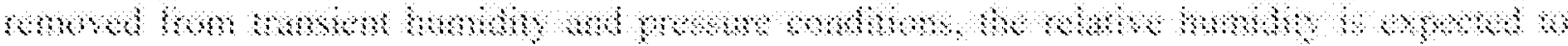

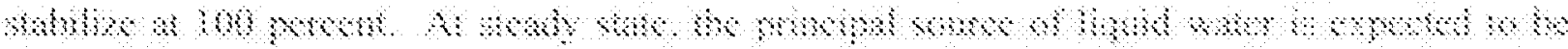

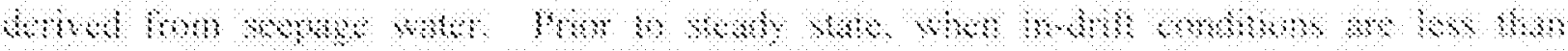

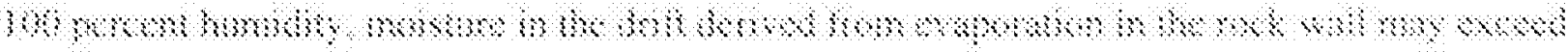

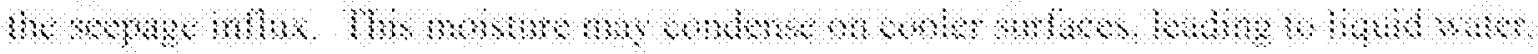




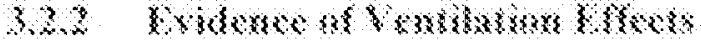

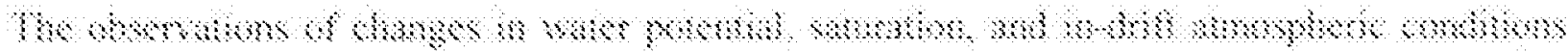

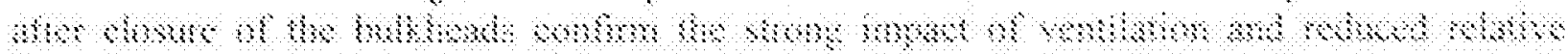

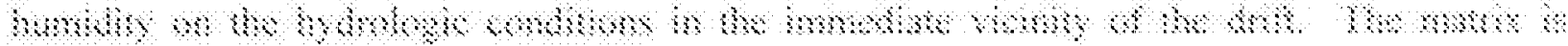

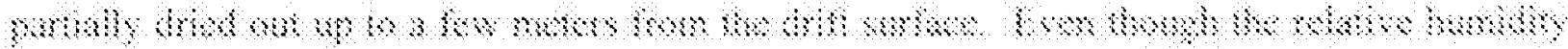

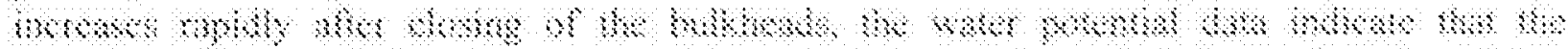

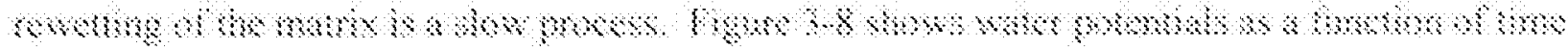

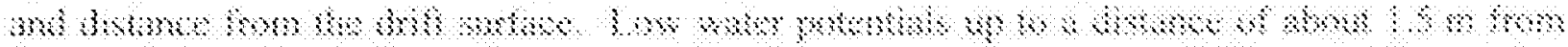

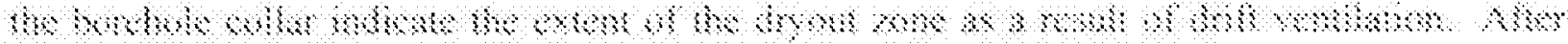

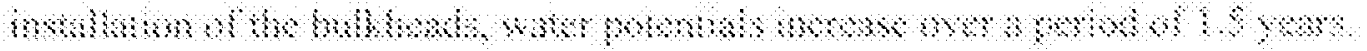

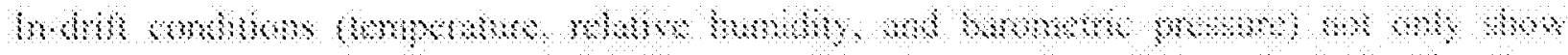

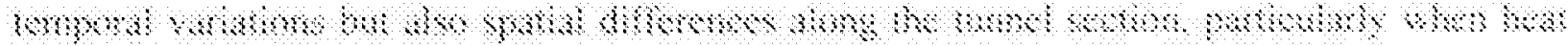

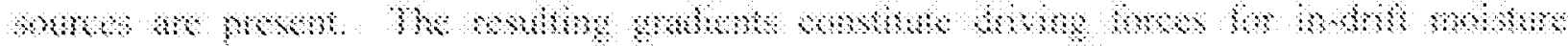

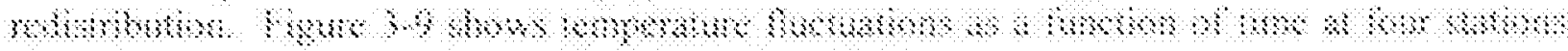

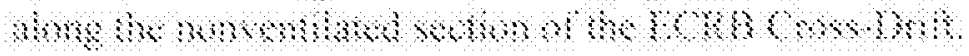

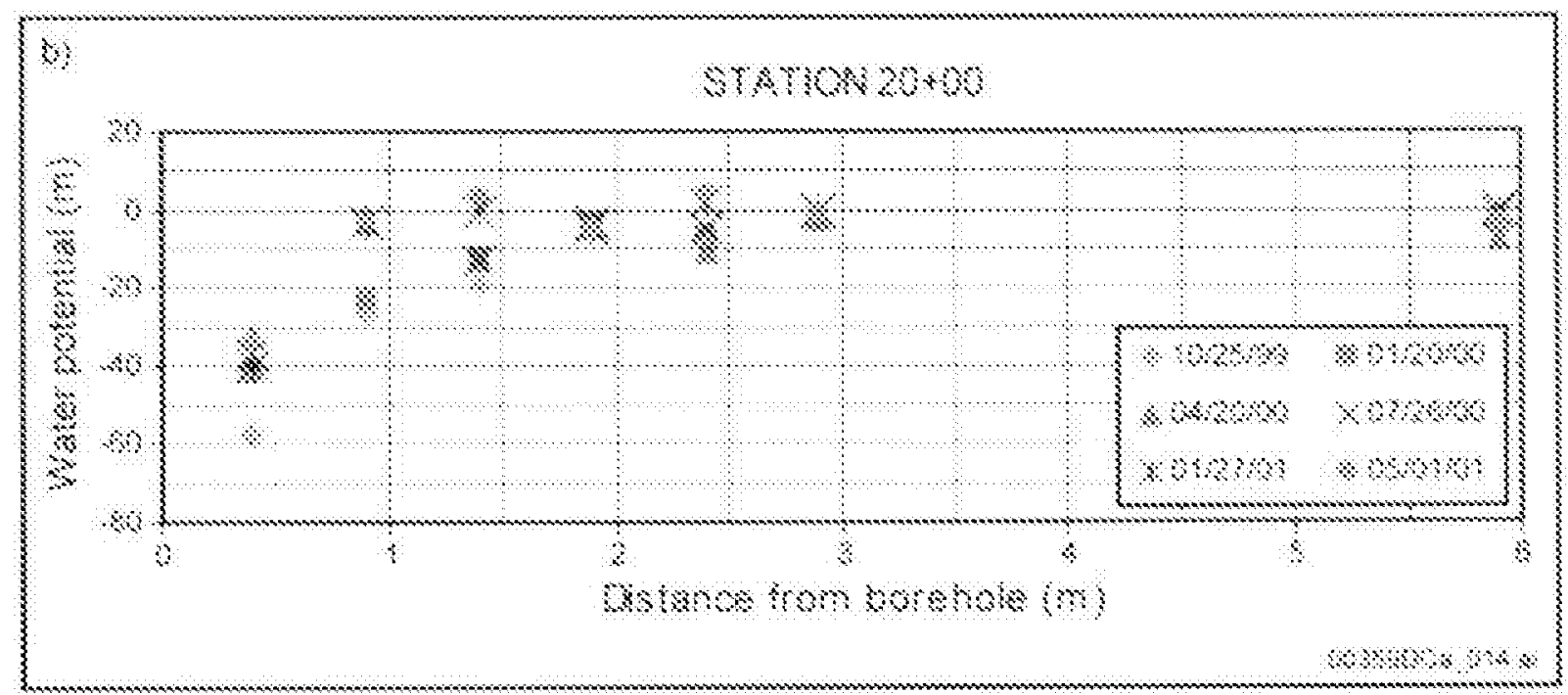

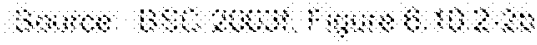

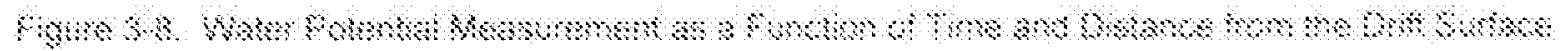




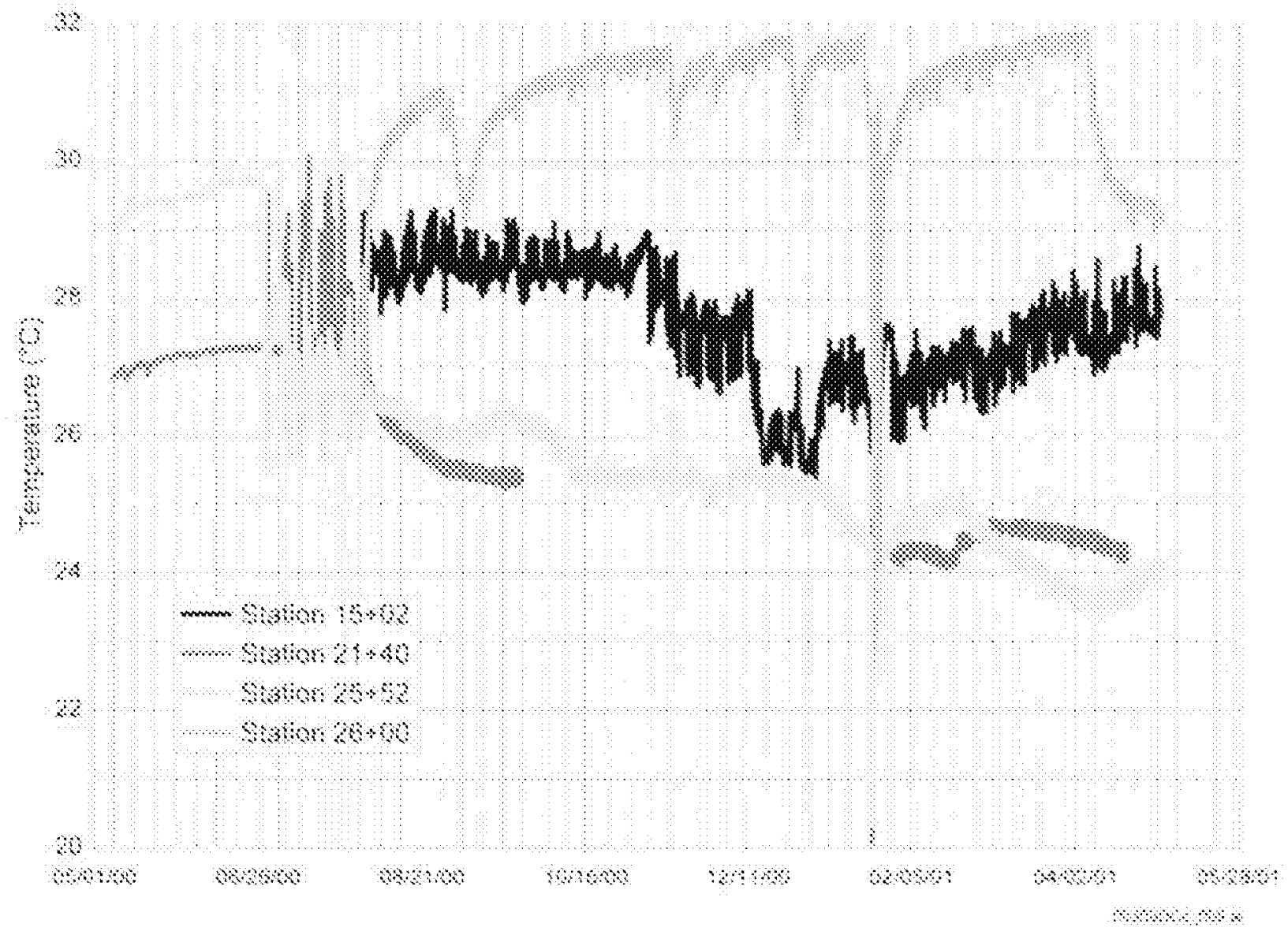

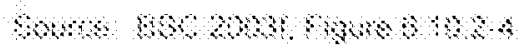

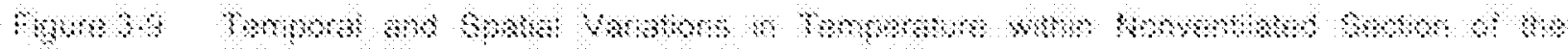

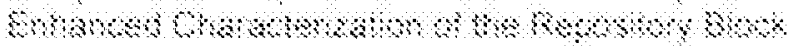

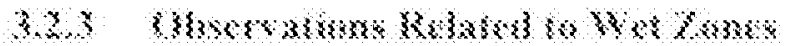

Wo mmo nms

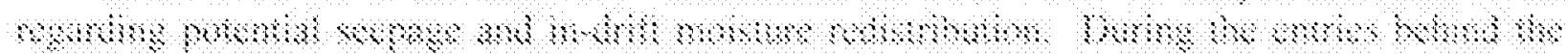

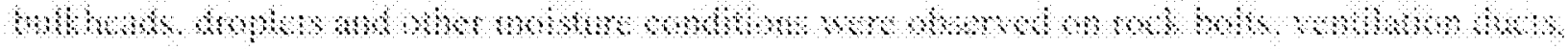

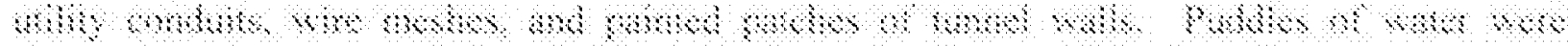

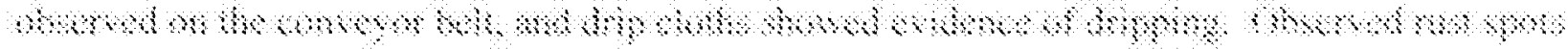

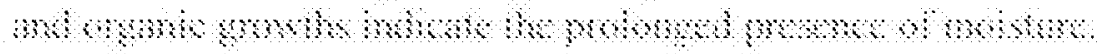

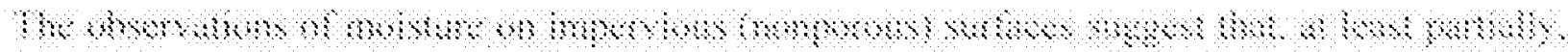

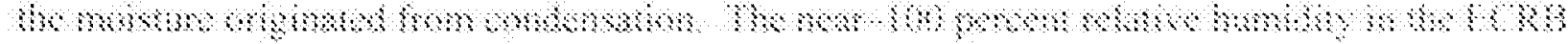

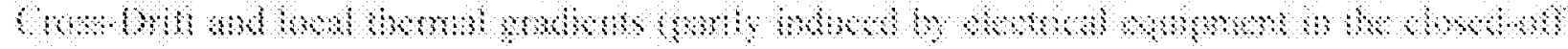

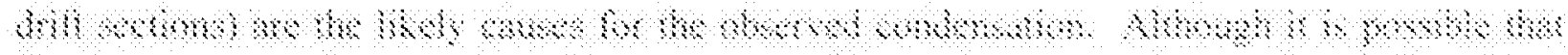

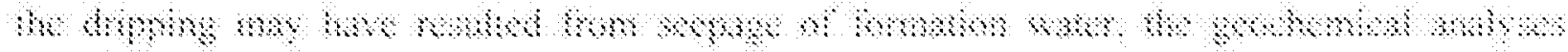

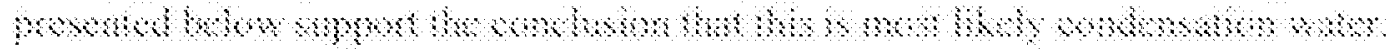




\subsubsection{Chemical and Isotopic Water Analyses}

Determining the origin of the moisture observed in the closed-off sections of the ECRB CrossDrift is of interest because it relates to the process inducing dripping (condensation or seepage) and affects the chemistry of the water potentially contacting waste packages. Chemical analyses and isotopic measurements were conducted on the water samples collected during the periodic entries into the nonventilated sections of the ECRB Cross-Drift. The chemical analyses included major anionic and cationic constituents (such as bromide, chloride, and lithium).

The initial water samples collected from the puddles on the conveyor belt were dark in color. Because the surface of the conveyor belt was covered by dust and rock fragments, the chemical analyses of these samples were not expected to provide meaningful signature about the source of water found in the puddles. Subsequent samples were taken from clean containers placed on top of the conveyor belt. These samples were found to be low in chloride and silica content, characteristic of condensates. The samples were also found to lack the chemical signature of the construction water that was spiked with $20 \mathrm{mg} / \mathrm{L}$ of lithium bromide. While these data clearly show that part of the observed moisture originated from condensation, they do not rule out the possibility that some of these waters are of mixed origins.

The hydrogen $(\delta \mathrm{D})$ and oxygen $\left(\delta^{18} \mathrm{O}\right)$ isotope compositions were also analyzed. The $\delta \mathrm{D}$ values range from $-48 \%$ to $-9 \%$, and the $\delta^{18} \mathrm{O}$ values range from $-3 \%$ to $-10.7 \%$. These values are higher than those found in construction water. The lag time between opening of bulkheads and sample collection ( 3 to 4 hours) is sufficient to result in a significant degree of evaporation of the samples. As seen in Figure 3-10, all samples from the ECRB Cross-Drift are shifted from the global meteoric water line. The offset is characteristic of waters that have undergone some degree of evaporation. The same degree of shifts for both the contaminated samples and the relatively clean samples may indicate that approximately the same amount of evaporation occurred.

The geochemical and isotopic analyses of water collected in the nonventilated ECRB Cross-Drift seem to indicate that condensation is a source of the dripping water.

\subsubsection{Summary}

Moisture monitoring in nonventilated sections of the ECRB Cross-Drift and ESF is an ongoing part of the field testing program. Observations of hydrologic and thermodynamic conditions in the drift itself and in the nearby rock lead to the following seepage-related findings:

1. Ventilation effects in ventilated drift sections have a significant impact on seepage, mainly through evaporation of potential seepage water at the drift surface but also through the development of a dryout zone around the opening.

2. Once ventilation effects are reduced or eliminated, the relative humidity of the initially dry in-drift environment generally increases in a short time period.

3. The high relative humidity in closed-off drift section leads to conditions that facilitate in-drift moisture redistribution processes, which may be associated with condensation 


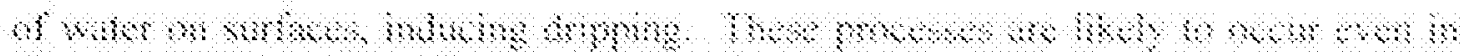

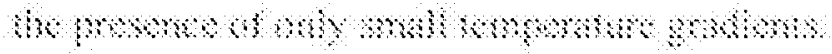

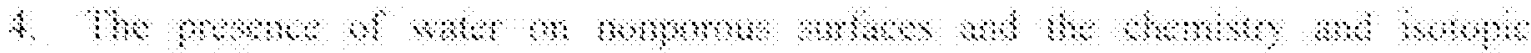

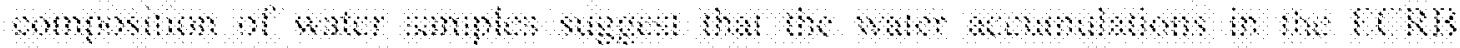

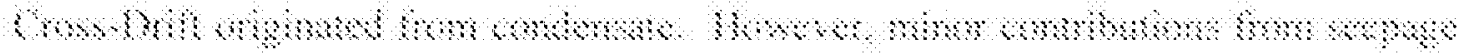

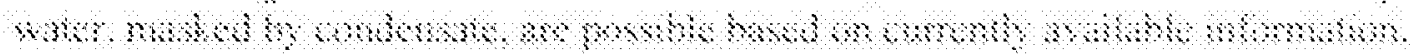

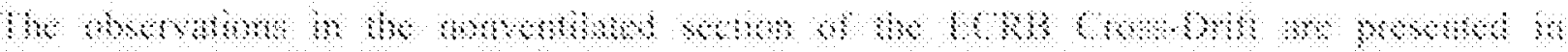

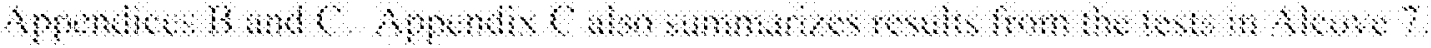

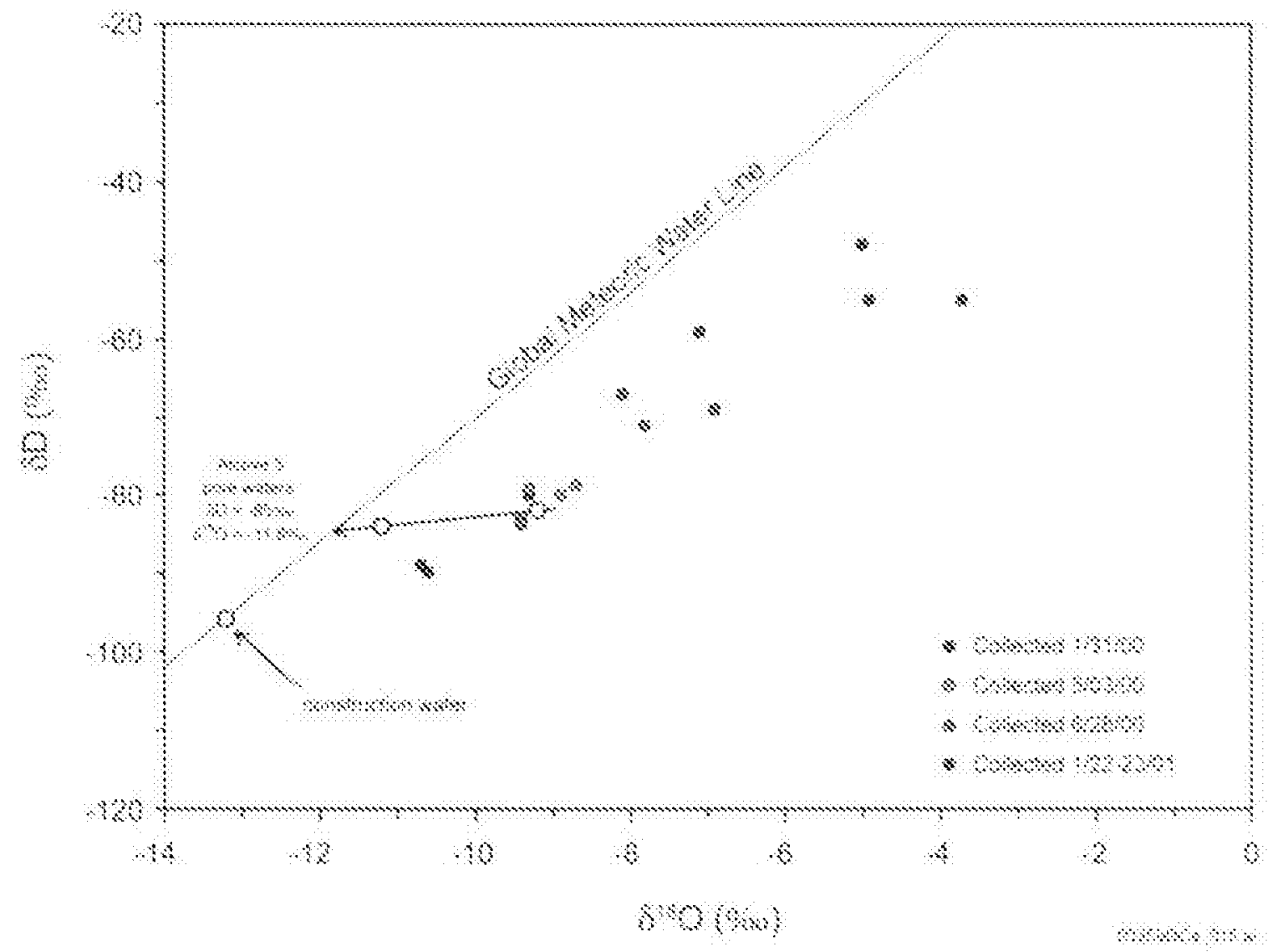

mate

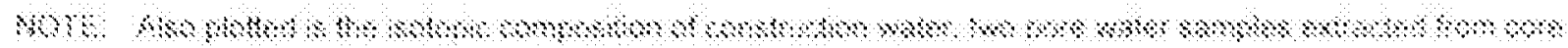

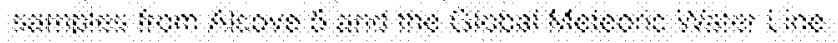

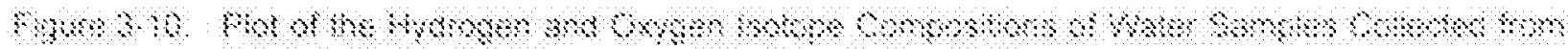

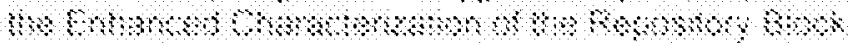




\subsection{COUPLED PROCESSES TESTING}

\subsubsection{Drift Scale Test}

As discussed in Sections 2.4 and 2.6, seepage is partly determined by the properties of the fractured rock. The properties may be altered as a result of coupled effects induced by heating of the repository. For example, increased temperatures lead to mechanical deformations that change the hydrologic properties of the fracture network (BSC 2003g). Moreover, mineral dissolution and precipitation during the thermal period may temporarily or permanently affect the apertures of fractures in the immediate vicinity of the waste emplacement drifts (BSC 2003h). These coupled effects during repository heating have been studied using numerical simulation and the DST, which is the largest underground thermal test carried out to date in the ESF.

The purpose of the DST is to evaluate the coupled thermal, hydrologic, chemical, and mechanical processes that take place in unsaturated fractured tuff over a range of temperatures (approximately $25^{\circ} \mathrm{C}$ to $200^{\circ} \mathrm{C}$ ). Details regarding the DST layout, borehole orientations, operation of the test, and measurements performed (as well as their uncertainties) are discussed in the Thermal Testing Measurements Report (BSC 2002b, Section 6.3) and Drift Scale Test As-Built Report (CRWMS M\&O 1998). In brief, the DST consists of an approximately 50 - $\mathrm{m}$-long drift that is $5 \mathrm{~m}$ in diameter. Nine electrical canister heaters were placed in this drift to simulate nuclear-waste-bearing containers. Electrical heaters were also placed in a series of horizontal boreholes (wing heaters) drilled perpendicularly outward from the central axis to both sides of the drift. These heaters were emplaced to simulate the effect of adjacent emplacement drifts. The DST heaters were activated on December 3, 1997, with a planned period of 4 years of heating, followed by 4 years of cooling. After just over 4 years, the heaters were switched off on January 14, 2002, and since that time the test area has been slowly cooling. Figure 3-11 shows a schematic view of the test layout with the main heater tunnel, the wing heaters, and the array of observation boreholes monitoring temperature, as well as chemical, mechanical, and hydrologic variables. Data on the evolution of gas phase, liquid phase and solid phase compositions, changes in water content and air permeabilities, and rock deformations collected during the DST were used to validate the related coupled models on thermal, hydrologic, chemical, and mechanical processes, as discussed in Sections 4.6 and 4.8.

No seepage has been observed during the DST. This observation is consistent with the effect of the vaporization barrier described in Section 1.5. However, the absence of observed seepage should not be directly used to evaluate seepage into repository drifts because the potential for seepage in the DST may have been reduced as a result of vapor losses through the bulkheads (BSC 2003b, Section 6.4.3.2).

Property changes induced by elevated temperatures as inferred from direct observations and associated modeling of the DST were examined for their impact on seepage, as discussed in Sections 4.6 and 4.8 . 


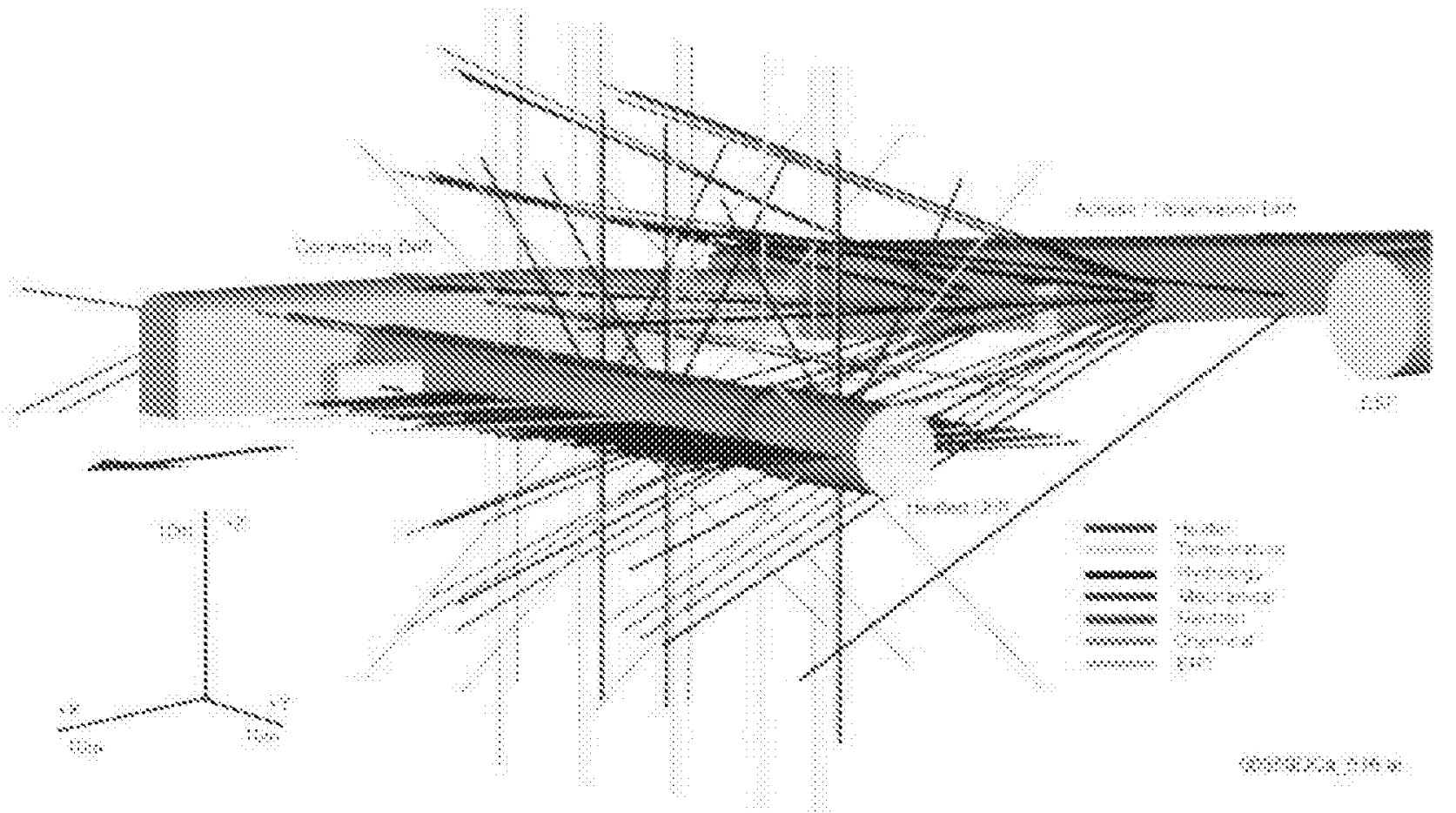

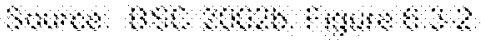

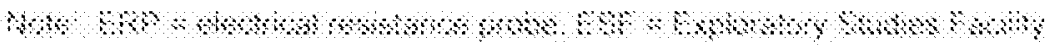

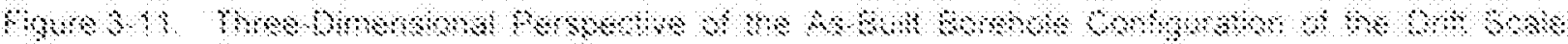
१ि:

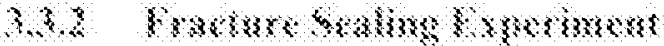

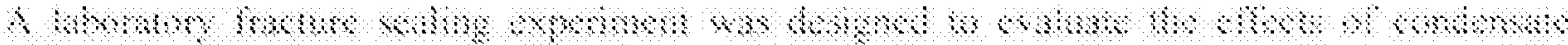

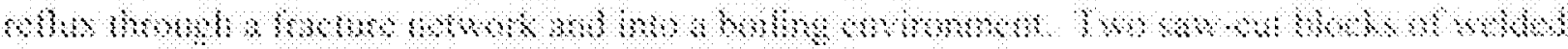

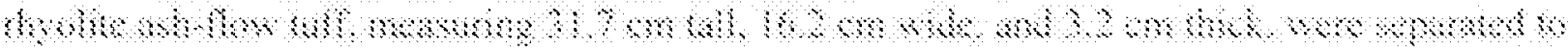

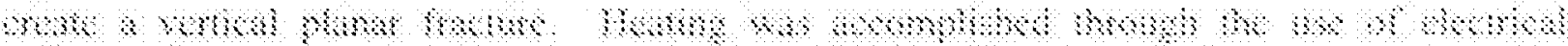

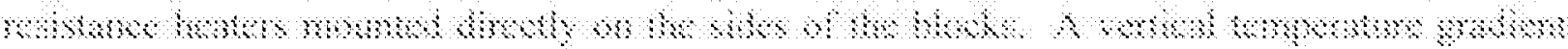

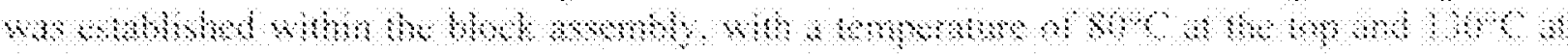

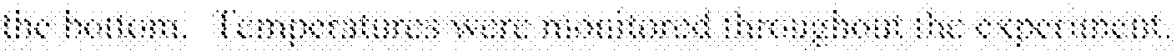

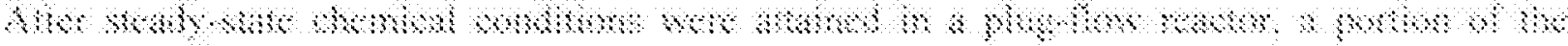

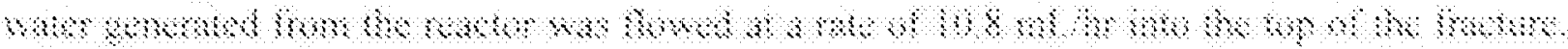

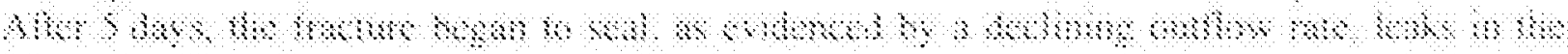

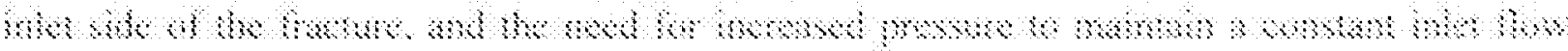

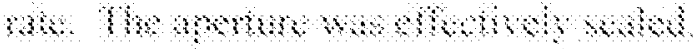




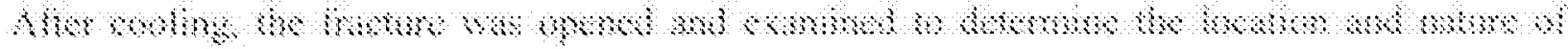

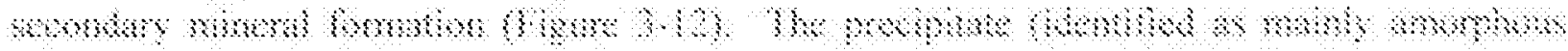

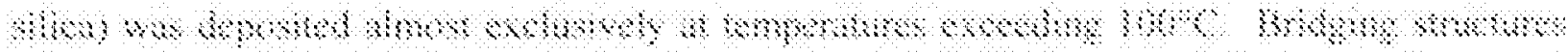

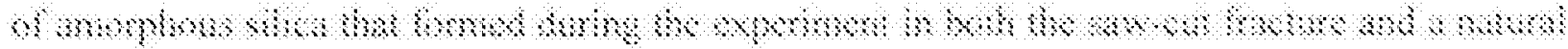

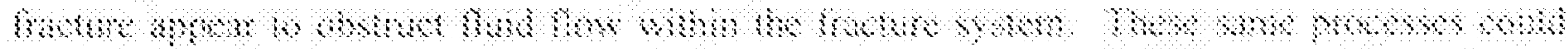

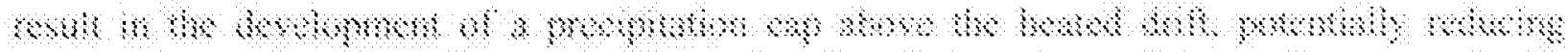

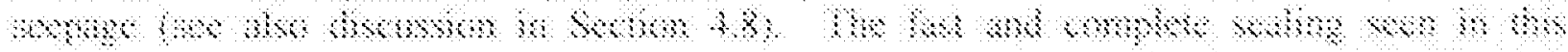

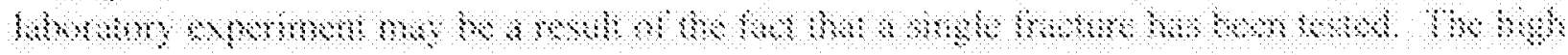

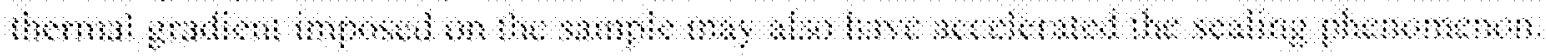
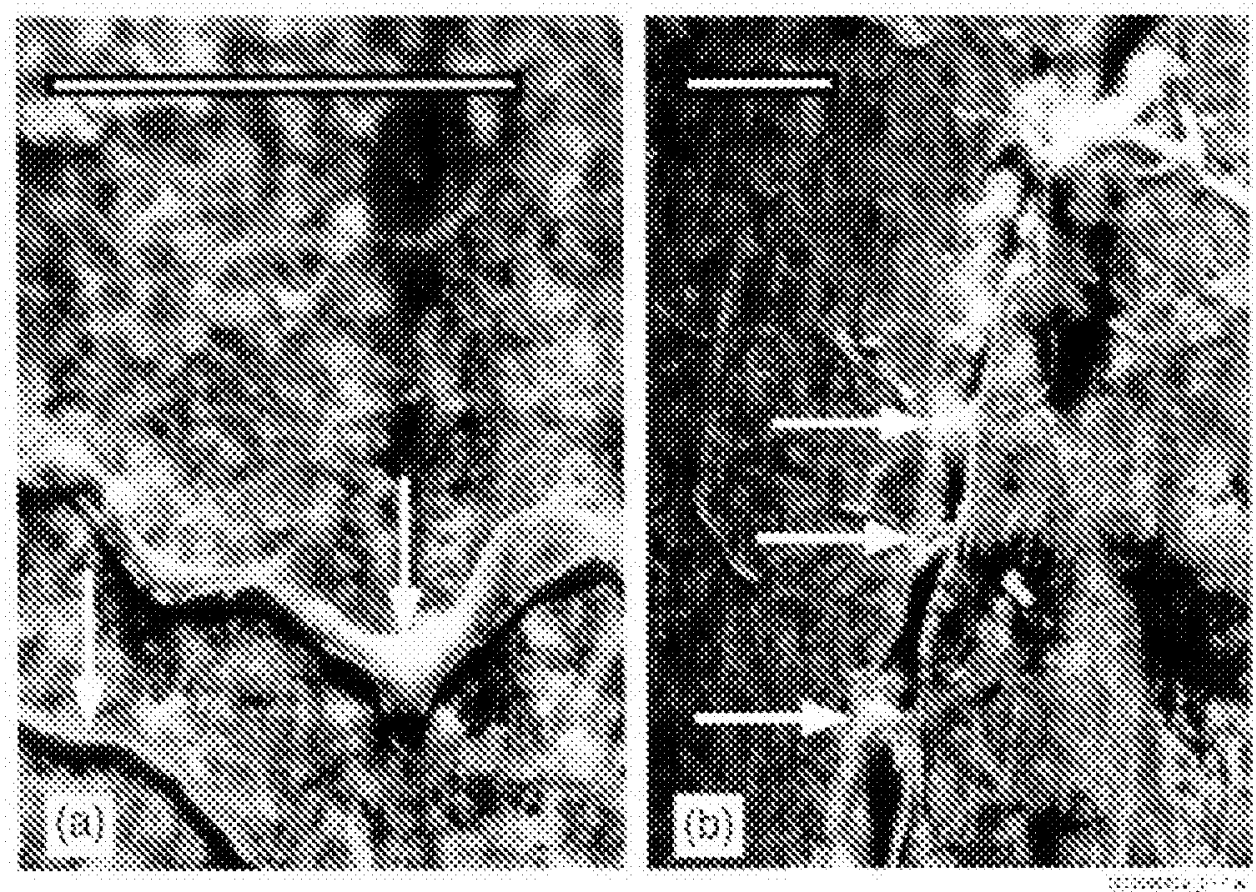

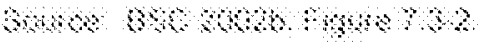

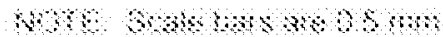

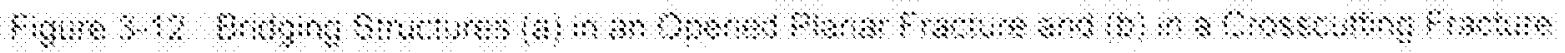

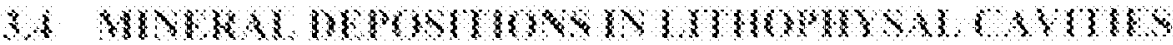

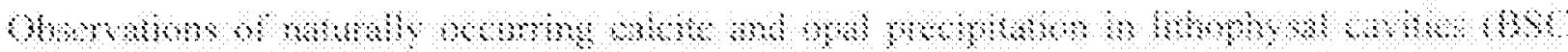

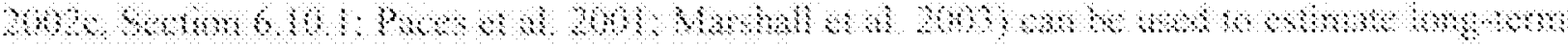

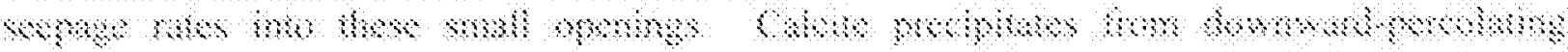

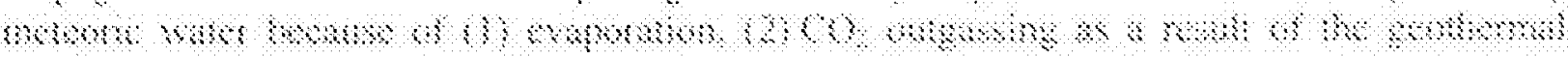

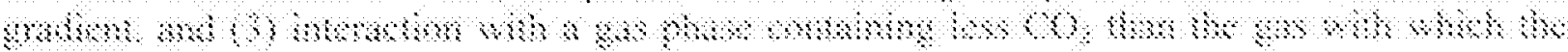

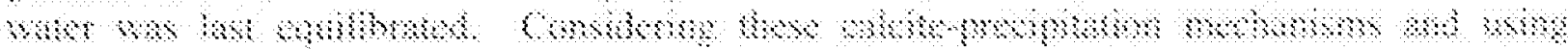

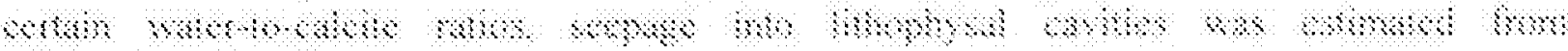

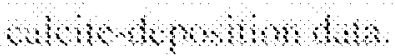


The calcite depositions on lithophysal cavity floors may not originate from dripping water (i.e., seepage); in fact, there is a lack of evidence of dripping from cavity ceilings (absence of stalactites or stalagmites at any scale), even where fractures containing coatings intersect lithophysae ceilings (Whelan et al. 2002, p. 744). This observation is consistent with the capillary barrier concept. Even if making the assumption that all calcite deposited in lithophysal cavities originated from seepage, the data indicate that (1) not all lithophysal cavities encountered seepage, and (2) seepage flux derived from mineral deposits is a very small fraction of percolation flux. Both conclusions corroborate the general concept of a capillary barrier reducing seepage below the value of the percolation flux.

Additional discussion of the analysis of secondary minerals in Appendix C.

\subsection{ABSENCE OF SEEPAGE IN VENTILATED DRIFTS}

So far, no dripping of natural percolation water has been observed in any of the ventilated openings at Yucca Mountain (Trautz and Wang 2002). While this finding can be considered consistent with the current understanding of the capillary diversion capacity of the fractured formation, the absence of seepage can also be explained by evaporation effects. The significant evaporation potential of the dry drift atmosphere is evident not only from theoretical considerations, but also from temporal observations of wet spots observed at the drift ceiling during liquid-release tests conducted in the ECRB Cross-Drift (see discussion of Figure 3-3 above) and the fact that a damp looking feature observed immediately after the dry excavation of Niche 1 (also referred to as Niche 3566) dried up before a bulkhead could be installed to increase the relative humidity in the opening. The damp looking feature was observed along a vertical wall; that is, it did not induce seepage. The feature did not reappear after sealing the niche with a bulkhead.

Because the evaporation potential in ventilated openings at Yucca Mountain evidently exceeds the seepage potential, an effort has been made to maximize relative humidity in the niches designated for seepage testing (see Section 3.1.3) in Alcove 7 and in the ECRB Cross-Drift (see Section 3.2). These tests and the related modeling studies confirm the impact of evaporation on the determination of seepage.

\subsection{NATURAL ANALOGS}

Natural analogs, such as those reported in Natural Analogue Synthesis Report (BSC 2002d, Section 8), provide evidence that the concept of water exclusion from underground openings is consistent with the process that actually occurs in caves, lava tubes, rock shelters, and buildings. The qualitative evidence for water exclusion and flow diversion was substantiated by quantitative seepage measurements in limestone caves. These studies show that seepage is considerably smaller than the pertinent percolation flux (BSC 2002d, Section 8.2), corroborating the seepage testing and modeling results at Yucca Mountain. Calcite-deposition data in lithophysal cavities (see Section 3.4) can be considered a natural analog at Yucca Mountain itself that further corroborates the concept. 


\section{SEEPAGE MODELING AND ABSTRACTION}

\subsection{PURPOSE AND GENERAL APPROACH}

A number of conceptual, analytical, and numerical models have been developed to help understand seepage-related processes and phenomena and to determine site-specific, seepage-relevant formation parameters. Some of the models are concerned with simulating in situ seepage tests (BSC 2003e), while others were developed for the prediction of seepage into intact and degraded waste emplacement drifts under ambient and thermal conditions (BSC 2003i; BSC 2003h; BSC 2003a). These drift-scale seepage models are linked to other models on different scales, specifically the mountain-scale model of the unsaturated zone at Yucca Mountain (BSC 2003c), models considering the coupled thermal-hydrologic-chemical (BSC 2003h) and thermal-hydrologic-mechanical (BSC 2003g) processes, scale-transition models providing flow-focusing factors (BSC 2001b, Section 6.4.2), as well as small-scale models evaluating flow within individual fractures (BSC 2003h). Quantitative and qualitative results from these process models are used in the seepage abstraction step (BSC 2003a) to arrive at a reasonable approach to handling seepage in TSPA calculations.

The general approach followed to analyze data from seepage experiments conducted at Yucca Mountain and to arrive at a calibrated and validated predictive seepage model is based on the recognition that (1) detailed simulation of individual seeps is not necessary to estimate average seepage rates into waste emplacement drifts, (2) certain factors affecting seepage can be lumped into effective parameters, (3) calibrating and validating a model against data from seepage experiments provides confidence that the model captures the relevant processes, (4) estimating effective parameters partly compensates for processes and features that are not explicitly considered in the model, and (5) the estimated parameters can be directly used in a predictive model that uses a consistent conceptualization.

The main advantage of this approach is that it relies directly on seepage-rate data, which inherently contain information about the relevant processes. Also, the calibration data (seepage rates on the scale of a drift section) are very similar to the quantity of interest for the subsequent predictions. The consistency between the calibration model used to derive seepage-relevant parameters and the predictive model used to forecast seepage minimizes conceptual differences. The appropriateness of the selected method and its potential advantages over alternative approaches are further discussed in Appendix D.

As discussed above, the seepage models are based on data showing seepage-relevant processes under in situ conditions; these data were described in Section 3. Some of these data were directly used to develop and calibrate the models. For example, air permeabilities (see Section 3.1.2) were used to generate and condition heterogeneous permeability fields for the seepage model. They were also used to derive statistical measures representing uncertainty and variability of this important, seepage-relevant parameter (see Section 4.9). Evaporation-rate and relative-humidity data (see Section 3.1.3) were used to determine the evaporative boundary layer thickness, which is part of a submodel used for the interpretation of seepage tests conducted in the ventilated ECRB Cross-Drift. Seepage-rate data measured during liquid-release tests (see Section 3.1.4) were the main data used for calibration of a drift-scale seepage model. Additional seepage-rate data were used for testing the capability of the calibrated model to make predictions 
under different conditions and at different locations. Data from the DST were used to corroborate the conceptual model supporting the abstraction of thermal-hydrologic-chemical and thermal-hydrologic-mechanical effects (see Sections 4.6 and 4.8 below).

The development of the seepage models involves the following steps:

1. Geostatistical parameters of the permeability field are determined from the results of air-injection test data.

2. Multiple realizations of the permeability field are generated, each of which is consistent with the geostatistical properties of the measured air permeabilities representing the excavation-disturbed zone in the drift vicinity and are mapped onto the computational grid.

3. A numerical model is developed for the simulation of liquid-release tests conducted in niches and along the ECRB Cross-Drift.

4. Seepage-relevant, model-related capillary-strength parameters are determined by calibrating the models against data from liquid-release tests.

5. The model is tested by comparing predicted seepage rates to observed data from seepage experiments not used for model calibration. This step provides confidence that the model is capable of predicting the seepage behavior above and below the seepage threshold.

6. A conceptually consistent model is developed for simulating seepage into waste emplacement drifts. Drift seepage is evaluated for ranges of percolation flux and other seepage-relevant hydrogeologic properties.

7. Sensitivity analyses are performed to examine the impact of drift degradation, ground support, above-boiling conditions during the thermal period, and thermal-hydrologic-chemical effects.

8. The results from Steps 6 and 7, along with other information on uncertainty and variability, are combined in the abstraction, providing the basis for a probabilistic evaluation of seepage in TSPA calculations.

Issues related to the general modeling approach are addressed in Appendix D.

The following sections describe the drift-scale models developed to estimate seepage-relevant formation parameters and to make predictive seepage calculations for TSPA.

\subsection{CONCEPTUAL AND NUMERICAL MODELS}

The drift-scale numerical seepage models consider three-dimensional flow through the unsaturated fracture network and seepage into the niches or the ECRB Cross-Drift. The fractured rock is conceptualized as a heterogeneous continuum with effective fracture permeabilities assigned to each grid block. A number of processes affecting seepage (such as film flow along the drift surface, impact of drift-wall roughness, and small-scale effects of 


\title{
Technical Basis Document No. 3: Water Seeping into Drifts
}

\author{
Revision 1
}

Prepared for:

U.S. Department of Energy

Office of Civilian Radioactive Waste Management

Office of Repository Development

P.O. Box 364629

North Las Vegas, Nevada 89036-8629

Prepared by:

Bechtel SAIC Company, LLC

1180 Town Center Drive

Las Vegas, Nevada 89144

Under Contract Number

DE-AC28-01RW12101 
Revision 1 


\section{CONTENTS}

Page

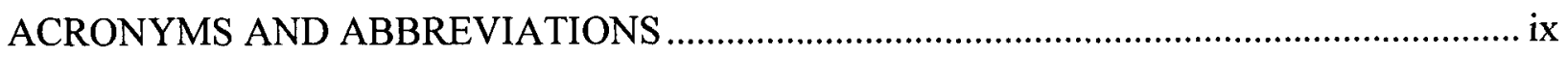

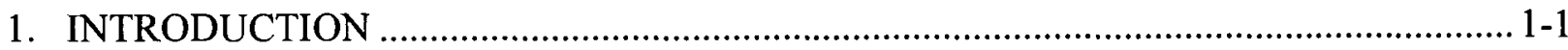

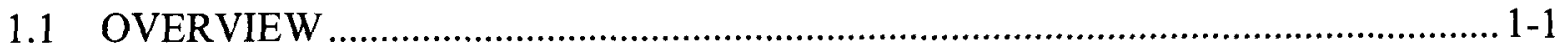

1.2 SIGNIFICANCE OF SEEPAGE FOR REPOSITORY PERFORMANCE ................. 1-3

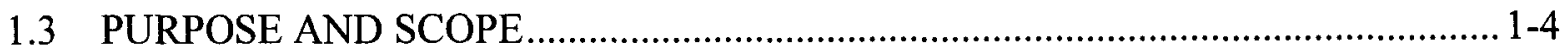

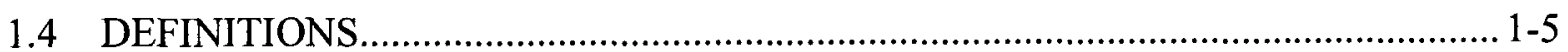

1.5 CAPILLARY AND VAPORIZATION BARRIERS ……….................................. 1-5

1.6 SUMMARY OF MODELING APPROACH …….................................................. 1-7

1.7 NOTE REGARDING THE STATUS OF SUPPORTING TECHNICAL
INFORMATION .............................................................................. $1-7$

2. PROCESSES AND FACTORS AFFECTING SEEPAGE ….............................................. 2-1

2.1 SUMMARY DESCRIPTION OF SEEPAGE PROCESS ......................................... 2-1

2.2 FACTORS AND PROPERTIES AFFECTING SEEPAGE ...................................... 2-3

2.3 THERMAL, HYDROLOGIC, CHEMICAL, AND MECHANICAL IMPACTS

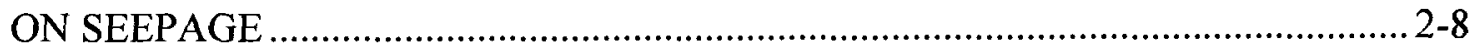

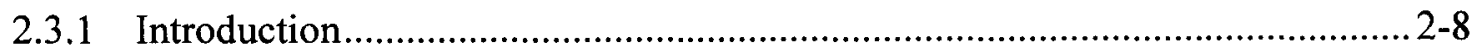

2.3.2 Excavation Effects ............................................................................... 2-8

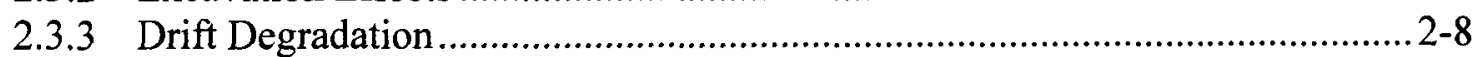

2.3.4 Seepage under Thermal Conditions ............................................................ 2-9

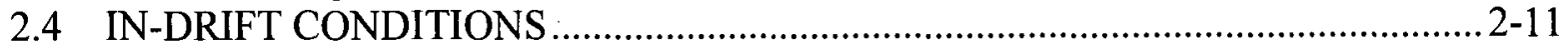

3. FIELD OBSERVATIONS AND SEEPAGE TESTING DATA ………............................ $3-1$

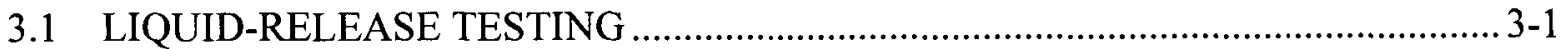

3.1.1 Description of Liquid-Release Tests.............................................................. 3-1

3.1.2 Air-Permeability Testing …….................................................................. 3-2

3.1.3 Relative-Humidity Monitoring …………....................................................... 3-3

3.1.4 Liquid-Release Tests in Niches and along the Enhanced Characterization of the Repository Block ............................................................................... 3-4

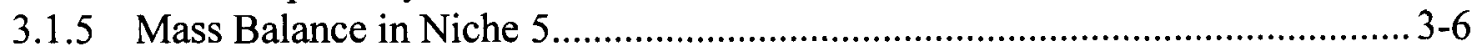

3.1.6 Alcove 8-Niche 3 Testing .......................................................................... 3-7

3.2 MOISTURE MONITORING IN NONVENTILATED DRIFT SECTIONS................3-9

3.2.1 Description of Passive Cross-Drift Hydrologic Tests and Alcove 7 ................ 3-9

3.2.2 Evidence of Ventilation Effects .................................................................3-11

3.2.3 Observations Related to Wet Zones......................................................... 3-12

3.2.4 Chemical and Isotopic Water Analyses ..................................................... 3-13

3.2.5 Summary .......................................................................................... 3-13

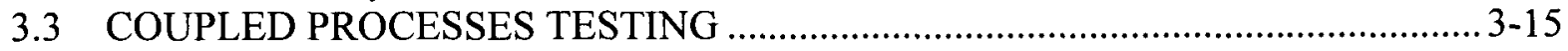

3.3.1 Drift Scale Test ..................................................................................... 3-15

3.3.2 Fracture Sealing Experiment...................................................................... 3-16 


\section{CONTENTS (Continued)}

Page

3.4 MINERAL DEPOSITIONS IN LITHOPHYSAL CAVITIES …............................ 3-17

3.5 ABSENCE OF SEEPAGE IN VENTILATED DRIFTS ….................................. 3-18

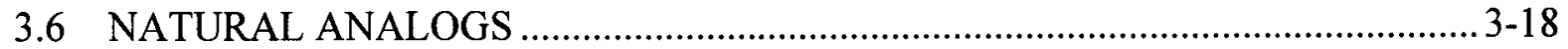

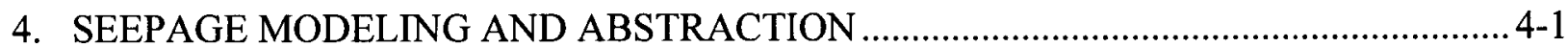

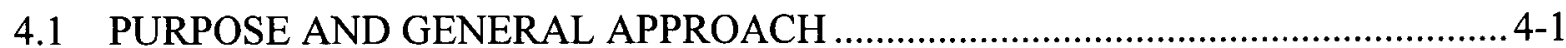

4.2 CONCEPTUAL AND NUMERICAL MODELS .......................................... 4-2

4.3 MODEL CALIBRATION AND VALIDATION ............................................... 4-6

4.4 PREDICTION OF AMBIENT SEEPAGE ................................................... 4-10

4.5 PREDICTION OF SEEPAGE UNDER THERMAL CONDITIONS ...................... 4-13

4.6 EVALUATION OF COUPLED THERMAL, HYDROLOGIC, AND

MECHANICAL EFFECTS ON SEEPAGE ....................................................4-19

4.7 EVALUATION OF DRIFT DEGRADATION EFFECTS ON SEEPAGE.............4-21

4.8 EVALUATION OF COUPLED THERMAL, HYDROLOGIC, AND CHEMICAL EFFECTS ON SEEPAGE............................................................. 4-23

4.9 SEEPAGE ABSTRACTION .................................................................... 4-26

4.10 SEEPAGE IN TOTAL SYSTEM PERFORMANCE ASSESSMENT .................... 4-31

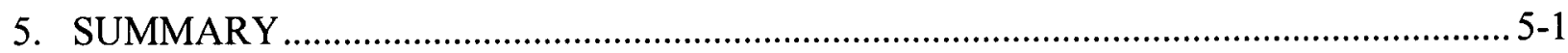

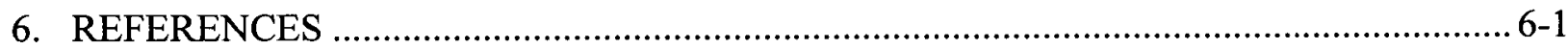

APPENDIX A - EFFECTS OF HETEROGENEITY ON THERMAL SEEPAGE (RESPONSE TO TEF 2.08 AND GEN 1.01 (COMMENT 15)) ................. A-1

APPENDIX B - USING TEST DATA TO REDUCE UNCERTAINTY IN TOTAL SYSTEM PERFORMANCE ASSESSMENT SEEPAGE ABSTRACTION (RESPONSE TO TSPAI 3.25)

APPENDIX C - IN SITU FIELD TESTING RESULTS AND ANALYSES (RESPONSE TO USFIC 4.01)

APPENDIX D - JUSTIFICATION OF CONTINUUM APPROACH FOR SEEPAGE MODELING (RESPONSE TO USFIC 4.06)

APPENDIX E - ALCOVE 8-NICHE 3 PRETEST PREDICTIONS (RESPONSE TO RT 3.06 AIN-1 AND SDS 3.02 AIN-1). 


\section{FIGURES}

Page

1-1. Components of the Postclosure Technical Basis for the License Application .. $1-1$

1-2. Schematic Showing Reduced Seepage and the Development of a Shadow Zone as a Result of the Flow Diversion Capability of the Capillary Barrier in the Unsaturated Zone

2-1. Schematic Showing Seepage Processes and Factors Affecting Seepage ........................ 2-1

2-2. Schematic of Flow-Channeling Effects on Various Scales ........................................ 2-5

2-3. Two-Dimensional Fracture Network at Yucca Mountain (a) and Simulated Steady-State Flux Distribution in the Fracture Network (b).

2-4. Schematic of Thermal-Hydrologic Processes Occurring in the Drift Vicinity as a Result of Repository Heating.

3-1. Schematic Geologic Map Showing Approximate Location of Niches and Systematic Testing Boreholes SYBT-ECRB-LA\#1-3

3-2. Temperature and Relative Humidity Measurements in Niche 4................................3-3

3-3. Wetting-Front Sequences Overlying Fracture Map of Niche 4 Crown for a Representative Liquid-Release Test

3-4. Seepage Rates Observed during a Representative Liquid-Release Test Conducted

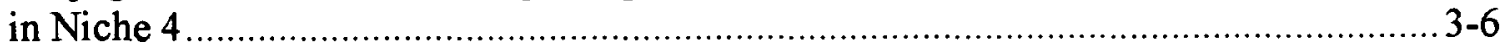

3-5. Schematic Illustration of the Alcove 8-Niche 3 Test Configuration..............................3-8

3-6. Infiltration Rate in Alcove 8 (a) and Seepage Rate in Niche 3 Test (b) ....................... 3-9

3-7. Schematic Illustration of the Location of Monitoring Stations in the Enhanced Characterization of the Repository Block and the Tunnel Boring Machine...................3-10

3-8. Water Potential Measurement as a Function of Time and Distance from the Drift Surface

3-9. Temporal and Spatial Variations in Temperature within Nonventilated Section of the Enhanced Characterization of the Repository Block.

3-10. Plot of the Hydrogen and Oxygen Isotope Compositions of Water Samples Collected from the Enhanced Characterization of the Repository Block .................... 3-14

3-11. Three-Dimensional Perspective of the As-Built Borehole Configuration of the Drift Scale Test.

3-12. Bridging Structures (a) in an Opened Planar Fracture and (b) in a Crosscutting Fracture

4-1. Examples of the Numerical Grid and One Realization of the Underlying Heterogeneous Permeability Field for the Simulation of Liquid-Release Tests (a) in a Niche, and (b) in the Enhanced Characterization of the Repository Block

4-2. Schematic Showing Two Fractures Intersecting a Drift

4-3. Saturation Distributions at the End of a Liquid-Release Test Conducted in (a) Niche 5 and (b) the Enhanced Characterization of the Repository Block as Simulated with the Calibrated Seepage Process Model. 


\section{FIGURES (Continued)}

Page

4-4. Calibration of Seepage-Rate Data from Liquid-Release Tests in Zone 2 of Boreholes (a) SYBT-ECRB-LA\#1, Zone 2, (b) SYBT-ECRB-LA\#2, Zone 2, (c) SYBT-ECRB-LA\#2, Zone 3, and (d) Borehole \#4 in Niche 5.

4-5. Validation of Seepage Model and Tptpmn Seepage-Relevant Parameters Using Data from Niche 3

4-6. Simulated Liquid Saturation Distribution in Heterogeneous Fracture Continuum in the Vicinity of a Waste Emplacement Drift.

4-7. Mean Seepage Percentage as a Function of Capillary-Strength Parameter and Mean Permeability for a Percolation Flux of 1,10, 50, 200, 400, 600, 800, and $1,000 \mathrm{~mm} / \mathrm{yr}$

4-8. Example of Numerical Grid for the Thermal-Hydrologic Seepage Model

4-9. Fracture Saturation and Liquid Flux for Tptpmn Submodel with Heterogeneous Permeability Field at (a) 100 Years and (b) 1,000 Years

4-10. Seepage Percentage for Tptpmn Submodel at Reference Thermal Mode and Tenfold Percolation Flux

4-11. (a) Simulated Changes in Absolute Air Permeability Caused by the Combined Effect of Moisture Redistribution and Stress-Induced Changes in Intrinsic Permeability and (b) an Example of a Comparison to Measured Data..

4-12. Calculated Drift Shape Changes as a Result of Rockfall in the Nonlithophysal Zone

4-13. Simulated Liquid Saturation Distribution in Heterogeneous Fracture Continuum in the Vicinity of a Waste Emplacement Drift with Changed Shape due to Rockfall

4-14. Example of Effects of Mineral Alteration as Predicted by the ThermalHydrologic-Chemical Seepage Model.

4-15. Relation and Information Flow between Primary Process Models and Seepage Abstraction.

4-16. Schematic Illustration of Random Sampling Procedure for Capillary-Strength Parameter $1 / \alpha$, Using Probability Distributions for Spatial Variability (Uniform) and Uncertainty (Triangular)

4-17. Probabilistic Total System Performance Assessment Procedure for Calculating Seepage at Selected Time Steps. 
Revision 1

\section{TABLE}

\section{Page}

Table 1-1. Seepage-Related Key Technical Issue Agreements Addressed in This Report ........ 1-2 
Revision 1

INTENTIONALLY LEFT BLANK 


\section{ACRONYMS AND ABBREVIATIONS}

AIN

DOE

DST

ECRB

ESF

GEN

KTI

LA

NRC

RT

SDS

TEF

TSPA

TSPAI

TSPA-LA

USFIC

USGS additional information needed

U.S. Department of Energy

Drift Scale Test

Enhanced Characterization of the Repository Block

Exploratory Studies Facility

General Agreement

Key Technical Issue

license application

U.S. Nuclear Regulatory Commission

Radionuclide Transport

Structural Deformation and Seismicity

Thermal Effects on Flow

total system performance assessment

Total System Performance Assessment and Integration

total system performance assessment for the license application

Unsaturated and Saturated Flow Under Isothermal Conditions

U.S. Geological Survey 
Revision 1

INTENTIONALLY LEFT BLANK 


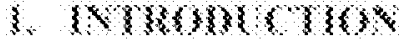

\section{MBQYKX:}

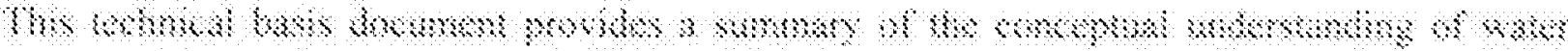

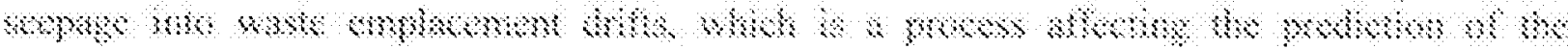

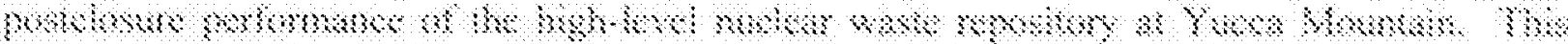

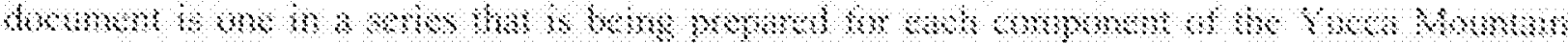

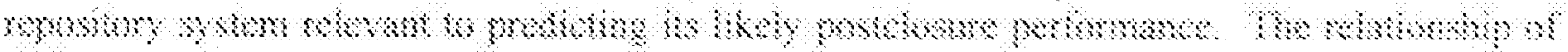

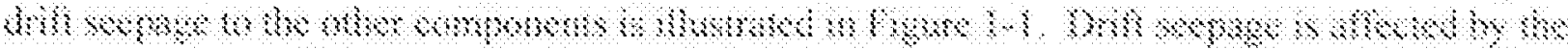

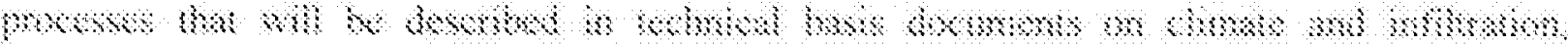

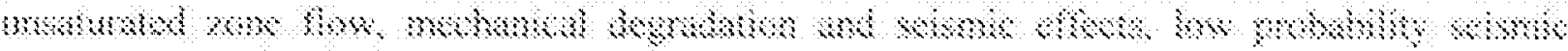
कon, sn

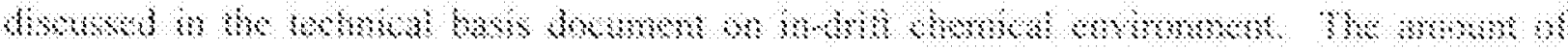

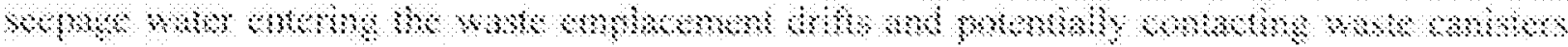

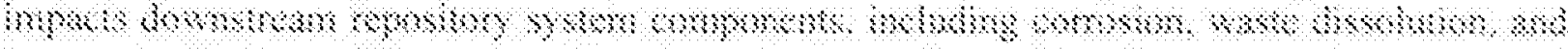

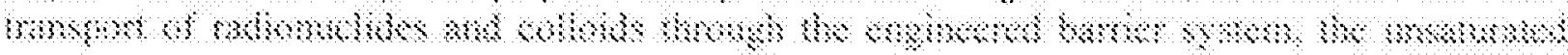

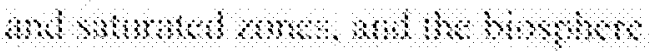

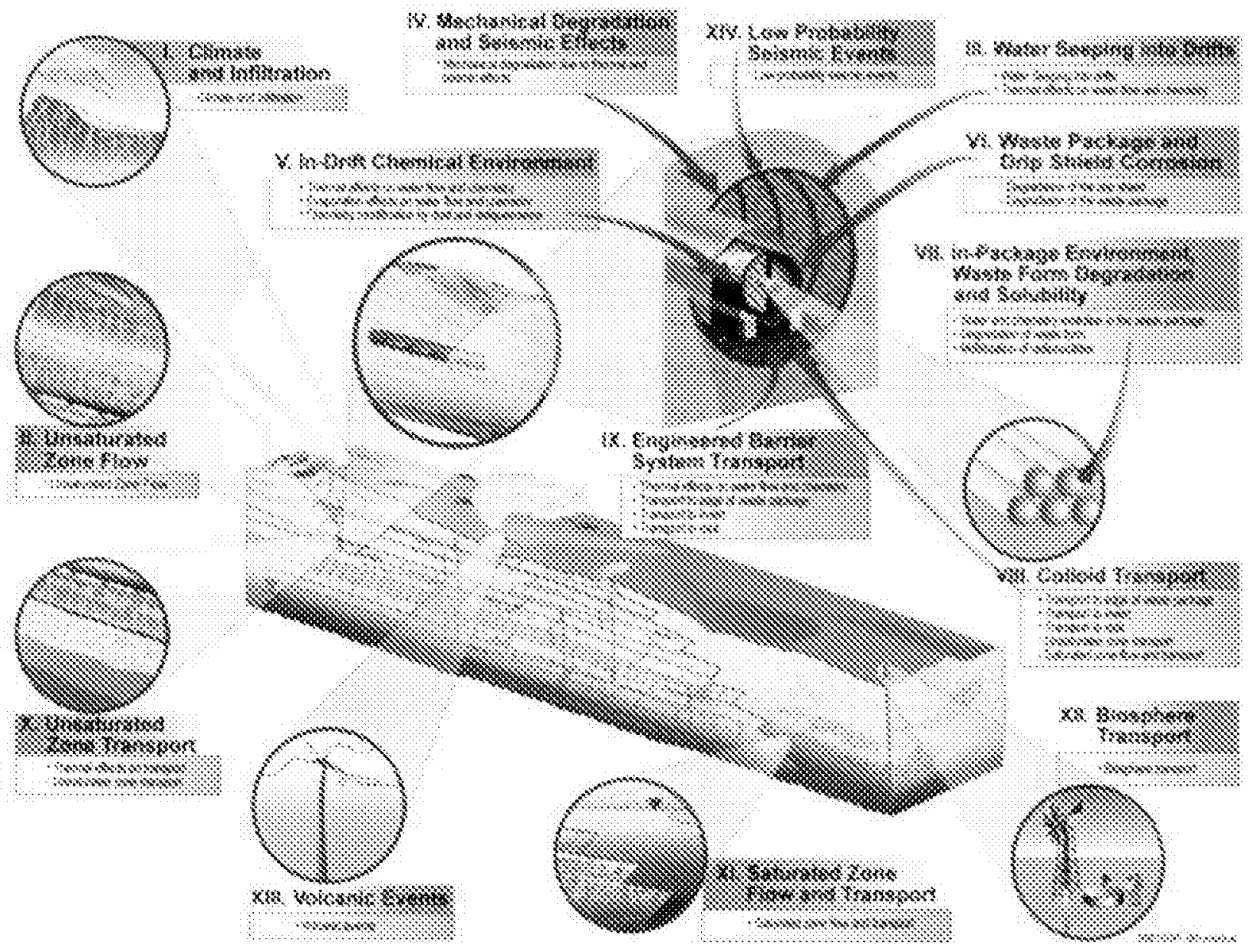

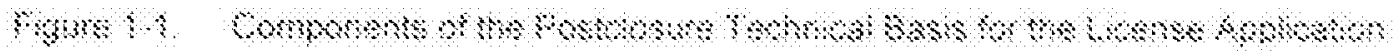


The information presented in this document, along with the associated references, forms an outline of the seepage-related studies supporting the ongoing development of the postclosure safety analysis that will comprise the license application (LA). This information is also used to respond to several open Key Technical Issue (KTI) agreements between the U.S. Nuclear Regulatory Commission (NRC) and the U.S. Department of Energy (DOE); detailed responses to these KTI agreements are provided in Appendices A through E, as shown in Table 1-1.

Table 1-1. Seepage-Related Key Technical Issue Agreements Addressed in This Report

\begin{tabular}{|l|c|l|}
\hline KTI Agreement/AIN & Appendix & \multicolumn{1}{c|}{ Short Description } \\
\hline $\begin{array}{l}\text { TEF 2.08, } \\
\text { GEN 1.01 (15) }\end{array}$ & A & Effects of heterogeneity on thermal seepage \\
\hline TSPAI 3.25 & B & Using test data to reduce uncertainty in TSPA seepage abstraction \\
\hline USFIC 4.01 & C & In situ field testing results and analyses \\
\hline USFIC 4.06 & D & Justification of continuum approach for seepage modeling \\
\hline RT 3.06, SDS 3.02 & E & Alcove 8-Niche 3 pretest predictions \\
\hline
\end{tabular}

Water is one of the principal agents determining corrosion of engineered barriers, waste dissolution, and radionuclide transport from the repository to the accessible environment. The amount and chemical composition of water seeping into waste emplacement drifts thus affects the long-term safety of the repository system at Yucca Mountain.

In the unsaturated zone, percolating water encountering a large underground opening is partly diverted around the cavity. This effect reduces the amount of liquid water entering the waste emplacement drift or prevents dripping altogether (i.e., the seepage flux is expected always to be smaller than the local percolation flux). This effect is referred to as a capillary barrier; it is an attribute of the unsaturated zone at Yucca Mountain. Moreover, during the early stages after closure, the heat from decaying radionuclides will vaporize water that approaches the waste emplacement drift. Both mechanisms limit the amount of water that potentially contacts the waste packages.

Characterizing and predicting seepage requires addressing a variety of processes and factors, including the distribution of water percolating through the mountain, the hydrogeologic properties of the fractured rock in the vicinity of a waste emplacement drift, the temperature and humidity conditions near and within the drift, the drift geometry, and the drift wall structure. These processes and factors are discussed in more detail in Section 2. A comprehensive testing program was designed and executed to understand seepage at Yucca Mountain and to obtain data supporting the models developed to predict drift seepage during the postclosure period. The testing program and data are presented in Section 3. Various process models were developed to analyze data from seepage experiments and to predict seepage into waste emplacement drifts under ambient and thermally elevated conditions. Experimental and modeling studies were performed to evaluate how seepage is affected by repository heat, mechanical deformation of the rock and the drift itself, changes in the chemical environment, and other perturbations. These modeling studies are summarized in Section 4.

Uncertainties and variabilities in the predicted seepage rates are examined and accounted for in a simplified but reasonable representation of seepage in a probabilistic total system performance 
assessment (TSPA) analysis. The testing and modeling program undertaken to understand and characterize seepage from fractured rock is considered suitable to provide an adequate basis for predicting seepage into waste emplacement drifts under ambient and thermally elevated conditions at Yucca Mountain.

\subsection{SIGNIFICANCE OF SEEPAGE FOR REPOSITORY PERFORMANCE}

The number of waste packages contacted by water, the corrosion performance of the engineered barriers, the dissolution and mobilization of radionuclides, and the release and migration of radionuclides to the accessible environment depend on the rate, chemical composition, and spatial and temporal distribution of water seeping into the emplacement drifts.

Percolating water encountering a waste emplacement drift is partly diverted around the opening because of the capillary barrier effect, which refers to the tendency of water to be held in the pores of unsaturated rock rather than dripping into a large opening. As a result, the seepage flux is expected to be smaller than the local percolation flux. This capillary barrier effect is an attribute of the unsaturated zone at Yucca Mountain.

While seepage is determined by features and processes occurring above the drift, the flow diversion phenomenon and reduction or prevention of water inflow into the drifts also affects the conditions below the repository, specifically the reduced saturation in the matrix and the fractures immediately beneath the drift. This is referred to as the drift shadow zone (see Figure 1-2). The saturation and flow conditions in the shadow zone impact diffusive releases at the interface between the drift invert and natural environment and the potential for the absence of fast advective transport of radionuclides through the fracture network.

A scientific research program has been undertaken to understand and characterize the fundamental processes contributing to seepage into underground openings excavated in the unsaturated, fractured formations at Yucca Mountain. In addition, a research program was designed to characterize the seepage-related properties of the repository host rock, providing the basis for the site-specific seepage predictions. Seepage was examined using theoretical, experimental, numerical, and natural analog studies. The key factors affecting seepage were identified, and site-specific, seepage-relevant parameters were determined through in situ testing. Numerical models were developed and calibrated against data that contain seepage-relevant information. These models were extensively tested to gain confidence in their ability to make predictions of drift seepage. Natural analogs were studied to corroborate the water-exclusion concept under unsaturated conditions.

Based on this research program, an understanding of the process of seepage into waste emplacement drifts has been gained. Seepage tests in the repository host units were performed to obtain site-specific characterization data related to seepage. A consistent and systematic approach to analyzing these data for use in subsequent seepage prediction models was developed. 


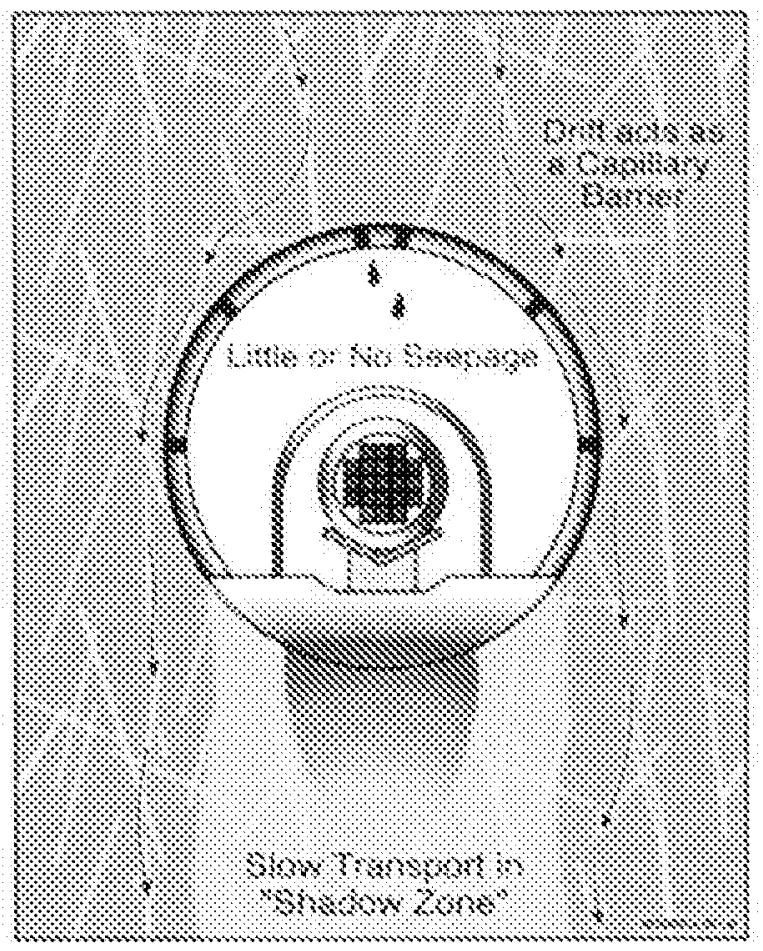

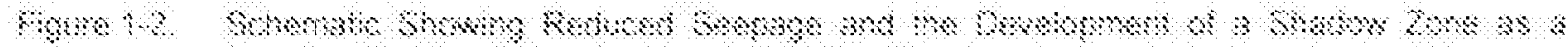

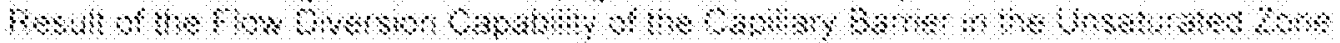

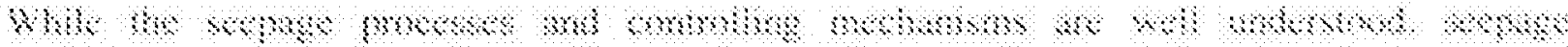

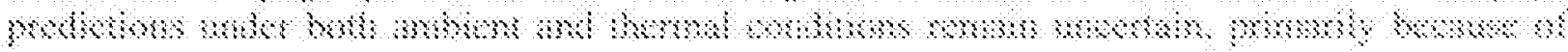

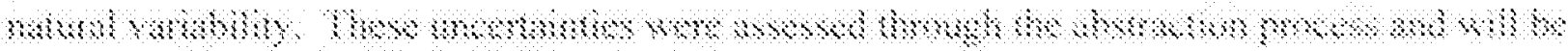

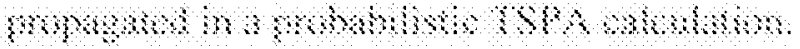

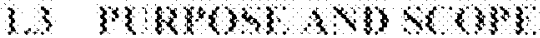

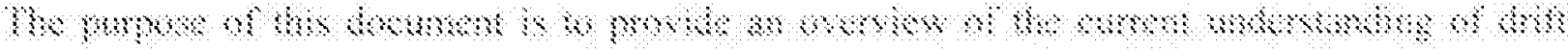

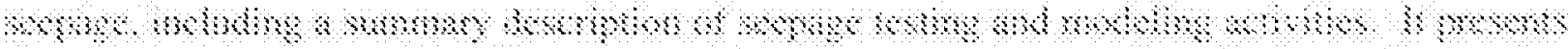

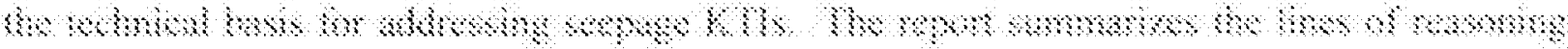

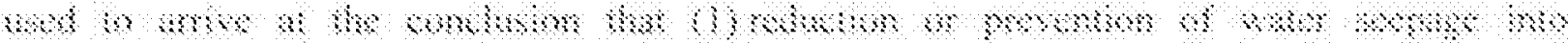

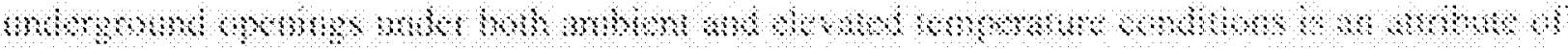

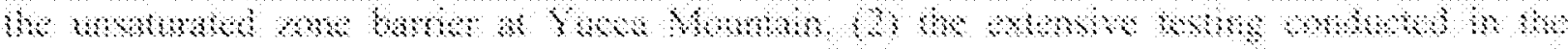

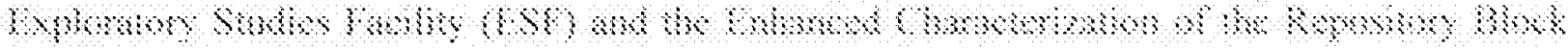

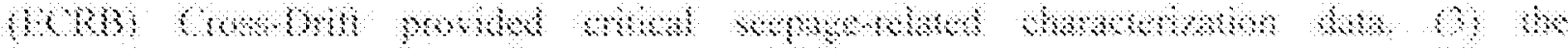

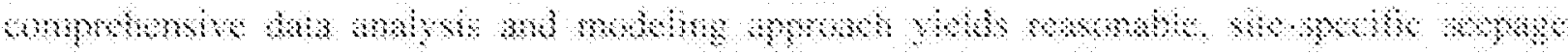
mo

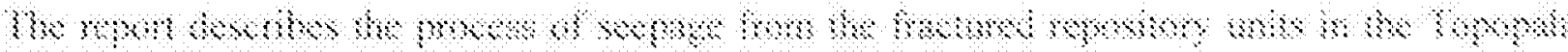

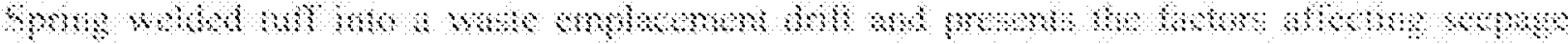

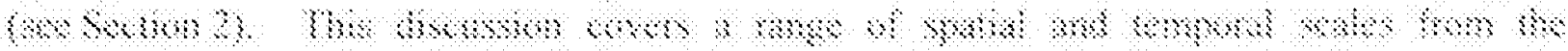

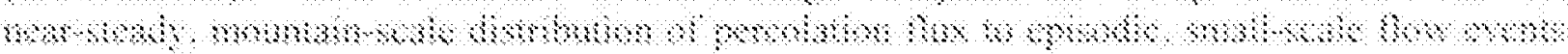

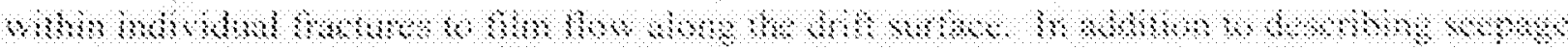
Moн 
hydrologic, chemical, and mechanical processes as they occur under increased temperature conditions and their impact on seepage.

The report provides a summary description of field tests performed at Yucca Mountain to obtain site-specific data that characterize seepage-relevant features and processes (see Section 3). It also discusses the suite of models developed to analyze these data, to predict seepage into waste emplacement drift sections, and to abstract the simulation results for use in probabilistic TSPA calculations (see Section 4).

This report does not describe in-drift processes that are affected by seepage water, which will be discussed in a technical basis document on the in-drift chemical environment. In-drift processes (specifically evaporation and condensation effects) are discussed here with respect to the interpretation of seepage test data.

\subsection{DEFINITIONS}

In the context of this report, seepage is defined as dripping of liquid water from the formation into an underground opening, such as a niche, alcove, access tunnel, or waste emplacement drift. According to this definition, seepage does not include advective or diffusive vapor flow into the opening or condensation of water vapor on surfaces, which may lead to drop formation and drop detachment. Some of the water entering an underground opening may evaporate or flow along the wall, thus not contributing to seepage in the sense defined here. In-drift moisture redistribution and potential condensate accumulation will be discussed in the technical basis document on in-drift chemical environment.

The seepage threshold is defined as the minimal percolation flux required to initiate seepage. A nonzero seepage threshold indicates the existence of effective water exclusion (Philip et al. 1989) capability of the formation. The presence of a seepage threshold can be directly observed from liquid-release tests conducted at different rates, which show that seepage ceases at a nonzero release rate.

\subsection{CAPILLARY AND VAPORIZATION BARRIERS}

In the unsaturated zone, percolating water encountering a waste emplacement drift tends to be diverted around the opening because of the capillary barrier effect. This effect is referred to as the water exclusion phenomenon (Philip et al. 1989), which reduces the amount of liquid water entering an underground opening or prevents dripping altogether, that is, the seepage flux averaged over a sufficiently large area (e.g., that of a drift section with the length of a waste package) will always be equal to or smaller than the local percolation flux. This effect is an attribute of the unsaturated zone barrier at Yucca Mountain.

The water-exclusion phenomenon has been extensively described in the literature (see Philip et al. 1989). The related water diversion capability is utilized in practical applications for the protection of landfills and hazardous waste sites. These standard engineering applications consider porous materials rather than fractured rocks. However, since the key factors affecting a capillary barrier are permeability and capillarity, properties also relevant for fractured rocks, the same effect applies to Yucca Mountain. 
Water exclusion from drifts has been extensively tested through the in situ seepage experiments described in In Situ Field Testing of Processes (BSC 2001a, Sections 6.2 and 6.11) and Seepage into an Underground Opening Constructed in Unsaturated Fractured Rock Under Evaporative Conditions (Trautz and Wang 2002). The experiments show that the seepage rate is less than the injection rate. Because of storage effects and evaporation, the reduced seepage rate by itself does not conclusively prove that water is diverted around the opening, which would directly assess the barrier capability of the natural system at Yucca Mountain. However, a combination of observed and simulated contributions to the water balance during a seepage test indicates that a substantial amount of water is diverted around the opening, confirming this water-exclusion phenomenon in the unsaturated zone at Yucca Mountain under ambient conditions (see Section 3.1.5).

After the emplacement of radioactive waste, the heat generated by the decay of the radionuclides will result in elevated rock temperatures for thousands of years after emplacement. For the current design, these temperatures are high enough to cause boiling in the rock. The thermally driven changes in water saturation affect the seepage potential. For above-boiling rock temperatures, vaporization of percolating water in the fractured rock overlying the repository will provide another effective process that greatly reduces (and most likely eliminates) seepage into the emplacement drifts during the thermal period, despite potentially increased reflux from the redistribution of water associated with vaporization and condensation of moisture above the drift. This additional process, referred to as the "vaporization barrier", and its effect on seepage during the thermal period are further discussed in Sections 2.6.4 and 4.5.

The term "capillary barrier" will be used throughout this technical basis document to refer to the flow diversion phenomenon occurring at the interface between two media with different capillary properties, where the medium with stronger capillarity overlies that of weaker capillarity. The term "vaporization barrier" will be used throughout this technical basis document to refer to the reduction of flow towards drifts as a result of vaporization occurring around a heated waste emplacement drift (BSC 2003a, Section 6.1.3). In these technical terms, the word "barrier" is used to describe the combined effect of a physical process occurring in a system with specific properties. This usage is slightly different from that in the definitions of natural and engineered barriers as given in Total System Performance Assessment-License Application Methods and Approach (BSC 2002a, Section 8.3.1).

In summary, partial or complete diversion of water around underground openings due to the capillary barrier effect in combination with vaporization during the thermal period will reduce seepage or even prevent water from dripping into waste emplacement drifts. In addition, the extent of a potential low-saturation and low-flux shadow zone beneath the drift (see Figure 1-2) and its potential effectiveness in delaying radionuclide transport from the invert of the waste emplacement drift to the accessible environment is related to the seepage-exclusion phenomenon. The capability of the capillary barrier to divert flow around underground openings in unsaturated fractured formations has been established theoretically, as well as through modeling and extensive field testing at Yucca Mountain. Natural analogs further confirm the existence and effectiveness of the capillary barrier effect. 


\subsection{SUMMARY OF MODELING APPROACH}

Seepage into an opening in unsaturated fractured rock depends on the percolation flux, the formation characteristics, the geometric features of the opening, and the thermodynamic conditions in the rock and the opening itself (for details, see Section 2). Specifically, the processes that need to be combined in a comprehensive conceptual model of seepage include (1) the mountain-scale distribution of percolation flux; (2) the intermediate-scale channeling of flow in the fracture network; (3) the drift-scale capillary-barrier effect; and (4) the micro-scale phenomena of evaporation, film flow, drop formation, and drop detachment at the drift surface where water leaves the formation and enters the drift. In addition, the thermodynamic environment in the opening (e.g., temperature, relative humidity, preclosure ventilation regime) will also affect seepage.

The analysis and modeling approach used to explain and reproduce seepage rates measured during liquid-release tests (see Section 3.1) and to predict seepage into waste emplacement drifts is described in detail in Section 4. The approach described in Section 4 is based on a process model of seepage in combination with effective parameters that are determined from in situ seepage experiments. Detailed predictions of drip frequency and individual seepage locations are not made; rather, calculated seepage rates are averaged in time and over a drift section of the approximate length of a waste package (i.e., they refer to the temporal and spatial scale of interest for a probabilistic assessment of seepage into a representative waste package). To support this approach, liquid-release tests were performed at rates below and above the seepage threshold. They covered the critical range of conditions expected under natural percolation conditions (which are most likely below the seepage threshold where no seepage occurs) and under localized, high flux conditions (as a result of wet climates combined with significant flow focusing) that may induce seepage. To summarize, the chosen approach focuses on the relevant drift- and waste-package scale and eliminates the need for auxiliary models and large spatial and temporal extrapolations from micro-scale models or low-resolution interpretation from site-scale models.

A key advantage of this approach is that it relies directly on seepage-rate data that contain information about the relevant processes. Moreover, the type of data used for calibration (i.e., seepage rates from liquid-release tests collected in a drift section, see Section 3.1) are conceptually very similar to the variable of interest (i.e., average seepage rates from a natural percolation) that needs to be predicted with the calibrated model. This consistency between calibration and prediction data minimizes potential conceptual differences between the calibration and prediction model. The appropriateness of this approach is further discussed in Appendix D. Finally, uncertainties and variabilities inherent in the seepage process are addressed by a probabilistic treatment of seepage in TSPA (see Section 4).

\subsection{NOTE REGARDING THE STATUS OF SUPPORTING TECHNICAL INFORMATION}

This document was prepared using the most current information available at the time of its development. This technical basis document and its appendices providing KTI agreement responses that were prepared using preliminary or draft information reflect the status of the Yucca Mountain Project's scientific and design bases at the time of submittal. In some cases this 
involved the use of draft analysis and model reports and other draft references whose contents may change with time. Information that evolves through subsequent revisions of the analysis and model reports and other references will be reflected in the LA as the approved analyses of record at the time of LA submittal. Consequently, the Project will not routinely update either this technical basis document or its KTI agreement appendices to reflect changes in the supporting references prior to submittal of the LA. 


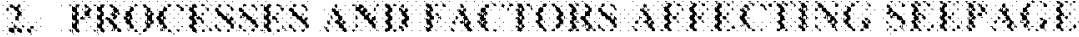

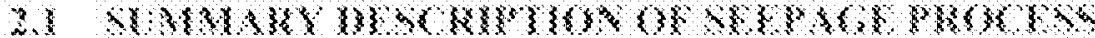

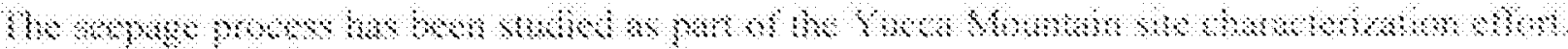

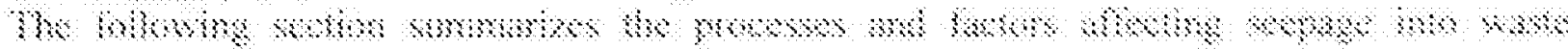
smosemsolstos.

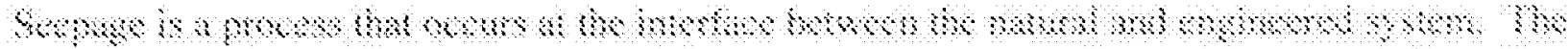

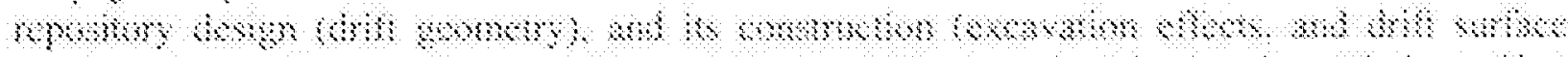

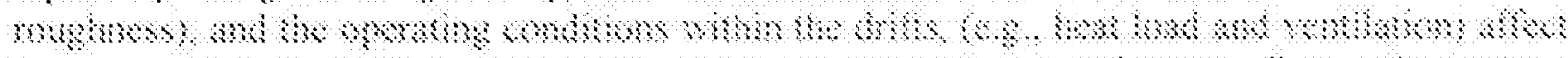

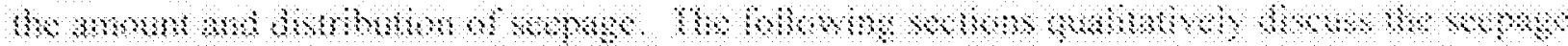

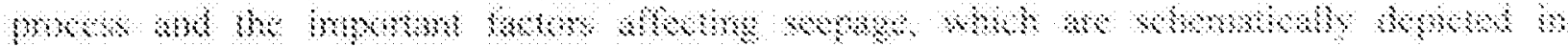

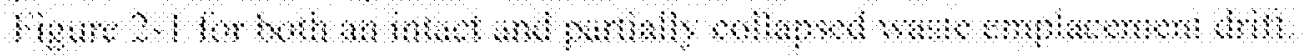

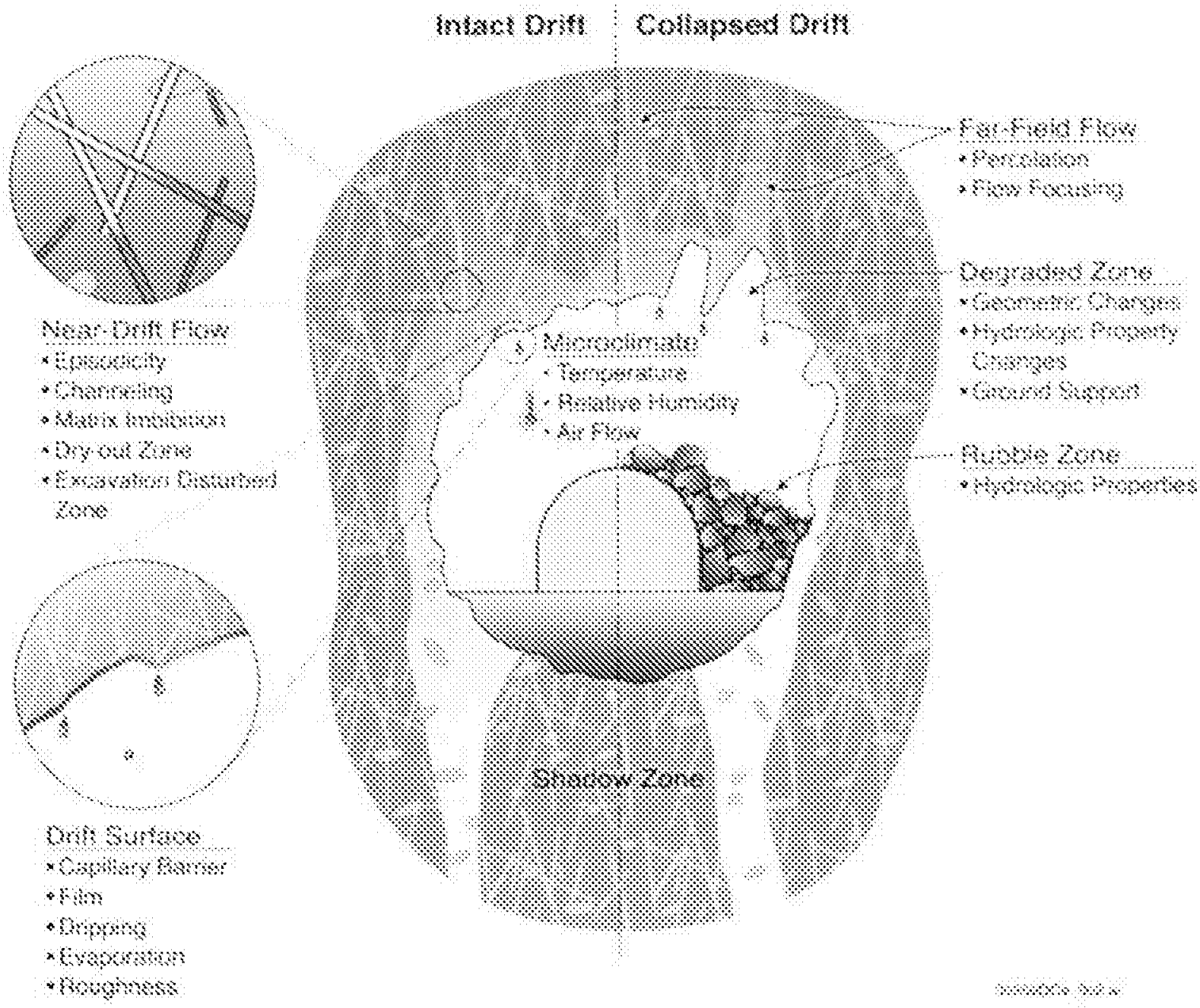

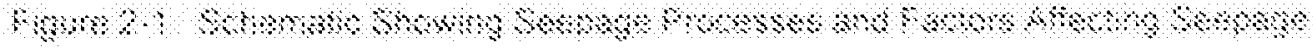


The majority of the precipitation on Yucca Mountain is removed by runoff and evapotranspiration. The remaining water penetrates the ground surface and starts to percolate downwards, driven by gravity and capillary forces (details will be discussed in the upcoming technical basis document on climate and infiltration). As this water percolates to depth, it is spatially redistributed (for details see the upcoming technical basis document on unsaturated zone flow and transport). Seepage into a section of waste emplacement drift is given by the local percolation flux minus the water that is diverted around the drift due to the capillary and vaporization barrier effects, minus water that flows as a film along the drift surface or that evaporates.

The detailed flow path is determined by the degree of fracturing, fracture geometry, orientation, connectivity, and the hydrogeologic properties of the fractures and the matrix. Depending on these factors, the water phase in the unsaturated fracture network will either disperse or concentrate along the flow path. Tilted contacts between hydrogeologic units (especially between welded and nonwelded tuffs) may affect the overall flow pattern or lead to a change in the frequency and spacing of flow channels. As flow concentration continues to occur, the distance between the individual channels carrying focused flow increases. As a result, the likelihood of two channels meeting and merging decreases with depth. Flow concentration and dispersion of flow paths also occurs within a rough-walled fracture where asperity contacts and locally larger fracture openings lead to small-scale redistribution of water within the fracture. A general discussion of channeling effects under unsaturated flow conditions can be found in Solute Channeling in Unsaturated Heterogeneous Porous Media (Birkholzer and Tsang 1997). Flow focusing is important for seepage because seepage depends on the local (rather than average) percolation flux. These issues are further discussed in Section 2.2.

As water approaches an emplacement drift (at a distance of one to several meters above the drift ceiling), conditions change in several ways that affect the amount of water that can seep into the opening. At early times after repository closure, the water will first encounter a dryout zone (defined as the zone of reduced saturation caused by preclosure drift ventilation or by boiling due to radioactive decay heat). Under boiling conditions, the dryout zone will be surrounded by a two-phase zone in which vapor-liquid counterflow (heat-pipe effect) occurs and a condensation zone with increased saturation. Preclosure ventilation and elevated temperatures are limited in time and do not affect long-term seepage.

Formation properties around the openings will be altered as a result of stress redistribution during drift excavation, which will lead to local opening or partial closing of fractures and potentially the creation of new fractures. Additionally, thermal expansion of the rock matrix will also induce changes in apertures. Finally, the local chemical environment, which is altered by evaporation and thermal effects, will lead to dissolution and precipitation of minerals, affecting flow properties of the fracture system and fracture-matrix interaction (see the technical basis document on in-drift chemical environment). These conditions lead to a flow pattern around a waste emplacement drift that is different from that in the undisturbed formation under ambient conditions (i.e., before excavation and waste emplacement).

When water penetrates the boiling zone (BSC 2003b, Sections 6.2 and 6.3) and reaches the immediate vicinity of the drift wall, it will still be prevented from seeping into the drift because of the capillary barrier effect (Philip et al. 1989). This effect leads to a local saturation build-up 
and, thus, the development of a higher water potential in the formation immediately adjacent to the drift. If the permeability tangential to the drift wall (i.e., permeability in the direction along the ceiling) and the capillarity of the fracture network within this region are sufficiently high, all or a portion of the water will be diverted around the drift under partially saturated conditions. Alternatively, however, the water potential in the formation may be higher than that in the drift, allowing water to exit the formation. At the drift surface, the water will either evaporate or follow the inclined, rough wall in a film or form a drop that may grow and eventually detach (Or and Ghezzehei 2000). Only this last mechanism is considered drift seepage according to the definition of Section 1.4.

The rate of water dripping into an opening in the unsaturated zone is expected to be significantly less than the local percolation rate because (1) the dryout zone around the drift reduces liquid water flow, potentially preventing water from reaching the drift surface, (2) the capillary barrier diverts water around the drift, thus bypassing the waste package, (3) water may flow along the drift surface without dripping into the opening, and (4) water may evaporate from the drift surface. Even if the seepage threshold were exceeded and seepage occurred, the seepage flux would be lower than the local percolation flux (i.e., the unsaturated zone at Yucca Mountain acts as a fully or partially effective barrier to water seeping into the waste emplacement drift).

\subsection{FACTORS AND PROPERTIES AFFECTING SEEPAGE}

Seepage is a process that occurs at the interface between the natural and engineered systems. Consequently, seepage is not only affected by hydrogeological factors (percolation flux, formation properties), but also by the design of the repository and waste emplacement drifts (location and geometry), the method of construction (excavation effects, drift surface roughness, ground support), and the conditions within the drifts (heat load, preclosure ventilation, and drift degradation).

The following sections describe the key factors affecting drift seepage and how they are included in the base-case conceptual model. The most important factors are the magnitude of the local percolation flux in relation to the formation's permeability, the strength of the capillary forces in the fractures, the connectivity of the fracture network in the immediate vicinity of the opening, the local topography of the rough drift wall, and the thermodynamic conditions in the drift.

Percolation Flux-The magnitude of the percolation flux is a key factor determining seepage. Seepage is initiated if the local percolation flux in individual flow channels and the accumulation of water from these channels near the drift ceiling exceeds the diversion capacity of the capillary barrier, the evaporation potential of the atmosphere in the drift, and the capacity of films to carry water along the drift surface. It is the local (rather than average) percolation flux that controls the onset of seepage.

The source of percolation flux at Yucca Mountain is net infiltration at the ground surface, stemming from precipitation events. Net infiltration is the fraction of precipitation that moves through the ground surface to a depth where the liquid water can no longer be removed by evaporation or transpiration. Net infiltration varies in space (as a result of several factors, such as vegetation, morphology, soil and bedrock, and runoff and runon conditions) and in time (USGS 2001). Time variations are short-term as a result of daily or seasonal fluctuations and 
long-term as a result of climatic changes. As infiltrating water percolates through the unsaturated zone, driven by gravity and capillary forces, the initial infiltration and flow patterns change depending on the hydrogeologic properties and their heterogeneities. On a large scale, several stratigraphic units of volcanic rock with significant differences in fracture frequency and matrix porosity can be distinguished at Yucca Mountain. Variations between units reflect the type of volcanic eruption, the rate of cooling, and the intensity of postdepositional processes.

In general, percolation flux through the Tiva Canyon welded tuff unit, the first fractured bedrock unit below alluvial deposits is governed by the imposed distribution of net infiltration. Flow in this unit occurs mostly in the fractures before entering the underlying Paintbrush nonwelded hydrogeologic unit (PTn). With its characteristics of high matrix porosity and low fracture frequency and the existence of tilted layers of nonwelded vitric and bedded tuff, the PTn can effectively divert percolating water into intercepting faults and fault zones (BSC 2003c). Also, the PTn unit dampens and homogenizes downward-moving transient pulses from surface infiltration events. Therefore, the percolation distribution below the PTn unit is considerably different from the distribution of net infiltration, both spatially and temporally. The geological unit below the PTn is the Topopah Spring welded tuff (TSw), a thick, densely fractured unit consisting of different subunits that will host the repository. The main subunits of interest are the upper lithophysal zone (Tptpul), the middle nonlithophysal zone (Tptpmn), and the lower lithophysal zone (Tptpll). The Tptpll will host the majority of the repository.

On an intermediate scale, there is also considerable heterogeneity within stratigraphic units. This kind of heterogeneity can focus water toward one drift location while diverting it away from another. Flow concentration on this scale (i.e., across the interface between a mountain-scale model and drift-scale models) is referred to as "flow focusing." Flow channeling and diversion of flow paths also happen within each rough-walled fracture where asperity contacts and locally larger fracture openings lead to small-scale redistribution of water within the fracture. In addition, asperity-induced flow instabilities may cause small-scale episodic flow within fractures, leading to high-frequency fluctuations. These factors are considered in the development of a prediction and abstraction for seepage quantification.

Flow concentration effects on various scales are schematically shown in Figure 2-2. Flow concentration, flow focusing, and channeling effects are uncertain. Flow simulations using a two-dimensional discrete fracture network model (see Figure 2-3) show that the average spacing between flow paths in a layered system tends to increase with depth (i.e., flow becomes more concentrated with the increase of depth under gravity-driven flow conditions). (The flow characteristic may change abruptly at interfaces between hydrogeologic units, leading to some local flow dispersion on a smaller scale in the unit with higher fracture density.)

Temporal fluctuations superimpose the spatial flow-channeling effects described above. The flux in a flow channel may be near steady state or episodic with a wide frequency spectrum, ranging from high-frequency fluctuations triggered by small flow instabilities to intermediate variabilities in percolation fluxes in response to changing weather conditions to long-term variations from climate changes. 


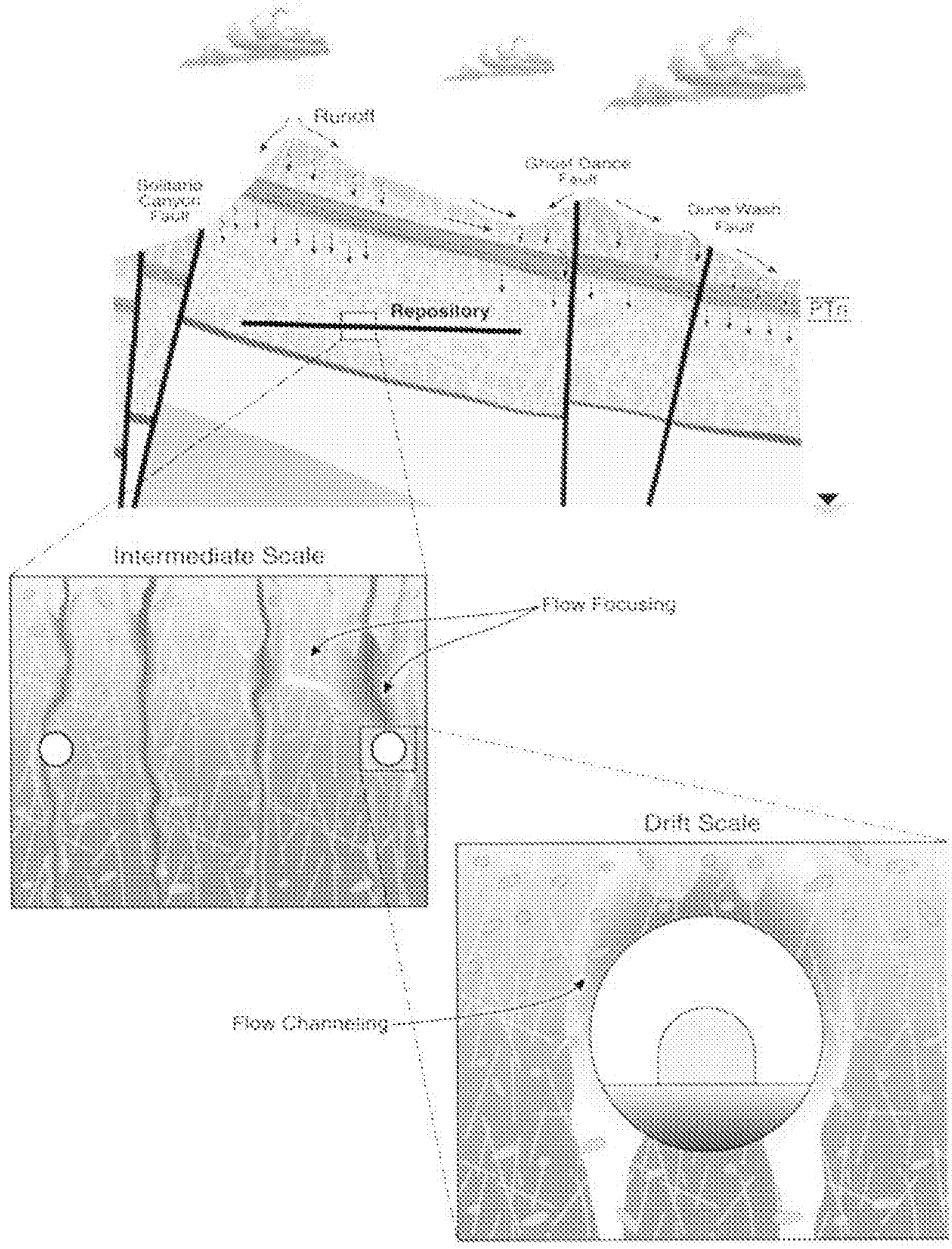

का

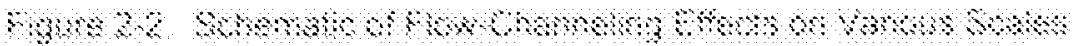




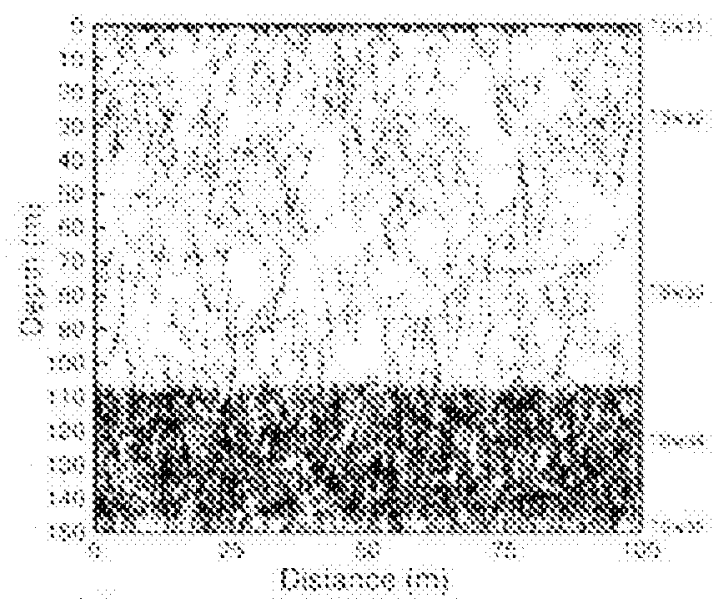

(a)

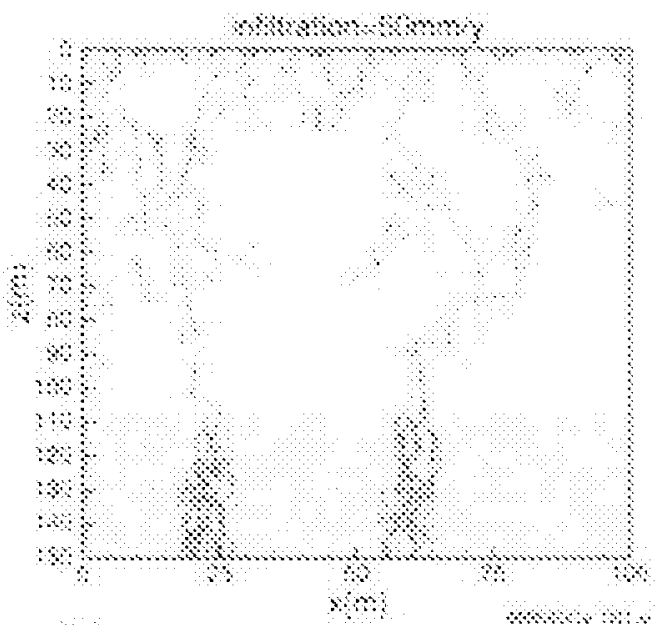

(b)

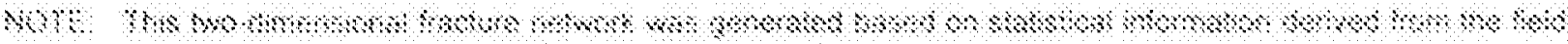

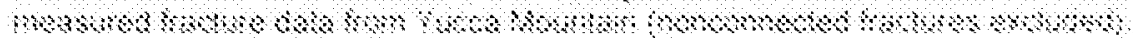

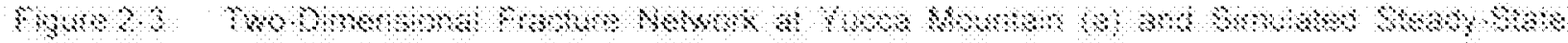

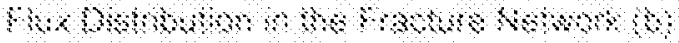

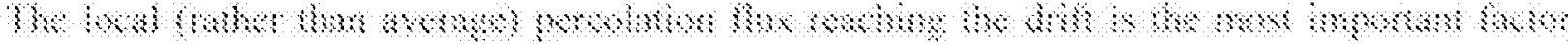

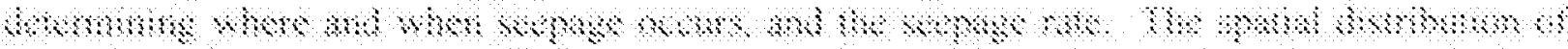

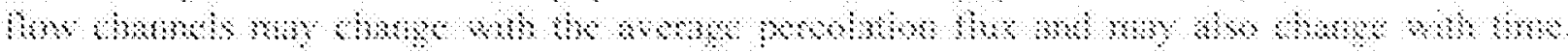

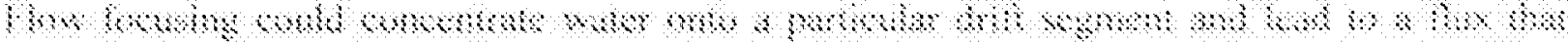

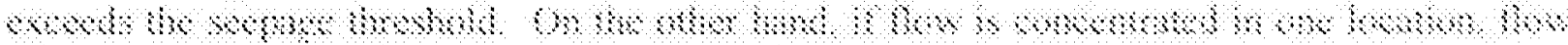

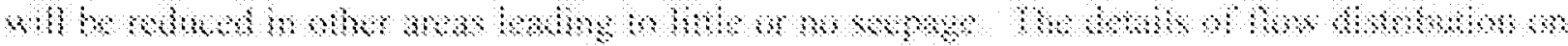

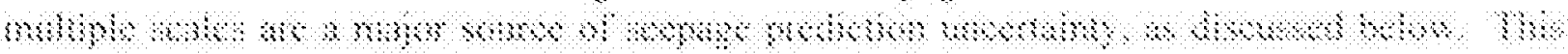

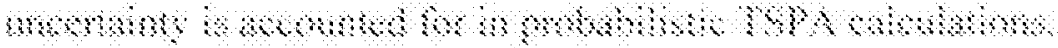

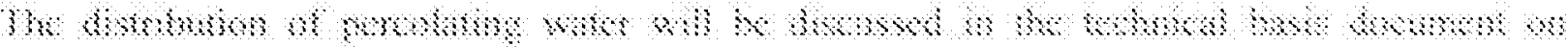

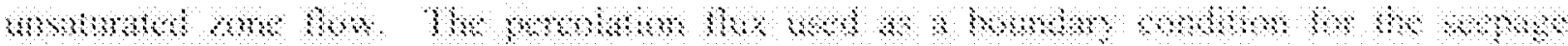

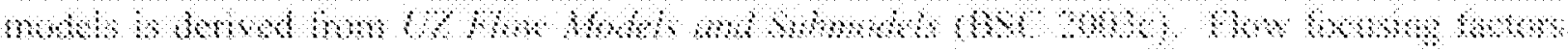

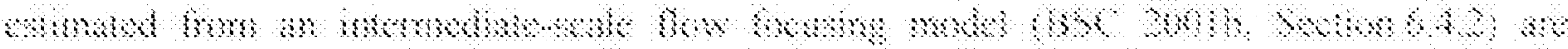

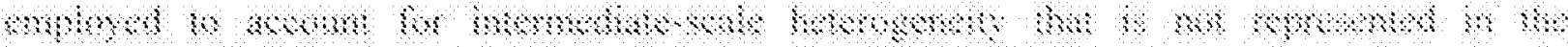

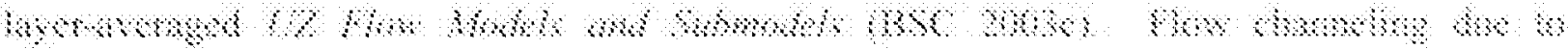

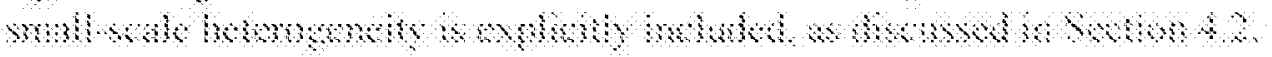

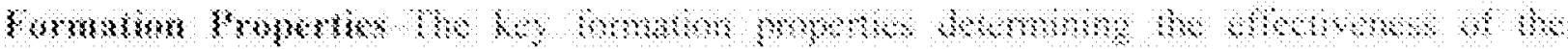

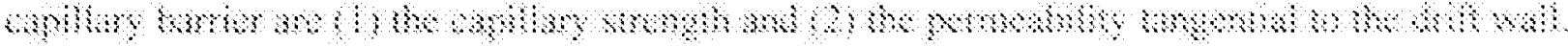

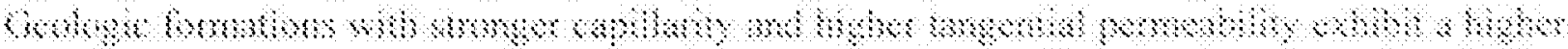

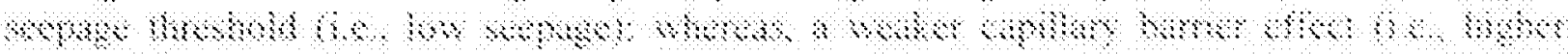

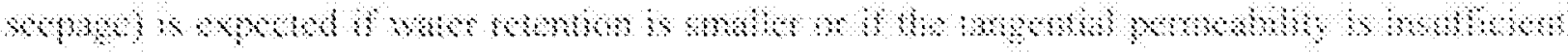

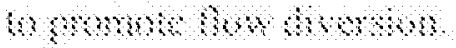

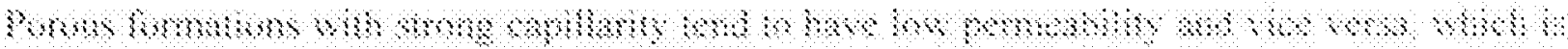

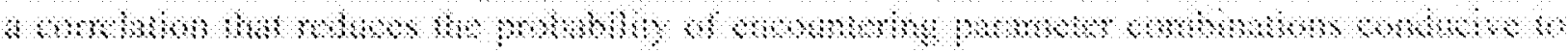

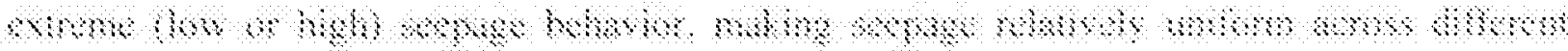


geologic units. However, this negative correlation between permeability and capillary strength may not necessarily apply to a fractured system, specifically if considering the seepage process on the scale of a waste emplacement drift. A given permeability may result from a network consisting of a few large fractures or, alternatively, a network of many small, well-connected fractures. The first network with few large fractures would exhibit relatively weak capillarity, whereas the second network with many small fractures would have stronger capillarity. Moreover, if the predominant fracture orientation is aligned with the drift axis (see Section 4.2, Figure 4-2a), little or no tangential permeability is available and seepage is increased. For flow diversion to occur, the fracture system must have sufficient connectivity and permeability to provide the necessary effective diversion pathways in tangential direction around the drift.

Heterogeneities in formation properties on the scale of a drift diameter or smaller may enhance seepage if they promote flow channeling and increase the probability of locally exceeding the seepage threshold. Intermediate-scale heterogeneities (from approximately $100 \mathrm{~m}$ to a drift diameter) may focus water into flow channels that either encounter or bypass the waste emplacement drifts. Large-scale heterogeneities may divert water (e.g., along contacts between hydrostratigraphic units) or concentrate it into local features (such as faults). Heterogeneities on these scales thus have roles in determining the fraction of waste packages encountering seepage and the seepage amount. The heterogeneous nature of the formation implies that certain regions are more prone to seepage than others, with some areas exhibiting properties that are strongly adverse to seepage.

The impact of lithophysal cavities on flow and seepage is twofold: (1) lithophysal cavities are essentially obstacles to water flow because they act as capillary barriers, focusing the water that flows around them, and (2) lithophysal cavities intersected by the drift lead to a rough drift ceiling, potentially creating seepage points at local low points on the ceiling. Both effects tend to promote seepage.

The capillarity and permeability of the fracture network alone do not determine seepage. Water emanating from the fracture network may not drip but be transported as film flow along the drift surface or evaporate (see Section 2.4). Hence, seepage is not only affected by the characteristics of the host rock but also by factors unrelated to the hydrogeologic properties of the fracture system.

Drift Geometry and Drift-Wall Properties-The overall drift size and geometry can change the seepage threshold and the seepage amount. Generally, a large drift exhibits a significantly lower seepage threshold. More water accumulates in the high-saturation region near the drift boundary because it needs to move over a longer diversion distance around the wider opening. In a heterogeneous, fractured formation, the importance of drift shape and drift geometry may be diminished relative to that of flow channeling and local ponding (Birkholzer et al. 1999, pp. 372 to 379 ).

The effectiveness of a capillary barrier is greatest if the shape of the cavity follows an equipotential surface. In a homogeneous medium, parabolic cavities are more efficient in preventing seepage than circular or flat-roofed openings. Breakouts in the drift ceiling, caused by rockfall and drift degradation, may change the overall drift geometry and lead to local low points in the ceiling, which may trap water, reduce or prevent flow diversion, and initiate 